Summer 2019

\title{
Slip and strain accumulation along the Sadie Creek fault, Olympic Peninsula, Washington
}

Cody Duckworth

Western Washington University, w.cody.duck10@gmail.com

Follow this and additional works at: https://cedar.wwu.edu/wwuet

Part of the Geology Commons

\section{Recommended Citation}

Duckworth, Cody, "Slip and strain accumulation along the Sadie Creek fault, Olympic Peninsula, Washington" (2019). WWU Graduate School Collection. 896.

https://cedar.wwu.edu/wwuet/896 


\title{
SLIP AND STRAIN ACCUMULATION ALONG THE SADIE CREEK FAULT, OLYMPIC PENINSULA, WASHINGTON
}

\author{
By \\ Cody Duckworth \\ Accepted in Partial Completion \\ Of the Requirements for the Degree \\ Master of Science
}

ADVISORY COMMITTEE:

Co-Chair, Dr. Colin Amos

Co-Chair Dr. Elizabeth Schermer

Dr. John Loveless

GRADUATE SCHOOL

David L. Patrick, Interim Dean 


\section{MASTER'S THESIS}

In presenting this thesis in partial fulfillment of the requirements for a master's degree at Western Washington University, I grant to Western Washington University the non- exclusive royalty-free right to archive, reproduce, distribute, and display the thesis in any and all forms, including electronic format, via any digital library mechanisms maintained by WWU.

I represent and warrant this is my original work and does not infringe or violate any rights of others. I warrant that I have obtained written permissions from the owner of any third party copyrighted material included in these files.

I acknowledge that I retain ownership rights to the copyright of this work, including but not limited to the right to use all or part of this work in future works, such as articles or books. Library users are granted permission for individual, research and non-commercial reproduction of this work for educational purposes only. Any further digital posting of this document requires specific permission from the author.

Any copying or publication of this thesis for commercial purposes, or for financial gain, is not allowed without my written permission.

Cody Duckworth

July 19, 2019 
Slip and strain accumulation along the Sadie Creek fault, Olympic Peninsula, Washington

\author{
A Thesis \\ Presented to \\ The Faculty of \\ Western Washington University
}

In Partial Fulfillment

Of the Requirements for the Degree

Master of Science

by

William Cody Duckworth

July 2019 


\section{ABSTRACT}

Upper-plate faulting in the Olympic Peninsula of Washington State reflects the interaction of crustal blocks within the Cascadia forearc as well as contributions from various earthquake cycle processes along the Cascadia subduction zone (CSZ). These processes include interseismic coupling, megathrust earthquakes, and aseismic slow slip events. In this study I utilize high resolution airborne lidar, field mapping of deformed surficial deposits and landforms, optically stimulated luminescence (OSL) dating and radiocarbon dating to reconstruct fault slip rates since Late Pleistocene deglaciation on the Sadie Creek fault (SCF), located north of the Olympic Mountains. This mapping reveals the SCF as a $\sim 14$ km-long NW-striking, subvertical, dextral strike-slip fault with a subordinate dip-slip component. Field and lidar measurements of 48 scarp profiles and 11 laterally offset stream channels indicate that faulting of late Pleistocene and younger surfaces varies along strike with dextral slip ranging from 4.0-26.0 m (average of $14.3 \pm 7.5 \mathrm{~m}$ ) and dip-slip displacement ranging from $0.7-6.5 \mathrm{~m}$ (average of $3.4 \pm 1.6 \mathrm{~m}$ ). Reevaluation of fault slip on the adjacent Lake Creek Boundary Creek fault (LCBCF), which connects with the SCF beneath Lake Crescent, shows a slightly higher range of dextral slip (4.5$29.7 \mathrm{~m}$, average of $15.9 \pm 8.9 \mathrm{~m})$ and lower range of dip-slip displacement $(0.8-4.6 \mathrm{~m}$, average of $2.3 \pm 0.9 \mathrm{~m}$ ) suggesting that slip on the SCF may be more oblique than on the LCBCF. OSL and radiocarbon ages of deposits deformed by the SCF and LCBCF suggest that channels formed throughout post-glacial time and thus record different amounts of slip depending on channel age. Therefore, channels that record the largest magnitude of slip are interpreted as the oldest channels and produce a preferred dextral slip rate of $1.3-2.3 \mathrm{~mm} / \mathrm{yr}$ since retreat of the Juan de Fuca lobe of the Cordilleran ice sheet at $14 \mathrm{ka}$. Comparing this slip rate to geodetically constrained models of forearc deformation, I determine how shorter-term (decadal) stresses contribute to fault slip and strain accumulation within the upper plate. This approach uses an 
elastic block model and a boundary element method model to estimate the stress on the SCF and LCBCF as a result of different earthquake cycle processes in the forearc and on the CSZ. Models of coseismic stress transfer from a full-length rupture on the CSZ and elastic block models which together consider the interactions of forearc blocks and CSZ coupling - both produce comparable estimates to the post-glacial slip rate and kinematics of the SCF and LCBCF. As such, the SCF and LCBCF play an important role in the permanent accumulation of strain observed in the GPS velocity field but may be modulated by stress transferred from CSZ earthquakes. 


\section{Acknowledgments}

This research was supported by funding from the US Geological Survey EdMap program, the Geological Society of America, the Western Washington University Graduate School, and the Western Washington University Geology Department. All lidar DEMS used for mapping and topographic analysis were obtained from the Washington Department of Natural Resources.

I am indebted to my advisors Colin Amos and Liz Schermer, as well as my committee member, Jack Loveless, for their guidance, constructive feedback, and commitment to my learning. Thanks to Ysabel Perez, Michael Polenz, Brian Sherrod, Steve Angster, Alan Nelson, Katie Alexander, and Grant Williams for their assistance and discussion in the field as well as Tammy Rittenour and Carlie Ideker for their OSL lab assistance at Utah State University. The Washington Department of Natural Resources was generous in allowing access to forest land, helping with photogrammetry surveys, and for refinement of geologic maps. Additional thanks to Erin Wirth for providing her research group's subduction zone slip distributions. 


\section{Table of Contents}

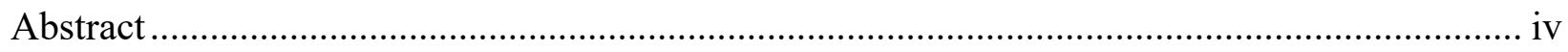

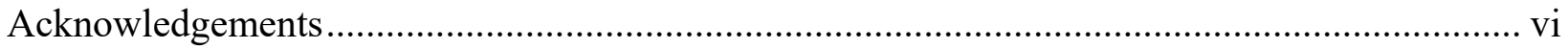

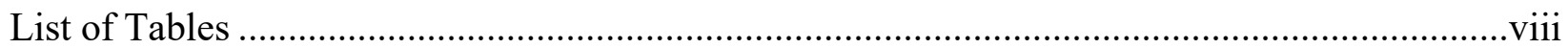

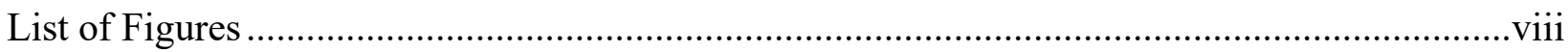

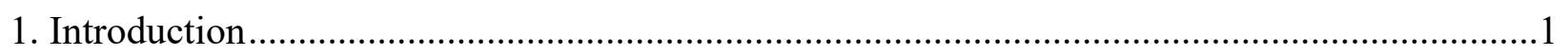

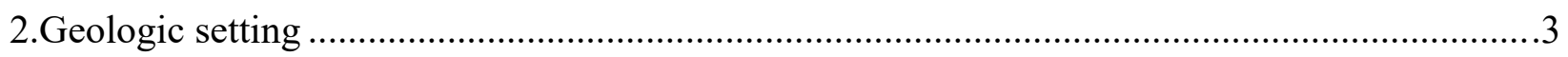

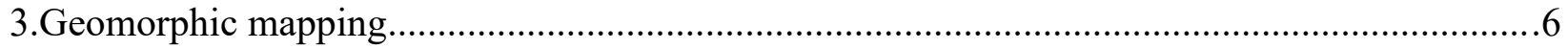

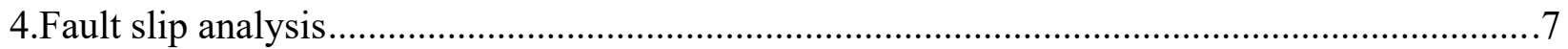

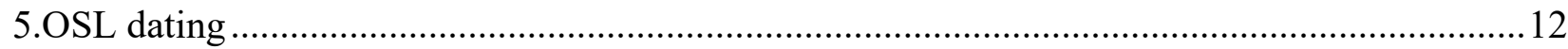

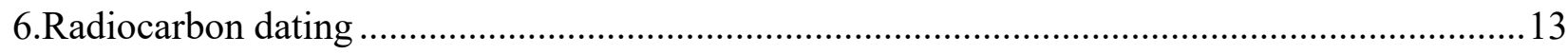

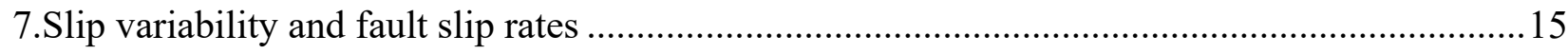

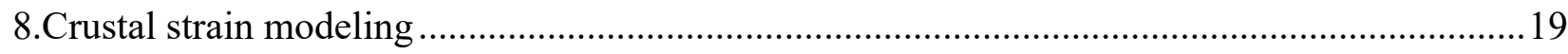

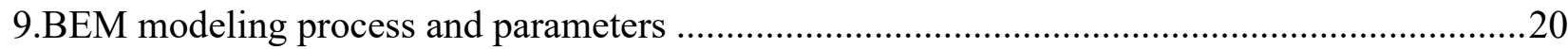

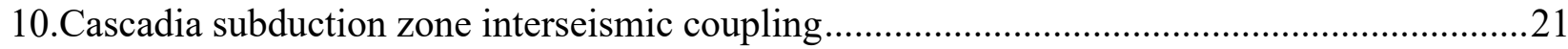

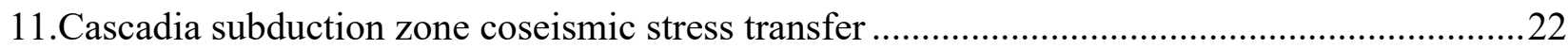

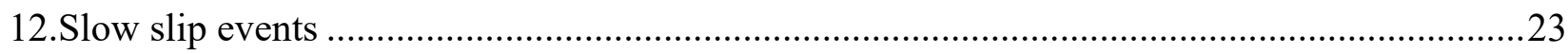

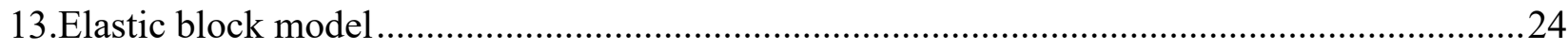

14.Implications for permanent strain accumulation within the Cascadia forearc ..........................26

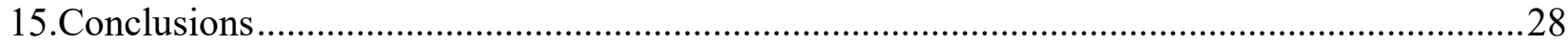

Appendix I Measurement and evaluation of strike-slip displacement...........................................30

Appendix II Application of methods in forested terrain ..............................................................

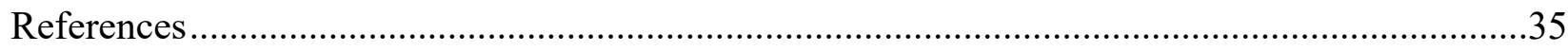

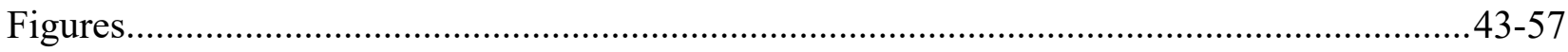

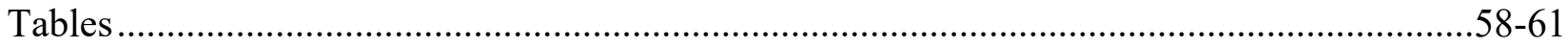

Supplementary documents ....................................................................................62-242 


\section{List of figures}

Figure 1. Overview of the Cascadia forearc and northern Olympic Peninsula...........................43

Figure 2. Geomorphology and geologic deposits surrounding the SCF ..................................44

Figure 3. Examples of dip-slip and strike-slip displacement measurements .............................45

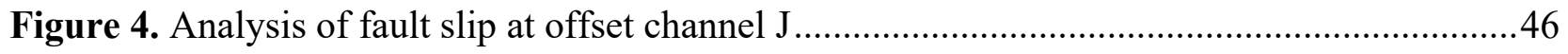

Figure 5. Models of dip-slip and strike-slip displacement in relation to channel formation. ........47

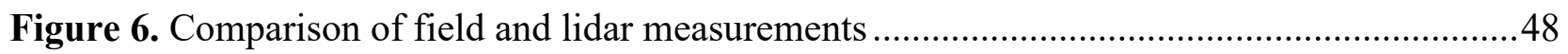

Figure 7. Sadie Creek and Lake Creek-Boundary Creek fault slip.....................................49-50

Figure 8. Comparison of strike-slip and dip-slip displacement on the SCF and LCBCF. ............51

Figure 9. Comparison of strike-slip displacement with radiocarbon ages .................................52

Figure 10. Workflow for BEM and elastic block modeling processes. .....................................53

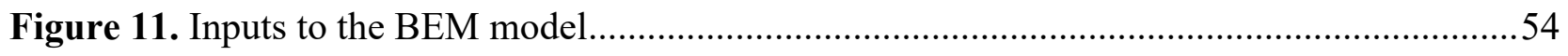

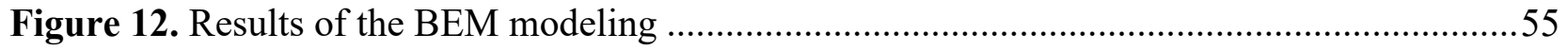

Figure 13. Configurations of crustal blocks used in the elastic block modeling ..........................56

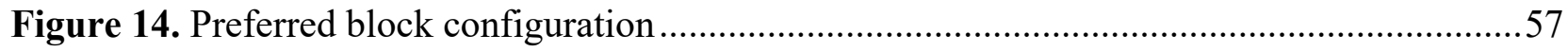

\section{List of tables}

Table 1. Summary of strike-slip displacement along the SCF and LCBCF ..............................58

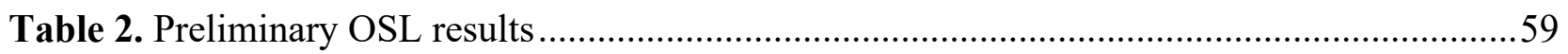

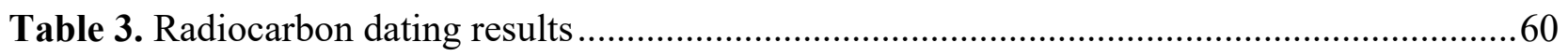

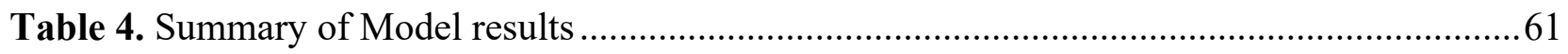

Supplementary documents

S1. Surficial map of the SCF $.62-64$

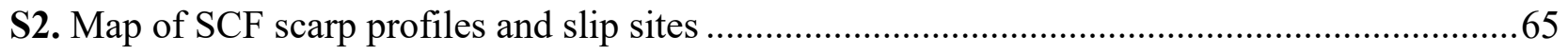

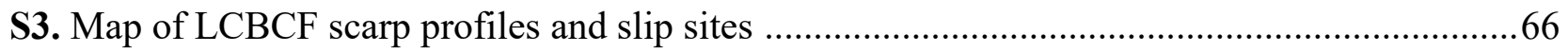

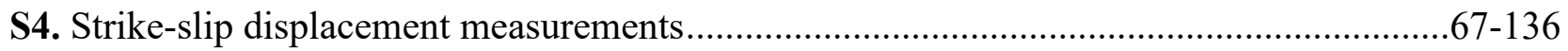

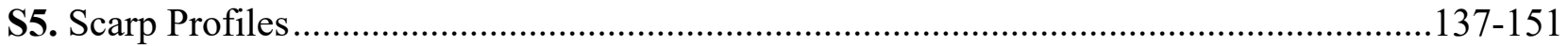

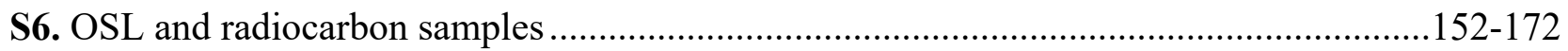

S7. CSZ coseismic slip distributions and BEM model results........................................173-239

Supplementary tables

TS1. SCF dip-slip displacement ..... $.240-241$

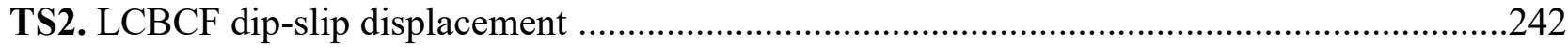




\section{INTRODUCTION}

Characterization of the tectonic development and seismic hazard of subduction zone forearcs requires an understanding of the long- and short- term processes that impose stress on upper plate faults. Accumulation of permanent strain in forearcs is attributed to interactions of crustal blocks (Allmendinger et al., 2009; Lamb and Smith, 2013; Nicol and Wallace, 2007; McCaffrey et al., 2007; Wells et al., 1998) and/or some component of inelastic deformation related to the megathrust earthquake cycle on the underlying subduction zone (Delano et al., 2017; Finley et al., 2019; Melnick et al., 2012; Savage, 1983). Short-term strain resulting from these processes can be examined through continuous Global Positioning System (GPS) geodetic measurements that measure strain accumulation within the forearc (Allmendinger et al., 2009). These data integrate motion over the last few decades, a fraction of the duration of the earthquake cycle $\left(10^{1}\right.$ to $\left.10^{3} \mathrm{yr}\right)$ and thus may not reflect longer-term $\left(>10^{3} \mathrm{yr}\right)$ rates or kinematics of deformation. Characterization of patterns in forearc deformation therefore requires a comparison of geodetic data to measurements made over multiple time scales (e.g., Allen et al., 2004; Delano et al., 2017; Finley et al., 2019; McCaffrey et al., 2007, 2013; Melnick et al., 2012; Nicol and Wallace, 2007).

Short-term strain accumulation within the Cascadia subduction zone (CSZ) forearc (Figure 1a) is well documented through continuous and campaign GPS measurements over the past $\leq 25$ years (e.g., McCaffrey et al., 2007, 2013). The majority of strain accumulation in the upper plate, observed through GPS velocity fields, is thought to be dominantly elastic and will thus be accommodated along the CSZ interface during large megathrust earthquakes (Leonard et al., 2010, 2004). Conversely, interseismic subduction zone coupling and stress transfer during megathrust earthquakes may also drive slip on upper plate faults (Delano et al., 2017; Gomberg 
and Sherrod, 2014), as has been documented in Chile (Farías et al., 2011; Melnick et al., 2012), and Japan (Kato et al., 2011; Imanishi et al., 2012).

Numerous airborne lidar and seismic reflection studies have revealed many active faults in western Washington state (Figure 1a and 1b) (Barnett et al., 2010; Blakely et al., 2002; Johnson et al., 1999; Pratt et al., 1997). Active faults accommodate primarily N-S shortening within the Cascadia forearc, approximately parallel to the Cascadia subduction zone, through reverse slip and lateral motion (Figure 1b). Generally, slip is dextral-oblique (e.g., the southern Whidbey Island fault; Johnson et al., 1996; Sherrod et al., 2008) on NW-striking faults and sinistral-oblique on NE-striking faults (e.g., the Saddle Mountain fault; Barnett et al., 2015; Witter et al., 2008). Furthermore, faults that strike E-W show reverse motion (e.g., the Seattle fault; Blakely et al., 2002; Johnson et al., 1999) (Figure 1b). Fault slip in the Cascadia forearc has been explained by two different sources of stress: (1) the earthquake cycle on the Cascadia subduction zone, driven by oblique convergence between the Juan de Fuca and North American plates (Delano et al., 2017; Finley et al., 2019); and/or (2) interactions of rigid crustal blocks within the Cascadia forearc (McCaffrey et al., 2007, 2013; Savage and Wells, 2015; Wells et al., 1998; Wells and Simpson, 2001).

This study focuses on the NW striking Sadie Creek fault (SCF), located on the northern flank of the Olympic Peninsula, where lidar data reveal distinct, laterally continuous fault traces and dextrally offset geomorphic markers that record a history of late Quaternary faulting (Nelson et al., 2017) (Figure 1b and 1c). The SCF, originally identified in gravity anomalies (MacLeod et al., 1977) and later named by Joyner (2016), was first mapped by Nelson et al. (2017) after the release of a high resolution lidar dataset in 2015 (Washington Department of Natural Resources, 2015). In this study, I combine geomorphic mapping and radiocarbon and OSL dating to 
constrain the post-glacial geomorphic development of the area affected by the SCF. Together with fault mapping and measurements of fault slip made through lidar analysis, I determine the slip rate and kinematics along the SCF over a $10^{3}-10^{4} \mathrm{yr}$. timescale. Slip rate and kinematics are compared to the magnitude and direction of slip estimated by an elastic block model and a boundary element method (BEM) model. The BEM model solves for the slip on the SCF and the associated Lake Creek-Boundary Creek fault (LCBCF; Figure 1b and 1c) that is necessary to entirely relieve the stress imposed onto the upper plate by the CSZ. Comparison of slip rate measurements to BEM modeling results constrains to what degree faulting on the Olympic Peninsula is driven by the CSZ. The elastic block model, in contrast, estimates the slip rate on the SCF/LCBCF by considering the entire interseismic velocity field - not just a single CSZ process. As such, the elastic block model constrains the effects of external stresses within the forearc in addition to those from CSZ coupling. The connections made between subduction zone processes and upper plate faults shed light on how permanent strain is retained within subduction zone forearcs, provide information on the stability of short-term processes over longer time scales, and contribute valuable information to nearby communities for the mitigation of seismic hazards.

\section{GEOLOGIC SETTING}

The Olympic Mountains of western Washington represent the structural and topographic high of the Cascadia forearc, and the only location where the Cascade accretionary wedge has been exposed subaerially (Brandon and Vance, 1992; Brandon et al., 1998) (Figure 1b). The accretionary complex consists of marine sedimentary rocks underthrust beneath Eocene marine to non-marine basalts of the Crescent Formation and Eocene-Miocene marginal marine 
sedimentary rocks (Tabor and Cady, 1978a; Brandon et al., 1998; Brandon and Vance, 1992;

Dragovich et al., 2002). Subsequent uplift and broad-scale doming of these rocks since $18 \mathrm{Ma}$ results in a regional east-plunging anticline across the Olympic Peninsula (Tabor and Cady, 1978b; Brandon et al., 1998) ( Figure 1b). Within the northern Olympic Peninsula, EoceneMiocene marine sedimentary rocks dip moderately $\mathrm{N}$ to NE and are cut by NE-dipping reverse faults (Dragovich et al., 2002; Tabor and Cady, 1978a). Bedrock faults have similar geometries to recently studied active faults, including the SCF and LCBCF on the northern Olympic Peninsula (Nelson et al, 2017) and the Canyon River fault and Saddle Mountain fault zone on the southern Olympic Peninsula (Barnett et al., 2015; Walsh and Logan, 2007) (Figure 1b.).

The Juan de Fuca lobe of the Cordilleran ice sheet, which split and flowed westward from the Puget Lobe at $\sim 48^{\circ}$ latitude (Figure 1), covered many high ridgelines in the northern Olympic Peninsula, reaching elevations of up to $1 \mathrm{~km}$ (Porter and Swanson, 1998; Polenz et al., 2004; Thorson, 1980). As such, the landscape and surficial geology of the northern Olympic Peninsula strongly shows the effects of the Juan de Fuca lobe. (Mosher and Hewitt, 2004; Tabor and Cady, 1978a). Alpine glaciers were extensive within the core of the Olympic Mountains during the last glacial maximum, however, deposits around the SCF and LCBCF were solely derived from the Juan de Fuca lobe, except for possible input of alpine-derived glacial outwash into the Elwha drainage (Figure 1c) (Dragovich et al., 2002; Polenz et al., 2004; Schasse, 2003). Existing radiocarbon ages suggest that the Juan de Fuca lobe of the Cordilleran ice sheet advanced to its maximum extent after ca.16 ka and had retreated by ca.14 ka. The timing of Juan de Fuca lobe advance is supported by radiocarbon dating of wood samples $\left(13,010-13,380{ }^{14} \mathrm{C} \mathrm{yrs}\right.$. BP; 15,300-16,200 Cal yrs. BP) from Lake Ozette, WA (Figure 1b) originally published by Heusser (1973) and later reinterpreted as pre-glacial wood in lodgment till by Haugerud and Hendy 
(2016). Radiocarbon dating of post-glacial wood $\left(12,380 \pm 90{ }^{14} \mathrm{C}\right.$ yrs. BP; $14,940-14,095$ Cal yrs. BP) from near Bellingham, WA (Kovanen and Easterbrook, 2001) and bone fragments $\left(11,960 \pm 17{ }^{14} \mathrm{C}\right.$ yrs. BP; 13,010-13,380 Cal yrs. BP) from the Manis Mastodon site in Sequim, WA (Waters et al., 2011) constrains the timing of Juan de Fuca lobe retreat (Figure 1b).

Recent work on the LCBCF including paleoseismic trenching (Nelson et al., 2017) and coring and seismic imaging of lacustrine megaturbidites within Lake Crescent (Leithold et al., 2019) provide constraints on earthquake timing and fault slip rate. Nelson et al. (2017) found evidence for two large, surface rupturing earthquakes at $1.3 \pm 0.8$ and $2.9 \pm 0.6 \mathrm{ka}$ and possible evidence for 2-3 earlier ruptures. Through seismic reflection and coring of large (up to $2 \mathrm{~m}$ thick) turbidite deposits in Lake Crescent, Leithold et al (2019) identified and dated four Holocene earthquakes at 7,165 - 7,005; 5,300 - 4,860; $4100-3,840$; and 3,225 - 2,960 Cal yrs. B.P. and also noted two other (undated) turbidites deeper within the lake stratigraphy. The age of the penultimate earthquake determined by Nelson et al. (2,900 \pm 600 cal. yrs. B.P.) correlates with the age of the most recent turbidite found by Leithold et al. (3,100 \pm 100 cal. yrs. B.P.). Discrepancies in the age of turbidite emplacement and the timing of surface ruptures on the LCBCF suggest that other seismic sources may have induced turbidite emplacement and/or that the LCBCF and SCF are segmented and do not always rupture together.

Dextral slip and vertical separation on the LCBC and SCF were measured by Nelson et al. (2017) as $\sim 11-28 \mathrm{~m}$ and 1-2 $\mathrm{m}$ respectively and, using deglaciation as a maximum age, result in a slip rate estimate of $\sim 1-2 \mathrm{~mm} / \mathrm{yr}$. Additionally, Nelson et al. (2017) used empirical relationships based on slip per earthquake and maximum rupture length to yield moment magnitude estimates of $M_{w}$ 7.1-7.5. Nelson et al. (2017) included some analysis of channels offset by the SCF, although they did not perform detailed geologic mapping or date landforms. 
The data presented here builds on their analysis by providing the necessary geologic context for understanding the cumulative displacement along the Sadie Creek fault and by modeling the dynamic processes that drive deformation on the SCF and LCBCF.

\section{GEOMORPHIC MAPPING}

I created a 1:10,000 scale geomorphic map of the surficial geology along the SCF (Figures 2 and S1) using a bare-earth lidar digital elevation model (DEM) and its derivatives (hillshade, slope, and contour maps) along with field mapping. This mapping delineates Paleogene bedrock from glacial and post-glacial deposits and the surface expression of the SCF. Using field observations from roadcuts, stream exposures, and test pits along with observations of the shape, size, and texture of deposits in lidar, this mapping identifies and describes Quaternary deposits that include: glacial till (Qgt), glacial outwash (Qgo), moraine crests, alluvial gravels $(\mathrm{Qal})$ and terraces $(\mathrm{Qt})$, fans $(\mathrm{Qf})$, colluvium $(\mathrm{Qc})$, and landslides $(\mathrm{Q} 1 \mathrm{~s})$ (Figures 2, and S1) . Additionally, cross-cutting relationships determined the relative ages of these deposits (e.g., fans are mapped as younger than the surfaces on which they have been deposited (Figures 2 and S1). I mapped the contacts between bedrock and Quaternary units, based on field exposures and bedding traces revealed in lidar imagery, but did not describe or distinguish between bedrock units. All descriptions of bedrock units that I present come from 1:100,000 scale mapping of the northern Olympic Peninsula (Schasse, 2003). Mapped active faults reflect locations where scarps laterally and/or vertically offset deposits or landforms (Figures 2,3, and 4).

Surficial mapping allows for interpretation of the history of the geomorphic and tectonic processes that have sculpted the landscape around the SCF. Glacially scoured bedrock overlain 
by glacial till, moraines, and outwash terraces reflect the imprint of the continental ice sheets that flowed westward across the area during the last glacial maximum. Glacial units are reworked by postglacial processes to form colluvial slopes (Qc), alluvial fans (Qf), landslide deposits (Q1s) and alluvial gravel/terrace deposits (Qal, Qt) (Figure 3B and 3C). The surface trace of the SCF is roughly linear, cuts glacial and post-glacial deposits and landforms, and is laterally continuous for $\geq 14 \mathrm{~km}$. I am unable to determine the western terminus of the SCF as fault scarps are well defined to the western edge of the available lidar data near the East Twin River (Figure 1c). The SCF switches from north facing east of the Lyre River to south facing west of the Lyre River and predominantly strikes NW-SE except between Sadie Creek and the East Twin River where it strikes west (Figures 1C, 2A and S2). Changes in scarp facing direction along with a laterally continuous fault trace and dextral offset of stream channels (e.g., Figures 3, 4) supports the interpretation of Nelson et al. (2017) that the SCF is a steeply dipping, right lateral-oblique strike-slip fault.

\section{FAULT SLIP ANALYSIS}

I combined field and lidar measurements to map and analyze geomorphic piercing lines displaced by the SCF. This study uses the channel analysis program, "3D_Fault_Offsets," of Stewart et al., (2017) to measure the strike-slip component of the total slip vector (herein referred to as "strike-slip" or "strike-slip displacement") within lidar data (the method of Stewart et al., 2017 also measures the dip-slip component, however, I find that these measurements are affected by geomorphic modification within the channel - see Appendices I and II). Additionally, I follow the scarp profiling methods of Thompson et al. (2002) to measure vertical separation and the dip-slip component of the total slip vector (herein referred to as "dip-slip" or "dip-slip 
displacement"). Both methods probabilistically cross-correlate offset geomorphic markers across a fault trace to measure fault slip and use a Monte Carlo approach to quantify the uncertainty involved in the calculation.

I measured 11 laterally offset stream channels (e.g., Figures 3 and 4) on the SCF and two stream channels on the LCBCF not previously measured by Nelson et al. (2017) to calculate the amount of strike-slip displacement (Figures S2, S3 and S4). In each case, points along morphologic markers of the stream channel (e.g., channel thalweg, riser midpoint, etc.) were identified within a lidar DEM based on relative elevations, steepness, and changes in concavity using 3D_Fault_Offsets. Markers were then regressed and projected onto the fault trace in order to measure the strike-slip displacement (Stewart et al., 2017) (Figures 4B and S4). For each channel, I visually assess the quality of marker identification (Table 1), removing measurements where automatically identified points do not appear to accurately follow their respective geomorphic feature, and interpret the distribution of measurements in terms of the geomorphic development of the channel. For example, a lower magnitude of strike-slip displacement measured from the channel thalweg than the midpoint of the riser may suggest that channel erosion has minimized the record of strike-slip displacement (Figure 5C). Thus, the measurement made from the channel riser midpoint represents a more accurate representation of strike-slip displacement. After all measurements are assessed, each slip measurement is assigned a probability distribution based on the spread of the individual marker measurements and the interpretation of channel development. Probability distributions of slip allow for errors to be quantified and assigned to each measurement. Finally, I evaluate the reported measurement by back-slipping the offset channel (Haddon et al., 2016; Stewart et al., 2017; Zielke, 2015) along the fault trace to the preferred value, lower bound, and upper bound of the reported offset. I 
adjust the probability distributions and resultant errors if the backslip does not visually show a satisfactory pre-fault reconstruction and compare to field measurements (Figure 6) (See Appendix I for detailed description of methods used for strike-slip displacement measurements, interpretation, error calculation, and quality assessment).

I analyzed 48 scarp profiles on the SCF to calculate the amount of dip-slip displacement. In each case, scarp profiles were extracted from the ground returns of the lidar point cloud, in 3 m-wide swaths orthogonal to the scarp face (Figure 3A). In cases where piercing lines could be traced (e.g., Figure 3, profiles NOL8E and NOL8W; Figure 4) a segmented profile was taken and combined. Regressions fit to the upthrown surface, downthrown surface (e.g., Figure 4C), and scarp face, along with parameters for the fault dip and fault position, were used in a Monte Carlo simulation to calculate the amount of vertical separation, the component of dip-slip on the fault plane, and their associated errors (Thompson et al., 2002). In each measurement, I assume a uniform distribution for the fault dip, ranging from $60^{\circ}$ to $90^{\circ}$ to the north and a trapezoidal distribution for the fault location, such that the fault has the highest probability of being located between the lower $1 / 3$ and $1 / 2$ of the scarp height (e.g., Thompson et al., 2002). I report the preferred dip-slip displacement as the median of the distribution produced by Monte Carlo simulation and the uncertainty for each measurement (Supplementary Table TS1, Figure S5) as the $95 \%$ confidence interval around the median.

I constrained the ratio of strike-slip to dip-slip displacement, rake, and the total amount of slip by combining the strike-slip measurements at each channel site with all dip-slip displacements measured from scarp profiles in the vicinity of the offset channel. Kernel density estimates fit to the distributions of dip-slip displacements of all profiles considered at each offset channel capture any variability between dip-slip measurements within their associated errors. In 
some instances, profiles were omitted from the fit of density functions if there was substantial geologic evidence that the dip-slip displacement measurement was of low quality (e.g., geomorphic modification at the scarp or uncertainty in the type of deposit on either side of the fault trace; SP02 in Figure 3c). I then conducted a Monte Carlo simulation using the kernel density distributions of the dip-slip measurements and the assigned probability distributions of the strike-slip measurements to calculate the strike-slip to dip-slip ratio, rake, and the total slip at each slip site. Reported strike-slip to dip-slip ratios, rakes and total slip and their uncertainties are given by the peak value (mode) of the kernel density fit to the result of the Monte Carlo simulation and the $95 \%$ confidence interval around the median, respectively (Table 1, Figure 7).

The process of calculating the strike-slip to dip-slip ratio, rake and total slip was repeated using the measurements on the LCBCF reported by Nelson et al. (2017) and for the two additional offset channels added by this study. Because Nelson et al. (2017) reported vertical separation (without errors) as opposed to dip-slip, I calculated dip-slip at their scarp profile locations using the same scarp profiling methods used in this study. Strike-slip measurements from offset features on the LCBCF presented by Nelson et al. (2017) were verified through backslipping and adjusted at several locations (Table 1, Figure S4). Strike-slip displacement measurements along the LCBCF based on backslipping were assigned triangular probability distributions, while the two additional strike-slip displacement measurements based on channel analysis were assigned Gaussian distributions (Appendix I, Figure S4).

Characterization of total fault slip and kinematics requires measurements of dip-slip and strike-slip displacement which, ideally, are made on the same feature. However, the only record of strike-slip displacement preserved on the SCF comes from debris flow channels, features that do not consistently preserve dip-slip displacement. As such, I calculate total slip, strike-slip to 
dip-slip ratios, and rake using strike-slip measurements from dextrally offset debris flow channels and dip-slip measurements from scarp profiles proximal to the offset channel. In order to combine dip-slip and strike-slip measurements in this manner, I assume that (1) the initial offset of the channel and formation of the fault scarp are the same age and (2) laterally offset markers within the channel are protected from geomorphic modification during the interseismic period (e.g., Figure 5B). If one of these assumptions is incorrect, then the measured strike-slip to dip-slip ratio will appear less than the true strike-slip to dip-slip ratio (e.g., Figure $5 \mathrm{~A} \& \mathrm{C}$ ). Therefore, all calculated strike-slip to dip-slip ratios, total slip, and rakes are minima (rake is skewed towards $\left.\pm 90^{\circ}\right)$.

Strike-slip displacement ranges from $\sim 3.5-30.0 \mathrm{~m}$ along the length of the SCF and LCBCF (Figures 7 and 8, Table 1). The largest strike-slip displacements on the SCF occur on the eastern section, between the Lyre River and Lake Crescent (Figure 7A between $\sim 12-15 \mathrm{~km}$, Figure S2). Comparable strike-slip magnitudes were measured at three locations on the LCBCF (Figures 7 and 8). The smallest strike-slip displacement was measured at site J, a location where a scarp is preserved within the channel (Figure 4). I report two strike-slip measurements from this site.

Dip-slip displacement ranges from $0.5-6.5 \mathrm{~m}$ along the SCF and $0.7-4.6 \mathrm{~m}$ along the LCBCF (Figures 7 and 8). Dip-slip displacement does not appear to have any distinct groupings or spatial correlations along the SCF with the exception of three measurements on the E-W striking portion of the SCF that have relatively large dip-slip displacement ( 4.1-6.5 m; Figure 7A, between $3 \mathrm{~km}$ and $5 \mathrm{~km}$ ), and measurements of faulted postglacial deposits that have relatively less dip-slip displacement (1.0-3.7m; Figure 7A, blue triangles). The rake is generally $>150^{\circ}(>2: 1$ strike-slip to dip-slip ratio) along strike of the SCF and LCBCF but most 
measurements show rakes of $\sim 170^{\circ}(\sim 6: 1$ strike-slip to dip-slip ratio) (Figures $7 \mathrm{~B}$ and $7 \mathrm{C}$, Table 1). I also note a slightly lower rake for the SCF than the LCBCF, due to the greater range in dipslip displacement present there (Figures, 7 and 8, Table 1).

\section{OSL DATING}

I used the single aliquot, regenerative method OSL dating of quartz and feldspar sand grains (Murray and Wintle, 2000; 2003) and radiocarbon dating of detrital charcoal to establish ages of offset deposits and features. OSL dating quantifies the number of electrons trapped within the crystal lattice of quarts and feldspar grains as a result of exposure to natural environmental radiation while the grains were buried. When the grains are exposed to light, the trapped electrons are released, effectively resetting, or "bleaching," the OSL ages (Rhodes, 2011; Duller, 2004). Under the assumption that grains were completely bleached prior to burial, OSL ages represent the time of deposition of the units.

In this study I collected eight OSL samples from deposits deformed by the SCF including glacial outwash (Qgo), ice contact (Qgoi), and alluvial fans (Qf) (Figures 2, S1, and S6). Sample sites were chosen were exposures or test pits showed concentrations of fine sand. 1.5-inch steel tubes were used to collect the target OSL material and the surrounding $30 \mathrm{~cm}$ of sediment was collected in large plastic bags for dose rate analysis. I performed all sample preparation and analysis at Utah State University under amber light $(590 \mathrm{~nm})$. First, sediment was extracted from the steel sample tubes and moisture content was measured by weighing the sediment before and after being dried. Each sample was then wet sieved to target fine sand and treated with bleach $\left(10 \% \mathrm{H}_{2} \mathrm{O}_{2}\right)$ and hydrochloric acid $(10 \% \mathrm{HCl})$ to remove organic and carbonate material. Sodium polytungstate $\left(2.7 \mathrm{~g} / \mathrm{cm}^{3}\right)$ was used to separate quartz and feldspar grains before being etched 
with hydrofluoric acid (47\% HF). Dose rate analysis was performed by ALS Chemex in Reno NV using ICP-MS and ICP-AES AES to determine K (\%), Rb (ppm), Th (ppm), and U (ppm) concentrations of the sediment. I use a minimum age model (Galbraith et al., 1999) to estimate the ages, which favors younger, more fully bleached (reset) samples.

OSL sample analysis was not completed in time for submission of this thesis. However preliminary results are generally consistent with expected ages based on dating of glacial and end-glacial deposits elsewhere within western Washington (Haugerud and Hendy, 2016; Heusser, 1973; Kovanen and Easterbrook, 2001; Mosher and Hewitt, 2004; Porter and Swanson, 1998), and models of landscape evolution in recently deglaciated settings (Ballantyne, 2017)

(Table 2). Results of the OSL analysis will be included in a publication in preparation once final dates become available.

\section{RADIOCARBON DATING}

This study used standard acid-base-acid pre-treatment protocol (Brock et al., 2010) for all radiocarbon samples before being analyzed using an accelerated mass spectrometer (AMS) by DirectAMS (www.directams.com). Results of the radiocarbon analysis yield ages in radiocarbon years B.P., which were calibrated to calendar years B.P. using the program OxCal (Ramsey, 2008, 2009) and the INTCAL13 calibration data of Reimer et al. (2013). Radiocarbon ages of detrital charcoal represent a maximum age of the deposit as the charcoal must already be present in the landscape before being mobilized and buried.

Eleven detrital charcoal samples were analyzed in this study, collected from different deposits along the trace of the SCF (Table 3, Figure 2, and Figure S6). Seven samples were collected from different debris flow deposits related to deposition within the offset channels (six 
samples collected from inside channels themselves and one sample from a debris flow fan at the base of the channel) (Figure 9 and Table 3). Samples were collected as deep in the exposure as possible in attempt to date the oldest deposits within that channel (the oldest deposits within a channel best bracket the age of channel formation), but were limited by the availability of charcoal, the size of deposits, and a shallow water table (which filled many test pits). The other four samples were collected from glacial till (Qgt), an alluvial terrace (Qt), and fan (Qf) deformed by the SCF (two samples, GB32 and BL02 were sampled from paleoseismic trenches) (Figures S1 and S6). Radiocarbon dates of one sample collected from a post-glacial fan (SCF18CD6) show a glacial age of 47,812 - 45,500 Cal yrs. BP (Table 3). As such, this old date suggests that the collected charcoal was recycled. Most calibrated dates from charcoal samples collected within channel-associated deposits fall between $\sim 3300$ and $\sim 1400$ Cal yrs. BP (Table 3, Figure 9). However, two other channel-associated samples produce ages of 5751-5982 Cal yrs. BP (sample SCF18-10-06), and 10,707-11,104 Cal yrs. BP (SCF18-11B-01; Table 3, Figure 9).

New radiocarbon and OSL ages from glacial and post-glacial deposits further constrain the age of deglacial of the Juan de Fuca Lobe in the northern Olympic Mountains. The deglacial age of the Juan de Fuca lobe (14,940-14,095 Cal yrs. BP) suggested by Kovanen and Easterbrook (2001) is similar to that of charcoal (14,196-13,794 Cal yrs. BP) sampled from coarse grained fluvial deposits, interpreted in the field as glacial outwash or alluvial fan (sample GB32, Table 3). As such, the charcoal ages reported in this study are consistent with a deglacial age of $\sim 14 \mathrm{ka}$ in the northern Olympic Mountains. The abundance of younger charcoal ( 11ka$1.5 \mathrm{ka}$ ) within debris flow channel/fan deposits and fluvial terraces (Table 3) suggests geomorphic activity within channels continued well into the Holocene, following the retreat of the Juan de Fuca lobe. This timeframe and style of Holocene geomorphic activity is consistent 
with models of landscape evolution in paraglacial settings which propose that sediment supply exhaustion and re-entry of vegetation into the landscape restricts geomorphic activity to major drainages, small channels on steep hillslopes, and landslides (Ballantyne, 2017).

\section{SLIP VARIABILITY AND FAULT SLIP RATES}

Both the range (3-30 m of strike-slip; $0.5-6.5 \mathrm{~m}$ of dip-slip; Figure 8, Table 1) and along-strike variability of strike-slip and dip-slip displacements along the SCF and LCBCF (Figure 7) reflects multiple post-glacial surface-rupturing earthquakes. Variability of cumulative fault slip can be explained by: (1) variable slip along strike during individual surface rupturing events; (2) age of offset features varying along strike (e.g., older features are offset by more earthquakes than younger features); and/or (3) surface rupturing events occurring at certain locations along strike more frequently than at other locations. Each of these scenarios on their own would produce different spatial distributions of fault slip. Variable slip along strike would yield seemingly random distributions of slip that reflect the cumulative effects of coseismic slip variability (e.g., Mcgill and Rubin, 1999); offset features of various age would produce distinct clusters of slip magnitudes (e.g., Zielke et al., 2010); and spatial variability in the frequency of earthquakes would yield different slip magnitudes along distinct fault strands.

The distribution of dip-slip and strike-slip displacement measured along strike of the SCF and LCBCF does not show distinct differences in fault slip between the SCF and LCBCF, aside from slightly higher dip-slip displacement on the SCF (Figure 8). This observation, along with paleoseismic evidence that correlates the timing of some but not all surface rupturing events across the LCBCF (Nelson et al., 2017), Lake Crescent (Leithold et al., 2019), and the SCF 
(Amos et al., 2019), suggests that spatial variability in the frequency of earthquakes, alone, does not control the variability of slip along the SCF/LCBCF.

I recognize three sites where single event displacements are possibly recorded by channel thalwegs, suggesting that the variability in slip may reflect differences in the age of the measured piercing lines. Of these channels, site J shows the best evidence for incremental offset because, at this location, a fault scarp preserved within the debris flow channel records less vertical separation $(3.7 \pm 0.2 \mathrm{~m})$ than the scarp on the interfluve $(5.0 \pm 0.3 \mathrm{~m}$; Figure 4). Additional slip measurements at site J show differential strike-slip displacement between the channel thalweg and the interfluve - the channel thalweg is offset $4.0 \pm 0.8 \mathrm{~m}$ while the interfluve is offset $8.3 \pm$ $1.8 \mathrm{~m}$ (Figure 4, Table 1). The strike-slip displacement of the riser midpoint at site $\mathrm{J}(6.4 \pm 1.0$ m; Figure 4D), which is less than that of the interfluve and more than the channel thalweg, may suggest that site $\mathrm{J}$ records three surface ruptures. However, the strike-slip displacement recorded by the riser midpoint is more likely less than the interfluve due to erosion during the interseismic period (e.g., Figure 5C). Because the channel thalweg represents a single event displacement and erosion is required to record incremental offset within a single channel (otherwise all markers would record only the cumulative displacement of all surface ruptures) then geomorphic modification likely took place during the interseismic period, reducing the recorded displacement of other channel markers like the riser midpoint. Additionally, the measurement of the riser midpoint displacement is within error of that from the interfluve, so I am unable to conclude that it is distinct.

Based on field measurements, lidar measurements, and radiocarbon dating of debris flow deposits, I suggest that channel $\mathrm{J}$ has been offset by at least two earthquake ruptures, where the upthrown side of the channel was cut off from the downthrown side during the most recent 
event. As such, the lateral offset of the channel thalweg represents a single event strike-slip displacement $(4.0 \pm 0.8 \mathrm{~m})$ and the offset of the interfluve represents the cumulative strike-slip displacement $(8.3 \pm 1.8 \mathrm{~m})$ of two or more events. Following my interpretation at Site J, the age of charcoal (2,310-2,120 Cal yrs. BP; Sample SCF18-03-0; Table 3) collected from a debris flow deposit in the upthrown (i.e. cutoff) channel must predate the most recent earthquake and postdate the penultimate earthquake. The age of the cutoff debris flow deposit agrees with paleoseismic evidence that postulates the most recent earthquake to be $\sim 1,300 \mathrm{Cal}$ yrs. BP, and the penultimate event to be $\sim 3,000$ Cal yrs. BP (Leithold et al., 2019; Nelson et al., 2017).

The other two channels that I interpret to record single event displacements, Site $\mathrm{H}$ on the SCF and Site OL03 on the LCBC, do not have scarps preserved within the channel. However, the strike-slip displacement of the channel thalwegs $(4.1 \pm 1.0 \mathrm{~m}$ and $4.5 \pm 2.4 \mathrm{~m}$, respectively) is substantially less from other markers outside the channels $(9.9-14.7 \mathrm{~m}$ and $26.0+11.8 /-8.0 \mathrm{~m}$, respectively) and similar to the site $\mathrm{J}$ thalweg. ( $4.0 \pm 0.8 \mathrm{~m}$; Figures 7, S4, and Table 1$)$. Taken together with my interpretation of site J, I conclude that the strike-slip displacement per event on the SCF and LCBCF is approximately $4.0 \pm 1.0 \mathrm{~m}$.

Despite evidence for piercing lines of varying age, the magnitude of strike-slip displacement does not correlate with the radiocarbon age of the channel deposits (Figure 9). If charcoal within channel deposits recorded the age of channel incision (before faulting), then the magnitude of strike-slip displacement would increase with channel age. Instead, most channel ages are young (between $\sim 3300$ and $\sim 1400 \mathrm{Cal}$ yrs. BP) with two older ages $(\sim 5,800$ and $\sim 11,000$ Cal yrs. BP; Figure 9, Table 3), suggesting that channels have routed debris flow sediment throughout the mid-to-late Holocene and likely have throughout post-glacial time. While geomorphic activity in channels has removed the record of dip-slip displacement within 
the channels (except for site J), these piercing lines still appear to be robust recorders of strikeslip displacement because a wide range of strike-slip magnitudes (including large amounts of slip) are still preserved. Therefore, strike-slip displacement may correlate better with channel age than the deposit age from radiocarbon dating. As such, the channels with most strike-slip displacement $(\sim 25 \pm 5 \mathrm{~m})$ are likely the oldest channels in the study area. These larger offsets may record the cumulative slip for all post-glacial surface rupturing events on the SCF, assuming a single event strike-slip displacement of $4 \pm 1 \mathrm{~m}$ and five post-glacial surface rupturing events from the nearby ( $\sim 2 \mathrm{~km}$ away) Bog Lemming trench of Amos et al. (2019). Based on evidence for channels of multiple age and inconsistent timing of some earthquakes on the SCF and LCBCF from paleoseismic studies, (Amos et al., 2019; Leithold et al., 2019; Nelson et al., 2017), the variability in slip along strike of SCF/LCBCF is likely a reflection of variability in the slip along strike of surface rupturing events, where these events occurred, and the age of the piercing lines that record the slip.

Based on models of landscape development in recently deglaciated settings, channel incision on steep, drift-mantled hillslopes occurs within a few hundred years after glacial retreat due the large sediment supply and lack of vegetation (Ballantyne, 2017). Therefore, older channels, which record the most strike-slip displacement, likely formed immediately after deglaciation, and are the best piercing lines in construction of a post-glacial fault slip rate for the SCF and LCBCF. Combination of a deglacial age of $14 \pm 1 \mathrm{ka}$, constrained through radiocarbon and OSL dating of glacial outwash, ice contact deposits and alluvial fans (Tables 2 and 3), and the total slip recorded by channels with the most offset $(25 \pm 5 \mathrm{~m})$ produces a preferred postglacial strike-slip rate of $1.3-2.3 \mathrm{~mm} / \mathrm{yr}$. Similarly, combination of the deglacial age with the range of dip-slip displacements on glacially derived deposits along the SCF and LCBCF (0.7-6.5 
m) yield a dip-slip rate of $0.05-0.5 \mathrm{~mm} / \mathrm{yr}$. Using the measurements of single event slip from site $\mathrm{J}$ and the empirical relations of Hemphill-Haley and Weldon (1999), I estimate the moment magnitude of paleo-earthquakes to be $\sim M_{\mathrm{w}}$ 7.2-7.5. Similarly, assuming a full rupture over the $\sim 60 \mathrm{~km}$ length of the LCBCF and SCF, empirical relationships (Wells and Coppersmith, 1994) indicate paleo-earthquake size of $\mathrm{M}_{\mathrm{w}}$ 7.1-7.2.

\section{CRUSTAL STRAIN MODELING}

I compare measured fault slip rates and kinematics with the predictions of geodetically constrained models of forearc deformation to determine what relationships exist between slip over millennia on the LCBCF/SCF, subduction zone processes, and forearc block interactions. Geodetic velocity fields within the Cascadia forearc show the influence of clockwise crustal block rotation, interseismic coupling along the Cascadia subduction zone (McCaffrey et al., 2007, 2013; Wells et al., 2014; Wells and Simpson, 2001), and repeated (quasi-periodic) slow slip events (Rogers and Dragert, 2003; Audet and Schaeffer, 2018; Mountjoy and Barnes, 2011; Peng and Gomberg, 2010). Additionally, geodetic displacement fields will capture the effects of CSZ coseismic slip during the next megathrust earthquake. Quantification of different tectonic processes through geodetically constrained subduction zone models presents the opportunity to understand the influence of short term $\left(10^{1} \mathrm{yr}.\right)$ tectonic processes on upper plate structures.

Here, I implement a boundary element method (BEM) model (Crouch and Starfield, 1983; Thomas, 1993) to estimate the stress imposed by three independent subduction zone processes: (1) interseismic coupling on a locked CSZ; (2) slow slip events; and (3) CSZ coseismic rupture. Additionally, I use an elastic block model (Meade and Loveless, 2009) to determine the how strain accumulation on SCF and LCBCF is related to forearc block 
interactions and interseismic coupling along the CSZ. Using the BEM model, I estimate the slip rate on the SCF and LCBCF required to relieve the imposed stress. I assume that the polygonal elements representing the SCF/LCBCF are shear traction-free surfaces (e.g., Cooke and Dair, 2011) and that the slip completely relieves the accumulated shear stress imposed by the tectonic process being modeled. The resulting slip rate distribution represents the coseismic slip distribution on the LCBCF/SCF, normalized by the recurrence interval. The amount and distribution of slip rates calculated from the BEM modelling are then compared to the measurements of long-term ( $\sim 14 \mathrm{ka})$ fault slip rate determined in this study.

\section{BEM MODELING PROCESS AND PARAMETERS}

The BEM model represents the 3-D geometry of the CSZ, SCF and LCBCF using triangular dislocation elements (TDEs) meshed together in an elastic half-space characterized by a shear modulus of $3 \times 10^{10} \mathrm{~Pa}$ and Poisson's ratio of 0.25 . Within the BEM model, the surface trace of the SCF and LCBCF is projected to a depth of $10 \mathrm{~km}$ and rotated to a $\sim 80^{\circ}$ dip to the north, consistent with bedrock mapping of the SCF and LCBCF (Polenz et al., 2004; Dragovich et al., 2002; Schasse, 2003; Tabor and Cady, 1978a). The geometry of the CSZ, also represented by a continuous mesh of TDEs, is based on slab depth contours derived from seismicity data (McCrory et al., 2012). On each TDE, I prescribe the traction rate or displacement (slip) rate in the strike, dip, and normal direction of each triangular element. On all TDEs, I prescribe zero displacement rate conditions in the element-normal direction to prevent opening or interpenetration across elements. On the CSZ TDEs, however, I prescribe the geodetically estimated slip (or slip rate) distribution from the modeled tectonic process in the strike and dip directions. Specifics on the creation of each CSZ slip distribution are described in the following 
sections. On the SCF and LCBCF TDEs, I assign zero shear traction in the strike and dip directions. As such, the BEM model estimates the slip rate distribution on the crustal fault elements necessary to achieve the prescribed zero shear traction rate conditions, which I interpret as the slip rate distribution required to completely relieve the shear traction imposed by modeled tectonic process (Figure 10).

\section{CASCADIA SUBDUCTION ZONE INTERSEISMIC COUPLING}

To model the effects of interseismic coupling on the LCBCF and SCF, I first calculate a slip deficit distribution on the CSZ using an elastic block model (Meade and Loveless, 2009), with microplate boundaries defined by Holocene-active faults (U.S. Geological Survey, 2006) and gradients in GPS velocities (Evans et al., 2015; Loveless and Meade, 2011). In order to isolate the effects of interseismic subduction zone coupling on the SCF/LCBCF, the block model does not include the LCBC/SCF as a block bounding segment when computing the CSZ slip deficit distribution. The CSZ slip deficit distribution (Figure 11A) is then input in the BEM model along with the SCF/LCBCF geometries and the boundary conditions described above to estimate the fault slip on the LCBCF and SCF necessary to relieve the stress imposed by interseismic coupling.

The slip rate distribution on the LCBCF and SCF produced by the BEM model predicts up to $1.6 \mathrm{~mm} / \mathrm{yr}$ of left lateral slip and up to $0.5 \mathrm{~mm} / \mathrm{yr}$ of reverse slip corresponding to a rake of $\sim 20-45^{\circ}$ (Figure $12 \mathrm{~A}$ and Table 4 ). The rate of reverse slip estimated by interseismic coupling is consistent with the magnitude and direction of the post-glacial dip-slip rate, however, the strikeslip component of modeled slip produces the opposite kinematics than shown by the geomorphic record of the SCF/LCBCF. 


\section{CASCADIA SUBDUCTION ZONE COSEISMIC STRESS TRANSFER}

Surface deformation during a rupture of the Cascadia subduction zone has not been measured geodetically within Cascadia as it has been in other subduction zones (e.g., Ito et al., 2011; Iinuma et al., 2012). However, dislocation models (e.g., Flüt et al., 1997; Wang et al., 2001, 2003; McCaffrey et al., 2007) and the paleoseismic record of offshore turbidites, coseismic subsidence, and tsunami deposits (Goldfinger et al., 2016; Priest et al., 2017; Atwater, 1987; Atwater and Hemphill-Haley, 1997) can estimate the recurrence interval and degree of deformation as a result of coseismic slip. I used 33 distributions of coseismic slip originally presented by Frankel et al. (2018) and Wirth et al. (2018) to model the stress imposed by a CSZ megathrust earthquake on the SCF and LCBCF. Each slip distribution is composed of several high stress-drop $M_{w} 8.0$ subevents superimposed on large, shallower background slip such that the total seismic moment of each model corresponds to $\mathrm{M}_{\mathrm{w}} 9.0$ (Frankel et al., 2018). Coseismic slip distributions are randomly seeded across three prescribed down-dip rupture extents based on the choices of the 2014 National Seismic Hazard Maps (Frankel et al., 2015; Petersen et al., 2002). These limits listed from deepest to shallowest are: (1) the top of the nonvolcanic tremor zone, (2) the $1 \mathrm{~cm} / \mathrm{yr}$ locking contour derived from inversion of GPS and uplift data, and (3) the midpoint of the edge of the locked zone in thermal modeling and the $1 \mathrm{~cm} / \mathrm{yr}$ locking location. The up dip rupture limit is specified to a depth of $5 \mathrm{~km}$ for all models (Frankel et al., 2018). Each slip distribution is converted to slip rate distributions using a recurrence interval of 500 years (Atwater and Hemphill-Haley, 1997; McCaffrey and Goldfinger, 1995; Priest et al., 2017) and are interpolated onto the triangular dislocation elements representing the geometry of the CSZ (McCrory et al., 2012). Slip rate distributions (e.g., Figure 11B; all 33 distributions shown 
in Figure S7) are then input into the BEM model with all necessary crustal fault geometries and boundary conditions. Two iterations of the BEM are run for each distribution, with variations in CSZ coseismic rake $\left(90^{\circ}, 115^{\circ}\right)$ to account for uncertainty in the rake of coseismic slip (McCaffrey et al., 2013)

The resulting slip rate distributions on the LCBCF and SCF from all model runs (Figure S7), assuming a CSZ coseismic rake of $90^{\circ}$, predicts $\sim 0.3$ to $1.5 \mathrm{~mm} / \mathrm{yr}$ of right lateral and $\sim 0.1$ to $0.3 \mathrm{~mm} / \mathrm{yr}$ of normal slip, corresponding to a rake of $\sim-145^{\circ}$ to $-175^{\circ}$ (Table 4 ). Models that assumed a CSZ coseismic rake of $115^{\circ}$ predicted slightly slower right lateral rates (up to 1.3 $\mathrm{mm} / \mathrm{yr}$ ) on the LCBC and SCF and faster normal rates (up to $0.5 \mathrm{~mm} / \mathrm{yr}$ ) (e.g., Figure $12 \mathrm{~B}$ and Table 4). Additionally, models with prescribed deep down-dip rupture limits and/or randomly seeded large magnitudes of slip in the northern CSZ predicted faster slip rates (both dip-slip and strike-slip) than models with shallower down-dip rupture limits. Overall these results suggest

that during a coseismic rupture of the CSZ, right lateral slip on the SCF and LCBCF is greatest if the rupture is deep, focused on the northern CSZ, and has a rake of $\sim 90^{\circ}$. In the scenarios that produce fast strike-slip rates, the magnitude and direction of dextral slip is consistent with the rates and kinematics of the $\mathrm{SCF} / \mathrm{LCBCF}$ during post-glacial time. However, all models of coseismic rupture produce slow rates of normal slip, inconsistent with the interpretation that Olympic Peninsula faults have reverse motion.

\section{SLOW SLIP EVENTS}

To model the stress imposed on the LCBCF and SCF during slow slip events, I combine the cumulative effects of 31 slow slip events from 1996-2017 (Molitors Bergman, 2017) to create a slow slip distribution on the CSZ TDEs. I convert the slow slip distribution to a slip rate 
distribution by normalizing over the time frame that the events occurred (21 years) and input the slip rate distribution into the BEM to estimate the fault slip on the LCBCF and SCF necessary to relieve the stress imposed by slow slip (Figure 11C). The BEM predicts up to $0.7 \mathrm{~mm} / \mathrm{yr}$ of right lateral slip and up $0.4 \mathrm{~mm} / \mathrm{yr}$ of normal slip, corresponding to a rake of $-125^{\circ}$ to $-165^{\circ}$ (Figure $12 \mathrm{C}$, Table 4). In comparison to the magnitude and direction of post-glacial deformation on the $\mathrm{SCF} / \mathrm{LCBCF}$, the modeled estimates of right lateral slip rate are too slow and the dip-slip motion is of the opposite slip sense.

\section{ELASTIC BLOCK MODEL}

I model the effects of the forearc block rotation on LCBCF and SCF using the same geodetically constrained elastic block model methodology used to calculate the CSZ interseismic slip deficit distribution except I define various combinations of block configurations in the northern Cascadia forearc where the LCBCF and SCF are represented as a block-bounding fault (Meade and Loveless, 2009) (Figure 13). I then use the GPS velocity field to simultaneously estimate block rotations, elastic deformation arising from fully coupled block boundaries, and spatially variable coupling on the CSZ. The relative motion of the Juan de Fuca and North American plates are constrained using the Euler pole of Miller et al. (2001). The block model estimates the slip rate and kinematics on all block-bounding fault segments that I compare to geologic rates of slip on all block-bounding faults, including the LCBCF and SCF. These models differ from the BEM models described above, in that the stress imposed on the LCBCF and SCF by subduction zone slip processes is not formally considered. Rather, these models estimate slip rates on all faults under the assumption that observed GPS velocities arise from the contribution 
of relative motion of tectonic blocks and the interseismic locking that occurs on the faults that bound them.

I test different block configurations (Figure 13) in northern Cascadia to determine how the location, number, and size of blocks affect the predicted slip rates and kinematics of the SCF and LCBCF. Specifically, I test three different styles of block configurations: (1) a small number of large blocks (Figure 13, bottom row); (2) a moderate number of intermediately sized blocks (Figure 13, middle row); and (3) a large number of small blocks (Figure 13, top row). Within these models, I adjust the SCF/LCBCF fault to (1) connect with the Darrington Devils Mountain fault zone (DDMFZ) (Figure 13, left column), (2) connect to the Southern Whidbey Island fault zone (SWIFZ) (Figure 13, middle column), or (3) not connect with any faults across the Puget Sound (Figure 13, right column). Each scenario is then checked to ensure that the rates and kinematics predicted by the model are comparable to the geologic rates and kinematics that have been measured on each Quaternary-active fault (Barnett et al., 2015; Johnson et al., 1999, 1996; Personius et al., 2014; Sherrod et al., 2008; Witter et al., 2008; U.S. Geological Survey, 2006).

The results of the elastic block modeling show only three configurations that predict dextral motion on the SCF/LCBCF: Intermediate sized blocks with the SCF/LCBCF connected to the DDMFZ, large blocks with the SCF/LCBCF connected to the DDMFZ, and large blocks with the SCF/LCBCF connected to the SMFZ (Figure 13, red boxes). None of the small block configurations or configurations that did not connect the LCBCF with faults across the Puget Sound produced right lateral slip on the SCF/LCBCF. Of the configurations that produced the correct kinematics, the configuration with intermediate sized blocks that connected the $\mathrm{SCF} / \mathrm{LCBCF}$ to the DDMFZ, produced slip rates $(2.8 \mathrm{~mm} / \mathrm{yr}$ dextral; $0.3 \mathrm{~mm} / \mathrm{yr}$ reverse $)$ and strike-slip to dip-slip ratios $(\sim 7: 1)$ on the LCBC/SCF that are most similar to the geologic rates 
and kinematics of deformation (Figure 14, Table 4). Other block bounding faults in this configuration produced kinematics that are consistent with kinematic interpretations of geologic data on each fault (e.g., left-lateral and reverse motion on the CRF). However, the slip rate magnitude and strike slip to dip slip ratio on several block bounding faults are inconsistent with geologic data. For example, the elastic block model produces fast left-lateral slip rates $(3.2 \pm 0.5$ $\mathrm{mm} / \mathrm{yr})$ and slow reverse slip rates $(0.5 \pm 0.6 \mathrm{~mm} / \mathrm{yr})$ on the Seattle fault (figure 14) whereas geologic and geophysical data characterize the Seattle fault as dominantly reverse with no strikeslip component (Blakely et al., 2002; Johnson et al., 1999). Despite discrepancies between the modeled slip rates and geologic slip rates on regional faults, the consistency in model estimates of kinematics and geologic data on regional faults permits the elastic block model as first-order explanation for the regional GPS velocity field and slip on the SCF/LCBCF.

\section{IMPLICATIONS FOR PERMANENT STRAIN ACCUMULATION WITHIN THE CASCADIA FOREARC}

Comparison of long term $\left(10^{3} \mathrm{yr}\right)$ with short term rates $\left(10^{1} \mathrm{yr}\right)$ and kinematics of deformation reveal that the stresses that contribute to short term strain are stable over longer timescales. Based on OSL dating, radiocarbon dating, and measurements of offset geomorphic features, I suggest that over the last $\sim 14 \mathrm{ka}$, the SCF and LCBCF have been characterized by slip rates of $1.3-2.3 \mathrm{~mm} / \mathrm{yr}$ and dominantly dextral kinematics (rakes of $\sim 170^{\circ}$ or a $\sim 6-1$ strike-slip to dip-slip ratio; Figure 7, Table 1). Of the four sources of stress modeled in this study, three sources produce right lateral kinematics on the SCF/LCBCF. Only two of these, however, produce slip rates and strike-slip to dip-slip ratios that are consistent with long term deformation. Interseismic strain accumulation produces left lateral slip on the SCF/LCBCF and slow slip 
events produce right lateral slip rates $(<0.7 \mathrm{~mm} / \mathrm{yr})$ and strike-slip to dip-slip ratios $(\sim 2: 1)$ that are too low relative to the long-term right lateral slip rate $(1.3-2.3 \mathrm{~mm} / \mathrm{yr})$ and strike-slip to dipslip ratio ( 6:1). As such, I suggest that these sources of stress do not individually drive slip on the $\mathrm{LCBCF} / \mathrm{SCF}$

Of the models that produced right lateral slip on the SCF/LCBCF, elastic block models and BEM models of CSZ coseismic stress transfer produce permissible matches with the longterm slip rate and rake/strike-slip to dip-slip ratio (Figures $12 \mathrm{~B}, 14$, and Table 4 ). The best match comes from geodetically constrained crustal block models, which treat the SCF/LCBCF and DDMFZ as a block boundary and estimate right lateral and reverse slip at rates consistent with long term deformation (Figure 14). While bedrock maps indicate that the dip-slip component of the SCF/LCBCF is reverse (Polenz et al., 2004; Dragovich et al., 2002; Schasse, 2003; Tabor and Cady, 1978a), I did not find any geomorphic evidence to constrain the kinematics of the dip-slip component over post-glacial time. For these reasons, I infer that coseismic stress transfer, which produces relatively fast rates of dextral and small rates of normal slip on the LCBC/SCF, to be a permissible factor in forearc fault deformation. Taken together, modeling results show that slip and permanent strain accumulation on the SCF/LCBCF might be explained by CSZ coseismic stress transfer, but models of crustal block interactions provide a more consistent model of deformation. These models are not exclusive - the SCF and LCBCF permanently accumulate strain as a result of forearc block interactions but may also be influenced by stresses related to CSZ earthquakes. More work that constrains the dip-slip component of SCF/LCBCF slip will help to further evaluate the role these models play in forearc faulting. 


\section{CONCLUSIONS}

Based on geomorphic mapping, fault slip analysis, and radiocarbon/OSL dating of offset geomorphic features and deposits along strike of the SCF and LCBCF, I characterize a postglacial chronology of geomorphic activity and constrain the long term $\left(10^{3}-10^{4} \mathrm{yrs}\right)$ rate and kinematics of faulting. Radiocarbon and OSL results suggest that the northern Olympic Mountains were deglaciated by $\sim 14 \mathrm{ka}$. Immediately following the retreat of the Juan de Fuca lobe, geomorphic instability in the paraglacial landscape mobilized sediment, deposited fans and terraces, and carved debris flow channels into the steep glacial till-mantled hillslopes.

Subsequent stabilization of the hillslopes, due the exhaustion of the sediment supply and re-entry of vegetation into the landscape, restricted Holocene geomorphic activity to debris flow deposition, channel incision, and landslides. Measurements of slip, derived from laterally offset stream channels and scarp profiles, suggest that the SCF and LCBCF are characterized by multiple post-glacial surface rupturing events, dominantly dextral motion ( 6 :1 strike-slip to dipslip ratio) along a steeply dipping fault plane, and a slip rate of 1.3-2.3 mm/yr. Empirical relationships of fault rupture length and slip per event produce earthquake size estimates of $\sim \mathrm{Mw}$ 7.1-7.5. Our results highlight the significant seismic risk that the SCF and LCBCF pose to nearby communities (e.g., Joyce and Port Angeles; Figure 1C).

The similarities between long-term and short-term deformation from geodetically constrained elastic block models and models of CSZ coseismic stress transfer suggest that the SCF and LCBCF play an important role in the accumulation of permanent strain within the Cascadia forearc. As such, the stresses that drive forearc block interactions explain the magnitude and direction of fault slip on the SCF/LCBCF but may be modulated by stresses related to CSZ earthquakes. Similarities further suggest that these stresses are stable over the 
length of the CSZ earthquake cycle, and that they are retained as fault slip on forearc faults. My results are consistent with existing models of forearc deformation in Cascadia (McCaffrey et al., 2007, 2013; Savage and Wells, 2015; Wells et al., 1998; Wells and Simpson, 2001), that attribute forearc fault slip to the interactions of rigid crustal blocks and CSZ coupling, and with studies in Japan (Kato et al., 2011; Imanishi et al., 2012) and Chile (Farías et al., 2011; Melnick et al., 2012) which attribute fault slip to stresses transferred from subduction zone ruptures. 


\section{APPENDIX I. MEASUREMENT AND EVAULATION OF STRIKE-SLIP DISPLACEMENT}

To determine the amount of strike-slip displacement recorded by each offset channel I used the following four step approach:

(1) Remove poorly fit geomorphic markers. I removed geomorphic markers where the statistically-identified points did not appear to accurately follow their respective geomorphic feature, had a large degree of scatter, and/or followed features very similar to those included in other geomorphic markers (e.g., markers intended to identify the riser top that are actually identifying the riser midpoint). In almost all cases, the reason for a poor marker fit is attributed to poor lidar quality, the hummocky nature of the ground surface (most likely a result of dense vegetation), and/or obvious geomorphic modification (e.g., slumping, landsliding, road construction).

\section{(2) Interpret the distribution of slip measurements in terms of the geomorphic/tectonic} development of the offset channel site. In cases where the strike-slip displacement measurements made from the well-fit geomorphic markers were not significantly different, the preferred measurement of strike-slip displacement and uncertainty was derived from the Gaussian curve (e.g., Figure 3D, black curve labeled 'best') fit to the summed and normalized probability densities of all measurements being considered (e.g., Figure 3D, curve in red, labeled 'Sum'). In cases were markers were significantly different, a determination of the preferred amount of strike-slip displacement requires a geomorphic reason to favor certain measurements. If the largest measurement of strike-slip displacement comes from a marker that has likely not been affected by erosion within the channel (e.g., the interfluve or the protected channel margin), then I assume the other markers which record less slip are affected by erosion within the channel 
during the interseismic period. As such, the preferred strike-slip displacement measurement and uncertainty is derived from the Gaussian distribution of the largest offset marker. However, if unprotected markers measure the largest slip, I assume that the variability of the measurements to be the true uncertainty in the measurement. Doing so, I report the strike-slip displacement and uncertainty as a uniformly distributed range that encompasses all relevant geomorphic markers.

(3) Adjust errors based on backslipping and assign distributions to measurements. For each site I backslipped the lidar maps of each channel to the lower bound, upper bound, and preferred measurement of each channel to provide a visual check on the statistically derived measurements. Note that all backslipped images (Figure S4) represent the offset feature using a lidar- derived elevation color ramp (Figure S4, green = low, white = high), with half-meter contours overlaid on a slope-shade map. If backslips seemed reasonable I did not adjust the reported measurements and assigned a probability distribution appropriate for the original distribution (e.g., if reported strike-slip displacement was derived from a Gaussian distribution, then a Gaussian distribution for the reported measurement was maintained). However, if backslipping showed that the reported strike-slip displacement was unreasonable, I trimmed or expanded the errors of the reported measurement to a value that would be reasonable based on additional backslipping. In cases where backslipping required adjusting the errors of Gaussian distributions, I assigned a triangular distribution to the reported measurement where the edges of the triangle represent the upper and lower error bounds and the peak represents the preferred strike-slip displacement. In cases where backslipping required adjusting the errors of a uniform distribution, I maintained the uniform distribution but adjusted its bounds.

(4) Assign quality ranking to the reported measurement of strike-slip displacement. Quality rankings of I to IV ( $\mathrm{I}=$ best, IV = worst $)$ are based on the quality of the lidar at the offset 
location, the fit of the geomorphic markers, the degree of geomorphic modification around the fault, and the obliquity of the offset channel to the fault. (e.g., Table 1, Figure S4)

\section{APPENDIX II. APPLICATIONS OF METHODS IN FORESTED TERRAIN}

My study of recently discovered strike-slip surface ruptures in the heavily forested Olympic Mountains presents the opportunity to evaluate the channel measuring program, “3D_Fault_Offsets," outside of the sparsely vegetated, alluvial channels that it was originally designed and tested for (Stewart et al., 2017). Throughout the process of measuring 11 offset debris flow channels on the SCF and three offset debris flow channels on the LCBCF, 3D_Fault_Offsets consistently misidentified various channel markers (Figure S4). Of the nine channel features that 3D_Fault_Offsets automatically identifies, the channel riser tops and riser bottoms were the most consistently misrepresented. Alternatively, the channel thalweg, riser midpoints and, less occasionally, max elevations were often identified by 3D_Fault_Offsets with reasonable accuracy and were the primary markers that this study to measure strike-slip displacement (Figure S4).

Using the markers that accurately traced the geomorphic features of the offset channel to calculate dip-slip displacement, I made the following observations: (1) dip-slip displacement measurements often showed the wrong kinematics (e.g., a channel that crosses a south-side-up scarp will have automatically-identified marker with north-side-up displacement); (2) the distribution of dip-slip displacement measurements from various channel markers did not consistently reflect the same distribution of strike-slip displacement measurements (i.e., if a marker records a large strike-slip displacement, then the same marker often doesn't record a large dip-slip displacement, relative to the other markers); and (3) dip-slip displacement 
measurements derived from channel thalwegs were consistently within error of zero slip. For most channels I attribute observation (3) to geomorphic modification within the channel, but the inconsistencies noted in observations (1) and (2) reflect shortcomings with the use of the automatically identified channel markers in dip-slip displacement calculations. Furthermore, dipslip displacement measurements are more susceptible to misidentified points than strike-slip displacement calculations due the relative magnitude of strike-slip to dip-slip displacement along the SCF and LCBCF. For example, if a channel is dextrally offset $15 \mathrm{~m}$, vertically offset $1.5 \mathrm{~m}$ and 3D_Fault_Offsets identifies a channel marker within a one meter error of its true location (in all directions), then the strike-slip displacement measurement will be affected by a small amount but the strike-slip displacement may become indiscernible. For these reasons I choose to use dipslip displacement measurements derived from scarp profiles taken outside of channels in order to calculate total slip, strike-slip to dip-slip ratios, and rake.

I attribute the errors in marker identification and dip-slip displacement calculation produced by 3D_Fault_Offsets to the shape of the debris flow channels, which do not have distinct terraces, and the hummocky nature of the digital elevation models used in this study. While the lidar data was gridded at a relatively high resolution $(1.0 \mathrm{~m}$ and $0.5 \mathrm{~m}$ resolution DEMs were used), the rolling nature of the forested ground surface and irregularities in the density of the point cloud used to construct the DEM resulted in a dataset characterized by rough surfaces. Because 3D_Fault_Offsets uses relative elevations, steepness, and changes in concavity to automatically identify the location of channel markers, the roughness of the DEMs produced many inaccurate markers that were not removed by the filtering method of Stewart et al (2017). Additionally, smoothing the DEM by resampling it to greater pixel sizes did not prove effective for reducing error. Despite the challenges of using 3D_Fault_Offsets in steep forested terrain, we 
found the program to be an effective tool for measuring strike-slip displacement when the user cautiously removes (manually) misidentified points, interprets the measured strike-slip displacement in the context of the geomorphic development of the channel, and uses backslipping the check the quality of the measurement. 


\section{REFERENCES}

Allen, M., Jackson, J., and Walker, R., 2004, Late Cenozoic reorganization of the Arabia-Eurasia collision and the comparison of short-term and long-term deformation rates: Tectonics, $\mathrm{v}$. 23, doi: 10.1029/2003TC001530.

Allmendinger, R.W., Loveless, J.P., Pritchard, M.E., and Meade, B., 2009, From decades to epochs: Spanning the gap between geodesy and structural geology of active mountain belts: Journal of Structural Geology, v. 31, p. 1409-1422, doi: 10.1016/j.jsg.2009.08.008.

Amos, C.B., Schermer, E.R., Angster, S., Delano, J., Duckworth, W.C., Nelson, A.R., and Sherrod, B.L., 2019, A post-glacial record of large, strike-slip earthquakes on the Sadie Creek fault, northern Olympic Peninsula, WA [Abstract]: Seismological Society of America Annual Meeting,.

Atwater, B.F., 1987, Evidence for great Holocene earthquakes along the outer coast of Washington State: Science, v. 236, p. 942-944.

Atwater, B.F., and Hemphill-Haley, E., 1997, Recurrence intervals for great earthquakes of the past 3,500 years at northeastern Willapa Bay, Washington: USGS Professional Paper 1576.

Audet, P., and Schaeffer, A.J., 2018, Fluid pressure and shear zone development over the locked to slow slip region in Cascadia: Science Advances, v. 4, p. 1-7, doi: 10.1126/sciadv.aar2982.

Ballantyne, C.K., 2017, Paraglacial geomorphology: Quaternary Science Reviews, v. 21, p. $1935-2017$.

Barnett, E.A., Haugerud, R.A., Sherrod, B.L., Weaver, C.S., Pratt, T.L., and Blakely, R.J., 2010, Preliminary atlas of active shallow tectonic deformation in the Puget Lowland, Washington: USGS Open File Report 2010-1149, p. 32.

Barnett, E.A., Sherrod, B.L., Hughes, J.F., Kelsey, H.M., Czajkowski, J.L., Walsh, T.J., Contreras, T.A., Schermer, E.R., and Carson, R.J., 2015, Paleoseismic evidence for late Holocene tectonic deformation along the Saddle Mountain fault zone, southeastern Olympic Peninsula, Washington: Bulletin of the Seismological Society of America, v. 105, p. 38-71, doi: $10.1785 / 0120140086$.

Blakely, R.J., Wells, R.E., Weaver, C.S., and Johnson, S.Y., 2002, Location, structure, and seismicity of the Seattle fault zone, Washington: Evidence from aeromagnetic anomalies, geologic mapping, and seismic-reflection data: Bulletin of the Geological Society of America, v. 114, p. 169-177, doi: 10.1130/0016-7606(2002)114<0169:LSASOT>2.0.CO;2.

Brandon, M.T., Roden-Tice, M.K., and Garver, J.I., 1998, Late Cenozoic exhumation of the Cascadia accretionary wedge in the Olympic Montains, northwest Washington State: Geological Society of America Bulletin, v. 110, p. 985-1009.

Brandon, M.T., and Vance, J.A., 1992, Tectonic evolution of the Cenozoic olympic subduction complex, Washington State, as deduced from fission track ages for detrital zircons: American Journal Of Science, v. 292, p. 565-636. 
Brock, F., Higham, T., Ditchfield, P., and Ramsey, C.B., 2010, Current pretreatment methods for ams radiocarbon dating at the oxford radiocarbon accelerator unit (ORAU): Radiocarbon, $\mathrm{v}$. 52, p. 103-112, doi: 10.1017/S0033822200045069.

Cooke, M.L., and Dair, L.C., 2011, Simulating the recent evolution of the southern big bend of the San Andreas fault, Southern California: Journal of Geophysical Research, v. 116, p. 20, doi: 10.1029/2010JB007835.

Crouch, S.L., and Starfield, A.M., 1983, Boundary Element Methods in Solid Mechanics: With Applications in Rock Mechanics and Geological Engineering: Boston, George Allen \& Unwin.

Delano, J.E., Amos, C.B., Loveless, J.P., Rittenour, T.M., Sherrod, B.L., and Lynch, E.M., 2017, Influence of the megathrust earthquake cycle on upper-plate deformation in the Cascadia forearc of Washington State, USA: Geology, v. 45, p. 1051-1054, doi: 10.1130/G39070.1.

Dragovich, J.D., Logan, R.L., Schasse, H.W., Walsh, T.J., Lingley, W.S., Norman, D.K., Gerstel, W.J., Lapen, T.J., Schuster, E., and Meyers, K.D., 2002, Geologic map of Washington - Northwest quadrant: Washington Division of Geology and Earth Resources, GM-50, p. 72.

Duller, G.A.T., 2004, Luminescence dating of Quaternary sediments: Recent advances: Journal of Quaternary Science, v. 19, p. 183-192, doi: 10.1002/jqs.809.

Evans, E.L., Loveless, J.P., and Meade, B.J., 2015, Total variation regularization of geodetically and geologically constrained block models for the Western United States: Geophysical Journal International, v. 202, p. 713-727, doi: 10.1093/gji/ggv164.

Farías, M., Comte, D., Roecker, S., Carrizo, D., and Pardo, M., 2011, Crustal extensional faulting triggered by the 2010 Chilean earthquake: The Pichilemu Seismic Sequence: Tectonics, v. 30, p. 1-11, doi: 10.1029/2011TC002888.

Finley, T., Morell, K., Leonard, L., Regalla, C., Johnston, S.T., and Zhang, W., 2019, Ongoing oroclinal bending in the Cascadia forearc and its relation to concave-outboard plate margin geometry: Geology, v. 47, p. 155-158.

Flüt, P., Hyndmand, R.D., and Wang, K., 1997, Three-dimensional dislocation model for great earthquakes of the Cascadia Subduction zone: Journal of Geophysical Research, v. 102, p. 20539-20550.

Frankel, A., Chen, R., Petersen, M., Moschetti, M., and Sherrod, B., 2015, 2014 Update of the Pacific Northwest Portion of the U.S. National Seismic Hazard Maps: Earthquake Spectra, v. 31.

Frankel, A., Wirth, E., Marafi, N., Vidale, J., and Stephenson, W., 2018, Broadband synthetic seismograms for magnitude 9 earthquakes on the Cascadia Megathrust based on 3D simulations and stochastic synthetics, Part 1: Methodology and overall results: Bulletin of the Seismological Society of America, v. 108, p. 2347-2369, doi: 10.1785/0120180034.

Galbraith, R.F., Roberts, R.G., Laslett, G.M., Yoshida, H., and Oleey, J.M., 1999, Optical dating of single and multiple grains of quartz from Jinmium Rock Shelter, northern Australia: Part I, experimental design and statistical models.: Archaeometry, v. 41, p. 339-364. 
Goldfinger, C., Galer, S., Beeson, J., Hamilton, T., Romsos, C., Patton, J., Nelson, C.H., Hausmann, R., and Morey, A., 2016, The importance of site selection, sediment supply, and hydrodynamics: A case study of submarine paleoseismology on the northern Cascadia margin, Washington USA: Marine Geology, doi: 10.1016/j.margeo.2016.06.008.

Gomberg, J., and Sherrod, B., 2014, Crustal earthquake triggering by modern great earthquakes on subduction sone thrusts: Journal of Geophysical Research: Solid Earth, v. 119, p. 12351250, doi: 10.1002/2012JB009826.

Haddon, E.K., Amos, C.B., Zielke, O., Jayko, A.S., and Bürgmann, R., 2016, Surface slip during large Owens Valley earthquakes: Geochemistry, Geophysics, Geosystems, v. 17, p. 22392269, doi: 10.1002/2015GC006033.

Haugerud, R.A., and Hendy, I., 2016, Collapse of the Juan de Fuca lobe of the Cordilleran ice sheet [abstract]: Geological Society of America Abstract Program, v. 48, abst num. 121-8, doi: 10.1130/abs/2016AM-281516.

Hemphill-Haley, M.A., and Weldon, R.J., 1999, Estimating prehistoric earthquake magnitude from point measurements of surface rupture: Bulletin of the Seismological Society of America, v. 89, p. 1264-1279.

Heusser, C.J., 1973, Environmental sequence following the Fraser advance of the Juan de Fuca Lobe, Washington: Quaternary Research, v. 3, p. 284-306.

Iinuma, T., Hino, R., Kido, M., Inazu, D., Osada, Y., Ito, Y., Ohzono, M., Tsushima, H., Suzuki, S., Fujimoto, H., and Miura, S., 2012, Coseismic slip distribution of the 2011 off the Pacific Coast of Tohoku Earthquake (M9.0) refined by means of seafloor geodetic data: Journal of Geophysical Research, v. 117, p. 1-18, doi: 10.1029/2012JB009186.

Imanishi, K., Ando, R., and Kuwahara, Y., 2012, Unusual shallow normal-faulting earthquake sequence in compressional northeast Japan activated after the 2011 off the Pacific coast of Tohoku earthquake: Geophysical Research Letters, v. 39, p. 1-7, doi: 10.1029/2012GL051491.

Ito, T., Ozawa, K., Watanabe, T., and Sagiya, T., 2011, Slip distribution of the 2011 off the Pacific coast of Tohoku Earthquake inferred from geodetic data: Earth Planets Space, v. 63, p. 627-630, doi: 10.5047/eps.2011.06.023.

Johnson, S.Y., Dadisman, S. V., Childs, J.R., and Stanley, W.D., 1999, Active tectonics of the Seattle fault and central Puget Sound, Washington-Implications for earthquake hazards: Geological Society of America Bulletin, v. 111, p. 1042-1053.

Johnson, S.Y., Potter, C.J., Miller, J.J., Finn, C., and Weaver, C.S., 1996, The southern Whidbey Island fault: An active structure in the Puget Lowland, Washington: GSA Bulletin, v. 108, p. 334-354.

Joyner, C.N., 2016, Lacustrine Megaturbidites and Displacement Waves: The Holocene Earthquake History of the Lake Creek-Boundary Creek Fault at Lake Crescent, Washington, USA, M.S. Thesis, Department of Marine, Earth, and Atmospheric Sciences, North Carolina State University, Raleigh, North Carolina, p. 187.

Kato, A., Sakai, S., and Obara, K., 2011, A normal-faulting seismic sequence triggered by the 
2011 off the Pacific coast of Tohoku Earthquake: Wholesale stress regime changes in the upper plate: Earth, Planets and Space, v. 63, p. 745-748, doi: 10.5047/eps.2011.06.014.

Kovanen, D.J., and Easterbrook, D.J., 2001, Late Pleistocene, post-Vashon, alpine glaciation of the Nooksack drainage, North Cascades, Washington: GSA Bulletin, v. 113, p. 274-288.

Lamb, S., and Smith, E., 2013, The nature of the plate interface and driving force of interseismic deformation in the New Zealand plate-boundary zone, revealed by the continuous GPS velocity field: Journal of Geophysical Research: Solid Earth, v. 118, p. 3160-3189, doi: $10.1002 /$ jgrb.50221.

Leithold, E.L., Wegmann, K.W., Bohnenstiehl, D.R., Joyner, C.N., and Pollen, A.F., 2019, Repeated megaturbidite deposition in Lake Crescent, Washington, USA, triggered by Holocene ruptures of the Lake Creek-Boundary Creek fault system: Geological Society of America Bulletin, p. 1-17, doi: 10.1130/B35076.1/4664641/b35076.pdf.

Leonard, L.J., Currie, C.A., Mazzotti, S., and Hyndman, R.D., 2010, Rupture area and displacement of past Cascadia great earthquakes from coastal coseismic subsidence: Bulletin of the Geological Society of America, v. 122, p. 2079-2096, doi: 10.1130/B30108.1.

Leonard, L.J., Hyndman, R.D., and Mazzotti, S., 2004, Coseismic subsidence in the 1700 great Cascadia earthquake: Coastal estimates versus elastic dislocation models: Bulletin of the Geological Society of America, v. 116, p. 655-670, doi: 10.1130/B25369.1.

Loveless, J.P., and Meade, B.J., 2011, Stress modulation on the San Andreas fault by interseismic fault system interactions: Geology, v. 39, p. 1035-1038, doi: 10.1130/G32215.1.

MacLeod, N.S., Tiffin, D.L., Snavely, P.D., and Currie, R.G., 1977, Geologic interpretation of magnetic and gravity anomalies in the Straight of Juan de Fuca, U.S.-Canada: Canadian Journal of Earth and Sciences, v. 14, p. 223-238.

McCaffrey, R., and Goldfinger, C., 1995, Forearc deformation and great subduction earthquakes: Implications for Cascadia offshore earthquake potential: Science, v. 267, p. 856-859.

McCaffrey, R., King, R.W., Payne, S.J., and Lancaster, M., 2013, Active tectonics of northwestern U.S. inferred from GPS-derived surface velocities: Journal of Geophysical Research: Solid Earth, v. 118, p. 709-723, doi: 10.1029/2012JB009473.

McCaffrey, R., Qamar, A.I., King, R.W., Wells, R., Khazaradze, G., Williams, C.A., Stevens, C.W., Vollick, J.J., and Zwick, P.C., 2007, Fault locking, block rotation and crustal deformation in the Pacific Northwest: Geophysical Journal International, v. 169, p. 13151340, doi: 10.1111/j.1365-246X.2007.03371.x.

McCrory, P.A., Blair, J.L., Waldhauser, F., and Oppenheimer, D.H., 2012, Juan de Fuca slab geometry and its relation to Wadati-Benioff zone seismicity: Journal of Geophysical Research, v. 117, doi: 10.1029/2012JB009407.

McGill, S.F., and Rubin, C.M., 1999, Surficial slip distribution on the central Emerson fault during the June 28, 1992, Landers earthquake, California: Journal of Geophysical Research, v. 104, p. $4811-4833$. 
Meade, B.J., and Loveless, J.P., 2009, Block Modeling with Connected Fault-Network Geometries and a Linear Elastic Coupling Estimator in Spherical Coordinates: Bulletin of the Seismological Society of America, v. 99, p. 3124-3139, doi: 10.1785/0120090088.

Melnick, D., Moreno, M., Motagh, M., Cisternas, M., and Wesson, R.L., 2012, Splay fault slip during the Mw 8.82010 Maule Chile earthquake: Geology, v. 40, p. 251-254, doi: 10.1130/G32712.1.

Miller, M.M., Johnson, D., Rubin, C.M., Dragert, H., Wang, K., Qamar, A.I., and Goldfinger, C., 2001, GPS-determination of along-strike variation in Cascadia margin kinematics: Implications for relative plate motion, subduction zone coupling, and permanent deformation: Tectonics, v. 20, p. 161-176.

Molitors Bergman, E.G., 2017, Locating slow slip events in Cascadia across space and time, Honors Thesis, Smith College, Northampton, Massachusetts, p. 53, https://scholarworks.smith.edu/theses/1842.

Mosher, D.C., and Hewitt, A.T., 2004, Late Quaternary deglaciation and sea-level history of eastern Juan de Fuca Strait, Cascadia: Quaternary International, v. 121, p. 23-39, doi: 10.1016/j.quaint.2004.01.021.

Mountjoy, J.J., and Barnes, P.M., 2011, Active upper plate thrust faulting in regions of low plate interface coupling, repeated slow slip events, and coastal uplift: Example from the Hikurangi Margin, New Zealand: Geochemistry, Geophysics, Geosystems, v. 12, p. 1-26, doi: 10.1029/2010GC003326.

Murray, A.S., and Wintle, A.G., 2000, Luminescence dating of quartz using an improved singlealiquot regenrative-dose protocol: Radiation Measurement, v. 32, p. 57-73, doi: 10.1016/S1350-4487(99)00253-X.

Murray, A.S., and Wintle, A.G., 2003, The single aliquot regenerative dose protocol: Potential for improvements in reliability: Radiation Measurements, v. 37, p. 377-381, doi: 10.1016/S1350-4487(03)00053-2.

Nelson, A.R., Personius, S.F., Wells, R.E., Bradley, L.A., Buck, J., Schermer, E.R., and Reitman, N., 2017, Holocene earthquakes of magnitude 7 during westward escape of the Olympic Mountains, Washington: Bulletin of the Seismological Society of America, v. 107, p. 2394-2415, doi: 10.1785/0120160323.

Nicol, A., and Wallace, L.M., 2007, Temporal stability of deformation rates: Comparison of geological and geodetic observations, Hikurangi subduction margin, New Zealand: Earth and Planetary Science Letters, v. 258, p. 397-413, doi: 10.1016/j.epsl.2007.03.039.

Peng, Z., and Gomberg, J., 2010, An integrated perspective of the continuum between earthquakes and slow-slip phenomena: Nature Geoscience, v. 3, p. 599-607, doi: 10.1038/ngeo940.

Personius, S.F., Briggs, R.W., Nelson, A.R., Schermer, E.R., Zebulon Maharrey, J., Sherrod, B.L., Spaulding, S.A., and Bradley, L.A., 2014, Holocene earthquakes and right-lateral slip on the left-lateral Darrington-Devils Mountain fault zone, northern Puget Sound, Washington: Geosphere, v. 10, p. 1482-1500, doi: 10.1130/GES01067.1. 
Petersen, M.D., Cramer, C.H., and Frankel, A.D., 2002, Simulations of seismic hazard for the Pacific Northwest of the United States from earthquakes associated with the Cascadia Subduction zone: Pure and Applied Geophysics, v. 159, p. 2147-2168.

Polenz, M., Wegmann, K.W., and Schasse, H.W., 2004, Geologic map of the Elwha and Angeles Point 7.5-minute quadrangles, Clallam County, Washington: Washington Division of Geology and Earth Resources, Open File Report 2004-14.

Porter, S.C., and Swanson, T.W., 1998, Radiocarbon age constraints on rates of advance and retreat of the Puget Lobe of the Cordilleran Ice Sheet during the last glaciation: Quaternary Research, v. 50, p. 205-213, doi: 10.1006/qres.1998.2004.

Pratt, T.L., Johnson, S.Y., Potter, C., Stephenson, W., and Finn, C., 1997, Seismic reflection images beneath Puget Sound, western Washington State: The Puget Lowland thrust sheet hypothesis: Journal of Geophysical Research, v. 102, p. 27469-27489.

Priest, G.R., Witter, R.C., Zhang, Y.J., Goldfinger, C., Wang, K., and Allan, J.C., 2017, New constraints on coseismic slip during southern Cascadia subduction zone earthquakes over the past 4600 years implied by tsunami deposits and marine turbidites: Natural Hazards, v. 88, p. 285-313, doi: 10.1007/s11069-017-2864-9.

Ramsey, C.B., 2009, Bayesian analysis of radiocarbon dates: Radiocarbon, v. 51, p. 337-360, doi: $10.1017 / \mathrm{S} 0033822200033865$.

Ramsey, C.B., 2008, Deposition models for chronological records: Quaternary Science Reviews, v. 27, p. 42-60, doi: 10.1016/j.quascirev.2007.01.019.

Reimer, P.J., Bard, E., Bayliss, A., Beck, J.W., Blackwell, P.G., Ramsey, C.B., Buck, C.E., Cheng, H., Edwards, R.L., Friedrich, M., Grootes, P.M., Guilderson, T.P., Haflidason, H., Hajdas, I., Hatté, C., Heaton, T.J., Hoffmann, D.L., Hogg, A.G., Hughen, K.A., Kaiser, K.F., Kromer, B., Manning, S.W., Niu, M., Reimer, R.W., Richards, D.A., Scott, E.M., Southon, J.R., Staff, R.A., Turney, C.S.M., van der Plicht, J., 2013, IntCal13 and Marine13 radiocarbon age calibration curves 0-50,000 years cal BP: Radiocarbon, v. 55, p. 18691887, doi: 10.2458/azu_js_rc.55.16947.

Rhodes, E.J., 2011, Optically Stimulated Luminescence dating of sediments over the past 200,000 years: Annual Review of Earth and Planetary Sciences, v. 39, p. 461-488, doi: 10.1146/annurev-earth-040610-133425.

Rogers, G., and Dragert, H., 2003, Episodic tremor and slip on the Cascadia Subduction Zone: The chatter of silent slip: Science, v. 300, p. 1942-1943, doi: 10.1126/science.1084783.

Savage, J.C., 1983, A dislocation model of strain accumulation and release at a subduction zone: Journal of Geophysical Research, v. 88, p. 4984-4996.

Savage, J.C., and Wells, R.E., 2015, Identifying block structure in the Pacific Northwest, US: Journal Of Geophysical Research-Solid Earth, v. 120, p. 7905-7916, doi: 10.1002/ 2015JB012277.

Schasse, H.W., 2003, Geologic map of the Port Angeles 1:100,000 quadrangle: Washington Division of Geology and Earth Resources, Open File Report 2004-14. 
Sherrod, B.L., Blakely, R.J., Weaver, C.S., Kelsey, H.M., Barnett, E., Liberty, L., Meagher, K.L., and Pape, K., 2008, Finding concealed active faults: Extending the southern Whidbey Island fault across the Puget Lowland, Washington: Journal of Geophysical Research, v. 113, p. 1-25, doi: 10.1029/2007JB005060.

Stewart, N., Gaudemer, Y., Manighetti, I., Serreau, L., Vincendeau, A., Dominguez, S., Mattéo, L., and Malavieille, J., 2017, “3D_Fault_Offsets”, a Matlab code to automatically measure lateral and vertical fault offsets in topographic data; application to San Andreas, Owens Valley and Hope faults: Journal of Geophysical Research: Solid Earth, v. 213, p. 1-21, doi: 10.1002/2017JB014863.

Tabor, R.W., and Cady, W.M., 1978a, Geologic map of the Olympic Peninsula, Washington: U.S. Geological Survey, Miscellaneous Investment Series Map I-994 .

Tabor, R.W., and Cady, W.. M., 1978b, The structure of the Olympic Mountains, Washington analysis of a subduction zone: U. S. Geological Survey Professional Paper 1033, p. 38.

Thomas, A.L., 1993, Poly3D: a three-dimensional, polygonal element, displacement discontinuity Boundary Element computer program with applications to fractures, faults, and cavities in the Earth's crust, M.S. Thesis, Stanford University, Palo Alto, California, 69 p.

Thompson, S.C., Weldon, R.J., Rubin, C.M., Abdrakhmatov, K., Molnar, Peter, B., and Glenn, W., 2002, Late Quaternary slip rates across the central Tien Shan, Kyrgyzstan, central Asia: Journal of Geophysical Research, v. 107, p. 2203, doi: 10.1029/2001JB000596.

Thorson, R.M., 1980, Ice-Sheet Glaciation of the Puget lowland, Washington, during the Vashon Stade (late pleistocene): Quaternary Research, v. 13, p. 303-321, doi: 10.1016/00335894(80)90059-9.

U.S. Geological Survey, 2006, Quaternary fault and fold database for the United States:, http//earthquake.usgs.gov/hazards/qfaults/ (accessed June 2018).

Walsh, T.J., and Logan, R.L., 2007, Results of trenching the Canyon River fault, southeast Olympic Mountains, Washington: Geological Society of America Abstracts with Programs, v. 39, p. Poster 22-4.

Wang, K., He, J., Dragert, H., and James, T.S., 2001, Three-dimensional viscoelastic intersiesmic deformation model for the Cascadia subduction zone: Earth Planets Space, v. 53, p. 295-306.

Wang, K., Wells, R., Mazzotti, S., and Hyndman, R.D., 2003, A revised dislocation model of interseismic deformation of the Cascadia subduction zone: v. 108, p. 1-13, doi: 10.1029/2001JB001227.

Washington Department of Natural Resources, 2015, Washington Lidar Portal:, http://lidarportal.dnr.wa.gov/.

Waters, M.R., Stafford, T.W., McDonald, G.H., Gustafson, C., Rasmusse, M., Capellini, E., Szklarcyzk, D., Jensen, L.J., Gilbert, M.T.P., and Willerslev, E., 2011, Pre-Clovis mastodon hunting 13,800 years ago at the Manis Site, Washington: Science, v. 334, p. 351-353, doi: 10.1126/science. 1207663. 
Wells, R., Bukry, D., Friedman, R., Pyle, D., Duncan, R., Haeussler, P., and Wooden, J., 2014, Geologic history of Siletzia, a large igneous province in the Oregon and Washington Coast Range: Correlation to the geomagnetic polarity time scale and implications for a long-lived Yellowstone hotspot: Geosphere, v. 10, p. 692-719, doi: 10.1130/GES01018.1.

Wells, D.L., and Coppersmith, K.J., 1994, New empirical relationships among magnitude, rupture length, rupture width, rupture area, and surface displacement: Bulletin of the Seismological Society of America, v. 84, p. 974-1002.

Wells, R.E., and Simpson, R.W., 2001, Northward migration of the Cascadia forearc in the northwestern U.S. and implications for subduction deformation: Earth Planets Space, v. 53, p. $275-283$.

Wells, R.E., Weaver, C.S., and Blakely, R.J., 1998, Fore-arc migration in Cascadia and its neotectonic significance: Geology, v. 26, p. 759-762.

Wirth, E.A., Frankel, A.D., Marafi, N., Vidale, J.E., and Stephenson, W.J., 2018, Broadband synthetic seismograms for magnitude 9 earthquakes on the Cascadia megathrust based on 3D simulations and stochastic synthetics, Part 2 : Rupture parameters and variability: Bulletin of the Seismological Society of America, v. 108, p. 2370-2388, doi: $10.1785 / 0120180029$.

Witter, R.C., Givler, R.W., and Carson, R.J., 2008, Two post-glacial earthquakes on the saddle Mountain West fault, Southeastern Olympic Peninsula, Washington: Bulletin of the Seismological Society of America, v. 98, p. 2894-2917, doi: 10.1785/0120080127.

Zielke, O., Klinger, Y., and Arrowsmith, J.R., 2015, Fault slip and earthquake recurrence along strike-slip faults --contributions of high-resolution geomorphic data, Tectonophysics, $v$. 638, p. 43-62.

Zielke, O., Arrowsmith, J.R., Ludwig, L.G., and Akçiz, S.O., 2010, Slip in the 1857 and earlier large earthquakes along the Carrizo Plain, San Andreas: Science, v. 327, p. 1119-1122. 


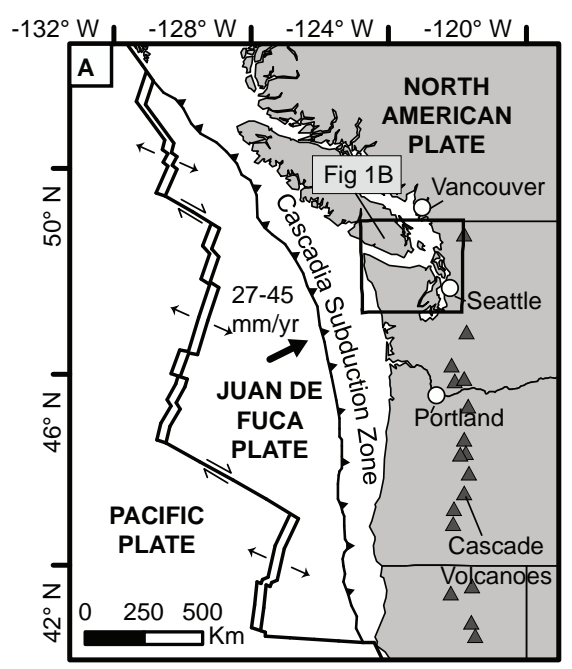

1B. Geologic Units and Features

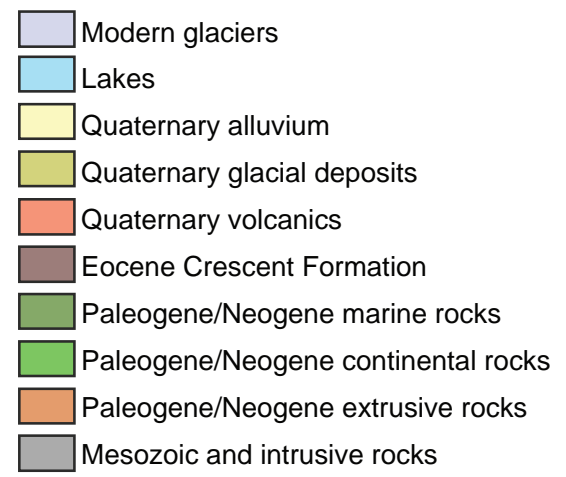

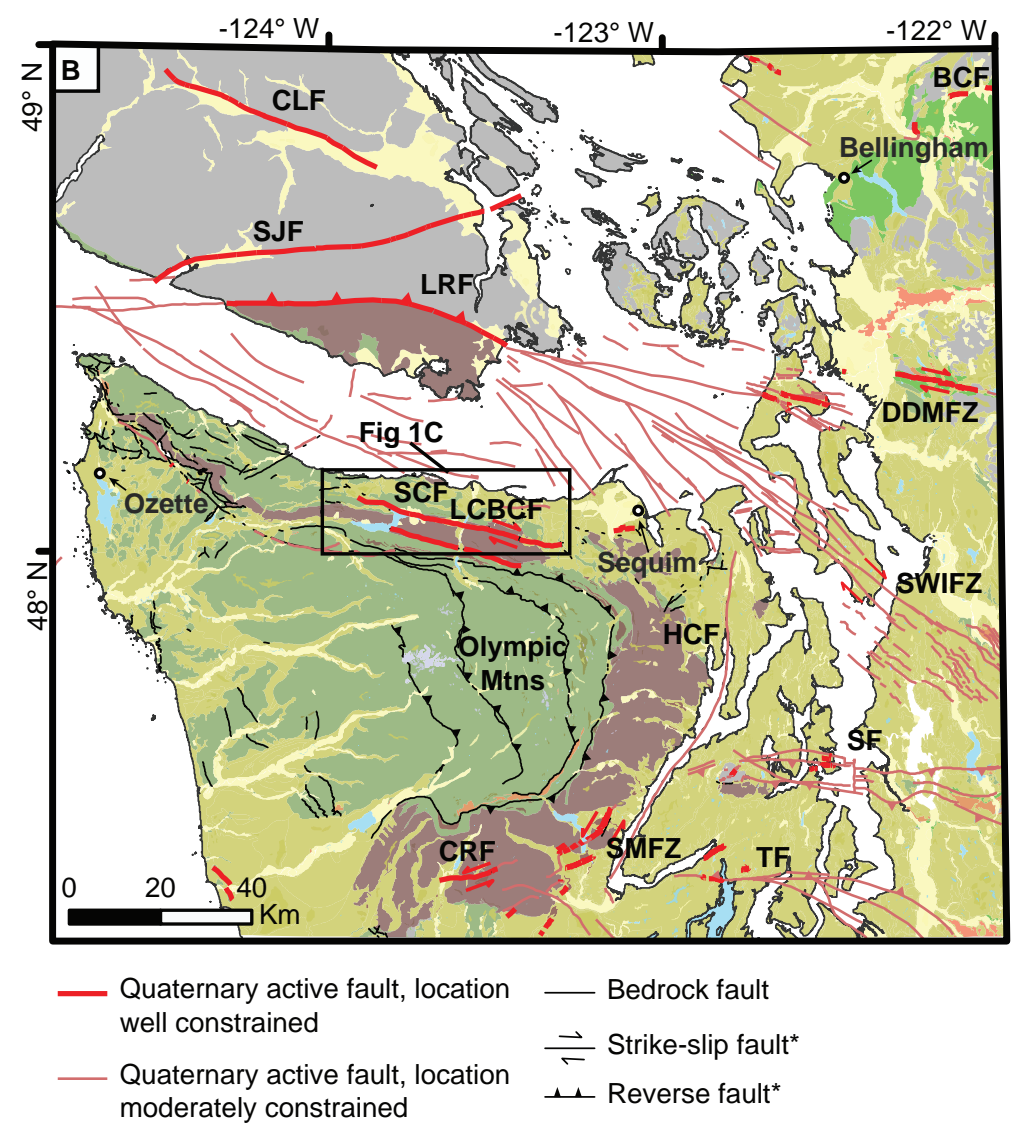

*Fault kinematics indicated where motion sense is well constrained.

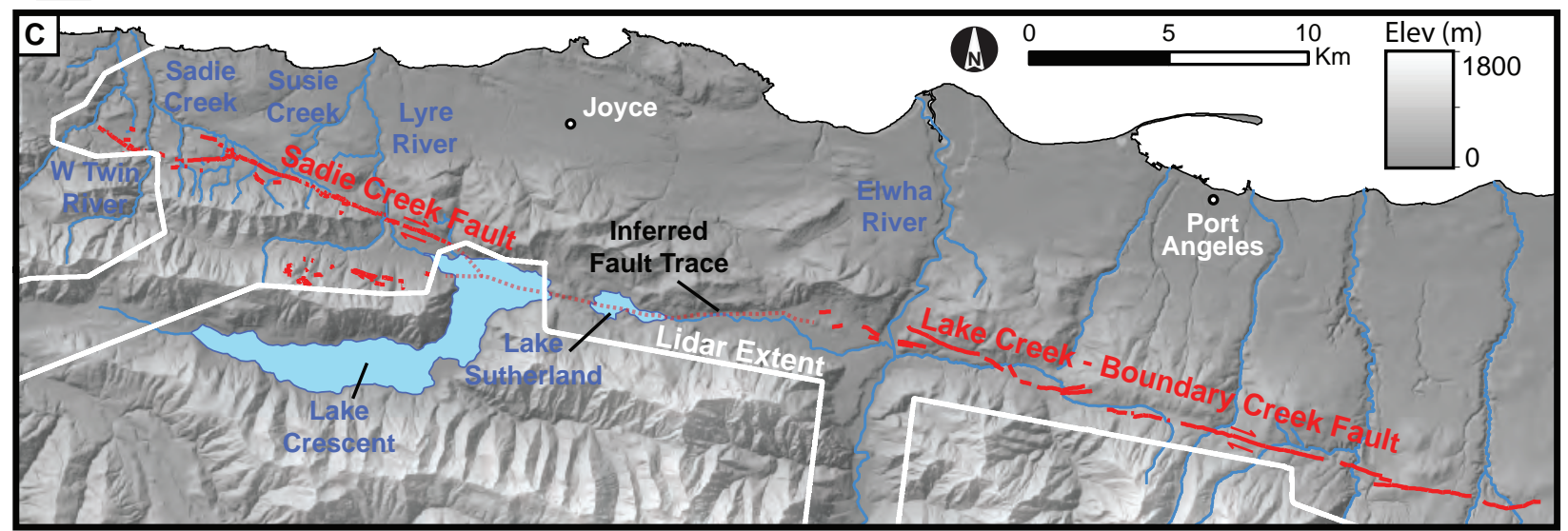

Figure 1. Tectonic setting and location of the Sadie Creek fault. (A) Plate-tectonic setting of the Cascadia subduction zone. Plate convergence rate and direction (black arrow) between the North American plate and Juan de Fuca plate is derived from DeMets et al. (2010). (B) Geologic map of northwestern Washington, USA and southern Vancouver Island, CAN. Bedrock and geologic units are simplified from Dragovich et al. (2002). Quaternary active faults in WA are from the USGS Quaternary Fault and Fold Database (U.S. Geological Survery, 2006). Quaternary active faults within Vancouver Island are from the British Columbia Geological Survey (2018). Abbreviations: (CRF) Canyon River Fault; (CLF) Cowichan Lake Fault; (DDMFZ) Darrington Devils Mountain Fault Zone; (HCF) Hood Canal Fault; (LCBC) Lake Creek-Boundary Creek Fault; (LRF) Leach River Fault; (SMFZ) Saddle Mountain Fault Zone; (SCF) Sadie Creek Fault; (SJF) San Juan Fault; (SF) Seattle Fault Zone; (SWIFZ) South Whidbey Island Fault Zone; (TF) Tacoma Fault. (C) Map showing the Sadie Creek Fault (this study) and the Lake Creek Boundary-Creek Fault (Nelson et al., 2017). 

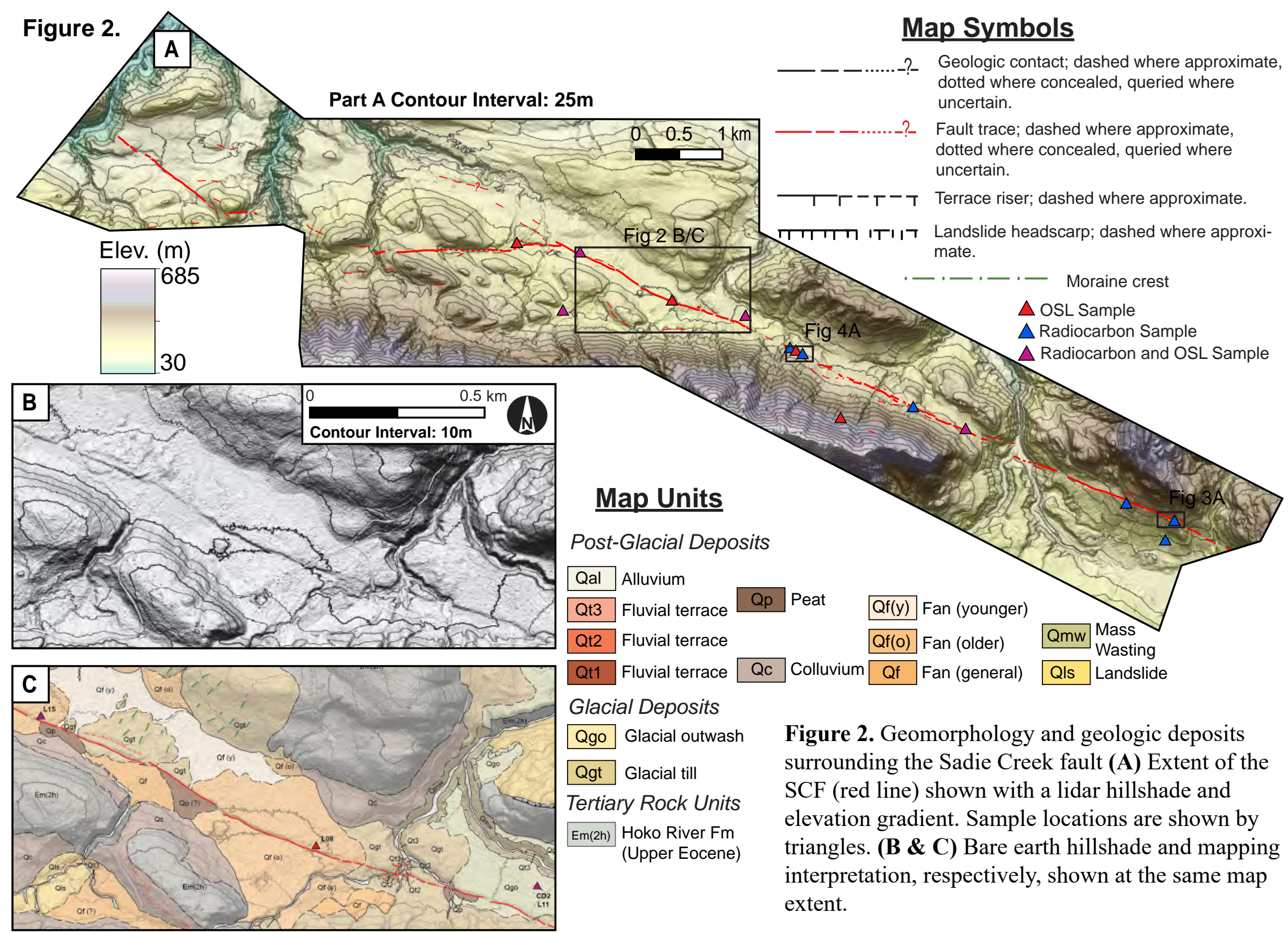

Glacial Deposits

Qgo Glacial outwash

Qgt Glacial till

Tertiary Rock Units

Em(2h) Hoko River Fm

(Upper Eocene)

Figure 2. Geomorphology and geologic deposits surrounding the Sadie Creek fault (A) Extent of the SCF (red line) shown with a lidar hillshade and elevation gradient. Sample locations are shown by triangles. (B \& C) Bare earth hillshade and mapping interpretation, respectively, shown at the same map extent. 


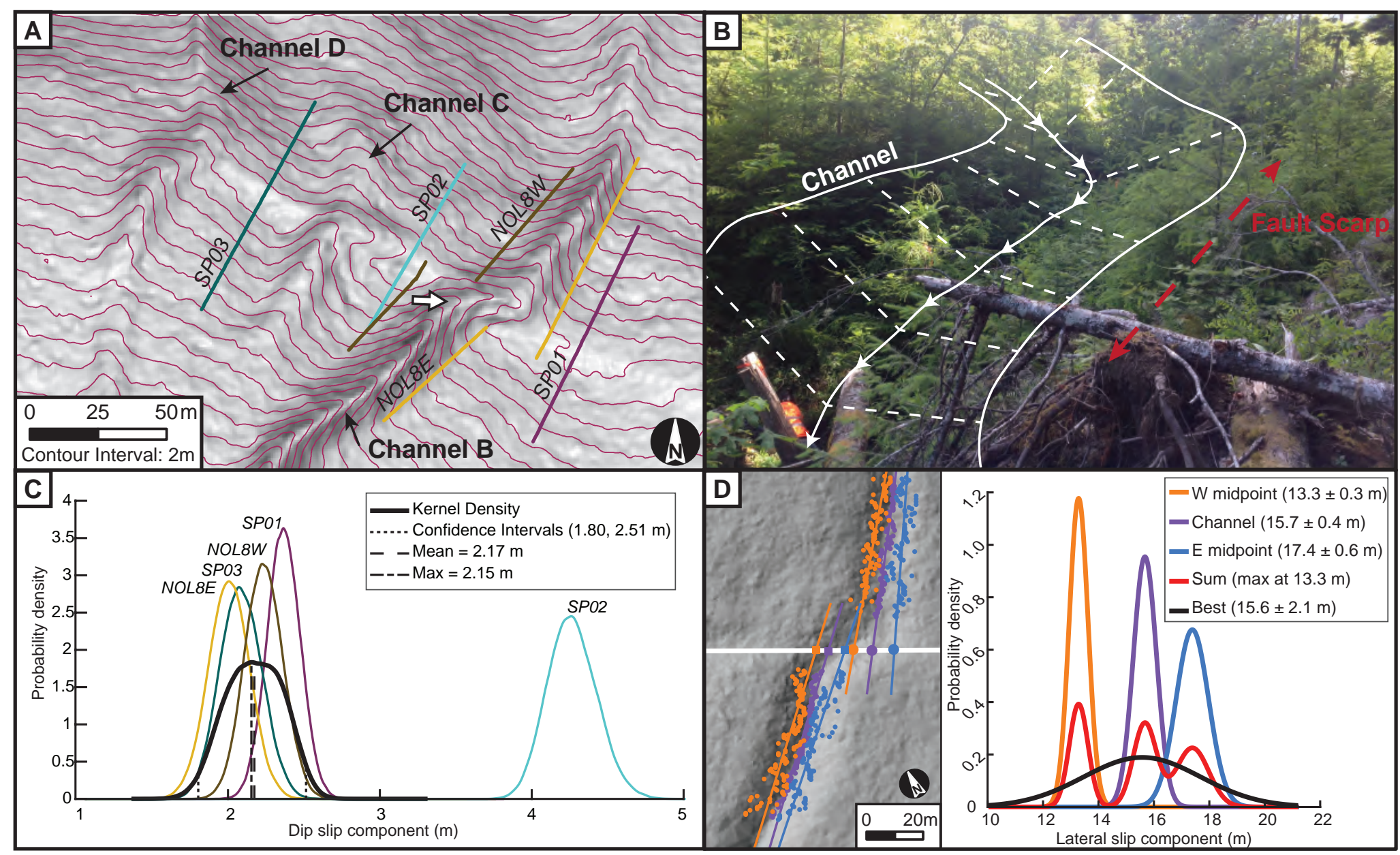

Figure 3. Examples of dip-slip and strike-slip displacement measurements. (A) Location and position of five scarp profiles (colored lines) and dextrally offset channels B, C, and D. (B) Annotated field photo of Channel B. Picture location and view direction is indicated by the white arrow in A. (C) Plot of dip-slip probability densities derived from the scarp profiles shown in A. Black line shows the estimated kernel density function fit to the all probability density functions, except SP02. (D) Automatically identified channel markers (left) and probability density function functions of strike-slip displacement measurements (right) from Channel B. The probability densities of the features are summed and normalized (red line) then fit with a Gaussian curve (black line). 


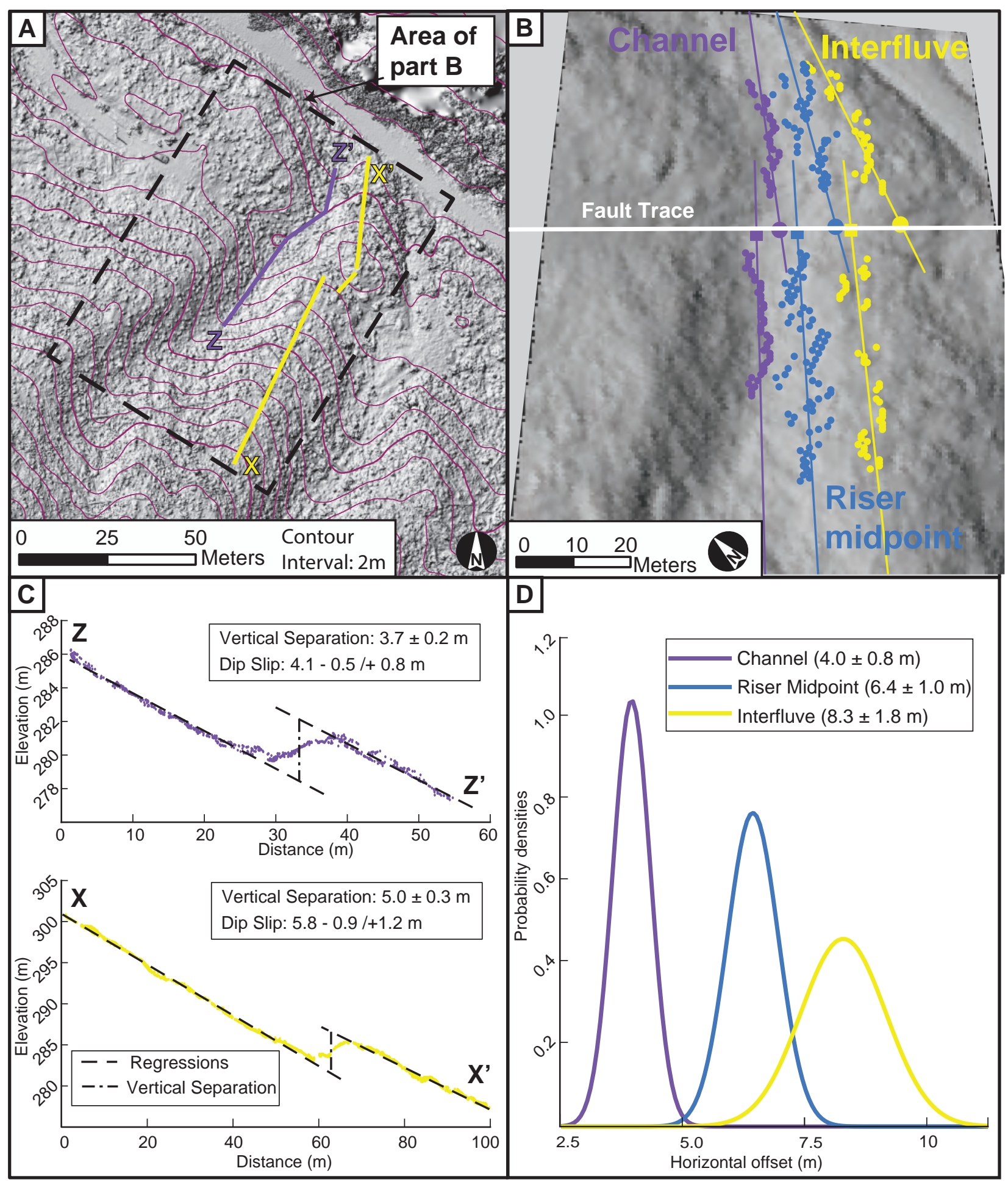

Figure 4. Analysis of strike slip and dip slip at offset channel J (location shown in Figure 2). (A) Map showing the location of scarp profiles. Basemap composed of lidar-derived contours superimposed onto structure-from-motion hillshade. (B) Map of channel features identified using 3D_Fault_Offsets (Stewart et al., 2017). Extent of map is shown in A. (C) Dip slip and vertical separation measurements from scarp profiles. (D) Probability density functions of strike slip displacement computed from the three channel makers shown in B. Note that there is a larger amount of dip slip and strike slip measured outside the channel than within the channel. 

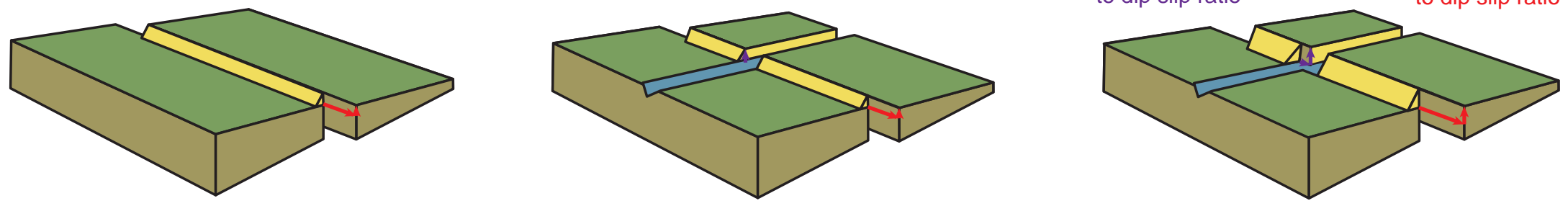

Earthquake displaces channel laterally and vertically.
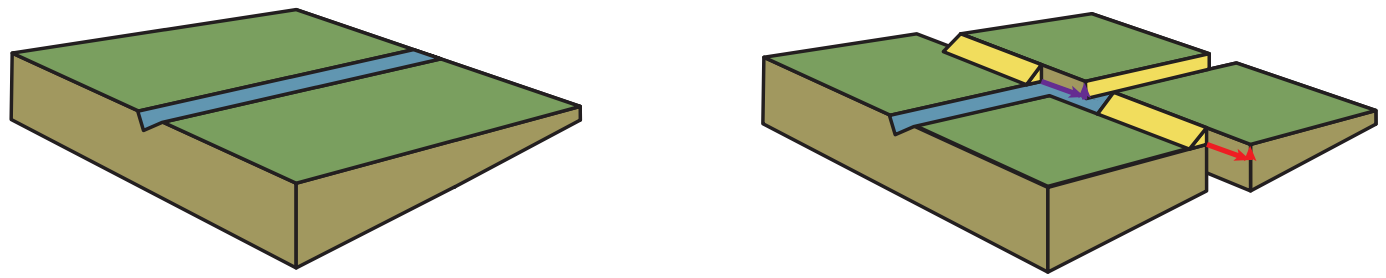

Lateral offset of channel and scarp grow during second earthquake.

Measured strike slip $\quad$ Actual strike slip to dip slip ratio

Earthquake displaces channel laterally and vertically. Erosion in channel reduces certainty in lateral slip measurement.
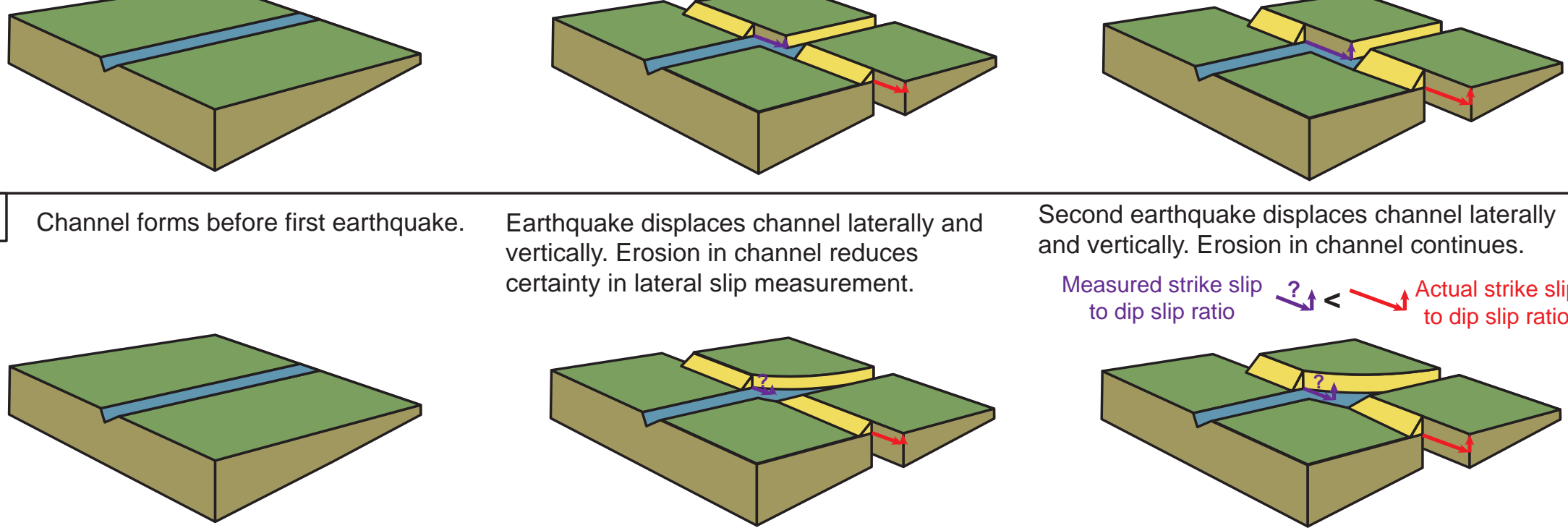

Second earthquake displaces channel laterally and vertically. Erosion in channel continues.

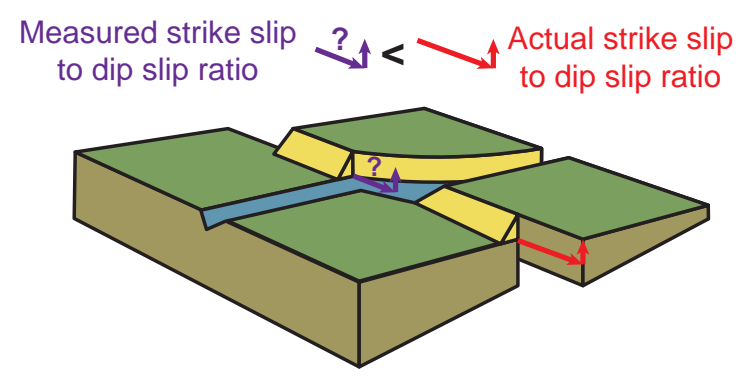

Figure 5. Models of strike slip and dip slip displacement accumulation in relation to channel formation. (A) Fault scarp forms before the channel. (B) Channel forms before fault scarp and geomorphic modification in the channel is negligible. (C) Channel forms before scarp, but erosion in channel reduces accuracy of the lateral slip measurement. Note that in all models the measured strike slip to dip slip ratios are less than or equal to the actual strike slip to dip slip ratios. 


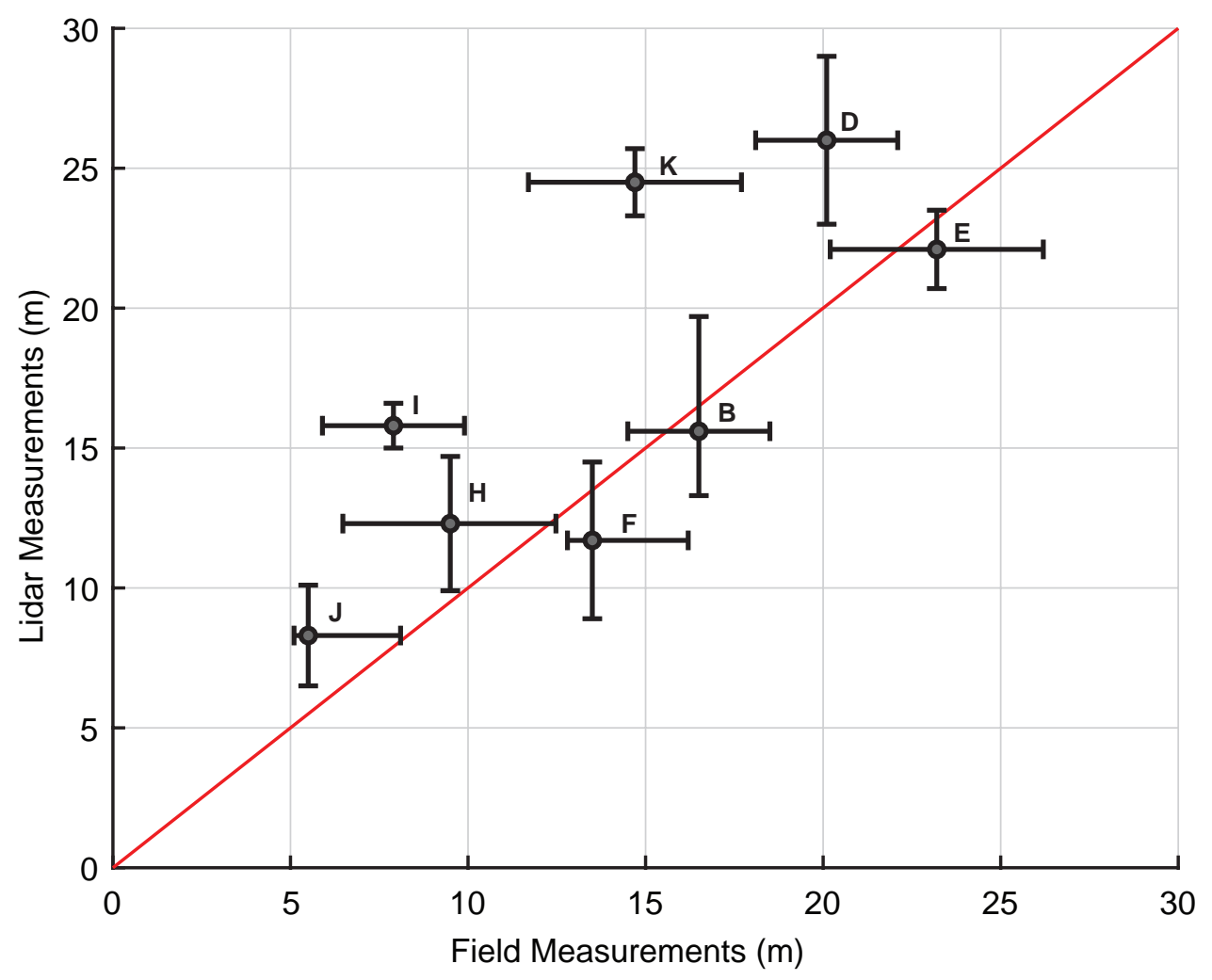

Figure 6 Comparison of eight measurements of dextral displacement made in the field and from lidar data. For reference, a one-to-one line (red) is plotted. The site letter for each channel is listed next to each measurement. Note that not all channels measured in lidar were measured in the field. 


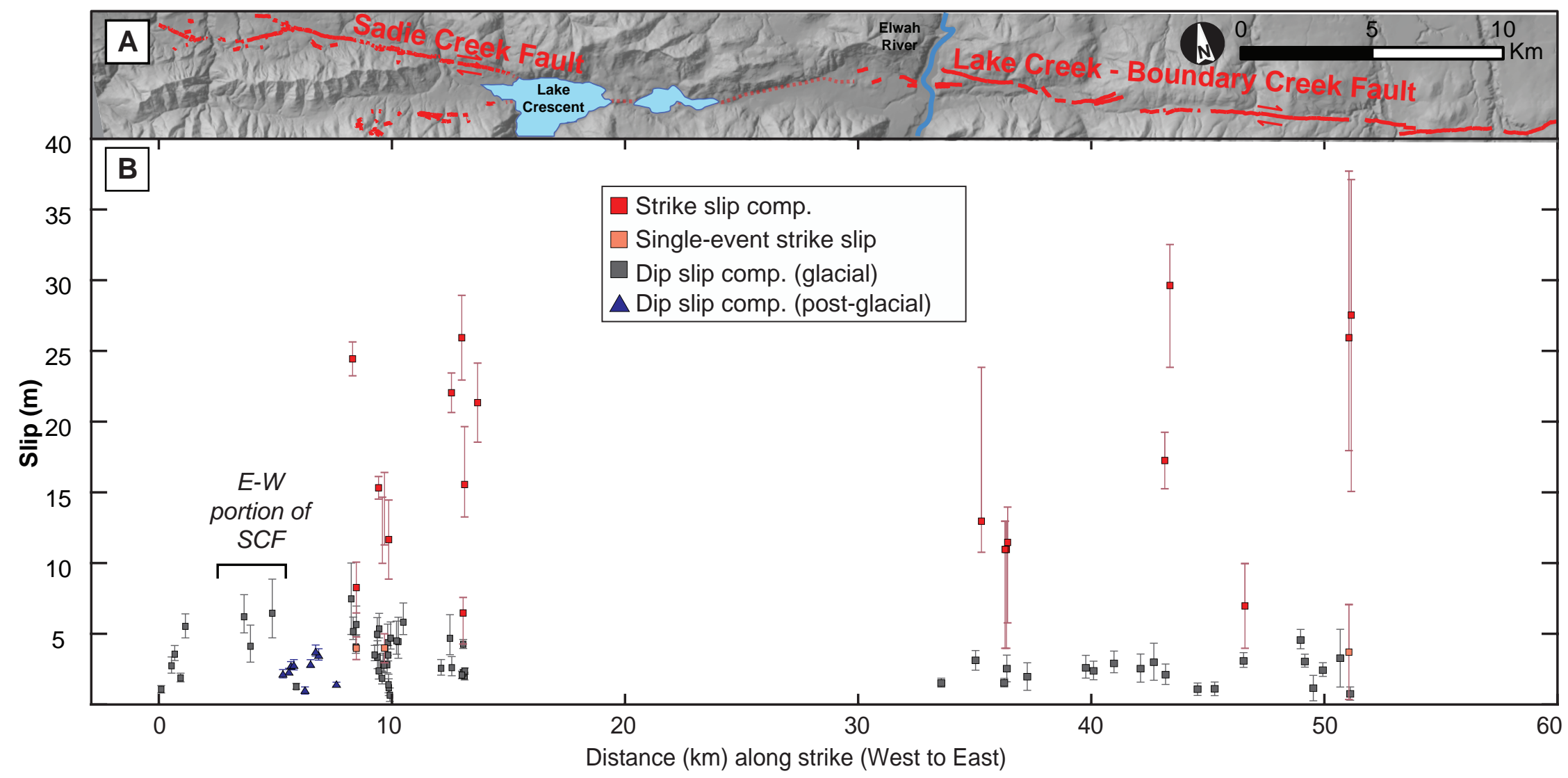

Figure 7. Sadie Creek and Lake Creek Boundary Creek fault slip. (A) Surface trace of SCF and LCBCF for reference. (B) Plot of strike slip, single event strike slip displacements, and dip slip measurements along strike of the SCF. (C, D, \& E; on next page) Plots of total slip, rake, and strike-slip to dip-slip ratios, respectively, calculated along strike of the SCF and LCBCF. Each point is colored by the quality ranking of the strike-slip displacement measurement used in each calculation. 


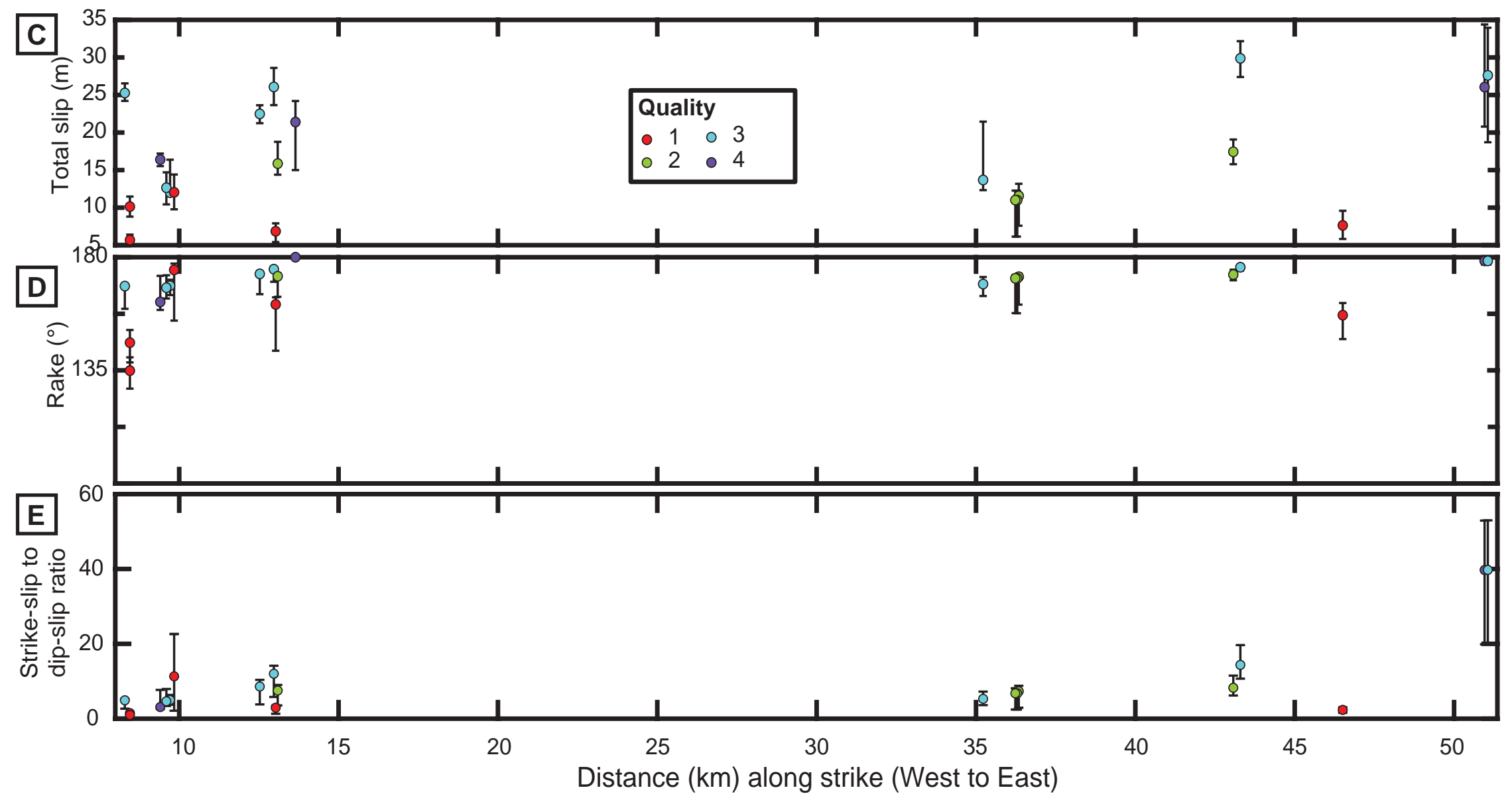

Figure 7. (continued) 

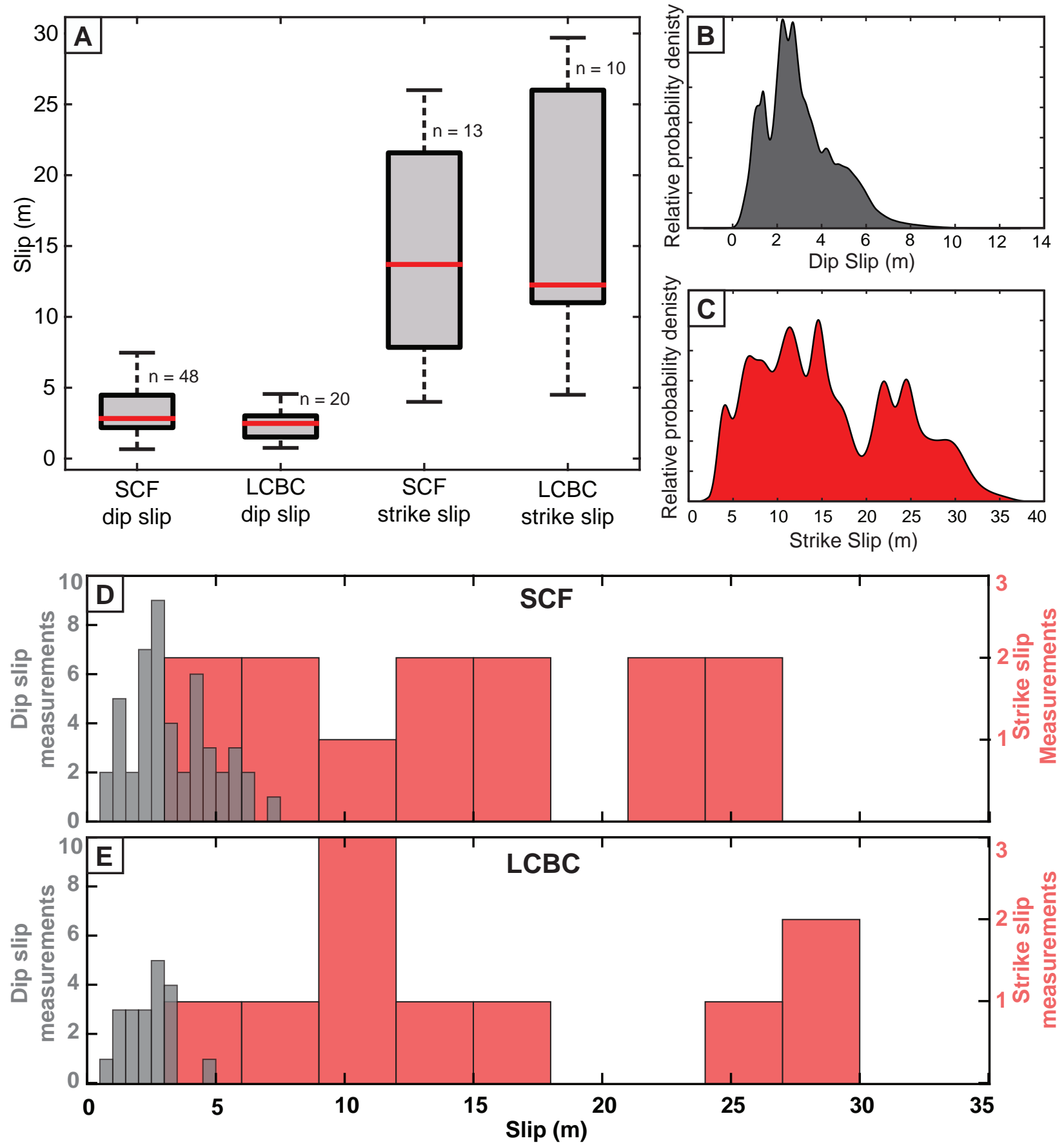

Figure 8. Comparison of strike slip and dip slip measurements on the SCF and LCBCF. (A) Standard box and whisker plot of preferred strike slip and dip slip measurements. Red line shows the median value of each subset. The number of measurements in each subset is indicated next to the respective box. (B \& C) Density functions showing the distribution of dip slip and strike slip measurements, respectfully. Plots are created by summing and normalizing the probability distributions of all measurements on the SCF and LCBCF. (D \& E) Histograms of the dip slip (gray) and strike slip (red) displacement measurements on the SCF (D) and LCBCF (E). The left y-axes and right y-axes correspond to the number of dip slip and strike slip measurements, respectively. 


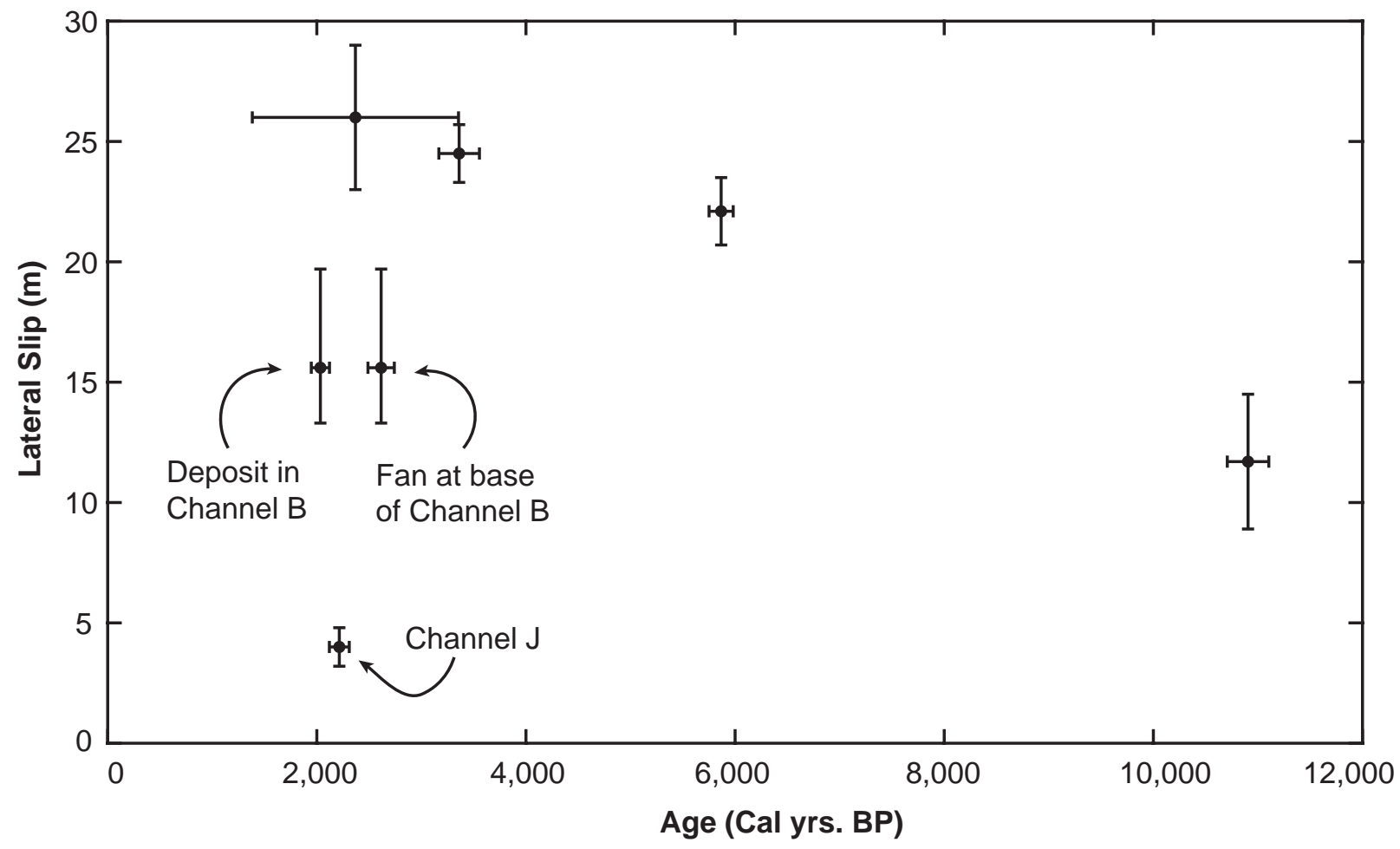

Figure 9. Plot of strike slip measurements vs. the age (in Cal yrs BP.) of detrital charcoal collected from channel-related deposits. Errors bars represent the $95 \%$ error about each measurement. All strike slip measurements are shown in Table 1, all radiocarbon ages are shown in Table 2. 


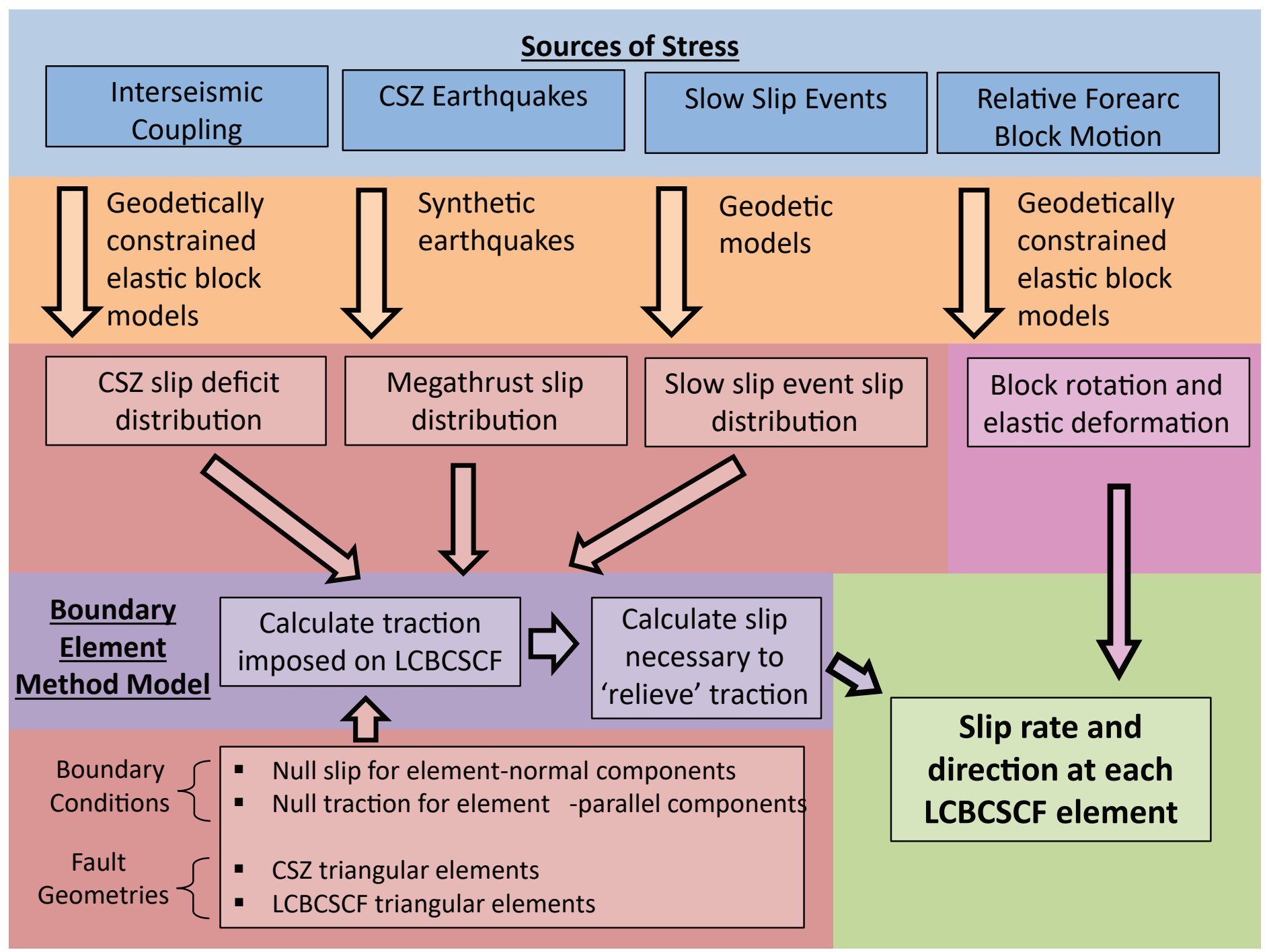

Figure 10. Workflow for BEM and elastic block modeling processes. Different modeled processes (sources of stress) are shown in blue; methods for quantifying the different processes are shown in orange; inputs for the BEM are shown in red; BEM modeling process is shown in purple; elastic block modeling process is shown in pink; and model outputs are shown in green. 


\section{BEM Model Inputs}

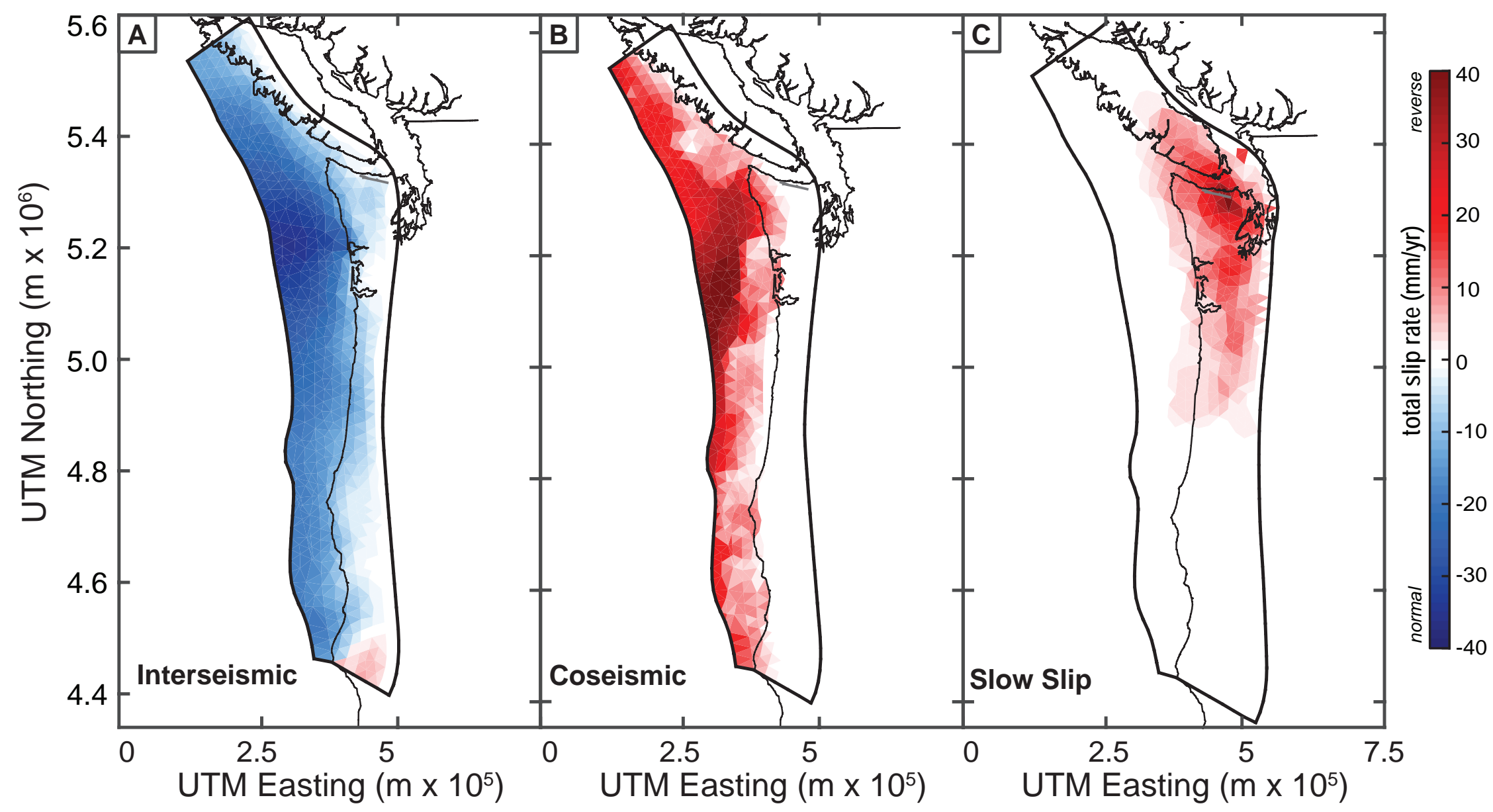

Figure 11. Inputs to the Boundary Element Method model. $(\mathbf{A}, \mathbf{B}, \mathbf{\&} \mathbf{C})$ show the magnitude of the input total slip rate distributions for interseismic coupling, an example coseismic rupture (csz005, Figure S7), and slow slip events, respectively. Slip magnitudes are colored according the sense of the dip-slip component. Positive (red) values indicate reverse motion while negative values (blue) represent normal motion. 


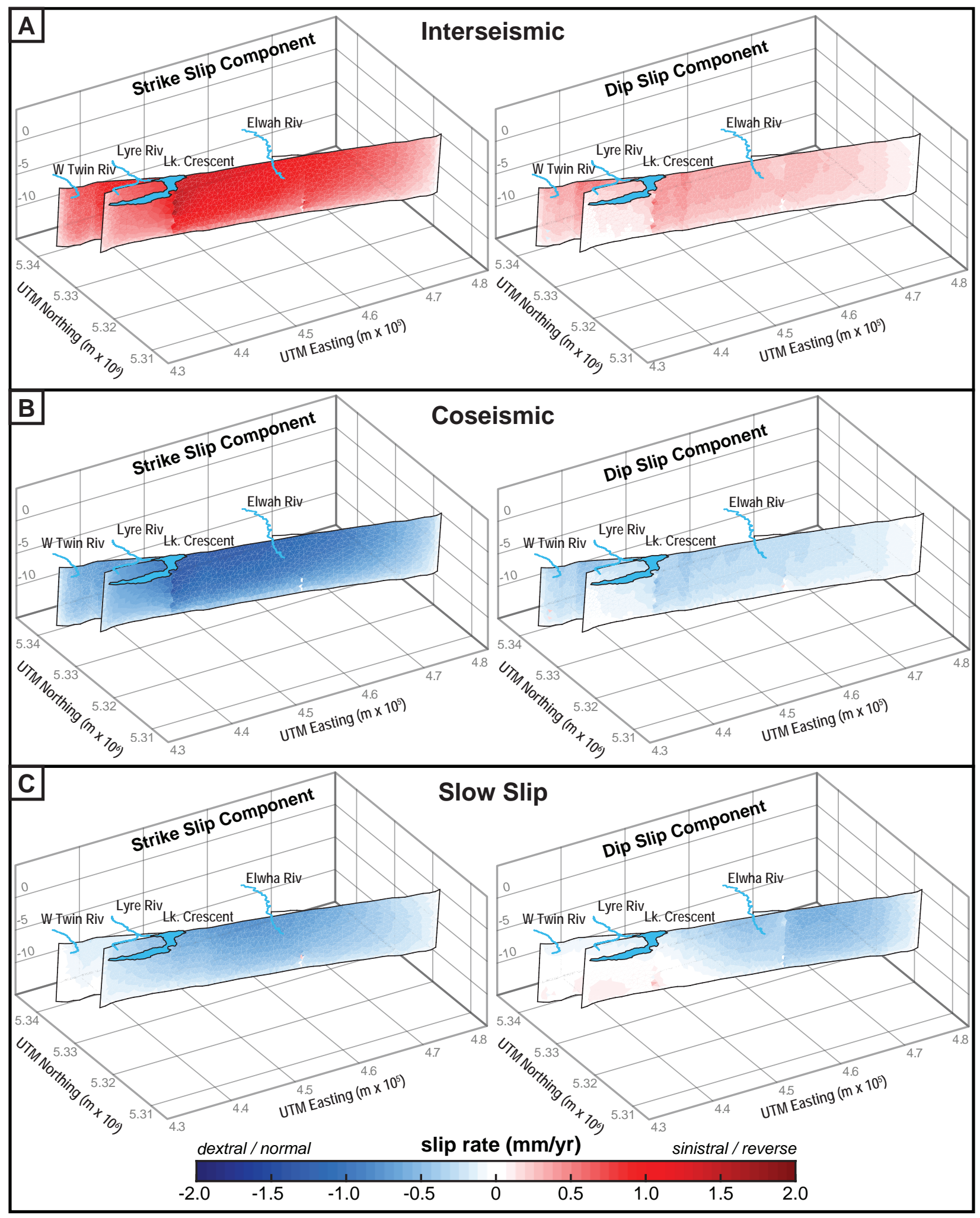

Figure 12. Results of Boundary Element Method modeling. (A, B, \& C) show the output dip slip (right) and strike slip (left) components of the estimated slip distributions on the SCF/LCBCF, respectively. (B) shows an an example of one CSZ rupture model (csz005, Figure S7). 


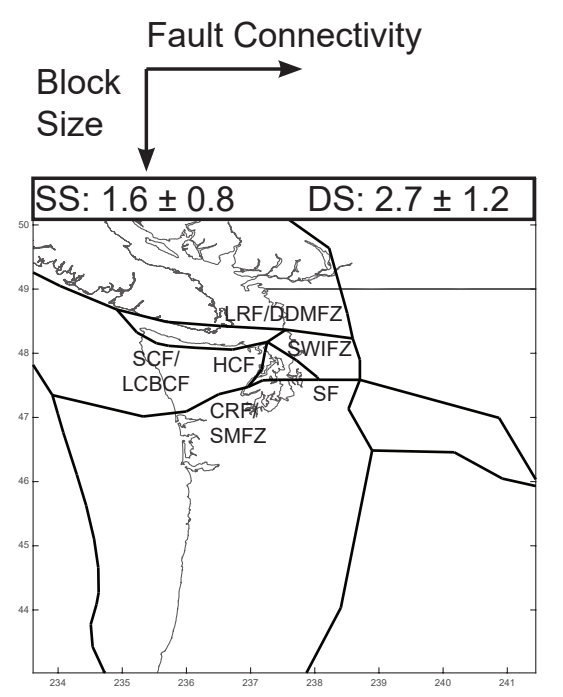

\section{Elastic Block Model Configurations}
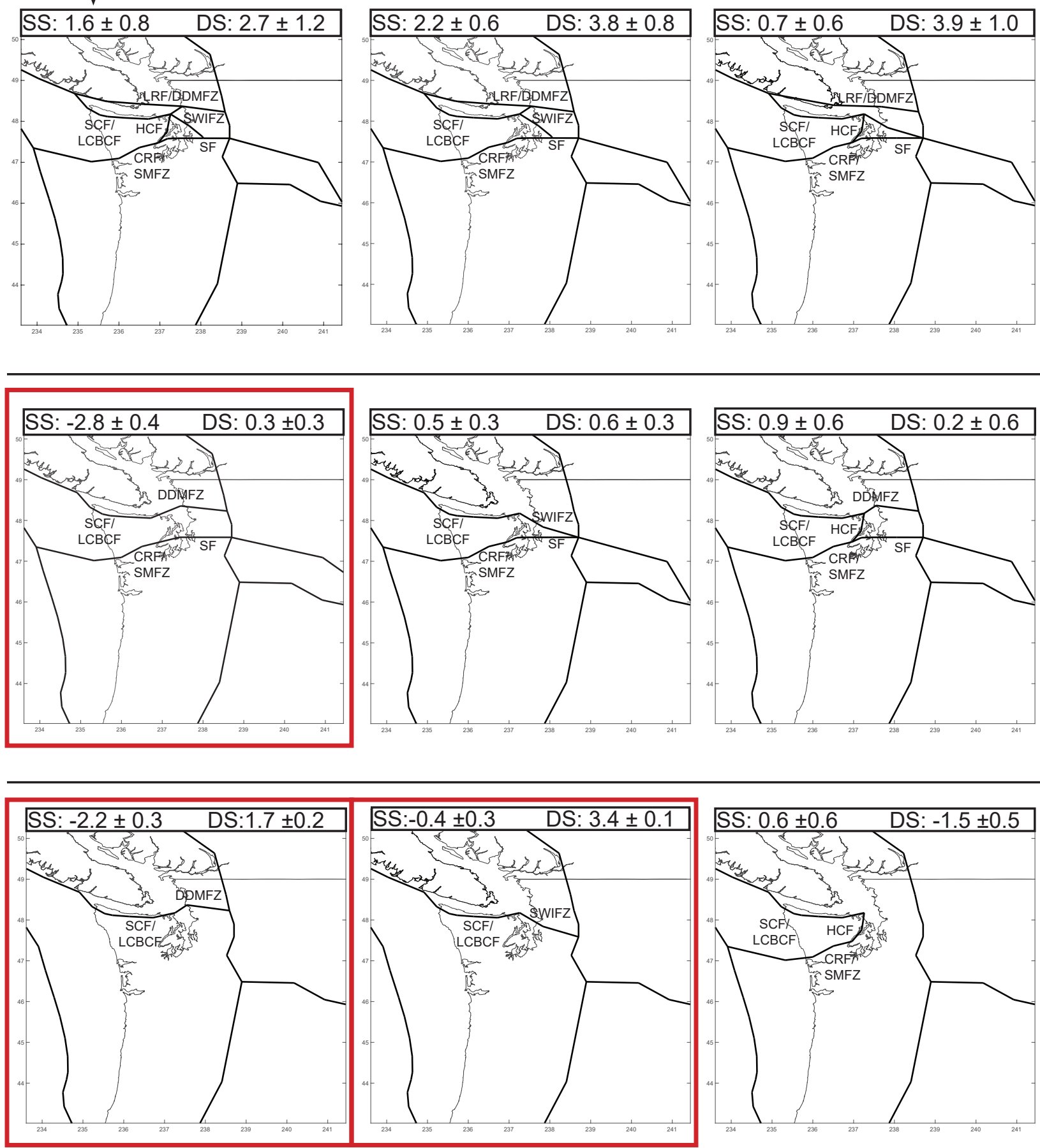

Figure 13. Configurations of crustal blocks (solid black lines) used in the geodetically constrained elastic block model. The estimated slip rates of the strike slip (SS; positive = sinistral) and dip slip (DS; positive = reverse) component on the LCBC/SCF are listed at the top of each configuration (in $\mathrm{mm} / \mathrm{yr}$ ). Rows organize block configurations by size while columns organize block configurations by the faults (abbreviations listed in Figure 1) that connect with the SCF/LCBCF to form block boundaries (left column connects with the DDMFZ, middle connects with the SWIFZ and right connects with the SMFZ/CRDt on the southern Olympic Mountains). Configurations which estimate the right lateral kinematics for the SCF/LCBCF are highlighted in red. 

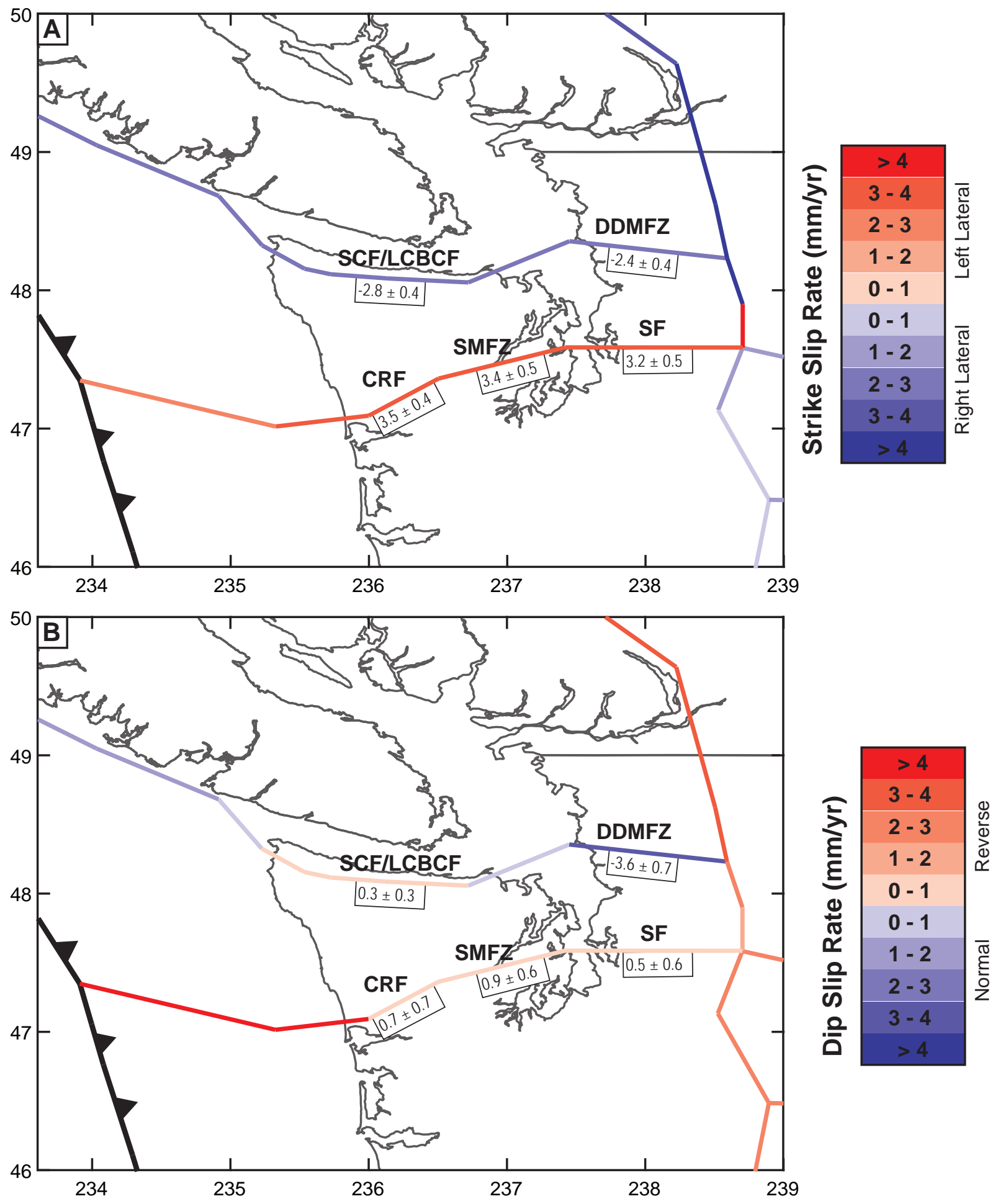

Figure 14. Preferred block configuration in the geodetically constrained elastic block model. (A \& B) Estimated strike slip rates and dip slip rates ( $\mathrm{mm} / \mathrm{yr}$ ), respectively, are colored by the magnitude and direction of slip. Sign convention is the same as in Figure 10. Fault abbreviations (black text) are the same as in Figure 1B. 


\section{TABLE 1 SUMMARY OF STRIKE-SLIP DISPLACEMENT ALONG THE SCF AND LCBCF}

\begin{tabular}{|c|c|c|c|c|c|c|c|c|c|c|c|c|c|c|c|}
\hline \multirow[b]{2}{*}{ Name } & \multirow[b]{2}{*}{ Distance* } & \multicolumn{4}{|c|}{ Strike-Slip Displacement (m) } & \multicolumn{3}{|c|}{ Dip-Slip Displacement (m) } & \multicolumn{3}{|c|}{ Strike-Slip to Dip-Slip Ratio (Rake) } & \multicolumn{3}{|c|}{ Total Slip (m) } & \multirow[b]{2}{*}{ Quality§ } \\
\hline & & $\begin{array}{l}\text { Pref- } \\
\text { erred }\end{array}$ & $\begin{array}{l}\text { Upper } \\
\text { Bound }\end{array}$ & $\begin{array}{l}\text { Lower } \\
\text { Bound }\end{array}$ & Distribution & $\begin{array}{l}\text { Pref- } \\
\text { erred }\end{array}$ & $\begin{array}{l}\text { Upper } \\
\text { Bound }\end{array}$ & $\begin{array}{l}\text { Lower } \\
\text { Bound }\end{array}$ & Preferred & $\begin{array}{l}\text { Lower } \\
\text { Bound } \\
\end{array}$ & $\begin{array}{c}\text { Upper } \\
\text { Bound } \\
\end{array}$ & $\begin{array}{l}\text { Pref- } \\
\text { erred }\end{array}$ & $\begin{array}{l}\text { Lower } \\
\text { Bound }\end{array}$ & $\begin{array}{l}\text { Upper } \\
\text { Bound }\end{array}$ & \\
\hline \multicolumn{16}{|l|}{ Sadie Creek Fault } \\
\hline $\mathrm{K}$ & 8294 & 24.5 & 25.7 & 23.3 & Gaussian & 5.3 & 6.2 & 4.6 & $4.9(169)$ & $2.7(159)$ & $5.3(169)$ & 25.3 & 24.2 & 26.5 & 3 \\
\hline $\mathrm{J}$ Interfluve & 8453 & 8.3 & 10.1 & 6.5 & Gaussian & 5.8 & 7.0 & 4.9 & $1.5(146)$ & $1.1(138)$ & $1.8(151)$ & 10.1 & 8.8 & 11.5 & 1 \\
\hline J Channel & 8453 & 4 & 4.8 & 3.2 & Gaussian & 4.1 & 4.9 & 3.6 & $1.0(135)$ & $0.8(128)$ & $1.2(140)$ & 5.7 & 5.1 & 6.4 & 1 \\
\hline I & 9405 & 15.8 & 16.6 & 15.0 & Gaussian & 4.1 & 6.2 & 1.9 & 3.1 (162) & $2.6(159)$ & 7.7 (173) & 16.4 & 15.5 & 17.2 & 4 \\
\hline H Interfluve & 9597 & --- & 14.7 & 9.9 & Uniform & 2.5 & 3.5 & 1.5 & $4.7(168)$ & 3.4 (164) & 7.9 (173) & 12.7 & 10.4 & 14.7 & 3 \\
\hline H Channel** & 9597 & 4.1 & 3.1 & 5.1 & Gaussian & $\mathbf{0}$ & 0 & 0 & --- (180) & --- (180) & --- (180) & 4.1 & 3.1 & 5.1 & 3 \\
\hline $\mathrm{G}$ & 9714 & -- & 16.4 & 11 & Uniform & 2.8 & 3.5 & 2.2 & 5.0 (169) & 3.7 (165) & $6.3(171)$ & 12.0 & 11.6 & 16.4 & 3 \\
\hline $\mathrm{F}$ & 9841 & 11.7 & 14.5 & 8.9 & Gaussian & 2.7 & 5.4 & 0.4 & $11.3(175)$ & $2.1(155)$ & $22.6(177)$ & 12.0 & 9.8 & 14.4 & 1 \\
\hline E & 12528 & 22.1 & 23.5 & 20.7 & Gaussian & 2.5 & 6.1 & 2.1 & $8.6(173)$ & $3.8(165)$ & $10.4(174)$ & 22.5 & 21.2 & 23.6 & 3 \\
\hline $\mathrm{D}$ & 12969 & 26 & 29 & 23 & Gaussian & 2.2 & 2.5 & 1.8 & $12.0(175)$ & $5.8(170)$ & $14.1(176)$ & 26.1 & 23.7 & 28.6 & 3 \\
\hline $\mathrm{C}$ & 13028 & 6.5 & 7.6 & 4.3 & Triangular & 2.2 & 2.5 & 1.8 & $2.9(161)$ & $1.3(143)$ & $3.5(164)$ & 6.9 & 5.4 & 7.9 & 1 \\
\hline B & 13091 & 15.6 & 19.7 & 13.3 & Triangular & 2.2 & 2.5 & 1.8 & $7.5(172)$ & $3.5(164)$ & 9.0 (174) & 15.9 & 14.4 & 18.8 & 2 \\
\hline $\mathrm{A}^{* *}$ & 13648 & 21.4 & 24.2 & 18.6 & Gaussian & 0.0 & 0.0 & 0.0 & $---(180)$ & --- (180) & --- (180) & 21.4 & 18.6 & 24.2 & 4 \\
\hline \multicolumn{16}{|c|}{ Lake Creek Boundary Fault*** } \\
\hline OL07 & 35223 & 13 & 23.9 & 10.8 & Triangle & 3.1 & 3.8 & 2.4 & $5.3(169)$ & $3.6(165)$ & $7.2(172)$ & 13.7 & 12.3 & 21.5 & 3 \\
\hline OL06 & 36233 & 11 & 13 & 4 & Triangle & 1.5 & 3.3 & 1.3 & $6.8(172)$ & $2.4(158)$ & $8.1(173)$ & 11.0 & 6.1 & 12.3 & 2 \\
\hline OL05 & 36295 & 11 & 13 & 4 & Triangle & 1.5 & 3.3 & 1.3 & $6.8(172)$ & $2.4(158)$ & $8.1(173)$ & 11.0 & 6.1 & 12.3 & 2 \\
\hline OL04 & 36342 & 11.5 & 14 & 5.8 & Triangle & 1.5 & 3.3 & 1.3 & $7.3(172)$ & $2.9(161)$ & $8.8(174)$ & 11.6 & 7.6 & 13.2 & 2 \\
\hline LCBC-CD2 & 43073 & 17.3 & 19.3 & 15.3 & Gaussian & 2.1 & 2.9 & 1.4 & $8.3(173)$ & $6.2(171)$ & $11.5(175)$ & 17.4 & 15.7 & 19.1 & 2 \\
\hline LCBC-CD1 & 43295 & 29.7 & 32.6 & 23.9 & Gaussian & 2.1 & 2.9 & 1.4 & $14.4(176)$ & $10.7(174)$ & $19.7(177)$ & 29.9 & 27.4 & 32.2 & 3 \\
\hline $\mathrm{MC}$ & 46507 & 7 & 10 & 4 & Triangle & 3.1 & 3.7 & 2.6 & $2.4(157)$ & $1.6(147)$ & $3.0(162)$ & 7.6 & 5.8 & 9.6 & 1 \\
\hline OL03 Interfluve & 50957 & 26 & 37.8 & 18 & Triangle & 0.8 & 1.2 & 0.3 & 39.7 (179) & $19.9(177)$ & $52.9(179)$ & 26.1 & 20.8 & 34.4 & 4 \\
\hline OL03 Channel** & 50957 & 4.5 & 2.1 & 6.9 & Gaussian & $\mathbf{0}$ & 0 & 0 & $--(\mathbf{1 8 0})$ & --- (180) & --- (180) & 4.5 & 2.1 & 6.9 & 4 \\
\hline OL02 & 51059 & 27.6 & 37.2 & 15 & Triangle & 0.8 & 1.2 & 0.3 & 39.8 (179) & $19.9(177)$ & $53.0(179)$ & 27.6 & 18.7 & 34.0 & 3 \\
\hline
\end{tabular}

*Measured in meters from West to East, beginning at the SCF terminus with the West Twin River and ending at the LCBCF terminus with Seibert Creek

**No measurable scarp. Vertical slip value of 0 was assigned.

*** LCBC lateral slip site (NOL01) originally reported by Nelson et al. (2017), was not able to be confidently identified by this study and is not included.

$\S$ Quality $(1=$ best, 4 = worst). See Supplemental Document S4 for description of quality evaluation. 
TABLE 2 PRELIMINARY OSL RESULTS

\begin{tabular}{|c|c|c|c|c|c|c|c|c|c|}
\hline $\begin{array}{c}\text { OSL }^{1} \\
\text { Sample }\end{array}$ & Deposit & $\begin{array}{l}\text { Depth } \\
\text { (m) }\end{array}$ & $\begin{array}{c}\text { Num of } \\
\text { Aliquots } \\
\text { (total run) }\end{array}$ & $\begin{array}{c}\text { Dose Rate } \\
\text { (Gy/ka) }\end{array}$ & $\begin{array}{l}\text { Equivalent } \\
\text { Dose }^{3} \\
\pm 2 \sigma(G y)\end{array}$ & $\begin{array}{l}\text { OSL Age } \\
\pm 2 \sigma(k a)\end{array}$ & $\begin{array}{c}{ }^{14} \mathrm{C}^{1} \\
\text { Sample }\end{array}$ & \multicolumn{2}{|c|}{$\begin{array}{l}{ }^{14} \mathrm{C} \text { Calibrated } \\
\text { age (range, old } \\
\text { to young) }\end{array}$} \\
\hline L07 & Qgo & 1.05 & $2(3)$ & $1.44 \pm 0.06$ & $18.20 \pm 2.66$ & $12.67 \pm 2.11$ & --- & --- & --- \\
\hline L08 & Qf (o) & 1.4 & $6(13)$ & $1.54 \pm 0.06$ & $26.62 \pm 4.50$ & $17.31 \pm 3.23$ & --- & --- & --- \\
\hline L09 & Qf (o) & 0.8 & $1(3)$ & $1.25 \pm 0.05$ & $17.82 \pm 1.39$ & $14.27 \pm 1.61$ & --- & --- & --- \\
\hline L11 & Qt1 & 0.75 & $2(3)$ & $1.46 \pm 0.06$ & $12.78 \pm 0.97$ & $8.75 \pm 0.97$ & $\mathrm{CD} 2$ & 4,155 & 3,921 \\
\hline L12 & Qgoi & 1 & $5(13)$ & $1.48 \pm 0.06$ & $26.56 \pm 4.10$ & $17.93 \pm 3.12$ & --- & --- & --- \\
\hline L13 & Qf (o) & 0.45 & $4(13)$ & $1.30 \pm 0.05$ & $18.75 \pm 3.89$ & $14.46 \pm 3.22$ & CD6 & 47,812 & 45,500 \\
\hline L14 & Qgt & 1.2 & $6(13)$ & $1.48 \pm 0.06$ & $32.27 \pm 4.79$ & $21.79 \pm 3.67$ & BL02 & 31,180 & 30,780 \\
\hline L15 & Qf $(0)$ & 1.6 & $3(9)$ & $1.53 \pm 0.06$ & $11.59 \pm 1.57$ & $7.57 \pm 1.19$ & GB32 & 14,196 & 13,794 \\
\hline
\end{tabular}

${ }^{1} \mathrm{OSL}$ and ${ }^{14} \mathrm{C}$ Sample names both begin with "SCF18-"

${ }^{2} \mathrm{Age}$ analysis using the single-aliquot regenerative-dose procedure of Murray and Wintle (2000) on 1-2mm small-aliquots of quartz sand. Number of aliquots used in age calculation and number of aliquots analyzed in parentheses.

${ }^{3}$ Equivalent dose (DE) calculated using the Central Age Model (CAM) of Galbraith and Roberts (2012). 
TABLE 3 RADIOCARBON DATING RESULTS

\begin{tabular}{|c|c|c|c|c|c|c|c|c|c|c|c|}
\hline \multirow{2}{*}{ Sample Name } & \multirow{2}{*}{$\begin{array}{c}\text { Sample } \\
\text { Type }\end{array}$} & \multirow{2}{*}{ Depth } & \multirow{2}{*}{ Location* } & \multirow{2}{*}{ Deposit } & \multicolumn{2}{|c|}{$\begin{array}{c}\text { Fraction of } \\
\text { Modern }\end{array}$} & \multicolumn{2}{|c|}{ Radiocarbon Age } & \multicolumn{3}{|c|}{ Calibrated Age (BP) } \\
\hline & & & & & pMC & $\begin{array}{c}1 \sigma \\
\text { error }\end{array}$ & BP & $\begin{array}{c}1 \sigma \\
\text { error }\end{array}$ & from & to & $\%$ \\
\hline SCF18-08-01 & charcoal & 0.77 & Site B Channel & Debris flow & 77.35 & 0.3 & 2,063 & 31 & 2,121 & 1,947 & 95.4 \\
\hline SCF18-CD12 & charcoal & 1.66 & Site B Fan & $\begin{array}{c}\text { Debris flow } \\
\text { fan }\end{array}$ & 73.14 & 0.3 & 2,513 & 33 & 2,741 & 2,489 & 95.4 \\
\hline SCF18-11B-01 & charcoal & 1.02 & Site F Channel & Debris flow & 30.44 & 0.19 & 9,555 & 50 & 11,104 & 10,707 & 95.4 \\
\hline SCF18-03-01 & charcoal & 1.5 & Site J Channel & Debris flow & 76.2 & 0.28 & 2,183 & 30 & 2,310 & 2,120 & 95.4 \\
\hline BL02 & charcoal & 1.35 & $\begin{array}{l}\text { Bog Lemming } \\
\text { Trench }\end{array}$ & $\begin{array}{l}\text { Sand lens } \\
\text { within till }\end{array}$ & 3.53 & 0.056 & 26,861 & 127 & 31,180 & 30,780 & 95.4 \\
\hline GB32 & Charcoal & 1.0 & $\begin{array}{l}\text { Ground Bear } \\
\text { Trench }\end{array}$ & Outwash/Fan & 22.02 & 0.17 & 12,150 & 65 & 14,196 & 13,794 & 95.4 \\
\hline SCF18-04-01 & charcoal & 1.38 & Site K Channel & Debris flow & 68.44 & 0.28 & 3,046 & 33 & 3,355 & 3,167 & 95.4 \\
\hline SCF18-09-04 & charcoal & 0.78 & Site D Channel & Debris flow & 82.41 & 0.3 & 1,554 & 29 & 1,528 & 1,383 & 95.4 \\
\hline SCF18-10-06 & charcoal & 0.89 & Site E Channel & Debris flow & 52.8 & 0.22 & 5,130 & 33 & 5,982 & 5,751 & 95.5 \\
\hline SCF18-CD2 & charcoal & 0.82 & Large Terrace & $\begin{array}{l}\text { Terrace/ } \\
\text { Outwash }\end{array}$ & 63.04 & 0.31 & 3,706 & 40 & 4,155 & 3,921 & 95.4 \\
\hline SCF18-CD6 & charcoal & 0.35 & GB Junction & Fan/ Outwash & 0.456 & 0.03 & 43,301 & 528 & 47,812 & 45,500 & 95.4 \\
\hline
\end{tabular}

*Sample locations shown in Supplemental Figures S1 and S6 
TABLE 4 SUMMARY OF MODEL RESULTS

\begin{tabular}{ccccc}
\hline Model & $\begin{array}{c}\text { Strike-Slip Rate } \\
\text { (mm/yr)* }\end{array}$ & $\begin{array}{c}\text { Dip-Slip Rate } \\
\text { (mm/yr)** }\end{array}$ & Rake & $\begin{array}{c}\text { Strike-Slip to Dip- } \\
\text { Slip Ratio }\end{array}$ \\
\hline \hline Interseismic & 0.5 to 1.6 & 0.1 to 0.5 & $20^{\circ}$ to $45^{\circ}$ & $<3: 1$ \\
Coseismic & -0.3 to -1.5 & -0.1 to -0.3 & -145 to $-175^{\circ}$ & $<10: 1$ \\
Slow Slip & -0.1 to -0.7 & -.1 to -0.4 & $-125^{\circ}$ to $-165^{\circ}$ & $<4: 1$ \\
Block & $-2.8 \pm 0.4$ & $0.3 \pm 0.3$ & 166 to $174^{\circ}$ & $4: 1$ to $10: 1$ \\
\hline \hline
\end{tabular}

* Positive values show left-lateral motion and negative values show right-lateral motion ** Positive values show reverse motion and negative values show normal motion 


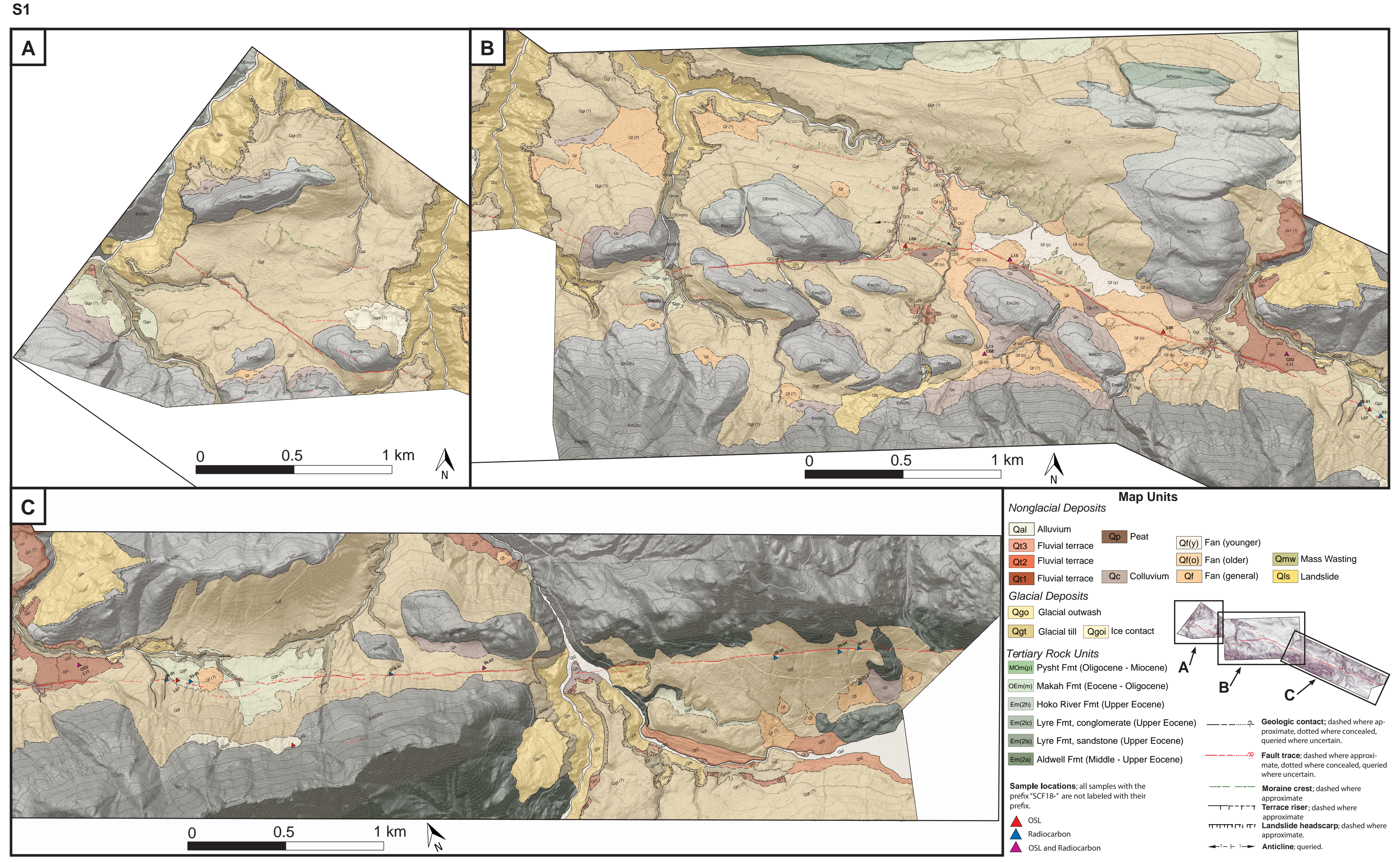




\section{Sadie Creek Fault Zone Description of Map Units}

\section{$\underline{\text { Postglacial Deposits }}$}

1. Alluvium (Qal, $\mathbf{Q t}_{\mathbf{1}}, \mathbf{Q t}_{\mathbf{2}}, \mathbf{Q t}_{\mathbf{3}}$ ) - Gravel, sand, silt, and clay, in varied amounts; variedly sorted; loose; typically bedded; mobilized by fluvial processes and deposited in streambeds and floodplains; clasts primarily derived from Olympic Peninsula sources but may contain small amounts of distally sourced sediment, originally transported into the map area by glacial ice from Canada. Unit Qal includes all variants of alluvium, whereas unit Qt is restricted to alluvium that forms river/stream terraces. Such terraces are planar surfaces that gently dip down valley and are formed by the aggradation of fluvial sediments and the subsequent incision into these sediments. Numeric subscripts of Qt delineate terraces by age, determined by the relative height of the terrace above the stream channel. Smaller numbers indicate older (higher) terraces while larger numbers indicate younger (lower) terraces.

2. Peat (Qp) - Organic-rich sediments deposited in closed depressions; includes peat, silt and clay in and near wetlands.

3. Colluvium (Qc) - Boulders, gravel, sand, silt, and clay, in varied amounts; poorly sorted; loose; somewhat stratified into slope-parallel layers; composition unique to upslope sediment sources, typically derived from Olympic Peninsula bedrock or Juan de Fuca Lobe till; deposited by gradual and rapid hillslope processes (e.g. soil creep, sheetwash, rainwash, rockfall, etc.) along relatively steep hillsides; mapped where colluvium is interpreted as being greater than $2 \mathrm{~m}$ thick.

4. Landslide (Qls) - Boulders, gravel, sand, silt and clay, in varied amounts, forming a slide body and toe; often associated with a steep headscarp that exposes underlying units; angular to rounded; unsorted; generally loose, unstratified, broken, and chaotic, but may include blocks that retain primary bedding structure; deposited by mass wasting processes; typically in unconformable contact with surrounding units. Unit Q1s includes both active and inactive (“ancient") slides.

5. Mass Wasting (Qmw) - Boulders, gravel, sand, silt, and clay in varied amounts; generally unsorted; typically loose; shown along mostly colluvium-covered slopes that appear potentially unstable; contains exposures of underlying units and landslides that we either could not map with confidence or are too small to show as separate features.

6. Fan (Qf, Qf $\mathbf{y}, \mathbf{Q f _ { \mathbf { o } }}$ ) - Boulders, gravel, sand, silt, and clay deposited in a fan shape at the edge of the mountain front and onto the valley floor; generally is coarser in upper reaches and finer towards the valley floor; clast or matrix supported, moderately to loosely stratified, moderately to poorly sorted, and subrounded to angular. In areas with multiple generations of fans, the designation of $(y)$, or (o) is given to deposit labels to delineate younger and older fans, respectively.

\section{Glacial Deposits}


1. Juan de Fuca Lobe till (Qgt) -Boulders, gravel, sand, silt and clay, in varied amounts; deposited directly by glacial ice of the Juan de Fuca lobe; unsorted; highly compacted; matrix supported; rounded to angular; gray in color where exposure is fresh, light yellowish brown where oxidized; characterized by distally sourced sediments rafted by glacial ice from Canada but may contain clasts of Olympic Peninsula bedrock; includes lodgment till, ablation till, and ribbed moraines. Lodgment till is characterized by over-compaction and is common along valley floors and hillslopes. Ablation till is loose, unstratifed, unsorted, primarily composed of yellowish brown silt and clay with minor amounts of gravels, and forms $<2 \mathrm{~m}$ thick blanket on top of lodgment till. Sublinear, evenly spaced ridges oriented orthogonal to ice flow direction are classified as "ribbed moraines" and may have formed as push moraines, grounding line moraines, or as till injection into ice fractures (Lundqvist, 1997; Hättestrand and Kleman, 1999; Boulton, 1986). Unit Qgt lies stratigraphically below units Qgo and Qgoi.

2. Recessional Outwash (Qgo, Qgoi $)$ - Dominantly gravel and sand with lesser amounts of silt and clay; characterized by distally sourced rock types but may contain more than $95 \%$ Olympic Peninsula bedrock clasts; well-rounded to subangular; loose; sorted; stratified; deposited by glacial meltwater during recession of the Juan de Fuca Lobe. The subscript " $i$ " designates outwash interpreted as ice-contact deposits.

\section{Eocene-Miocene Rock Units}

1. Bedrock - Bedrock units exposed in the map area include, from oldest to youngest, the Aldwell Formation (Em2a; middle Eocene), Lyre Formation (Em21s/Em2lc; upper Eocene), and Twin River Group, including the Hoko River Formation (Em $2 \mathrm{~h}$; upper Eocene), Makah Formation (OEmm; Oligocene-Eocene), and Pysht Formation (Momp; Miocene to Oligocene). These mostly marine sedimentary formations with lesser volcanic rocks stratigraphically overlie a basaltic basement formed by the Paleocene to Eocene Crescent Formation (not exposed in the map area). The location and geometry of bedrock units are extracted from Schasse (2003) as the distinction of bedrock units from one another is not within the scope of this study.

\section{References:}

Boulton, G.S., 1986, Push moraines and glacier-contact fans in marine and terrestrial environments: Sedimentology, v. 33, p. 677-698.

Hättestrand, C., and Kleman, J., 1999, Ribbed moraine formation: Quaternary Science Reviews, v. 18, p. 43-61, doi: 10.1016/S0277-3791(97)00094-2.

Lundqvist, J., 1997, Rogen moraine - An example of two-step formation of glacial landscapes: Sedimentary Geology, v. 111, p. 27-40, doi: 10.1016/S0037-0738(97)00004-3.

Schasse, H.W., 2003, Geologic Map of the Port Angeles 1:100,000 Quadrangle: Washington Division of Geology and Earth Resources, Open File Report 2004-14. 


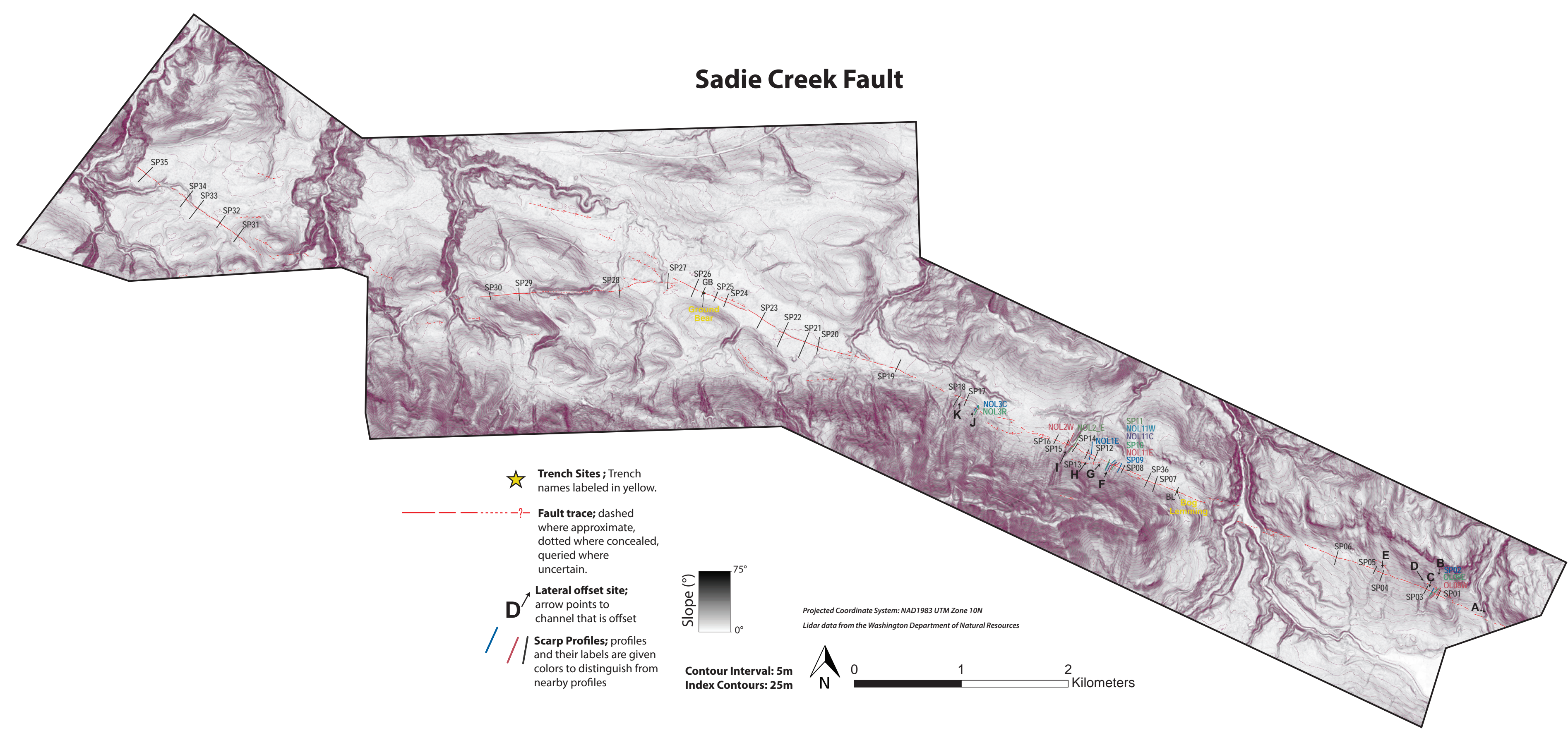




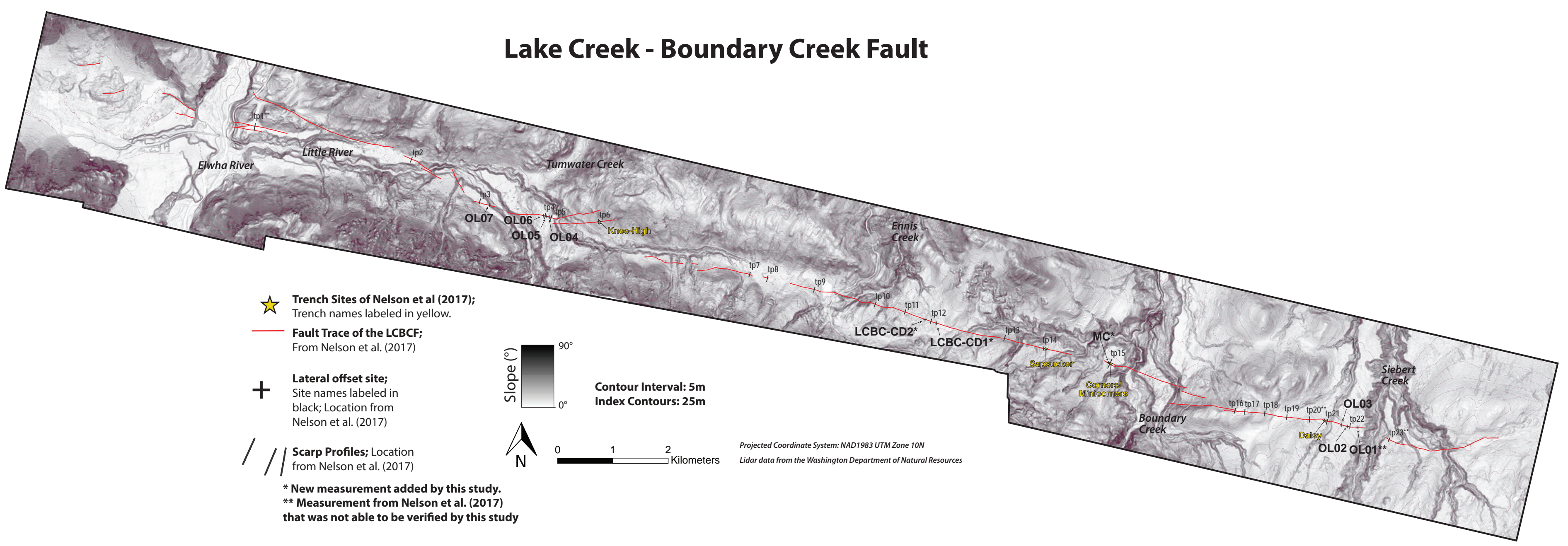




\section{Supplementary Document S4}

The following pages show all measurements of strike-slip displacement along the SCF and LCBCF. Measurements from the SCF are presented first (organized from E to W) and show a summary of the measurement ( $\left(1^{\text {st }}\right.$ page $)$, maps of all identified markers $\left(2^{\text {nd }}\right.$ page $)$, plots of measurements derived from channel markers deemed accurate ( $3^{\text {rd }}$ page), and slope-shade maps ( $0.5 \mathrm{~m}$ contours) backslipped to the preferred measurement, lower bound, and upper bound $\left(4^{\text {th }}\right.$ page). Measurements from the $\mathrm{LCBCF}$ are presented next (organized from $\mathrm{E}$ to $\mathrm{W}$ ) and follow the same format when a channel is the measured offset feature. For all other offset features, an un-backslipped slope-shade map ( $0.5 \mathrm{~m}$ contours) is shown with a summary of the measurement ( $1^{\text {st }}$ page) followed by slope-shade maps backslipped to the preferred measurement, lower bound, and upper bound ( $\left(2^{\text {nd }}\right.$ page). The errors displayed in the summary page $\left(1^{\text {st }}\right.$ page $)$ represent $2 \sigma$, but on all maps and plots are given as $1 \sigma$. Right lateral and N-side-up slip are shown as positive values and left lateral and S-side-up slip are shown as negative values. 


\section{Site A}

Well constrained features: Chan, W midpoint

Preferred Offset: $21.4 \mathrm{~m}$

Upper Bound: $24.2 \mathrm{~m}$

Lower Bound: $18.6 \mathrm{~m}$

Strike-Slip Displacement Distribution: Gaussian

Notes: The reported offset is derived from the Gaussian distribution of offset channel thalweg. The $\mathrm{W}$ midpoint appears to be affected by a landslide and is thus not considered.

Field Measurement: Not measured.

Quality: IV 

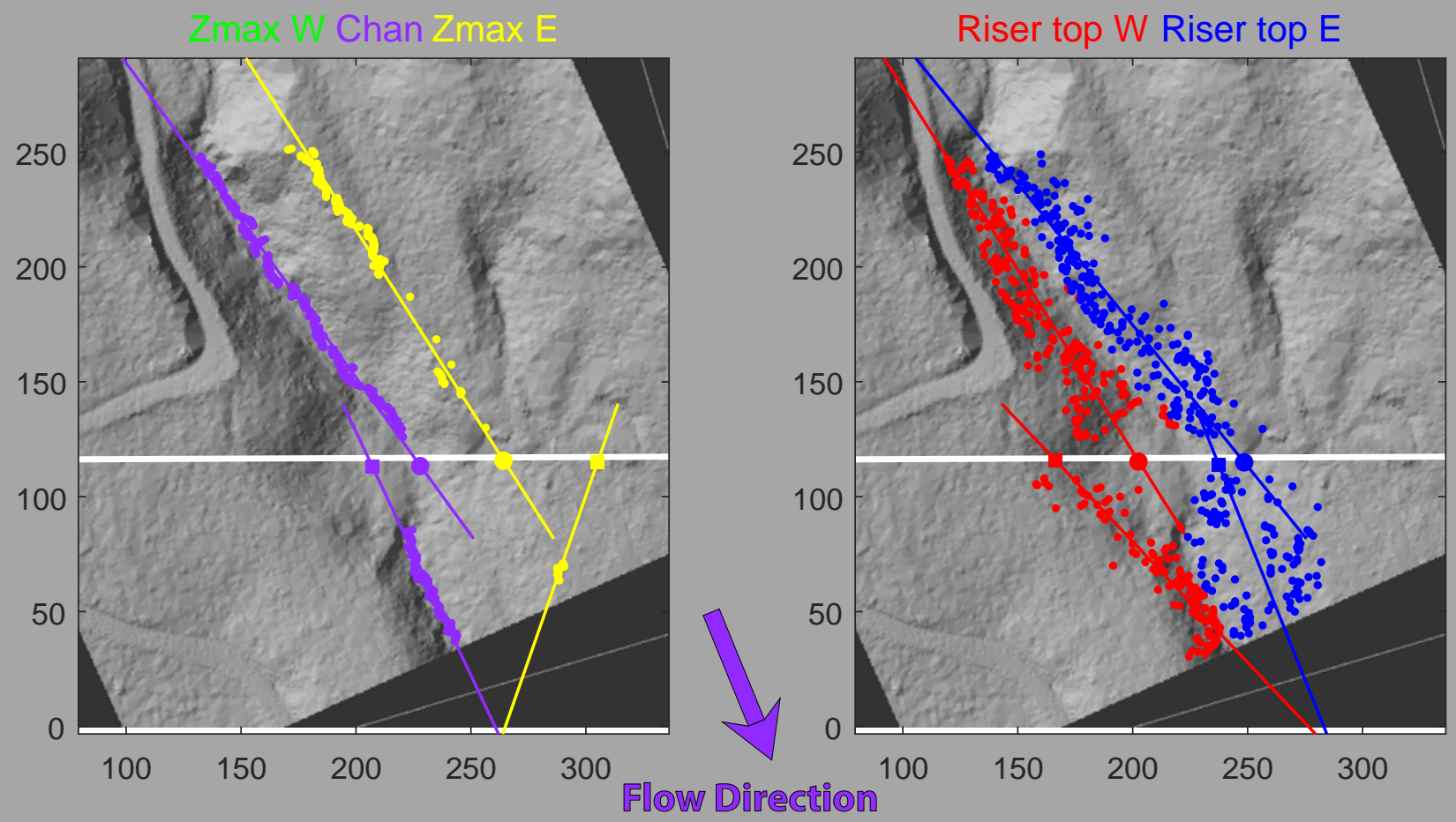

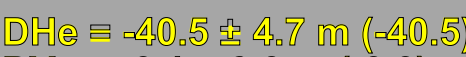

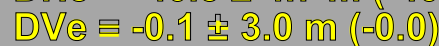

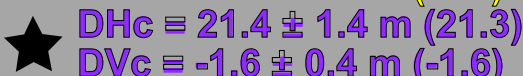

$\mathrm{DHw}=36.5 \pm 0.8 \mathrm{~m}(36.5)$

DVw $=-5.1 \pm 0.3 \mathrm{~m}(-5.1)$

$\mathrm{DHe}=11.6 \pm 1.2 \mathrm{~m}$ (11.5)

$\mathrm{DVe}=2.9 \pm 0.2 \mathrm{~m}(2.9)$

Riser mid E

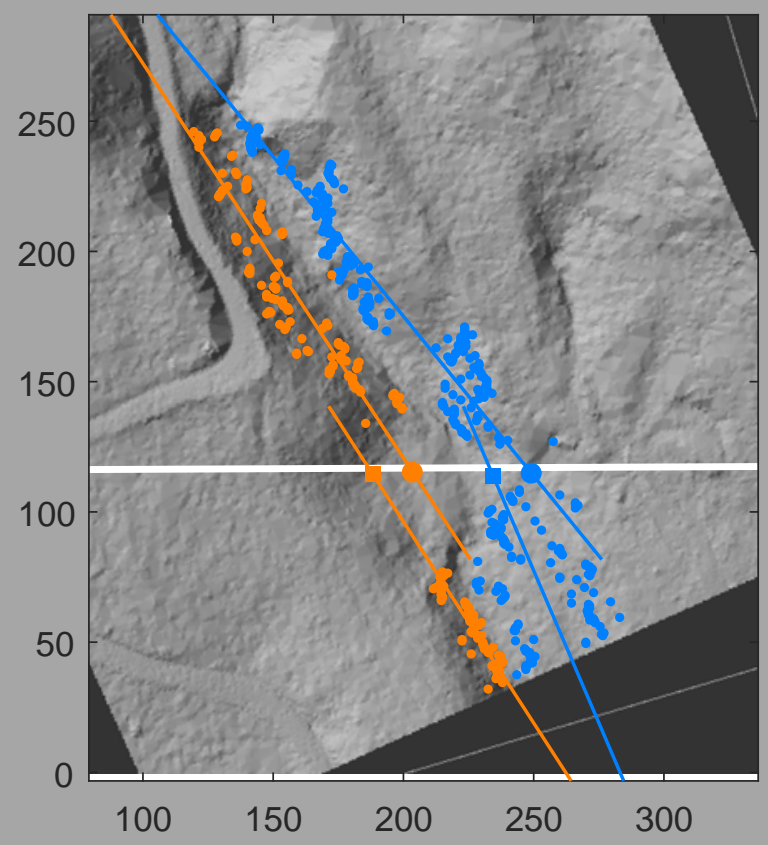

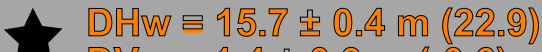

DVW

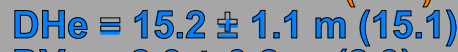

DVE $=2.9$ ? $0.2 \mathrm{~m}(2.9)$

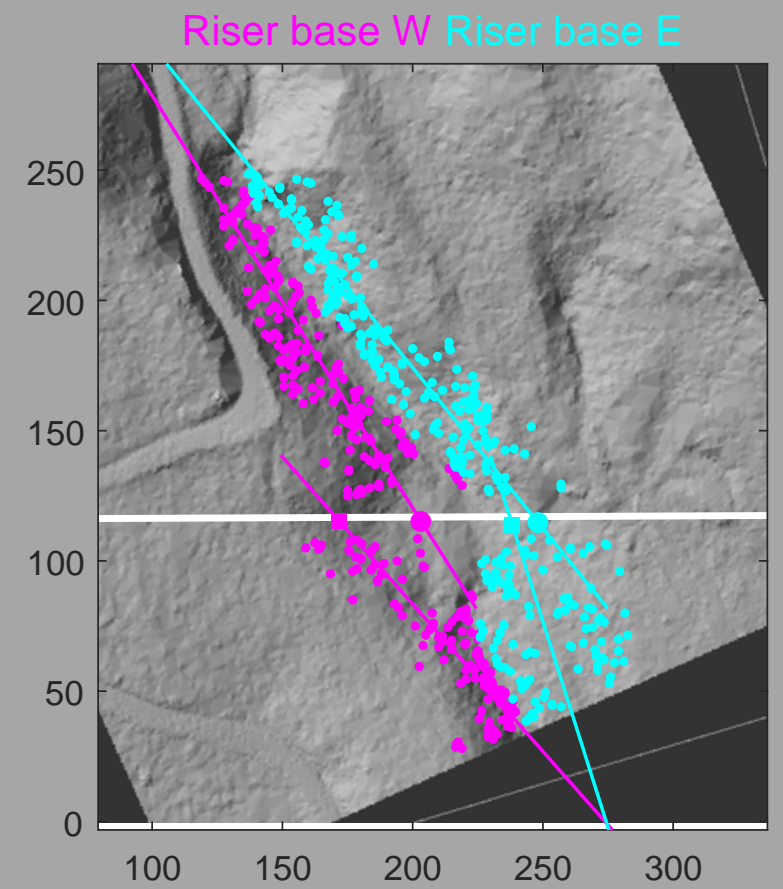

$\mathrm{DH} W=31.8$ 포 $0.6 \mathrm{~m}$ (31.9)

DVw $=-3.9 \pm 0.3 \mathrm{~m}(-3.9)$

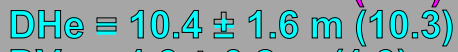

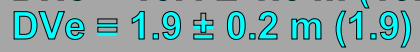




\section{Site A: Offset probability densities}
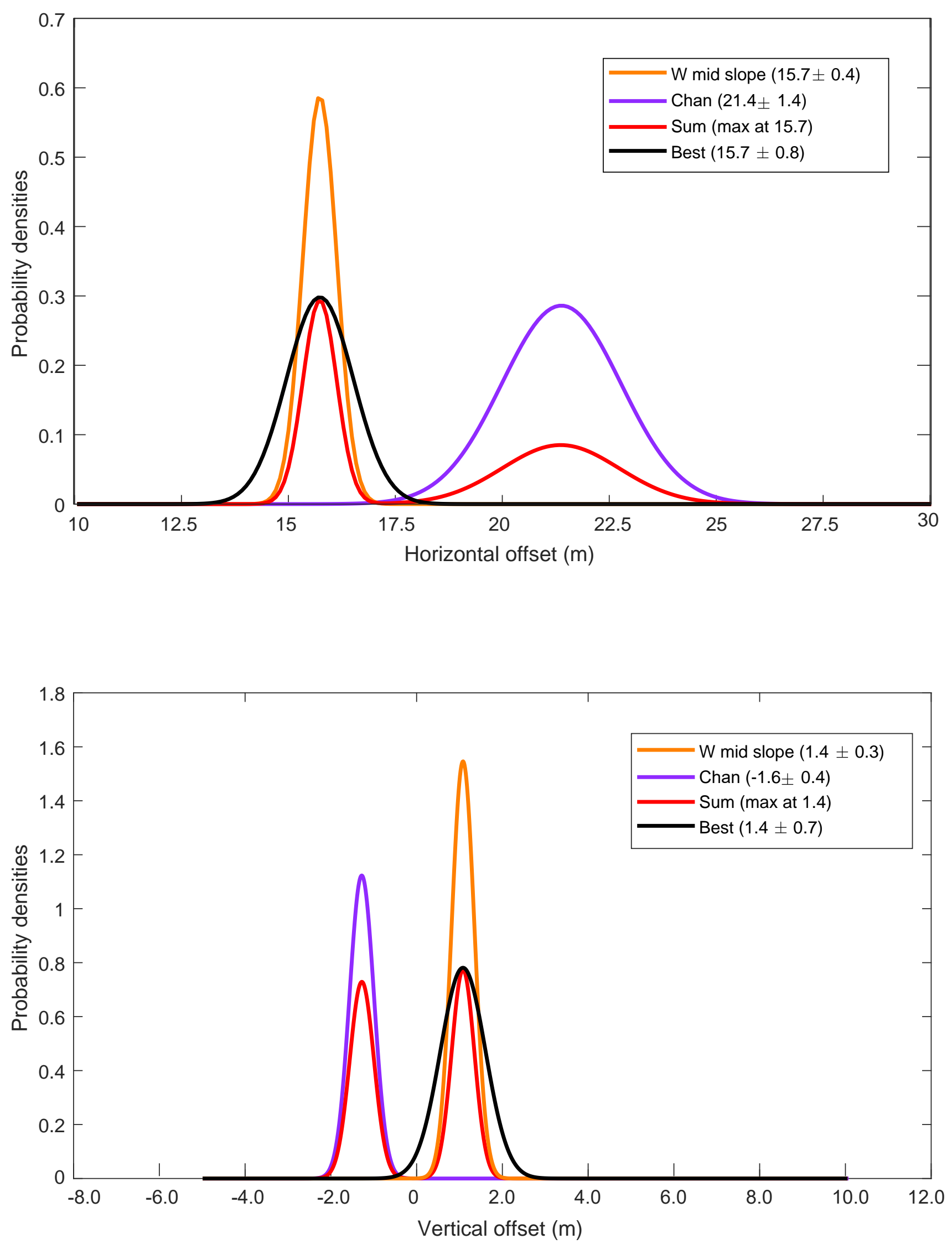
Site A

Original

Preferred: $21.4 \mathrm{~m}$
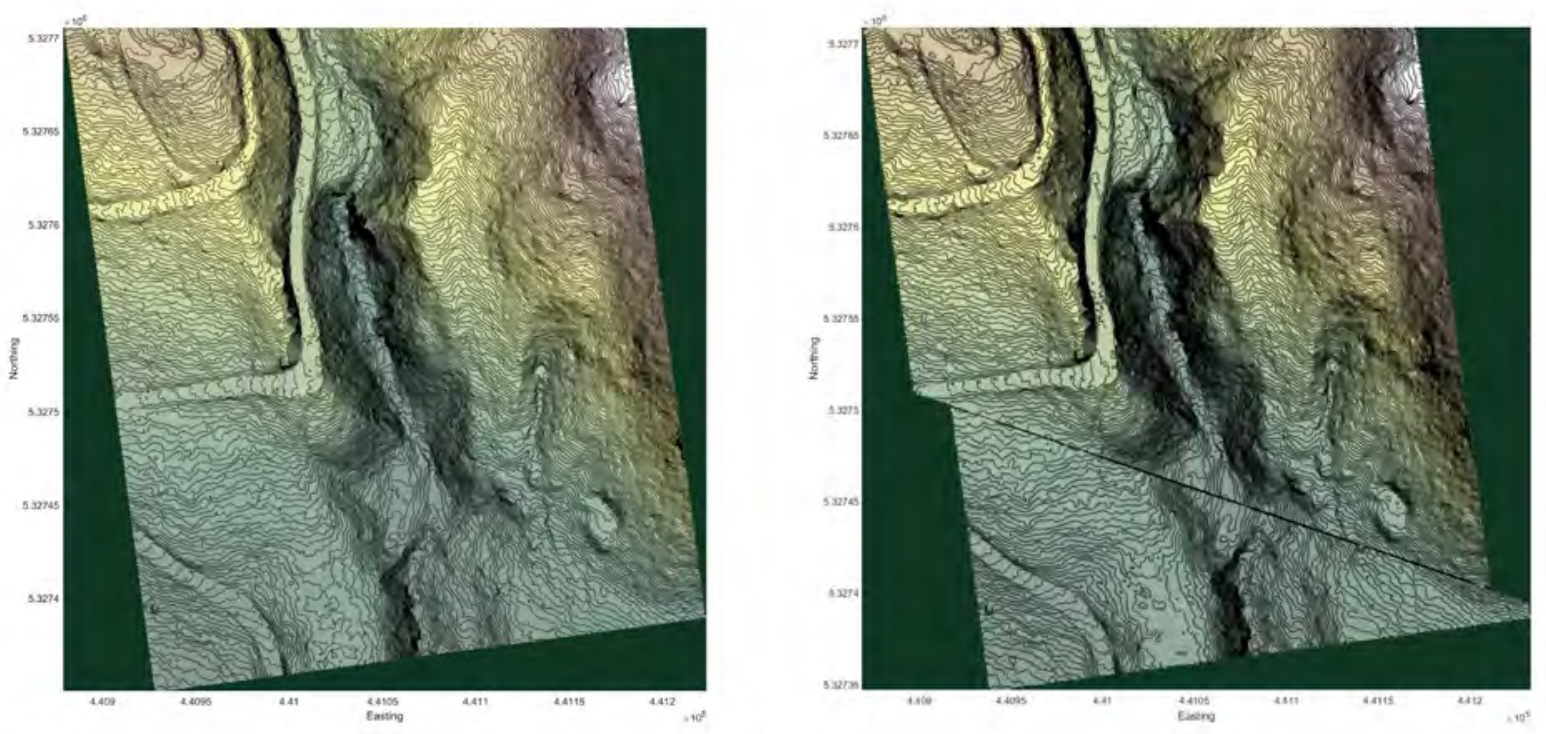

Lower Bound:18.6m

Upper Bound: 24.2m
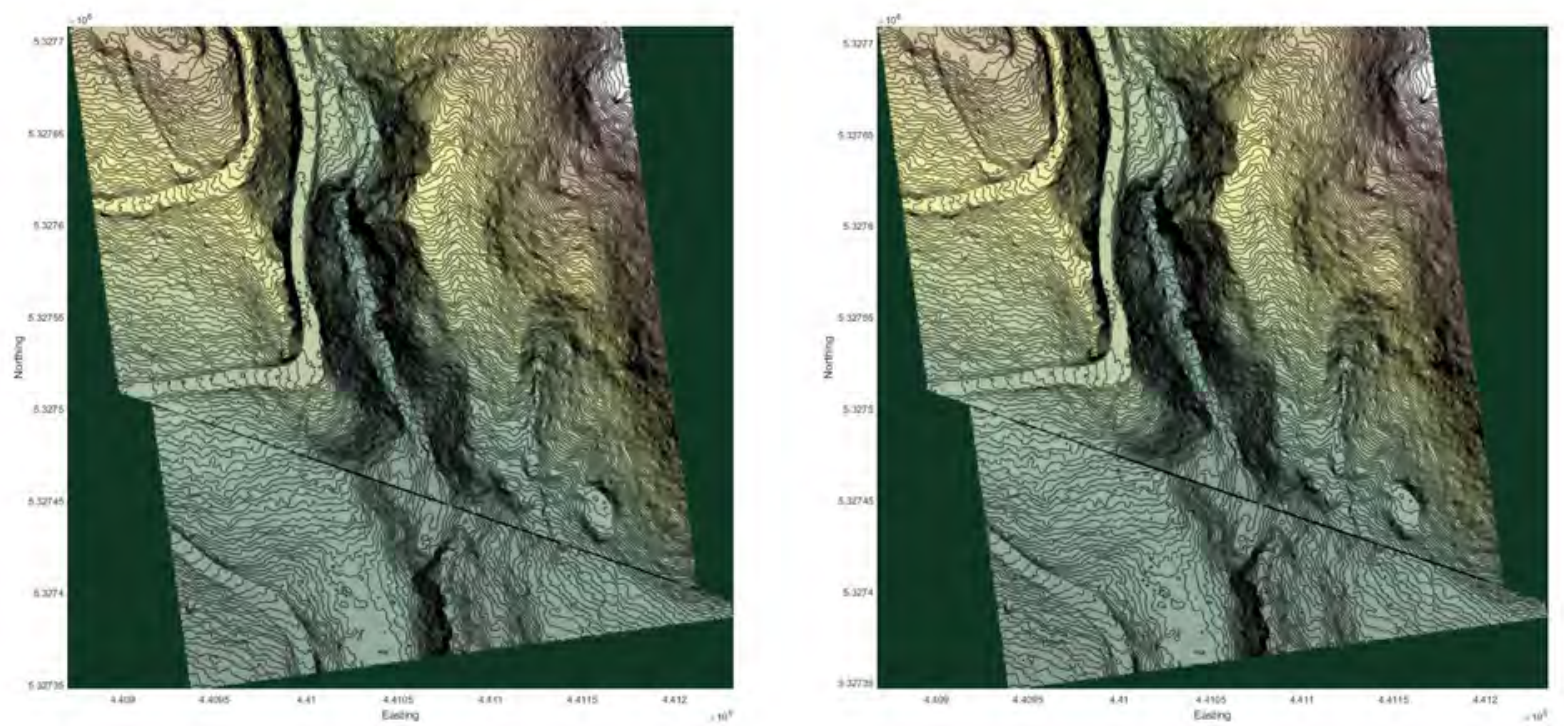


\section{Site B}

Well constrained features: Chan, W midpoint, E midpoint

Preferred Offset: $15.6 \mathrm{~m}$

Upper Bound: $19.7 \mathrm{~m}$

Lower Bound: $13.3 \mathrm{~m}$

Strike-Slip Displacement Distribution: Triangular. Lower error adjusted

from backslips.

Notes: Preferred value derived from 'Best' curve.

Field Measurement: $16.5 \pm 2 \mathrm{~m}$

Quality: II 


\section{Site B Offsets and uncertainties (10000 runs)}

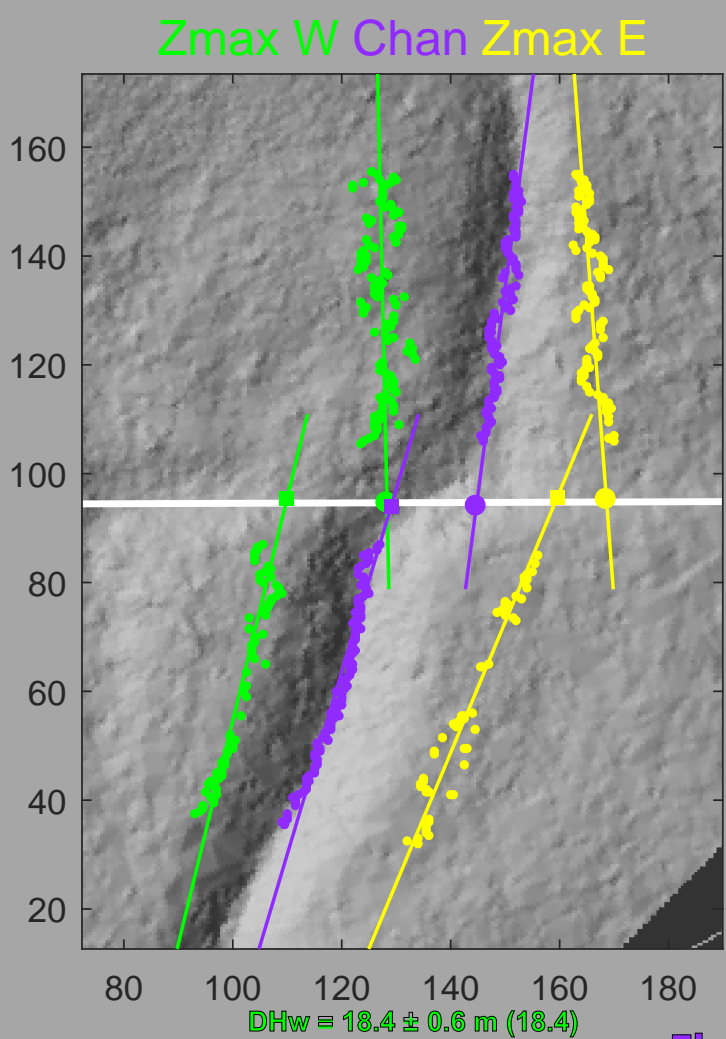

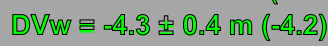

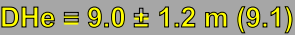

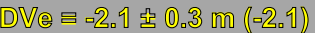

DHC $=15.7$ 표 $0.4 \mathrm{~m}(15.7)$

DVe $\equiv 0.3$ 폴 $0.2 \mathrm{~m}(0.3)$

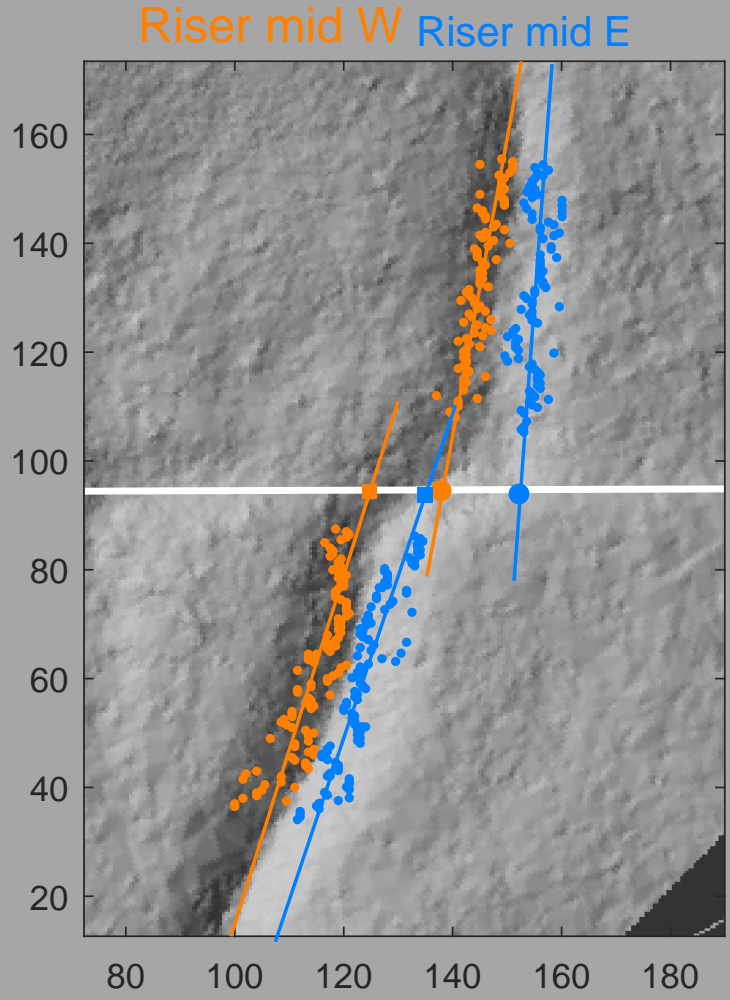

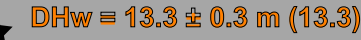

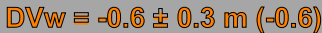

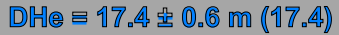

DV $=0.2$ s $0.2 \mathrm{~m}(0.2)$

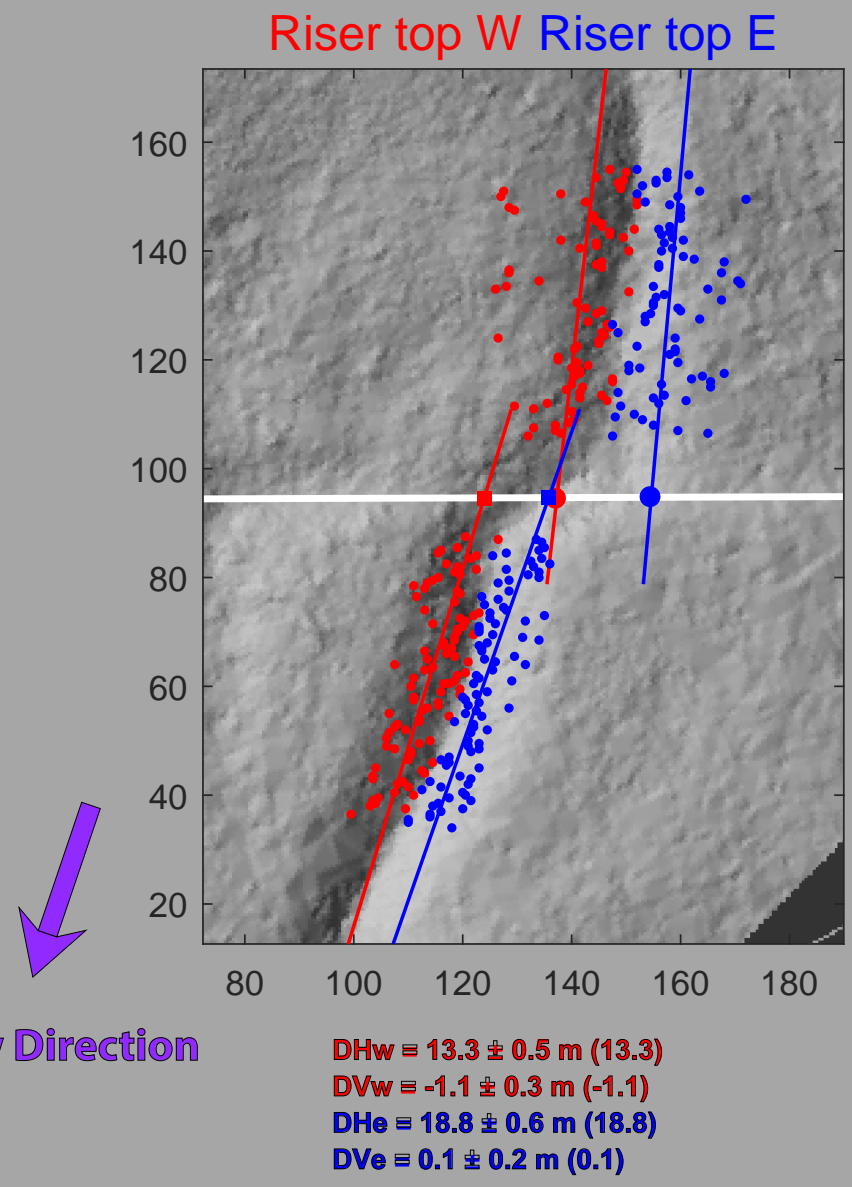

Riser base $\mathrm{W}$

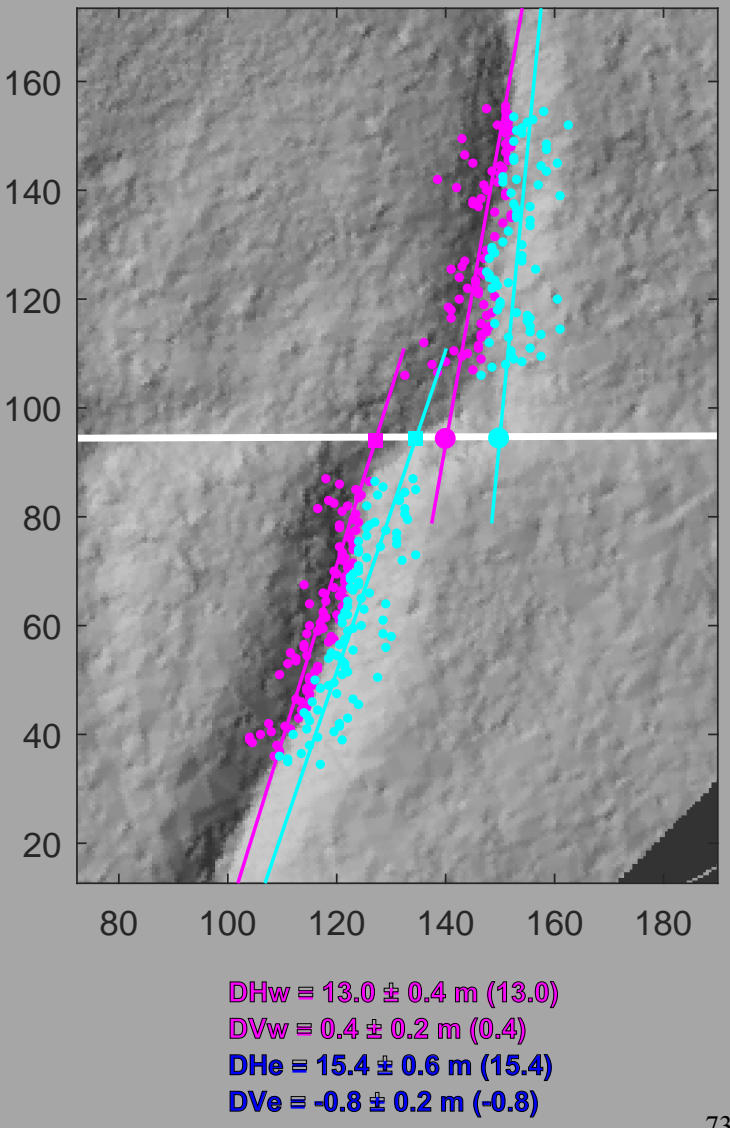




\section{Site B: Offset probability densities}
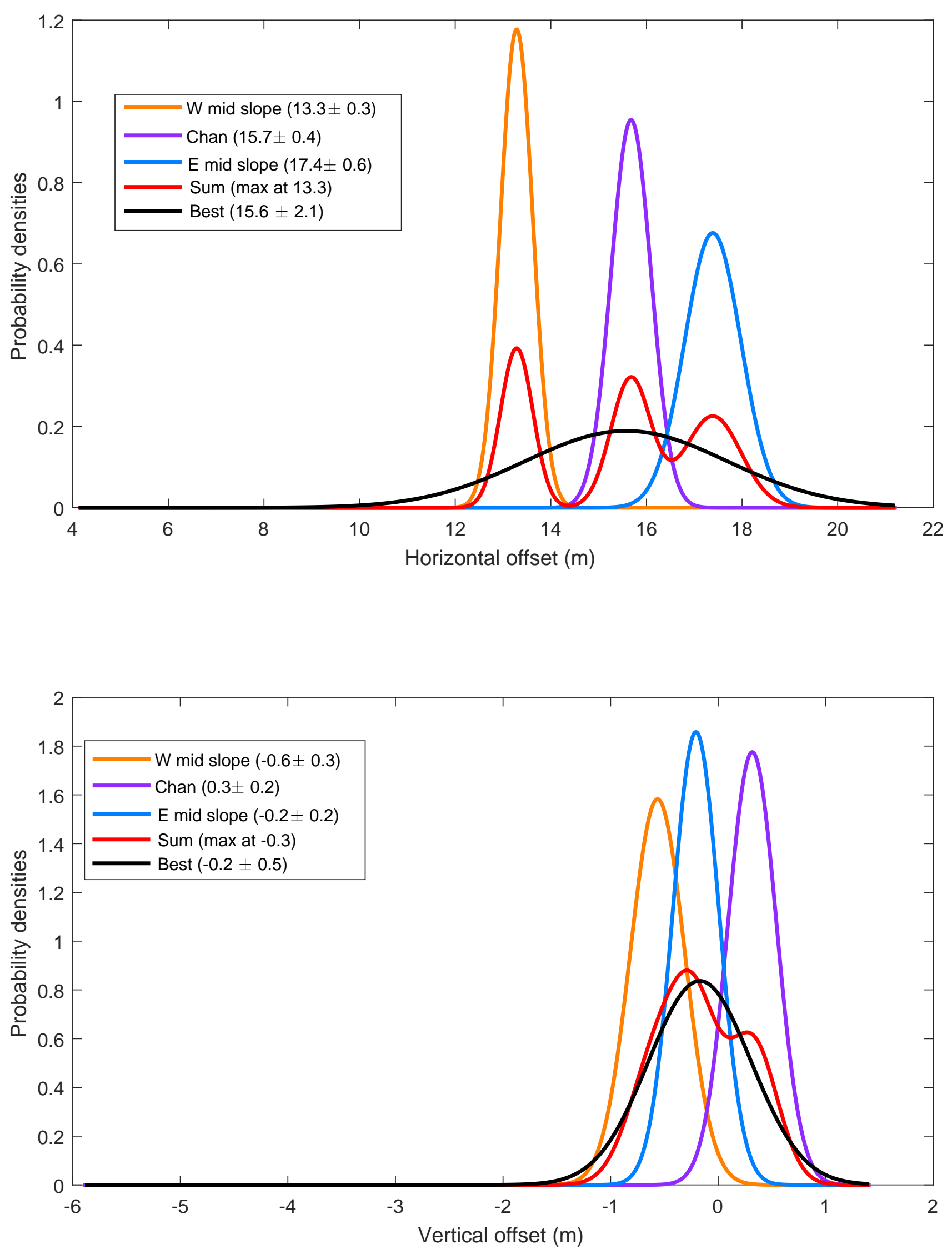
Site B

Original

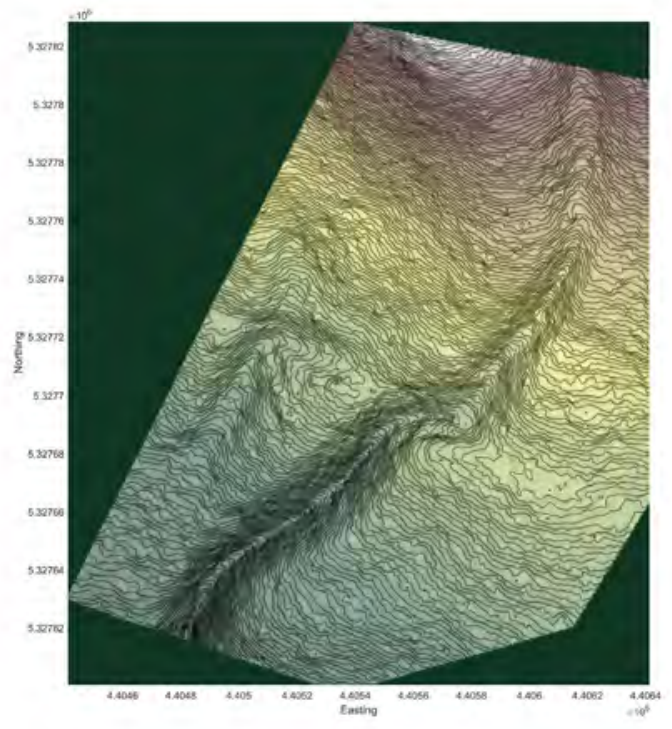

Lower Bound:13.3m

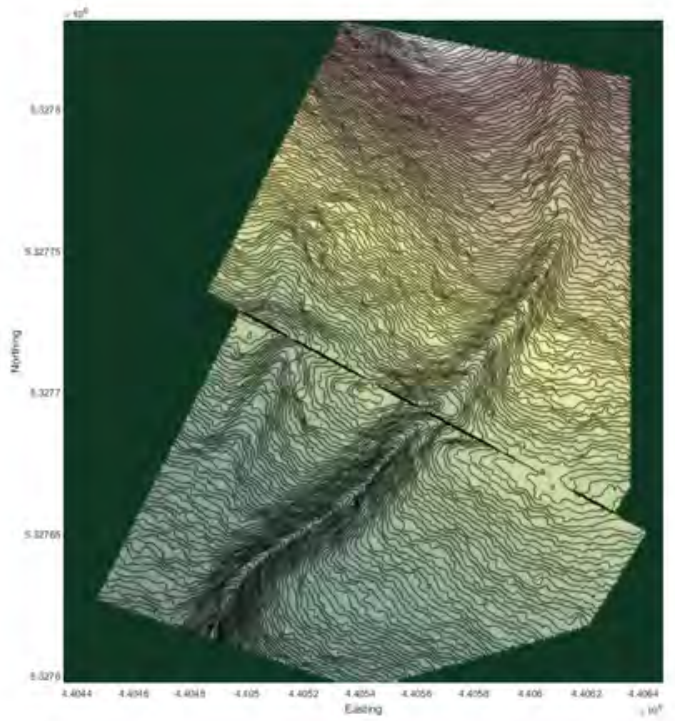

Preferred: $15.6 \mathrm{~m}$

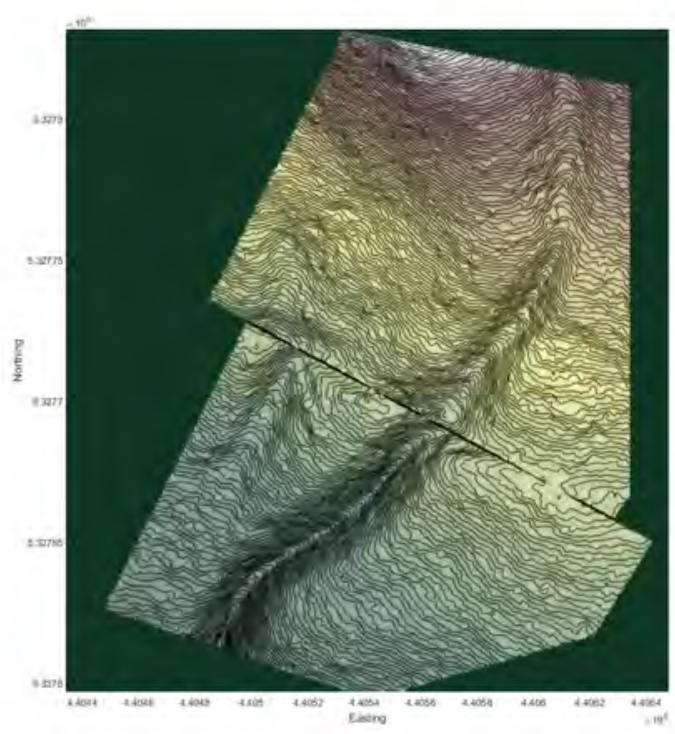

Upper Bound: $19.7 \mathrm{~m}$

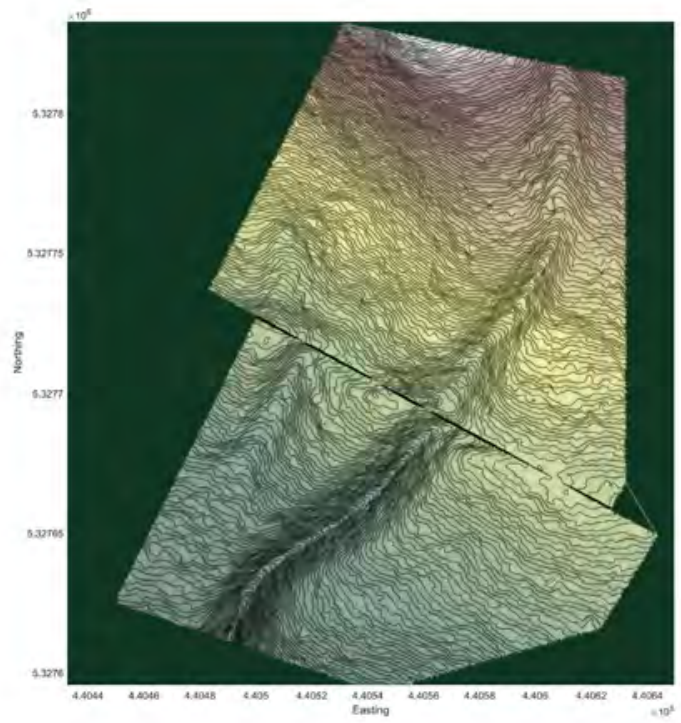




\section{Site C}

Well constrained features: W max, Chan, W midpoint

Preferred Offset: $6.5 \mathrm{~m}$

Upper Bound: $7.6 \mathrm{~m}$

Lower Bound: $4.3 \mathrm{~m}$

Strike-Slip Displacement Distribution: Triangle. Upper error adjusted

from backslips.

Notes: Preferred offset derived from peak of 'Best' curve.

Field Measurement: Not measured.

Quality: I 


\section{Site C Offsets and uncertainties (10000 runs)}
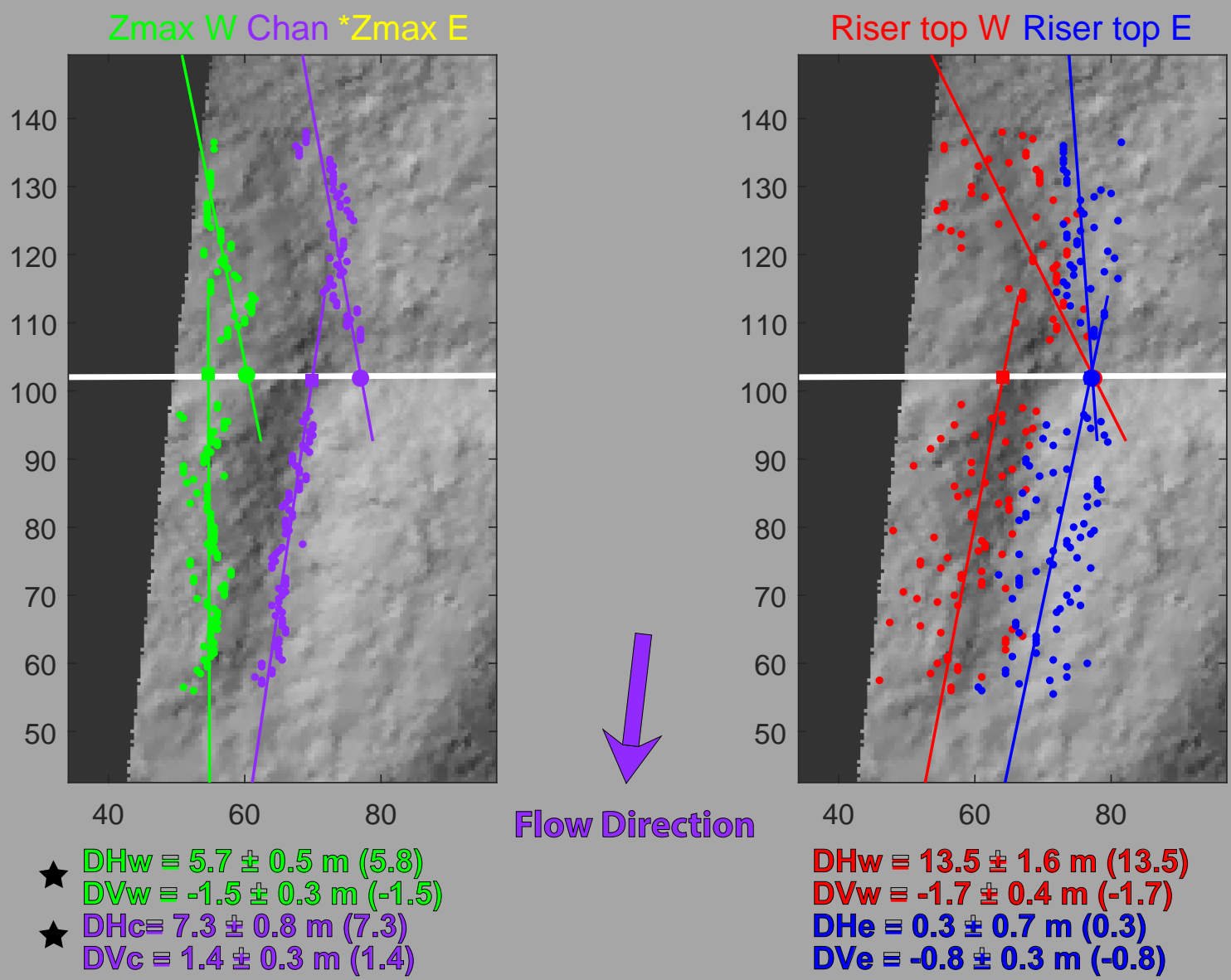

Flow Direction

$\mathrm{DHW} \equiv \mathbb{1 3 . 5} \pm 1.6 \mathrm{~m}(1.3 .5)$

$D V W=-1.7 \pm 0.4 m(-1.7)$

$\mathrm{DHe}=0.3 \pm 0.7 \mathrm{~m}(0.3)$

$\mathrm{DVe}=-0.8 \pm 0.3 \mathrm{~m}(-0.8)$
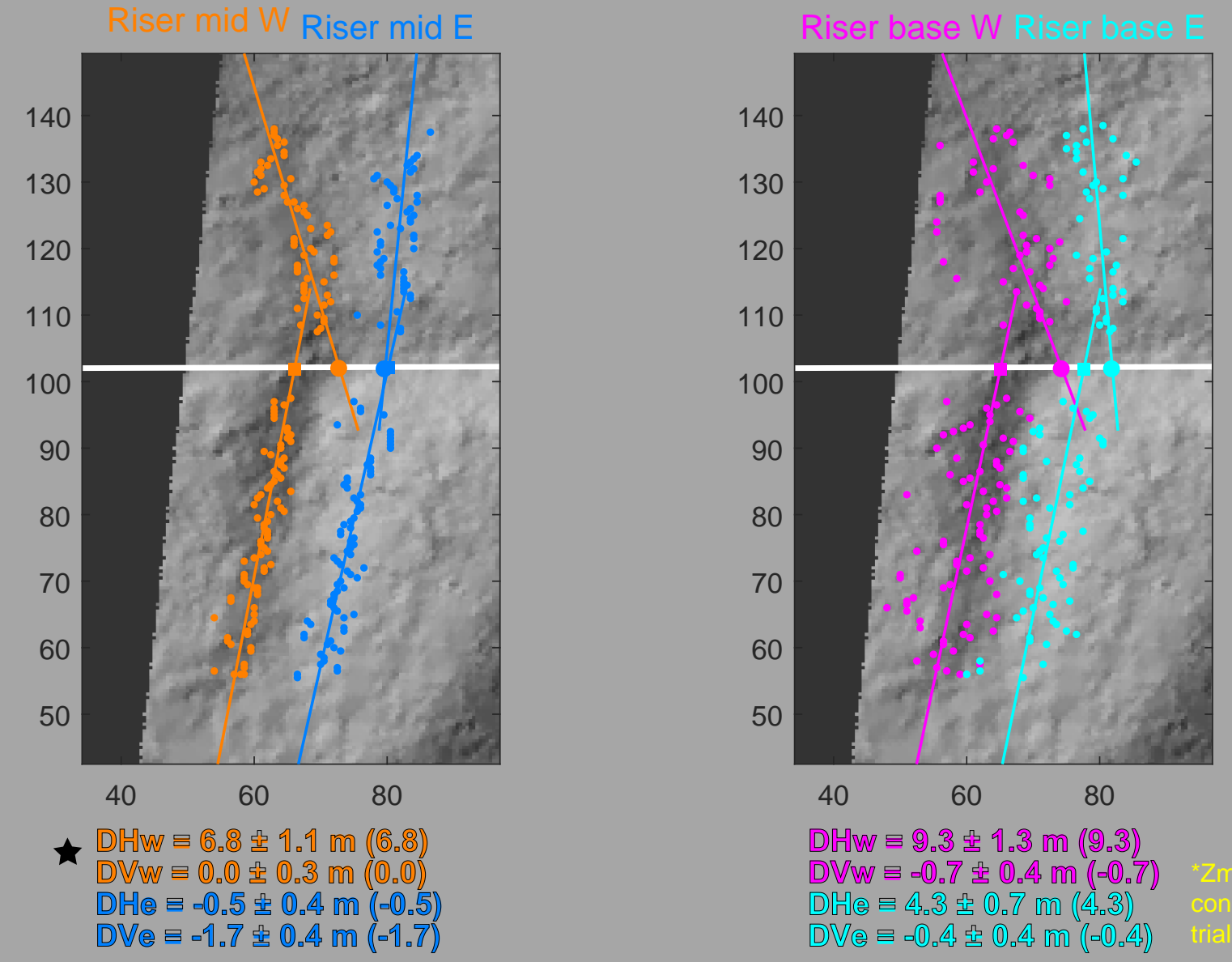

DHw 드. 9.3 $1.3 \mathrm{~m}(9.3)$

DVW $=0.7$ 눌 $0.4 \mathrm{~m}(=0.7)$

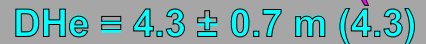
DVe

*Zmax E not

constrained in this trial 77 


\section{Site C: Offset probability densities}
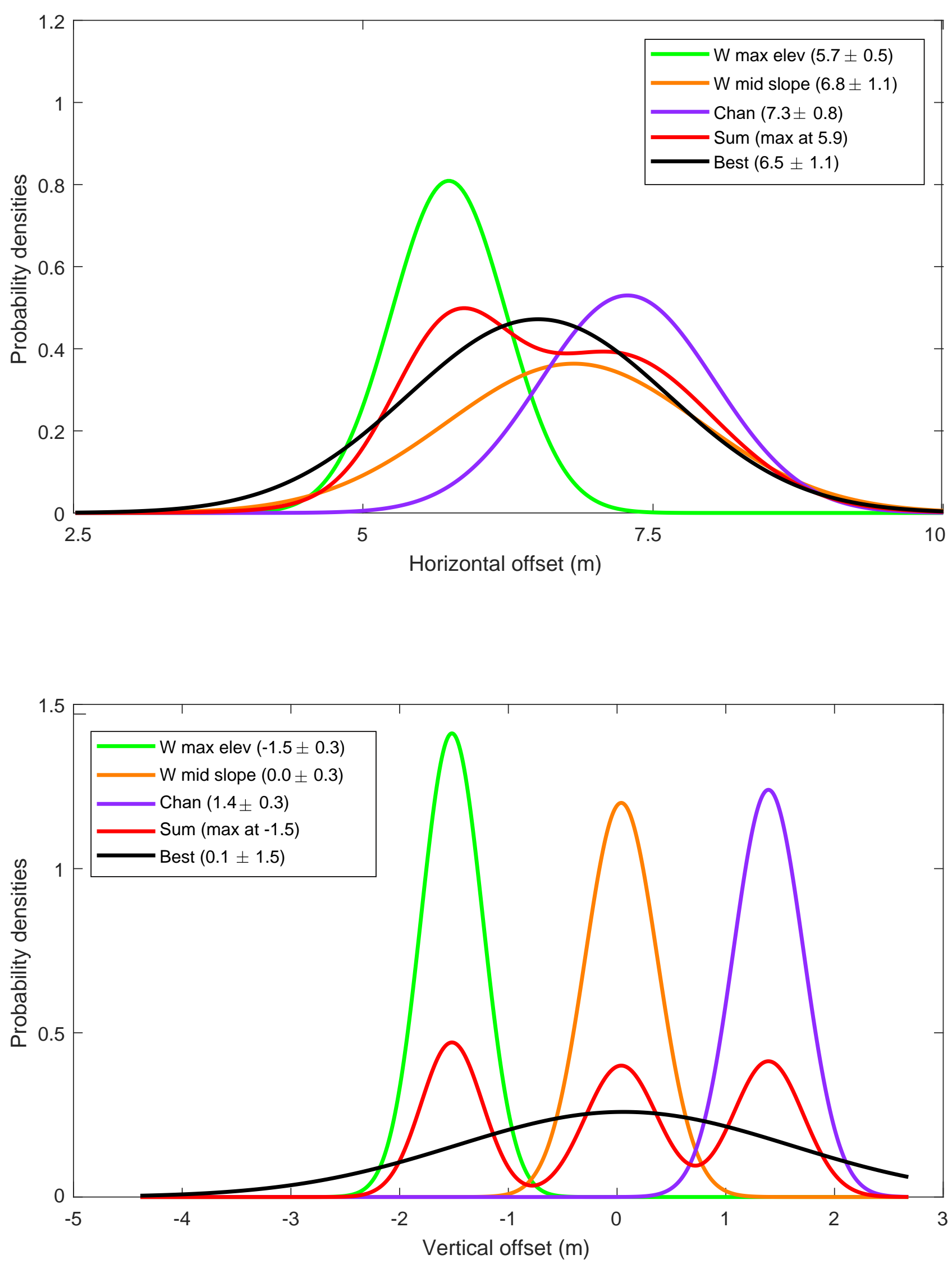
Site C

Original

Preferred: $6.5 \mathrm{~m}$
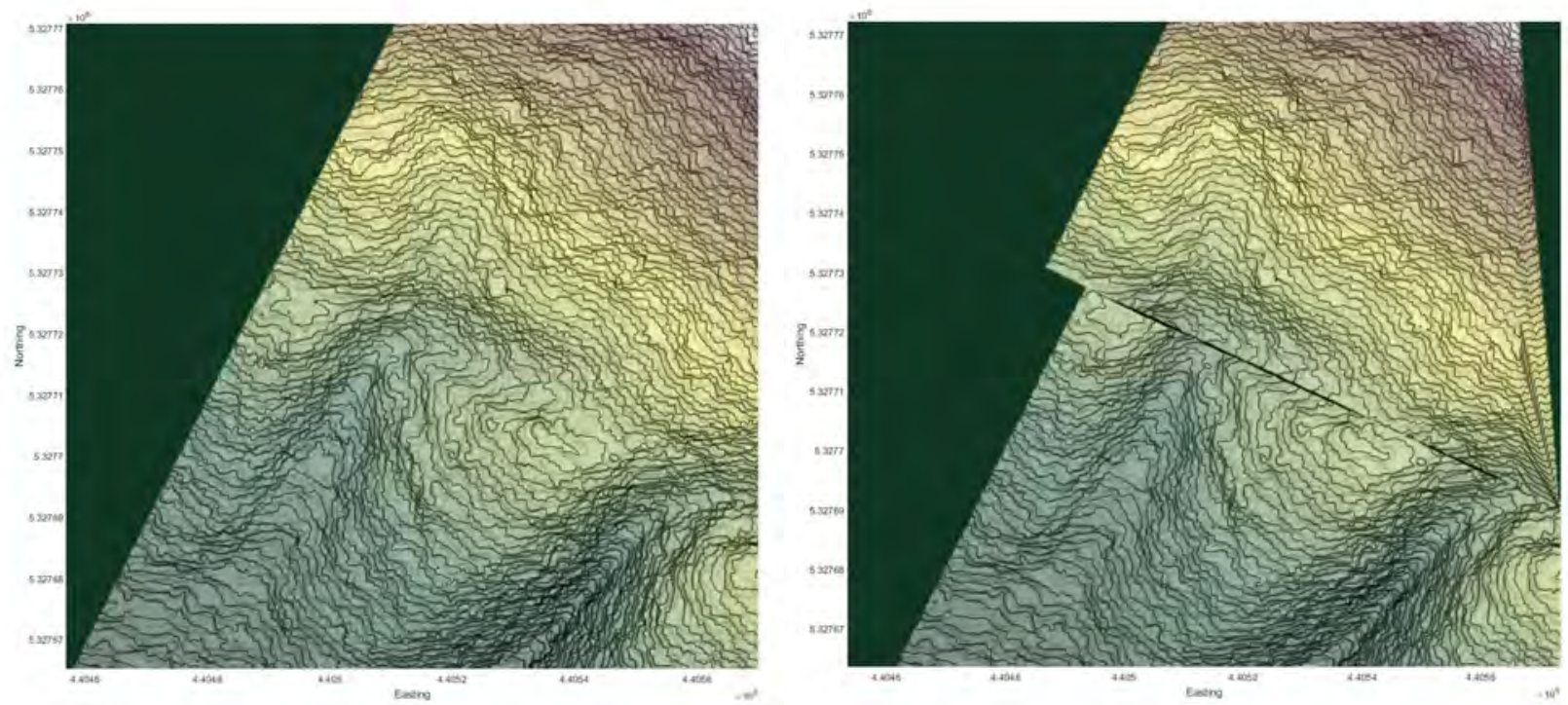

Lower Bound:4.3m

Upper Bound: $7.6 \mathrm{~m}$
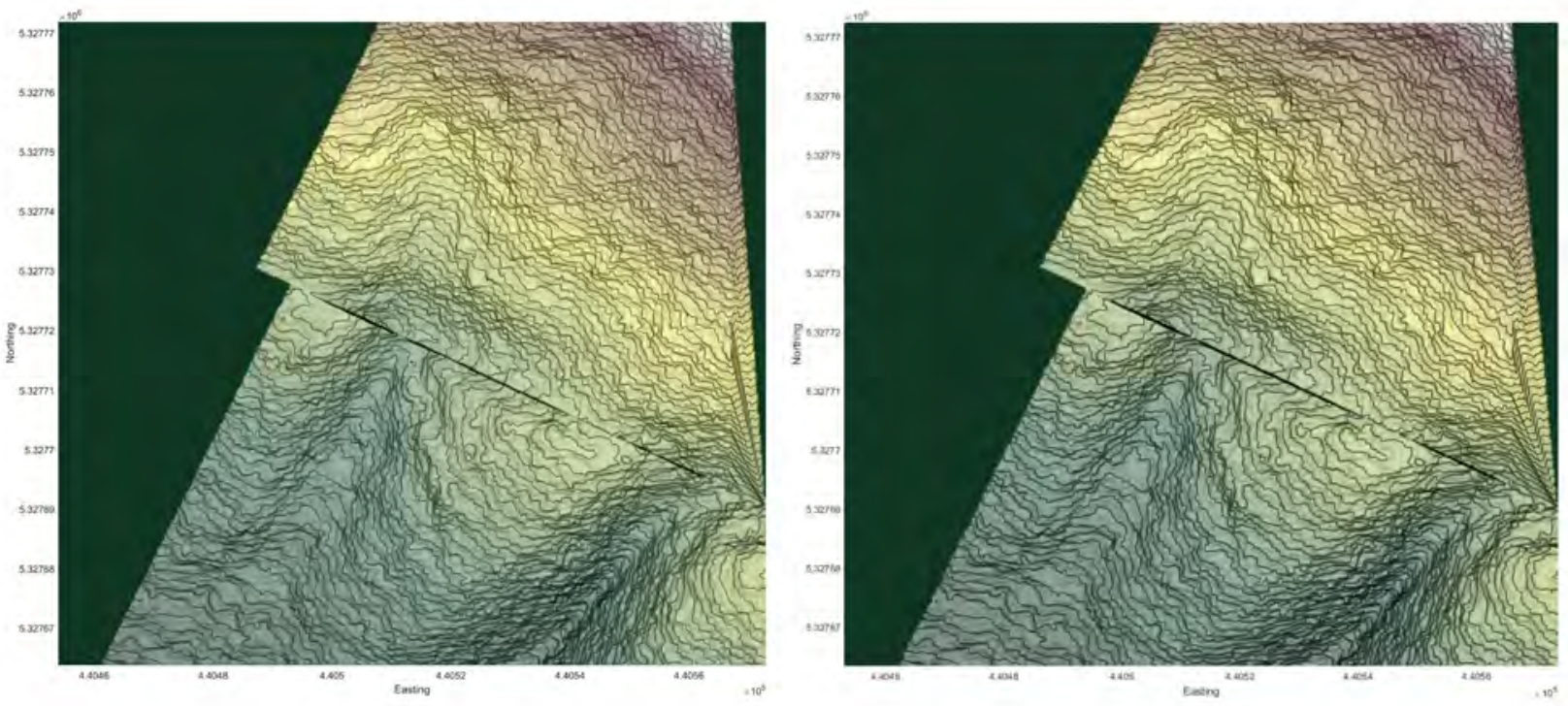


\section{Site D}

Well constrained features: Chan, E mid, W mid, E top

Preferred Offset: 26.0

Upper Bound: 29.0

Lower Bound: 23.0

Strike-Slip Displacement Distribution: Gaussian

Notes: Reported offset derived from 'Best' curve.

Field Measurement: $20.1 \pm 2.0 \mathrm{~m}$

Quality: III 


\section{Site D Offsets and uncertainties (10000 runs)}

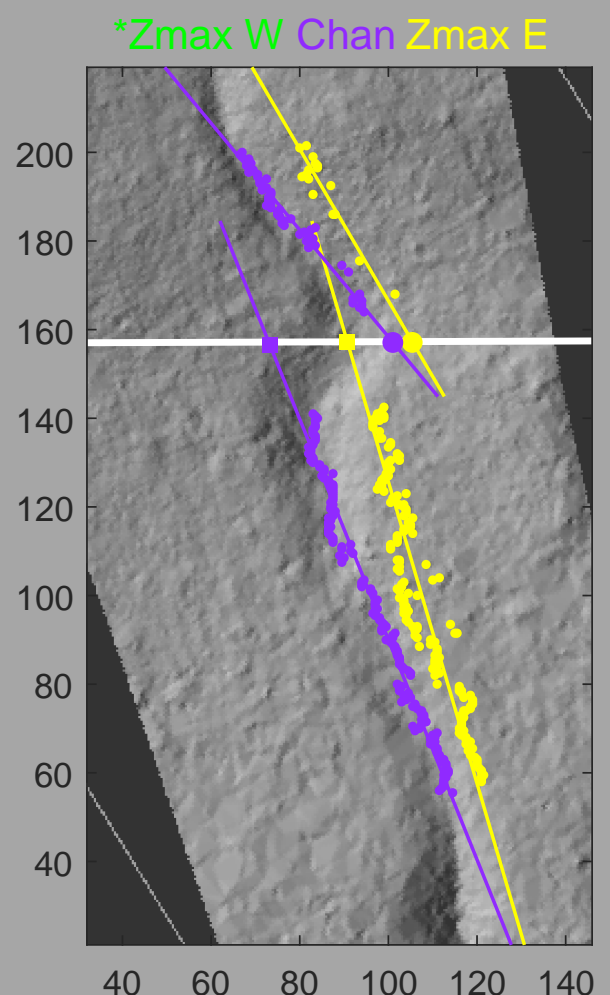

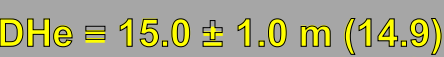

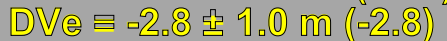

DHC : 28.1. $1.1 \mathrm{~g}(28.1)$

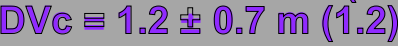

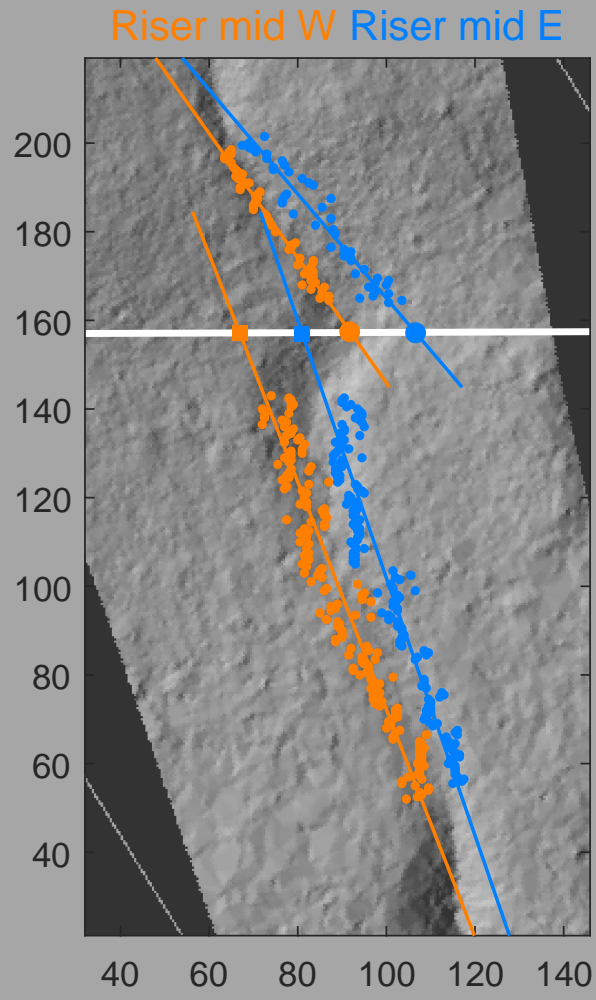

$\wedge$ D)

人 D)VW

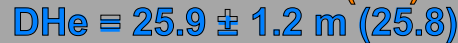

DVe $=0.0 .4$ 할 $0.7 \mathrm{~m}(-0.3)$

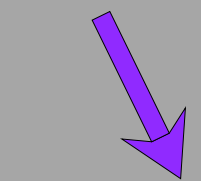

Fllow Direction

.

$\mathrm{DHW}=28.1 \pm 1.2 \mathrm{~m}(28.0)$

$D V w=0.5 \pm 0.7 \mathrm{~m}(=0.5)$

DHe $=26.0 \pm 1.0 \mathrm{~m}(26.0)$

$\mathrm{DVe}=-0.4 \pm 0.8 \mathrm{~m}(-0.4)$

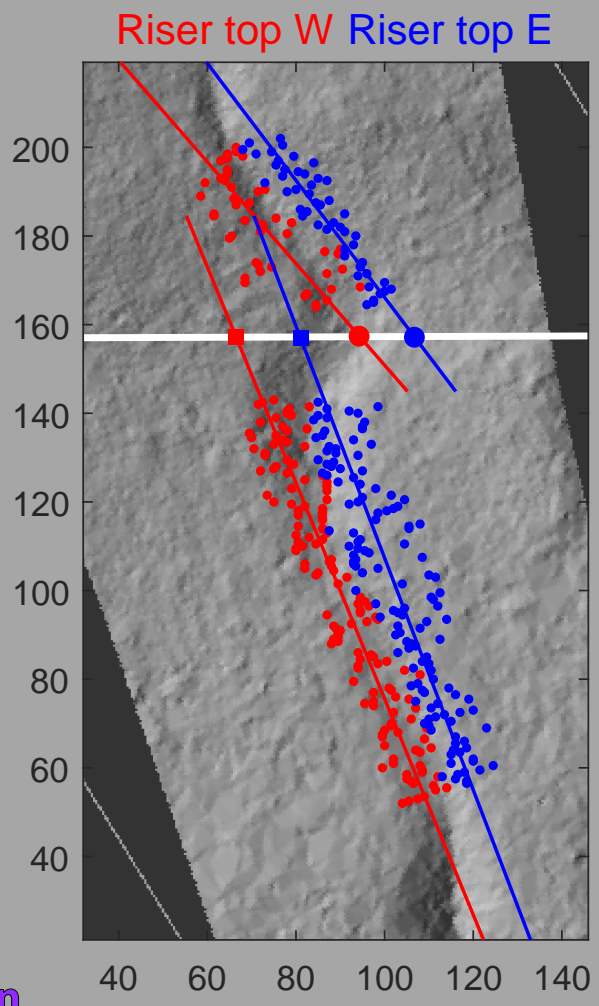

Riser base $\mathrm{W}$

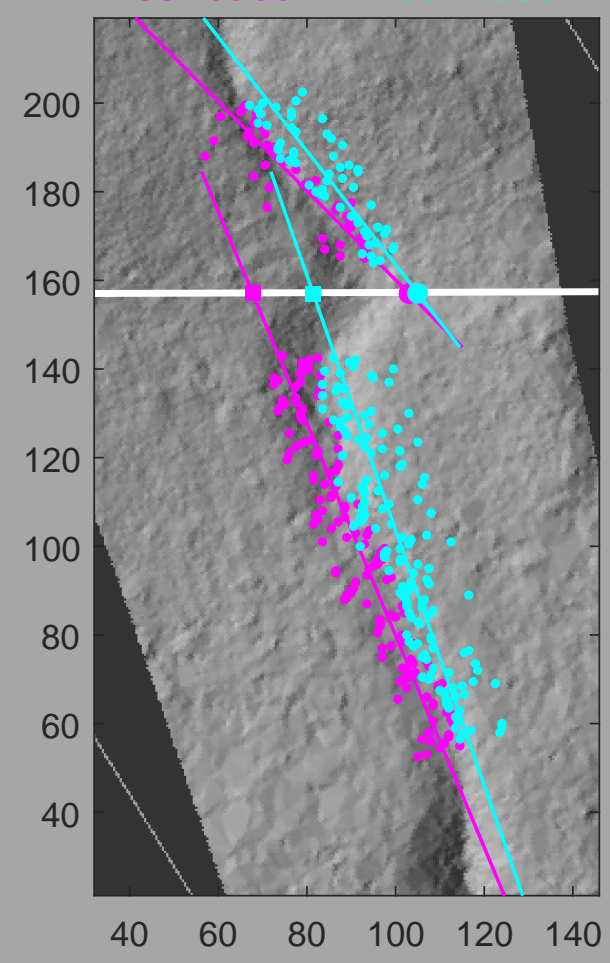

DUw = 35.7 t $1.5 \mathrm{~m}(35.6)$ DVW $=-1.7$ 푸 $0.8 \mathrm{~m}(-1.7)$

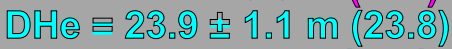

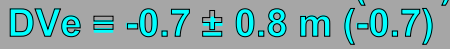


Site D : Offset probability densities
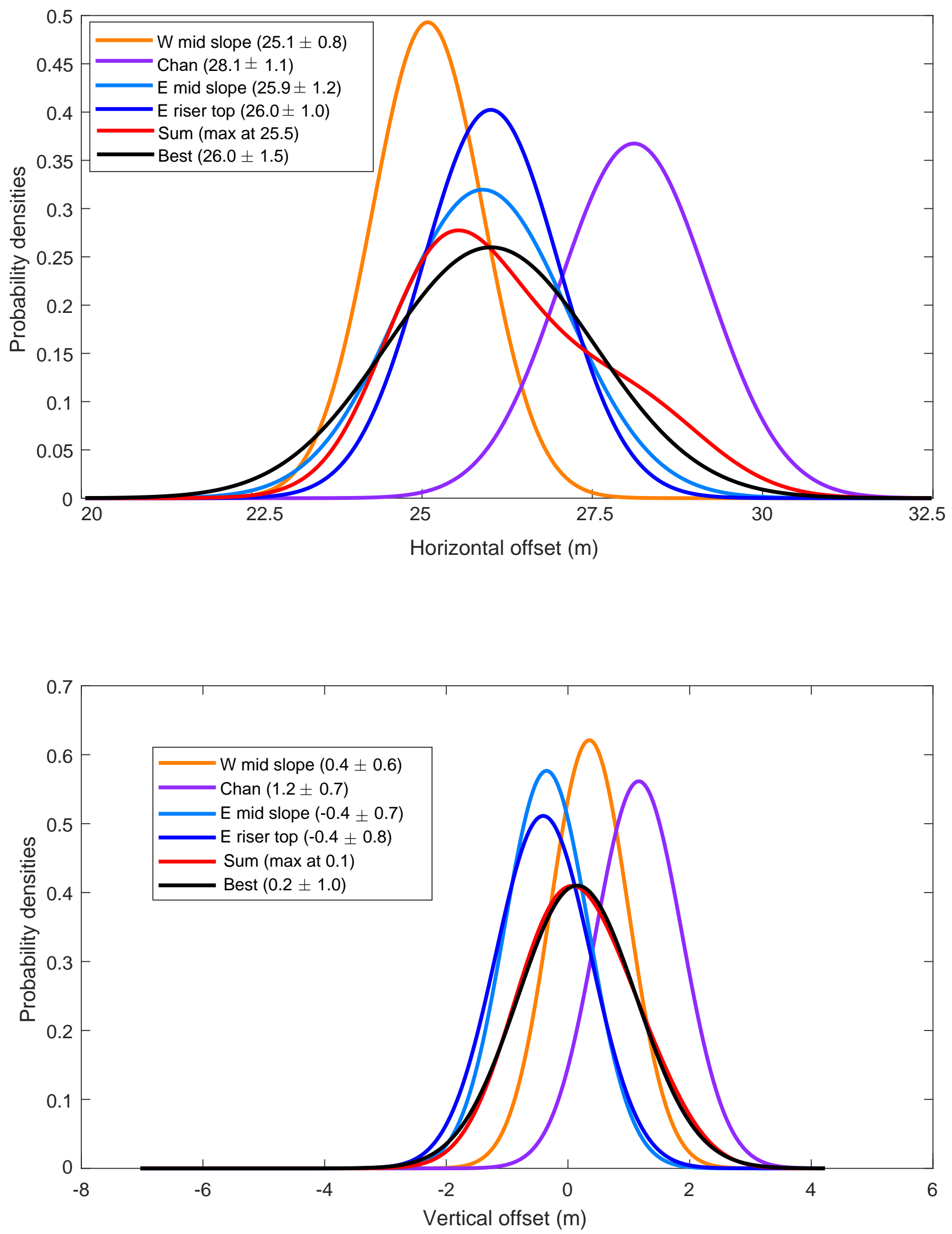
Site D

Original

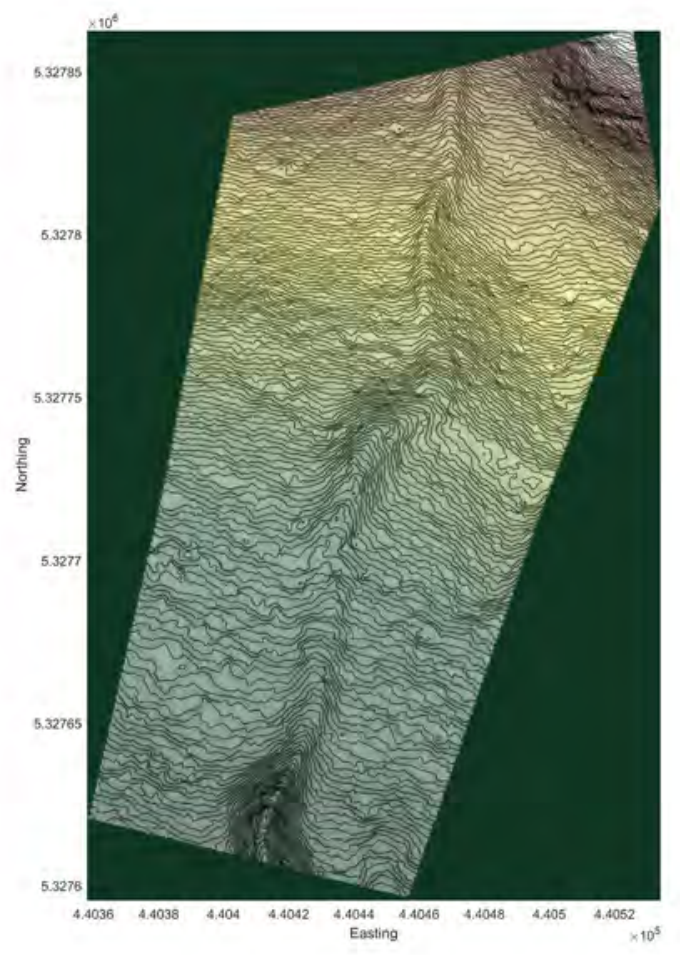

Lower Bound:23.0m

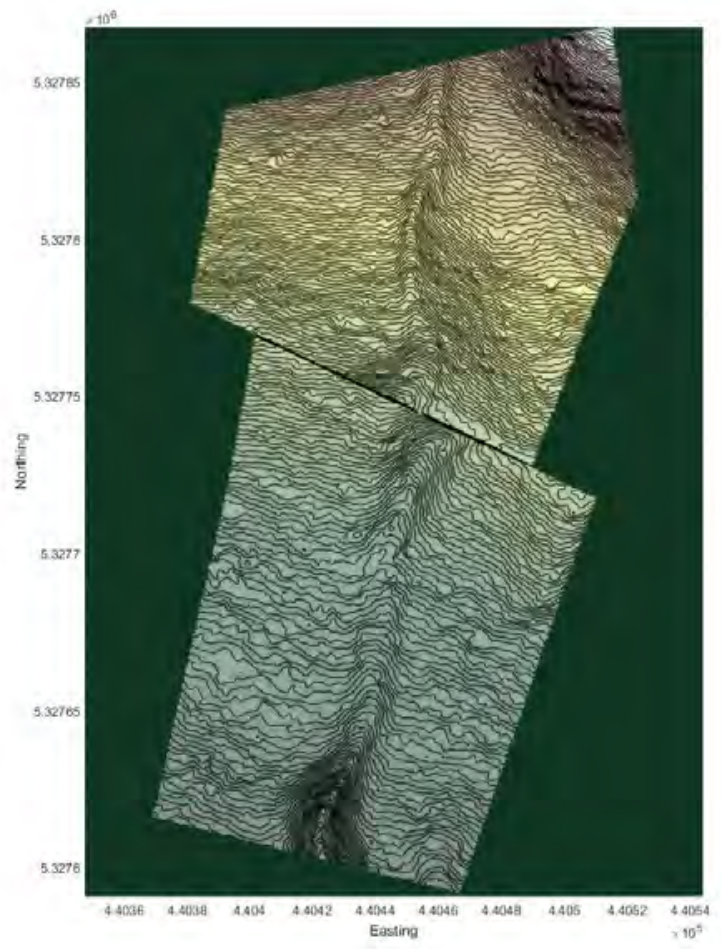

Preferred: $26.0 \mathrm{~m}$

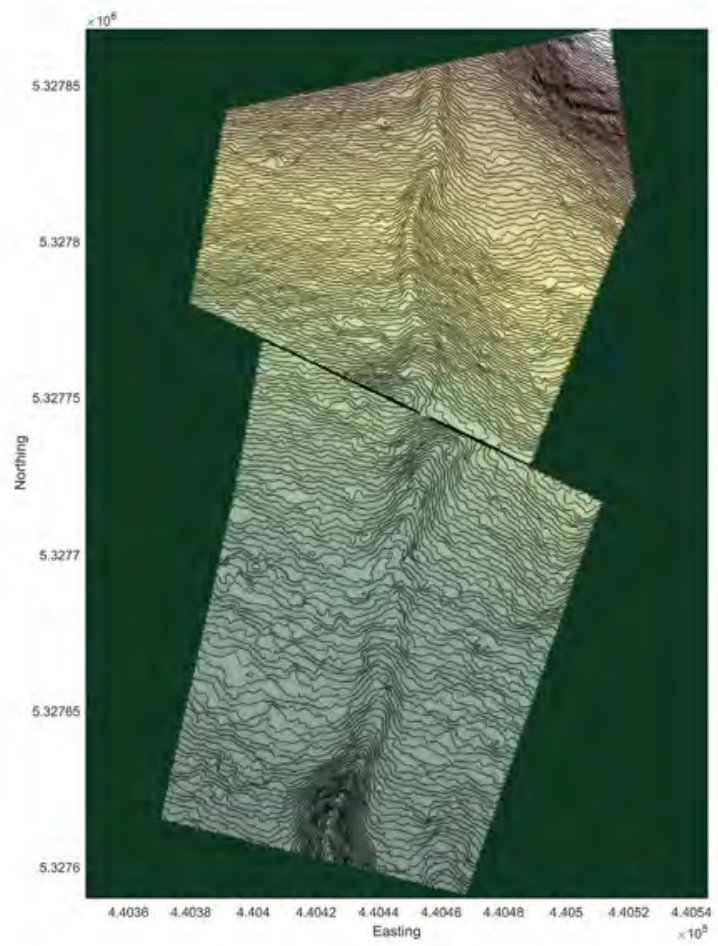

Upper Bound: 29.0m

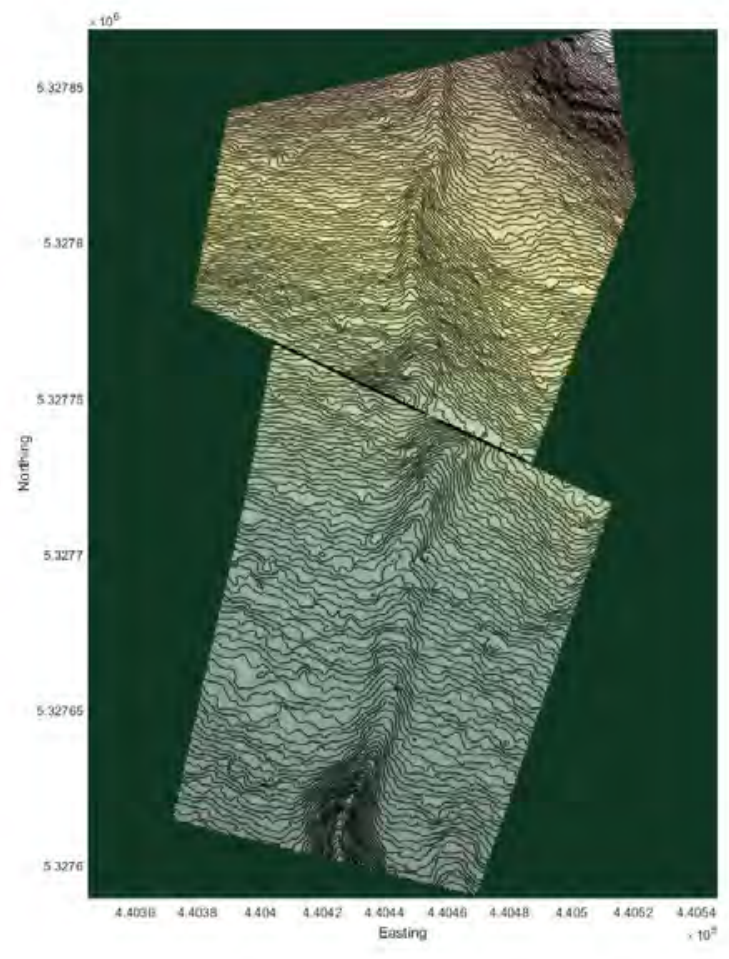




\section{Site E}

Well constrained features: Chan, E midpoint

Preferred Offset: 22.1

Upper Bound: 23.5

Lower Bound: 20.7

Strike-Slip Displacement Distribution: Gaussian

Notes: Reported offset derived from 'Best' curve.

Field Measurement: $23.2-2.0 /+3.0 \mathrm{~m}$

Quality: III 


\section{Site E Offsets and uncertainties (10000 runs)}

Chan *Zmax E

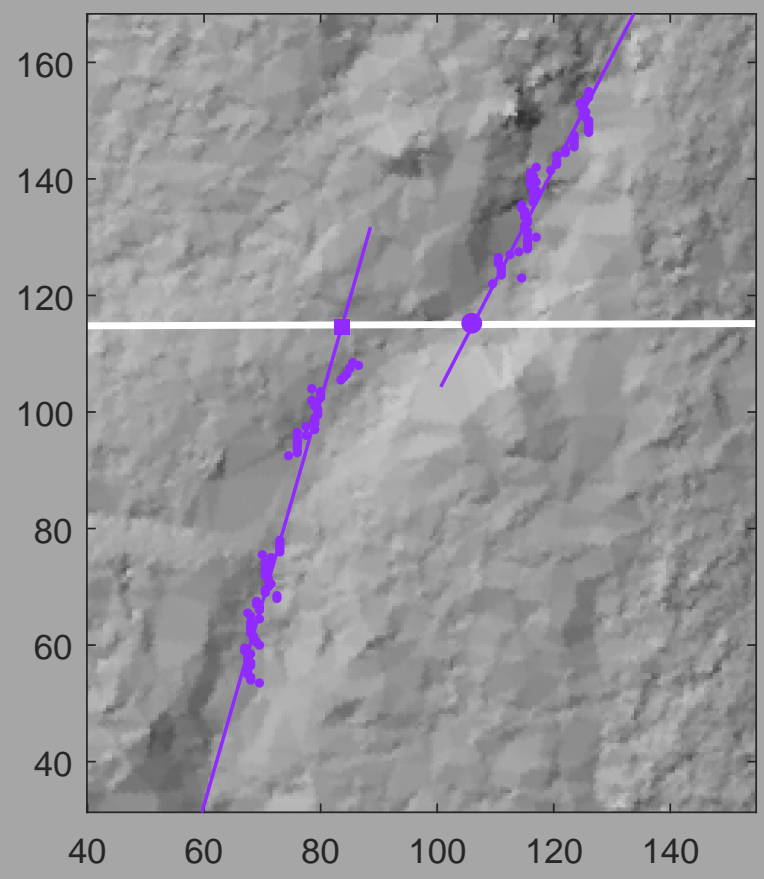

Riser top W Riser top E

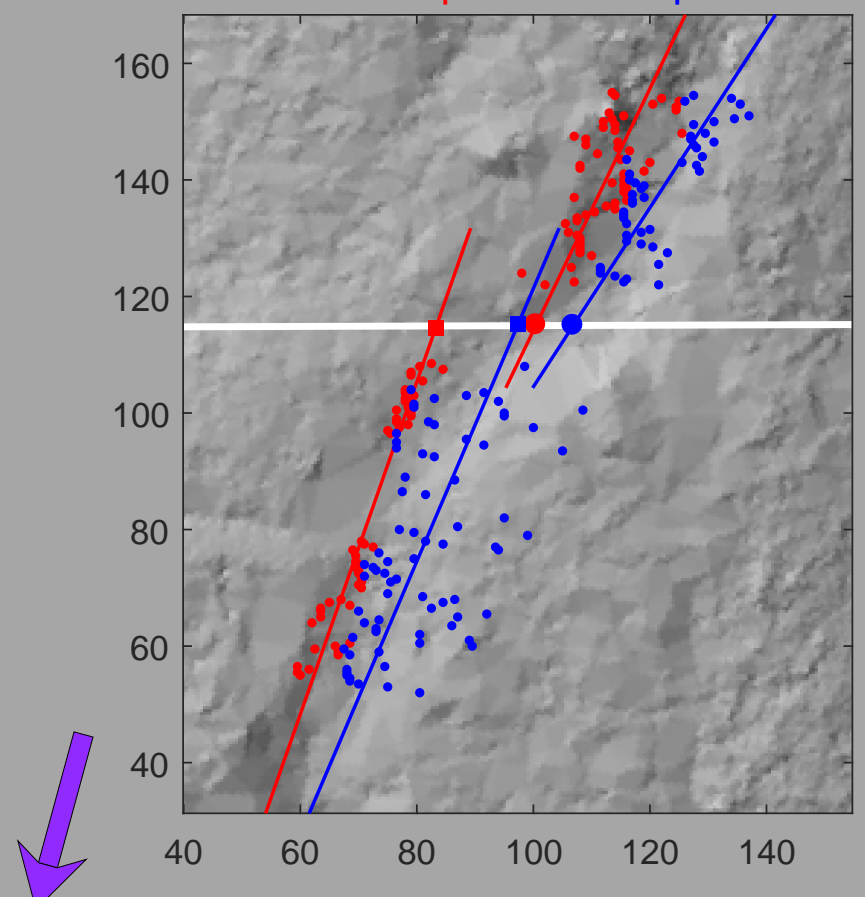

$D H w=17.2 \pm 0.5 \mathrm{~m}(17.2)$

$D V w=2.7 \pm 0.4 \mathrm{~m}(2.7)$

$\mathrm{DHe}=9.4 \pm 0.6 \mathrm{~m}(9.5)$

$\mathrm{DVe}=-1.4 \pm 0.3 \mathrm{~m}(-1.4)$

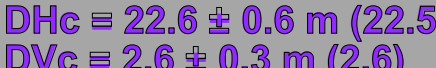

Flow Direction

N DVG $=2.6$ 로 $0.3 \mathrm{~m}(2.6)$
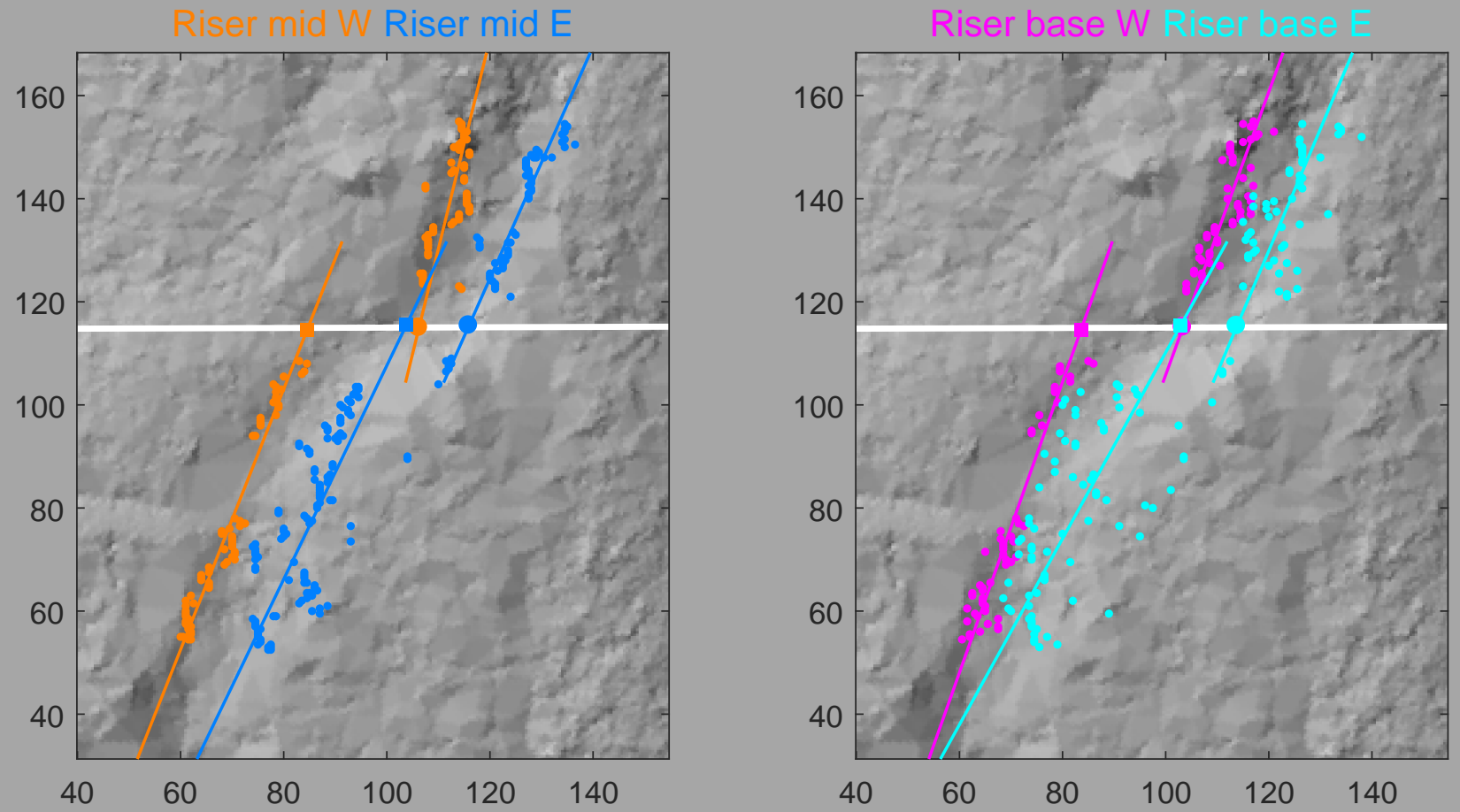

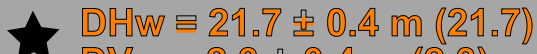

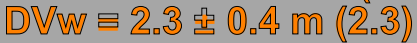

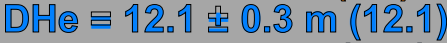

DVe = $=0.7$ t $0.2 \mathrm{~m}(-0.7)$

DHW $=1.9 .8$. $0.3 m(1.9 .8) \quad * Z m a x E$ and
DVW $=2.3 \pm 0.3 m(2.3)$

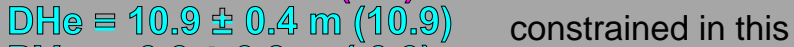

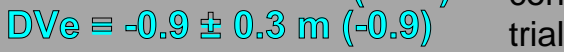




\section{Site E: Offset probability densities}
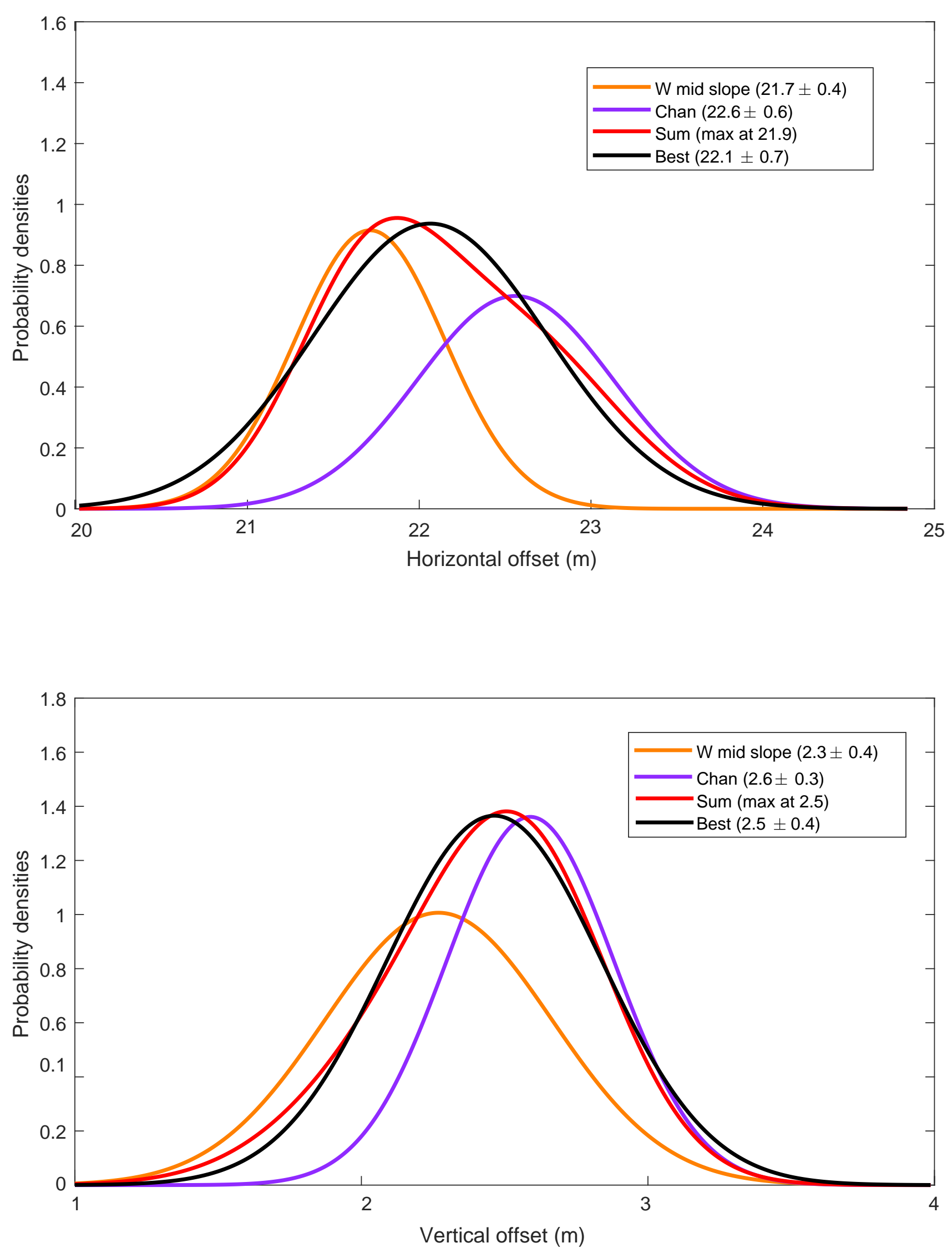
Site E

Original

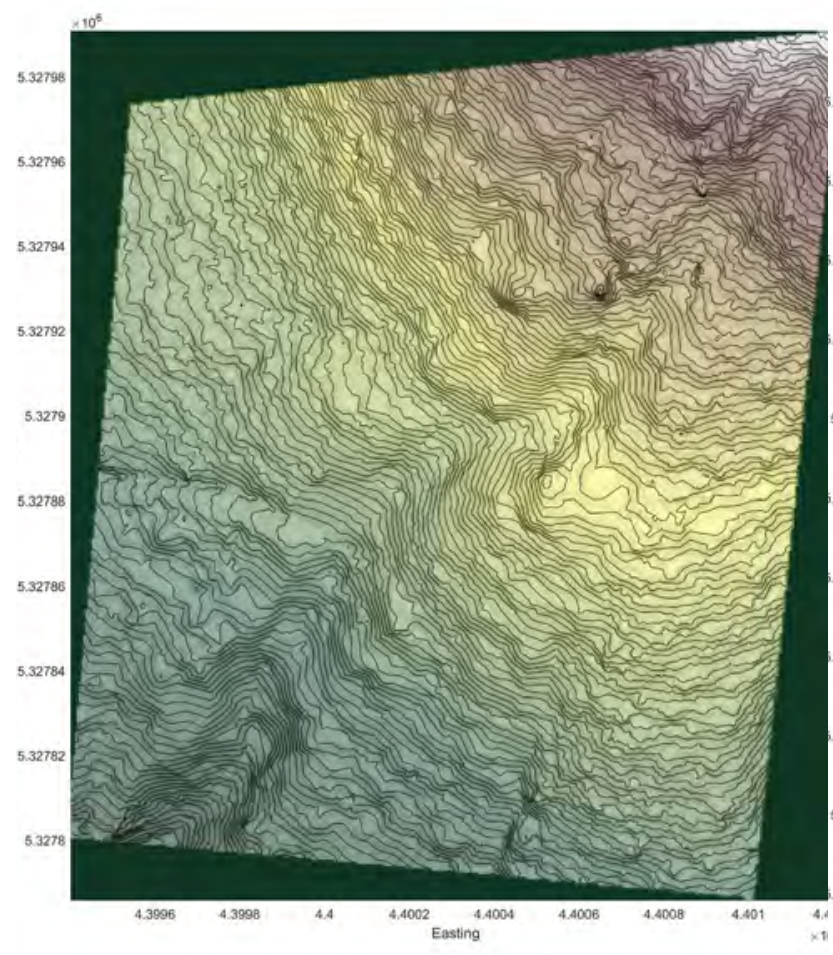

Preferred: $22.1 \mathrm{~m}$

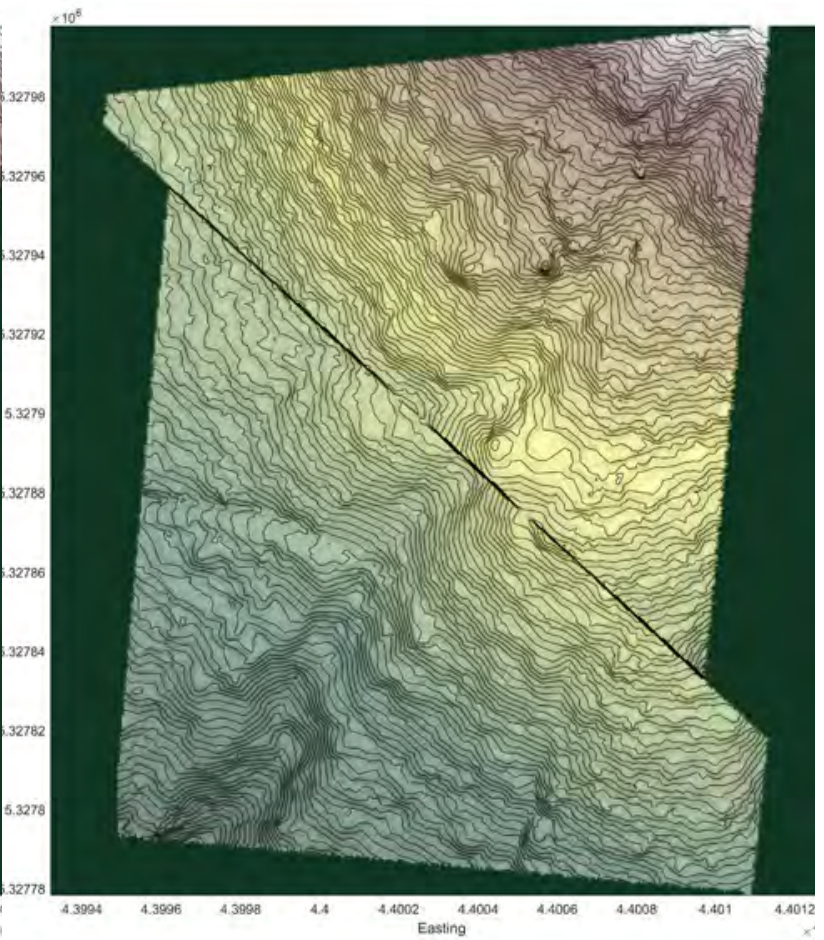

Lower Bound: $20.7 \mathrm{~m}$

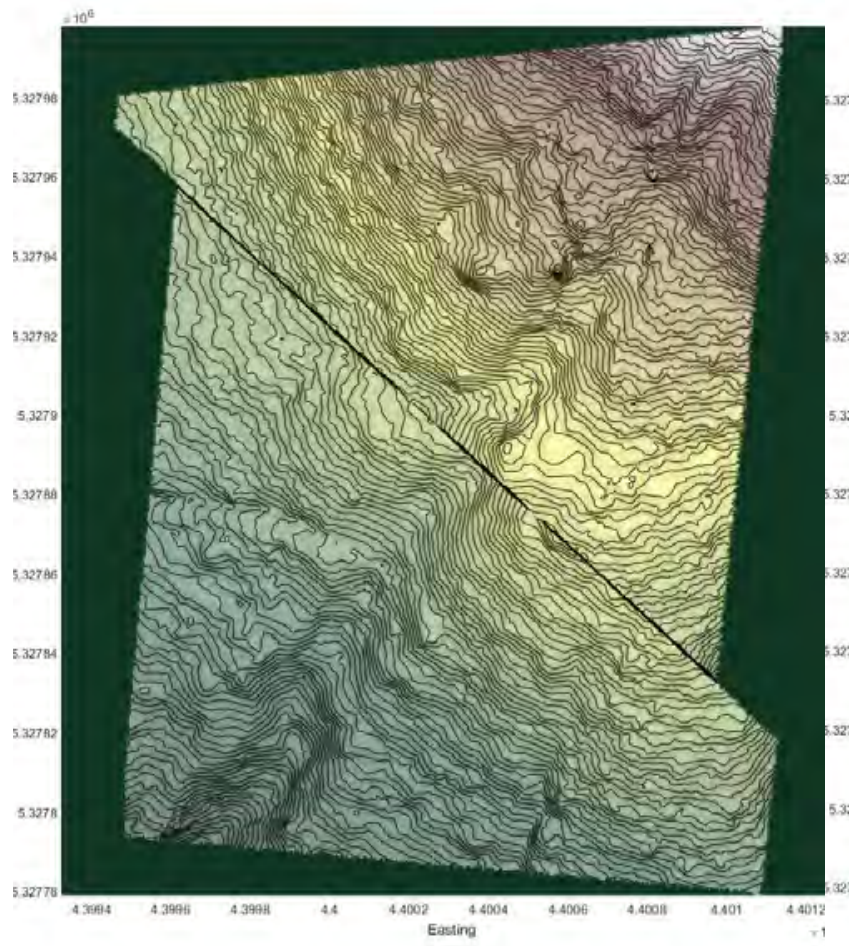

Upper Bound: 23.5m

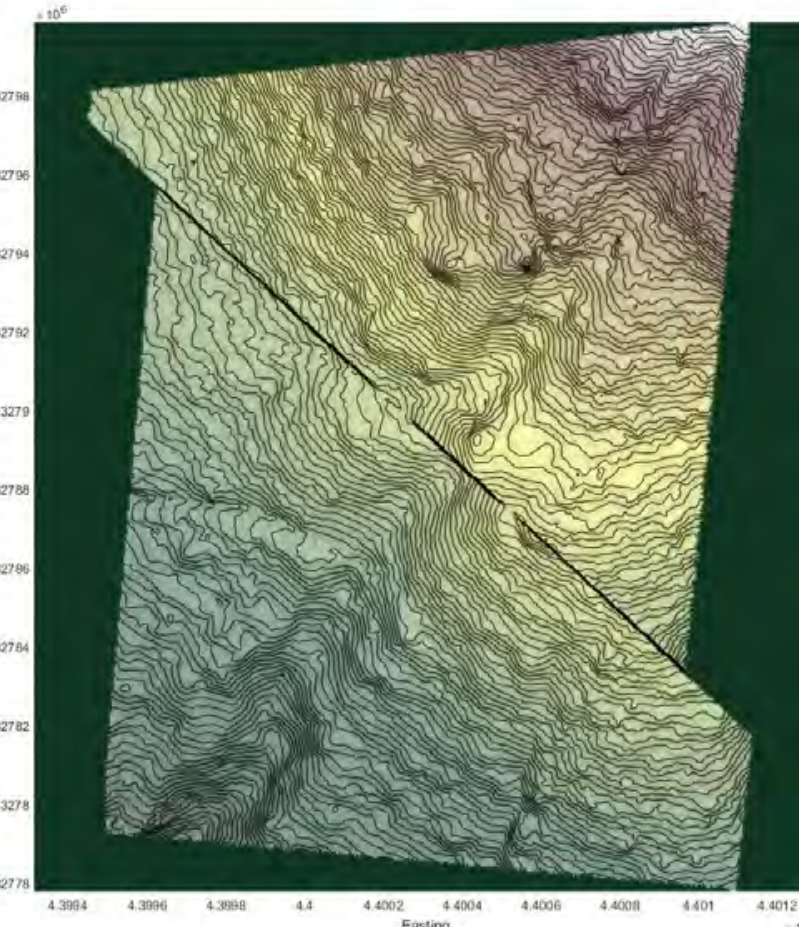




\section{Site F}

Well constrained features: W max, W mid, E mid

Preferred Offset: $11.7 \mathrm{~m}$

Upper Bound: $14.5 \mathrm{~m}$

Lower Bound: 8.9

Strike-Slip Displacement Distribution: Gaussian

Notes: Reported offset derived from 'Best' curve at site F2. Only one feature (the W max) was well constrained at site F1 and its distribution falls well within the distribution of the best curve from F2.

Field Measurement: $13.5-3.0 /+0.7 \mathrm{~m}$

Quality: I 


\section{Site F1 Offsets and uncertainties (10000 runs)}

Chan Zmax E

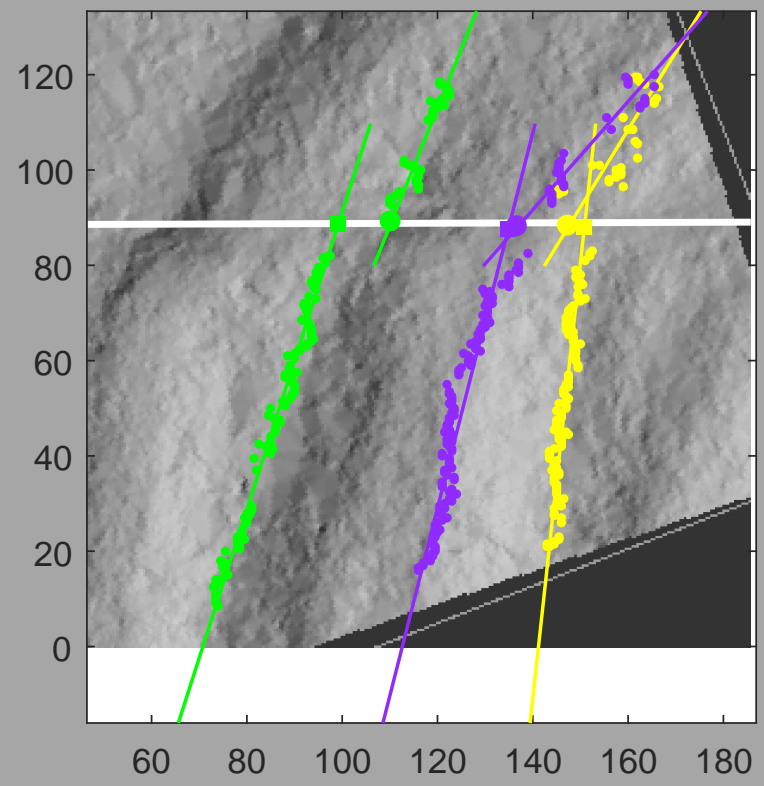

Riser top W Riser top E
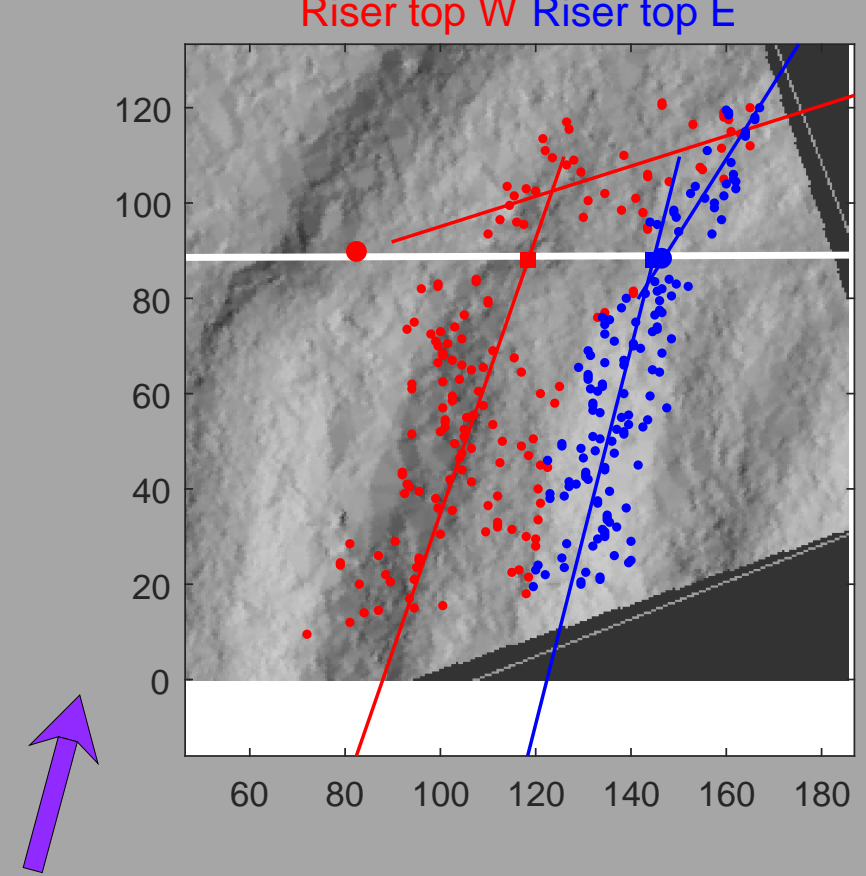

s. D纤

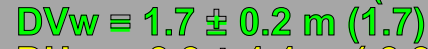

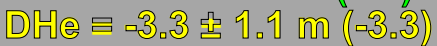

DVe = 0.2 f $0.3 \mathrm{~m}(0.2)$

$\mathrm{DH} \mathrm{c}=2.0$ 롤 $1.3 \mathrm{~m}(1.9)$

DVG $=2.1 \pm 0.2 \mathrm{~m}(2.1)$

Flow Direction

$$
\begin{aligned}
& D H w=-36.0 \pm 5.9 m(-35.8) \\
& D V w=8.5 \pm 1.0 m(8.4) \\
& D H e=2.0 \pm 0.8 \mathrm{~m}(2.0) \\
& D V e=0.9 \pm 0.2 \mathrm{~m}(0.9)
\end{aligned}
$$
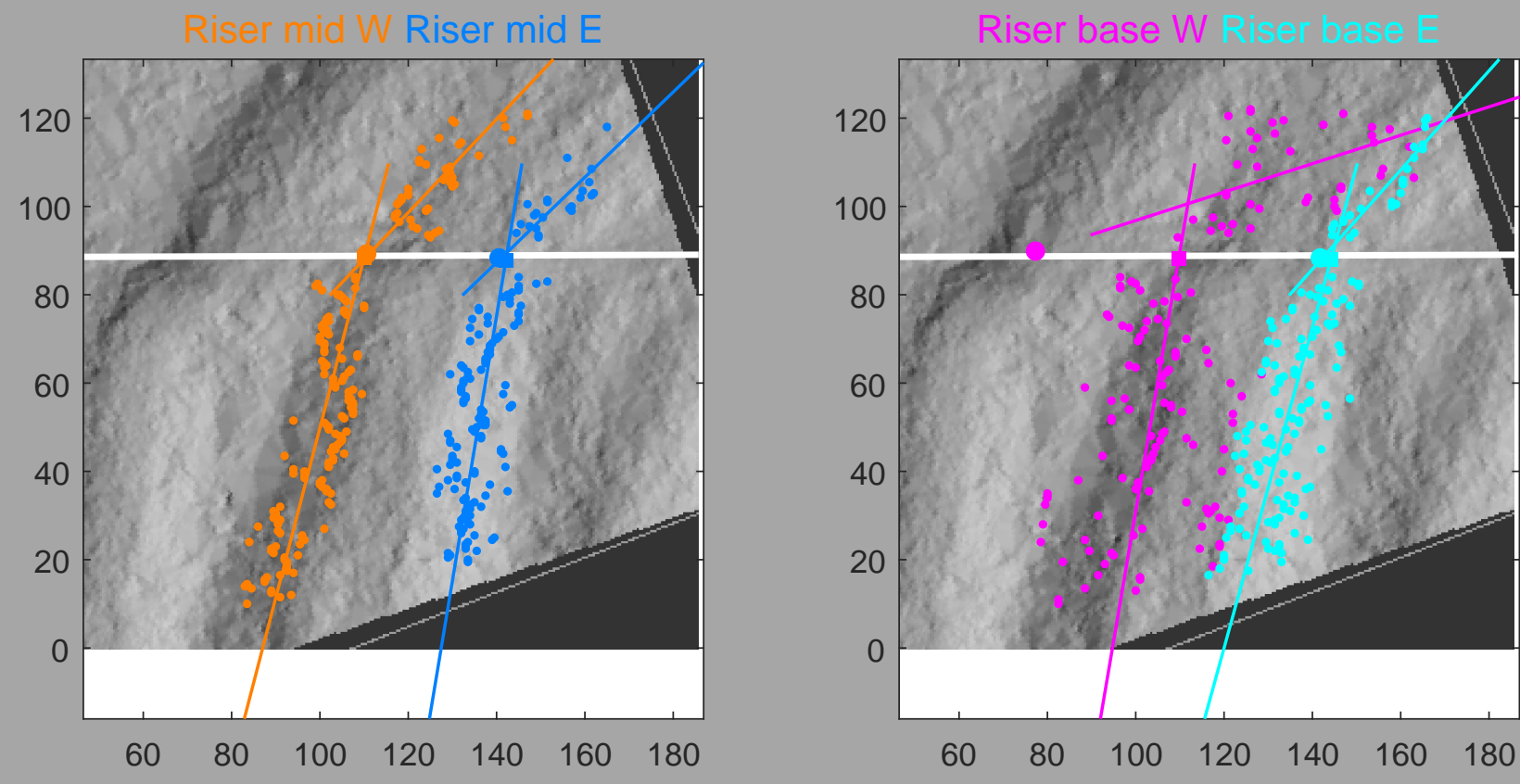

DИw (0.9) 1.44 m (0.9)

DVW $=3.8$ 대 $0.3 \mathrm{~m}(3.8)$

DHe 들 -1.3 표 $1.8 \mathrm{~m}(-1.3)$

DVe $=1.3$ 르 $0.3 \mathrm{~m}(1.3)$

DHW $=-32.3$ 랄 $6.3 \mathrm{~m}(-32.11)$

$\mathrm{DVW}=7.9 \mathrm{~g} 1.0 \mathrm{~m}(7.9)$

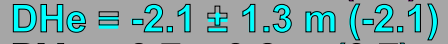

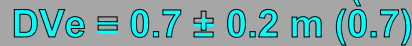




\section{Site F1 : Offset probability densities}
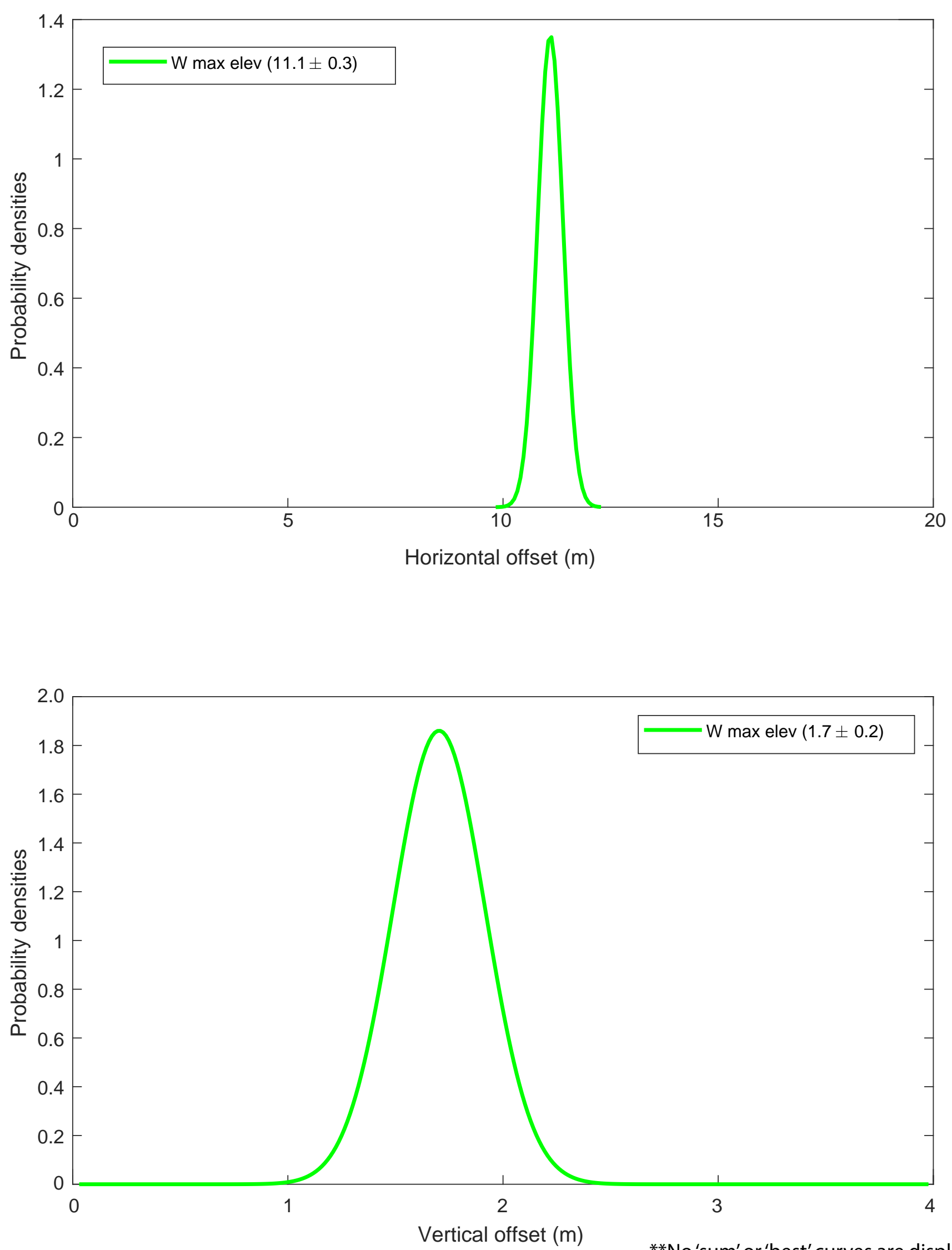

**No 'sum' or 'best' curves are displayed because only one geomorphic regression is deemed meaningful 


\section{Site F2 Offsets and uncertainties (10000 runs)}
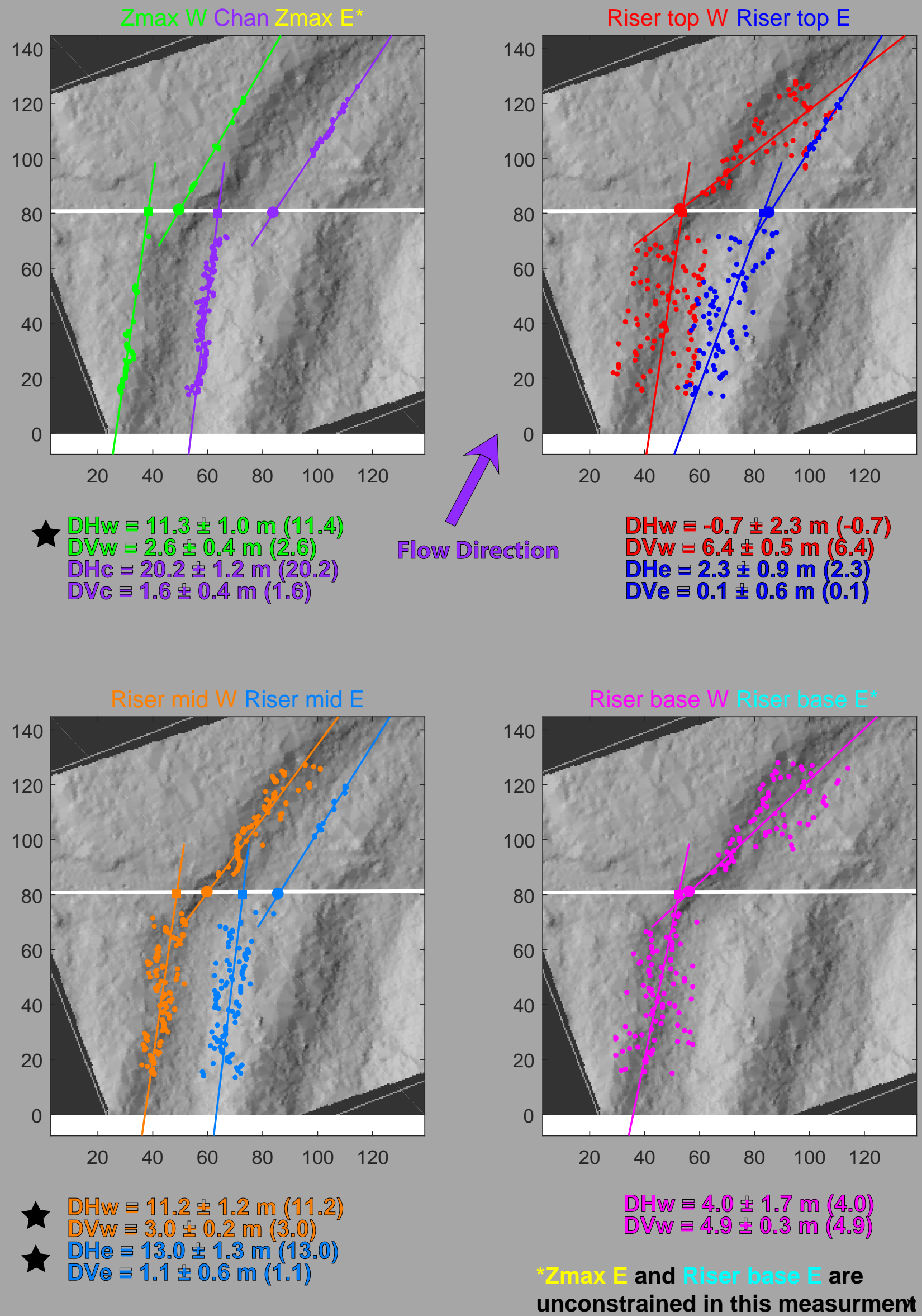

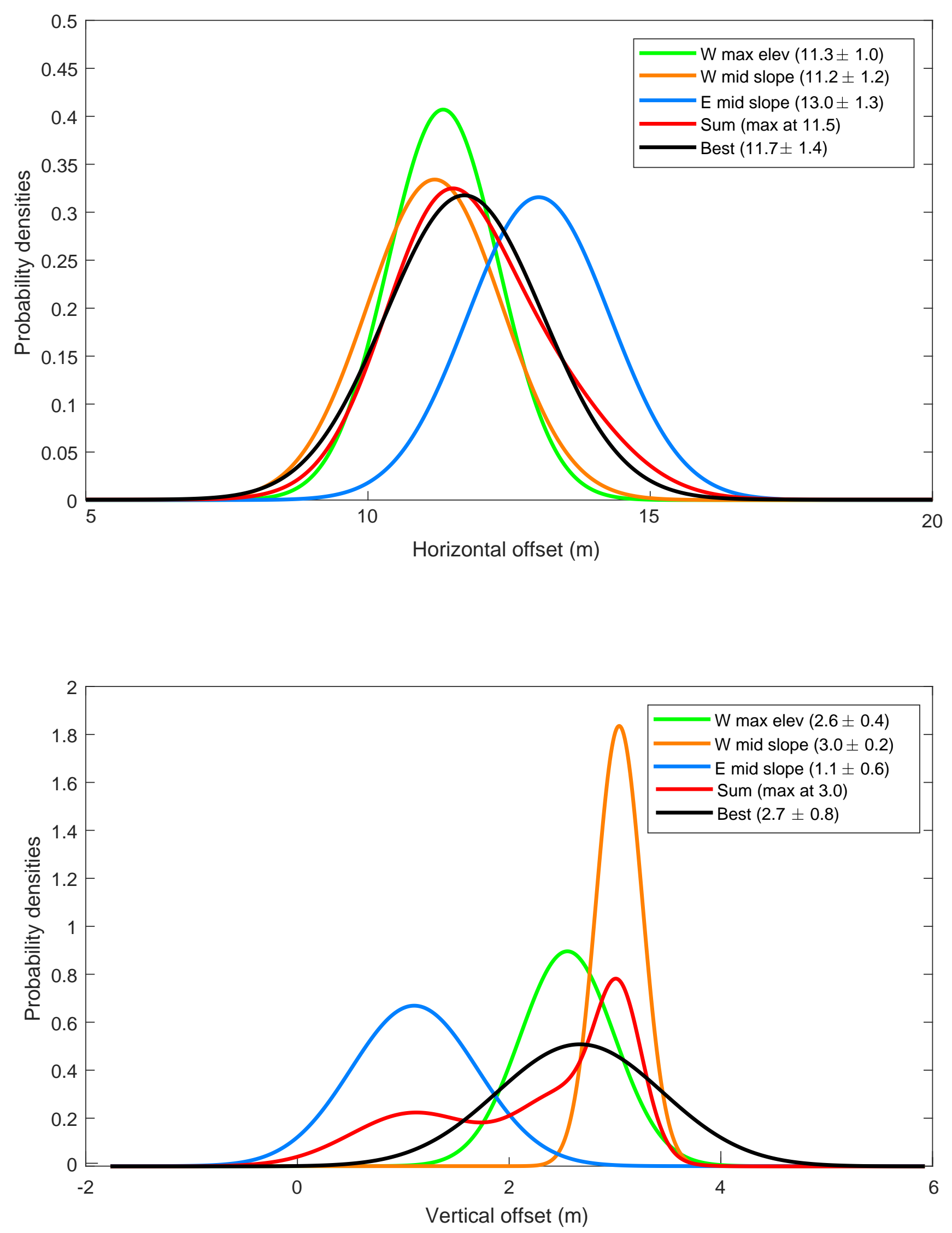
Site F

Original

Preferred: $11.7 \mathrm{~m}$
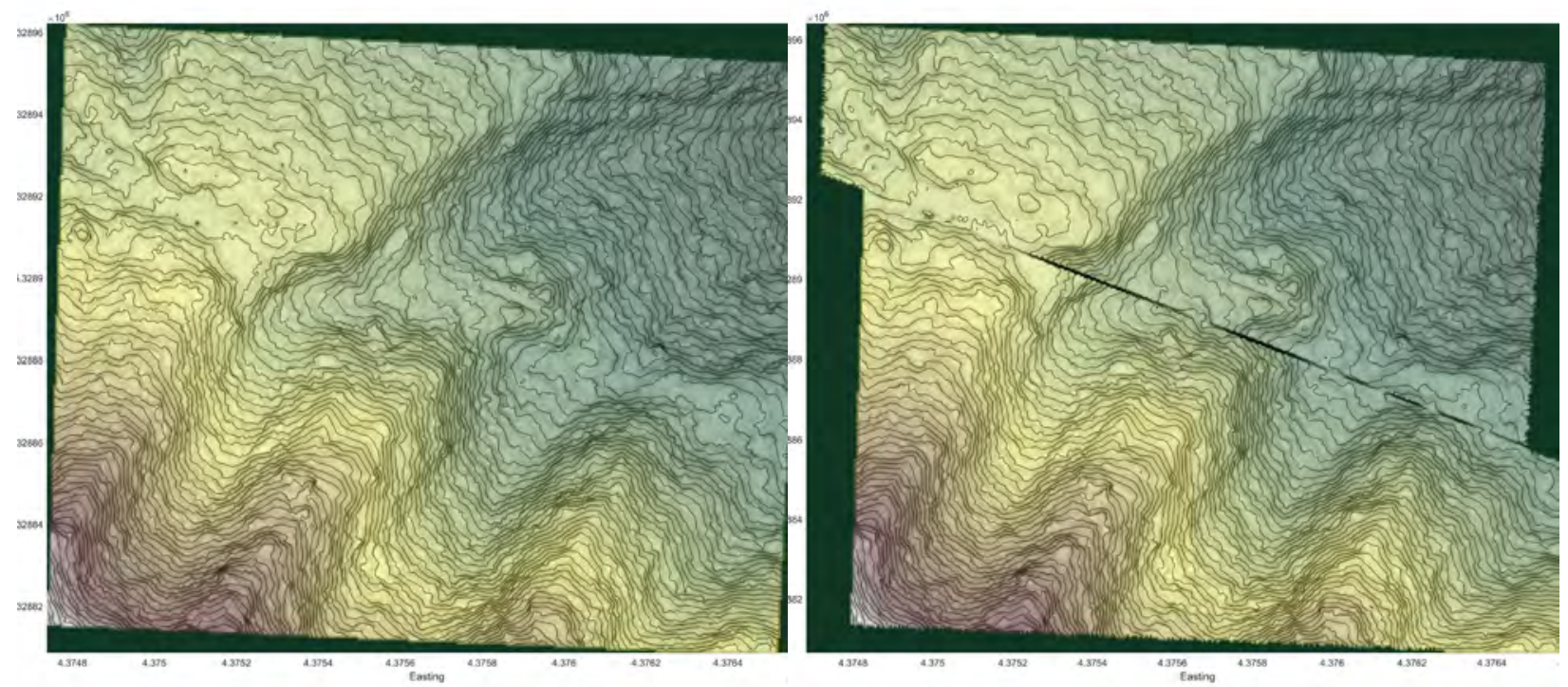

Lower Bound: $8.9 \mathrm{~m}$

Upper Bound: 14.5m
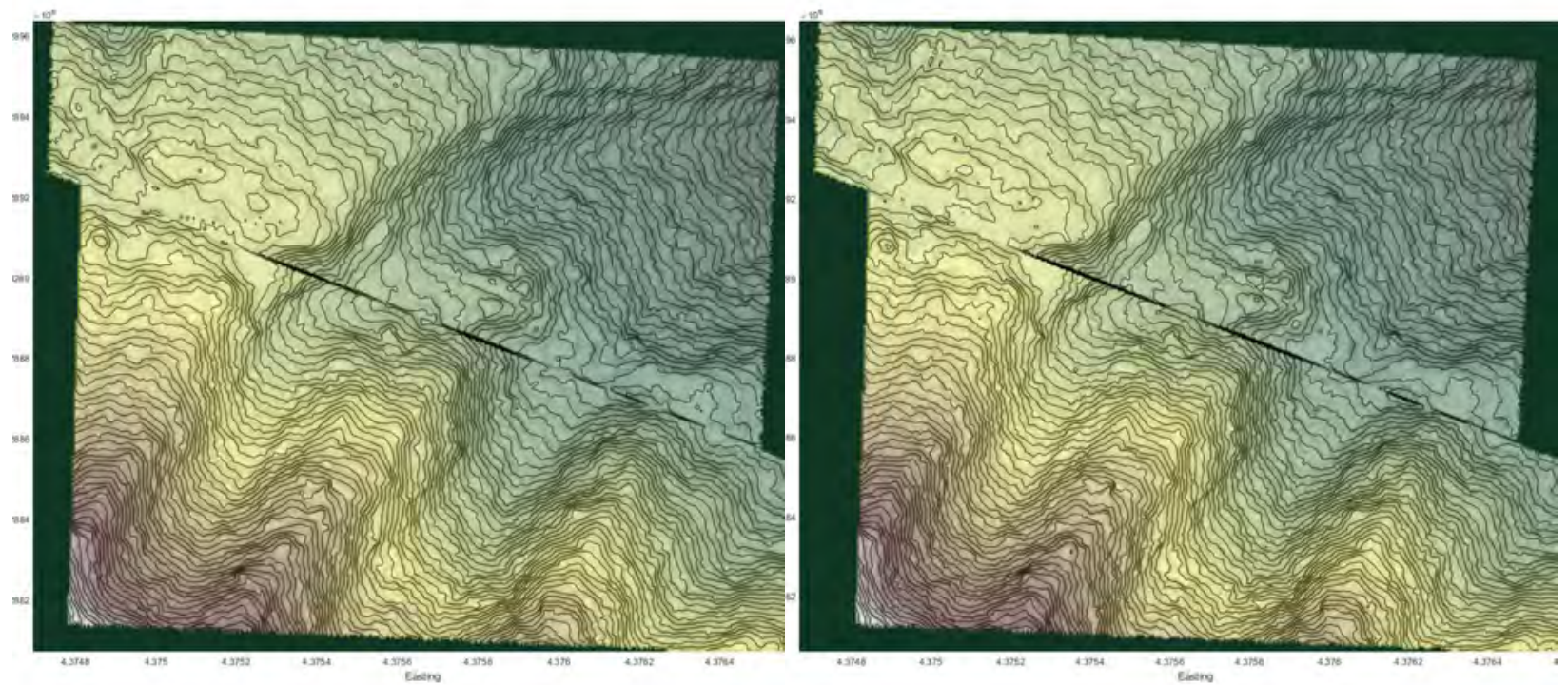


\section{Site G}

Well constrained features:

Preferred Offset: N/A

Upper Bound: 16.4

Lower Bound: 11.0

Strike-Slip Displacement Distribution: Uniform

Notes: The varying distributions of strike-slip displacement are not explained by the model described above for the geomorphic/tectonic development of the site. As such, I assume that the range of distributions reflects the true uncertainty in the measurement.

Field Measurement: Not measured.

Quality: III 


\section{Site G Offsets and uncertainties (10000 runs)}
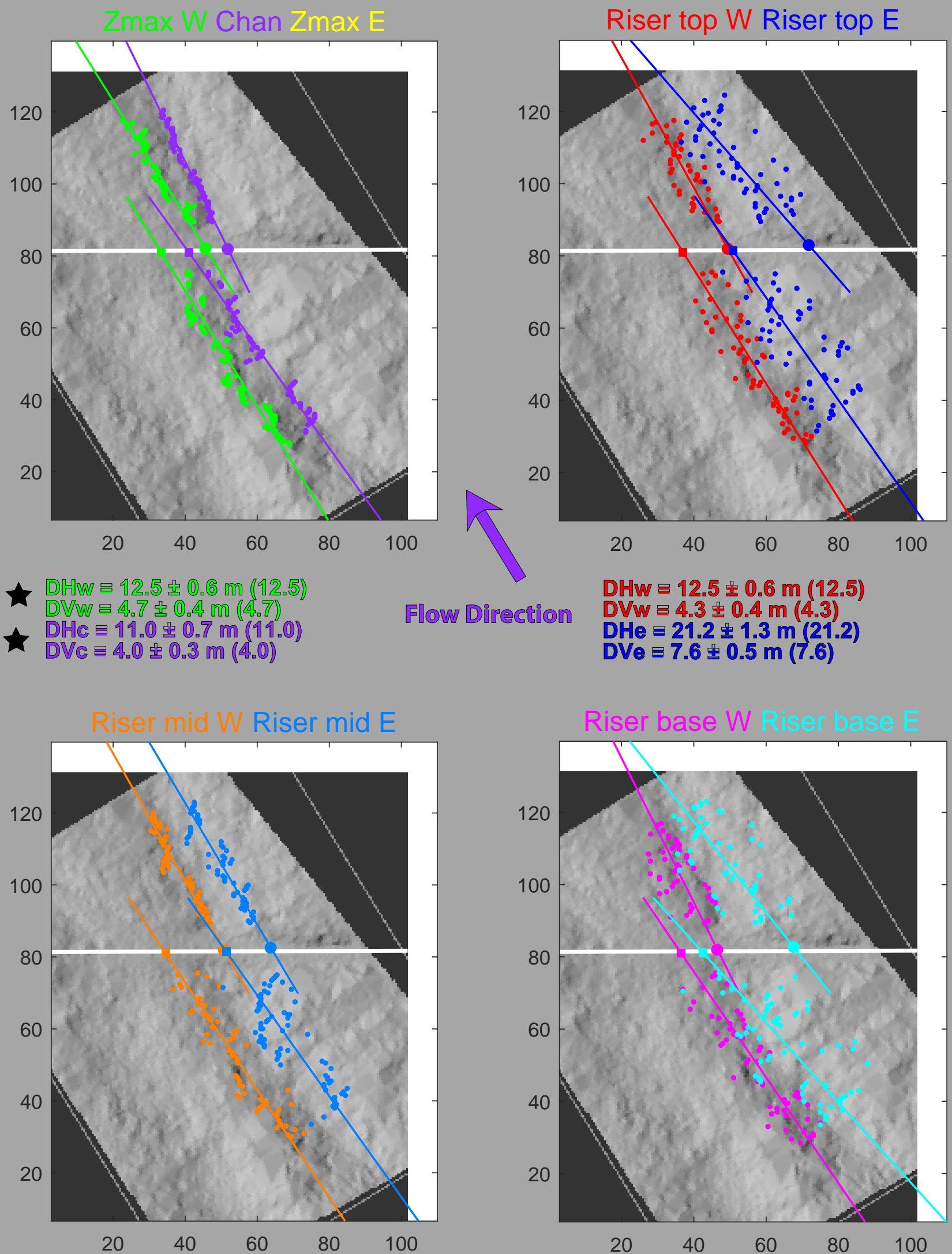

ᄉ DUw

人 DVW

$\mathrm{DH}$ 을 12.5 팔 $0.7 \mathrm{~m}(12.5)$

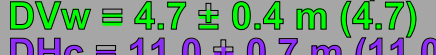

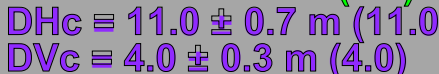

Flow Direction

$\mathrm{DH} w=12.5 \pm 0.6 \mathrm{~m}(12.5)$

$D V W=4.3 \pm 0.4 \mathrm{~m}(4.3)$

$\mathrm{DVe}=7.6 \pm 0.5 \mathrm{~m}(7.6)$

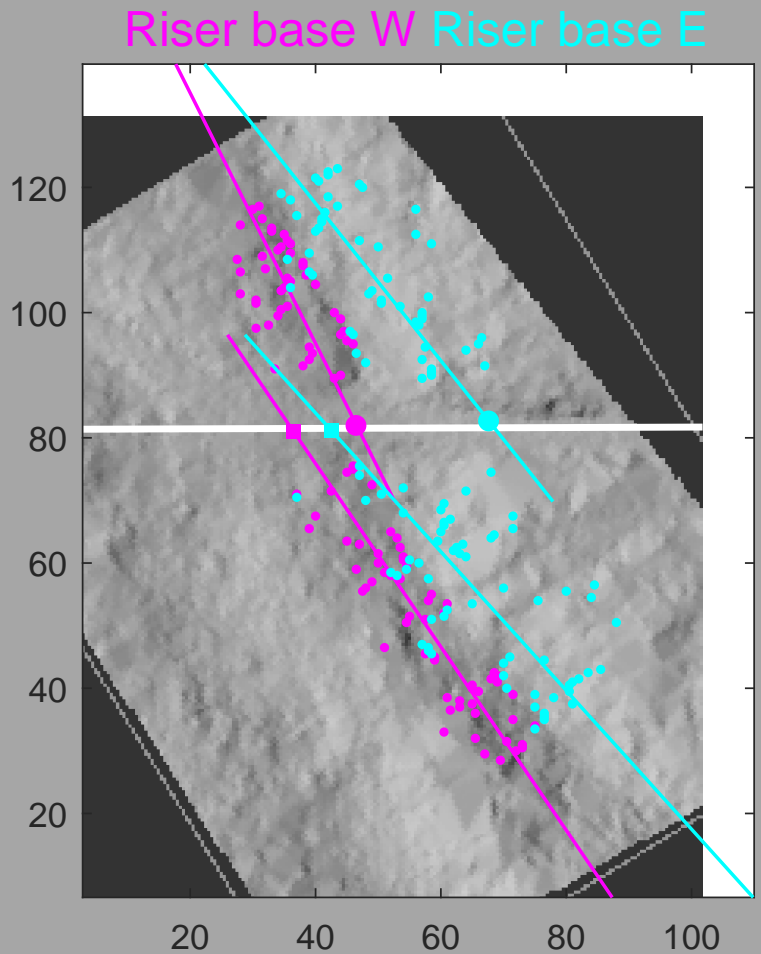

DHW $=10.1$. $0.7 \mathrm{~m}(10.1)$

DVW $=4,6$. $0.4 \mathrm{~m}(4,6)$

DUe = 25.3 돋 $1.2 \mathrm{~m}(25.3)$

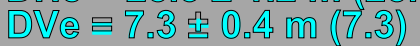

*Zmax 巨not

constrained dี

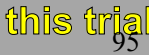




\section{Site G: Offset probability densities}
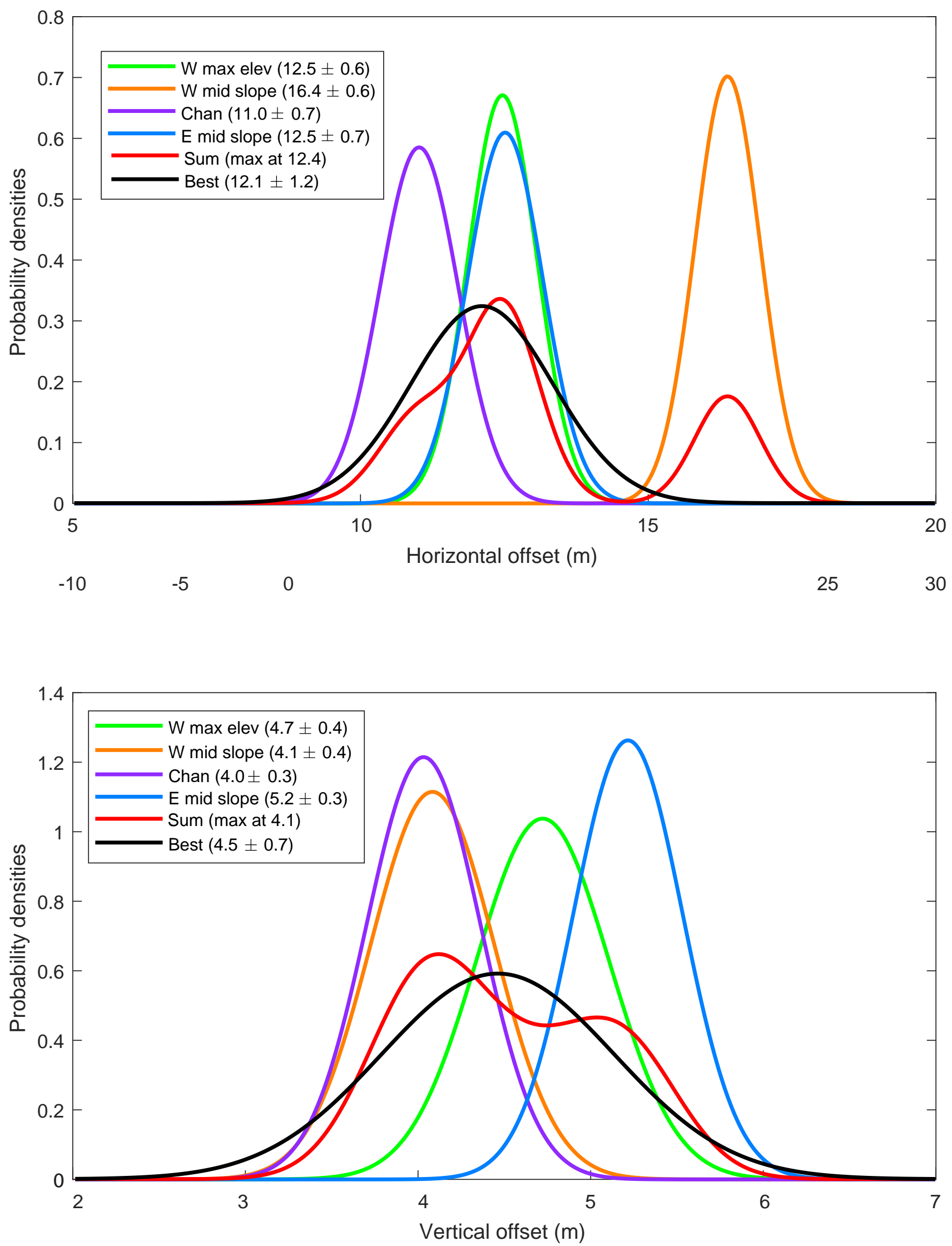
Site G

Original

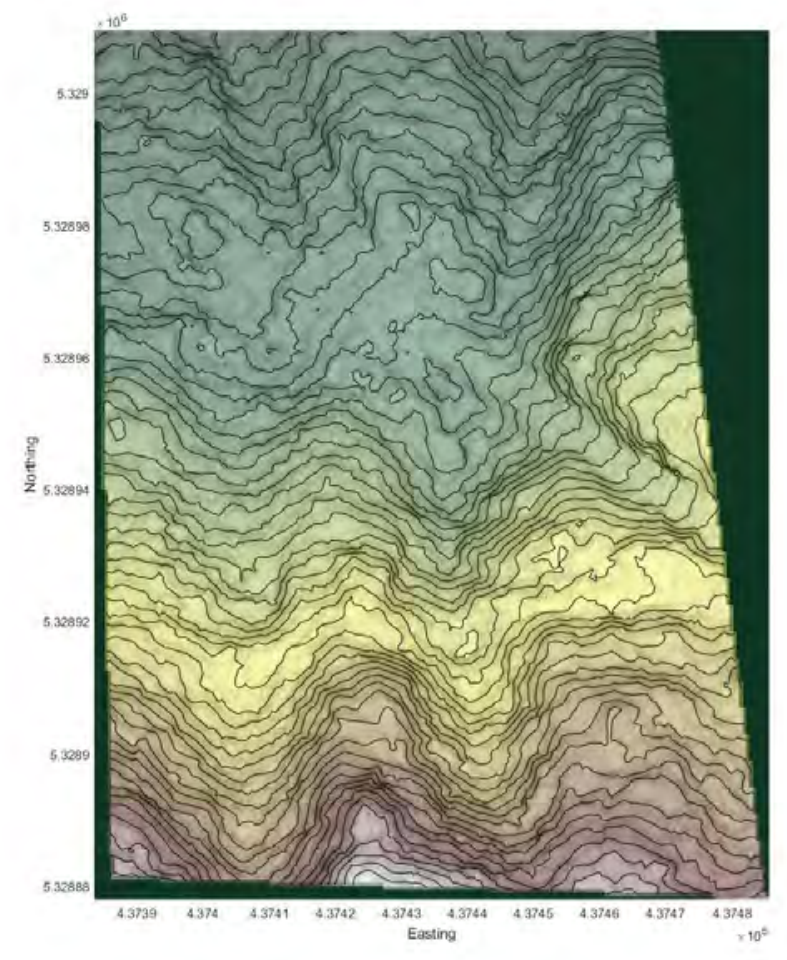

Lower Bound:11.0m

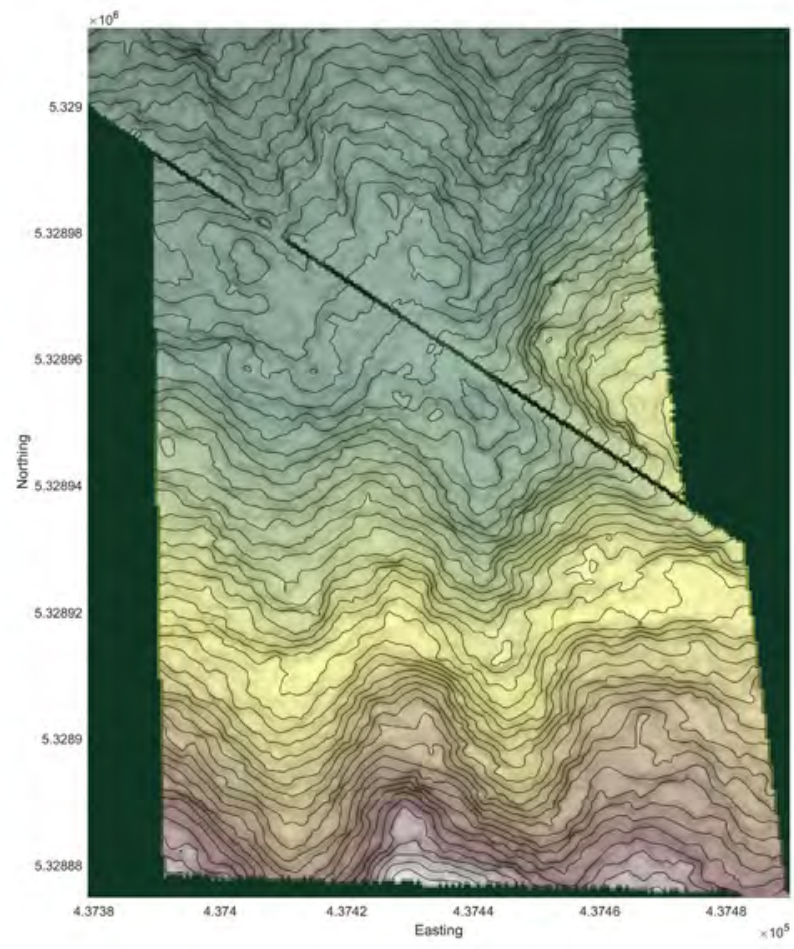

Upper Bound: 16.4m

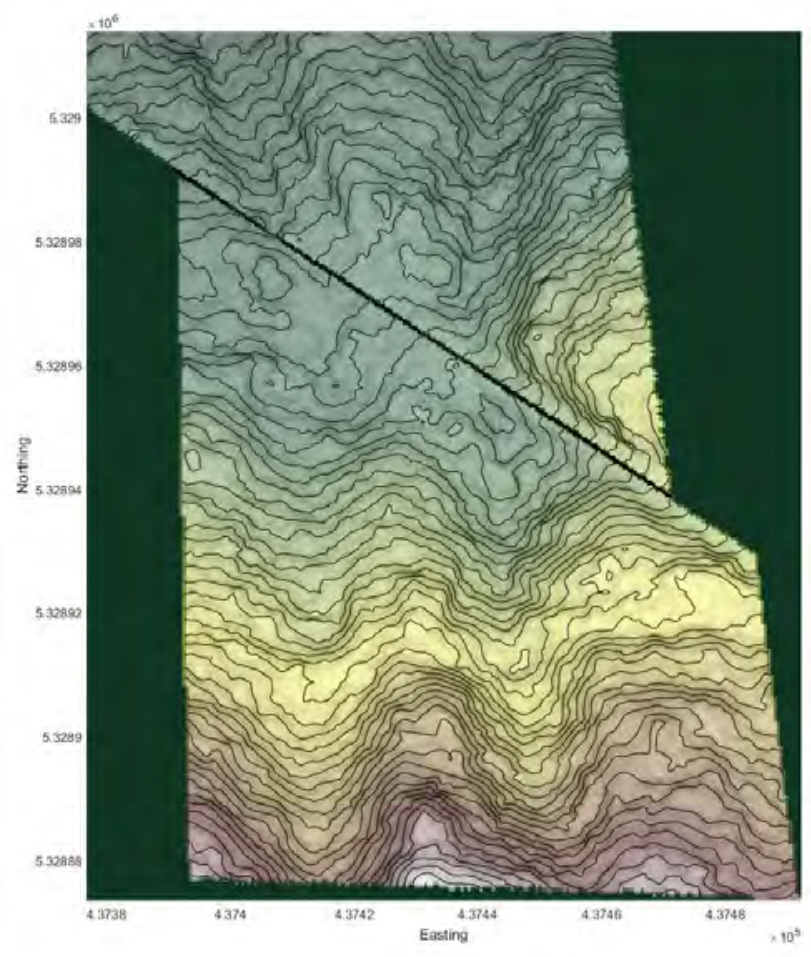




\section{Site $\mathbf{H}$}

Well constrained features: Chan, E midpoint, W midpoint

Preferred Offset: --

Upper Bound: 14.7

Lower Bound: 9.9

Strike-Slip Displacement Distribution: Uniform

Notes: The different distributions of strike-slip displacement between the $\mathrm{E}$ and $\mathrm{W}$ riser midpoints are not explained by the model described above for the geomorphic/tectonic development of the site (i.e., the unprotected side is offset more than the protected side). As such, I assume that the range of distributions between the two midpoint measurements reflects the true uncertainty in the measurement. The low value of the channel measurement suggests that this offset may reflect a single event displacement.

Field Measurement: 5.1m - 9.5m offset reported as a range in field (i.e., no preferred value). Quality: III 


\section{Site H Offsets and uncertainties (10000 runs)}
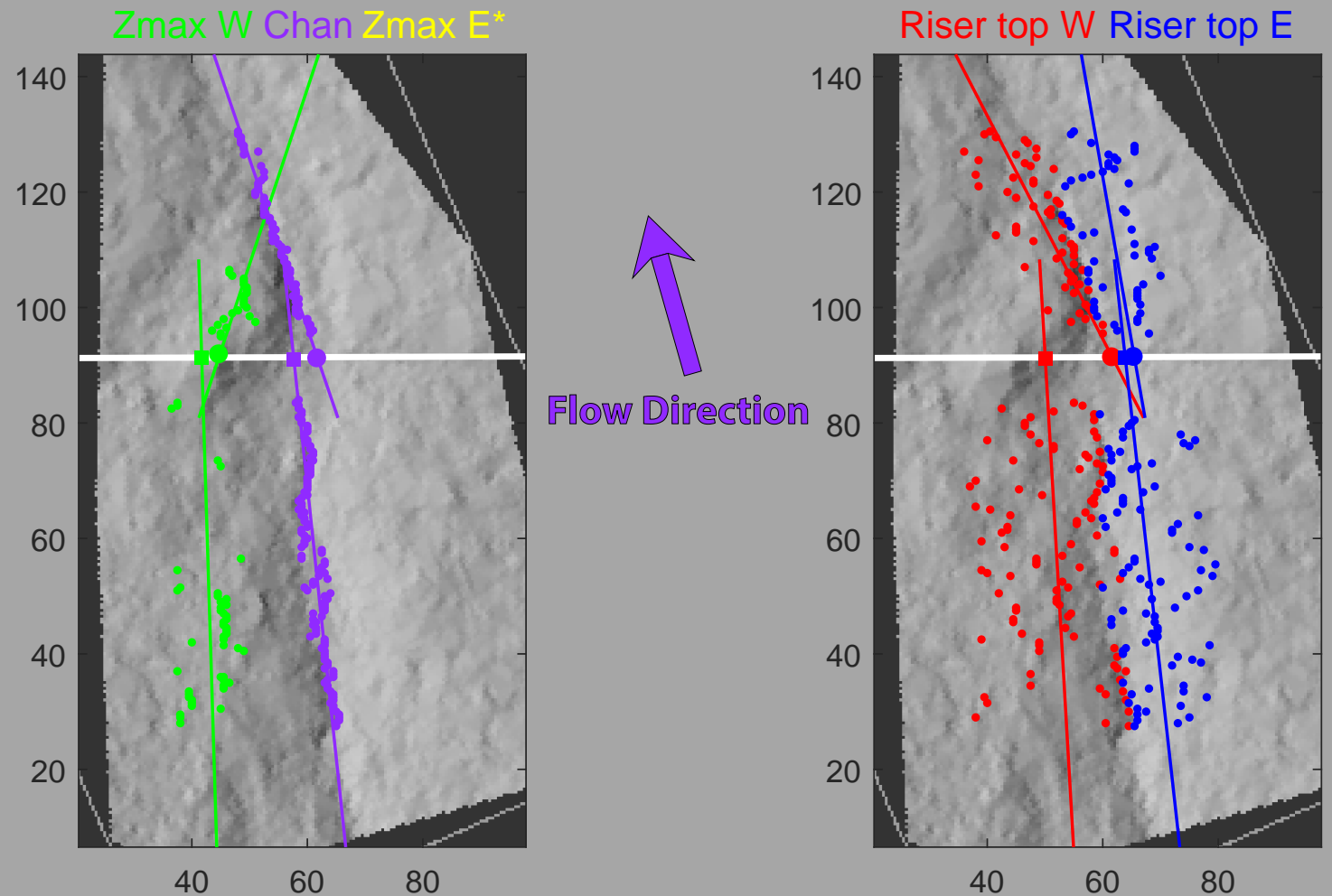

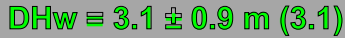

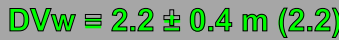

$\wedge$ DHe $=4.1$. $0.5 \mathrm{~m}(4.1)$

DVC $=0.7$ 훌 $0.2 \mathrm{~m}(0.7)$

Flow Direction

$\mathrm{DHw} \equiv 11.7 \pm 0.9 \mathrm{~m}$ (11.7)

$D V W \equiv 0.8 \pm 0.2 \mathrm{~m}(0.8)$

$\mathrm{DHe}=1.6 \pm 0.3 \mathrm{~m}(1.6)$

$\mathrm{DVe}=0.4 \pm 0.2 \mathrm{~m}(0.4)$

Riser mid E

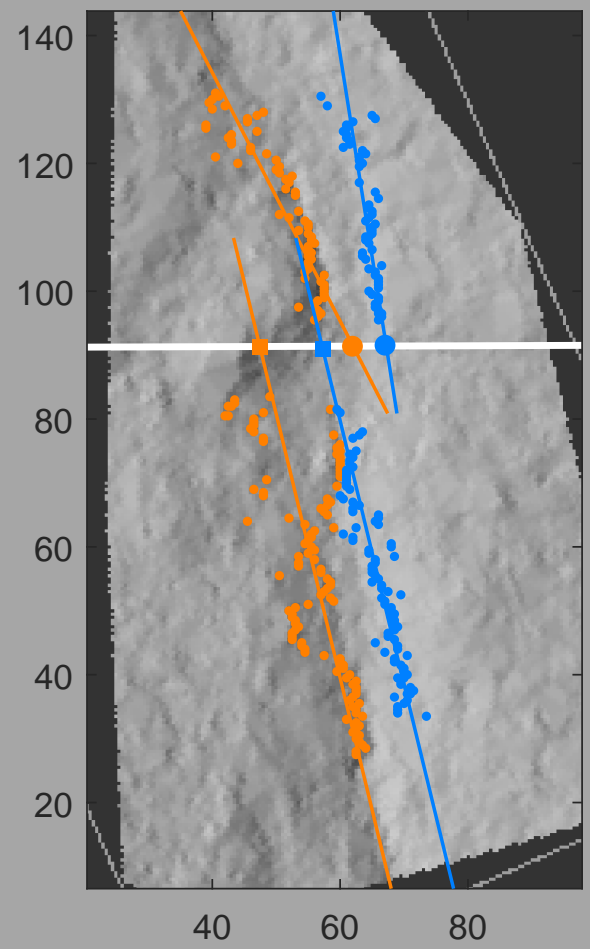

Riser base W

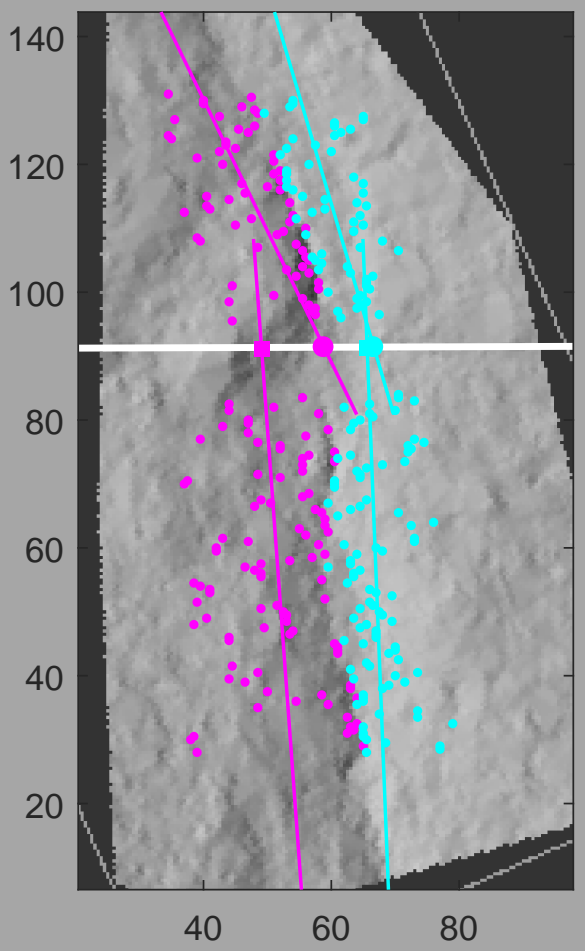

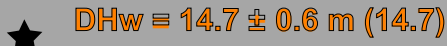

DHW $=9.8$ 폴 $0.9 \mathrm{~m}(9.8)$

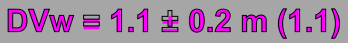

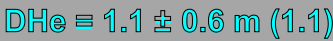

DVE 등 0.2 댐 0.2 m (0.2) 
Site H: Offset probability densities
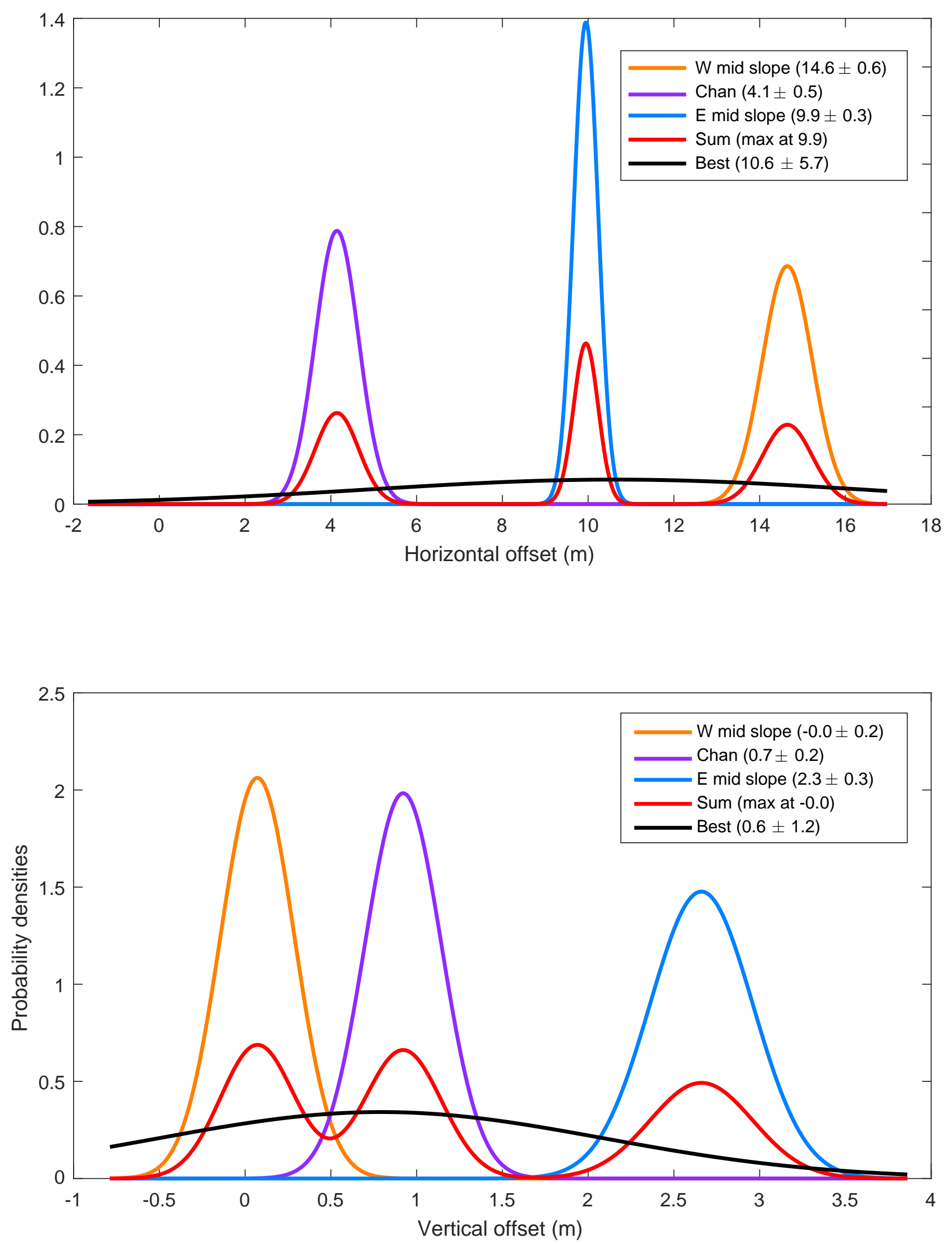


\section{Site $\mathbf{H}$}

Original

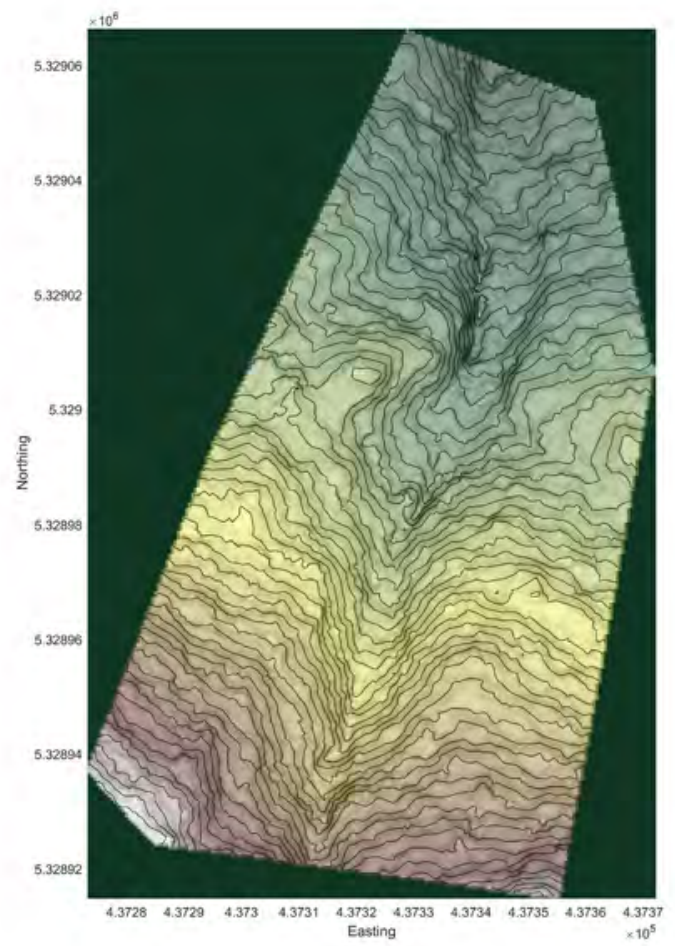

Lower Bound: 9.9m

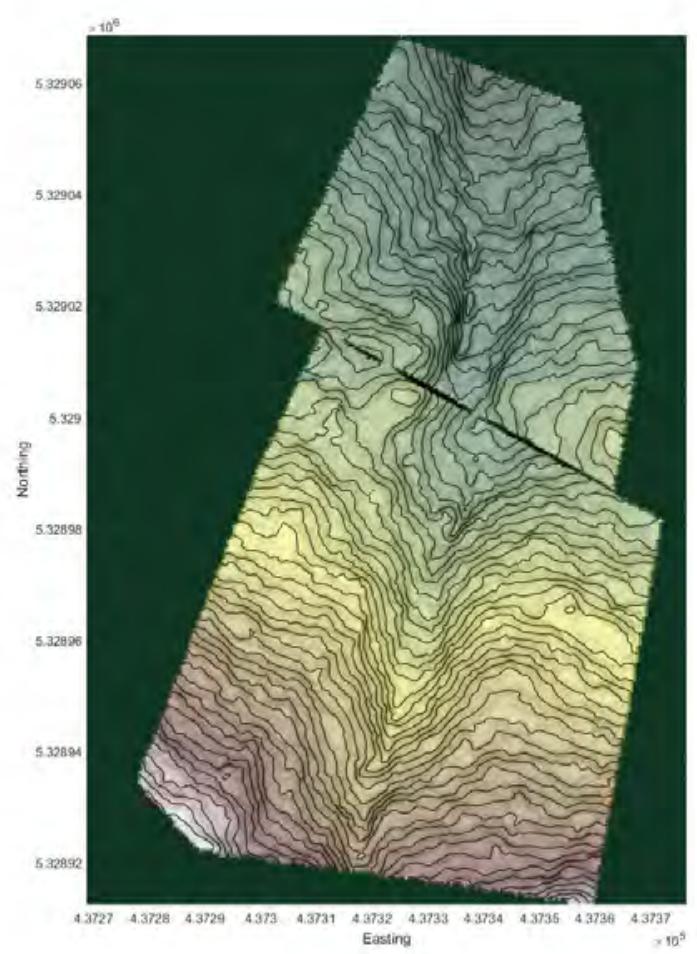

Upper Bound: 14.7m

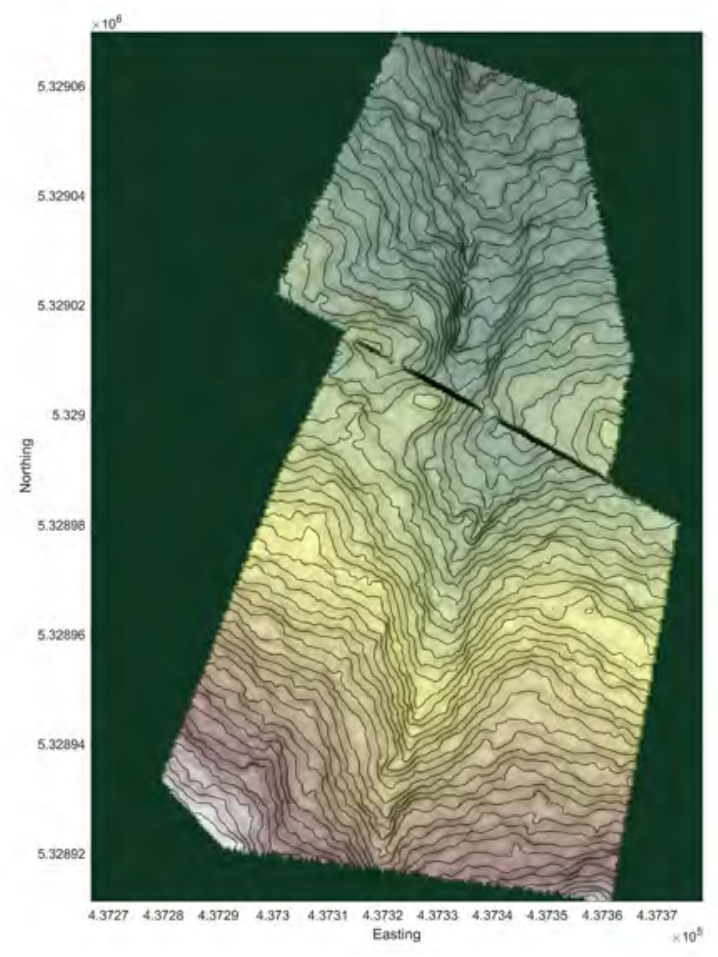




\section{Site I}

Well constrained features: $\mathrm{W}$ max, W mid

Preferred Offset: $15.8 \mathrm{~m}$

Upper Bound: 16.6m

Lower Bound: $15.0 \mathrm{~m}$

Strike-Slip Displacement Distribution: Gaussian

Notes: The reported offset is derived from the Gaussian distribution of offset max elevation (interfluve). I assume that the lower measurement derived from the channel midpoint is affected by geomorphic modification of the channel.

Field Measurement: $7.8 \mathrm{~m}$ (no errors recorded in the field)

Quality: IV 


\section{Site I Offsets and uncertainties (10000 runs)}
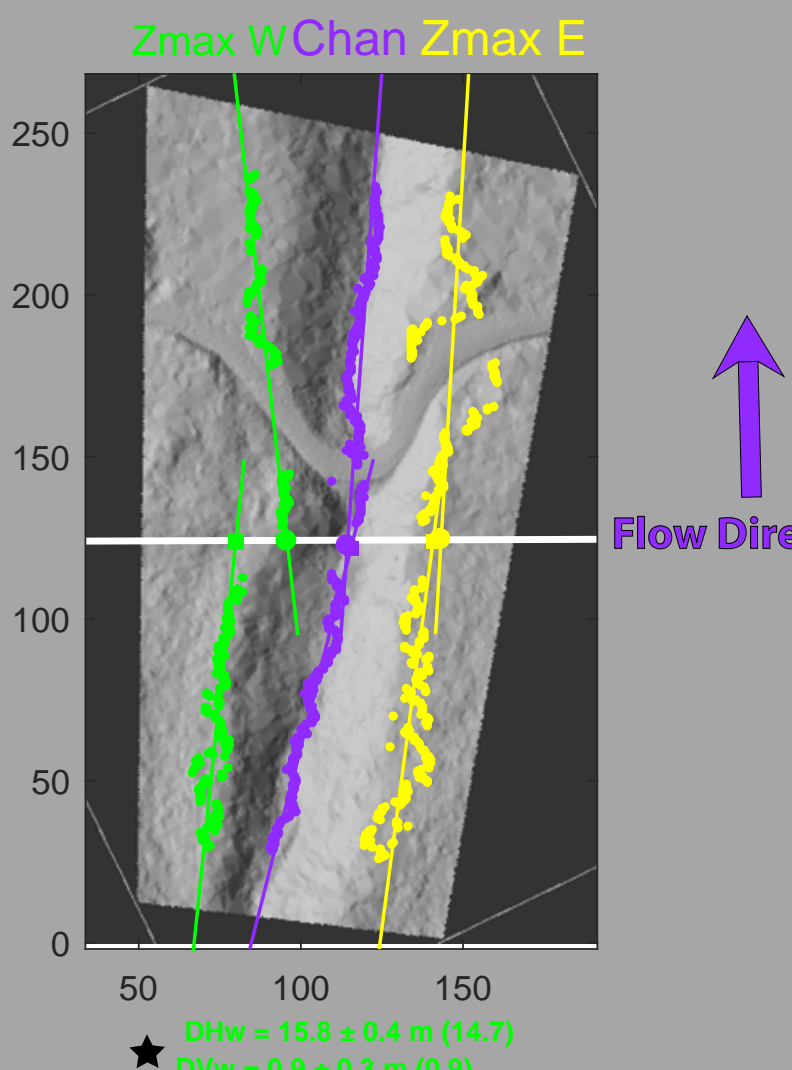

$\mathrm{DHe}=2.5 \pm 0.12 \mathrm{~m}(2.5)$

$\mathrm{DVe}=2.6 \pm 0.2 \mathrm{~m}(2.6)$

$\mathrm{DHr}=-1.1 \pm 0.6 \mathrm{~m}(-1.1)$

$\mathrm{DVc}=4.1 \pm 0.3 \mathrm{~m}$ (4.1)

Riser mid E
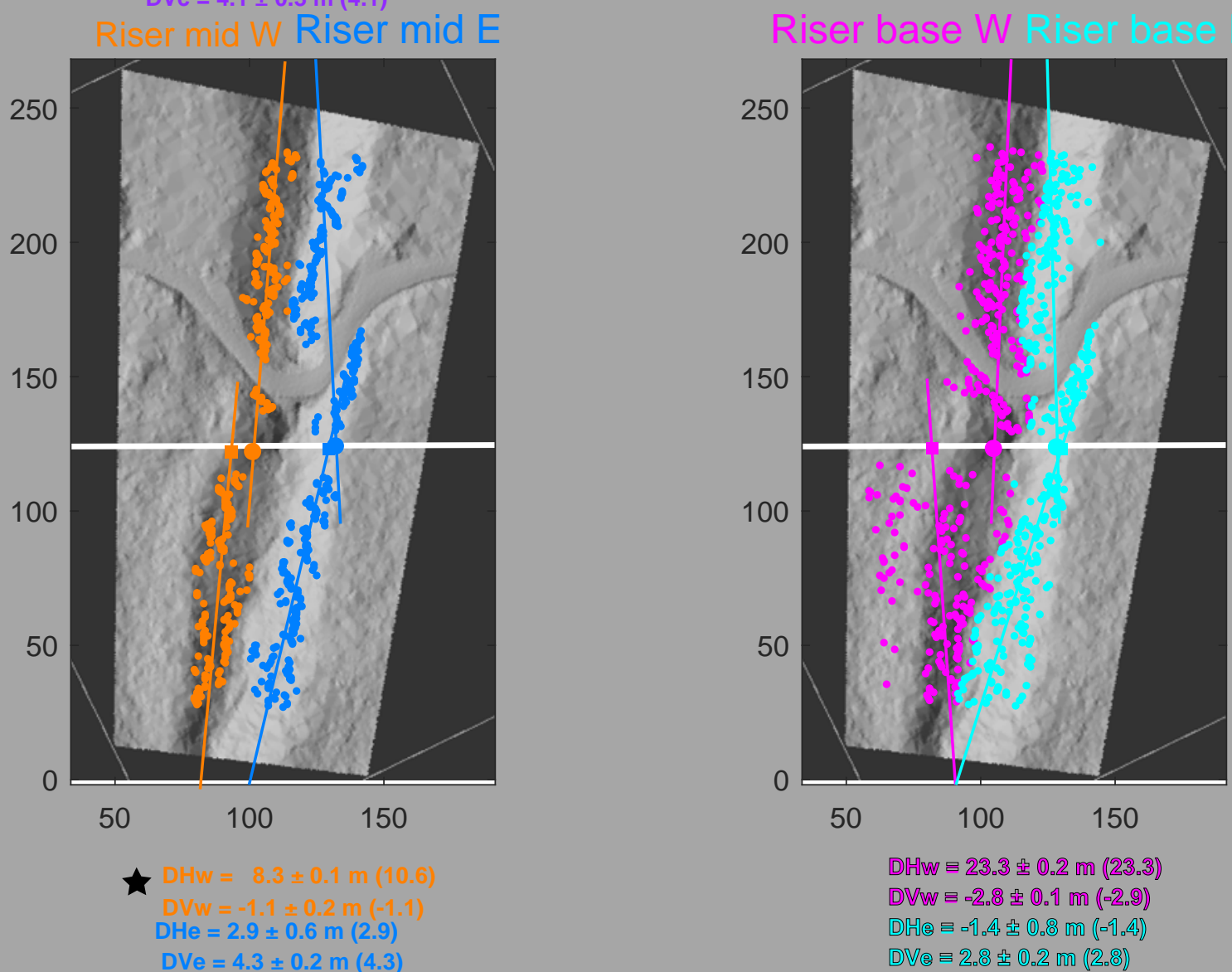

$\mathrm{DHe}=2.9 \pm 0.6 \mathrm{~m}(2.9)$

$\mathrm{DVe}=4.3 \pm 0.2 \mathrm{~m}(4.3)$ 


\section{Site I: Offset probability densities}
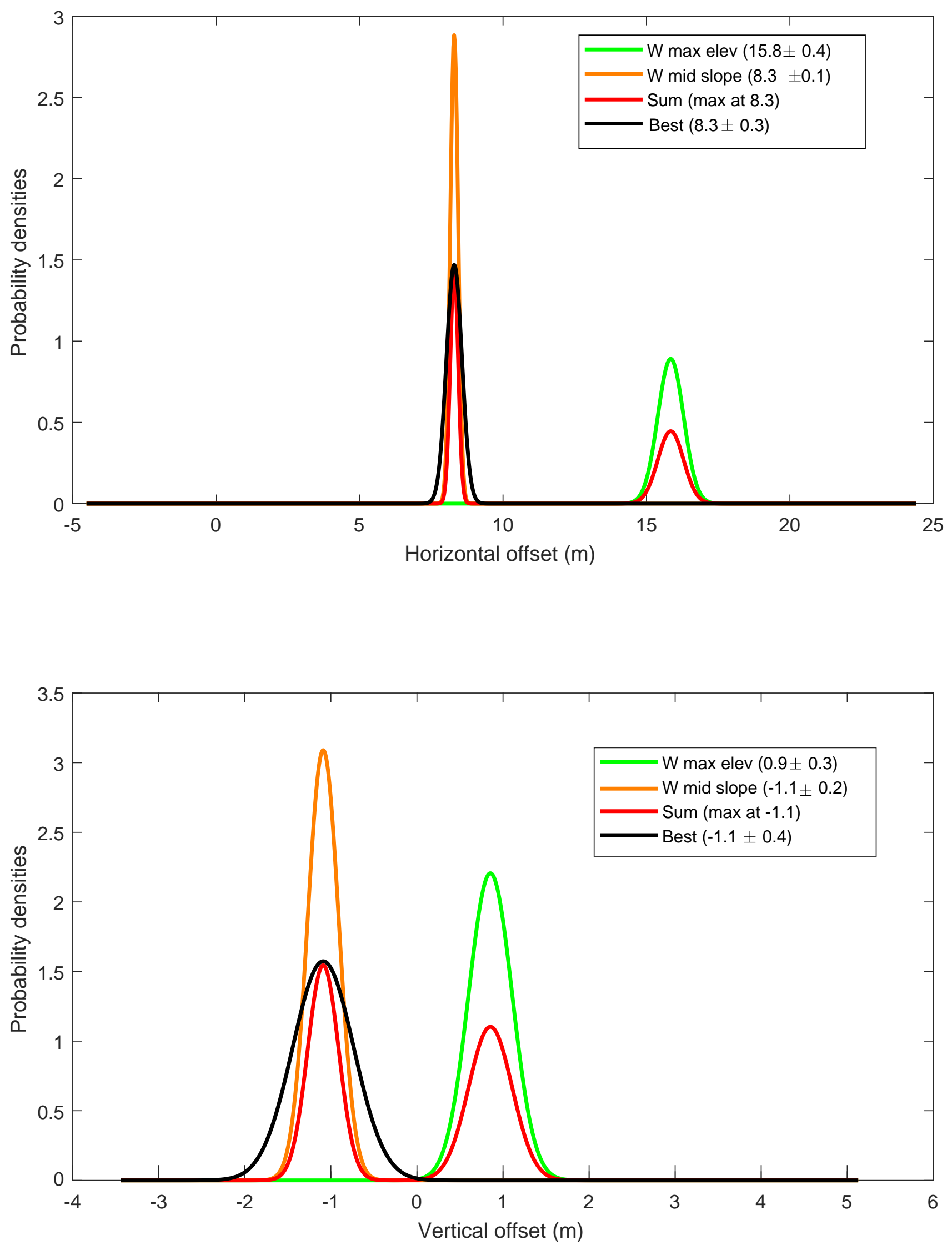


\section{Site I}

Original

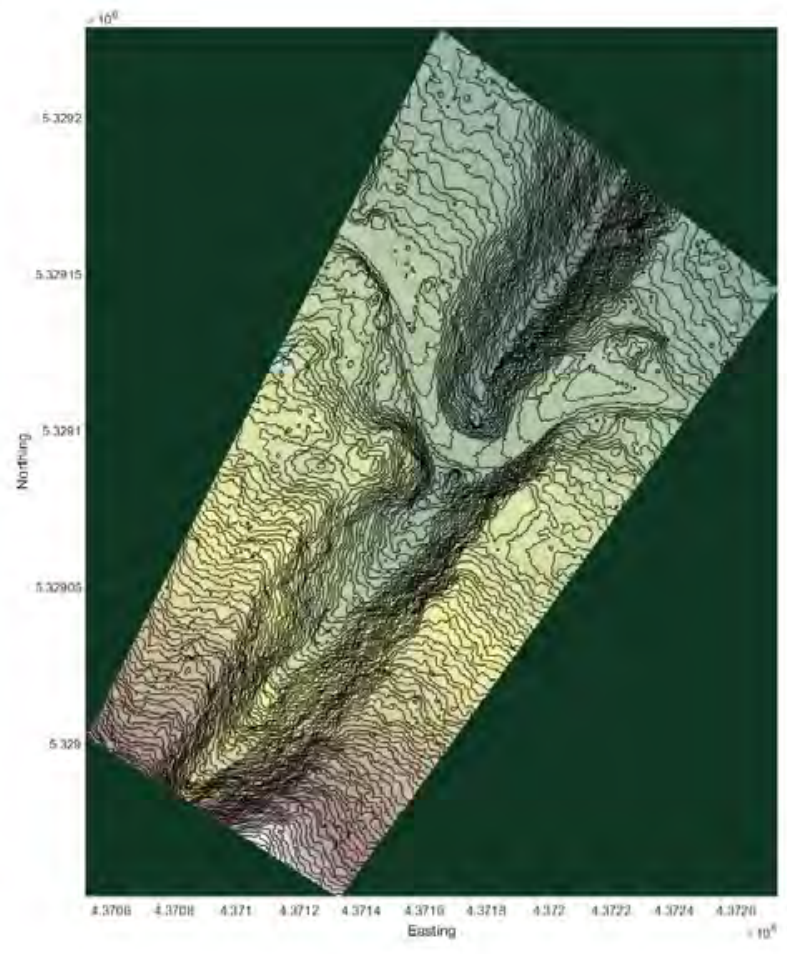

Preferred: $14.7 \mathrm{~m}$

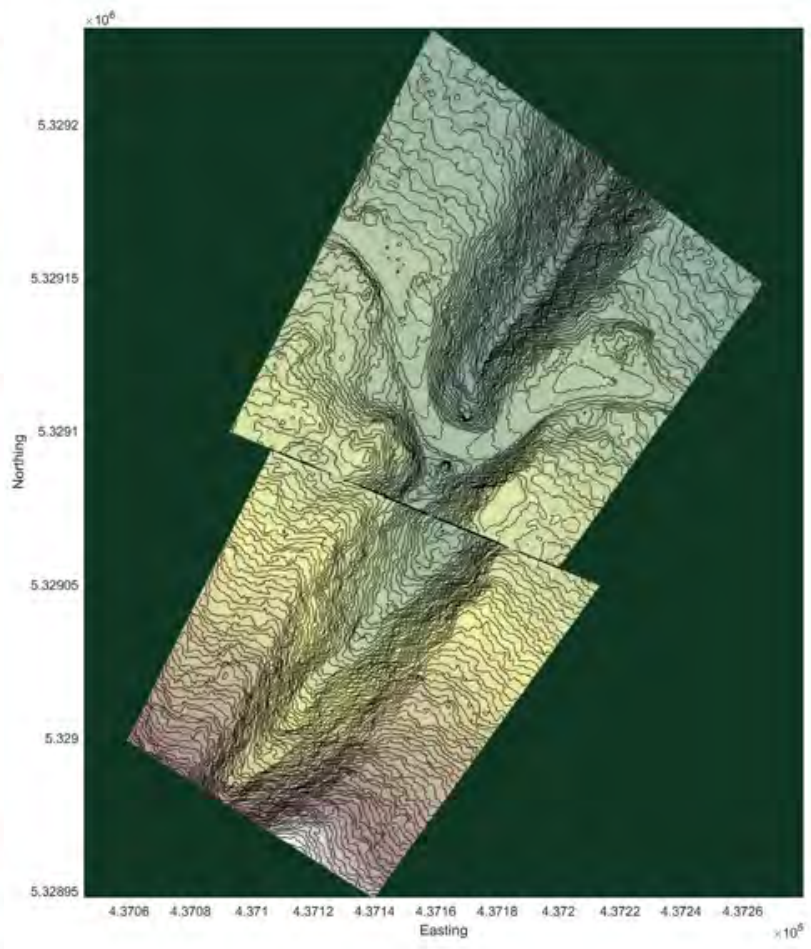

Lower Bound: 13.9m

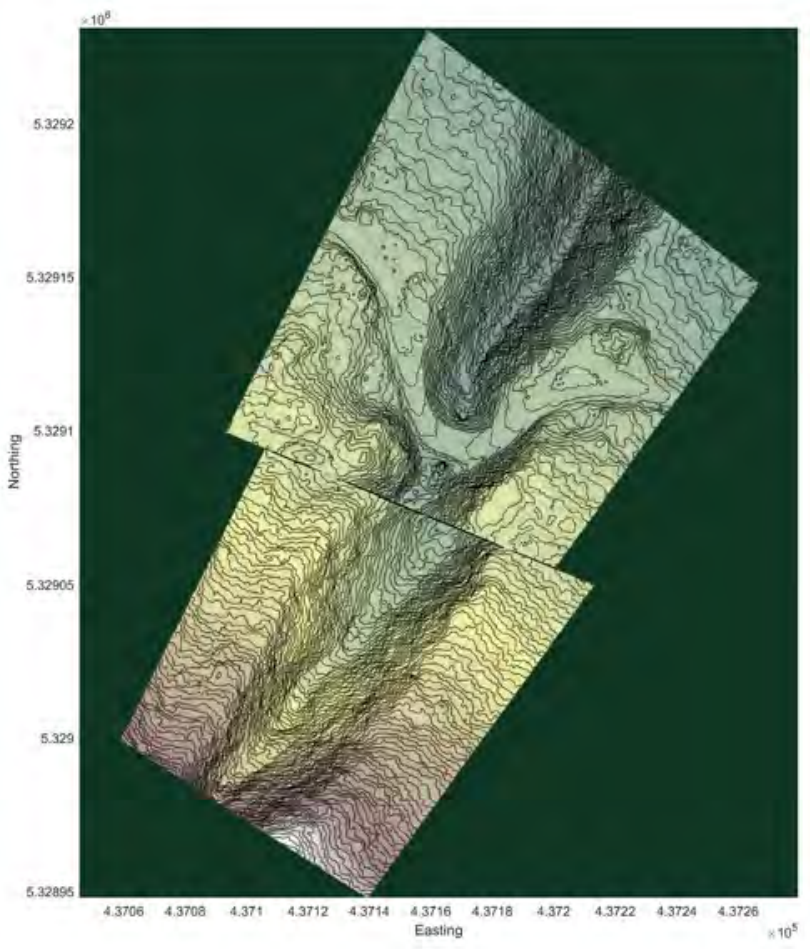

Upper Bound: 15.5m

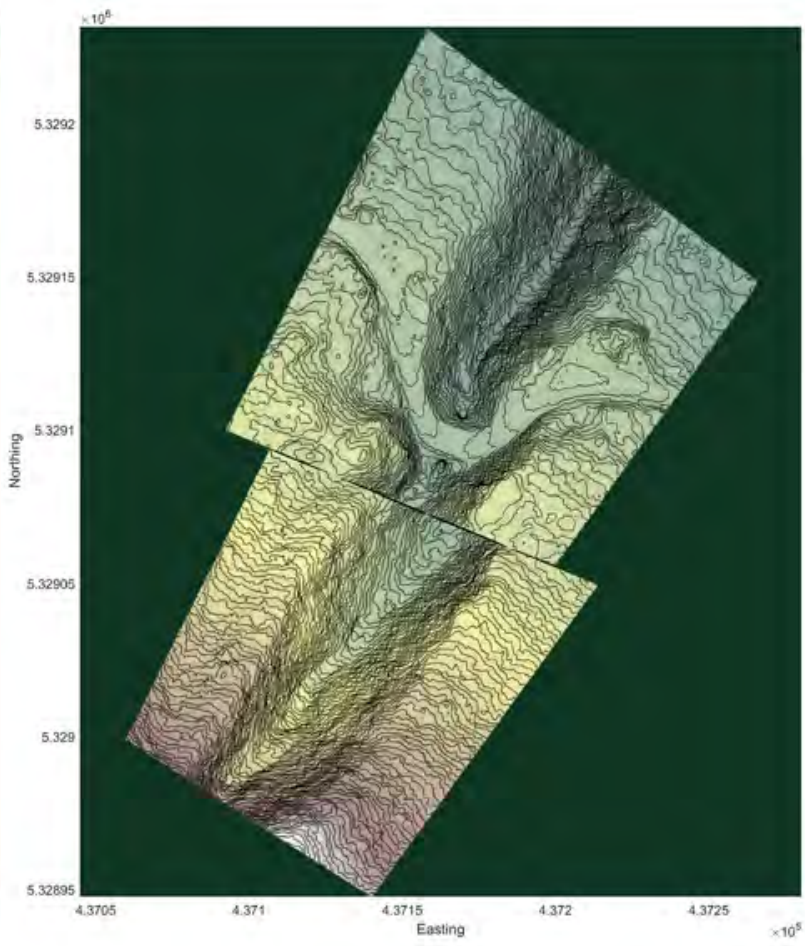




\section{Site J}

Well constrained features: Chan, W max, E max, W mid, E mid

Preferred Offset (channel): $4.0 \mathrm{~m}$

Upper Bound (channel): 4.8m

Lower Bound (channel): $3.2 \mathrm{~m}$

Preferred Offset (interfluve): $8.3 \mathrm{~m}$

Upper Bound (interfluve): 10.1m

Lower Bound (interfluve): $6.5 \mathrm{~m}$

Strike-Slip Displacement Distribution: Gaussian

Notes: I interpret two distinct measurements at this site; one inside the channel and one outside the channel. Differences in strike-slip displacement and scarp height, observed in the lidar data and in the field support the interpretation that two distinct offsets are present at this site. I report the channel preferred offset and uncertainties from the Gaussian distribution of the channel thalweg measurement and the interfluve preferred offset and uncertainties from the Gaussian distribution of the E max measurement.

Field Measurement: 5.1-8.0m

Quality: I 


\section{Site J Offsets and uncertainties (10000 runs)}

Chan Zmax E

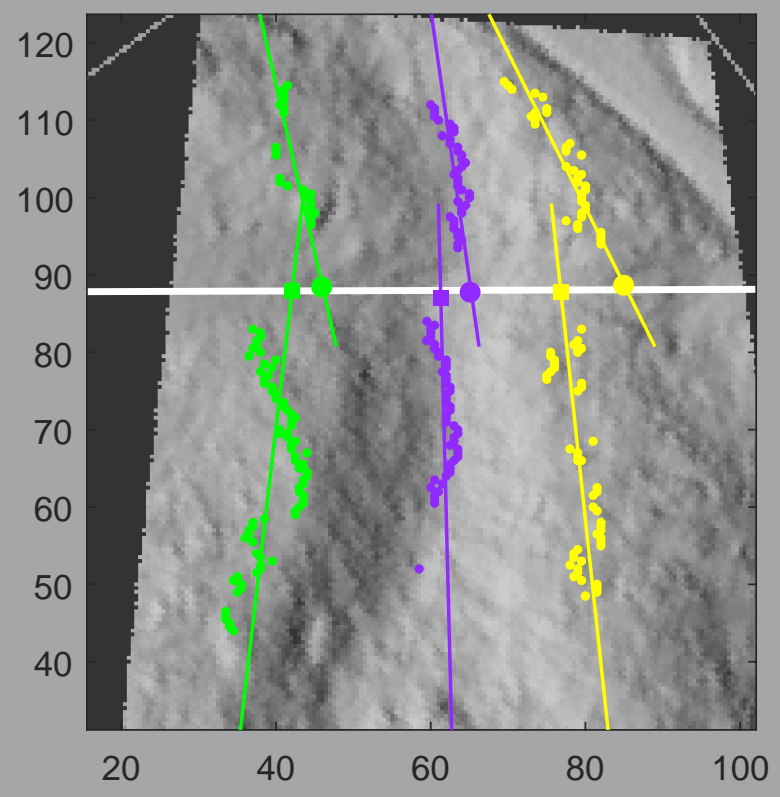

Riser top W Riser top E

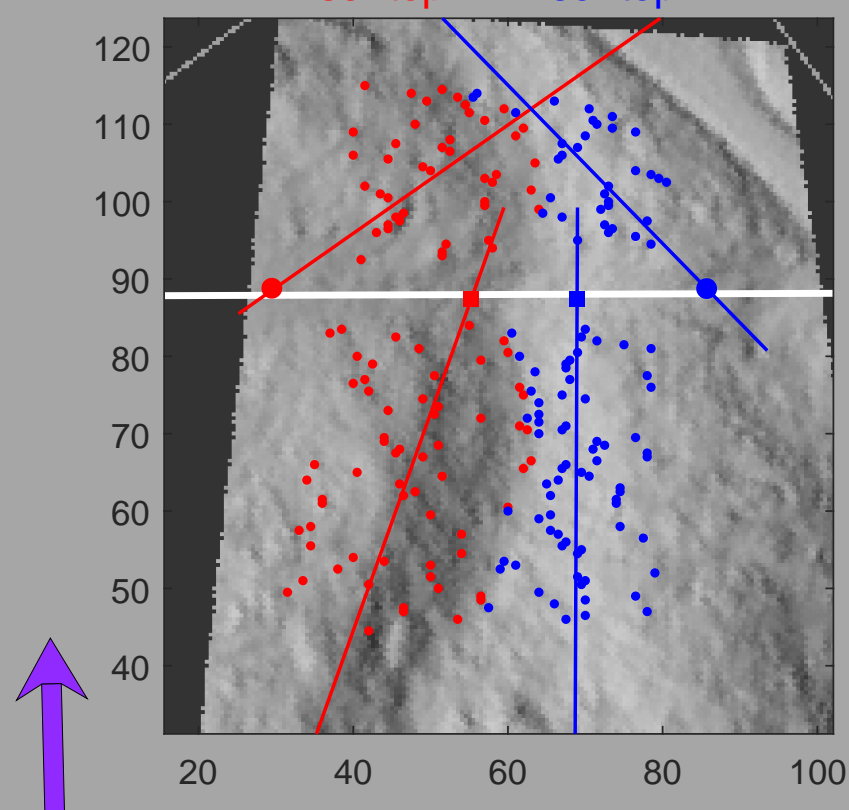

今 DHW

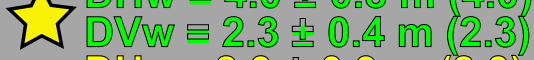

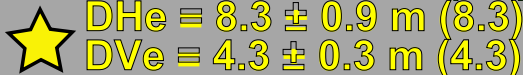

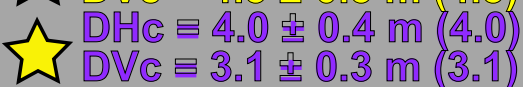

$\mathrm{DHW}=-25.9 \pm 3.9 \mathrm{~m}(-25.6)$

$\mathrm{DVW}=7.1 \pm 0.8 \mathrm{~m}(7.1)$

$\mathrm{DHe} \equiv 16.9 \pm 2.1 \mathrm{~m}(16.9)$

$\mathrm{DVe}=6.8 \pm 0.6 \mathrm{~m}(6.8)$
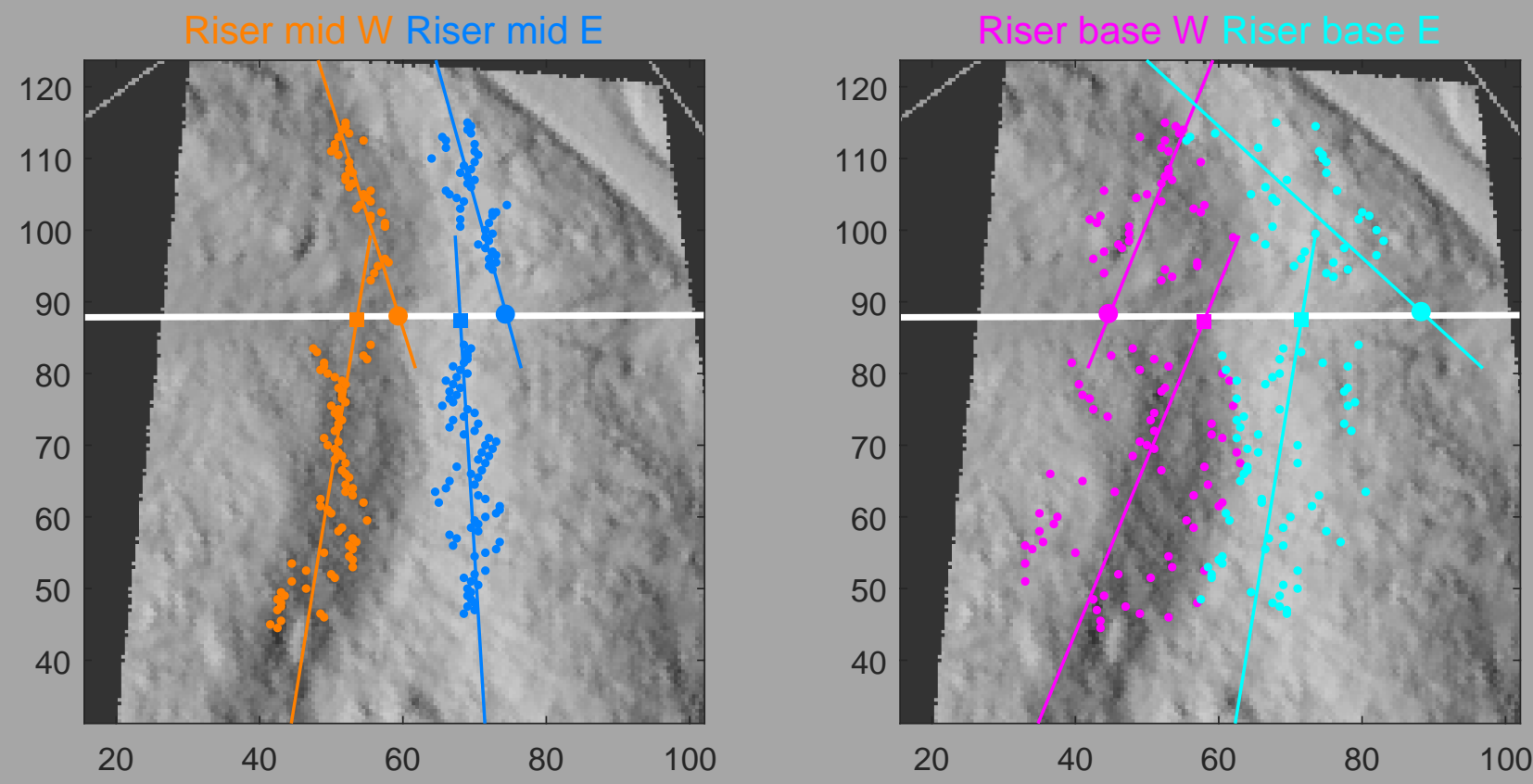

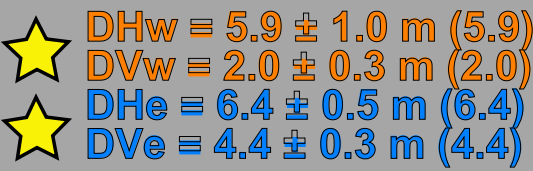

$\mathrm{DHW}=-1.3 .2 \mathrm{y} 0.7 \mathrm{~m}(-1.3 .1)$ DVw $=5.3$ 留 0.4 m $(5.3)$

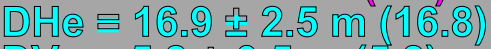

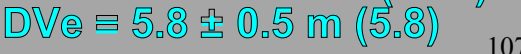




\section{Site J : Offset probability densities}
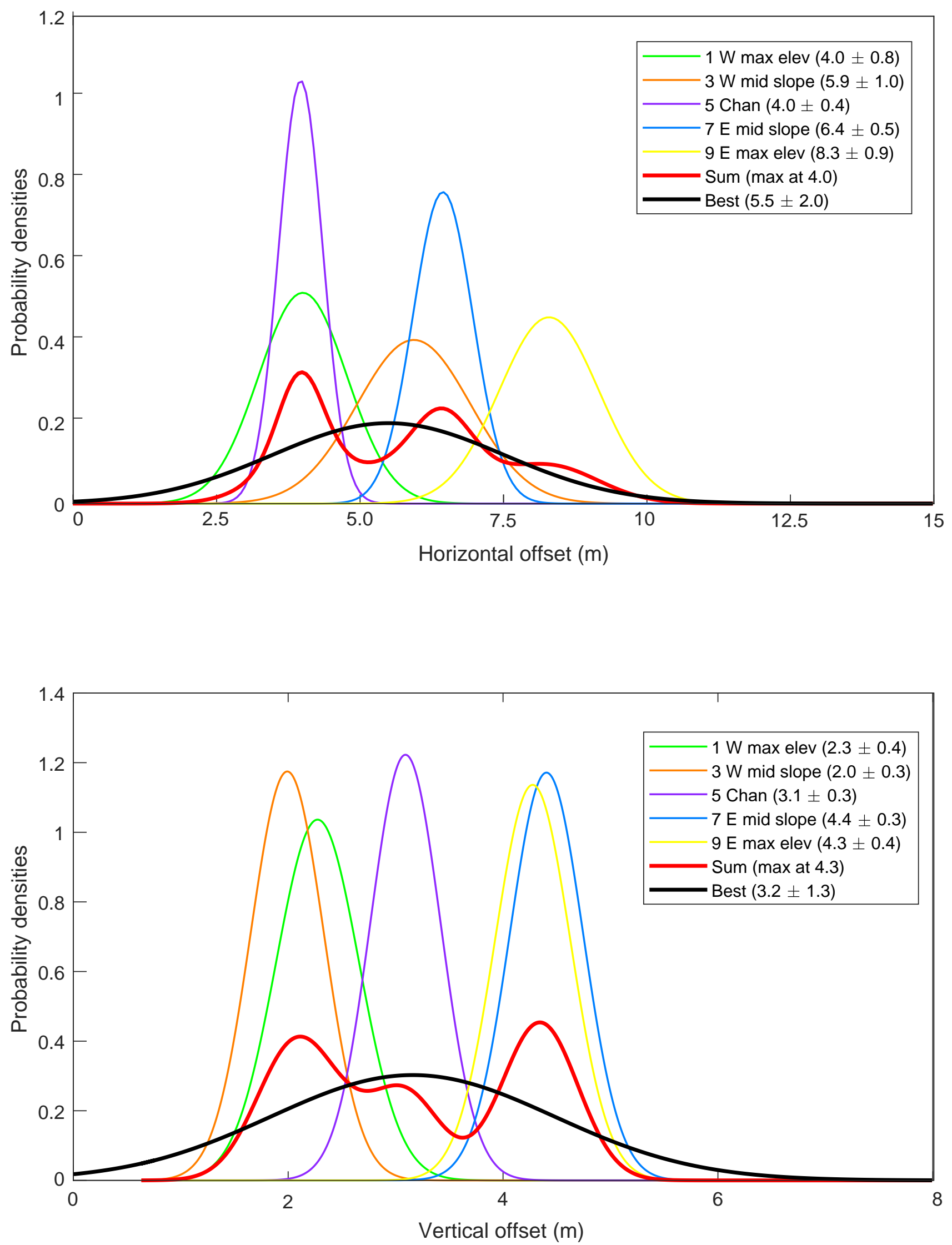


\section{Site J Channel}

Original

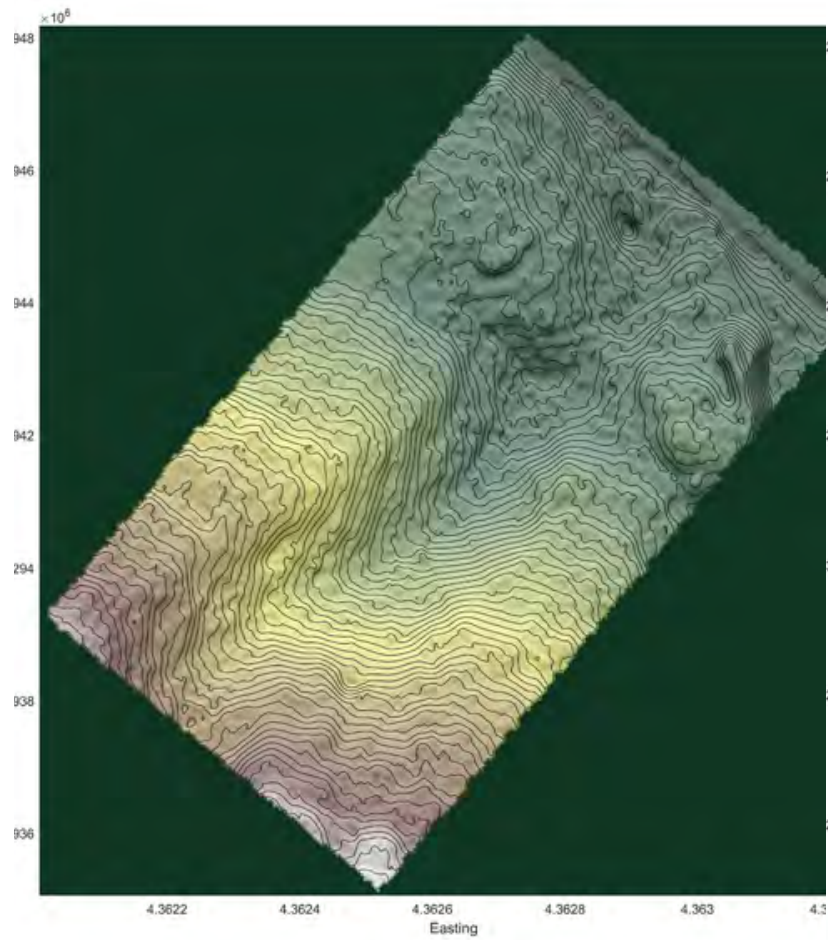

Preferred: $4.0 \mathrm{~m}$

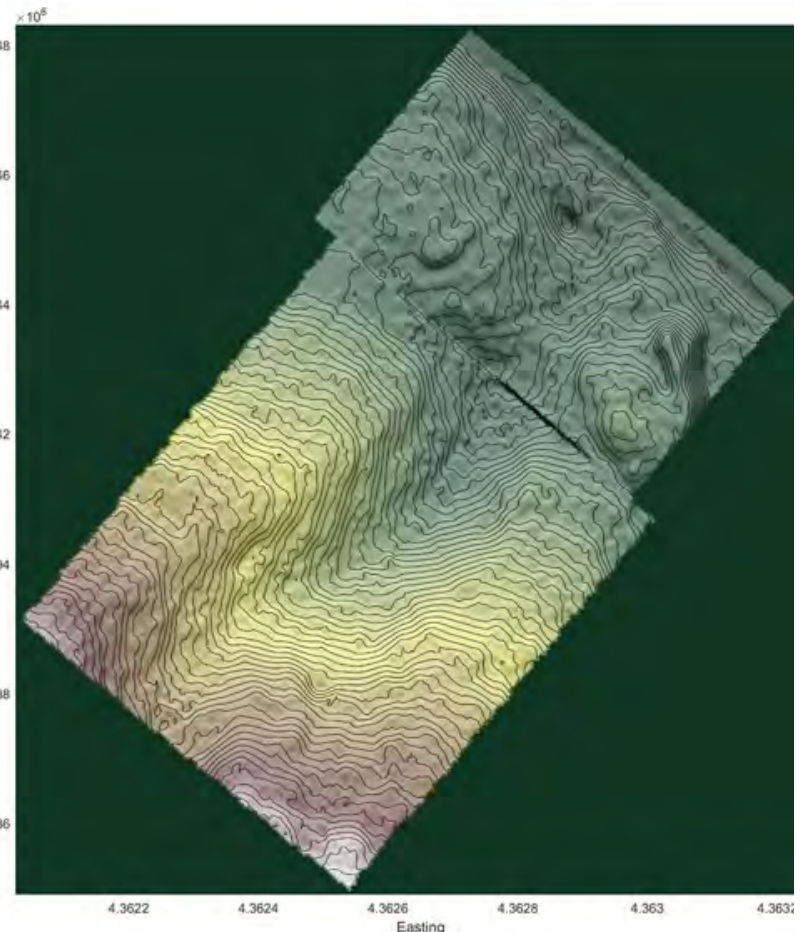

Lower Bound: $3.2 \mathrm{~m}$

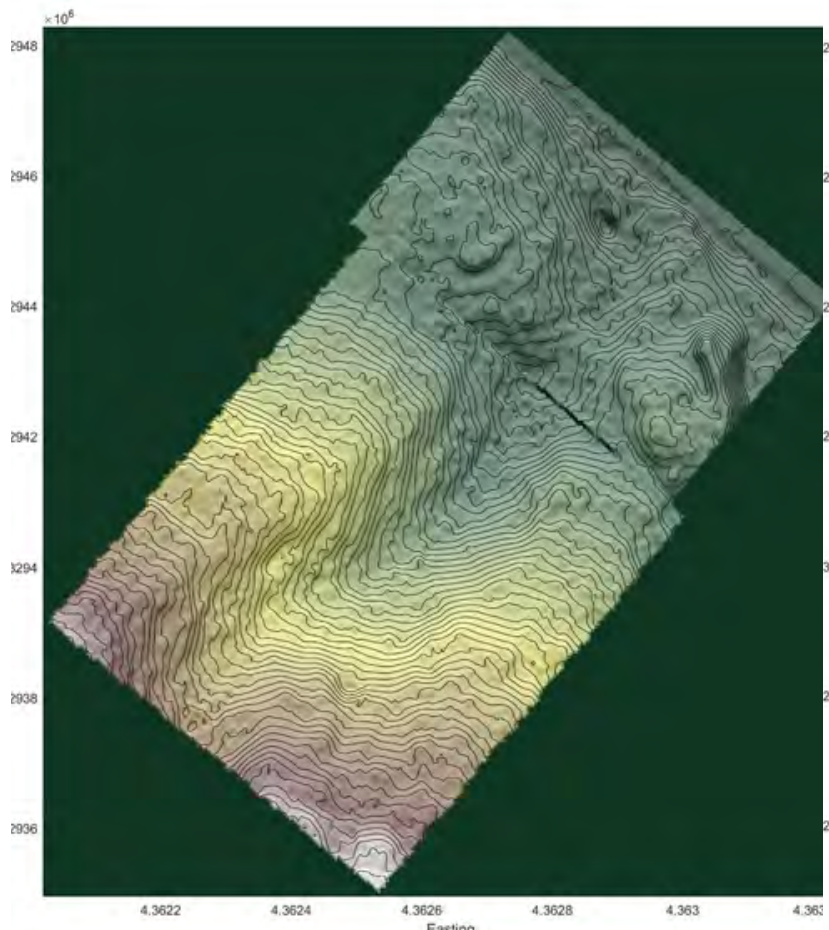

Upper Bound: 4.8m

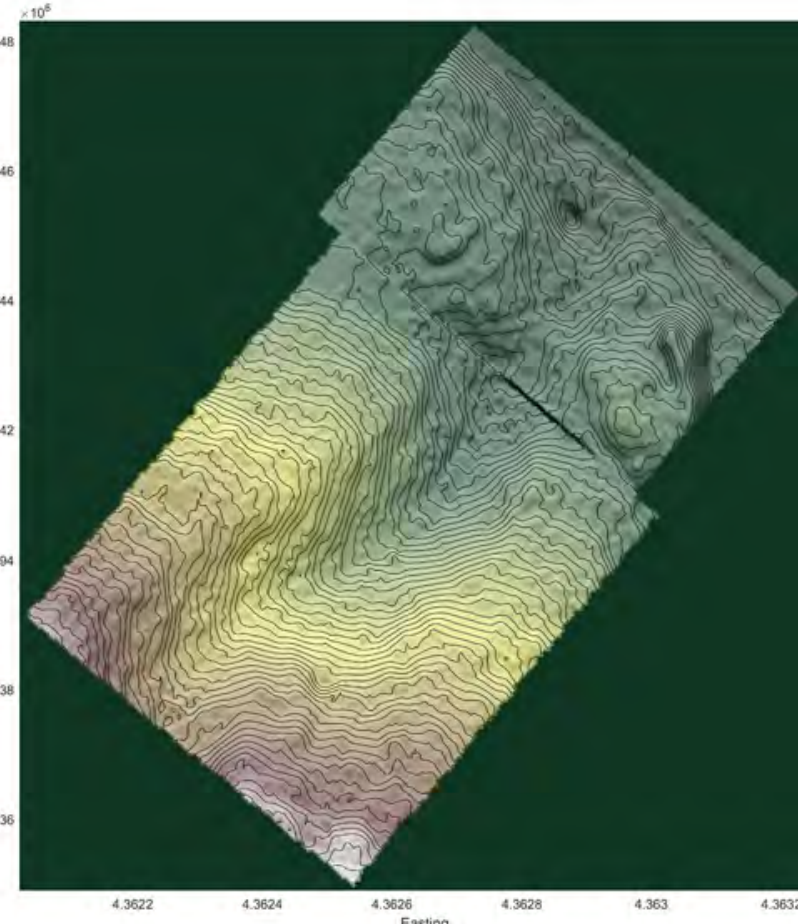




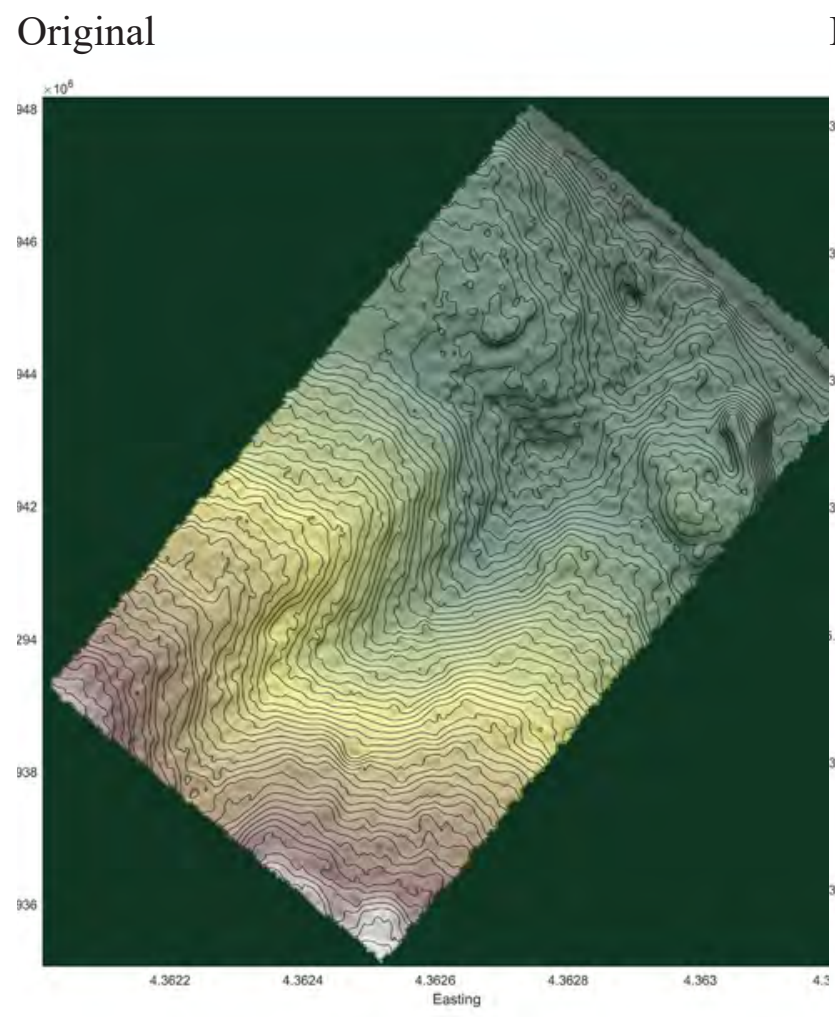

Preferred: $8.3 \mathrm{~m}$

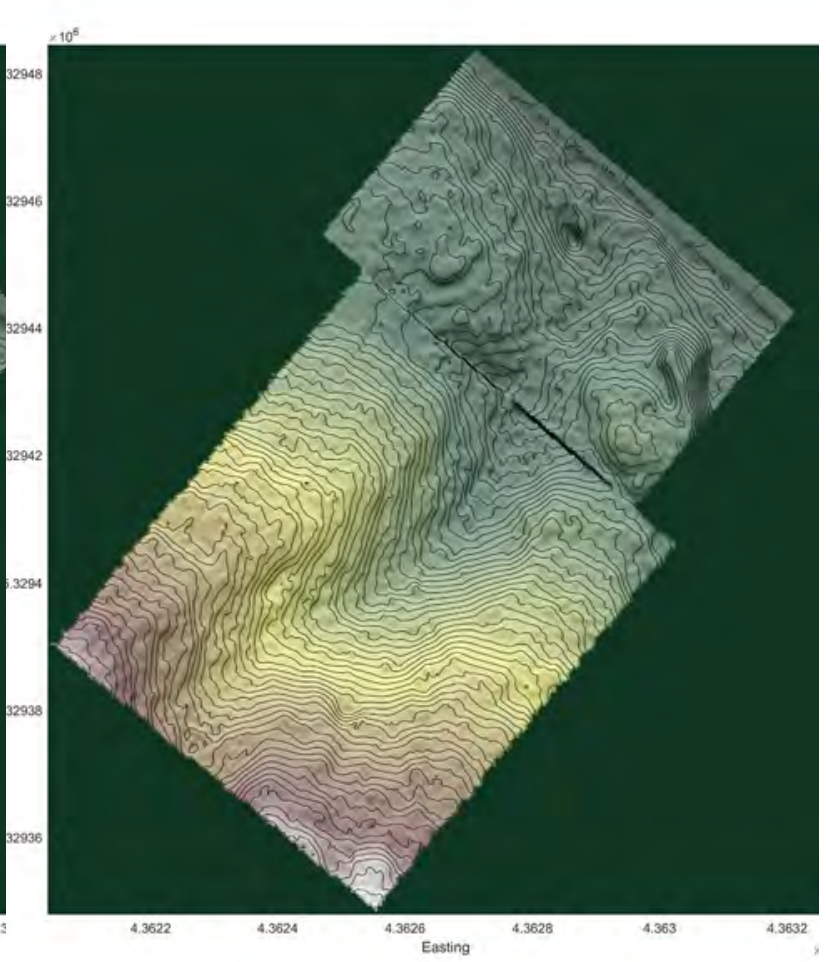

Lower Bound: $6.5 \mathrm{~m}$

Upper Bound: 10.1m
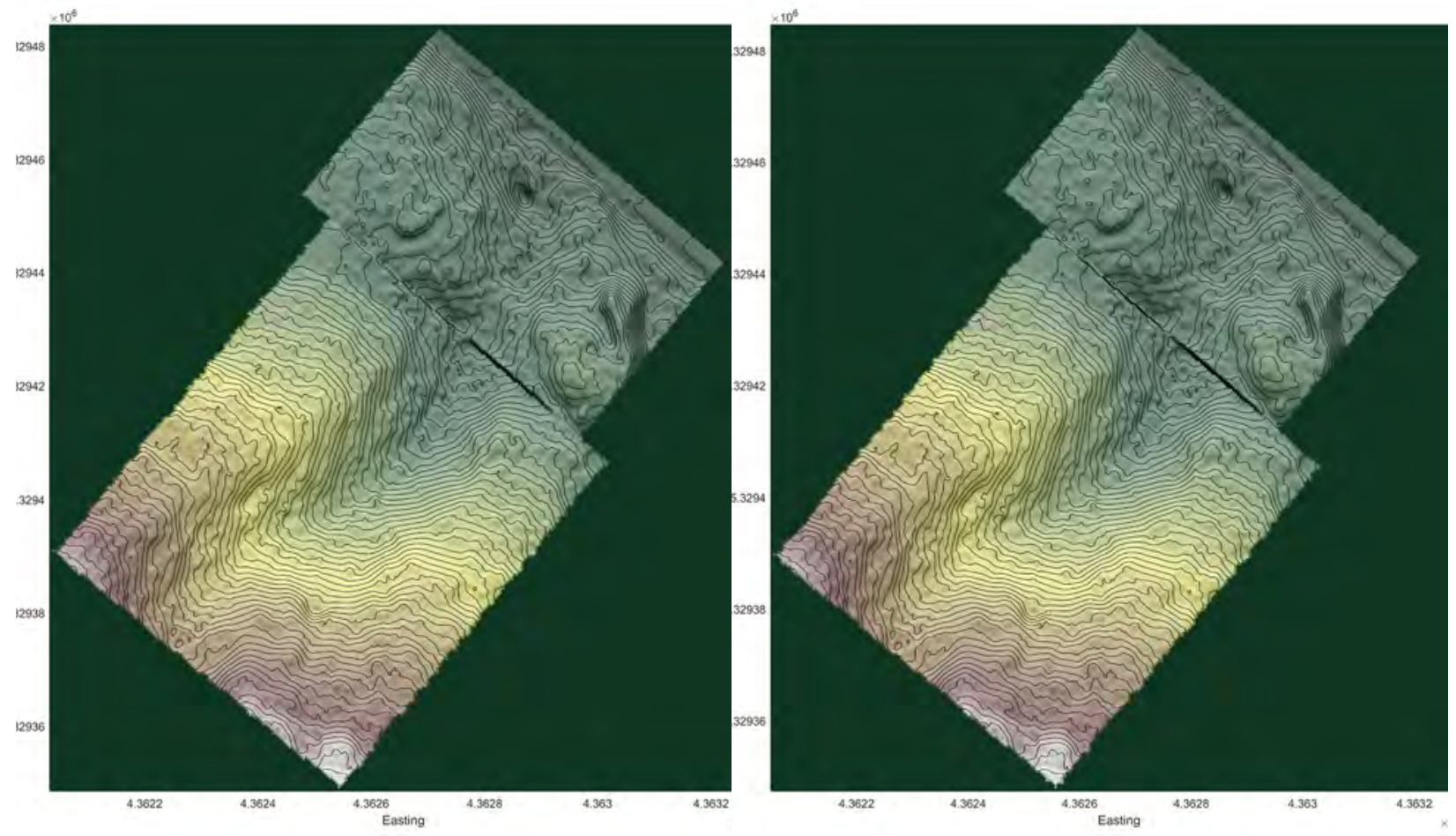


\section{Site K}

Well constrained features: W max, Chan, W mid, E mid

Preferred Offset: $24.5 \mathrm{~m}$

Upper Bound: $25.7 \mathrm{~m}$

Lower Bound: $23.3 \mathrm{~m}$

Strike-Slip Displacement Distribution: Gaussian

Notes: The reported offset is derived from the Gaussian distribution of offset $\mathrm{W}$ max elevation (interfluve). I assume that the lower measurements derived from the markers within the channel (Chan, E mid, W mid) are affected by geomorphic modification of the channel.

Field Measurement: $14.7 \mathrm{~m}$

Quality: III 

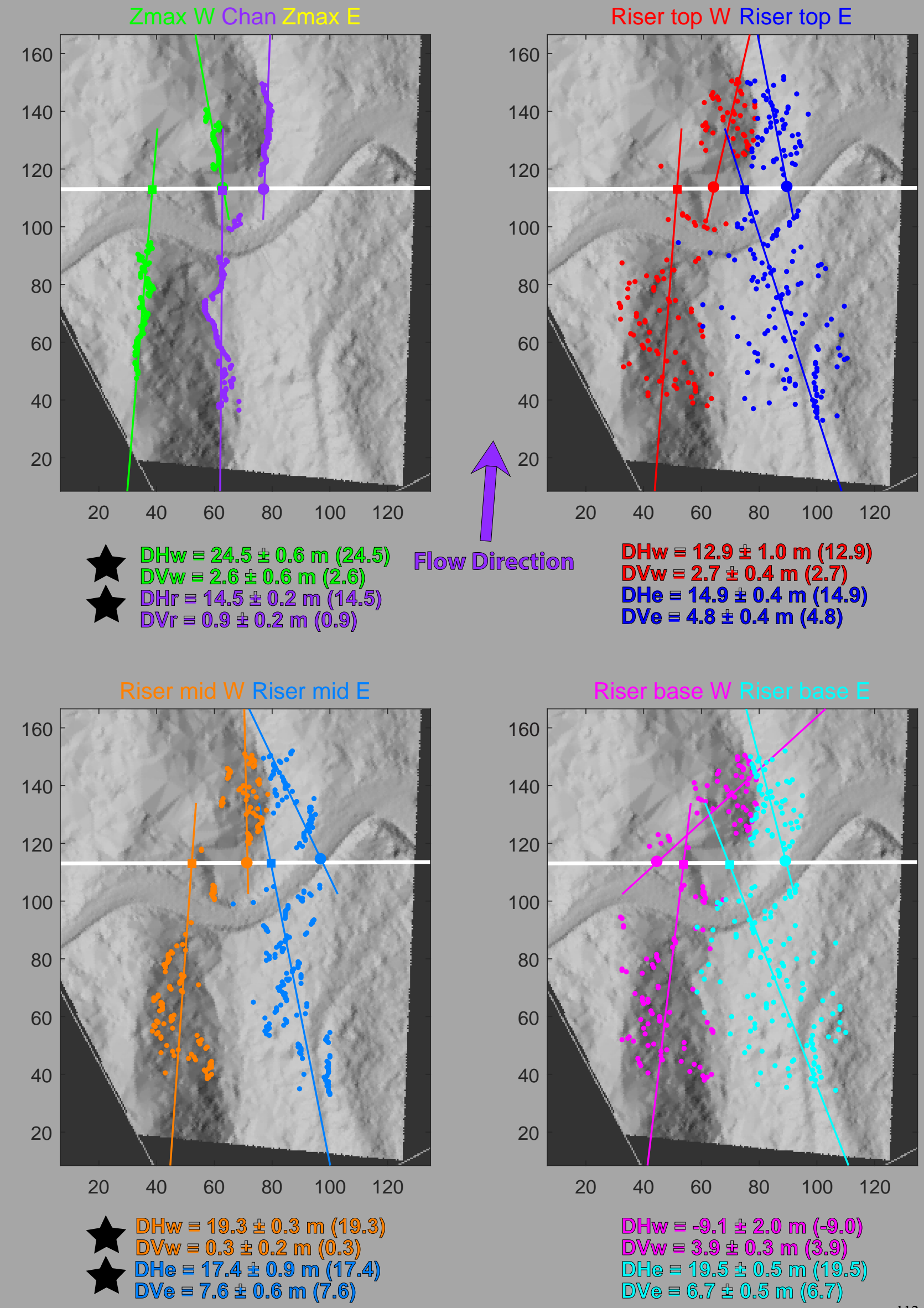
Site K: Offset probability densities
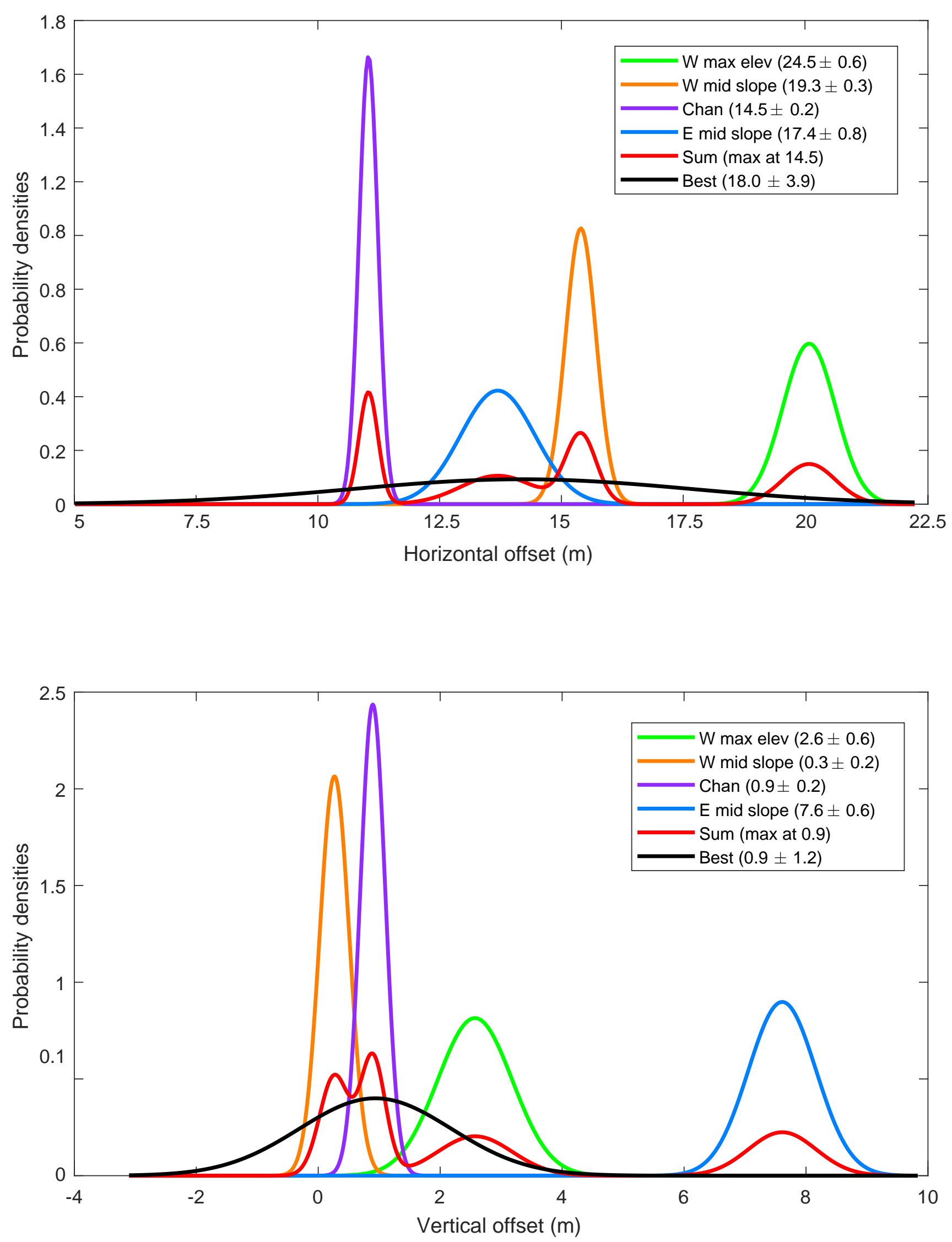


\section{Site K}

Original

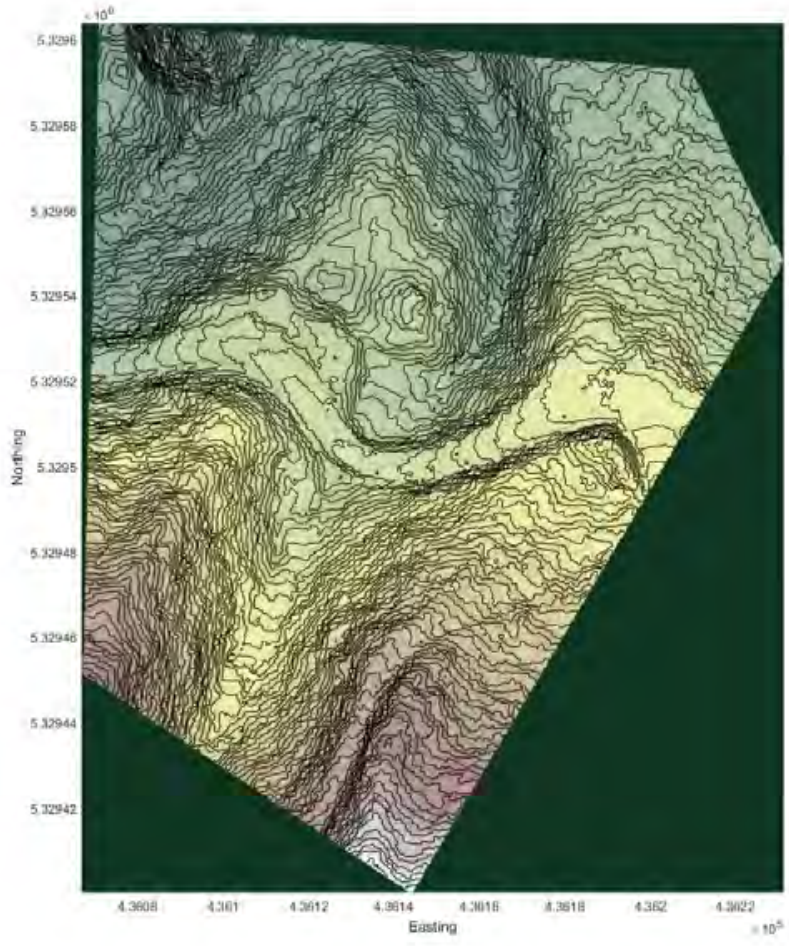

Preferred: $24.5 \mathrm{~m}$

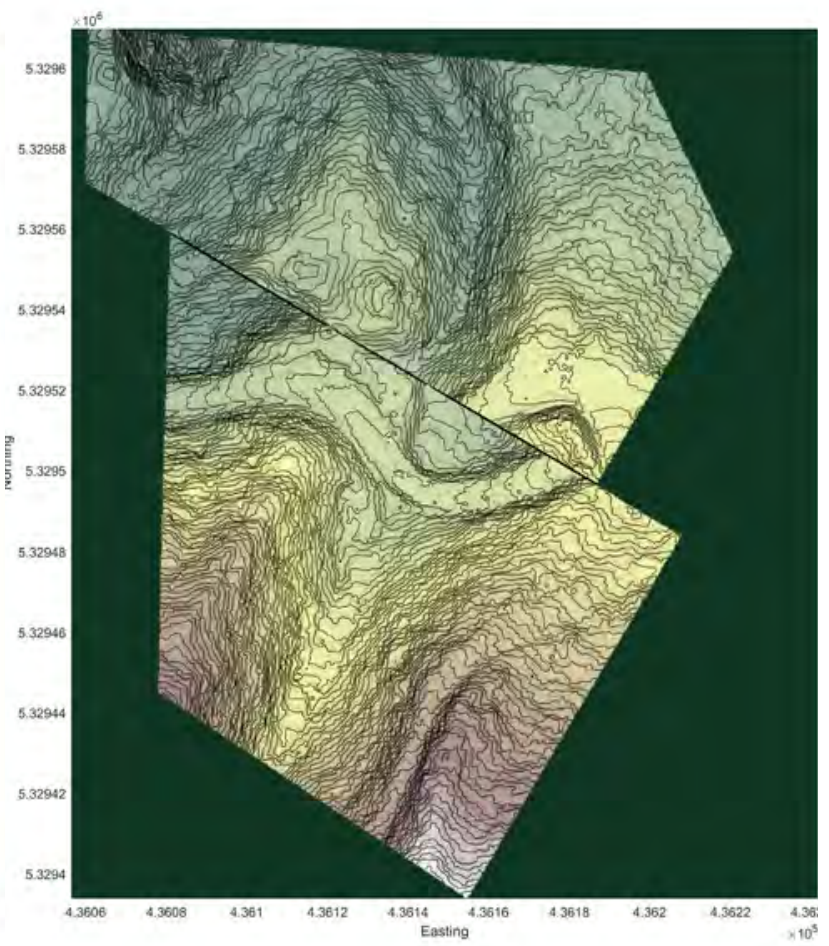

Lower Bound: 23.3m

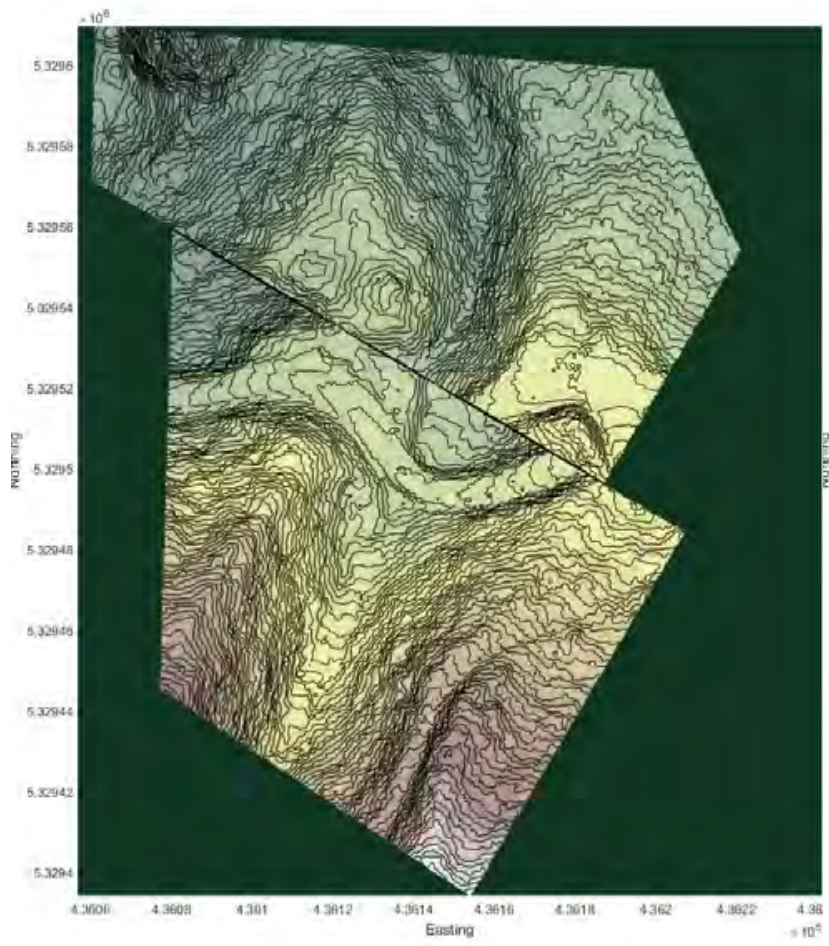

Upper Bound: 25.7m

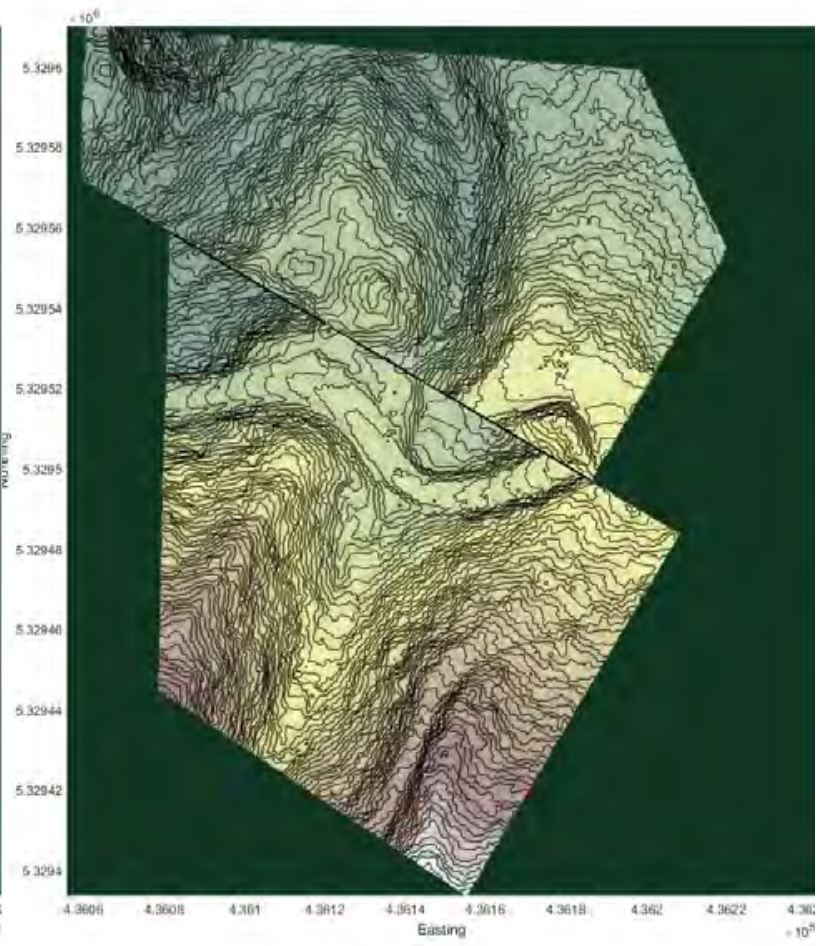




\section{Measurements of Strike-Slip Displacement on the Lake Creek Boundary Creek Fault}

Strike-slip displacement measurements presented by Nelson et al. (2017) were reevaluated for comparison of strike-slip displacement between the Sadie Creek fault and Lake Creek- Boundary Creek fault. However, most offset features analyzed by Nelson et al. (2017) are constructional features (i.e. not channels) and as such, could not be measured using the methods described above. At sites where the offset features are constructional, measurements of strike-slip displacement were calculated by backslipping the feature along the fault trace. In all cases where backslipping is used to calculate strikeslip displacement, I assign a triangular distribution such that the preferred measurement is represented by the peak of the triangle and the upper and lower bounds are represented by the left and right edges, respectfully.

This study additionally measured the strike-slip displacement of two offset channels ('LCBC-CD1', 'LCBC-CD2') and one offset ridge ('MC') on the LCBCF that were not reported by Nelson et al. (2017).

Note that this study has maintained the naming scheme of Nelson et al. (except for new measurements). Additionally, we have remeasured all features presented by Nelson et al., except OL01 which we interpret as logging road that crosses the LCBCF. Sites are listed from East to West. 


\section{OL02}

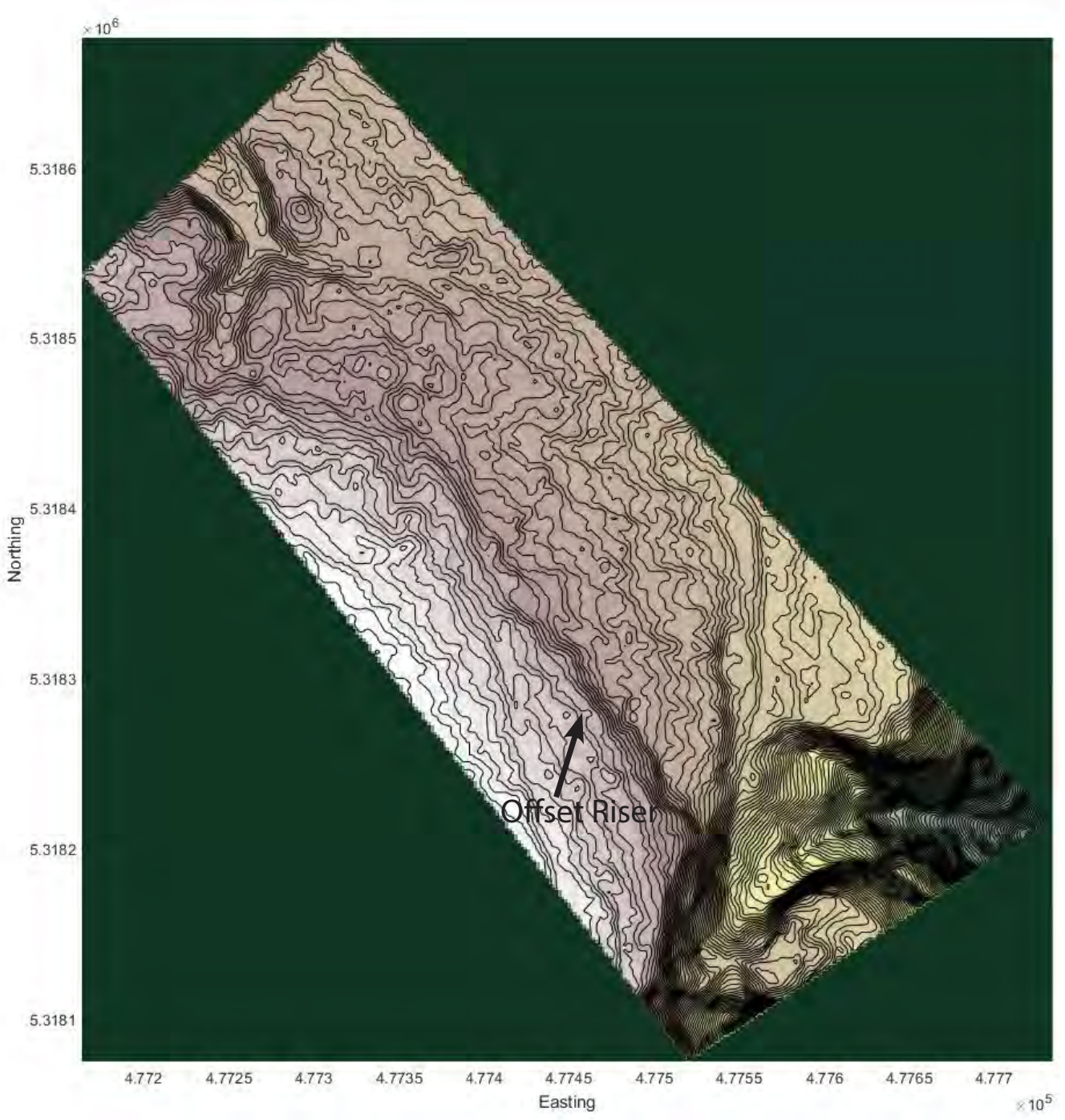

Nelson et al. (2017): $\quad$ This Study:

$\begin{array}{ll}\text { Min: } 15.0 \mathrm{~m} & \text { Min: } 15.0 \mathrm{~m} \\ \text { Pref: } 27.6 \mathrm{~m} & \text { Pref:27.6m } \\ \text { Max: } 37.2 \mathrm{~m} & \text { Max:37.2 }\end{array}$

Quality: III 


\section{Site OL02}

Orginal

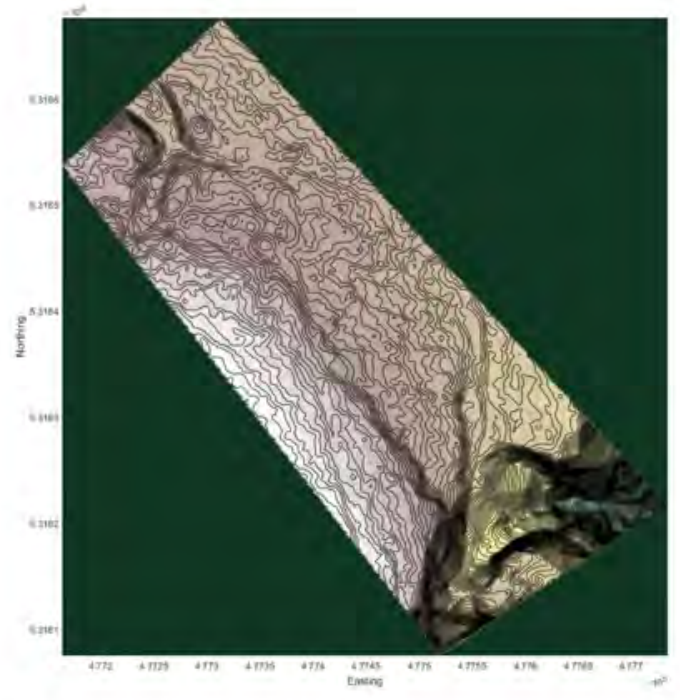

Lower Bound: $15.0 \mathrm{~m}$

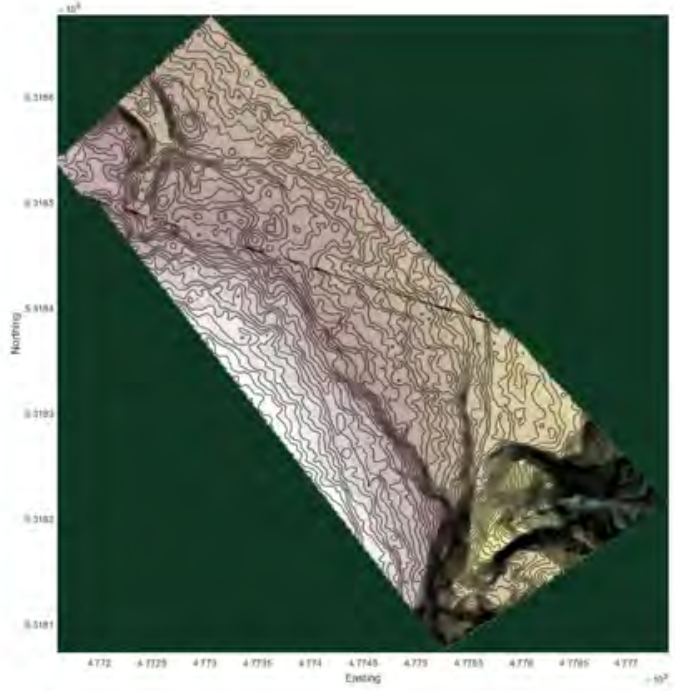

Preferred: $27.6 \mathrm{~m}$

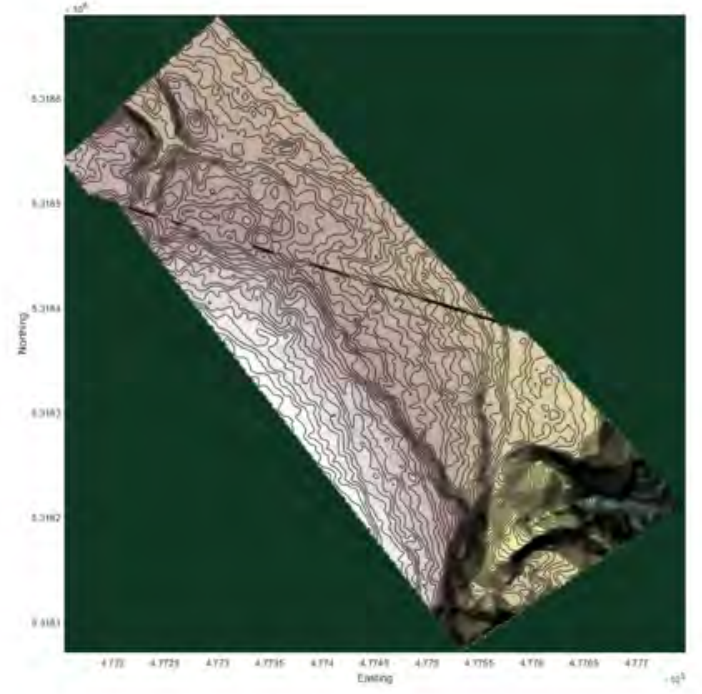

Upper Bound: 37.2m

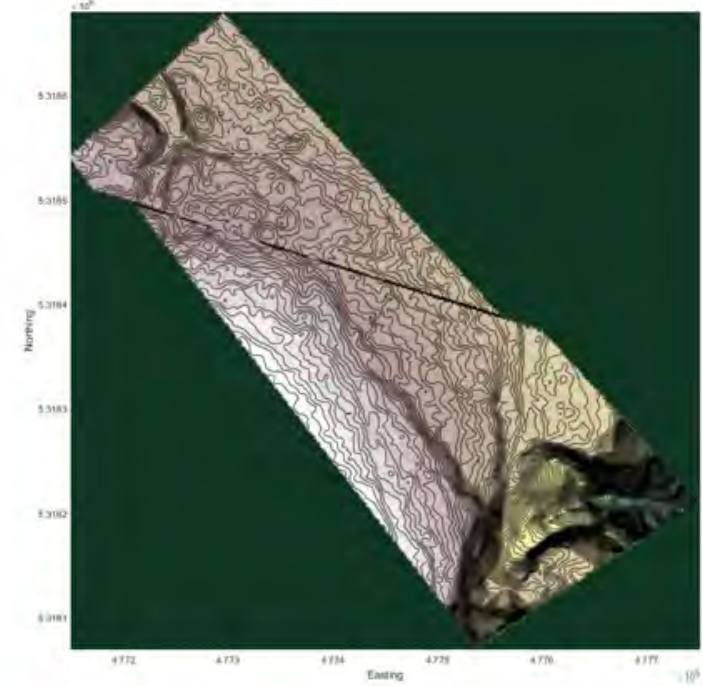




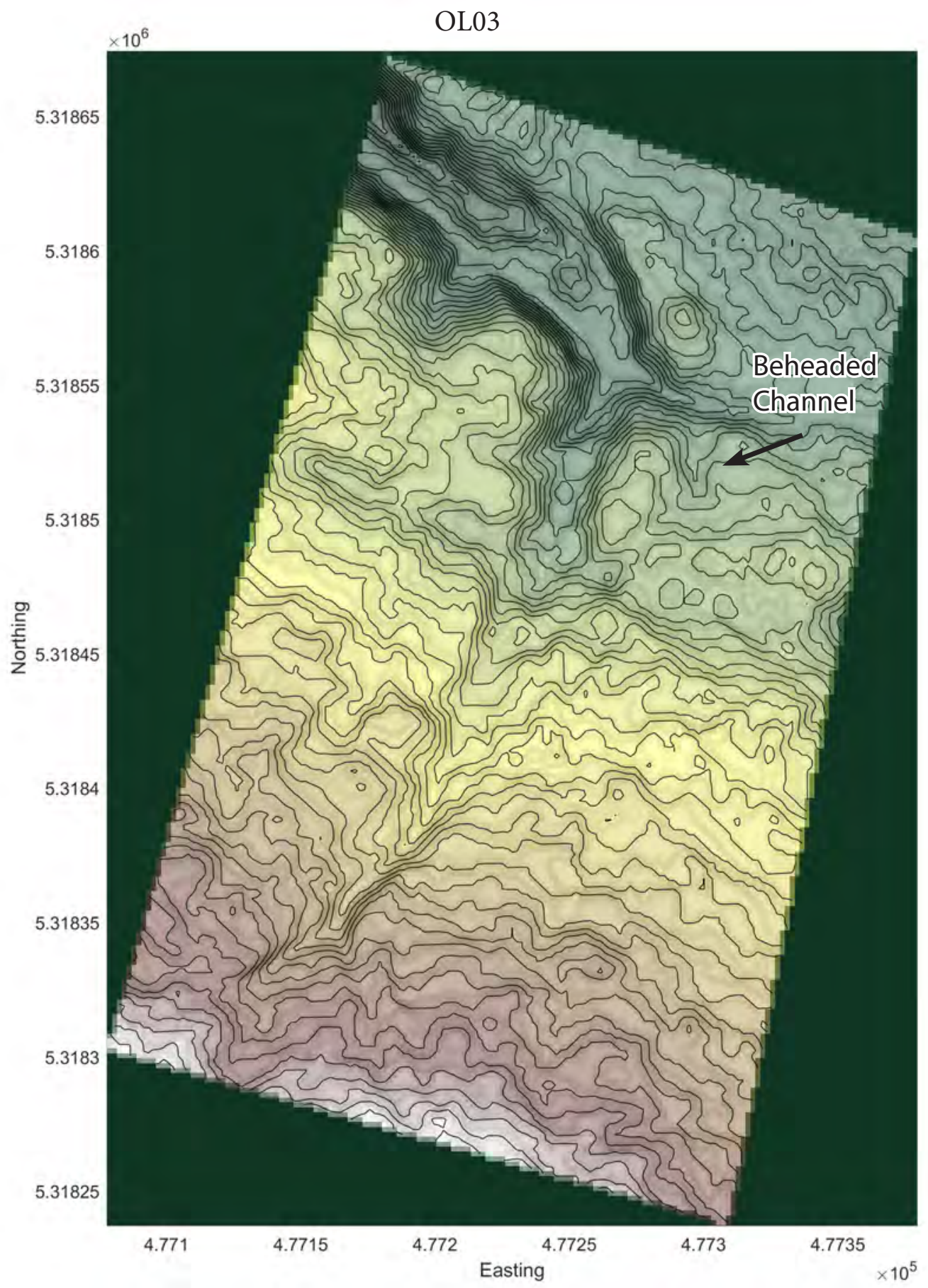

Nelson et al. (2017): This Study:

Min: $18.0 \mathrm{~m}$

Min: $18.0 \mathrm{~m}$

Pref: $26.0 \mathrm{~m}$

Pref: $26.0 \mathrm{~m}$

Max: $37.8 \mathrm{~m} \quad$ Max: $37.8 \mathrm{~m}$

Notes: I agree with the bounds presented by Nelson et al., if the feature truly is a beheaded channel. I also measured the active channel and calculated an offset of $3.7 \pm 2.4$ (see next two pages). Quality:IV 


\section{Site OL03}

Orginal

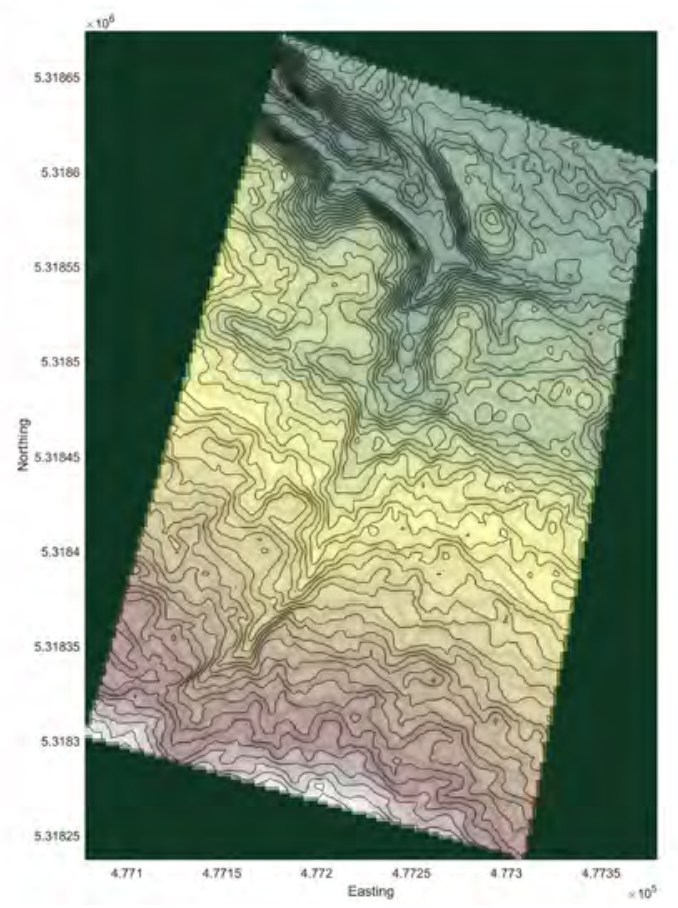

Lower Bound: 18.0m

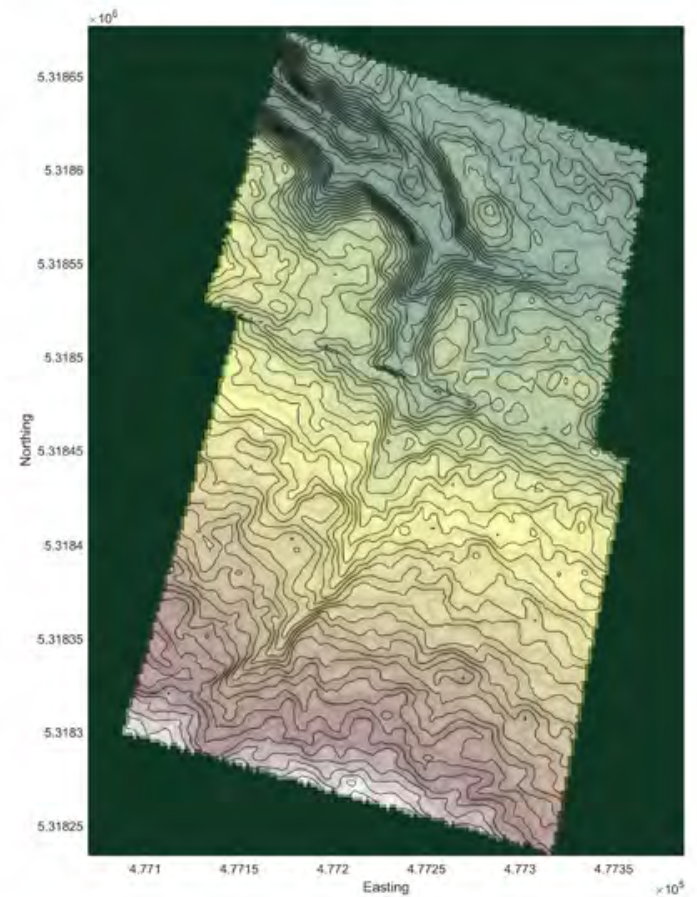

Preferred: $26.0 \mathrm{~m}$

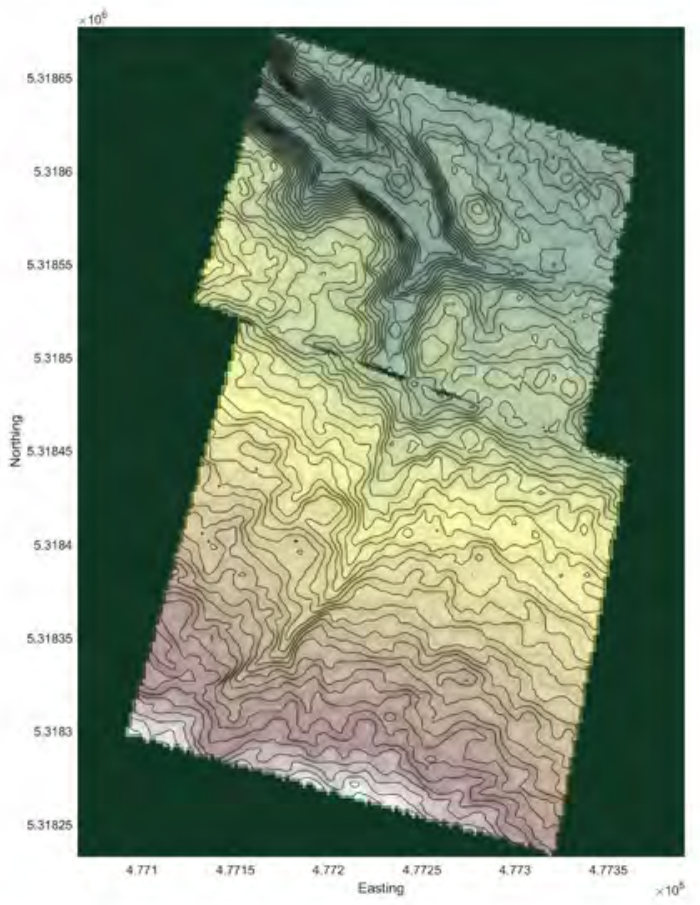

Upper Bound: 37.8m

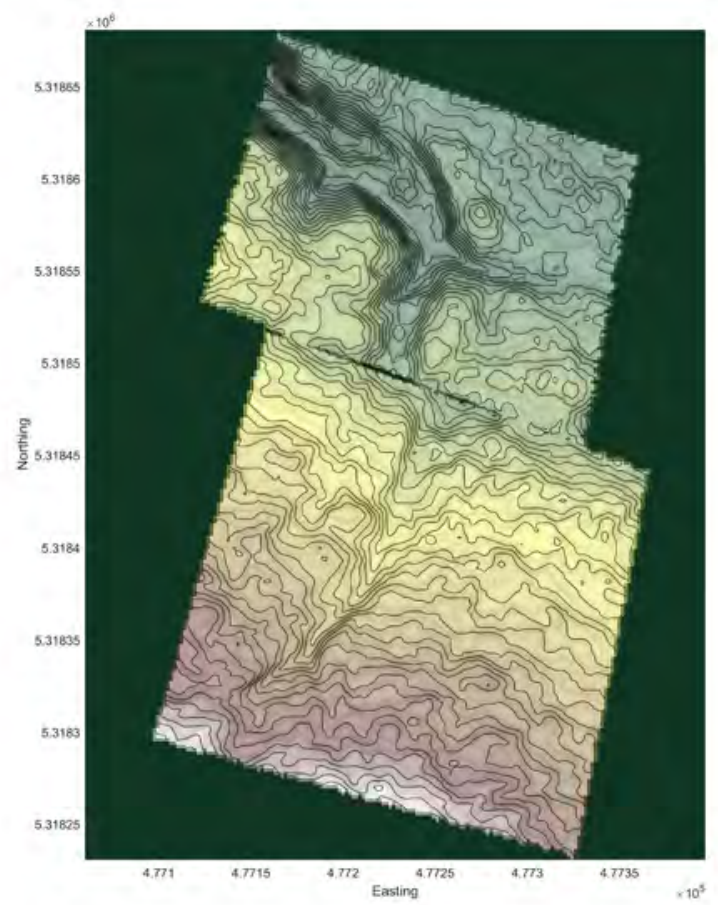




\section{Site ol3 Offsets and uncertainties (10000 runs)}
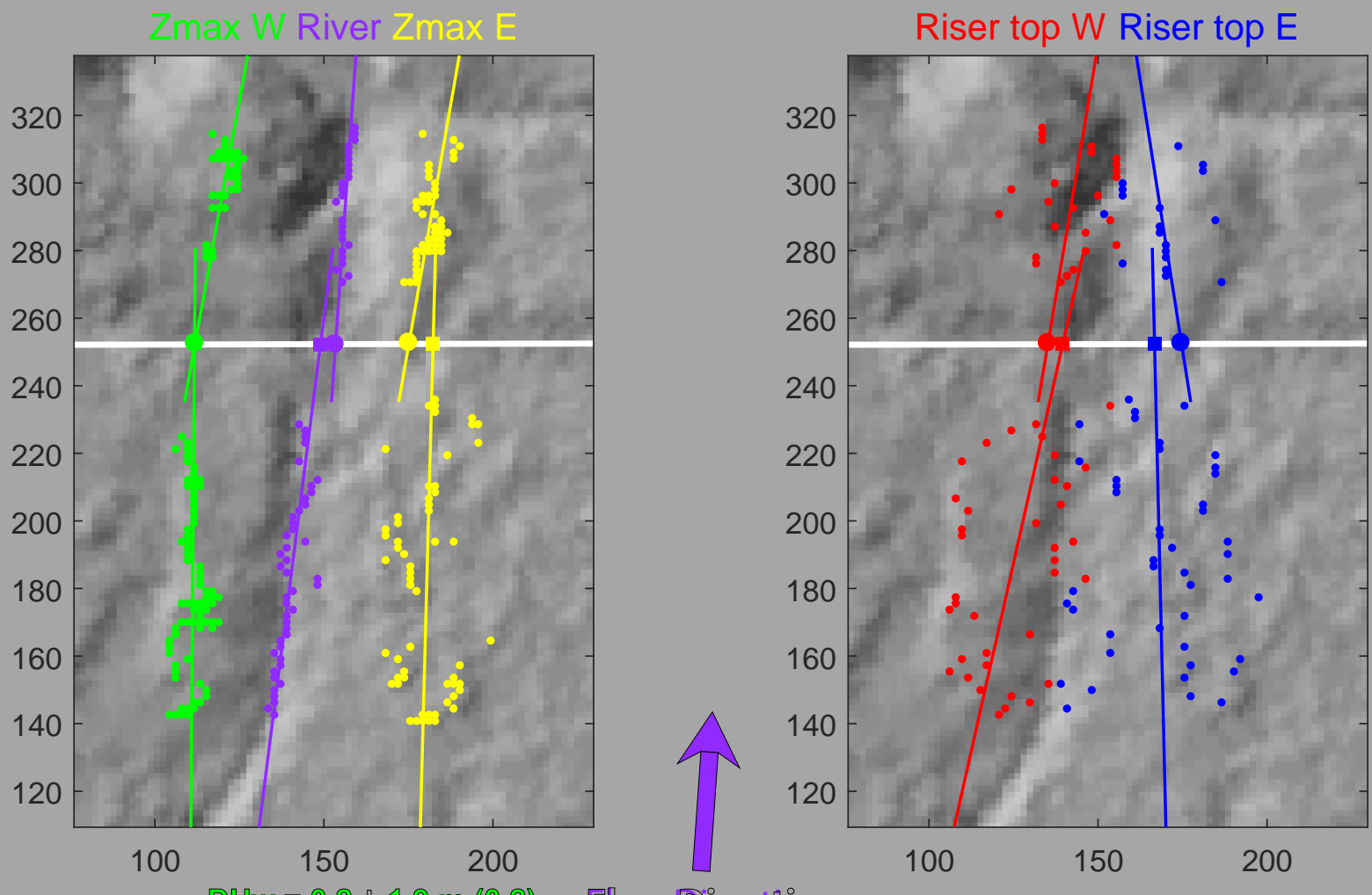

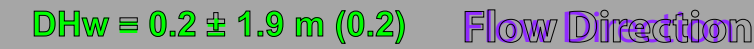

DVW $=0.8$. 0.9 m $(-0.8)$

D) ᄂ

DVe $=1.3$ 年 $0.6 \mathrm{~m}(1.04)$

DHr $=4.5 \pm 1.4 m(4.5)$

$\checkmark$ DVP $=0.7$ 留 $0.8 \mathrm{~m}(-0.6)$

DHW $=-4.5 \pm 3.0 \mathrm{~m}(-4.4)$

$\mathrm{DVW} \equiv 0.8 \pm 0.9 \mathrm{~m}(0.8)$

$\mathrm{DHe}=8.1 \pm 6.0 \mathrm{~m}(8.0)$

$\mathrm{DVe}=1.5 \pm 1.1 \mathrm{~m}(1.6)$

Riser mid E

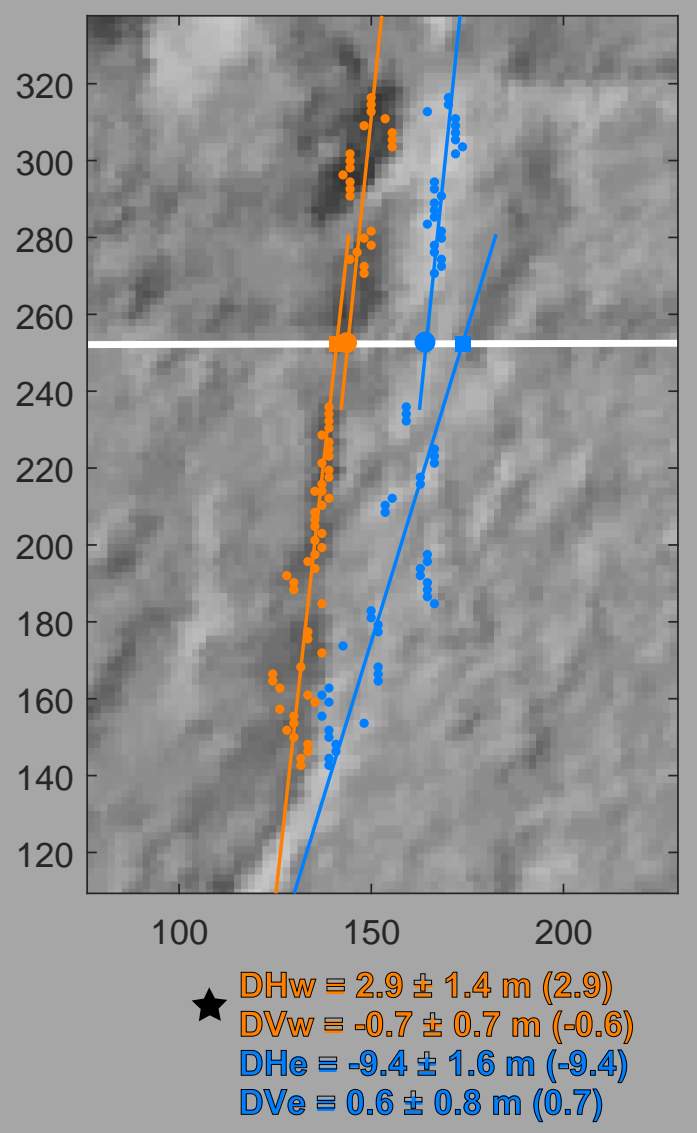

Riser base W

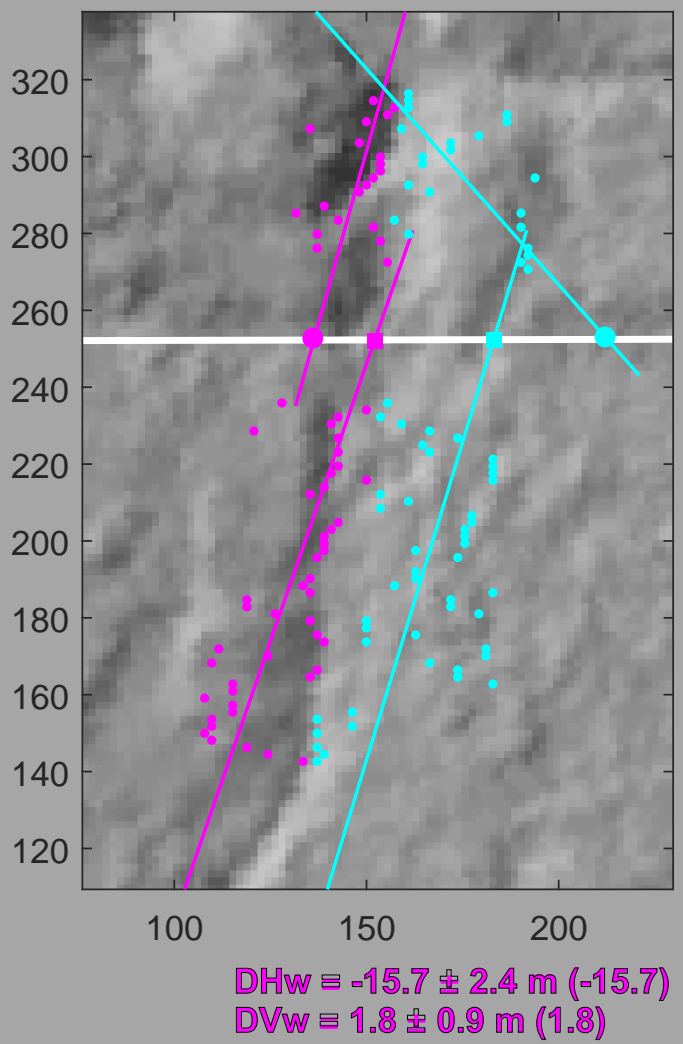

DU

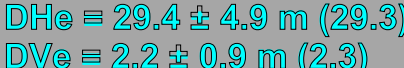




\section{Site ol3 : Offset probability densities}
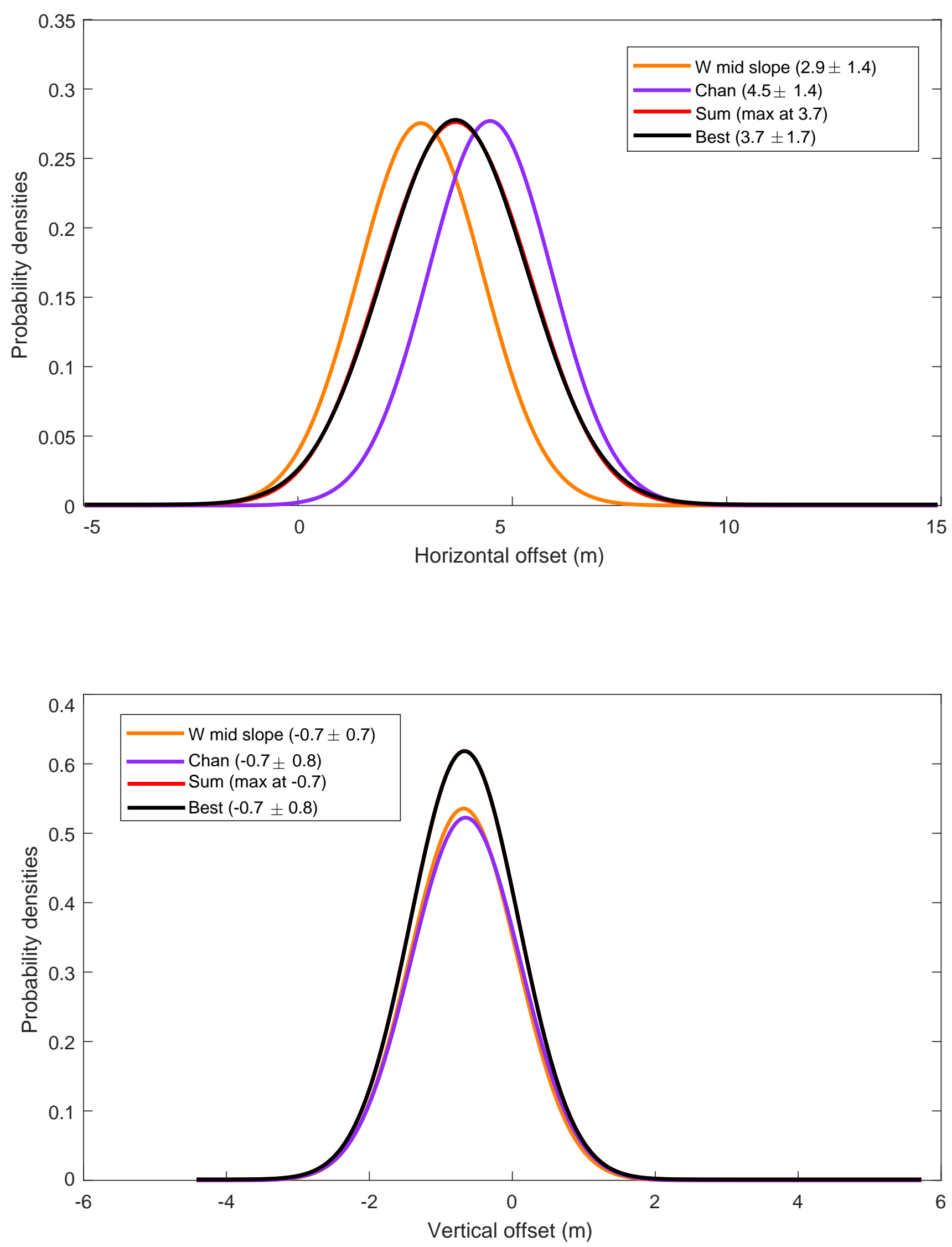


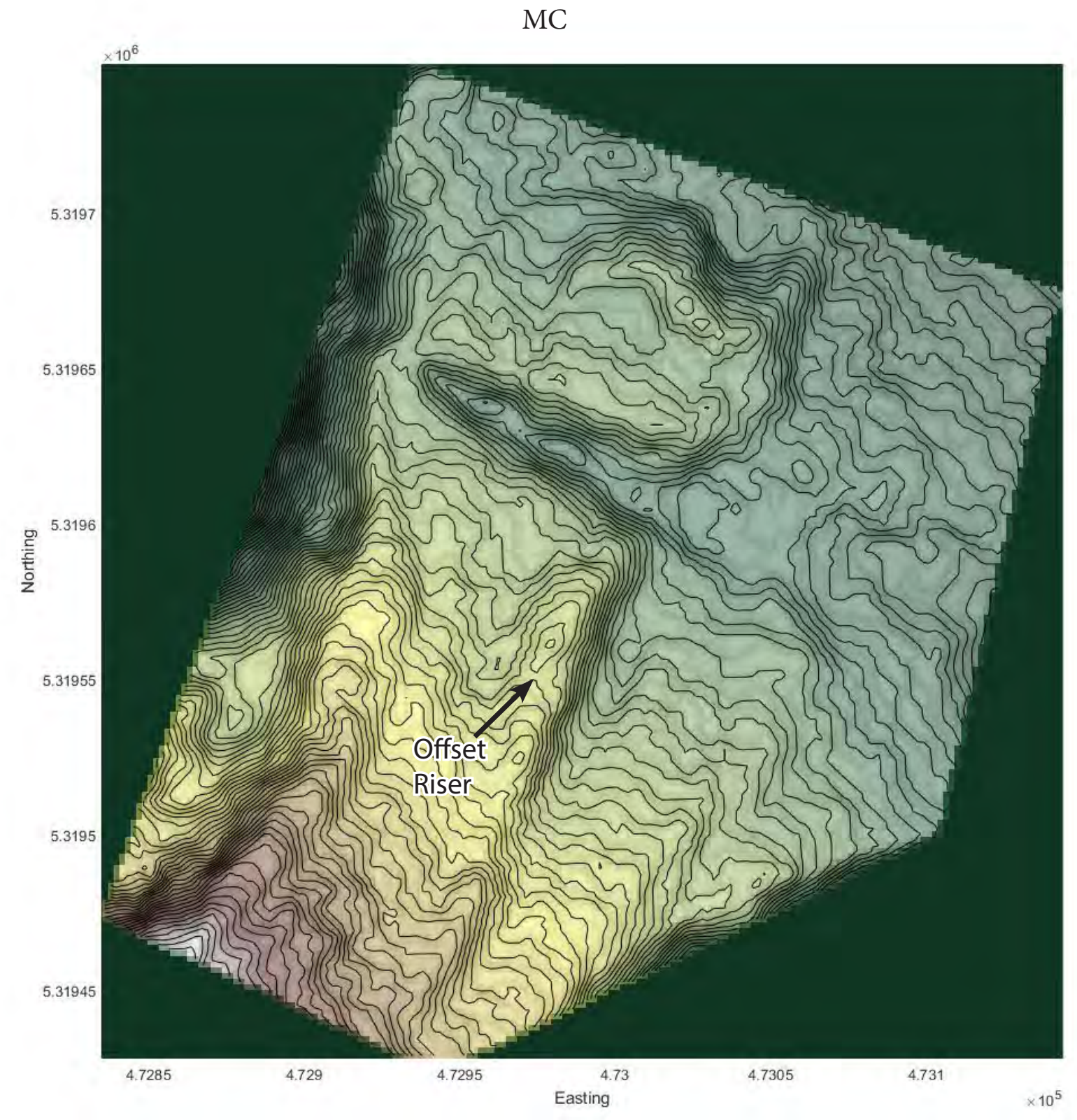

Nelson et al. (2017):

This Study:

Min: $4.0 \mathrm{~m}$

Pref: $7.0 \mathrm{~m}$

Min: N/A

Max: $10.0 \mathrm{~m}$

Pref: $7.0 \mathrm{~m}$

Max: N/A

Notes: Nelson et al. (2017) originally noted $7 \mathrm{~m}$ of right lateral offset in their supplemental data but did not provide any errors.

Quality: I 
Site MC

Orginal

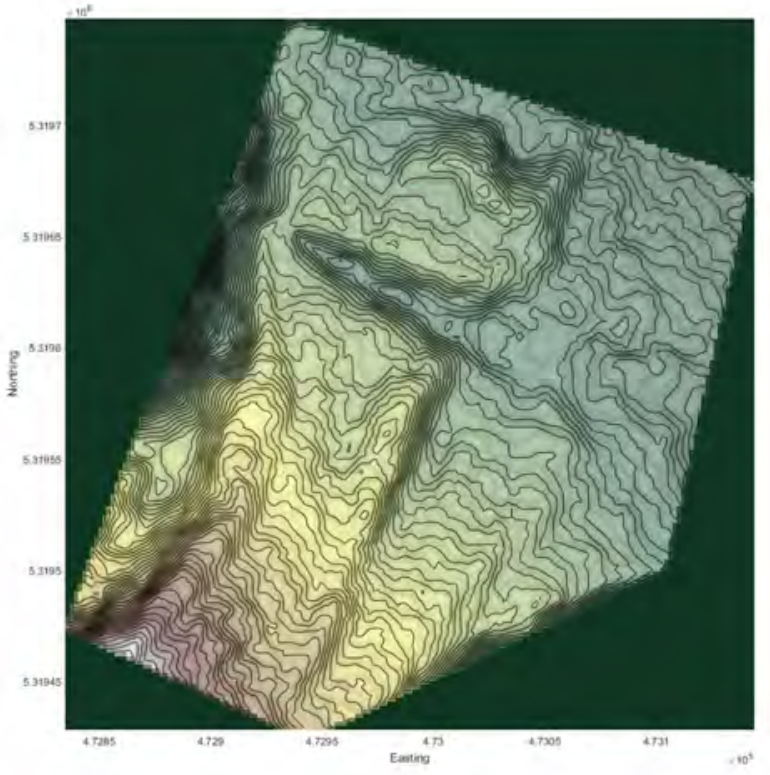

Preferred: $7.0 \mathrm{~m}$

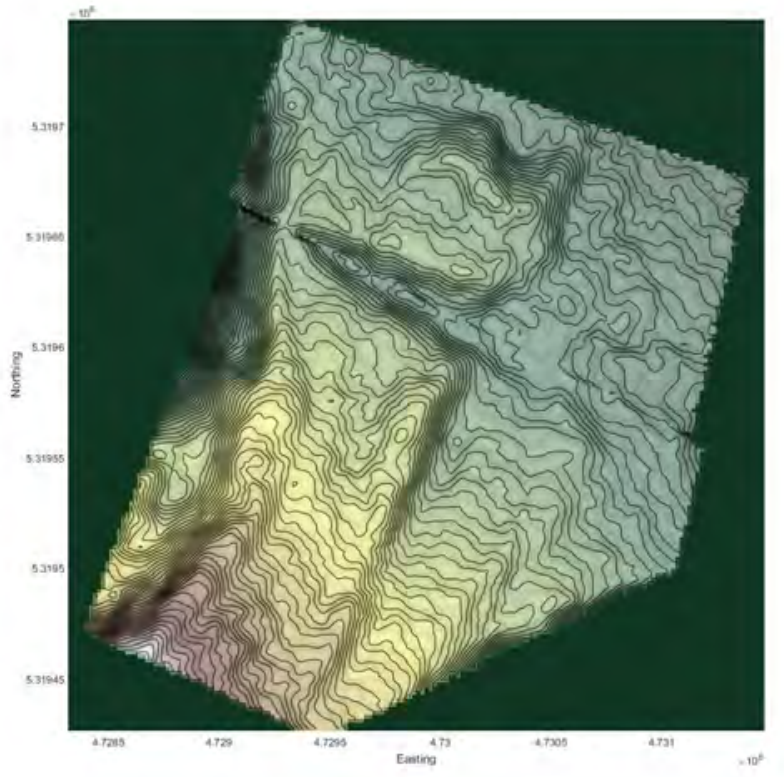

Lower Bound: $3.0 \mathrm{~m}$

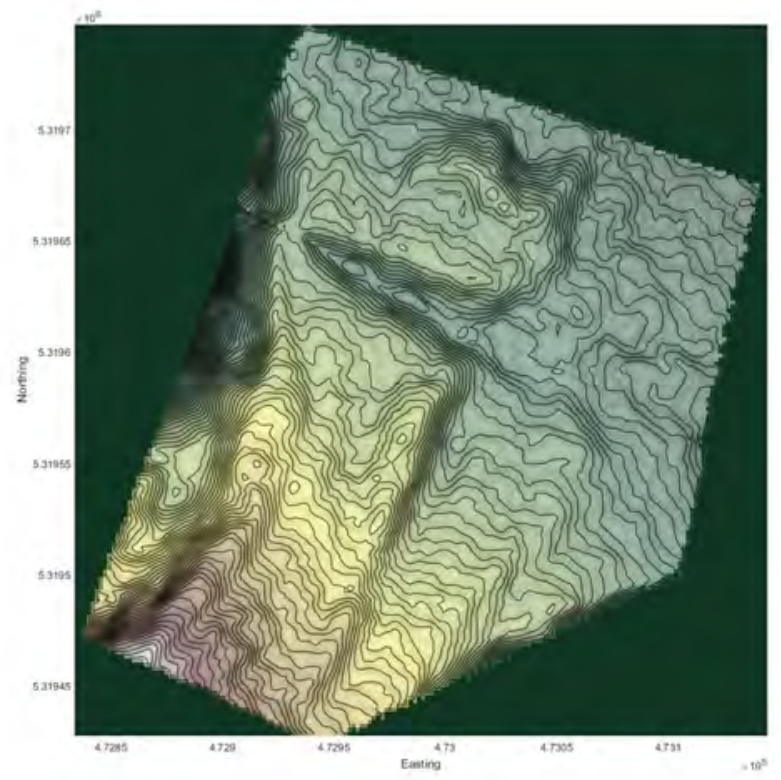

Upper Bound: 10.0m

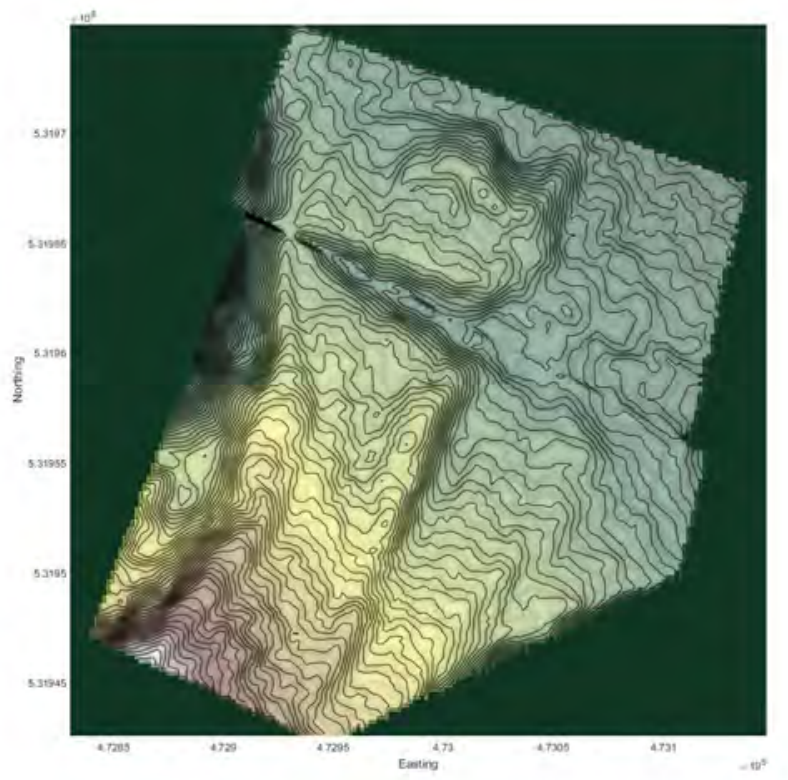




\section{Site LCBC-CD1}

Well constrained features: W max, W mid, Chan

Preferred Offset: $29.7 \mathrm{~m}$

Upper Bound: $32.6 \mathrm{~m}$

Lower Bound: $23.9 \mathrm{~m}$

Strike-Slip Displacement Distribution: Triangular

Notes: The reported offset is derived from the Gaussian distribution of offset W midpoint. I assume that the lower are affected by geomorphic modification of the channel. Additionally, backslipping has trimmed the upper error bound at this site.

Field Measurement: Site not visited

Quality: III 


\section{Site Icbc_cd1 Offsets and uncertainties (10000 runs)}
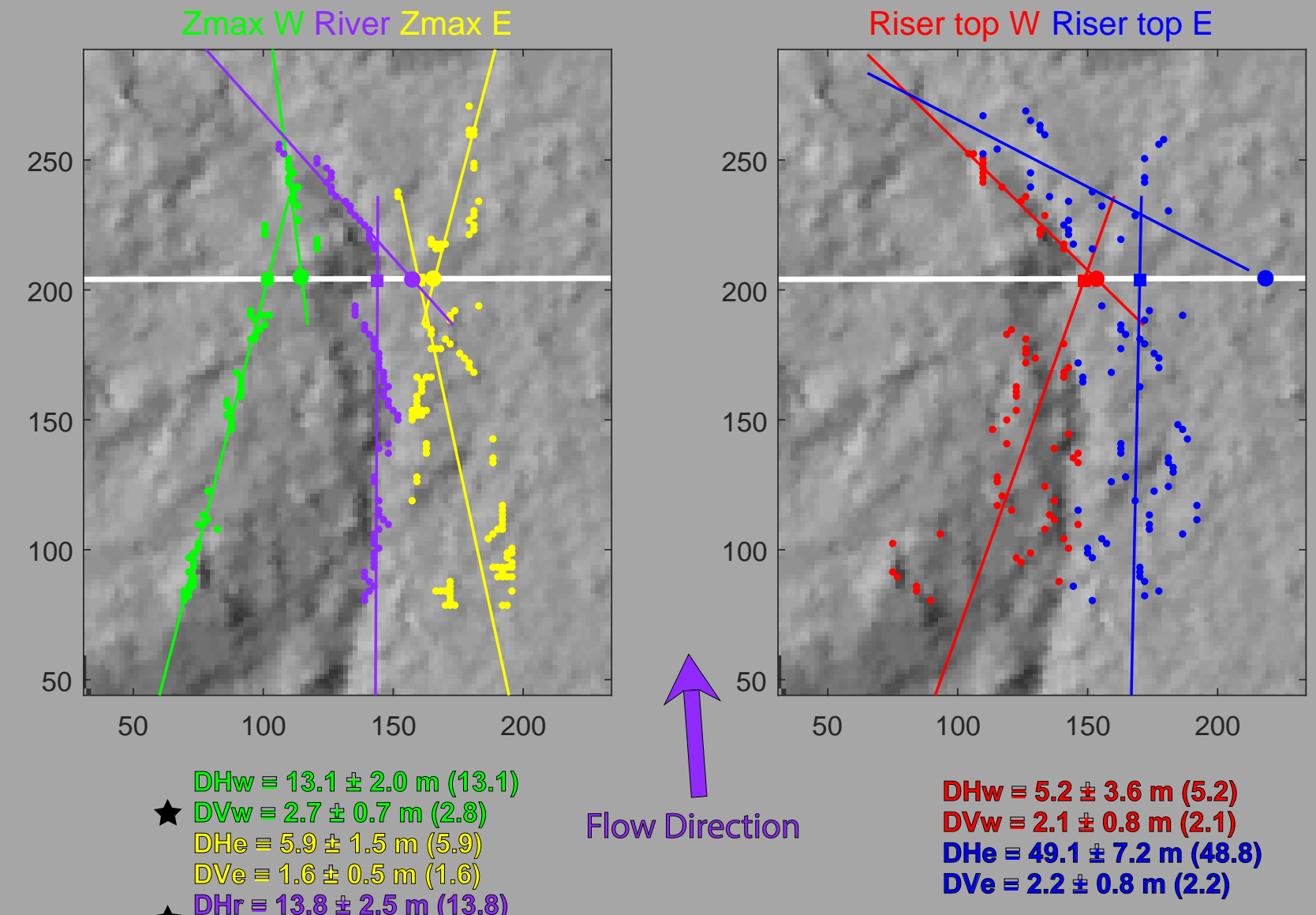

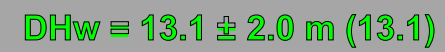

* DVw $=2.7$ 留 0.7 m (2.8)

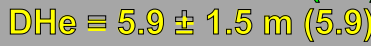

DVe $=1.6$ 皆 0.5 m (1.06)

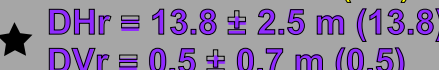

Flow Direction

$\mathrm{DHe}=49.1 \pm 7.2 \mathrm{~m}$ (48.8)

$\mathrm{DVe}=2.2 \pm 0.8 \mathrm{~m}(2.2)$

Riser mid E

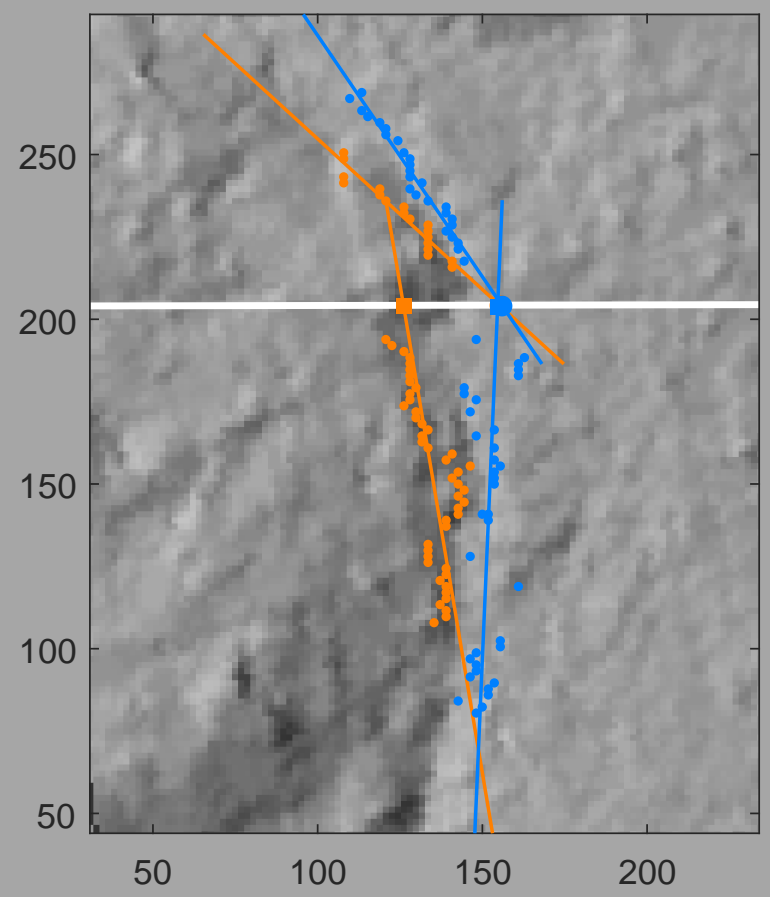

Riser base W

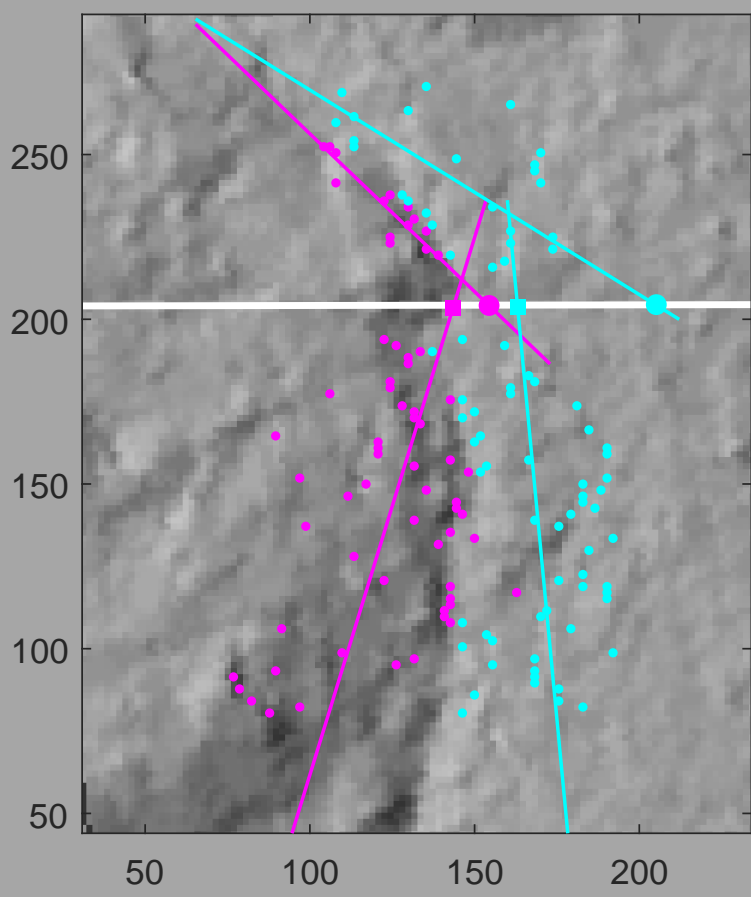

DHW $=11.4$ 해 $3.7 \mathrm{~m}$ (11.3)

$D V w=1.8$ 화 $0.9 \mathrm{~m}(1.8)$

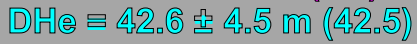

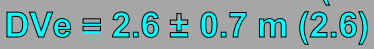


Site Icbc_cd1 : Offset probability densities
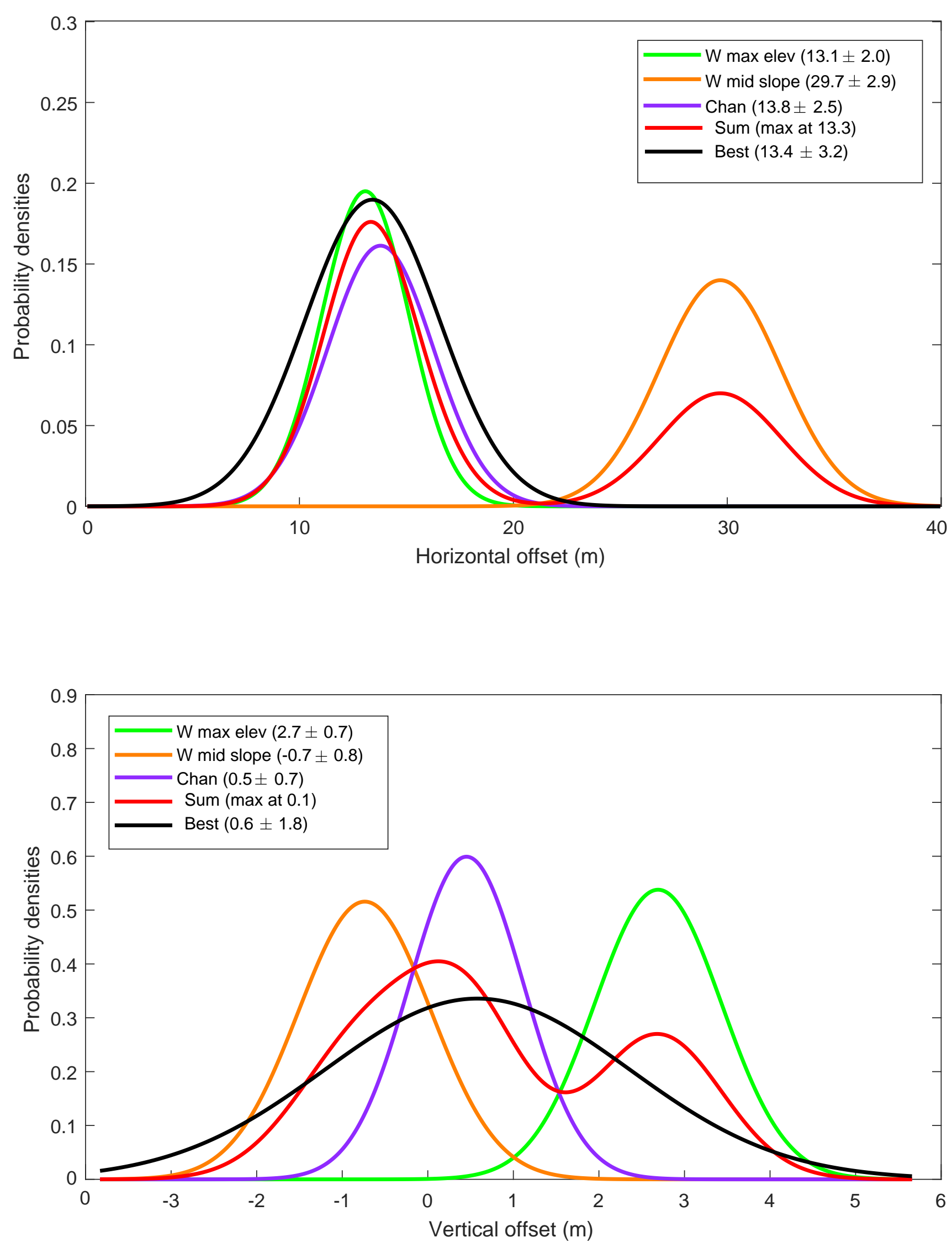


\section{Site LCBC-CD1}

Original

Preferred: $29.7 \mathrm{~m}$

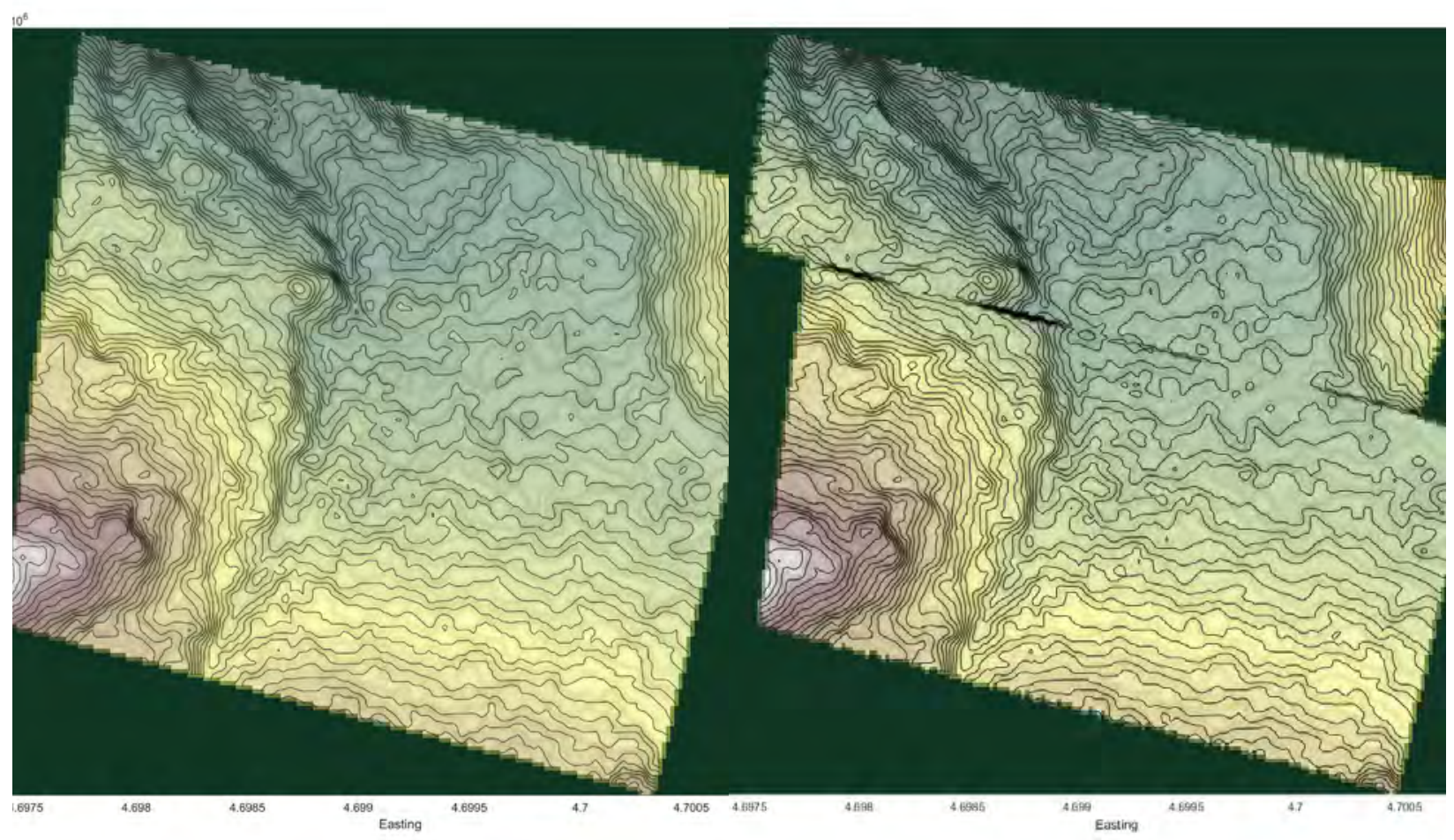

Lower Bound: 23.9m

Upper Bound: 32.6m

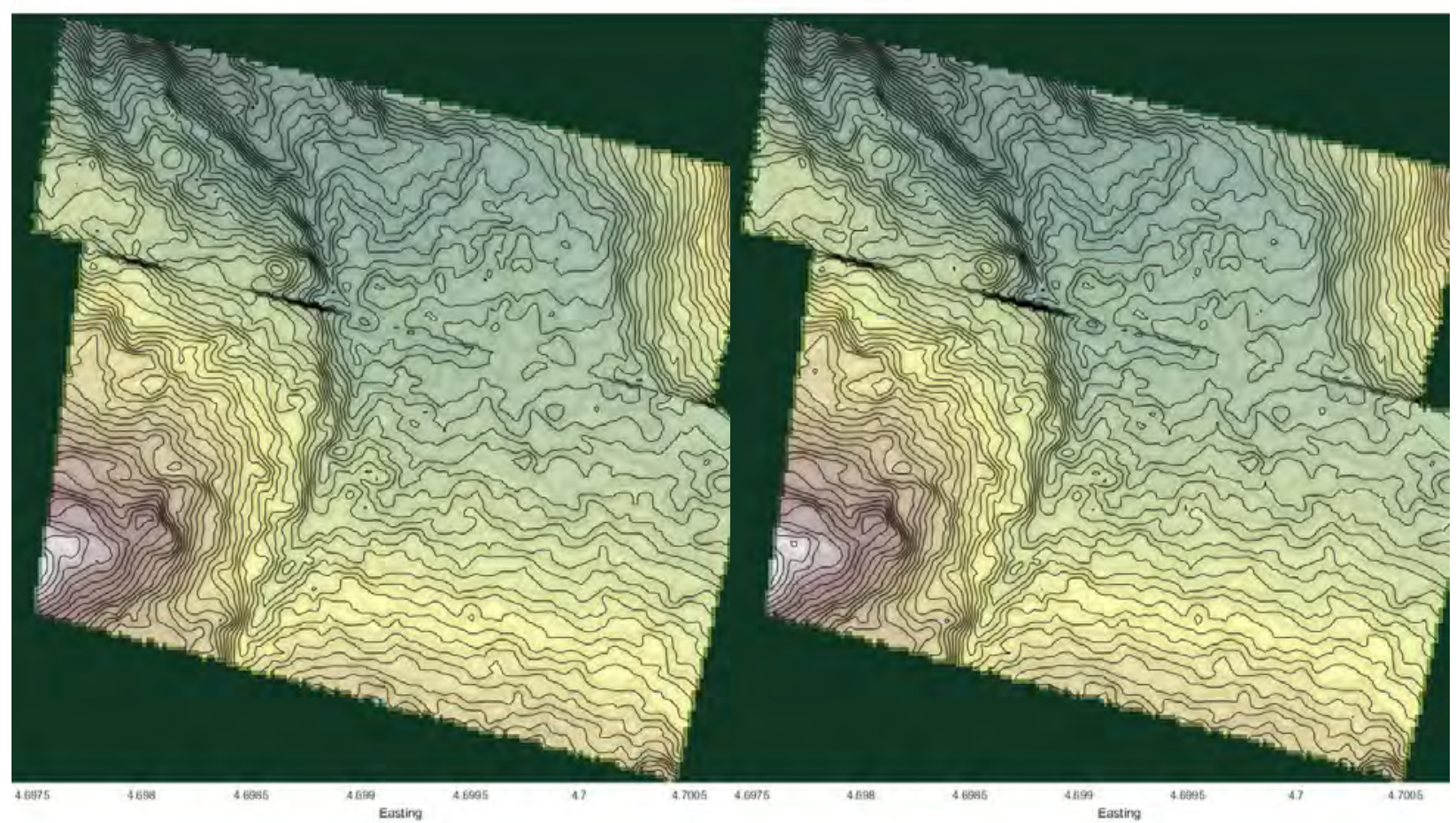




\section{Site LCBC-CD2}

Well constrained features: W mid, Chan, E Mid

Preferred Offset: $17.3 \mathrm{~m}$

Upper Bound: 19.3m

Lower Bound: $15.3 \mathrm{~m}$

Strike-Slip Displacement Distribution: Triangular

Notes: The reported offset is derived from the Gaussian distribution of offset E midpoint. I assume that the lower measurements derived from the markers within the channel (Chan, W mid) are affected by geomorphic modification of the channel as the E midpoint is located on the protected margin of the channel.

Field Measurement: Site not visited

Quality: II 
Site Icbc_cd2 Offsets and uncertainties (10000 runs)
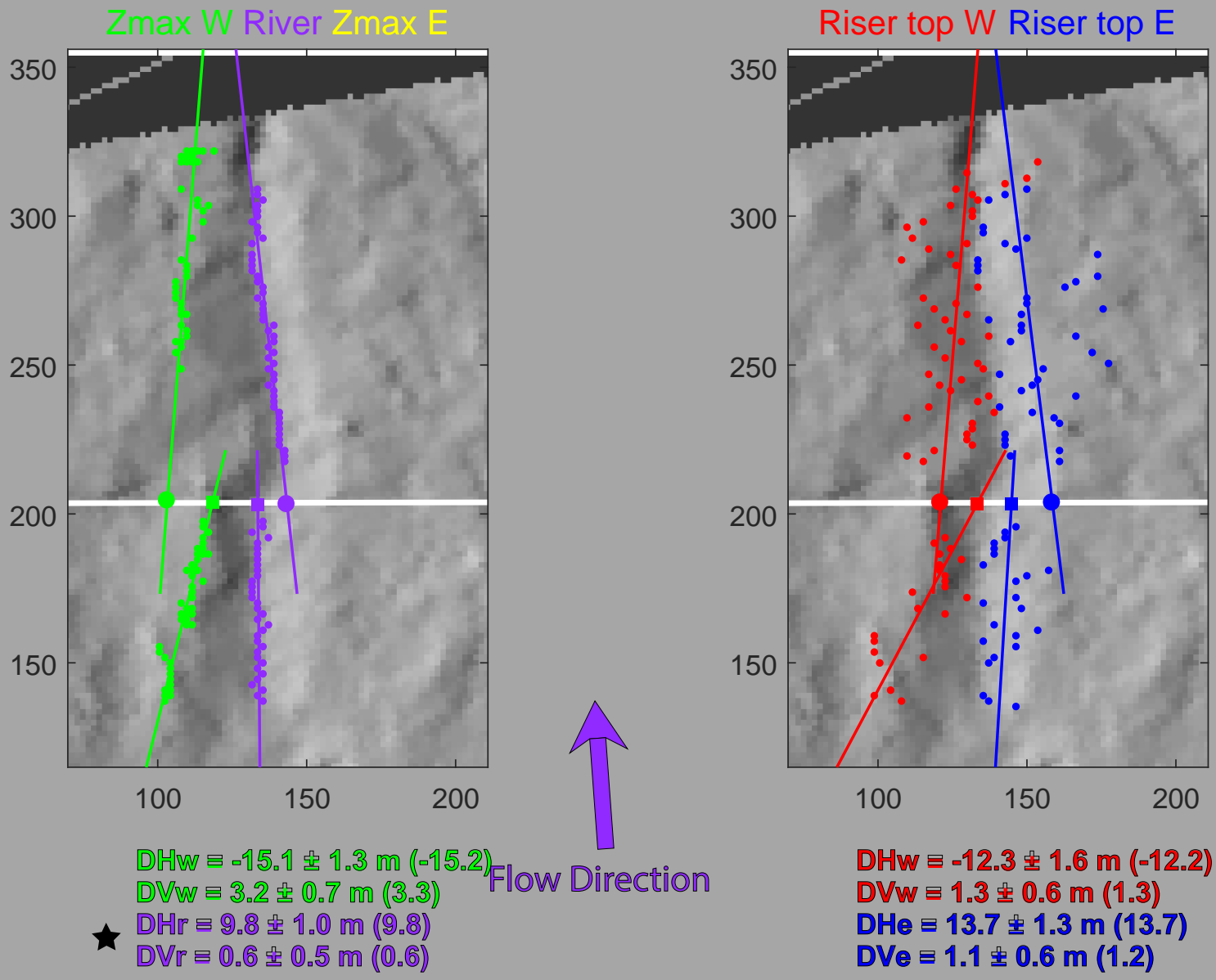

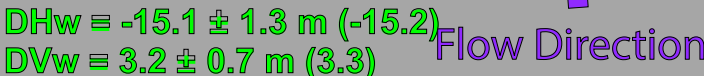
DHp $=9.8 \pm 1.0 \mathrm{~m}(0.8)$

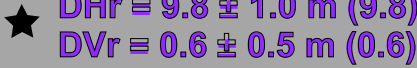

$$
\begin{aligned}
& \mathrm{DHe}=13.7 \pm 1.3 \mathrm{~m}(13.7) \\
& \mathrm{DVe}=1.1 \pm 0.6 \mathrm{~m} \text { (1.2) }
\end{aligned}
$$

Riser mid E

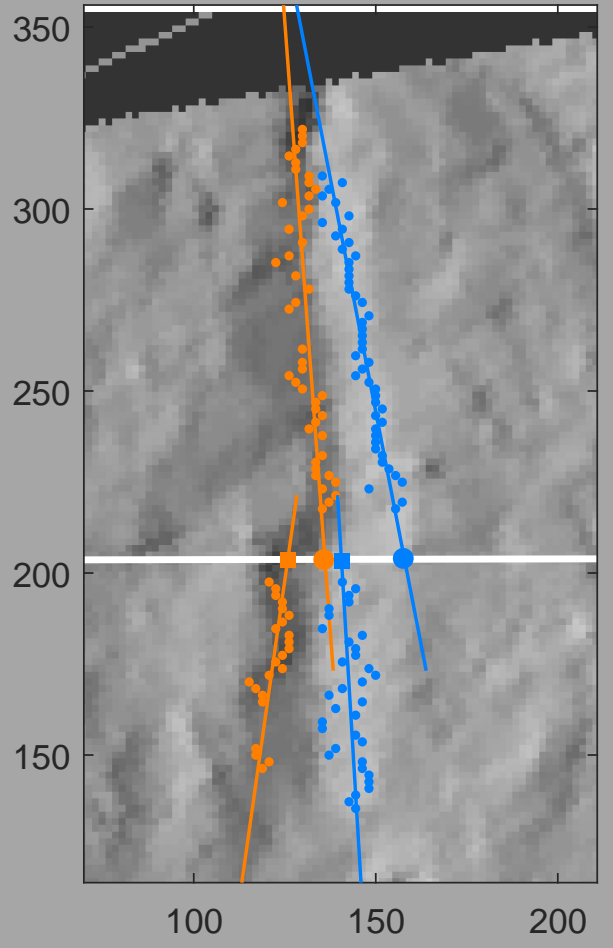

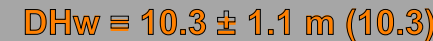
DVW

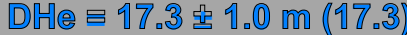
DVe $=2.5$ 홀 $0.5 \mathrm{~m}(2.5)$
Riser base W

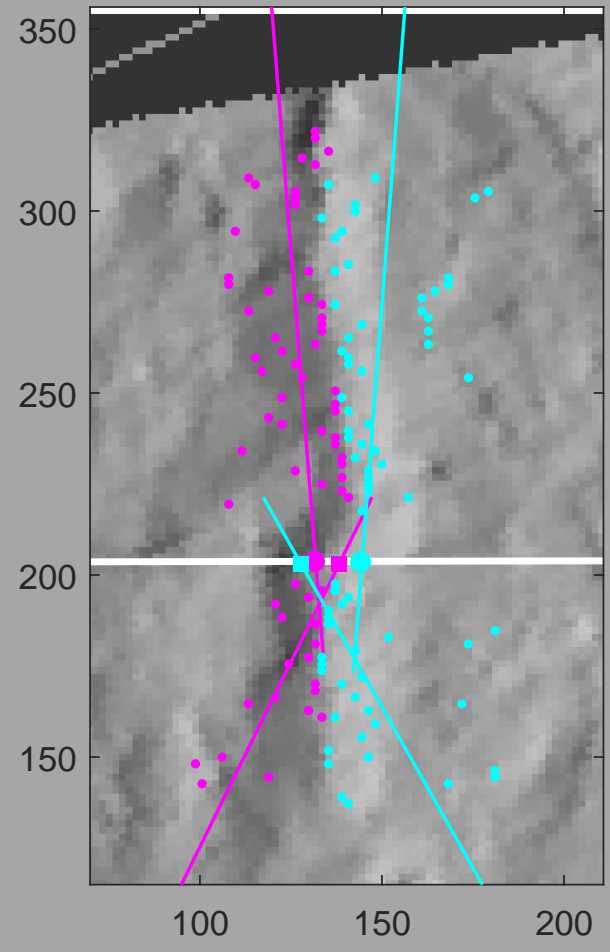

DHW $=-6.44$ t5 $1.8 \mathrm{~m}(-6.4)$ $\mathrm{DVW}=2.3 \pm 0.6 \mathrm{~m}(2.3)$

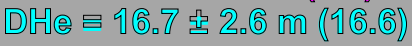

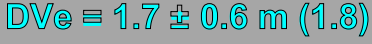




\section{Site Icbc_cd2 : Offset probability densities}
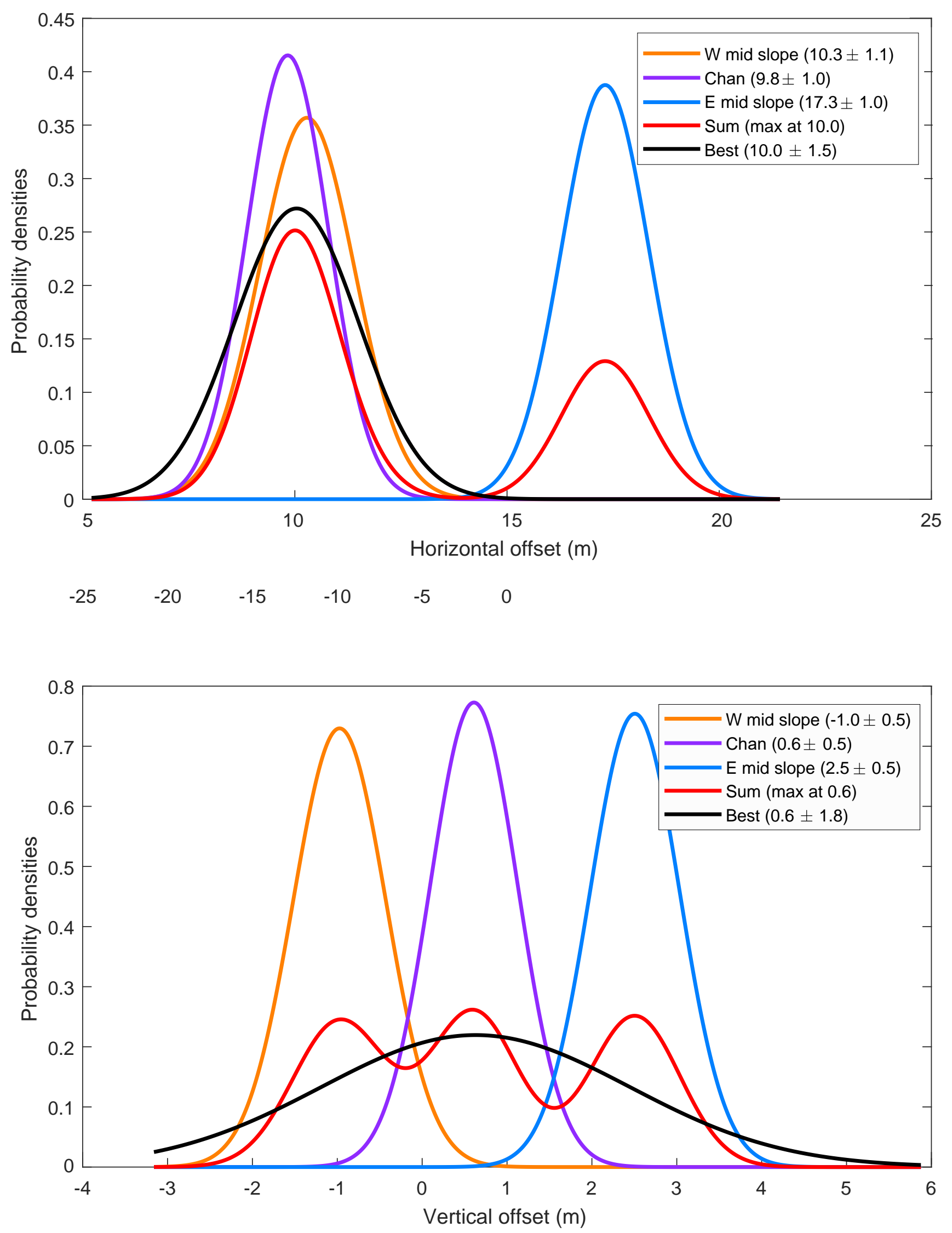


\section{Site LCBC-CD2}

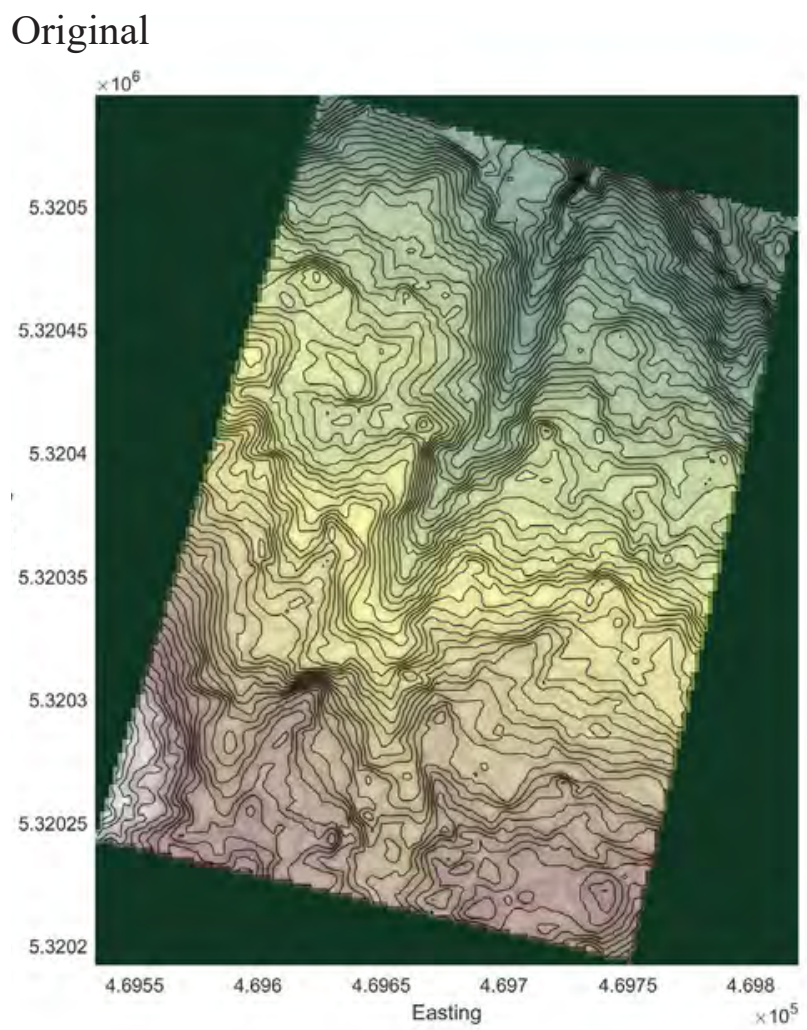

Preferred: $17.3 \mathrm{~m}$

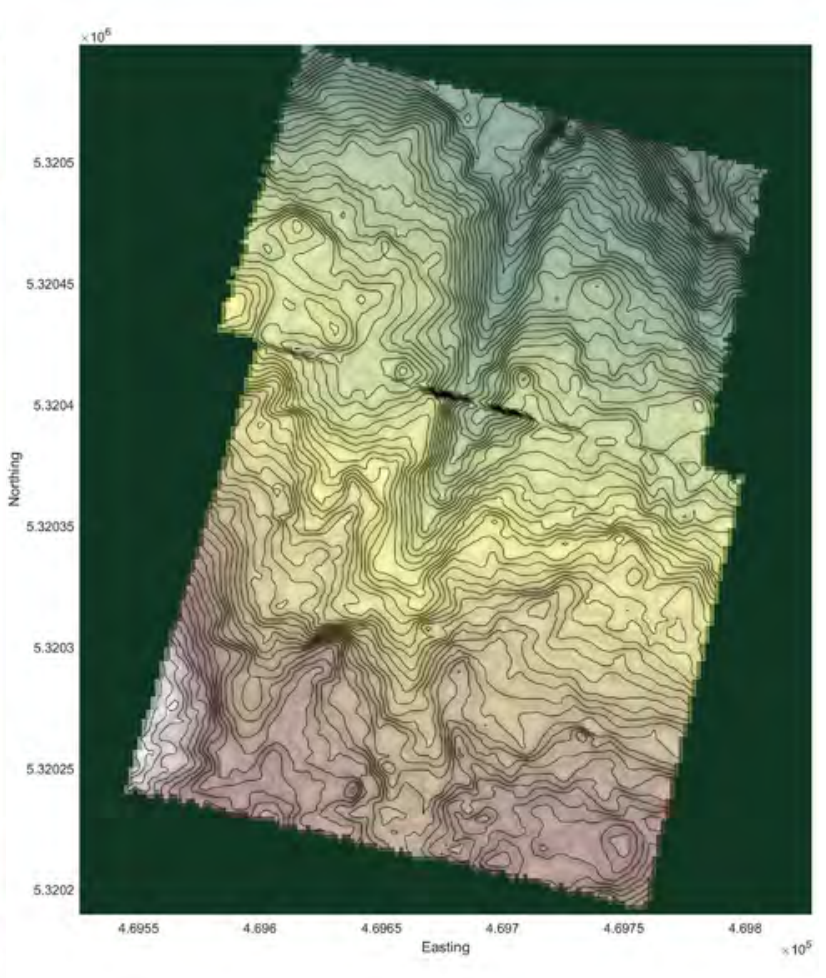

Lower Bound: 15.3m

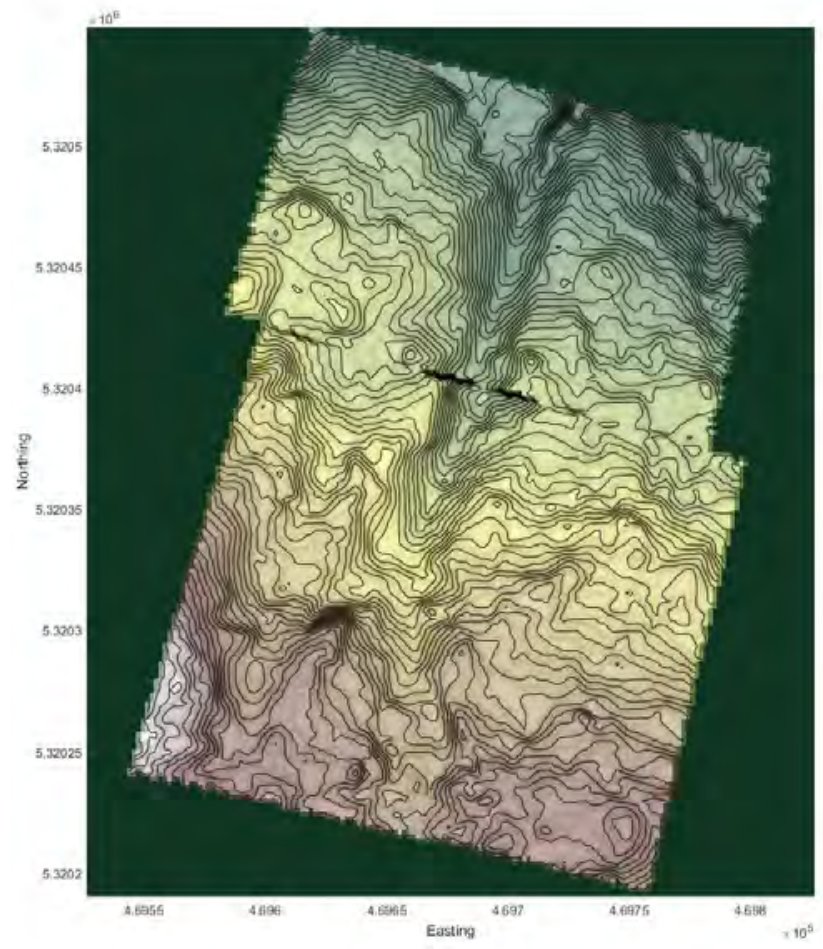

Upper Bound: 19.3m

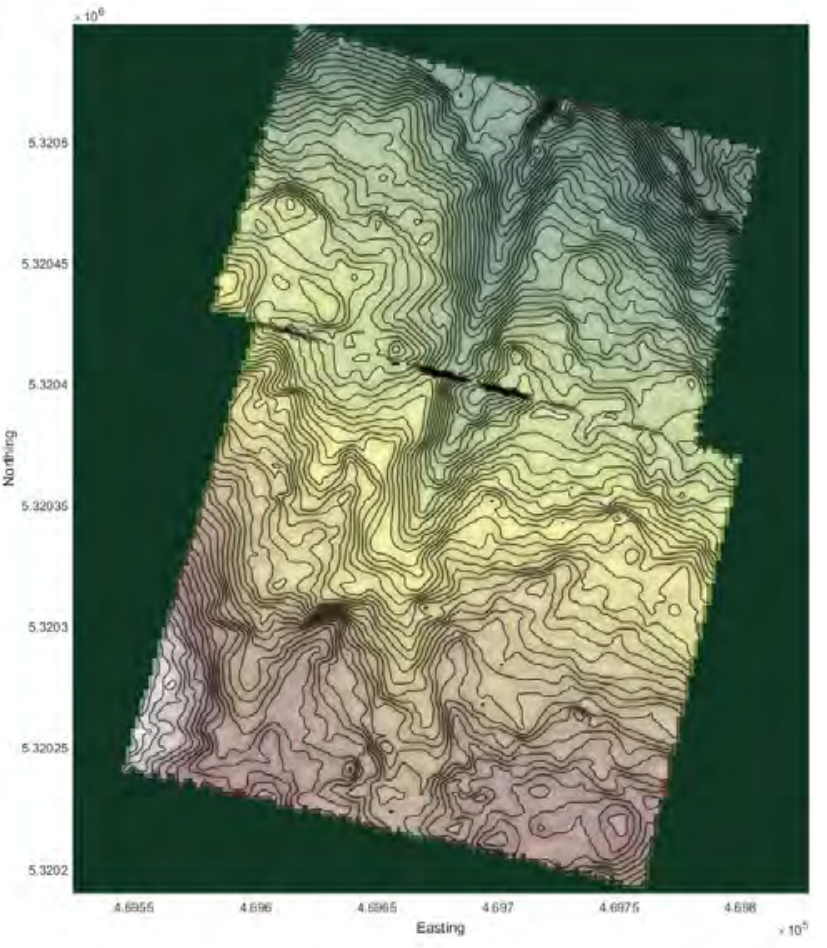




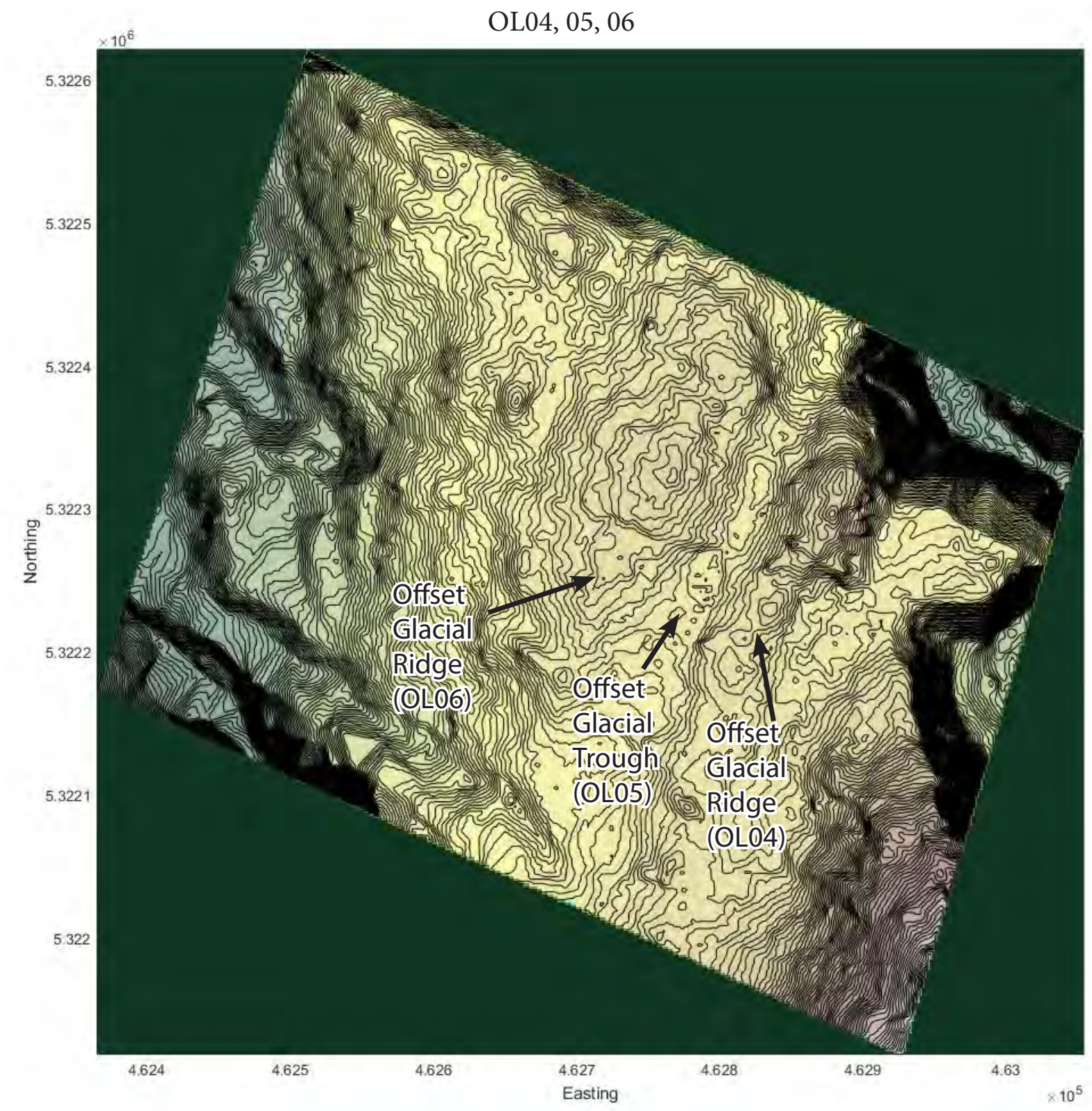

OL04 OL05 OL06 Notes: All of the upper bounds presented by

Nelson et al. (2017): $\quad$ Nelson et al. appear too high. For example, the

Min: $\quad 11.0 \mathrm{~m} \quad 6.5 \mathrm{~m} \quad 6.5 \mathrm{~m} \quad$ lowest Nelson et al. upper bound for this area

Pref: $\quad 13.0 \mathrm{~m} \quad 11.5 \mathrm{~m} \quad 11.5 \mathrm{~m} \quad(16.5 \mathrm{~m})$ appear too large for all three offset

Max: $19.0 \mathrm{~m} \quad 16.5 \mathrm{~m} \quad 22.0 \mathrm{~m} \quad$ features. Additionaly, backslipping suggests

This study: that the lower bound should be expanded for

$\begin{array}{llll}\text { Min: } & 5.8 & 4.0 & 4.0\end{array}$

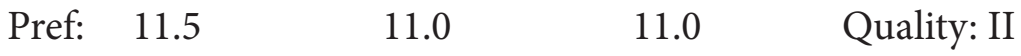

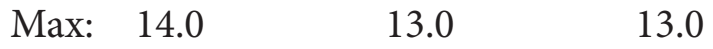




\section{Site OL04}

Orginal

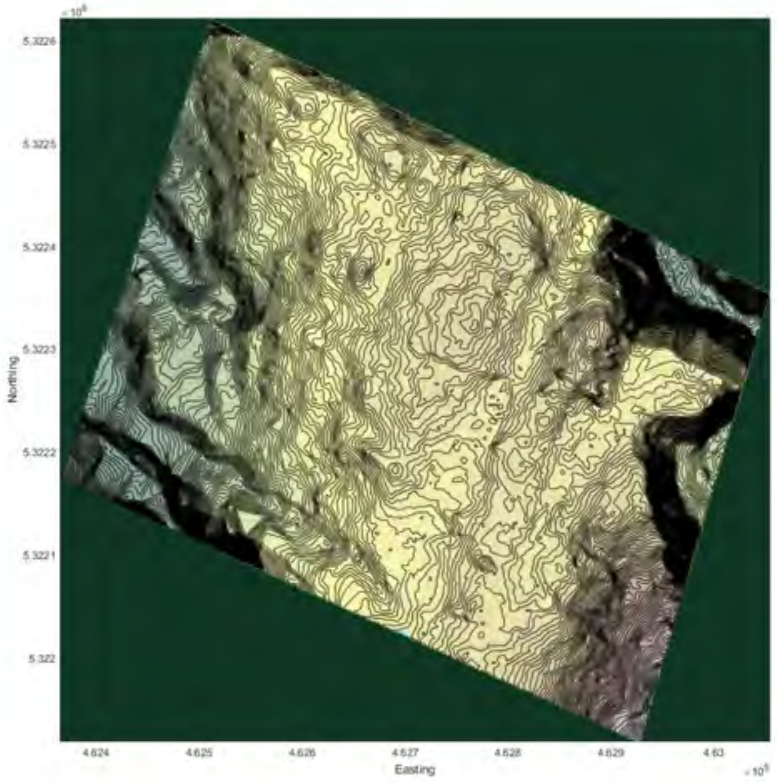

Lower Bound: 5.8m

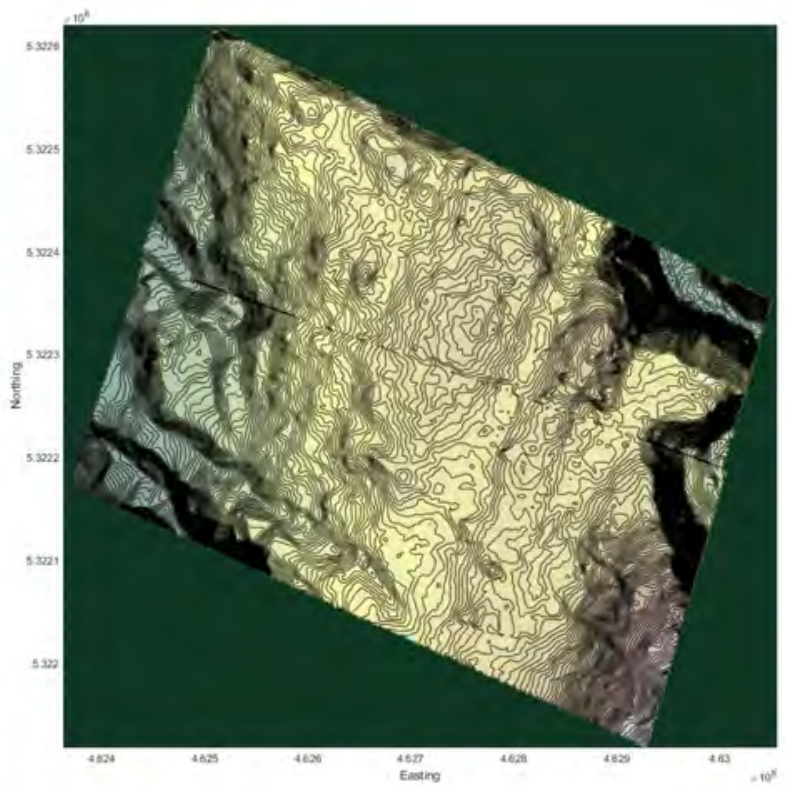

Preferred: $11.5 \mathrm{~m}$

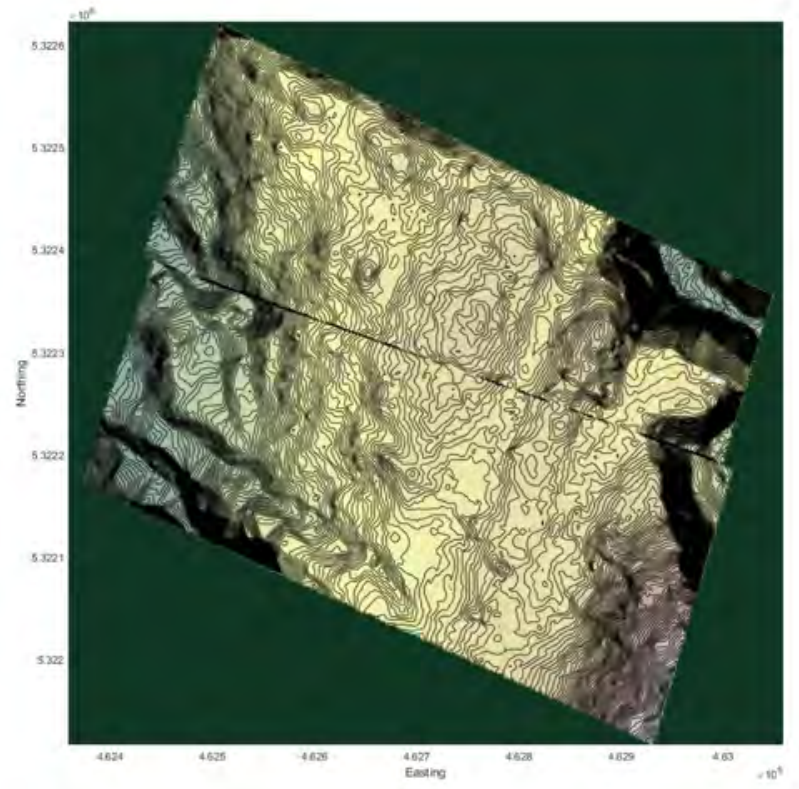

Upper Bound: 14.0m

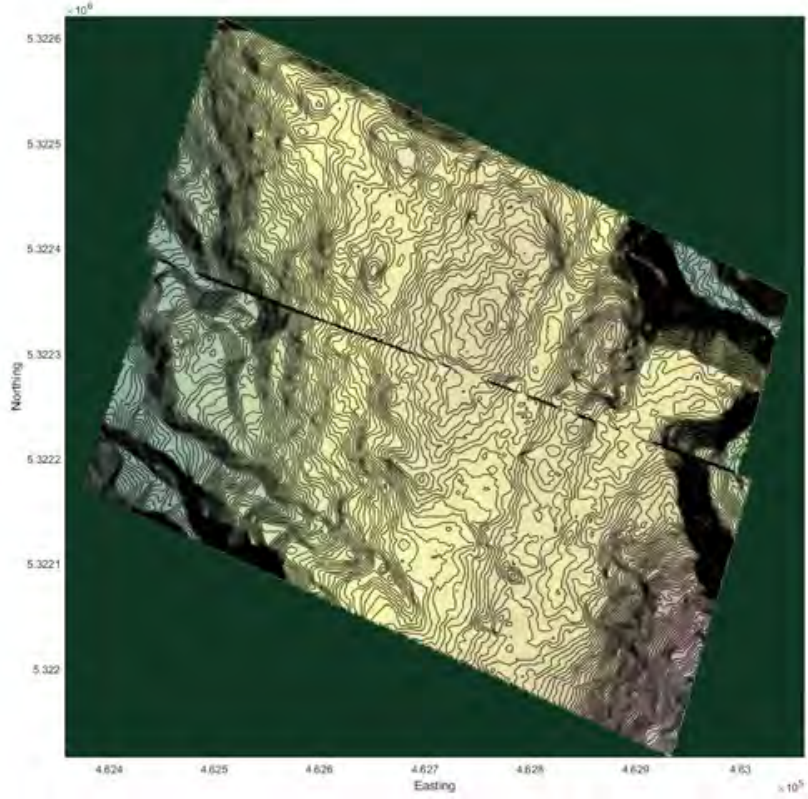


Site OL05 and OL06

Orginal

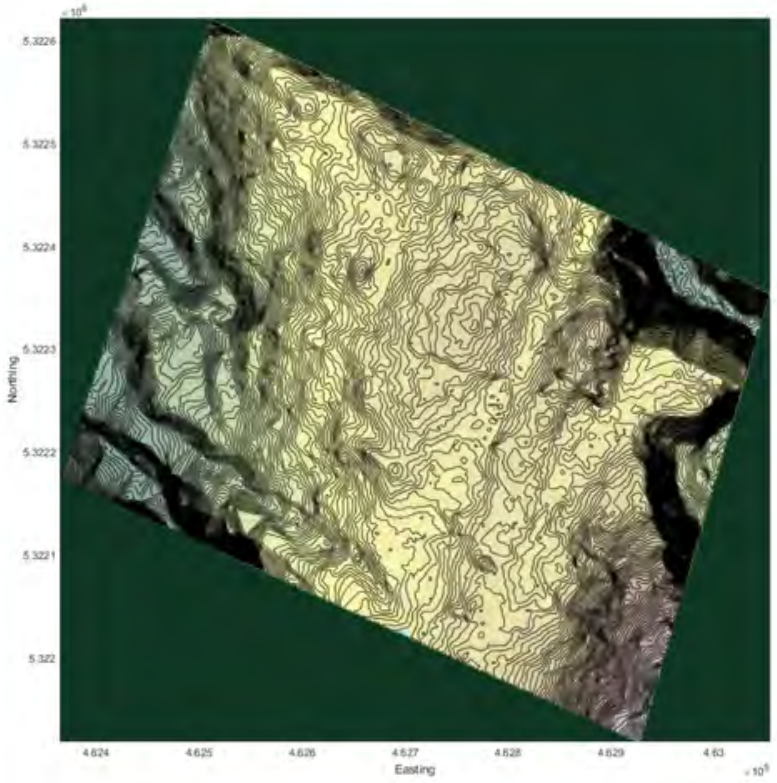

Lower Bound: 4.0m

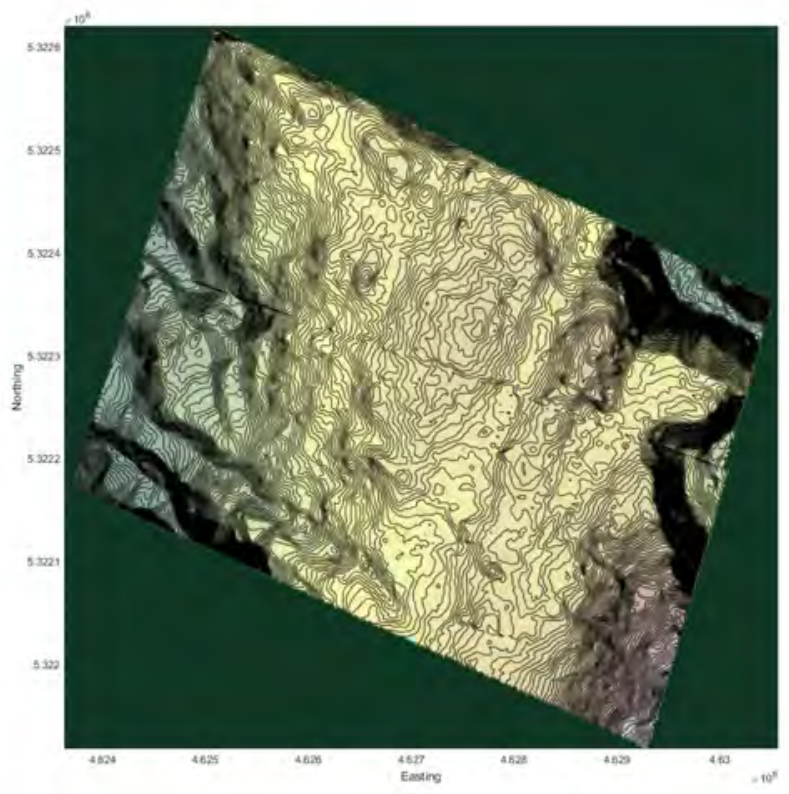

Preferred: $11.0 \mathrm{~m}$

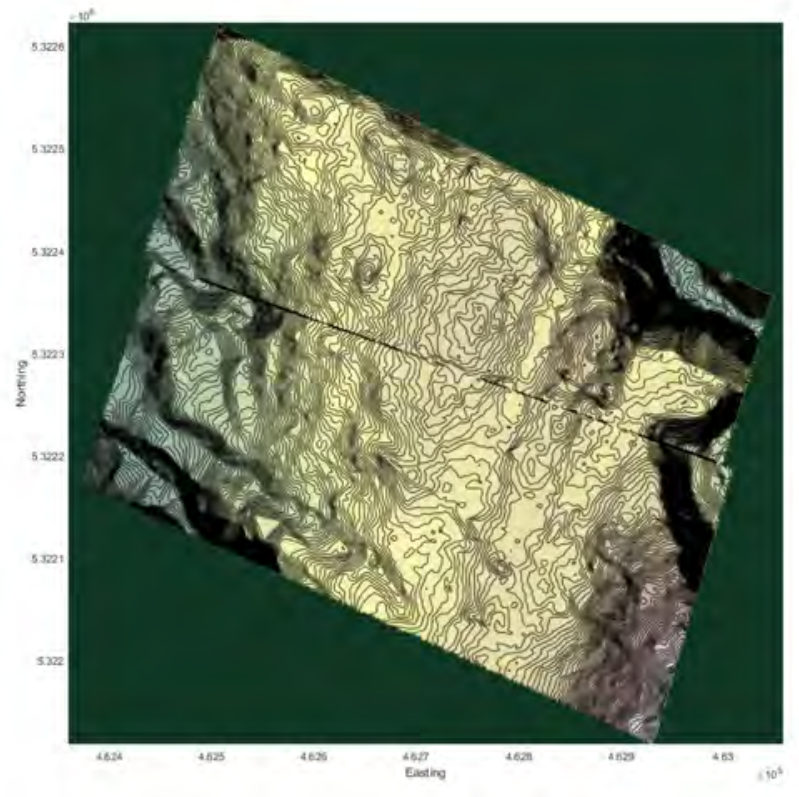

Upper Bound: 13.0m

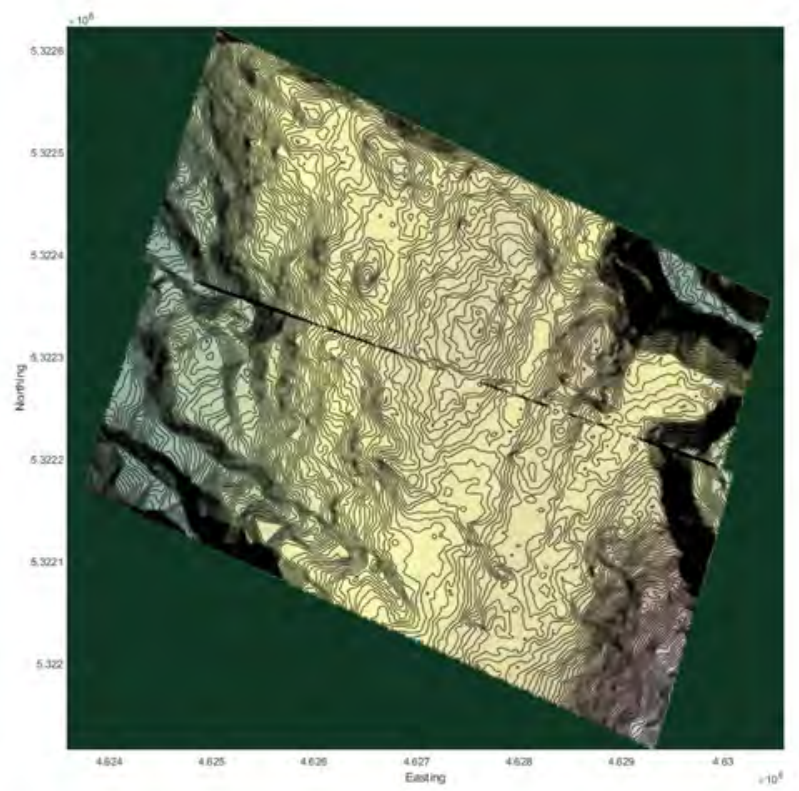




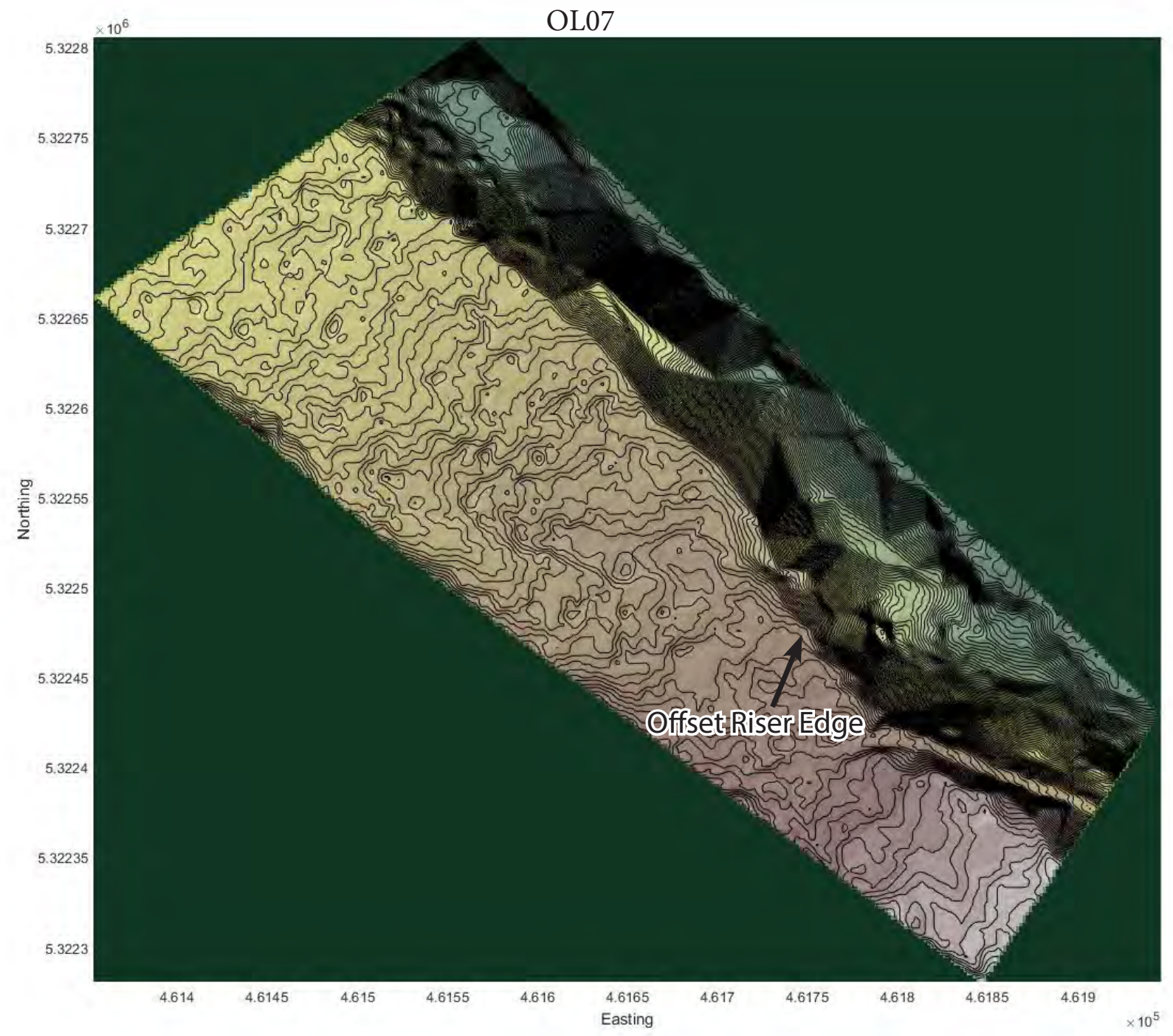

Nelson et al. (2017):

This Study:

Min: $10.8 \mathrm{~m}$

Min: $10.8 \mathrm{~m}$

Pref: $13 \mathrm{~m}$

Pref: $13 \mathrm{~m}$

Max: $23.9 \mathrm{~m}$

Max: $23.9 \mathrm{~m}$

Quality: III 


\section{Site OL07}

Orginal

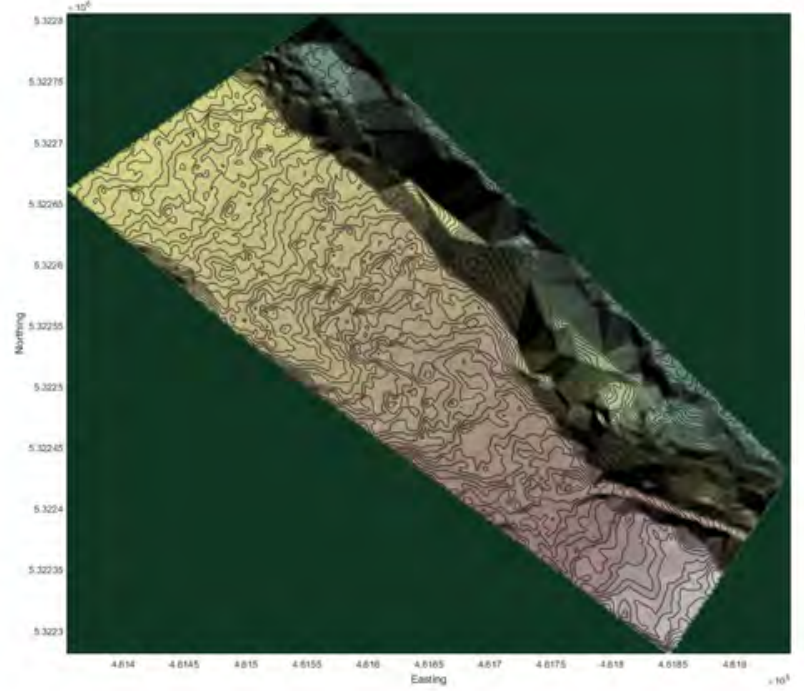

Preferred: $13.0 \mathrm{~m}$

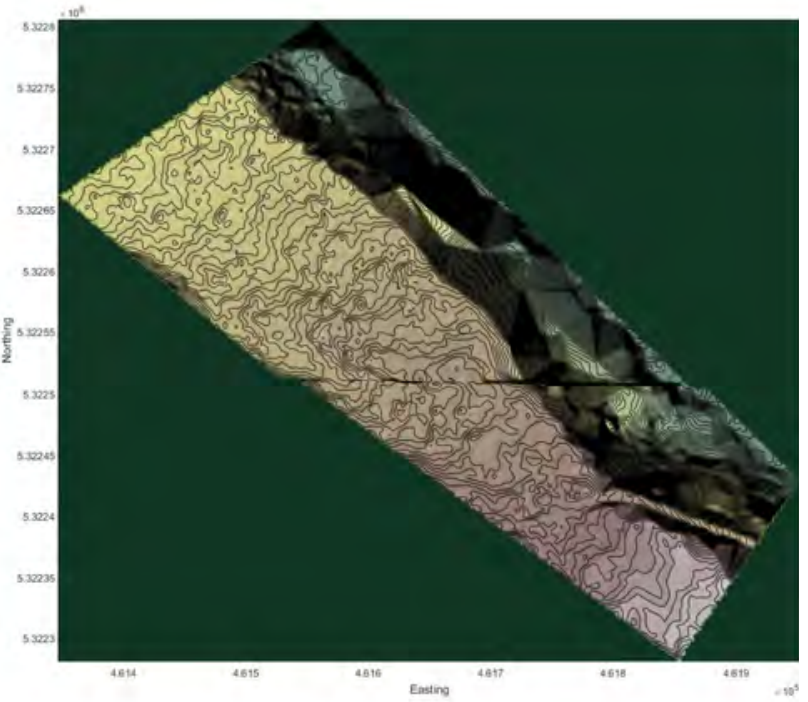

Lower Bound: 10.8m

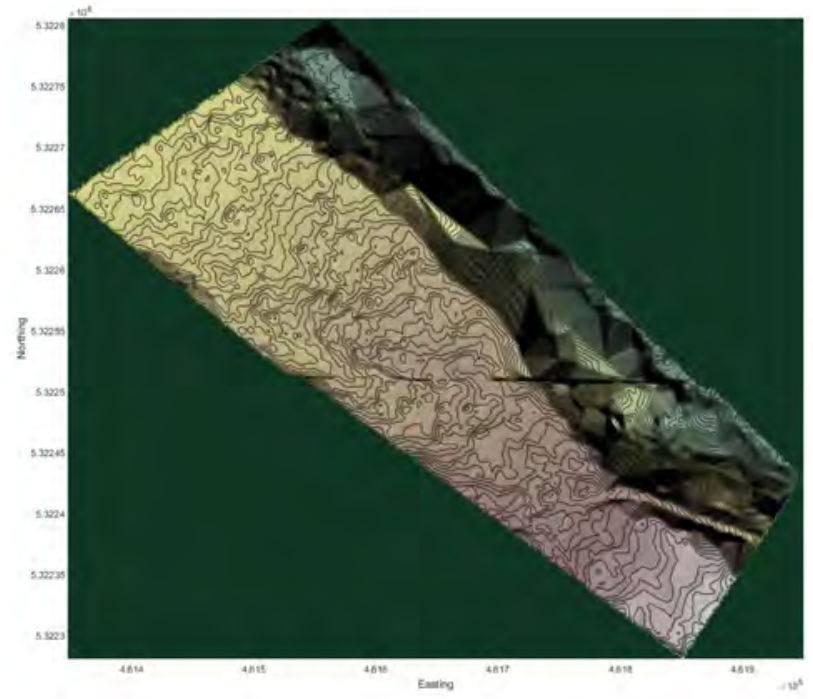

Upper Bound: 23.9m

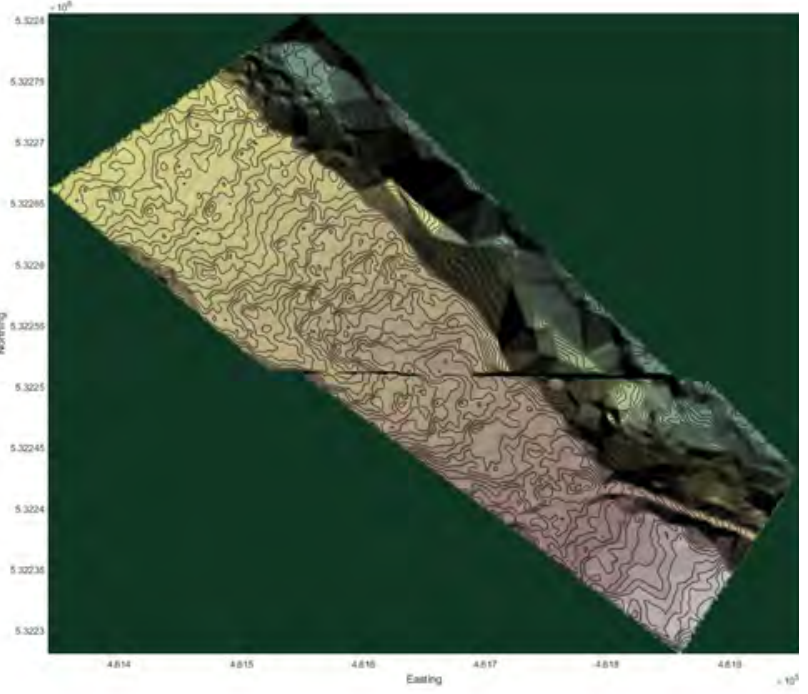




\section{Supplemental Document S5}

All scarp profiles used to calculate vertical separation ("Vsep") and dip-slip displacement ("Vslip"). Profiles are first presented for the SCF and then are presented for the LCBCF (beginning with profile "tp2"). Along each fault strand profiles are listed from E to W. The location of all profiles is presented in Supplemental Figures S2 and S3 and all measurements are listed in Supplemental Tables TS1 and TS2. 

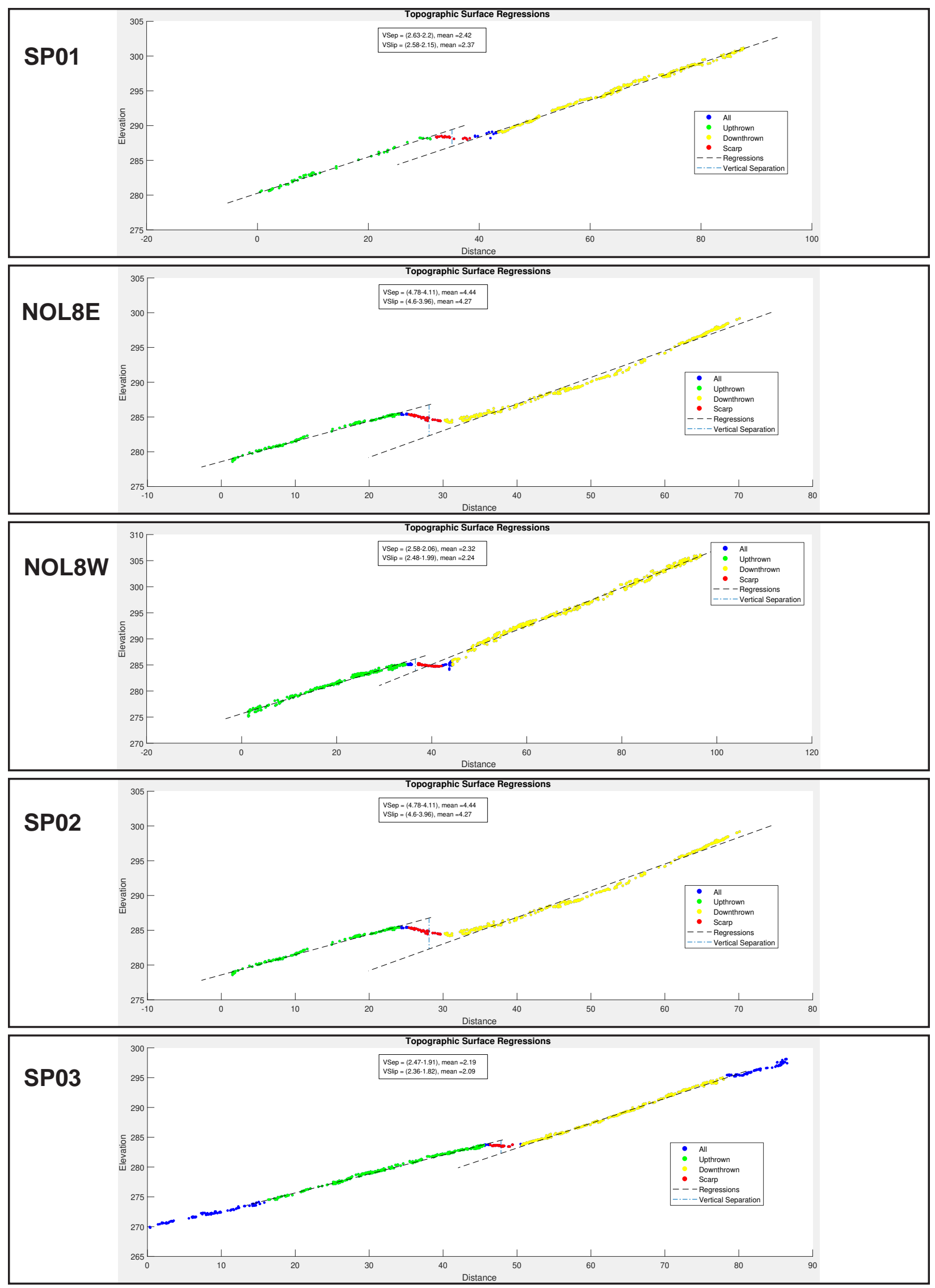

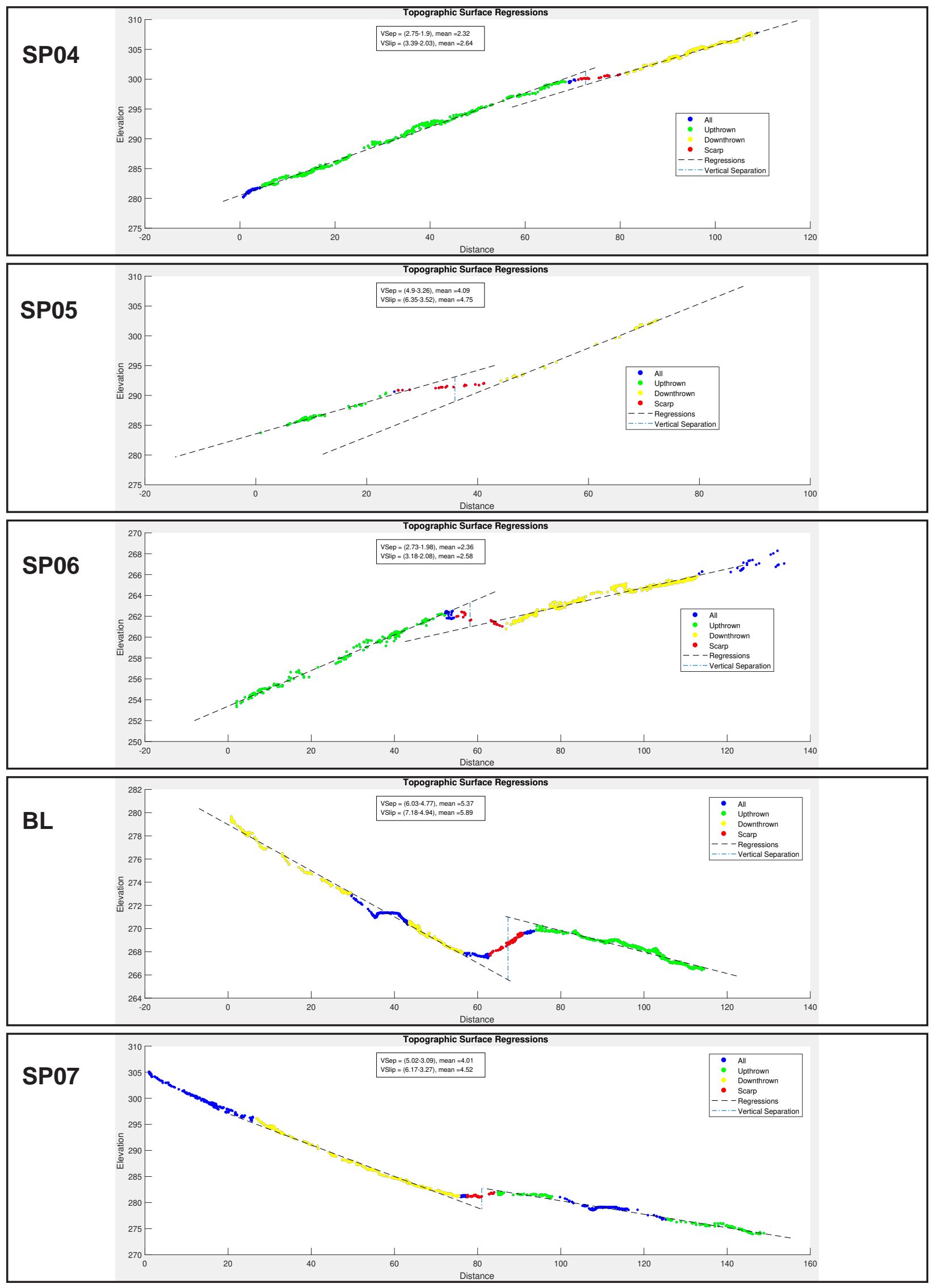

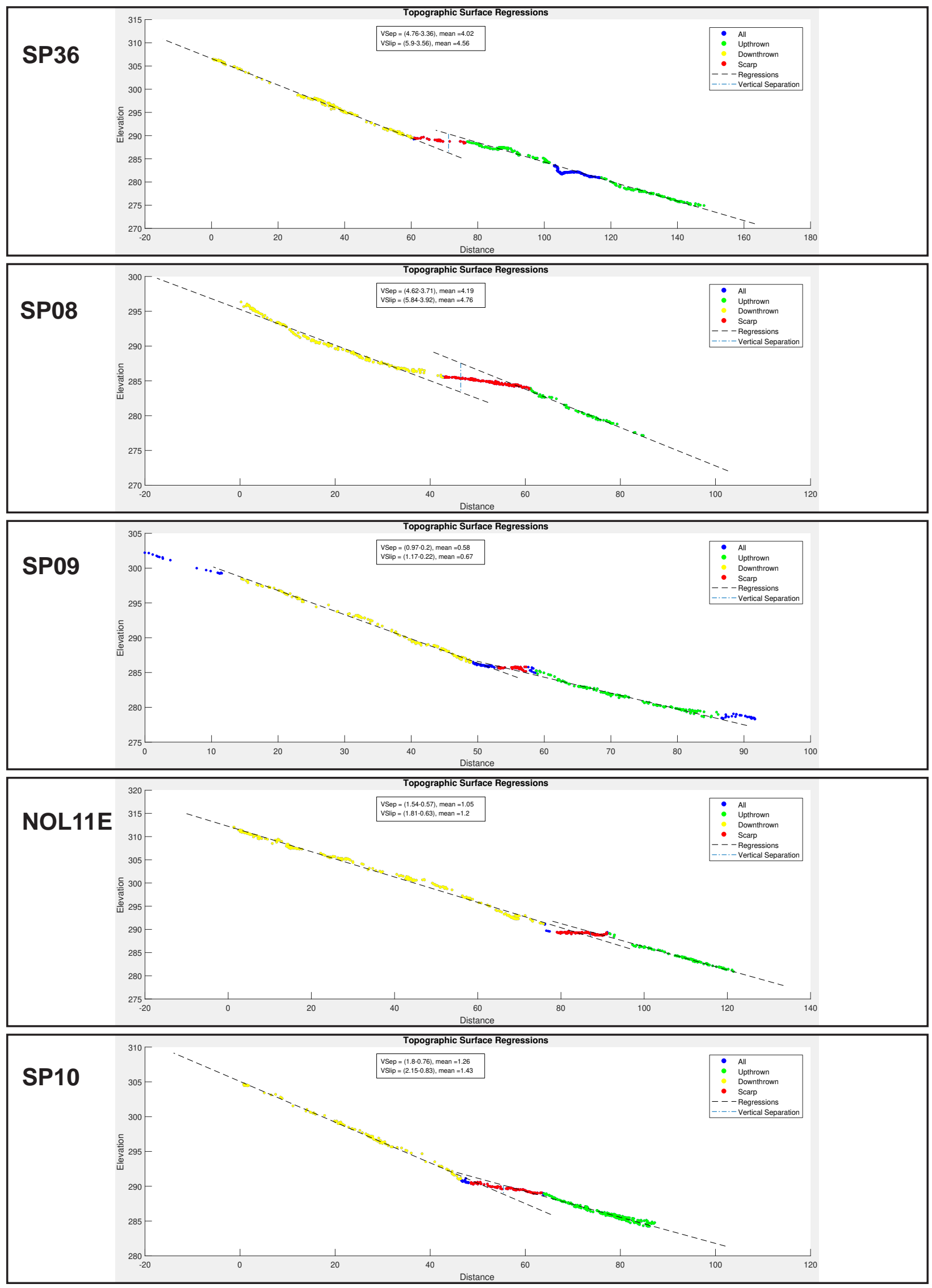

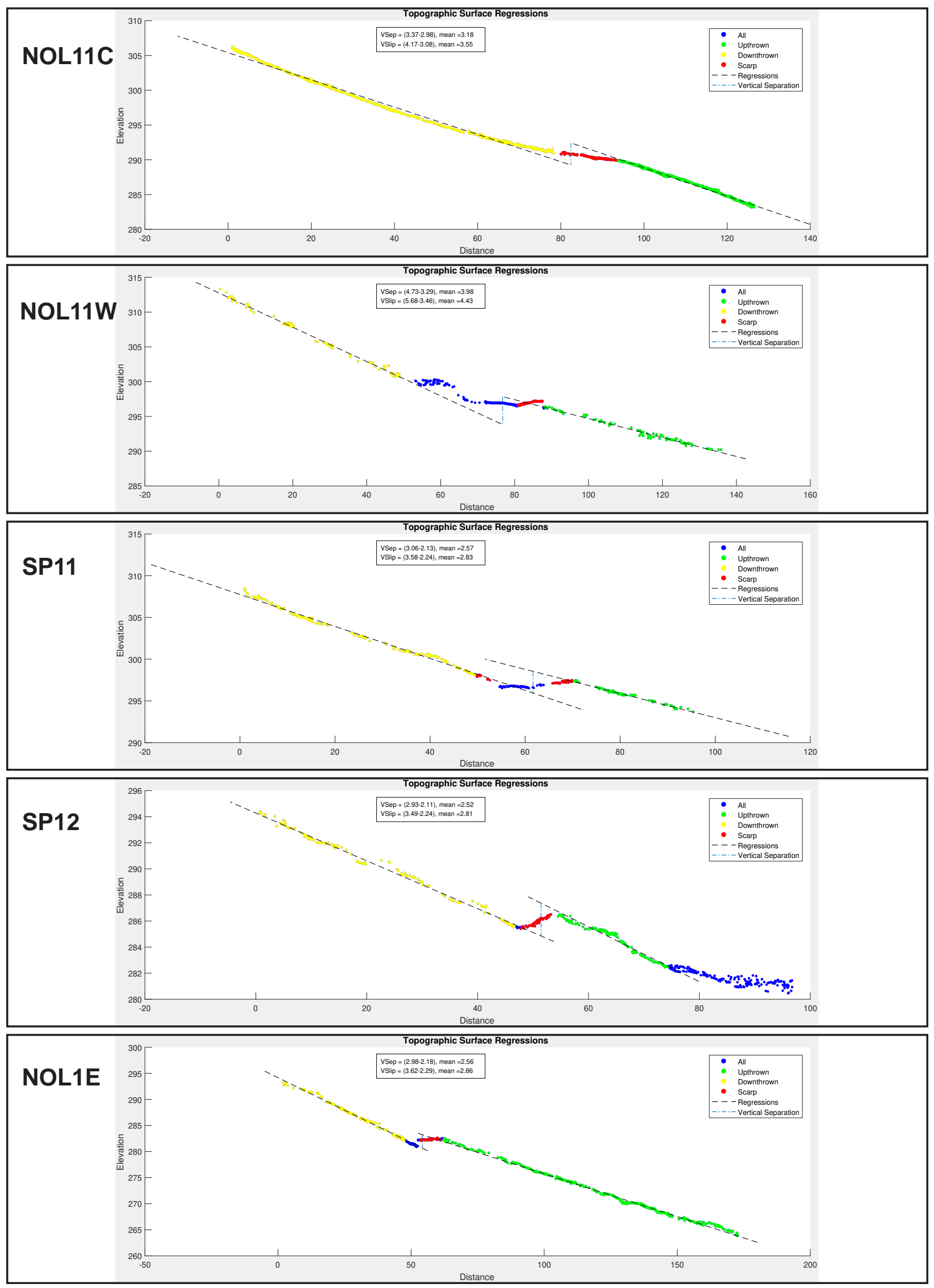

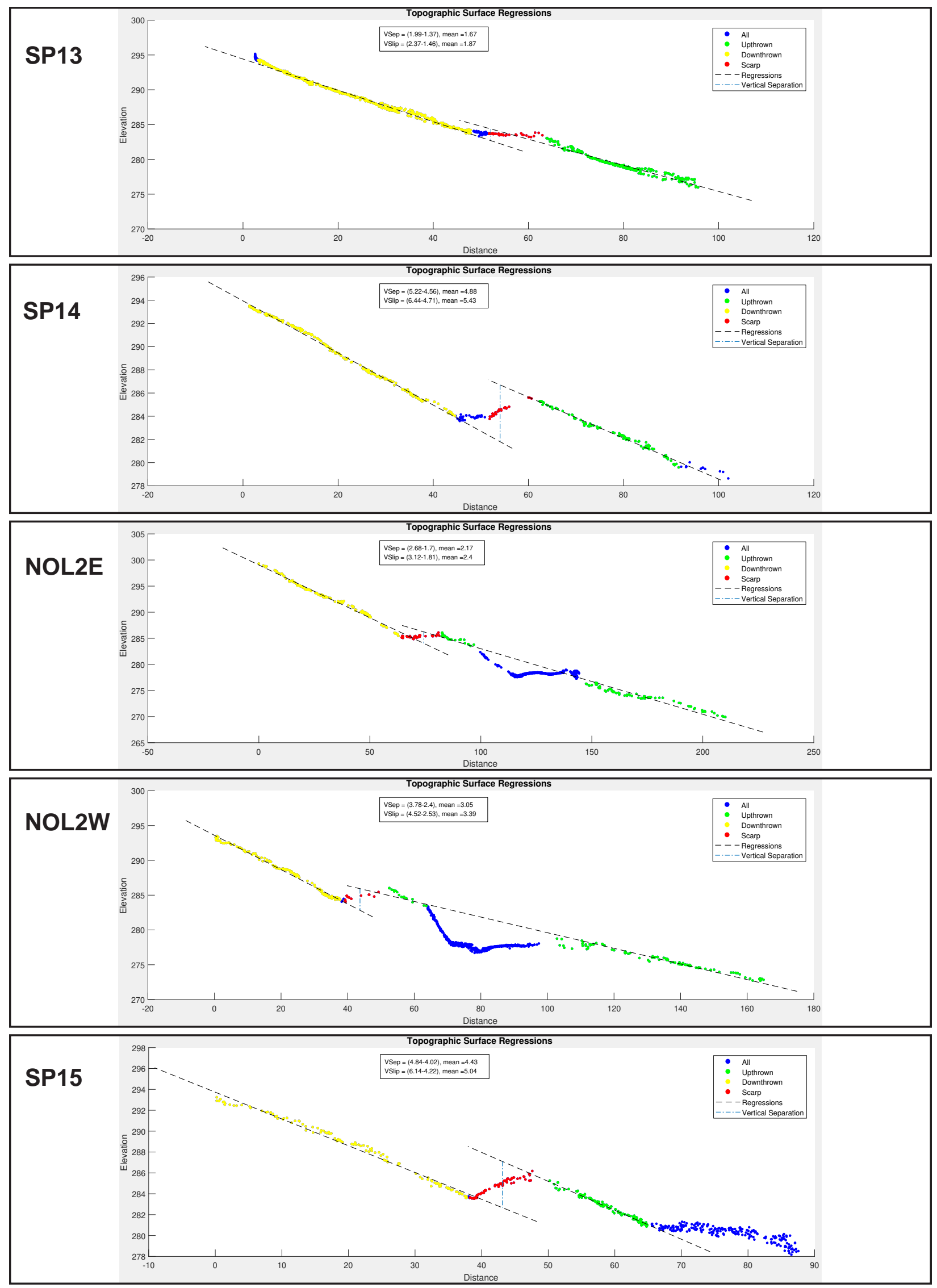

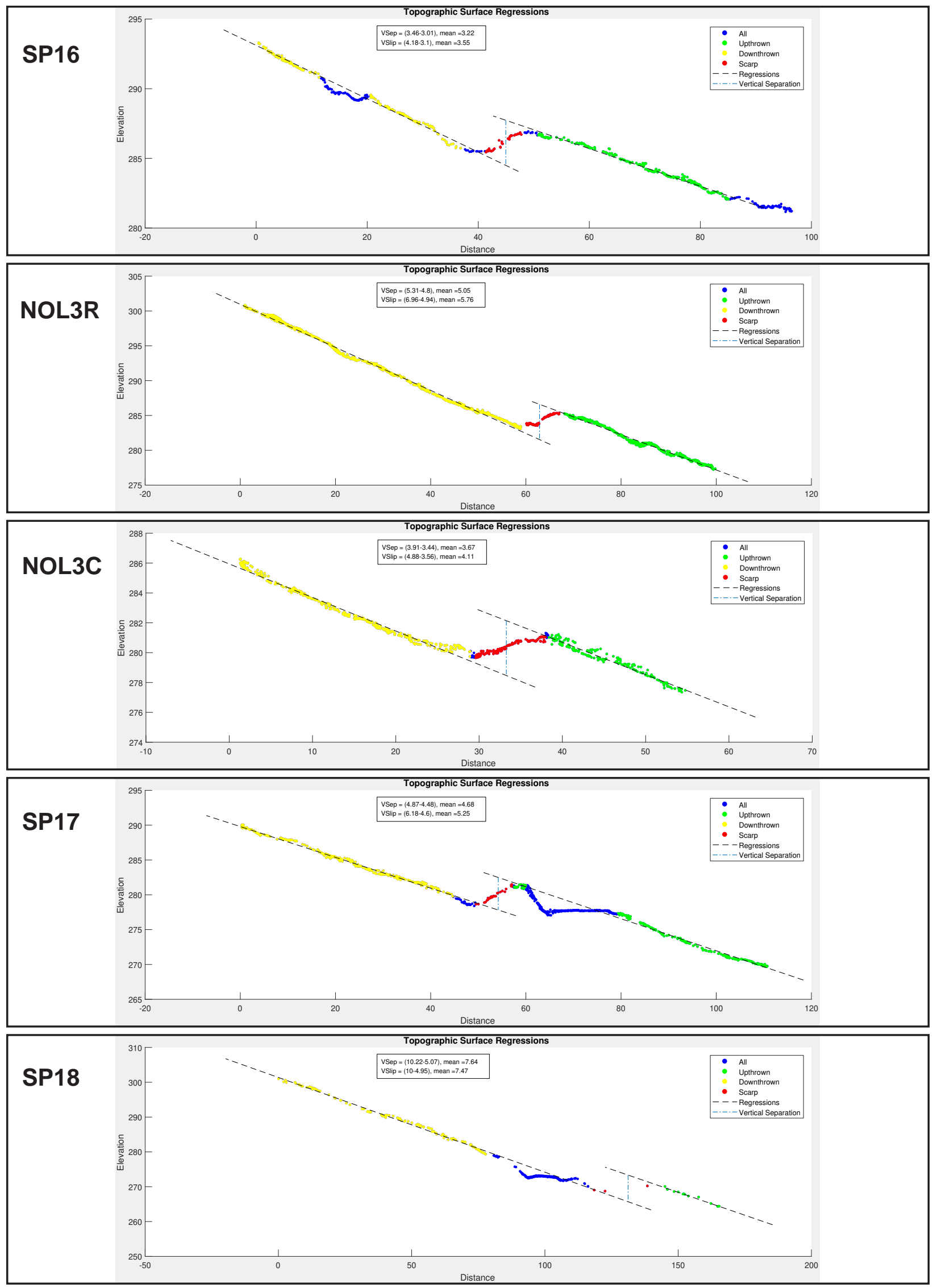

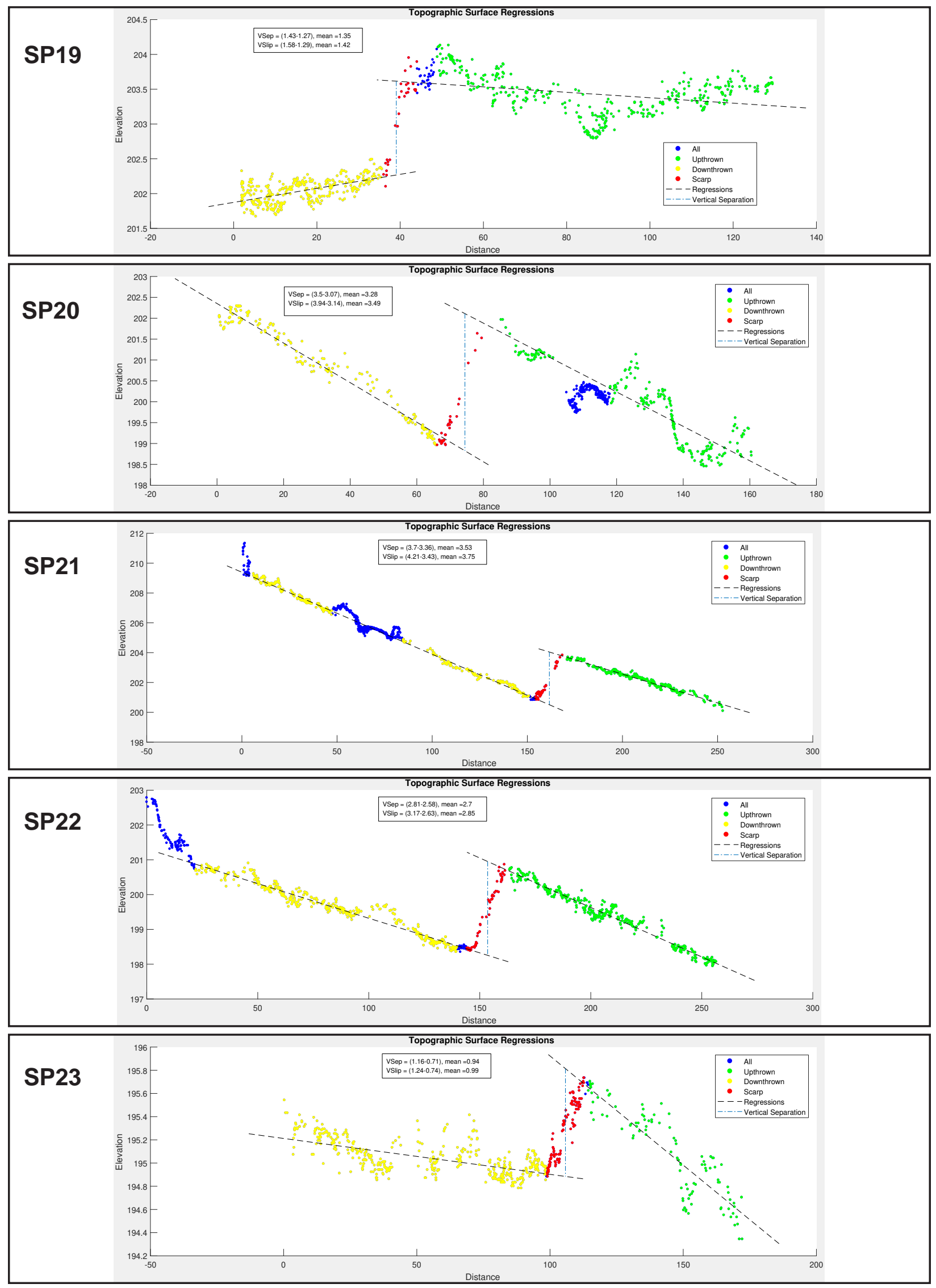

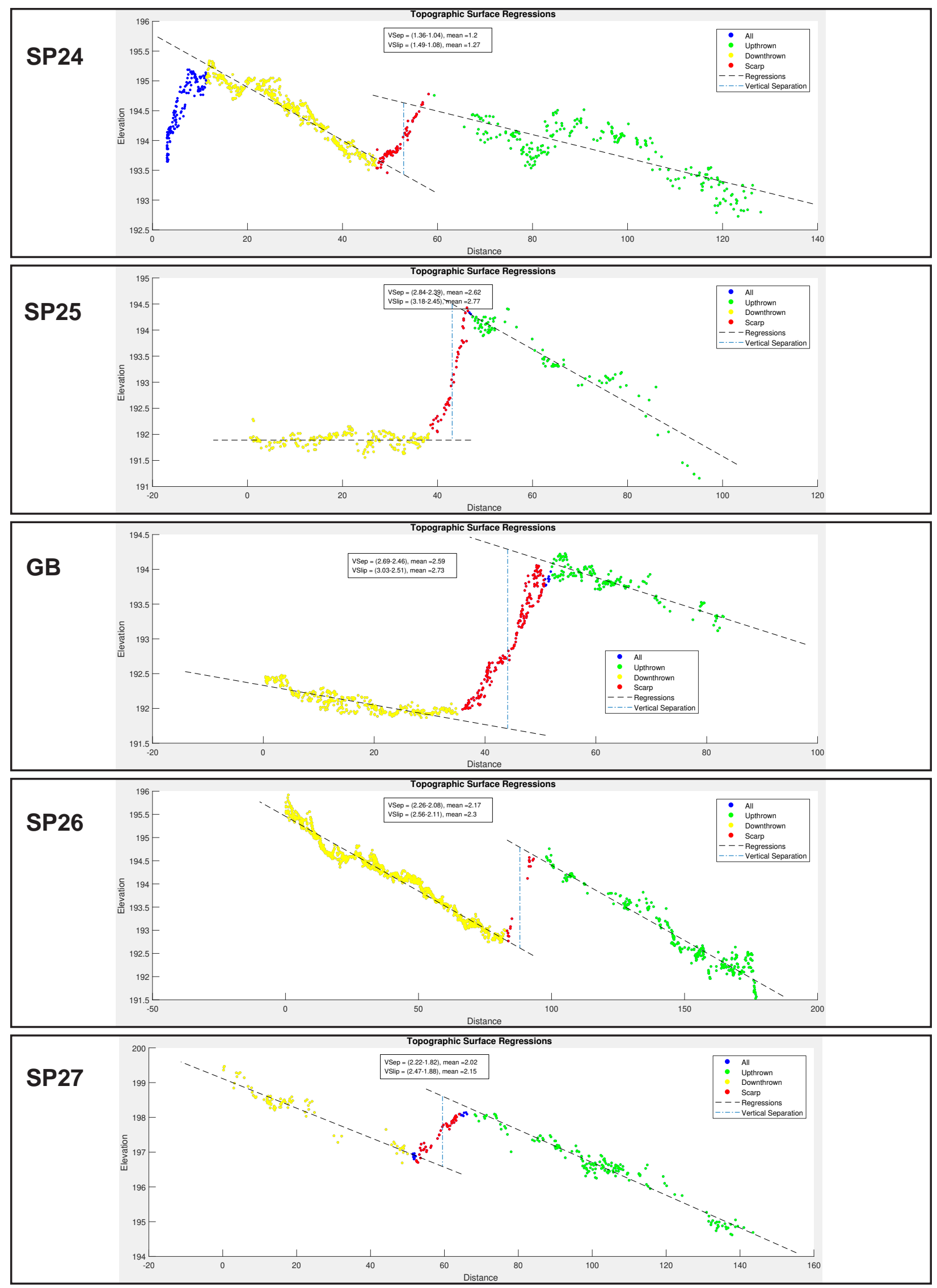

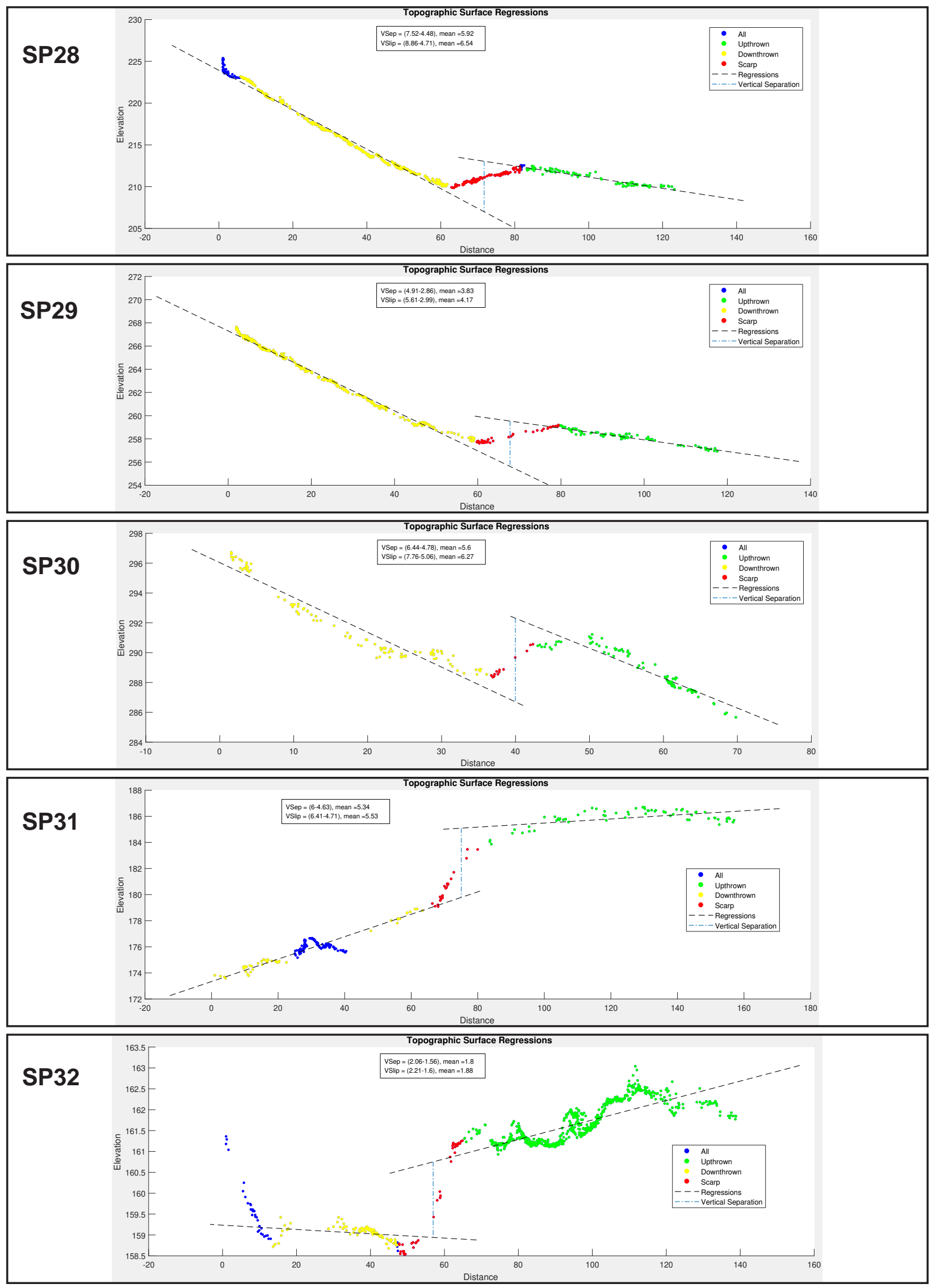

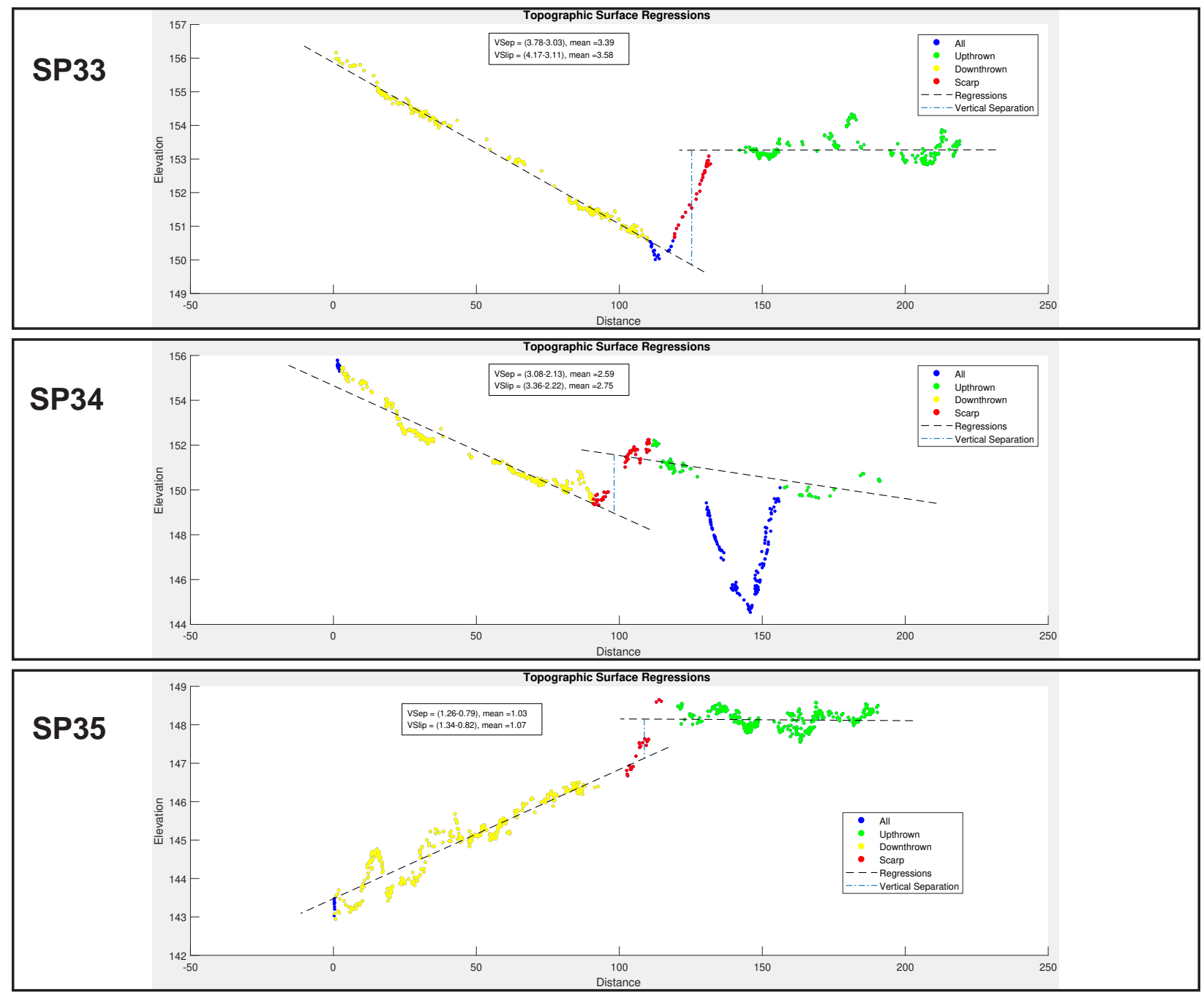

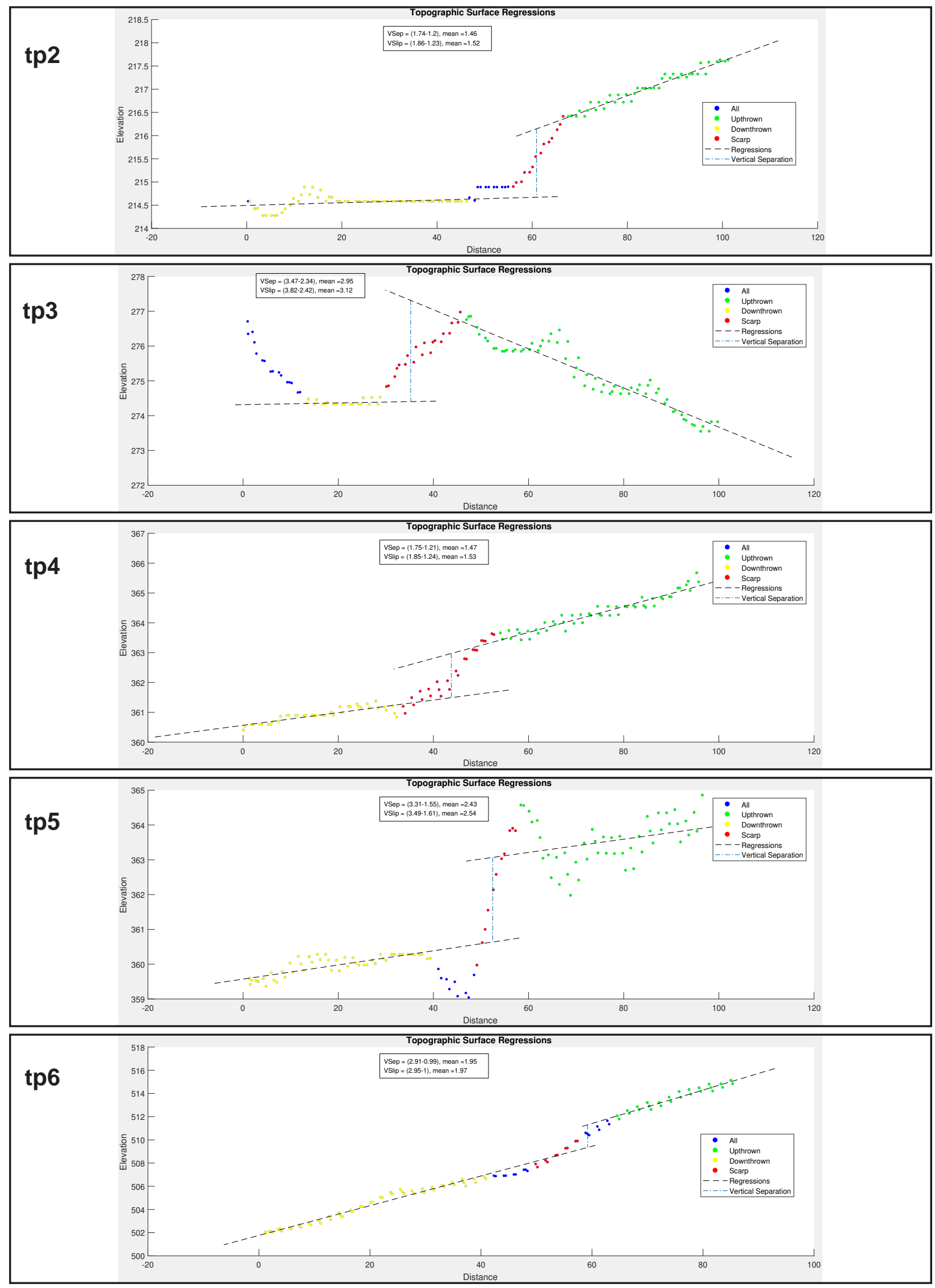

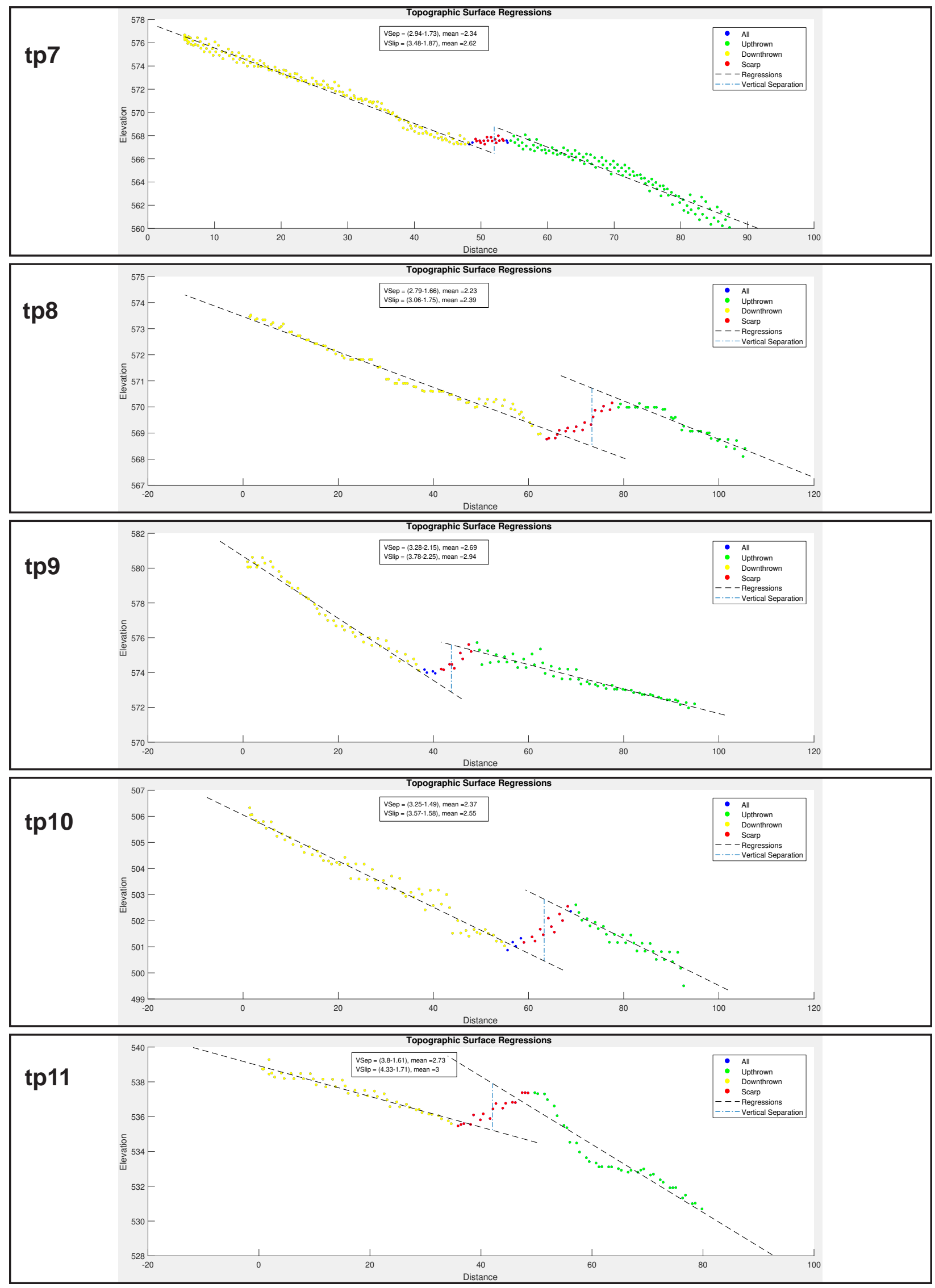

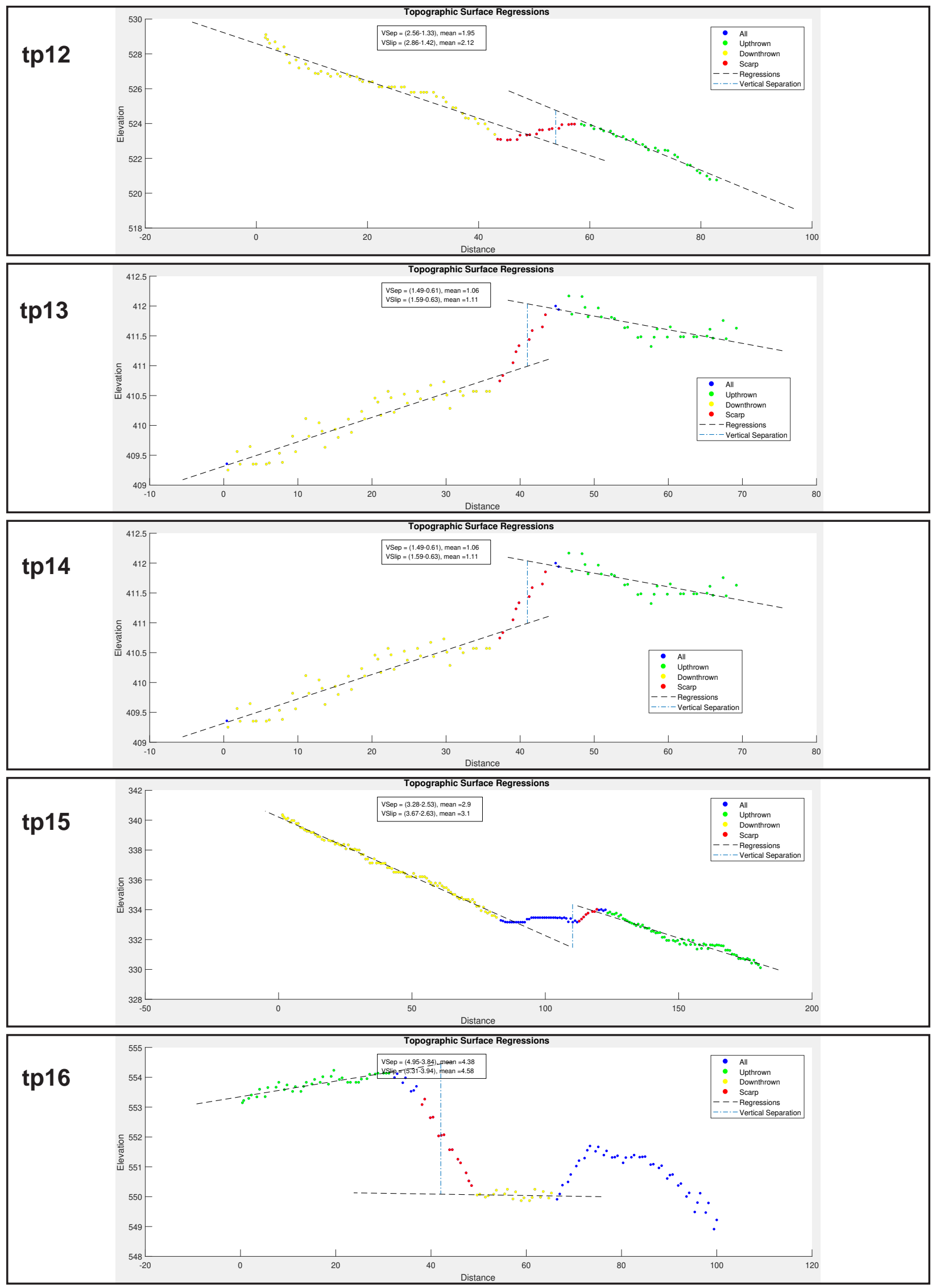

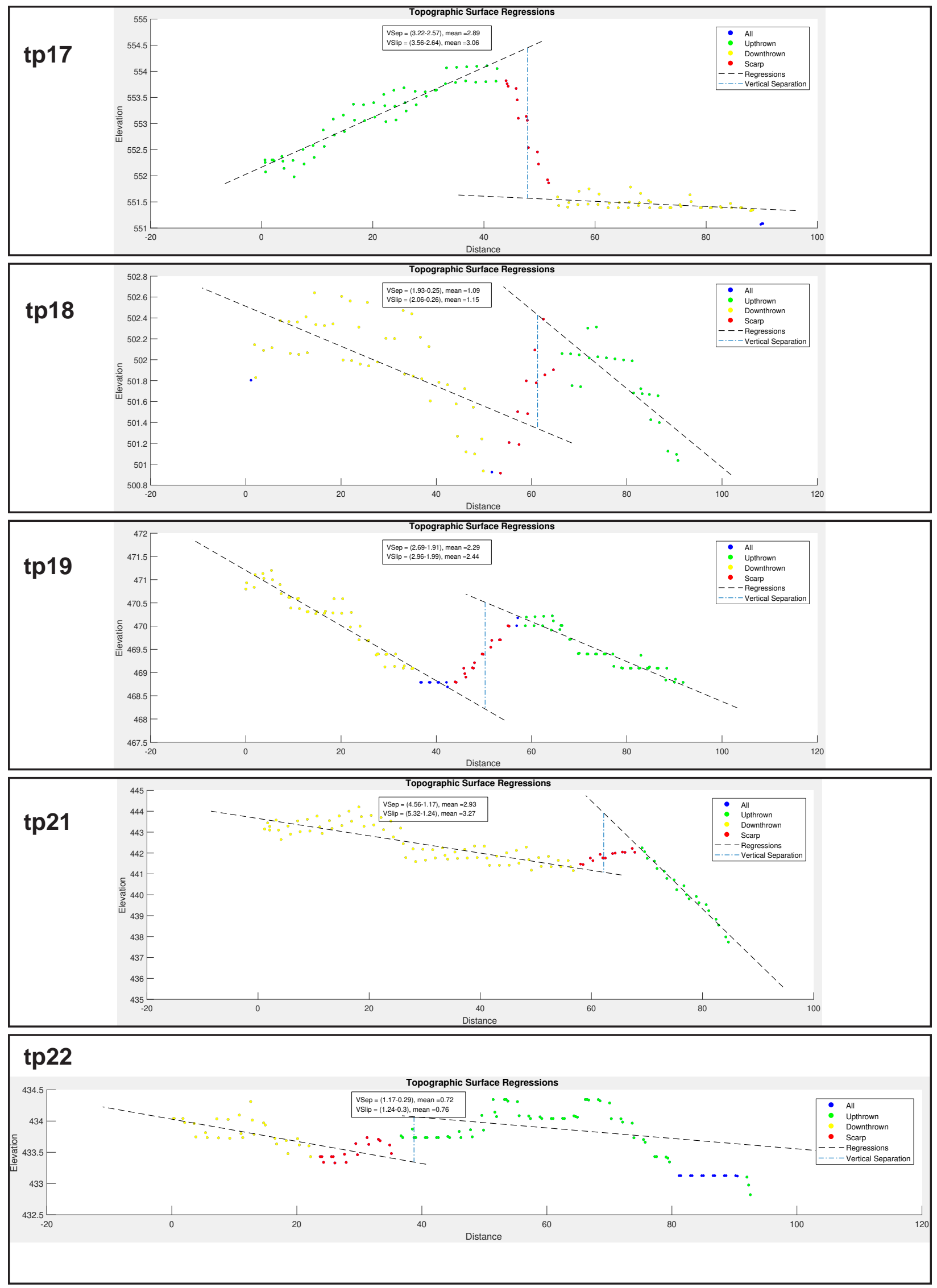


\section{Supplemental Document S6}
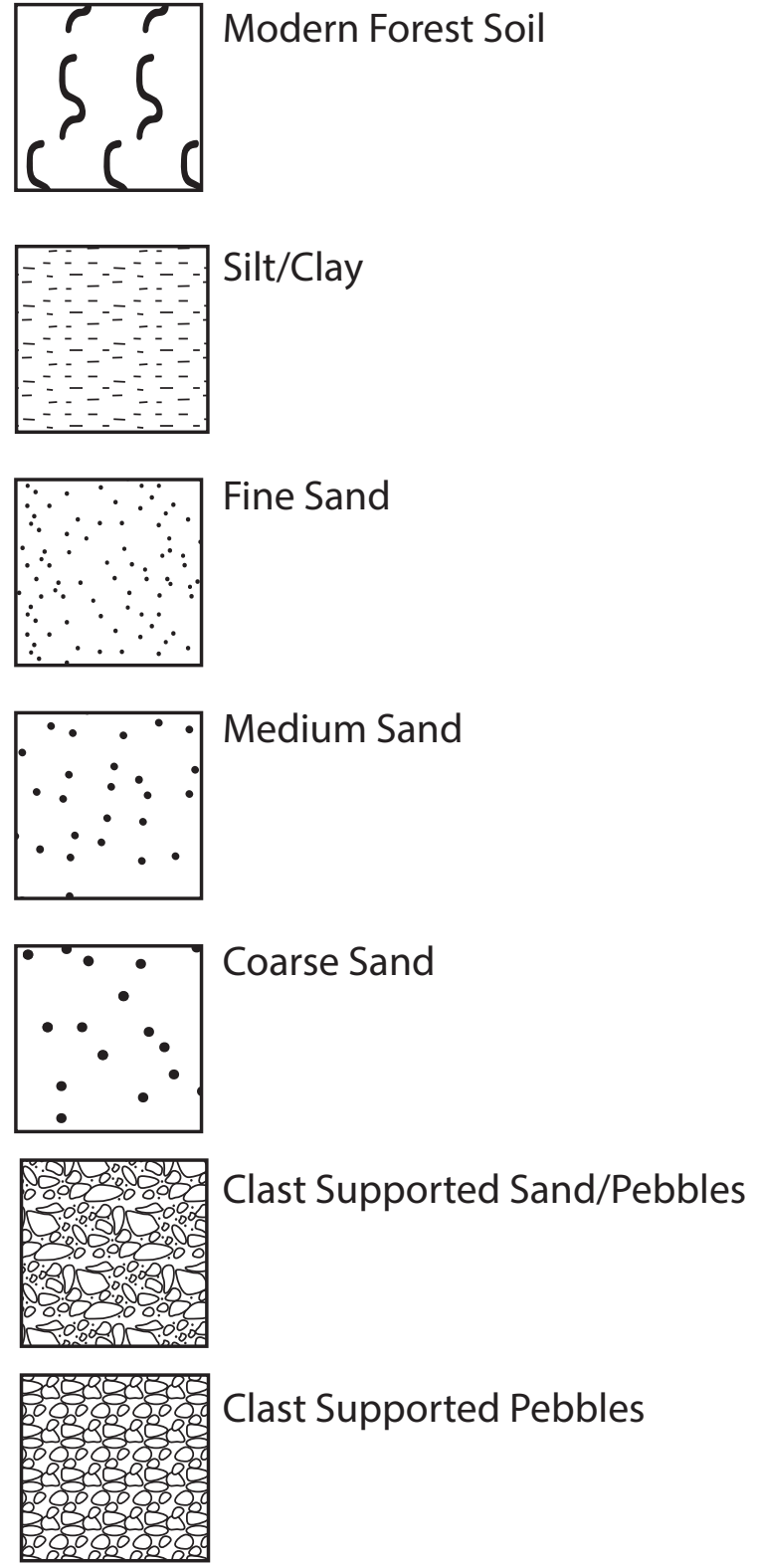

Clast Supported Pebbles
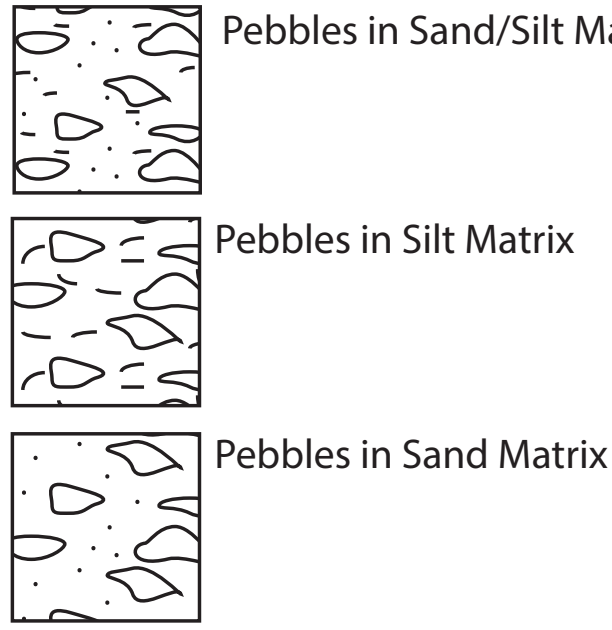
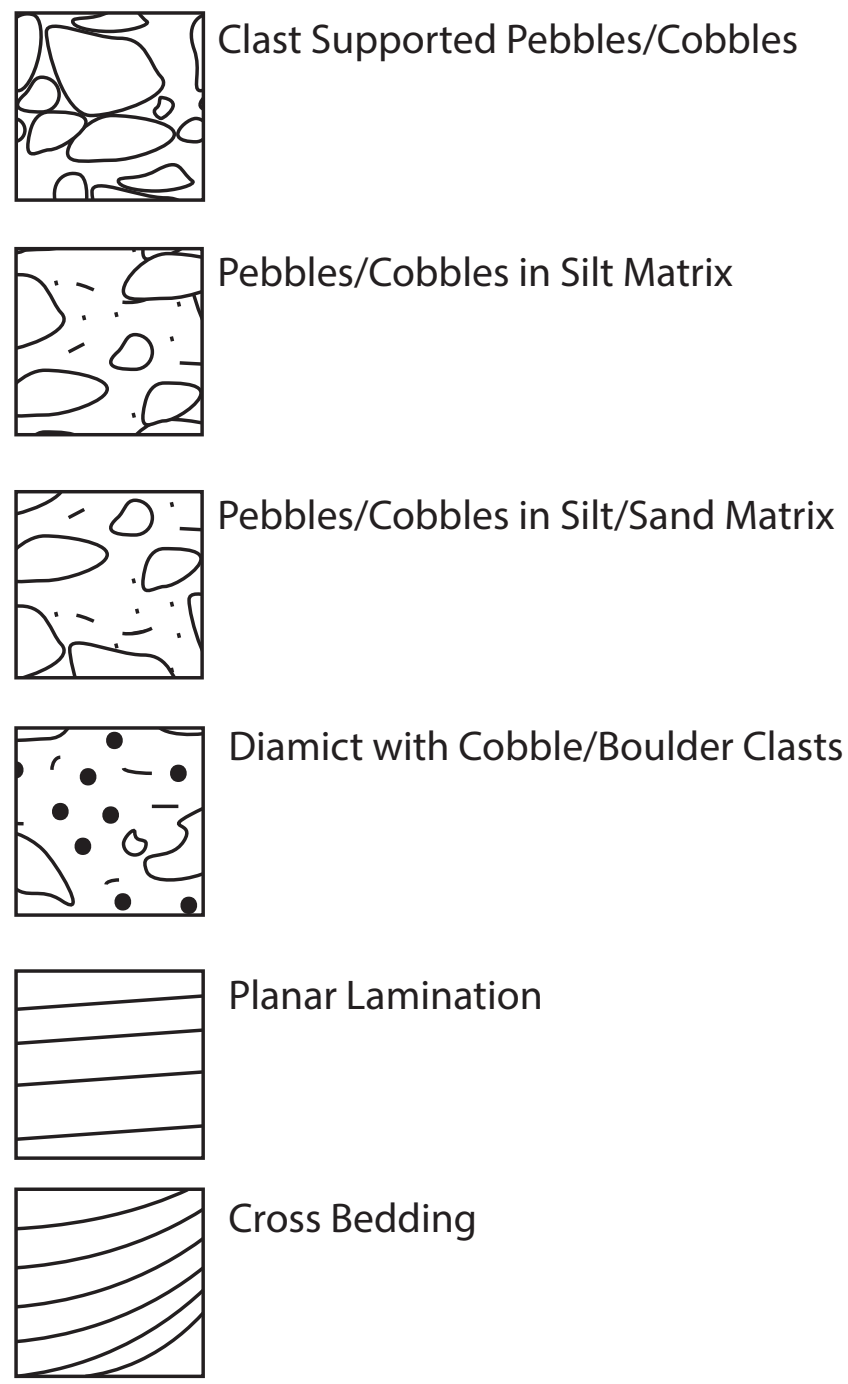

Charcoal

Key to lithologic units in sample locations. Please note that some units may contain multiple symbols (e. g., clast supported pebbles with cross bedding or medium and coarse sand).

The following pages are organized to show the location of all proximal samples (map) followed by field photos and lithologic interpretations. 


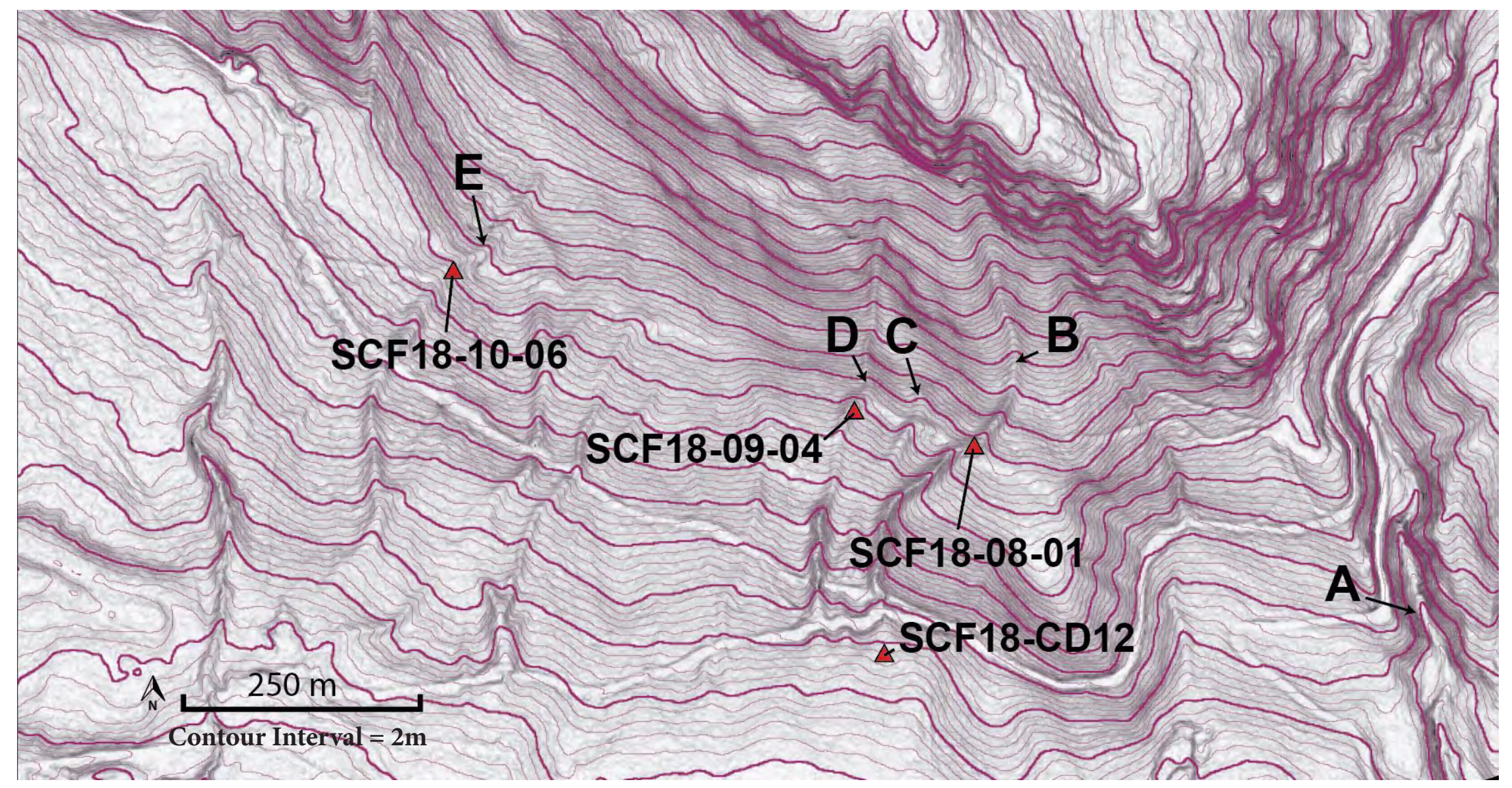




\section{SCF18-08-01}

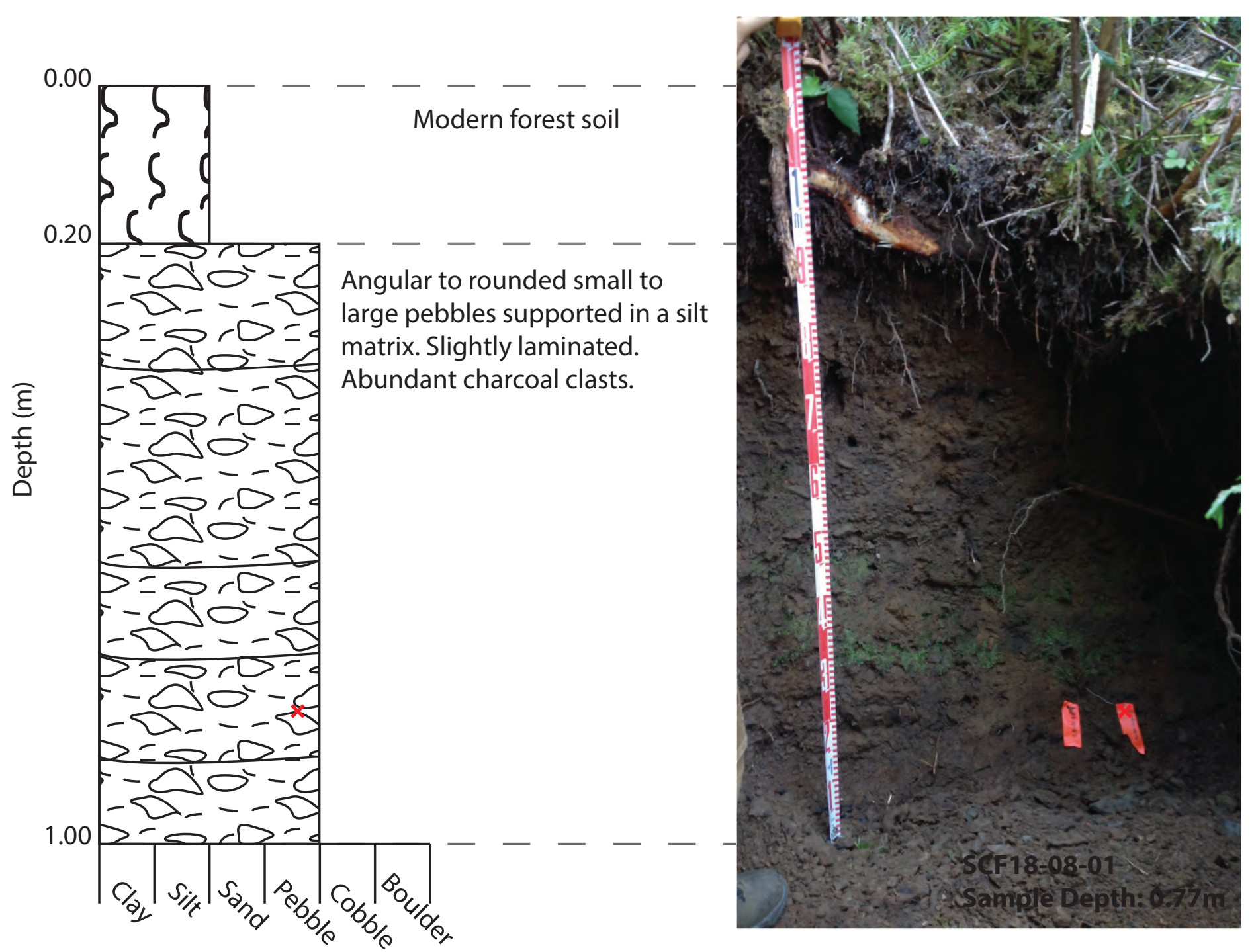




\section{SCF18-CD12}

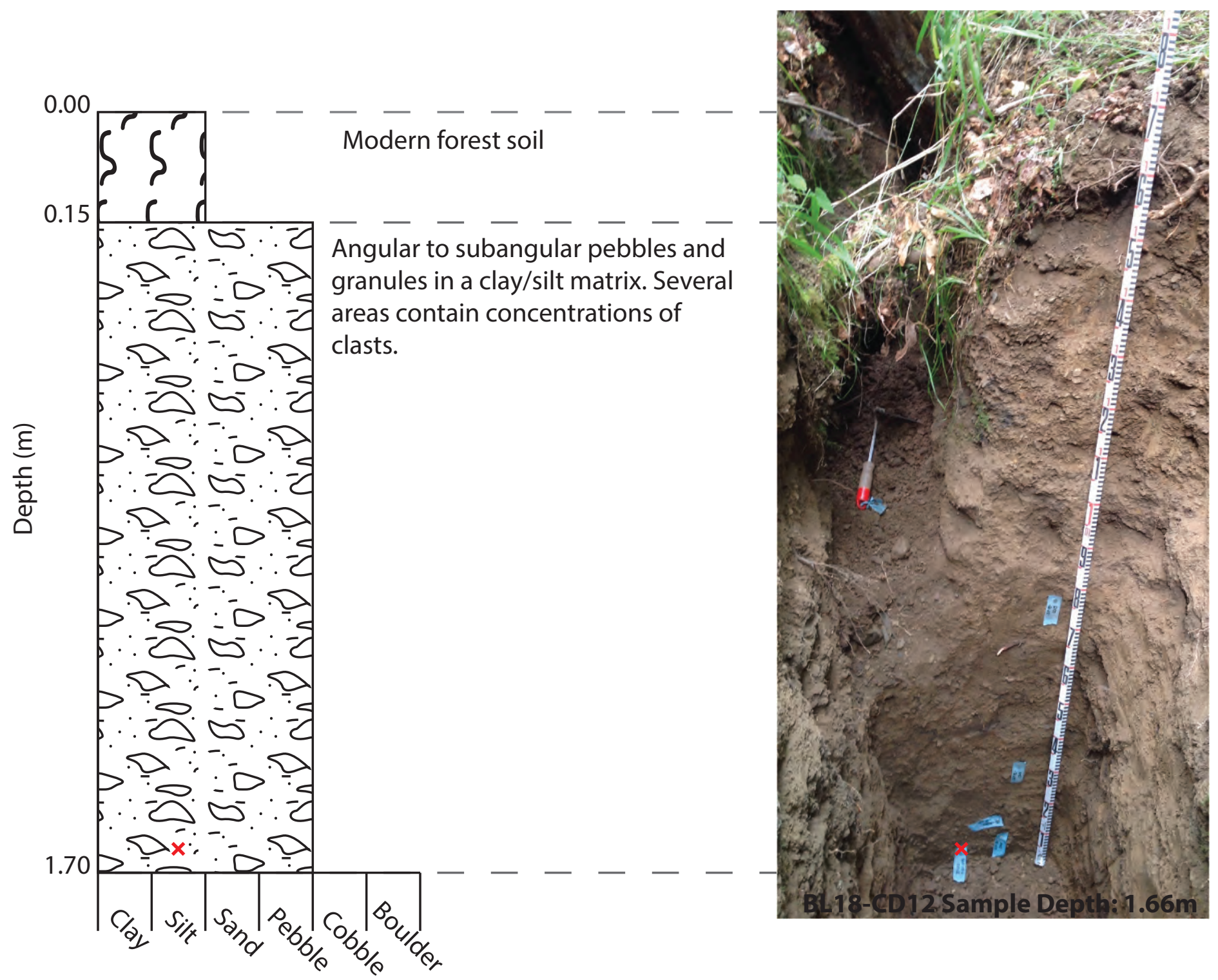


SCF18-09-04

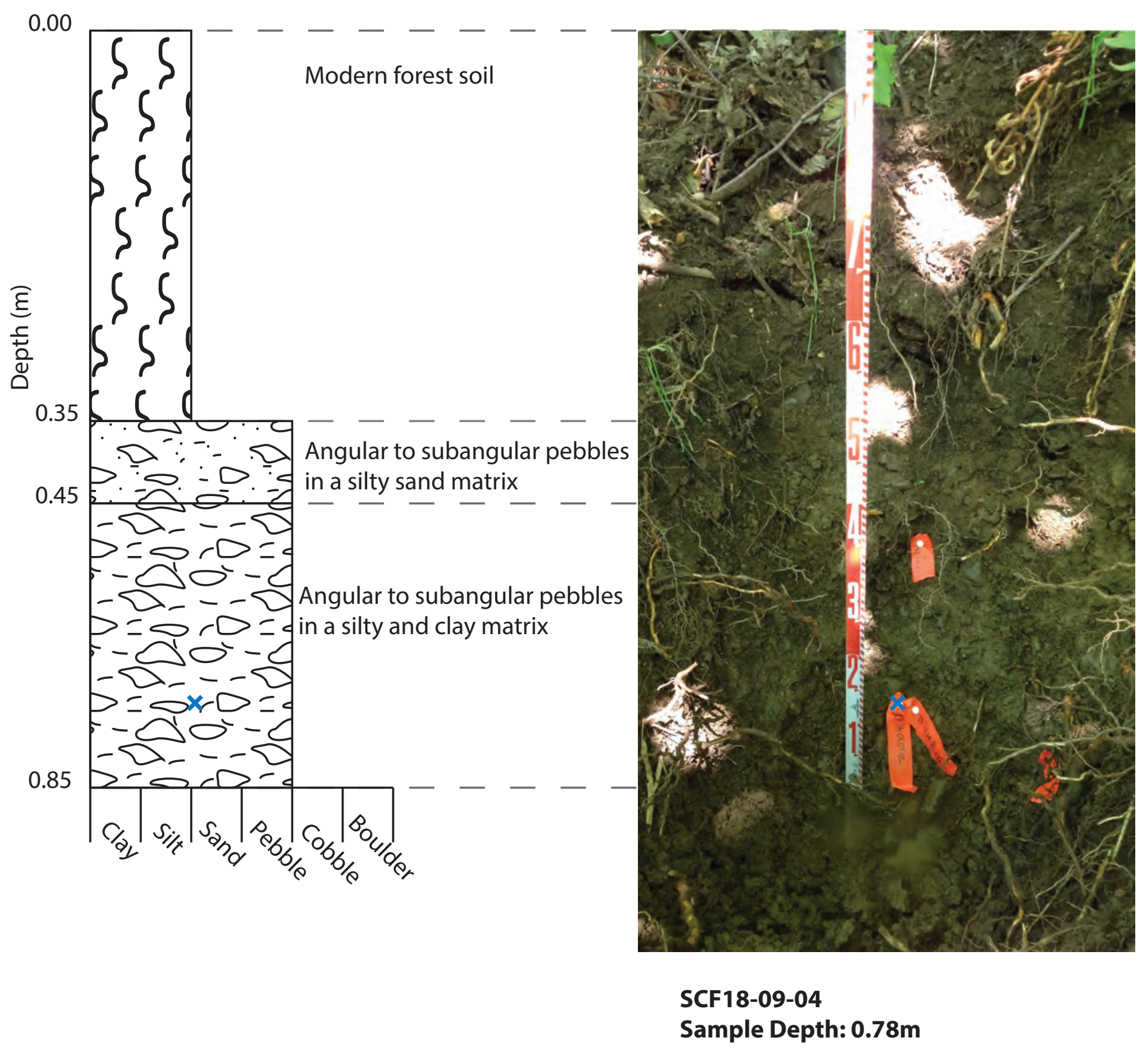




\section{SCF18-10-06}

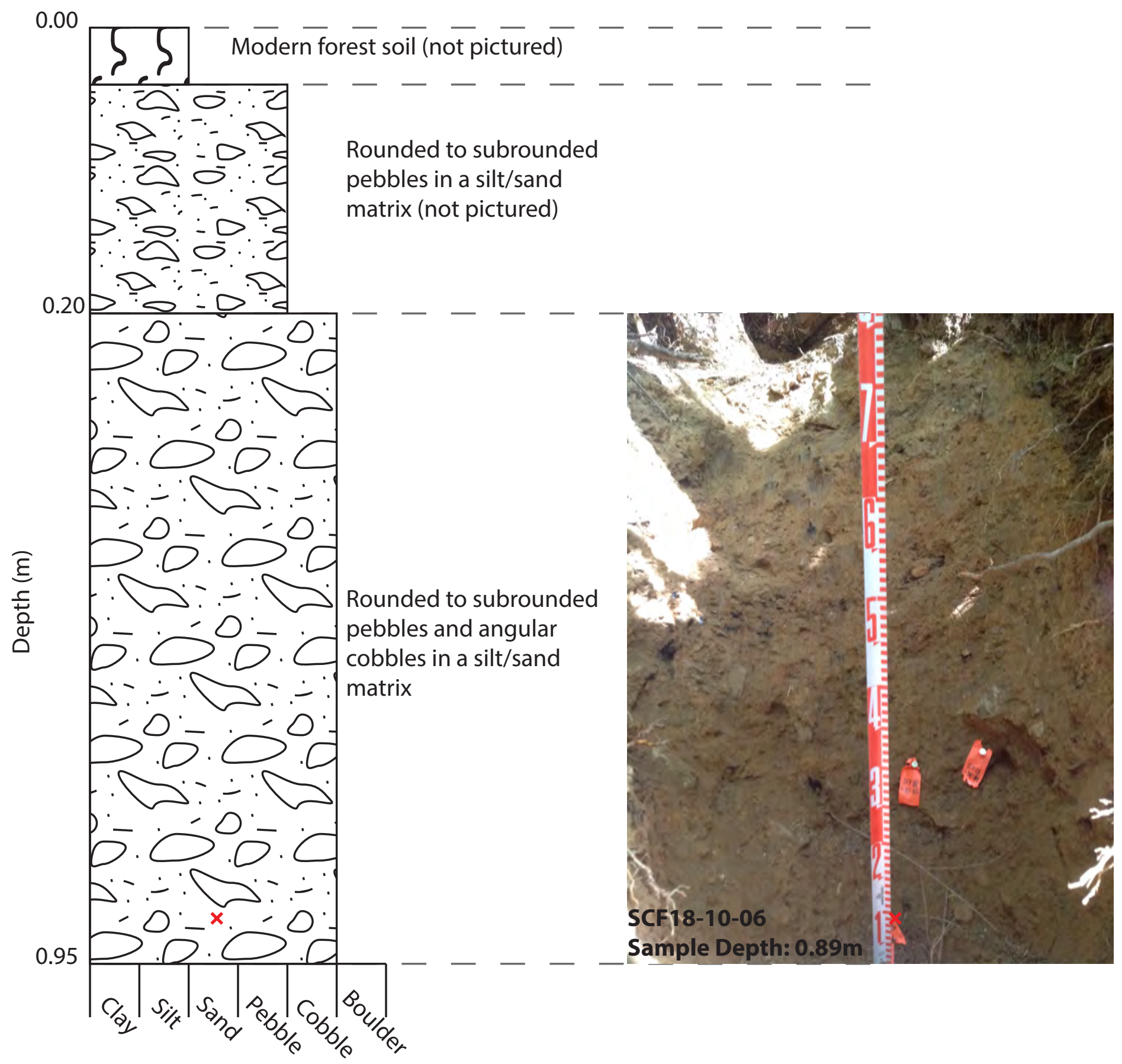




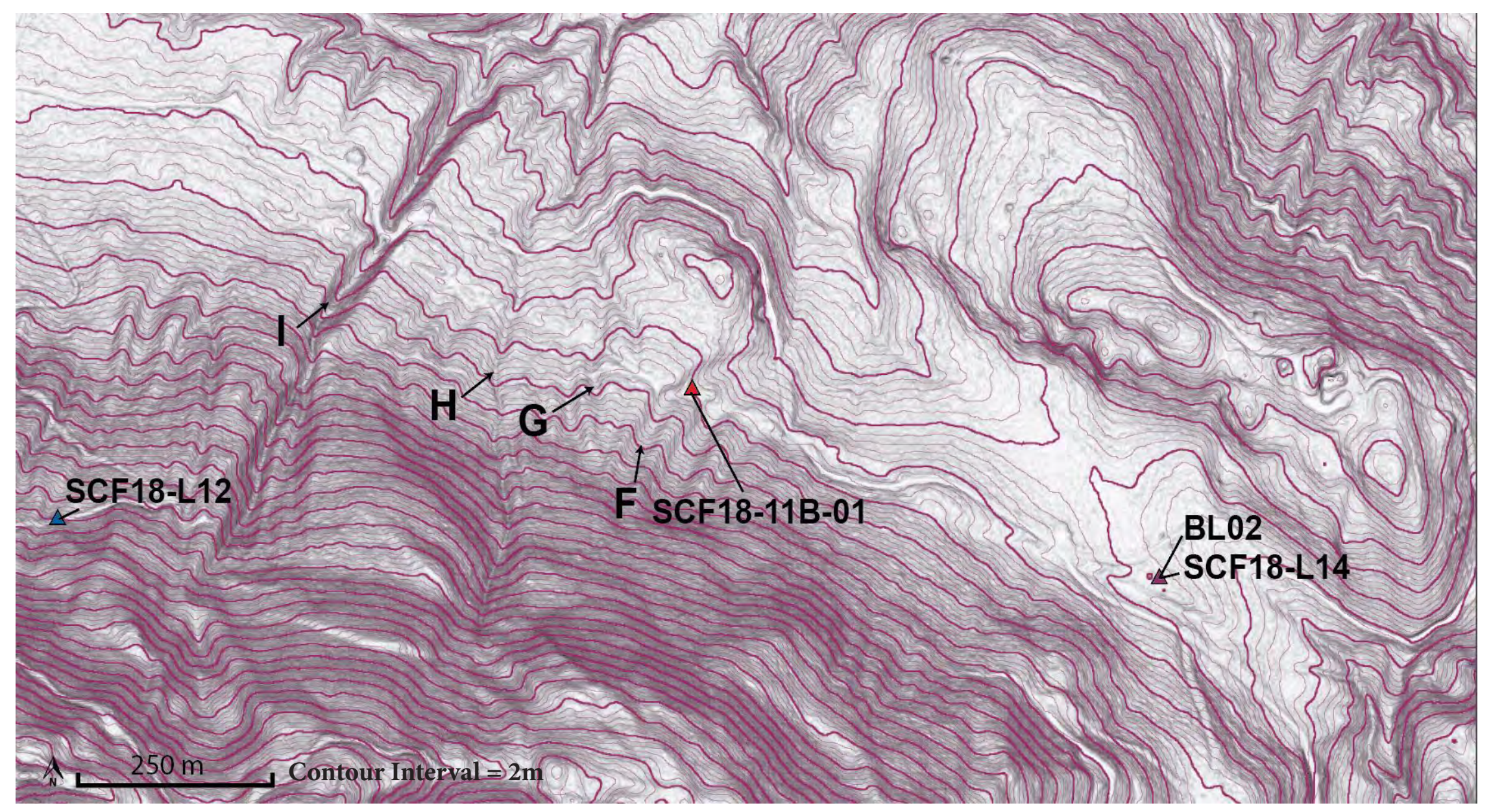




\section{SCF18-L14}

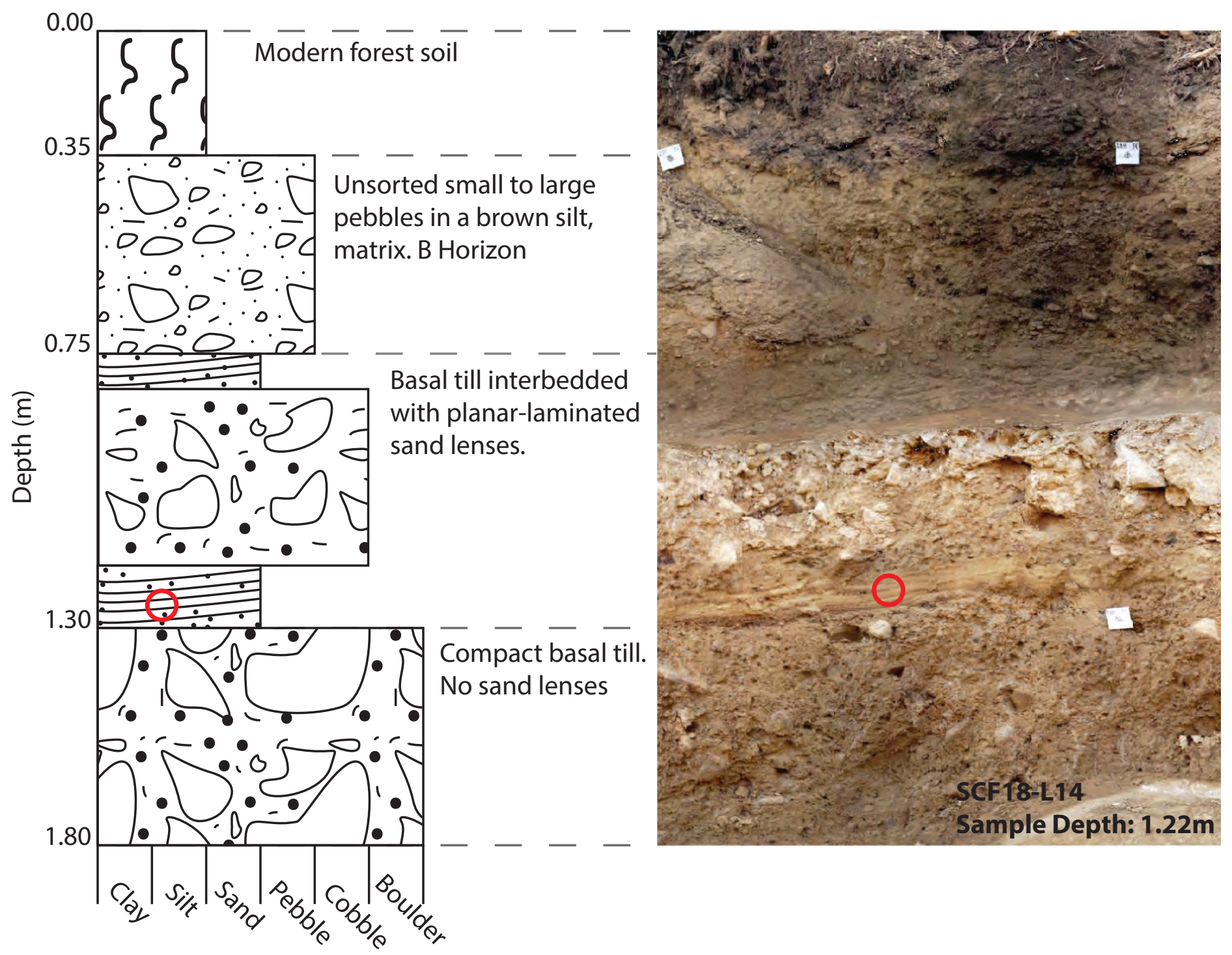




\section{BL02}

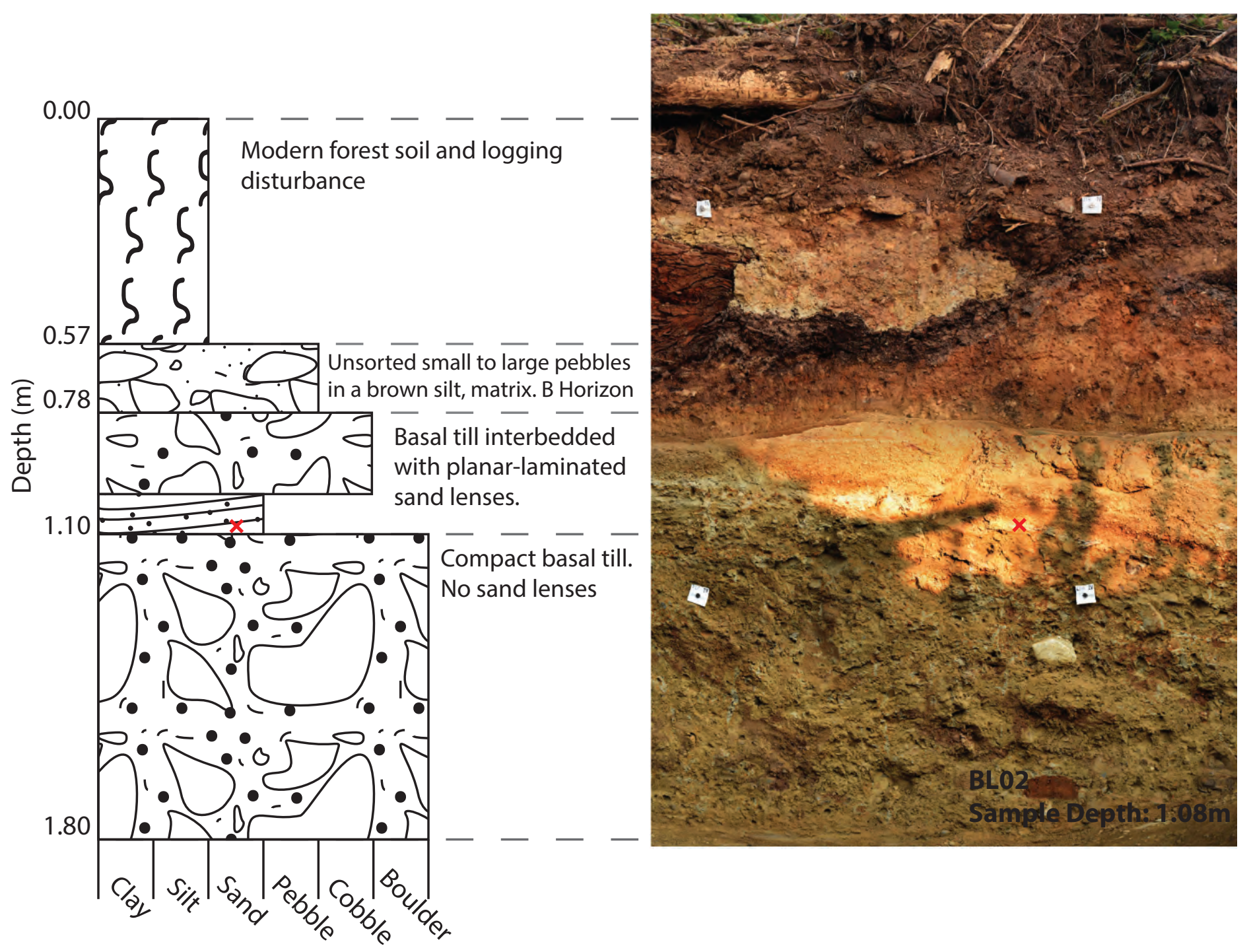




\section{SCF18-11B-01}

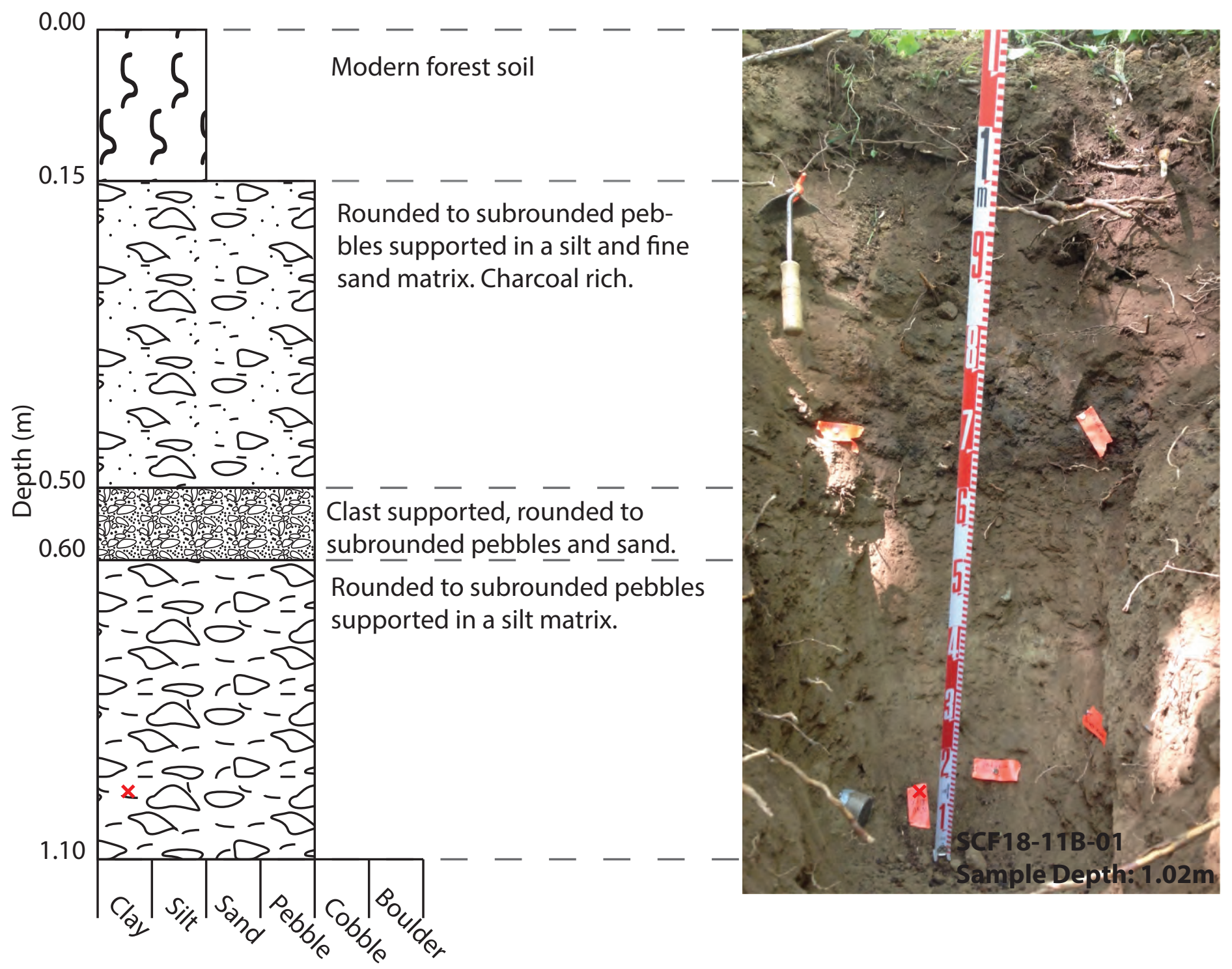




\section{SCF18-L12}
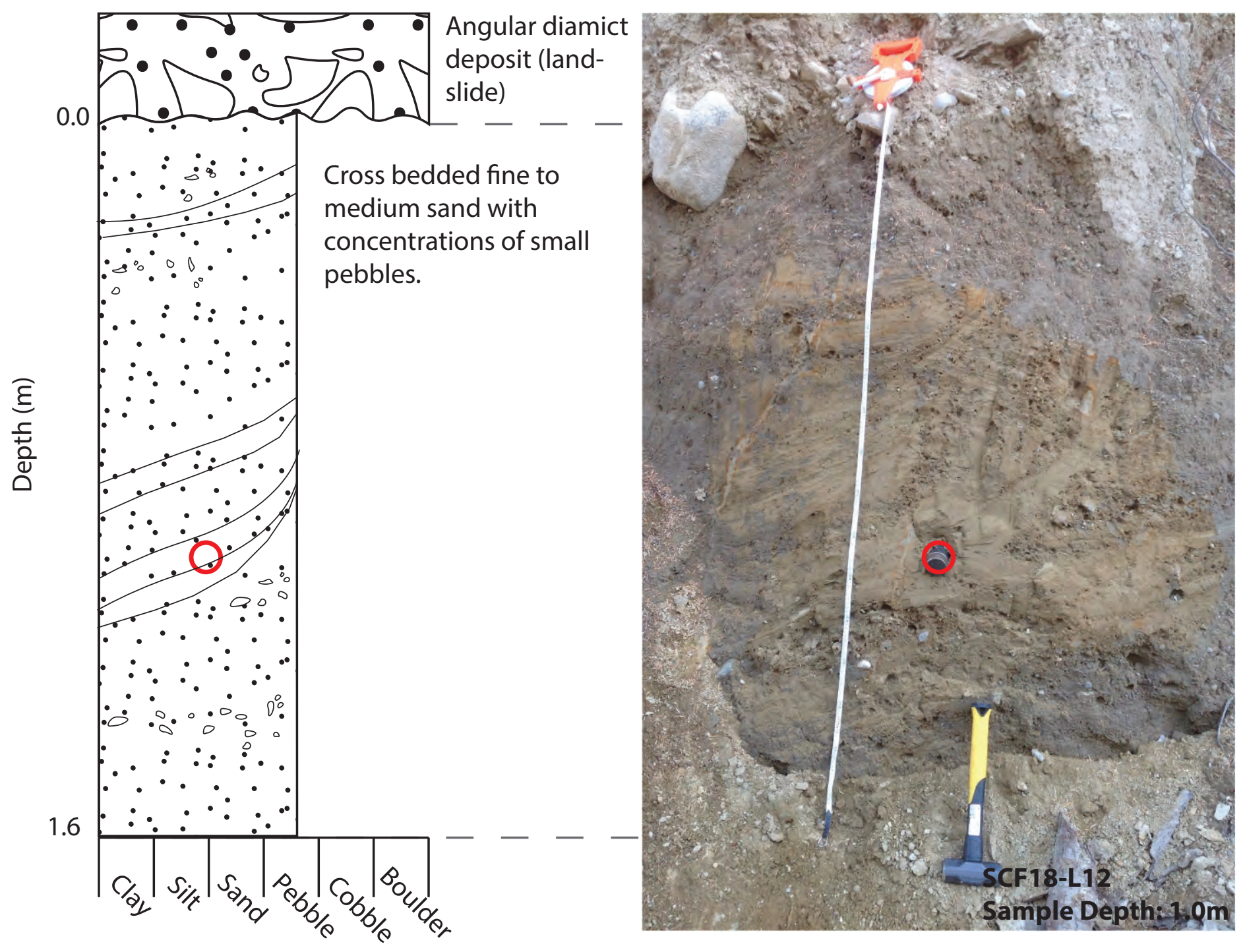


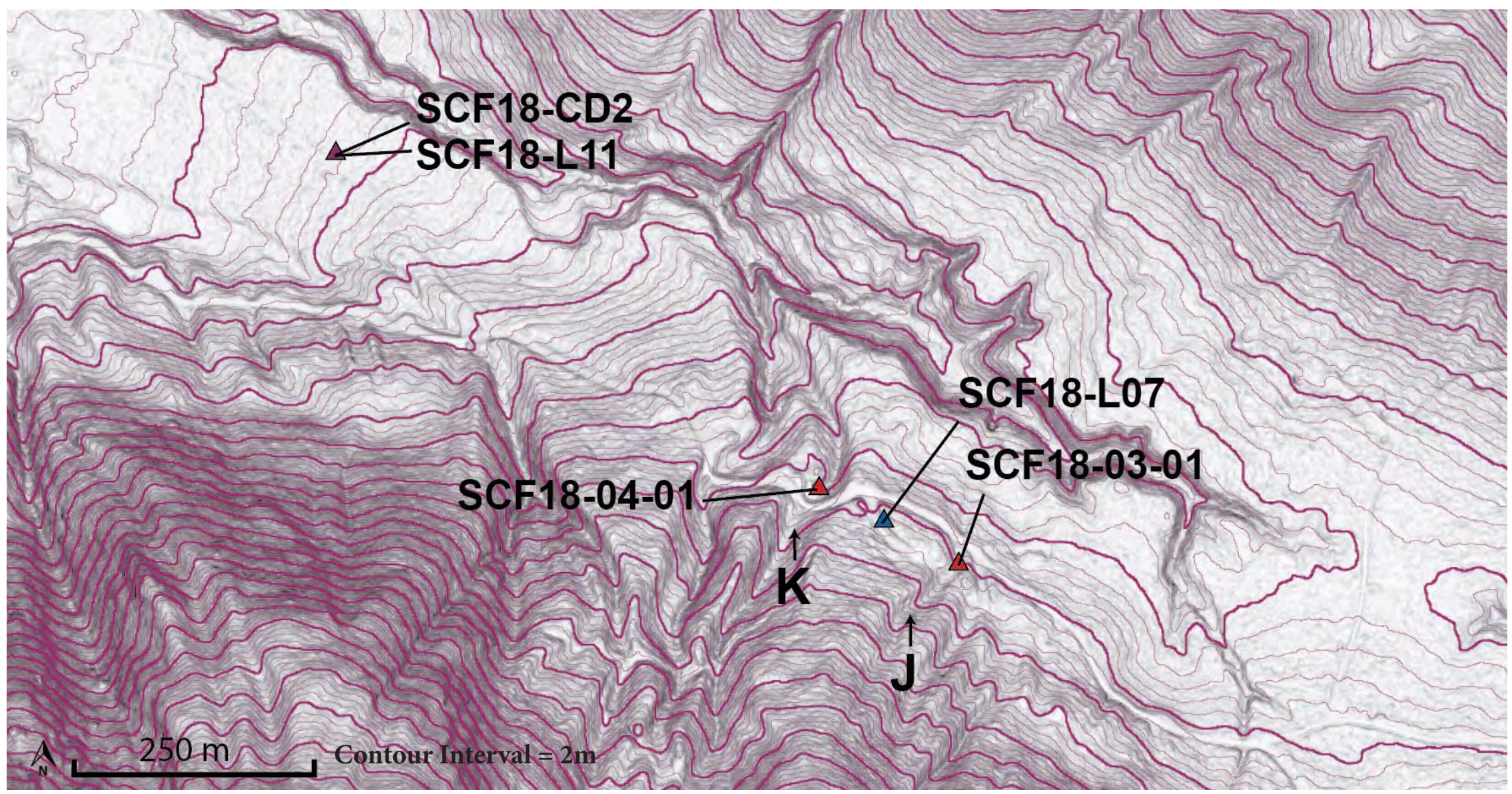




\section{SCF18-03-01}
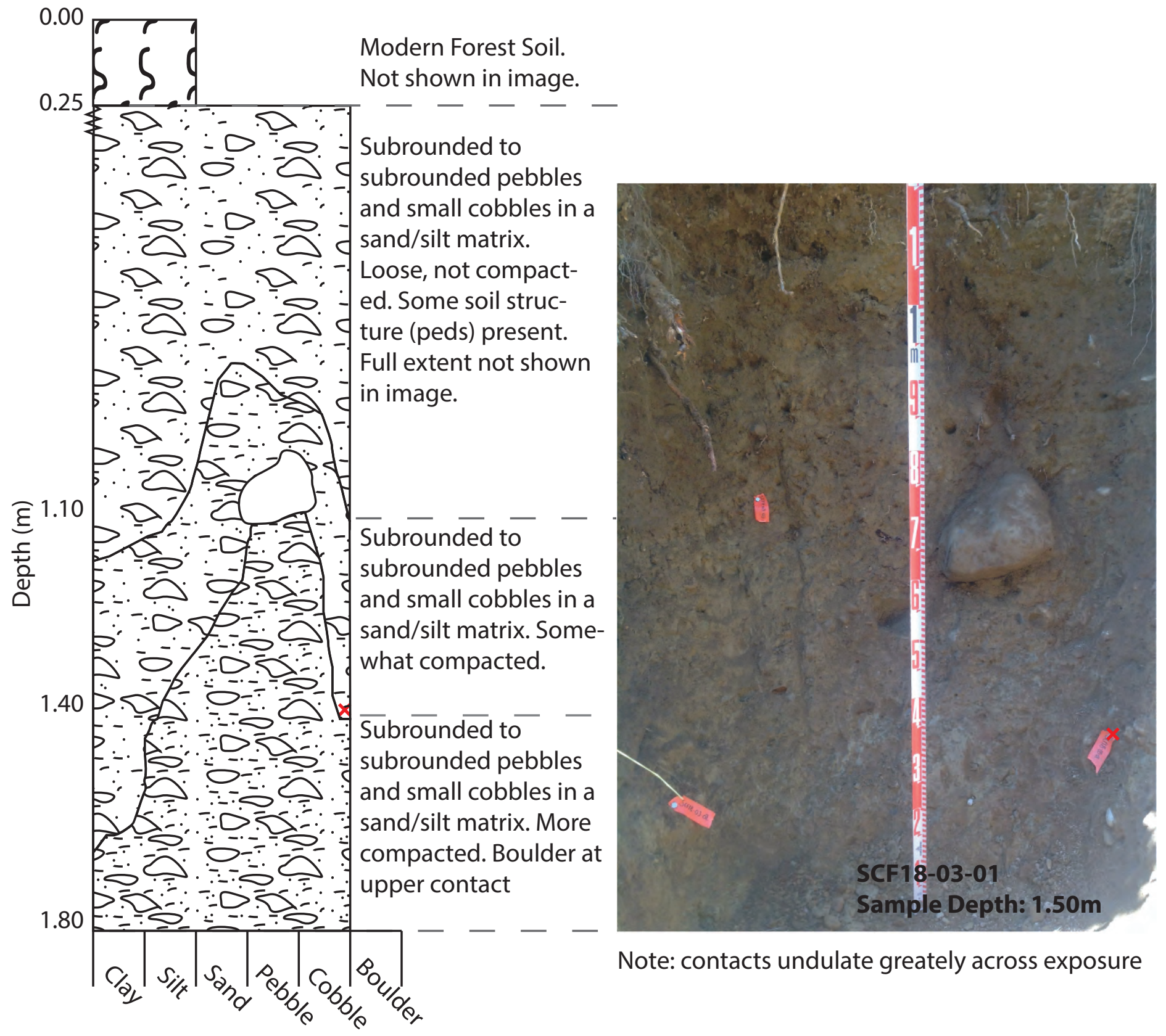

Note: contacts undulate greately across exposure 


\section{SCF18-L07}

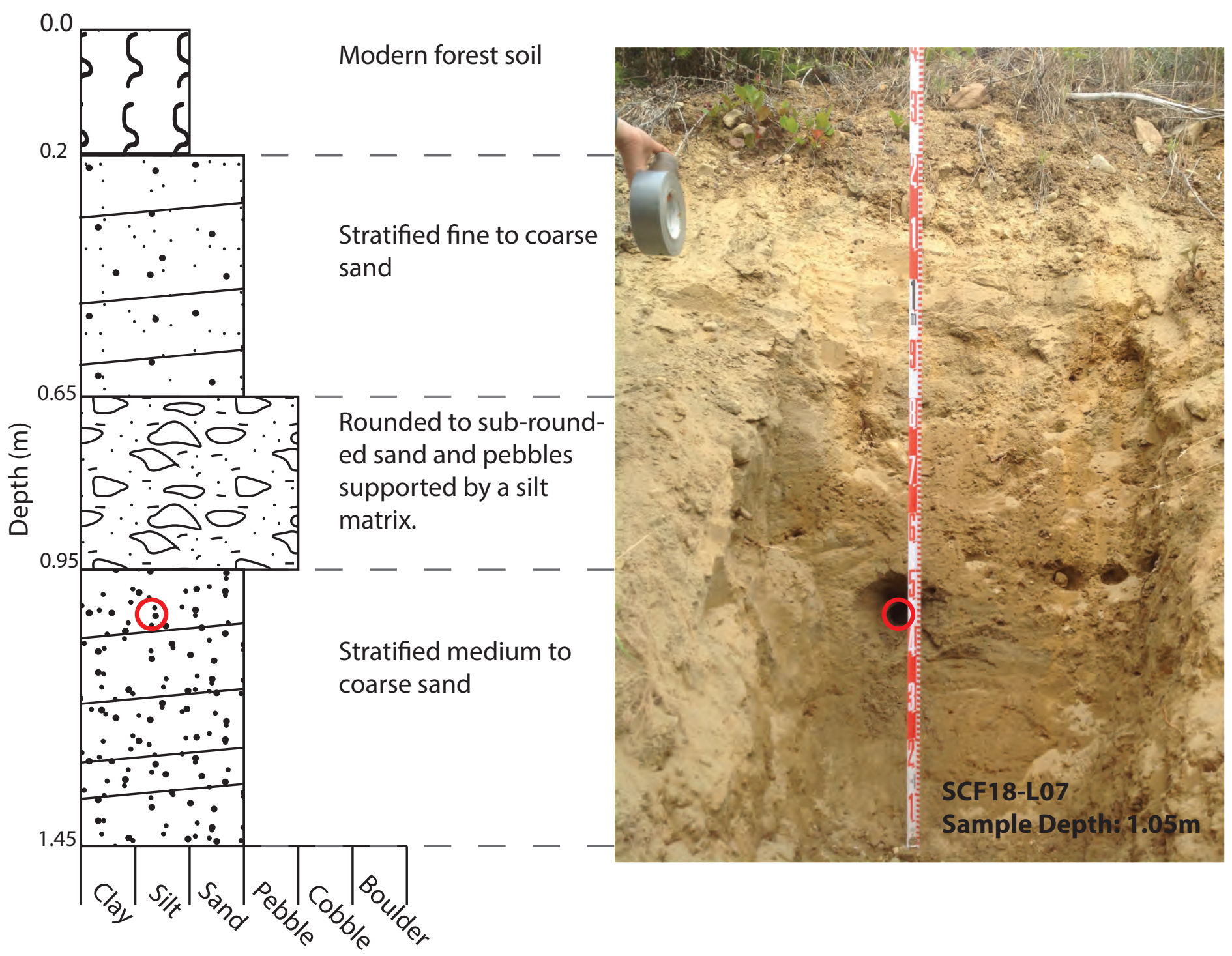




\section{SCF18-04-01}

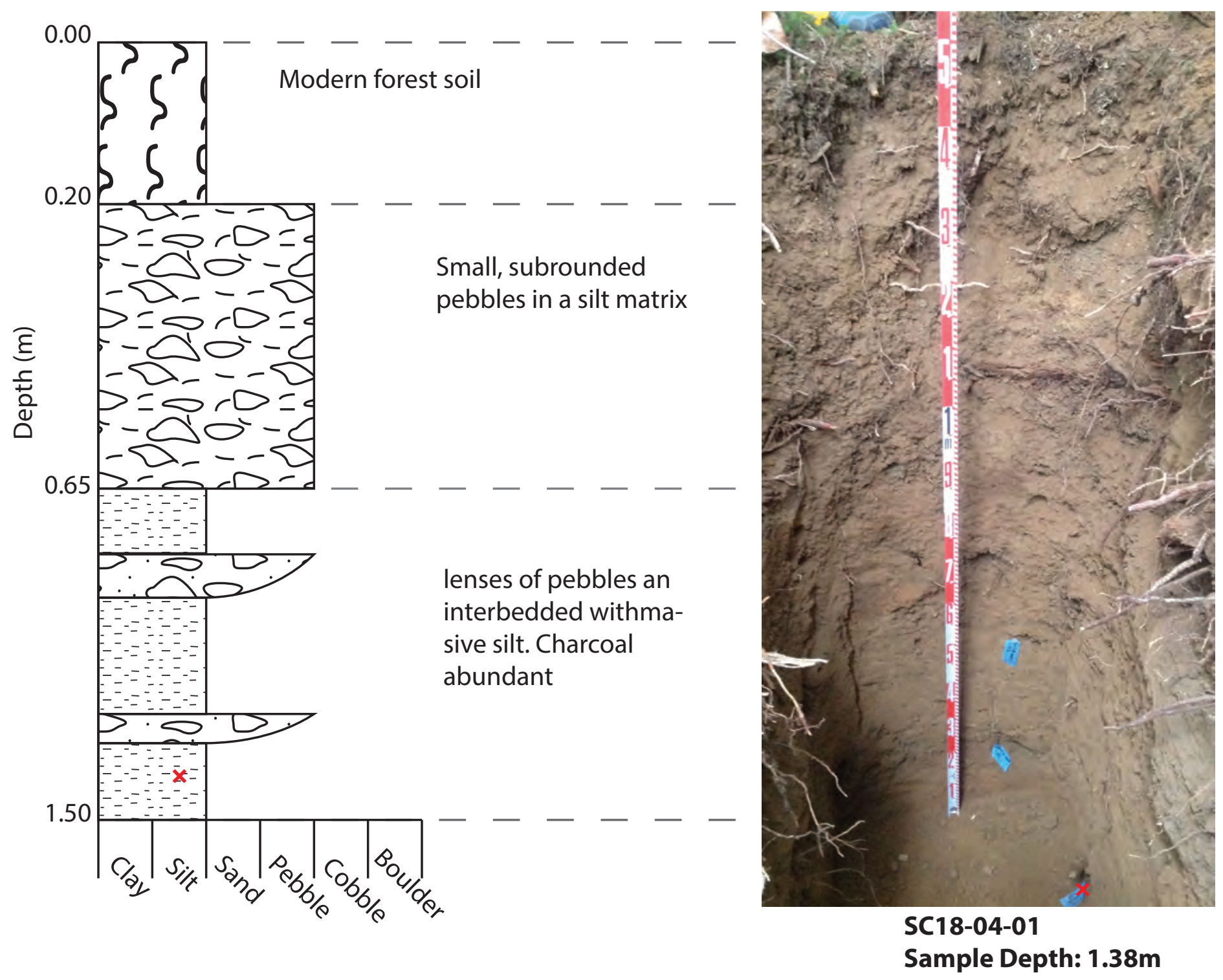

Note: sample take from right (in picture) wall of exposure 


\section{SCF18-L11 \& SCF18-CD2}

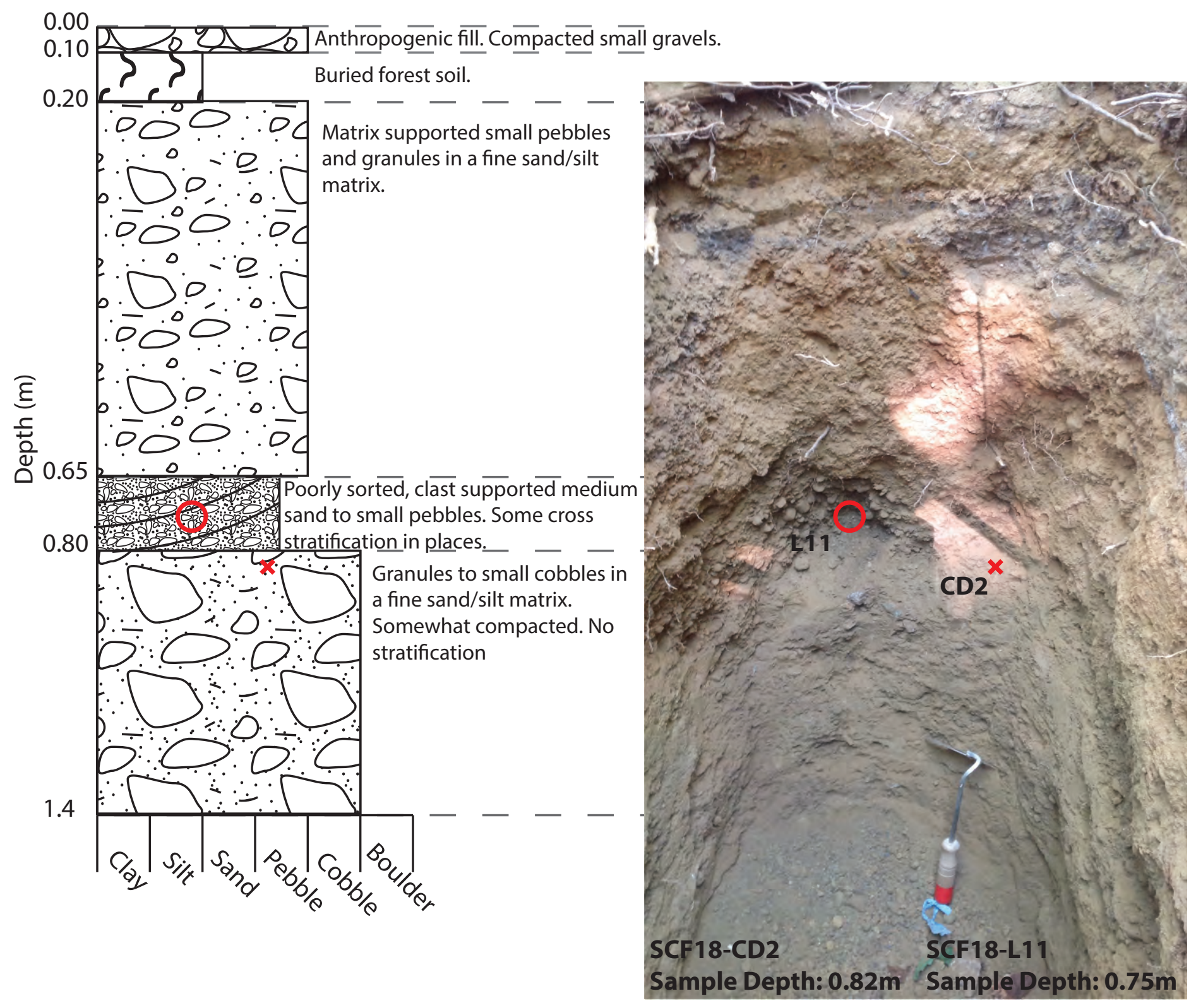




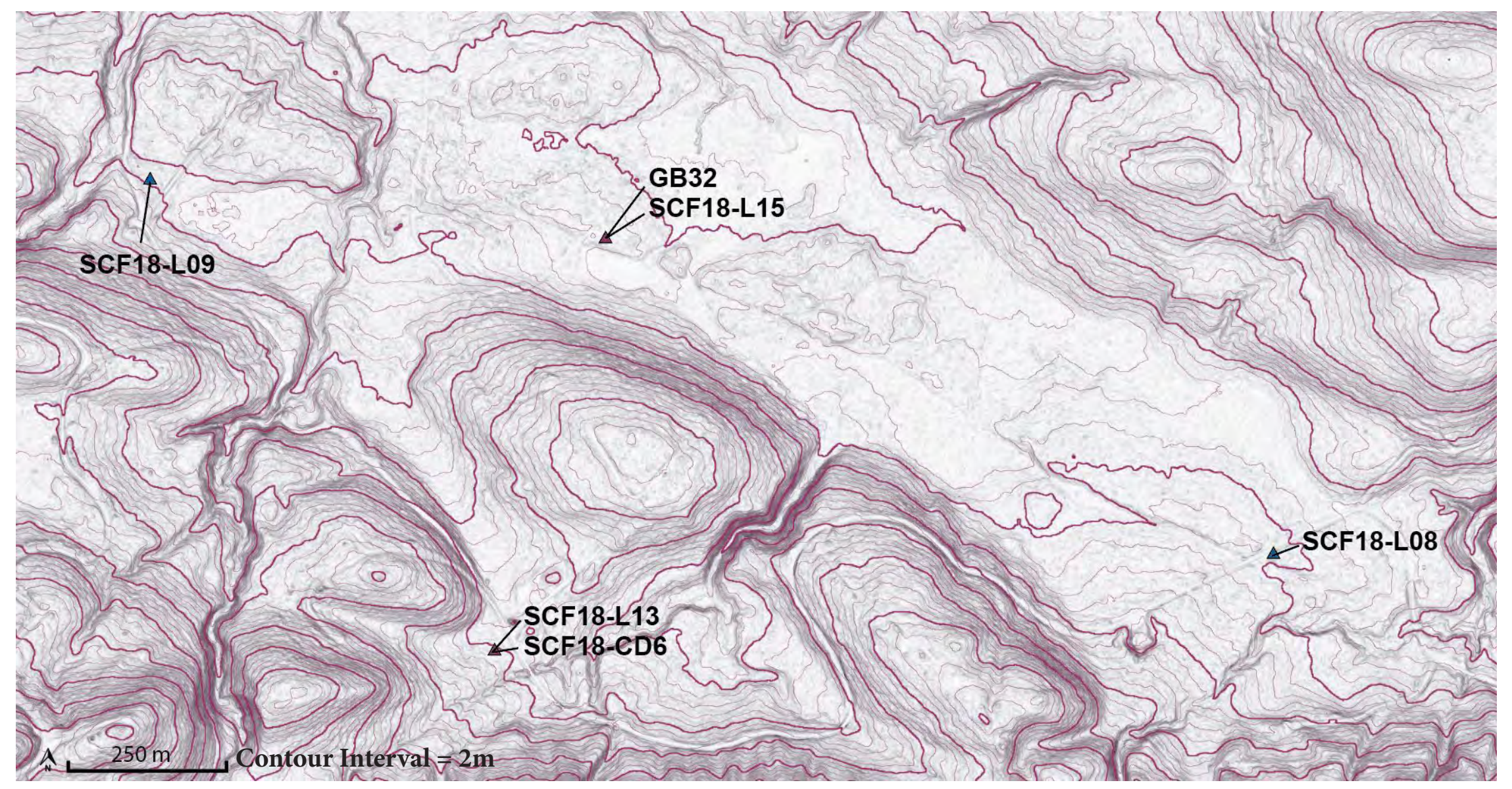




\section{SCF18-L08}

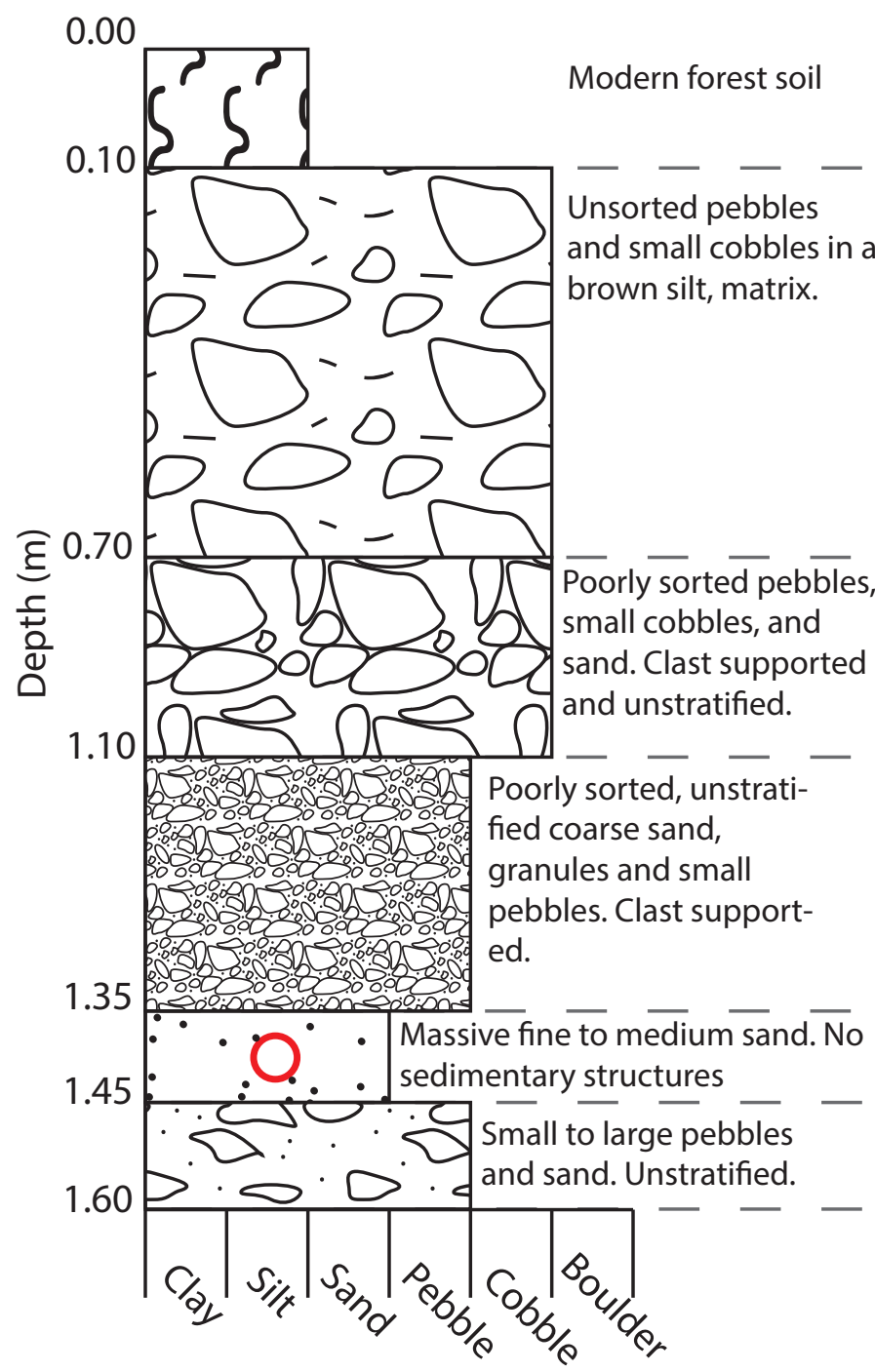

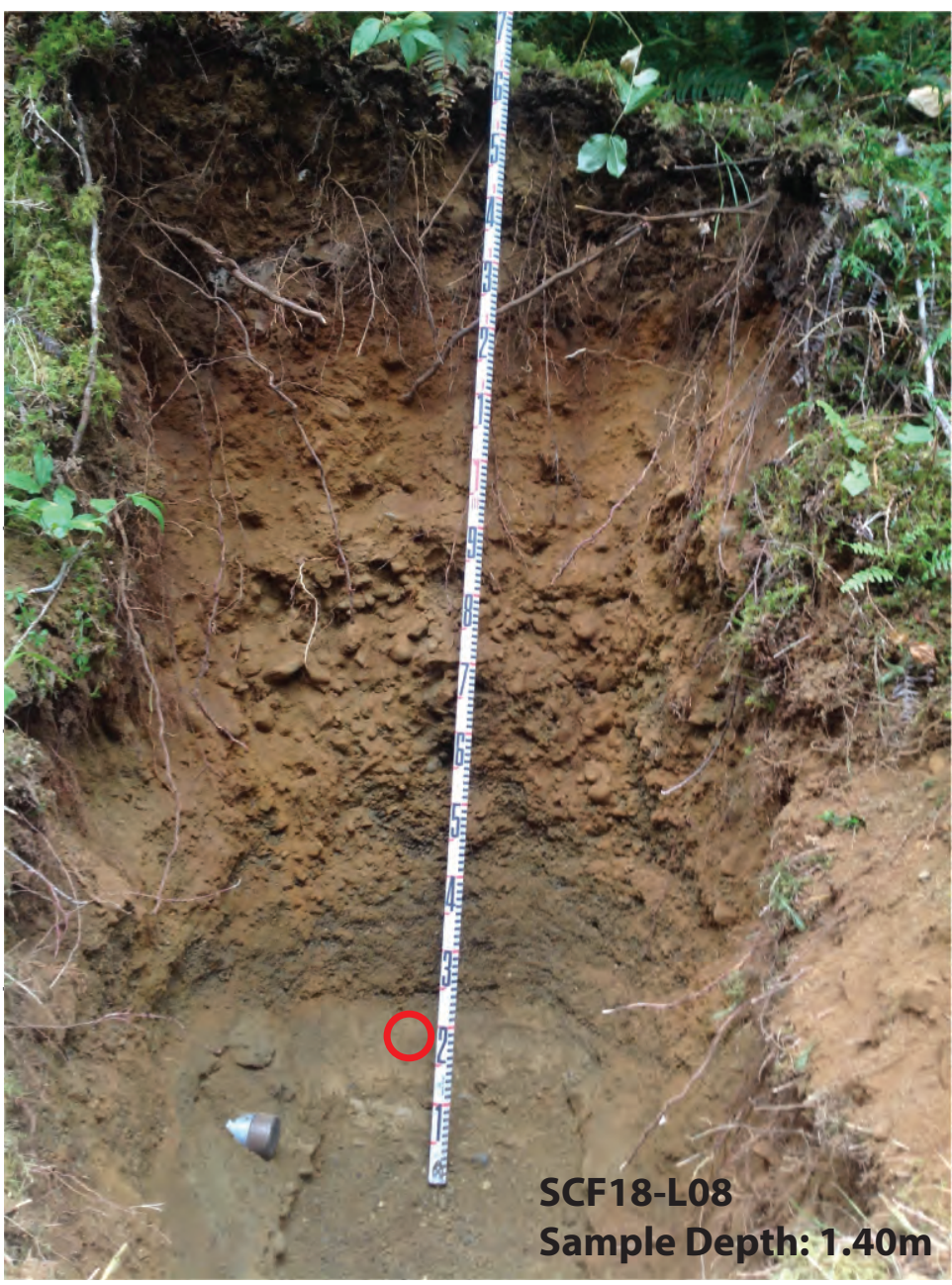

Note: Sample taken on side of exposure. Red circle marks equivalent sample position at front of exposure. 


\section{SCF18-L13 \& SCF18-CD6}

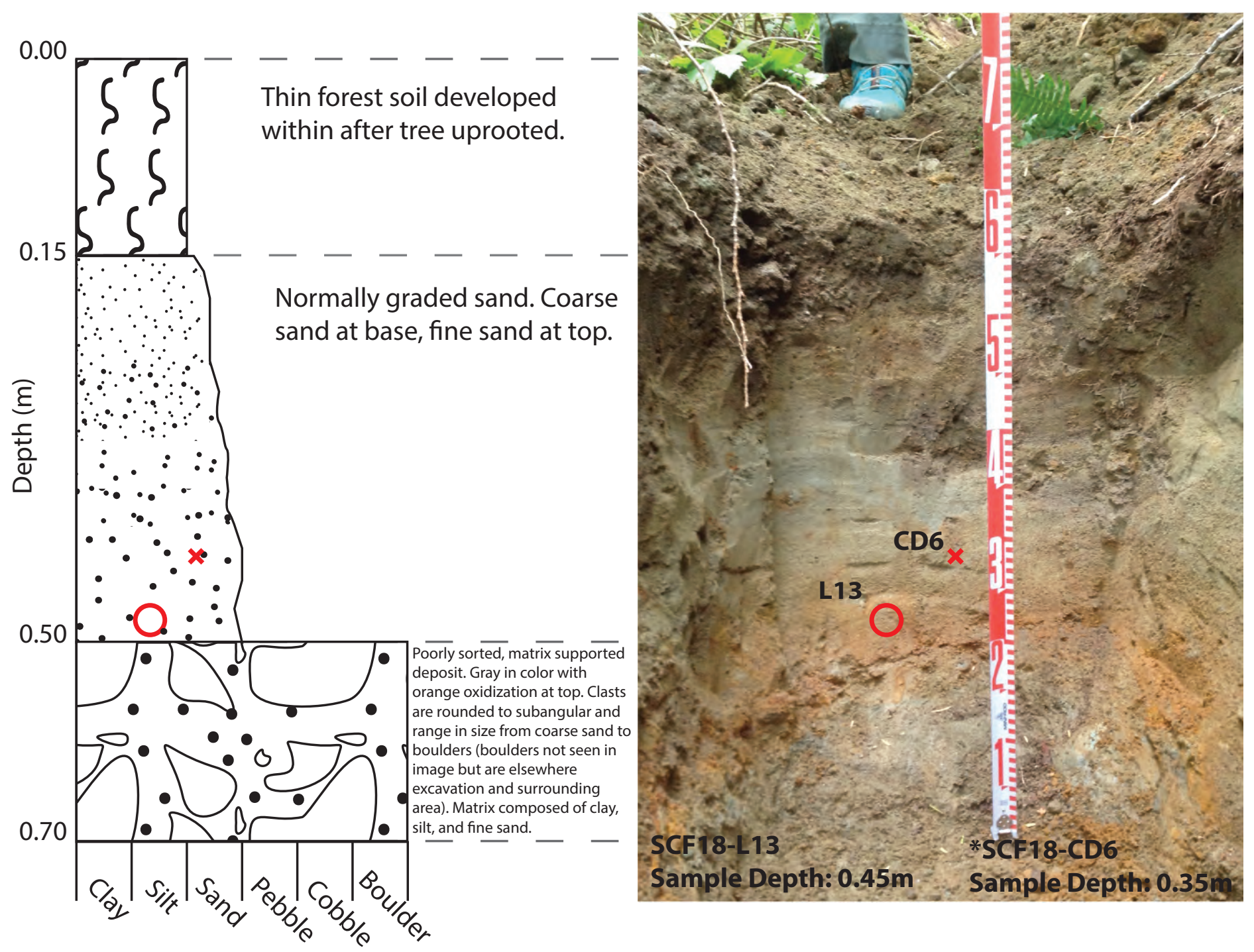

*SCF18-CD6 taken from opposite wall. X marks the approximate location of sample 


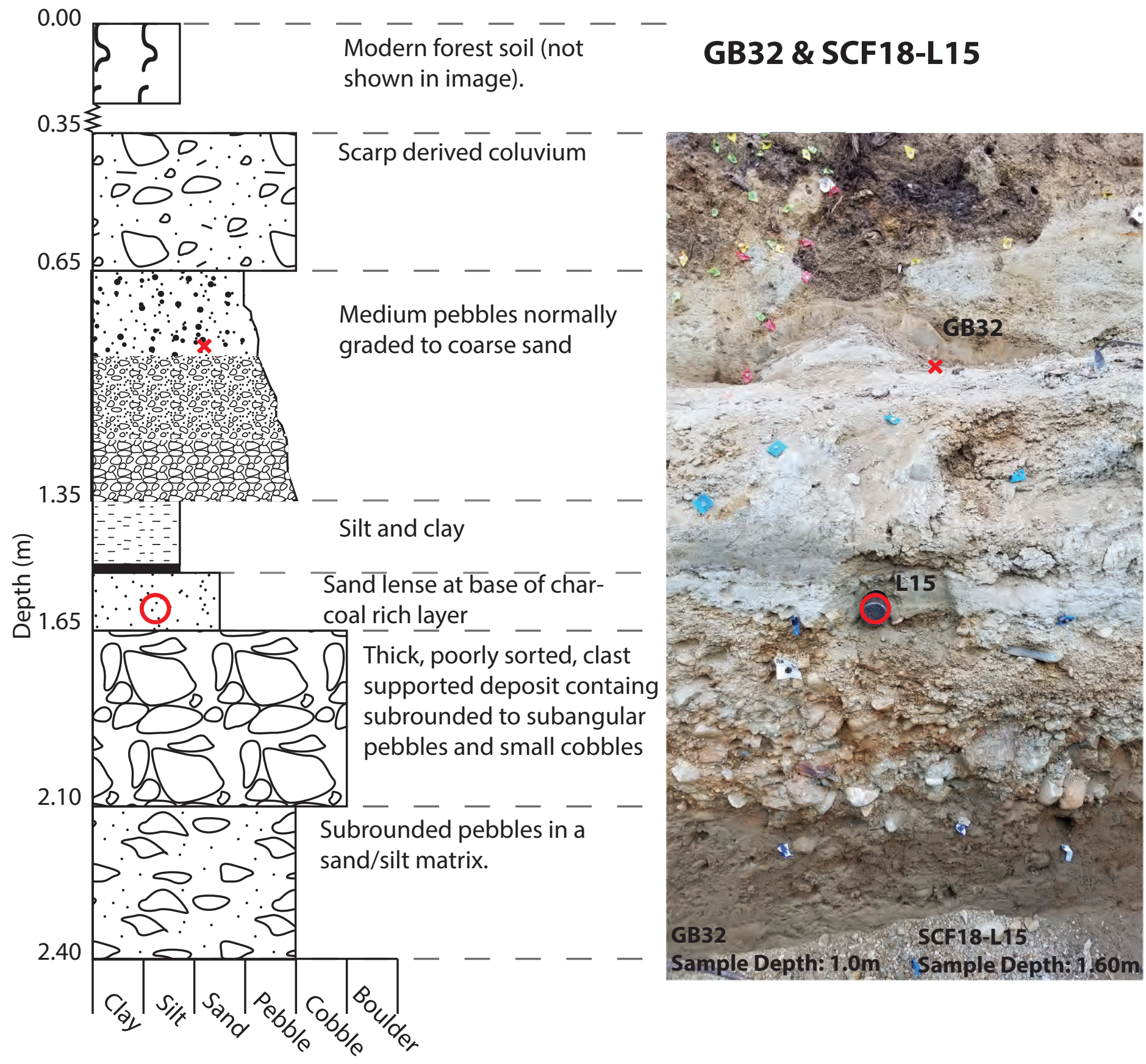

*GB32 taken from opposite wall of trench. X marks the approximate stratigraphic location of sample 


\section{SCF18-L09}

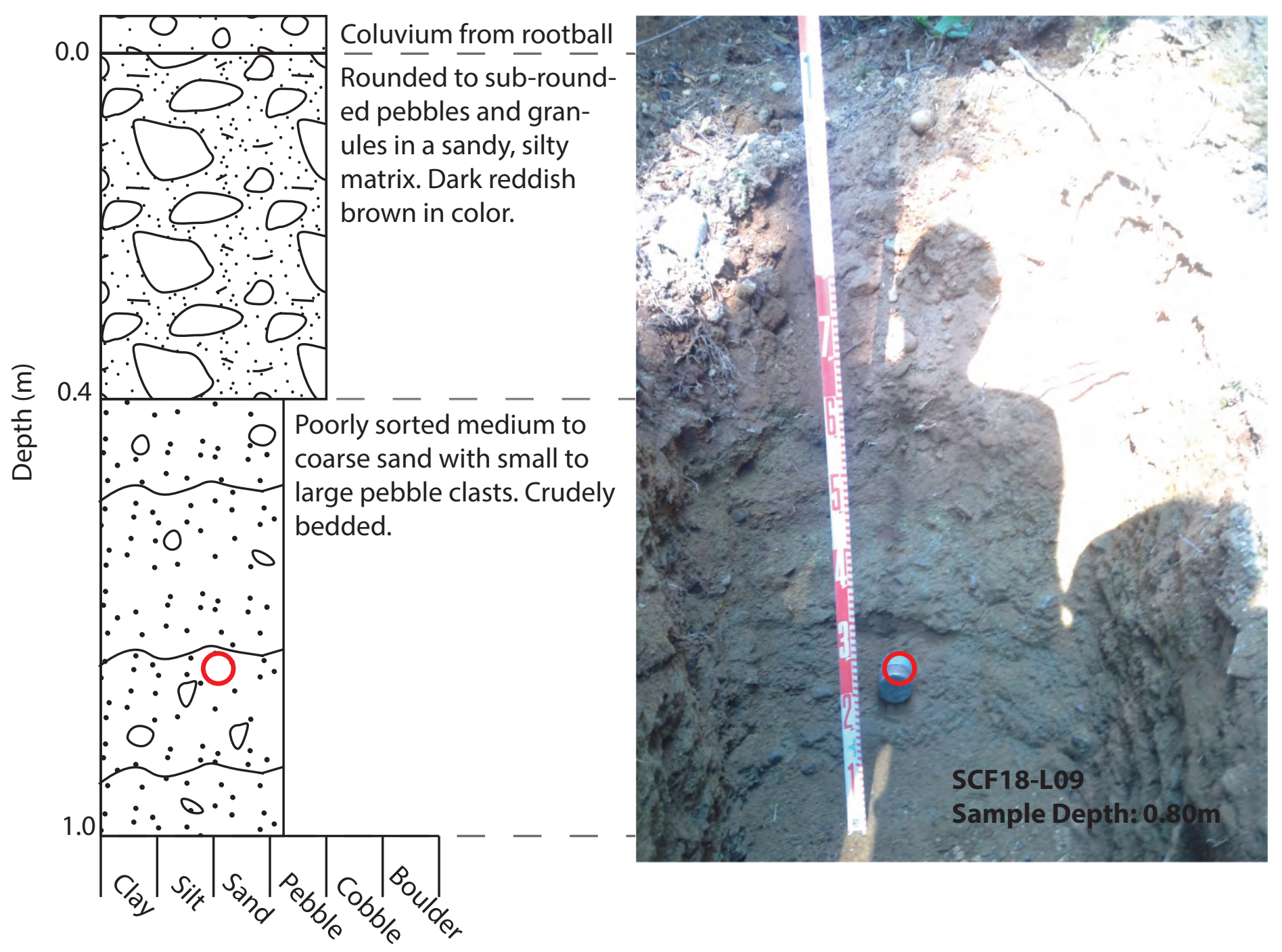




\section{Supplemental Document S7}

All 66 megathrust earthquake BEM models and results. Each following page shows an individual model run. The CSZ slip distribution used in each model are from Wirth et al. (2018) and Frankel et al. (2018). The rake of CSZ coseismic slip is listed in the top right corner of the page. 

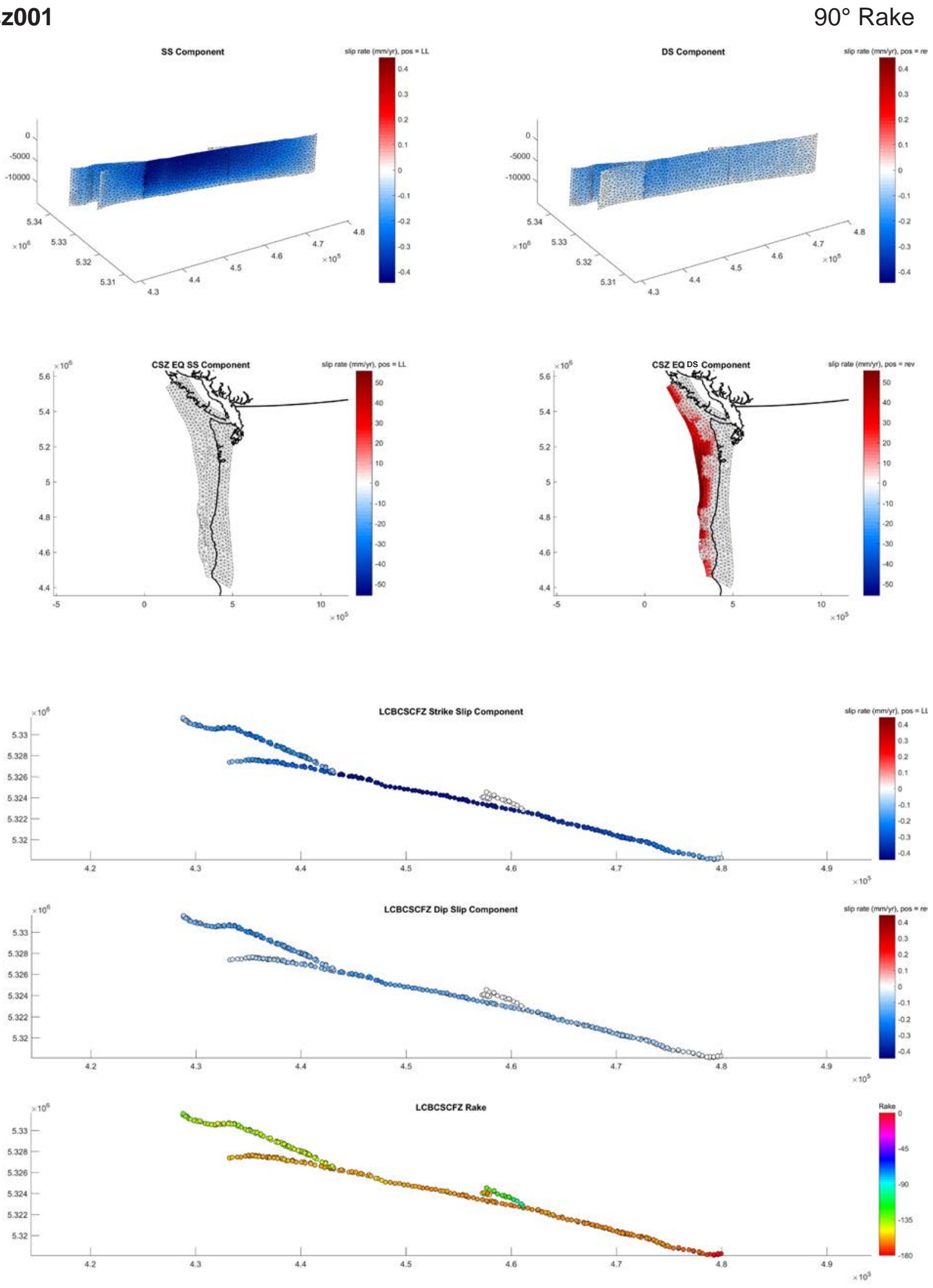

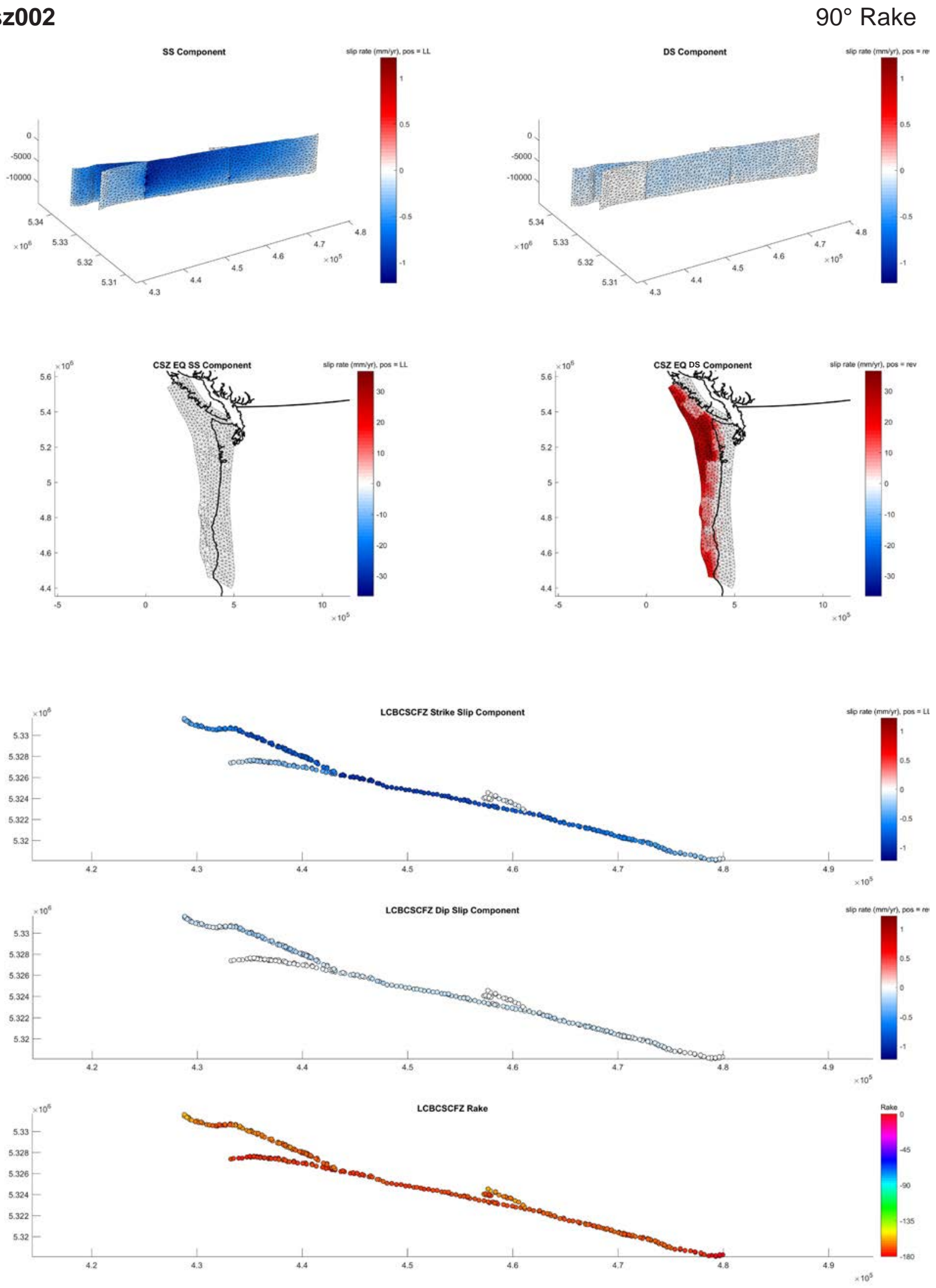

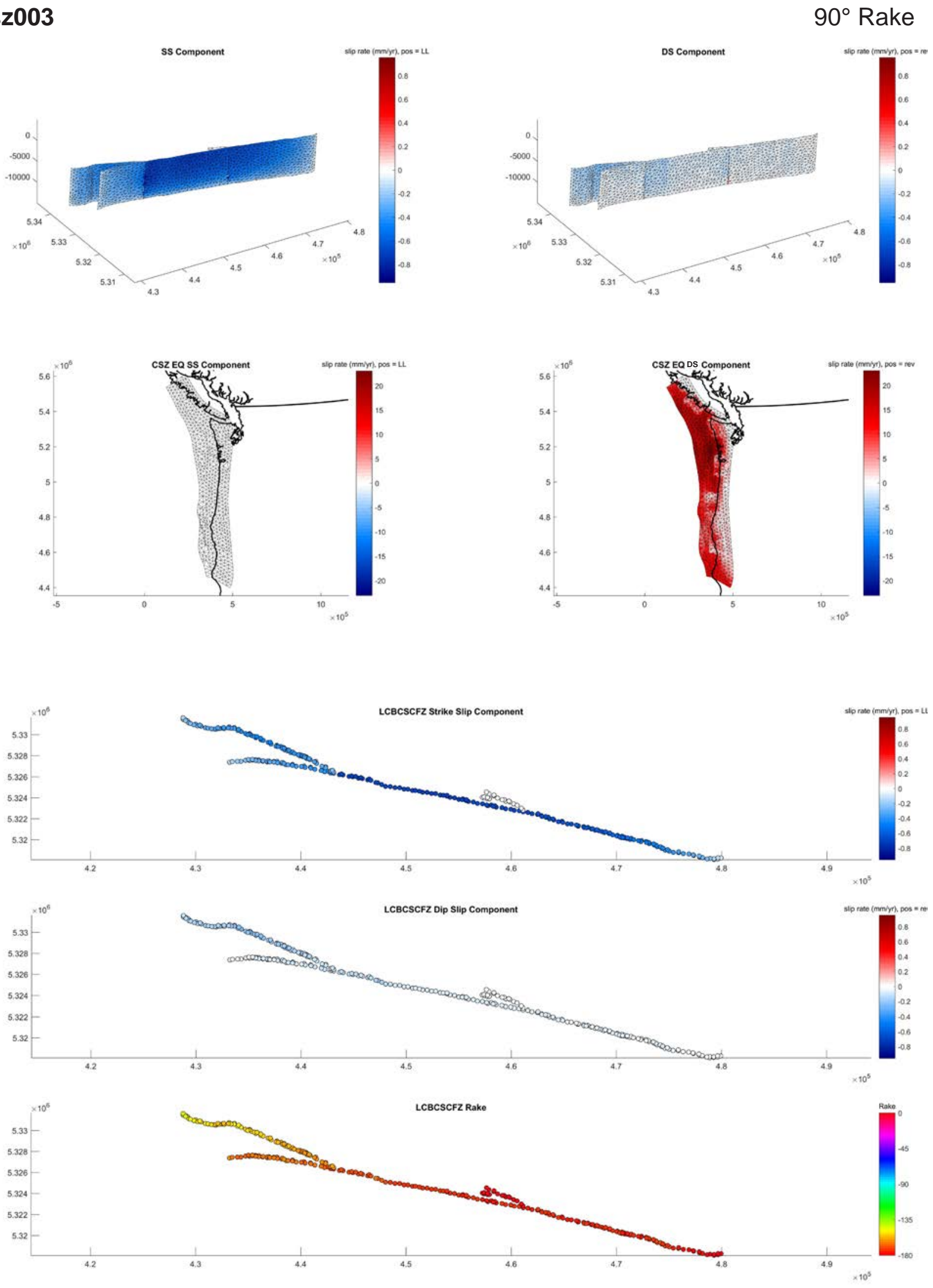

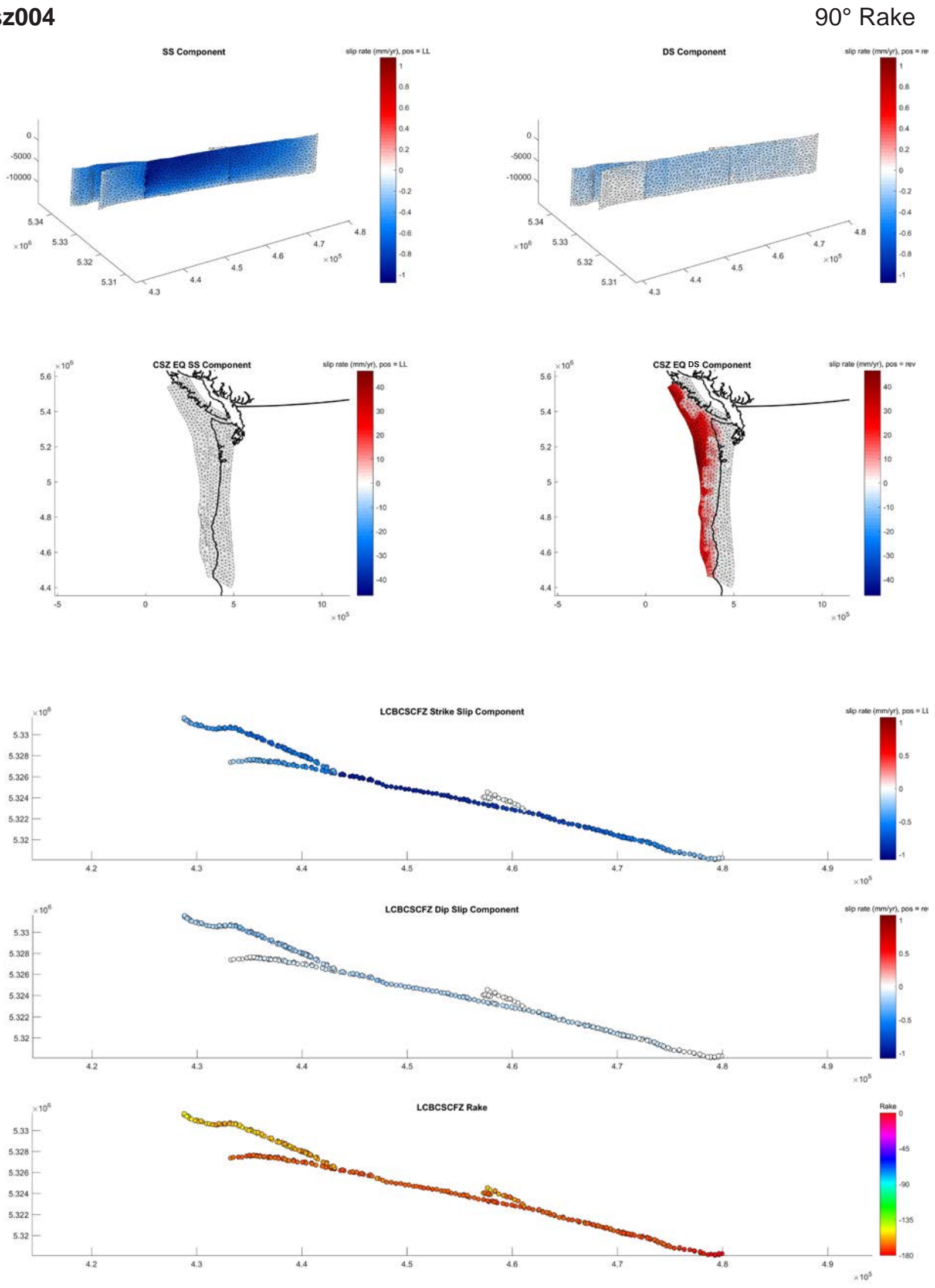

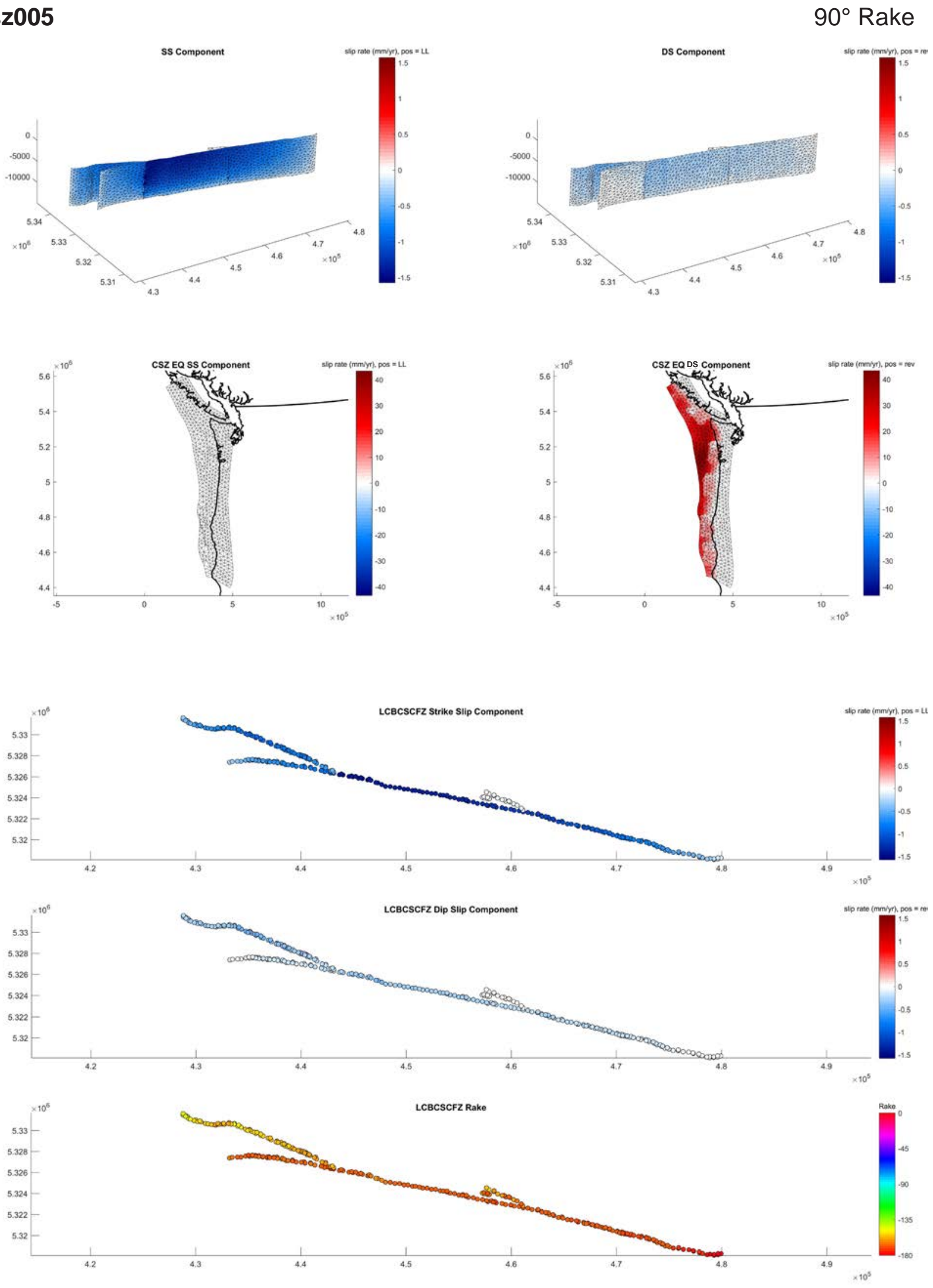

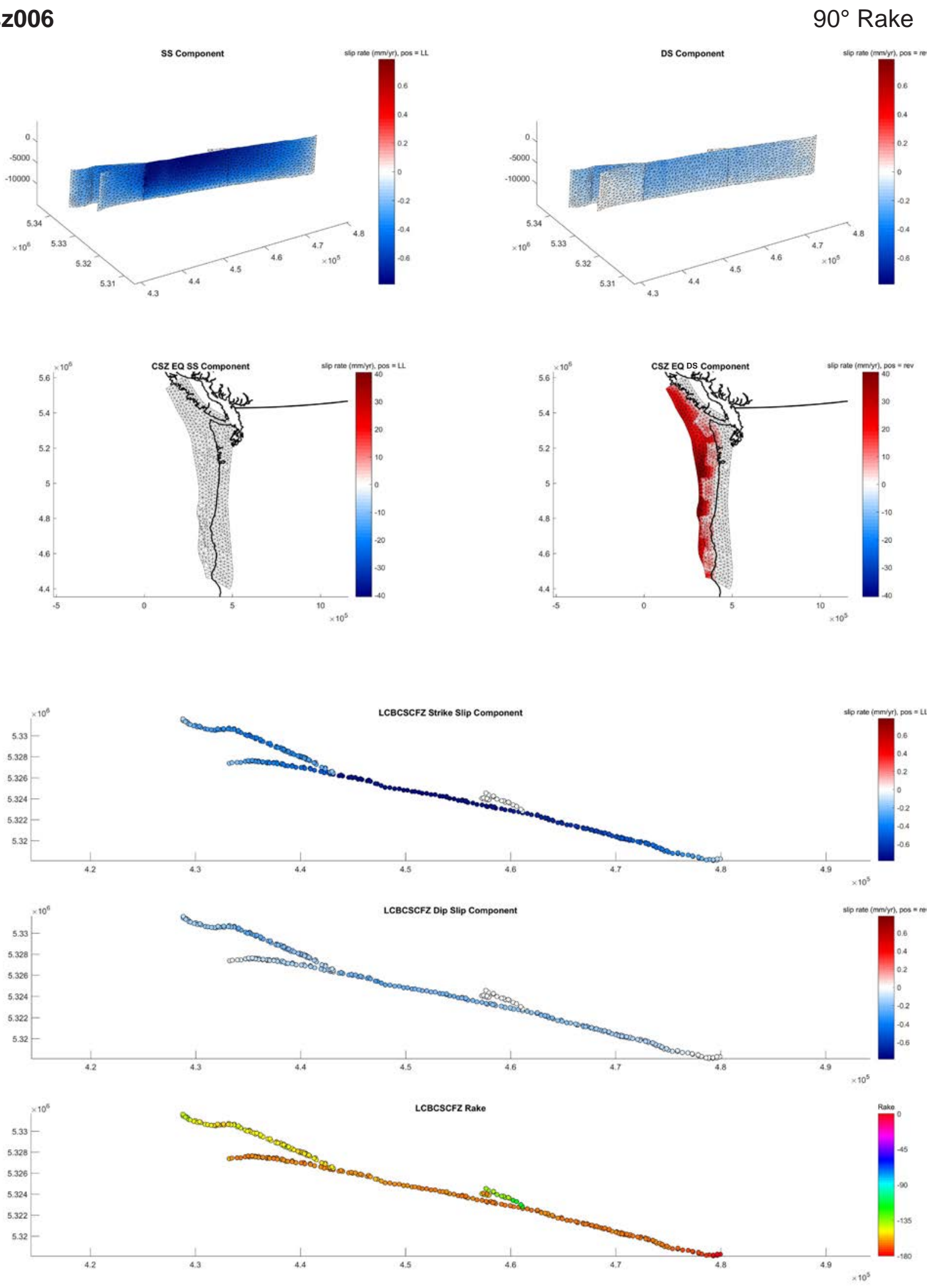

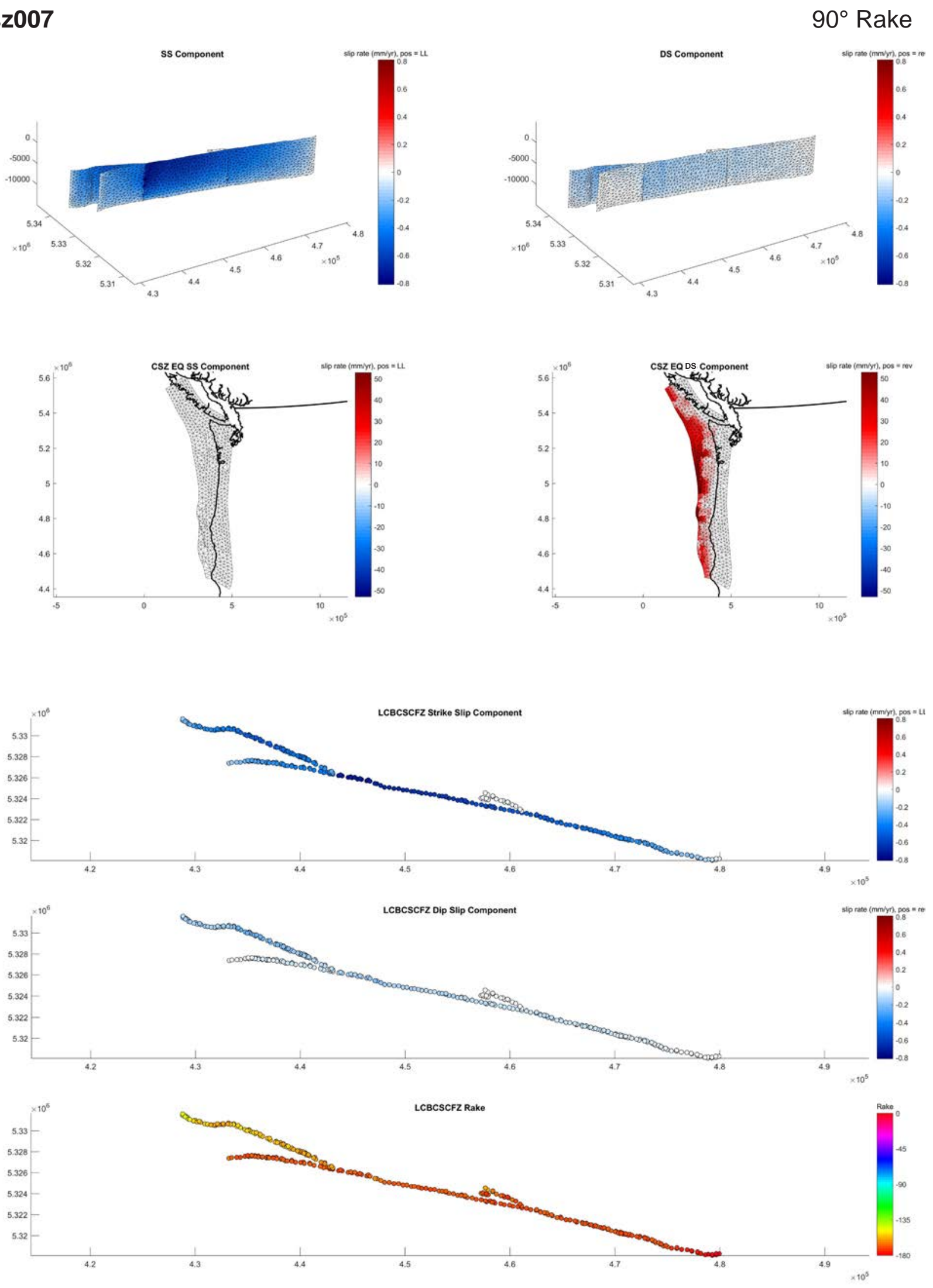

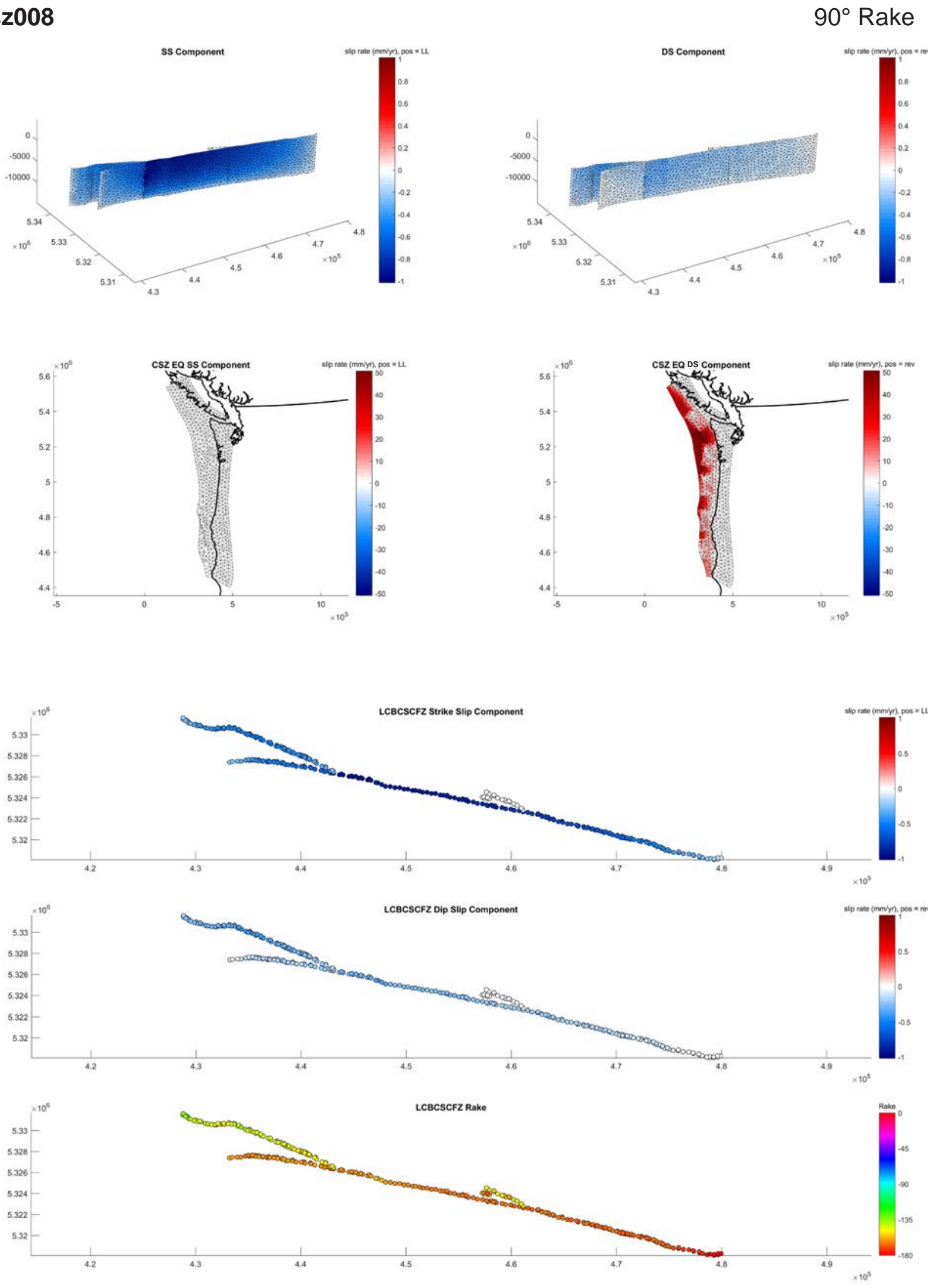

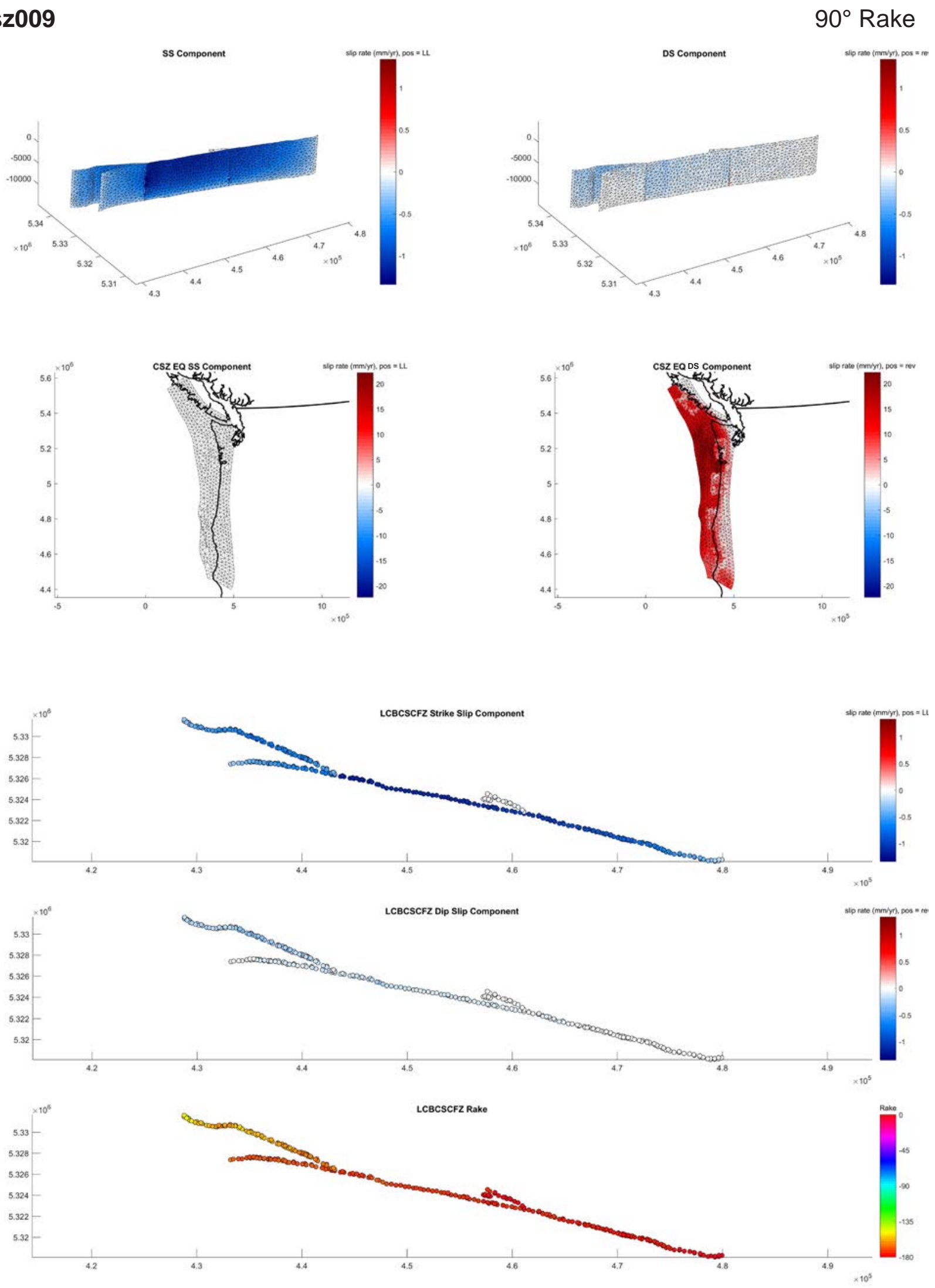

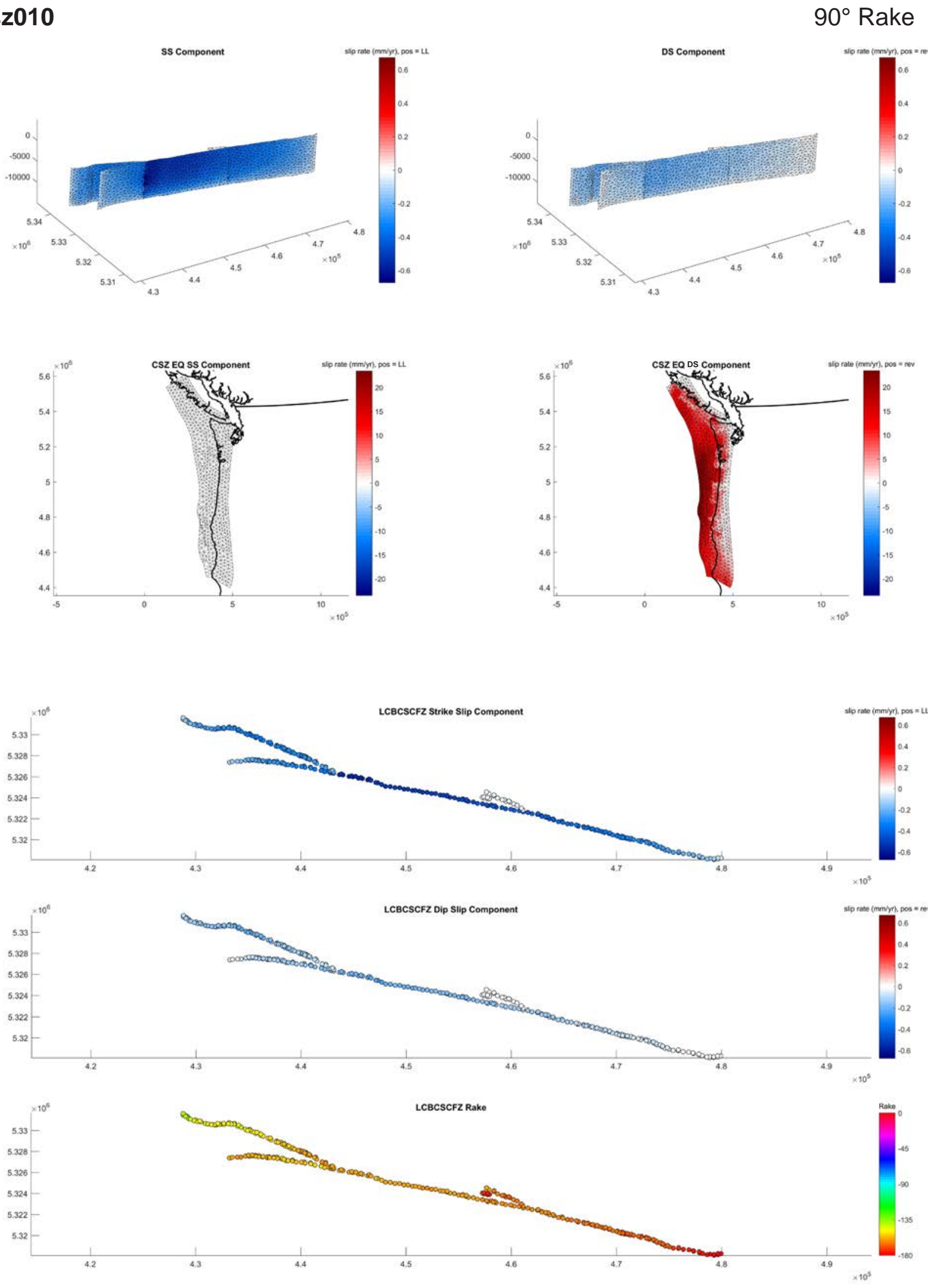

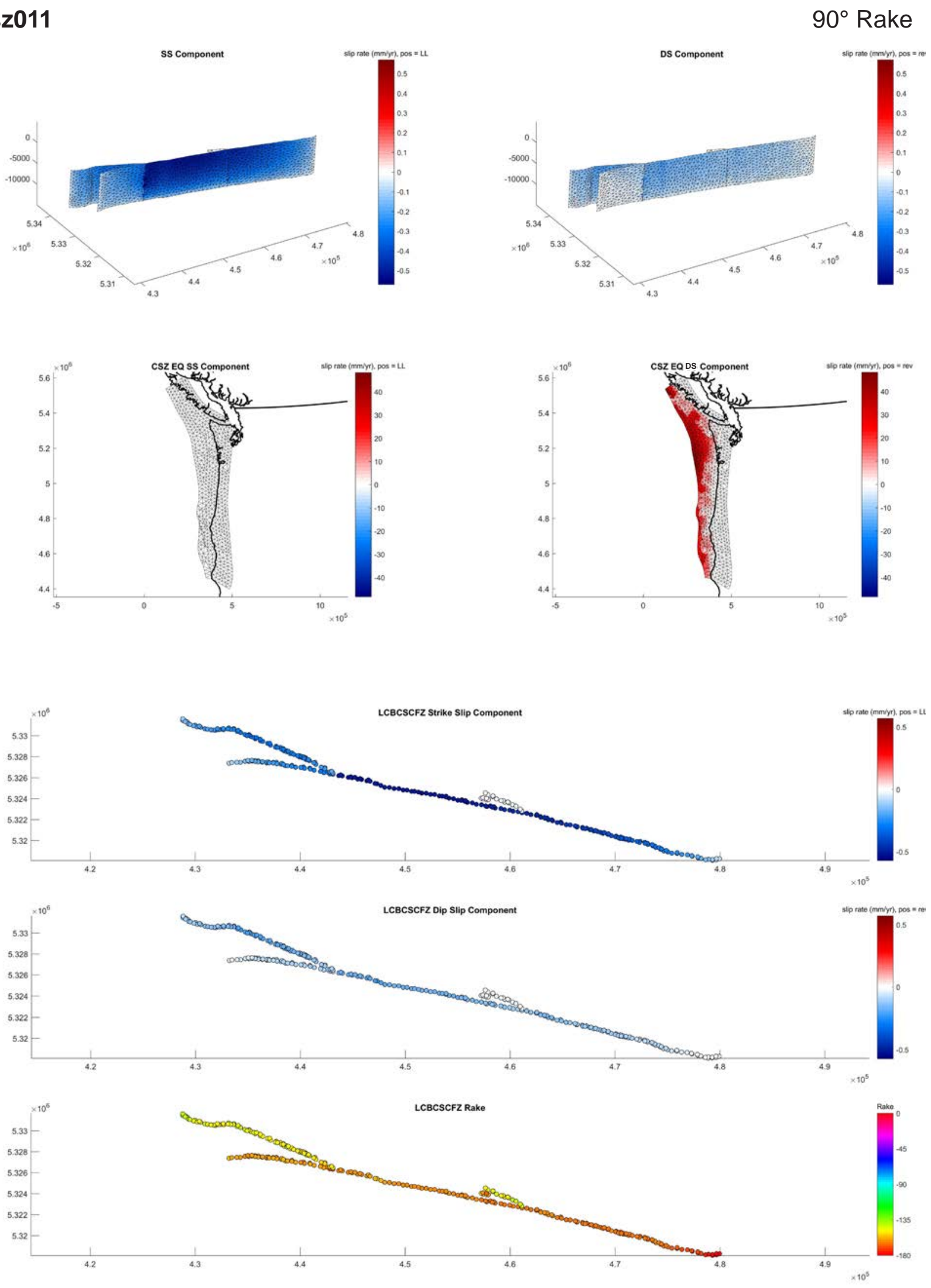

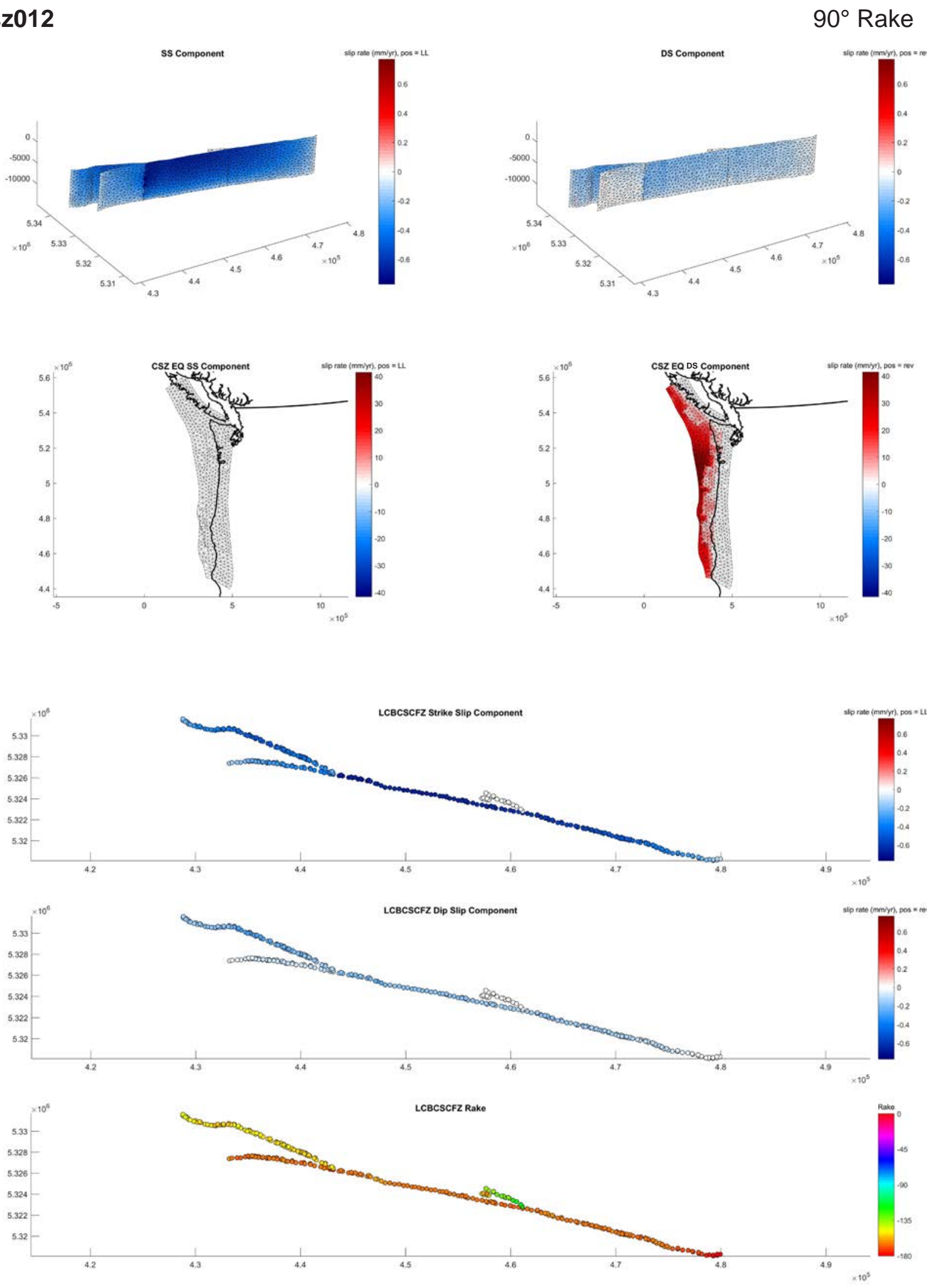

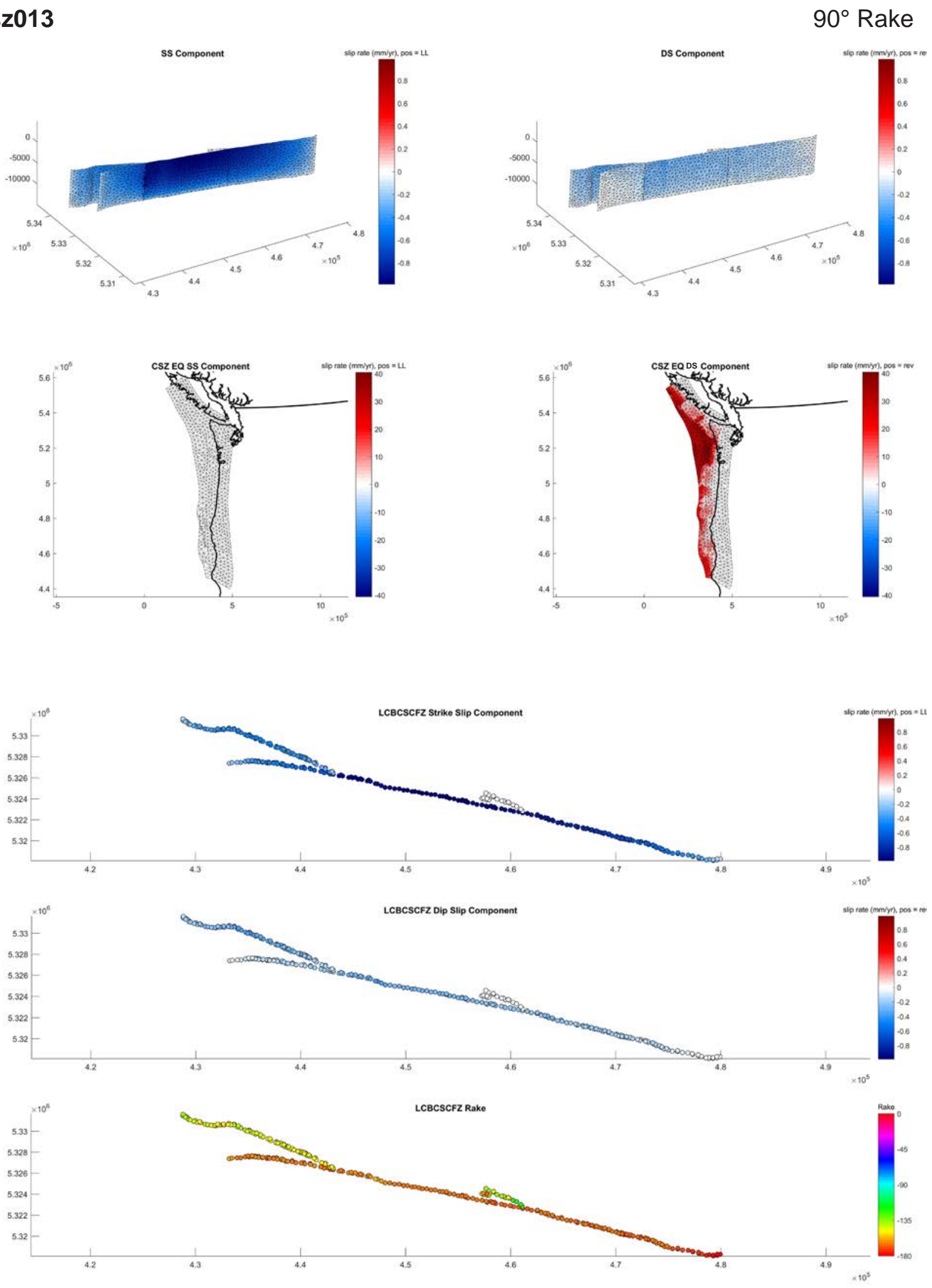

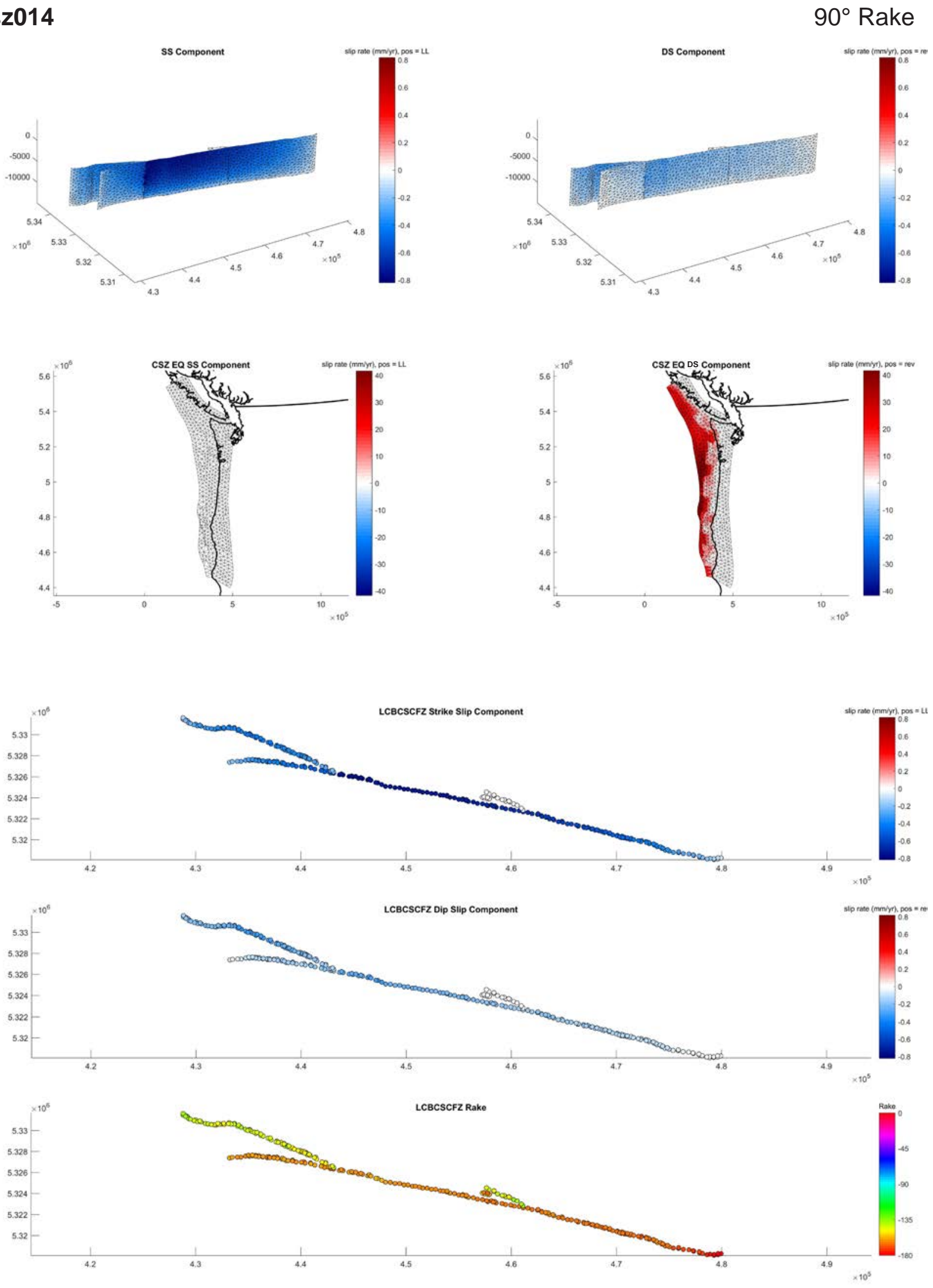

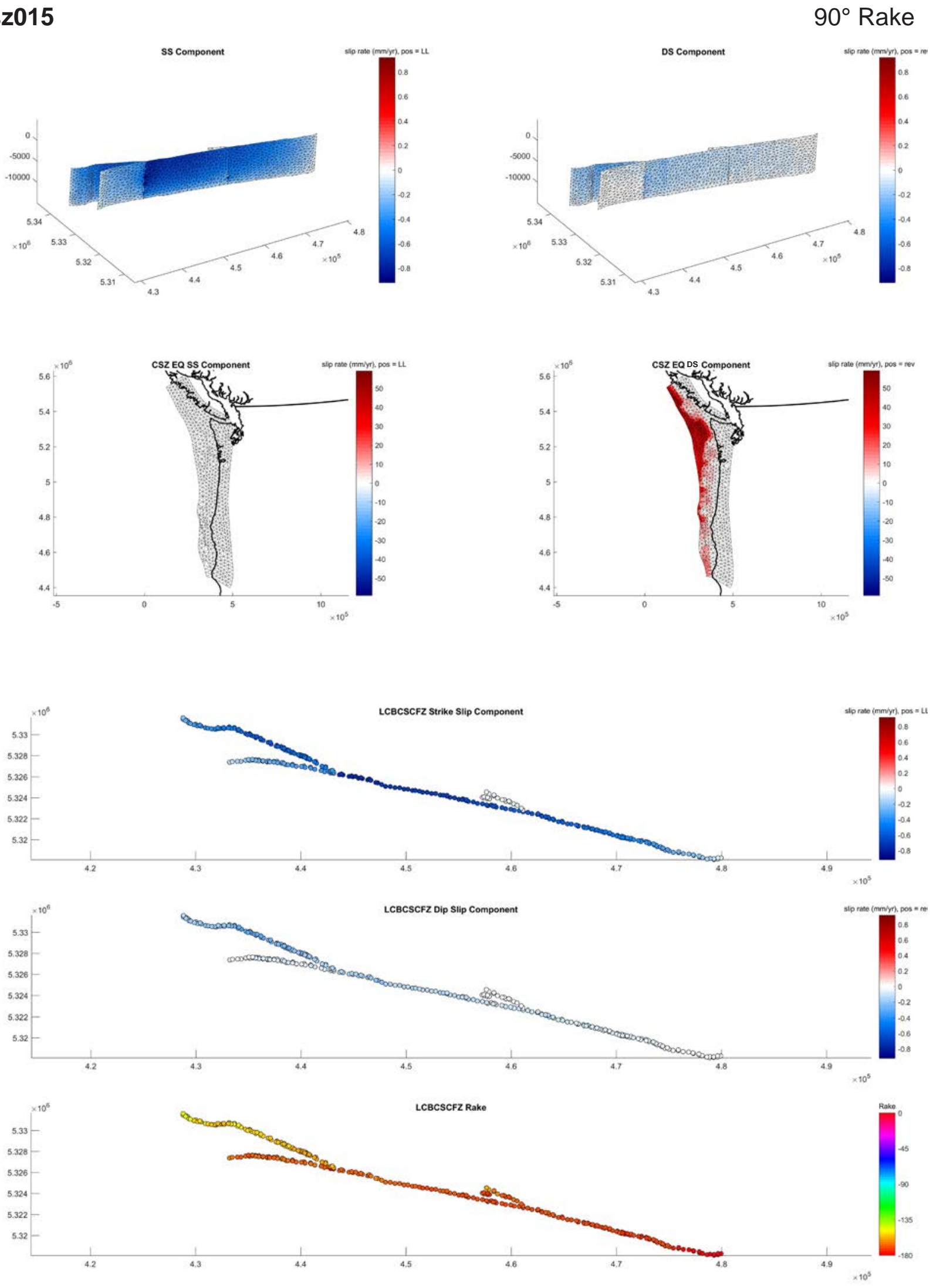

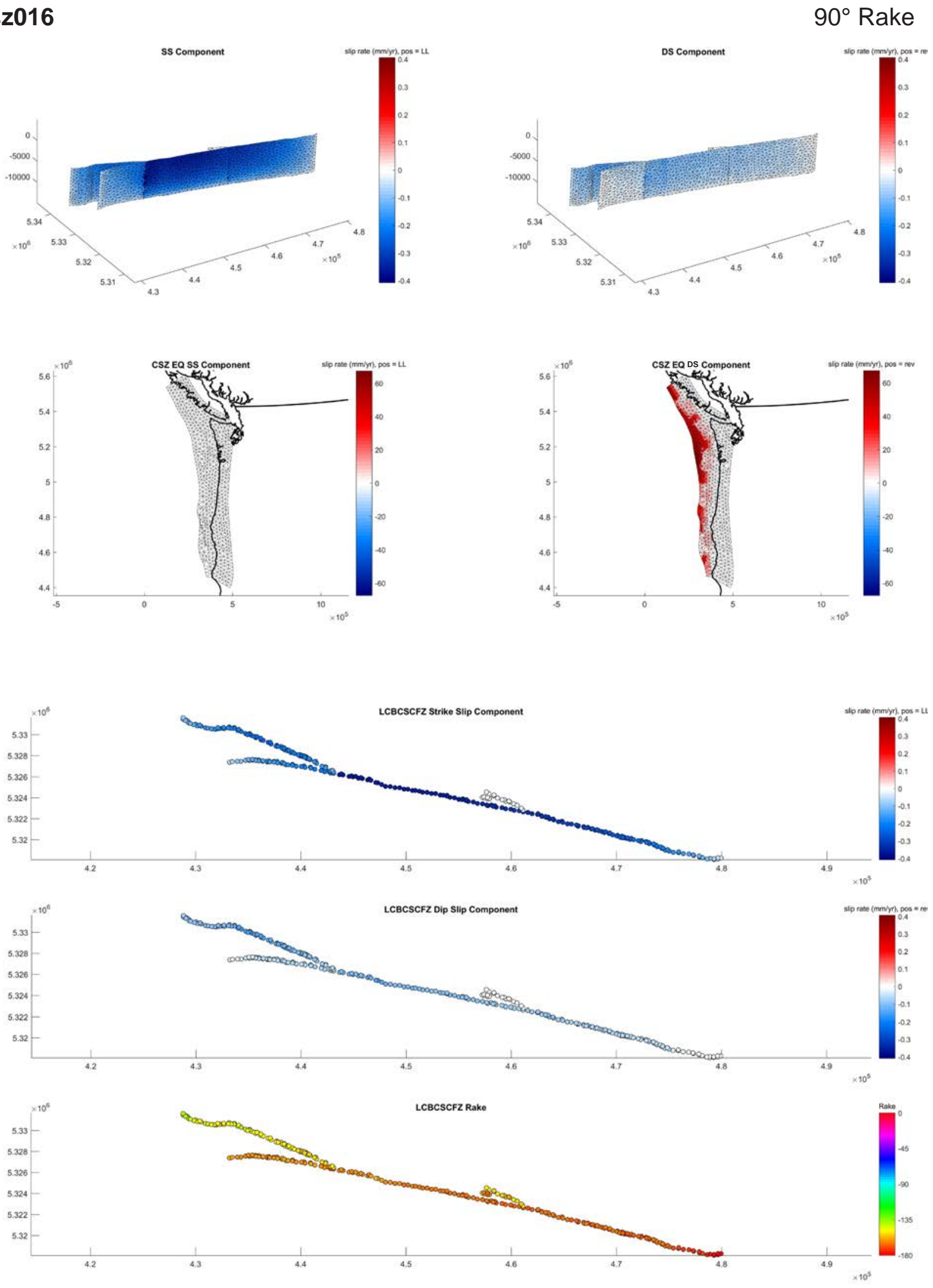

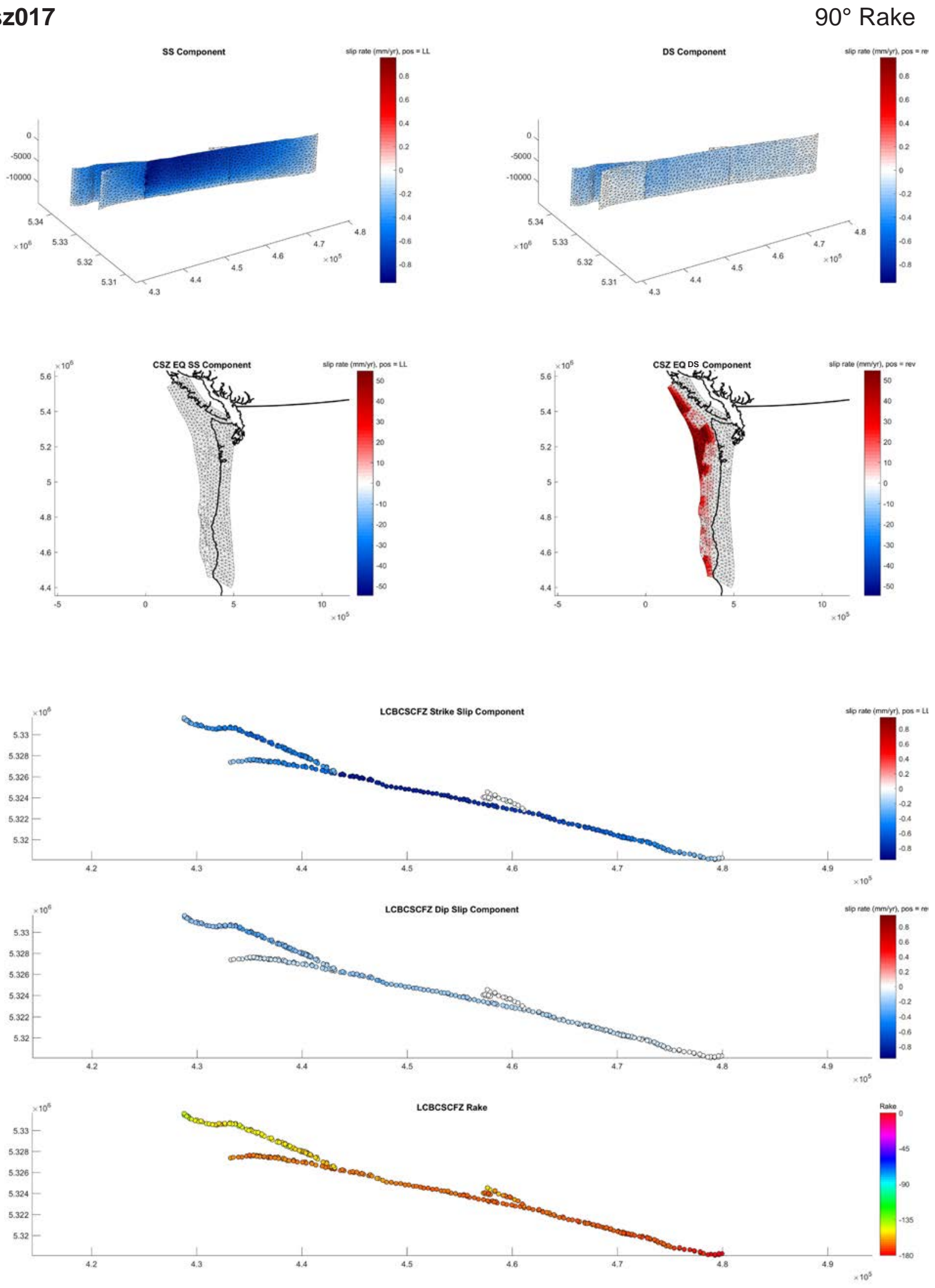

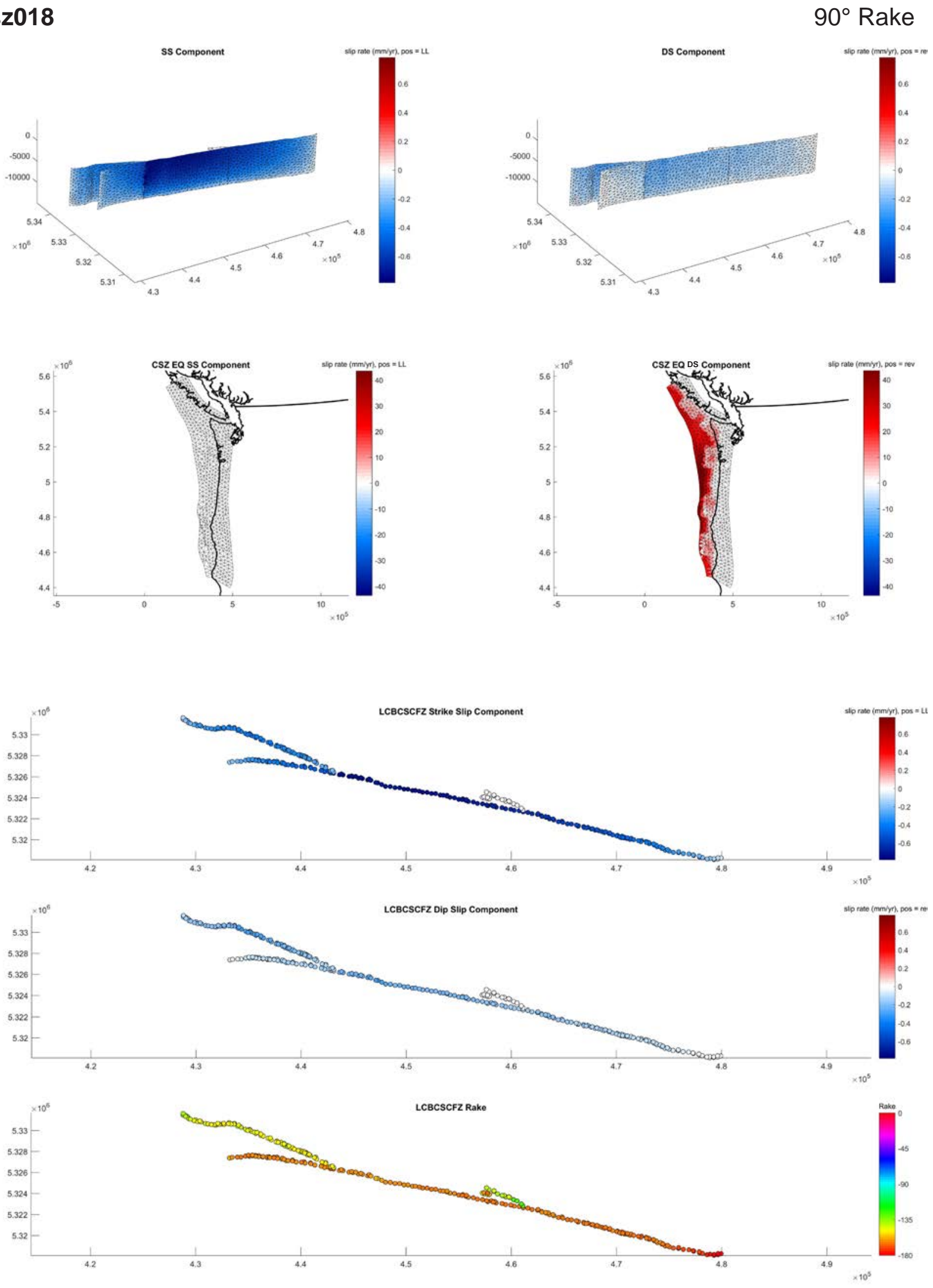

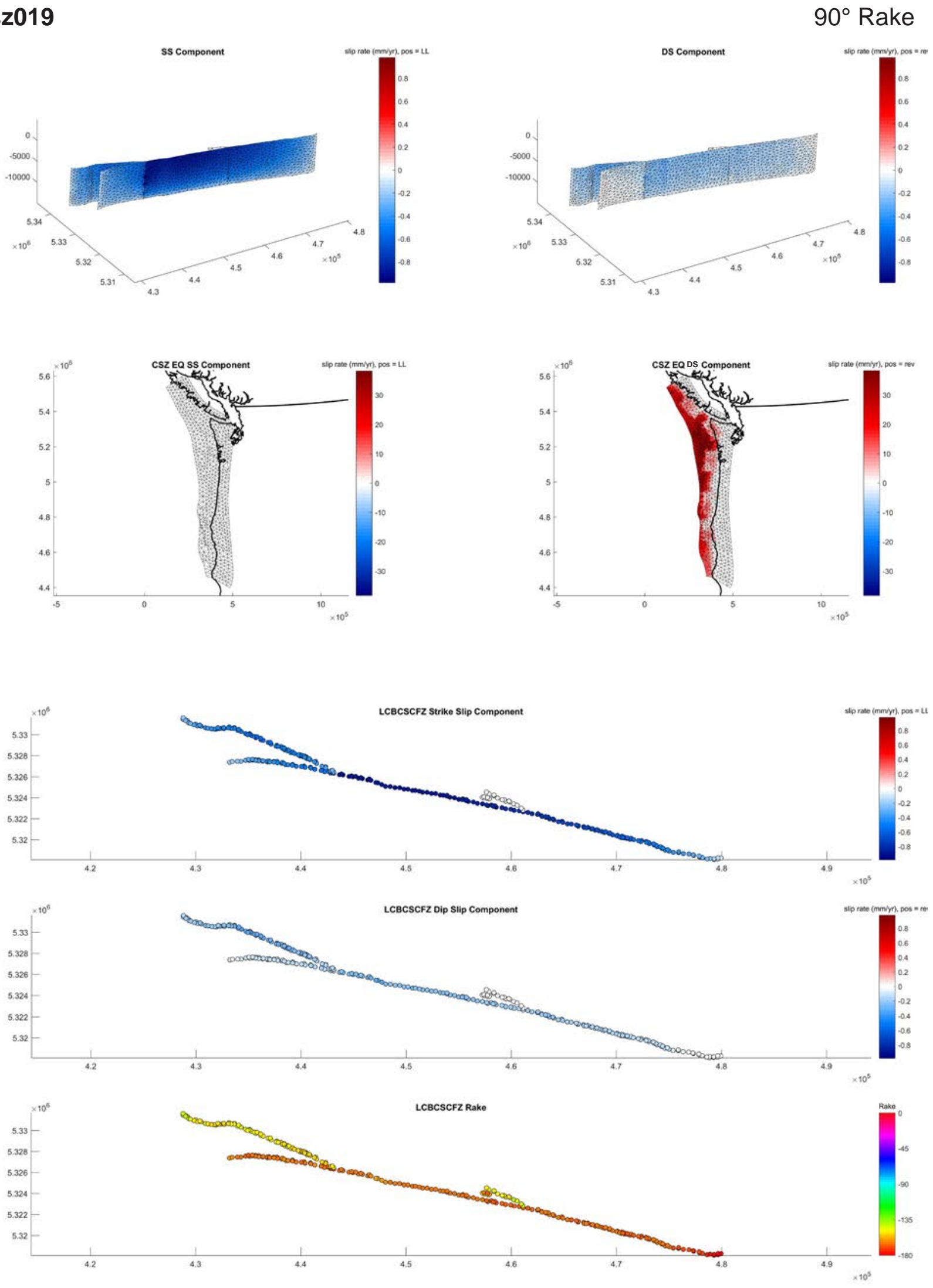

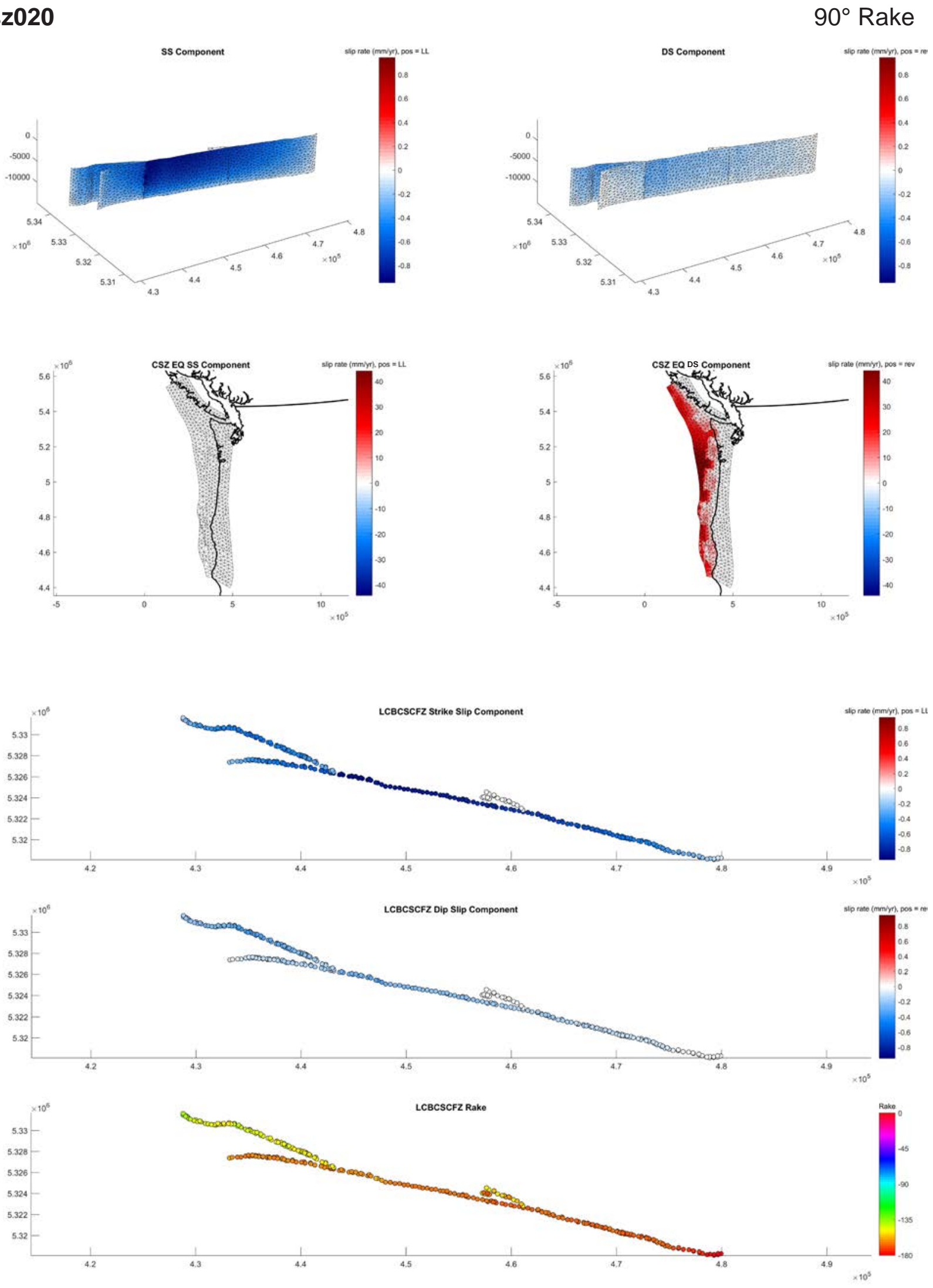

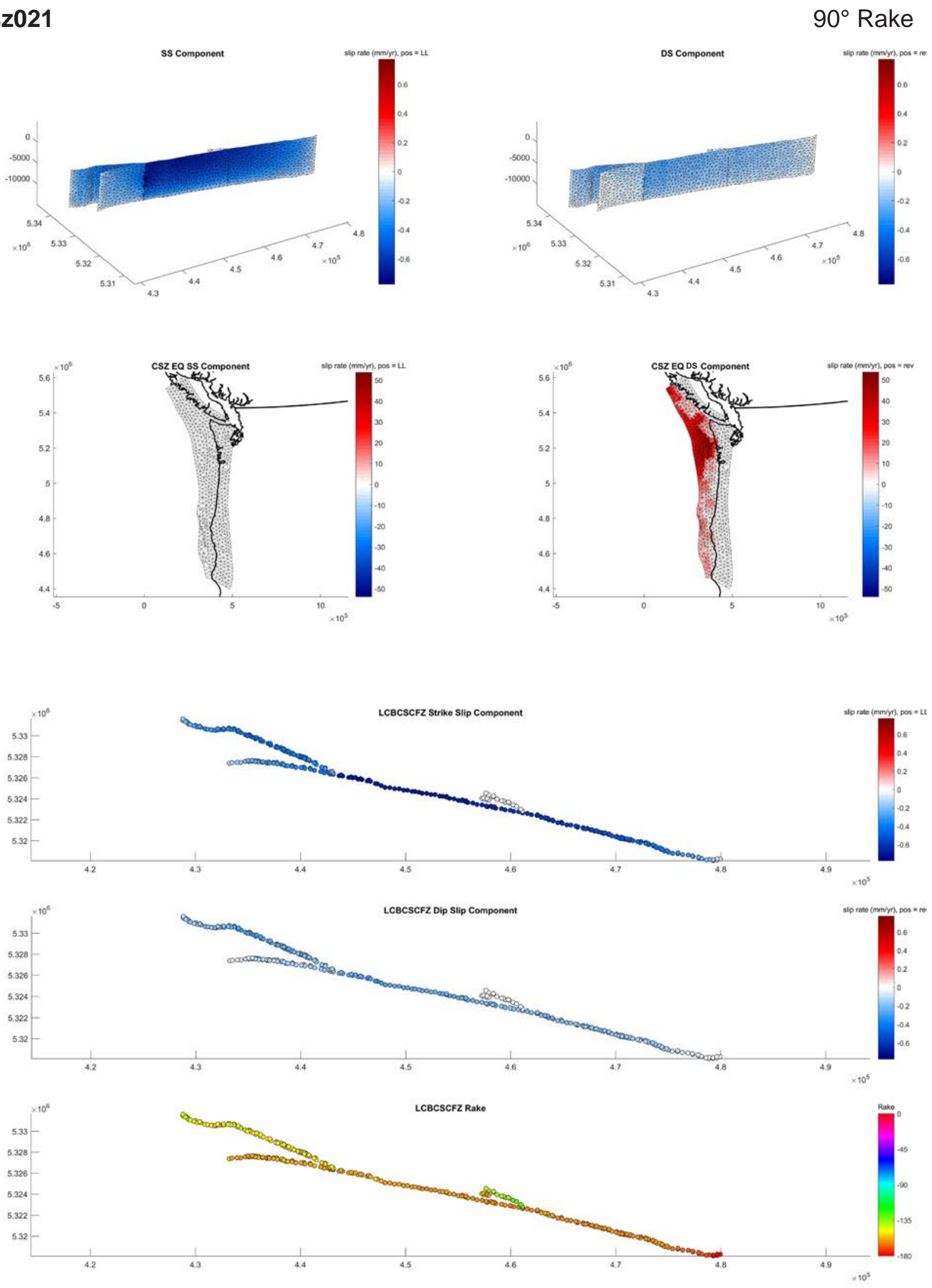

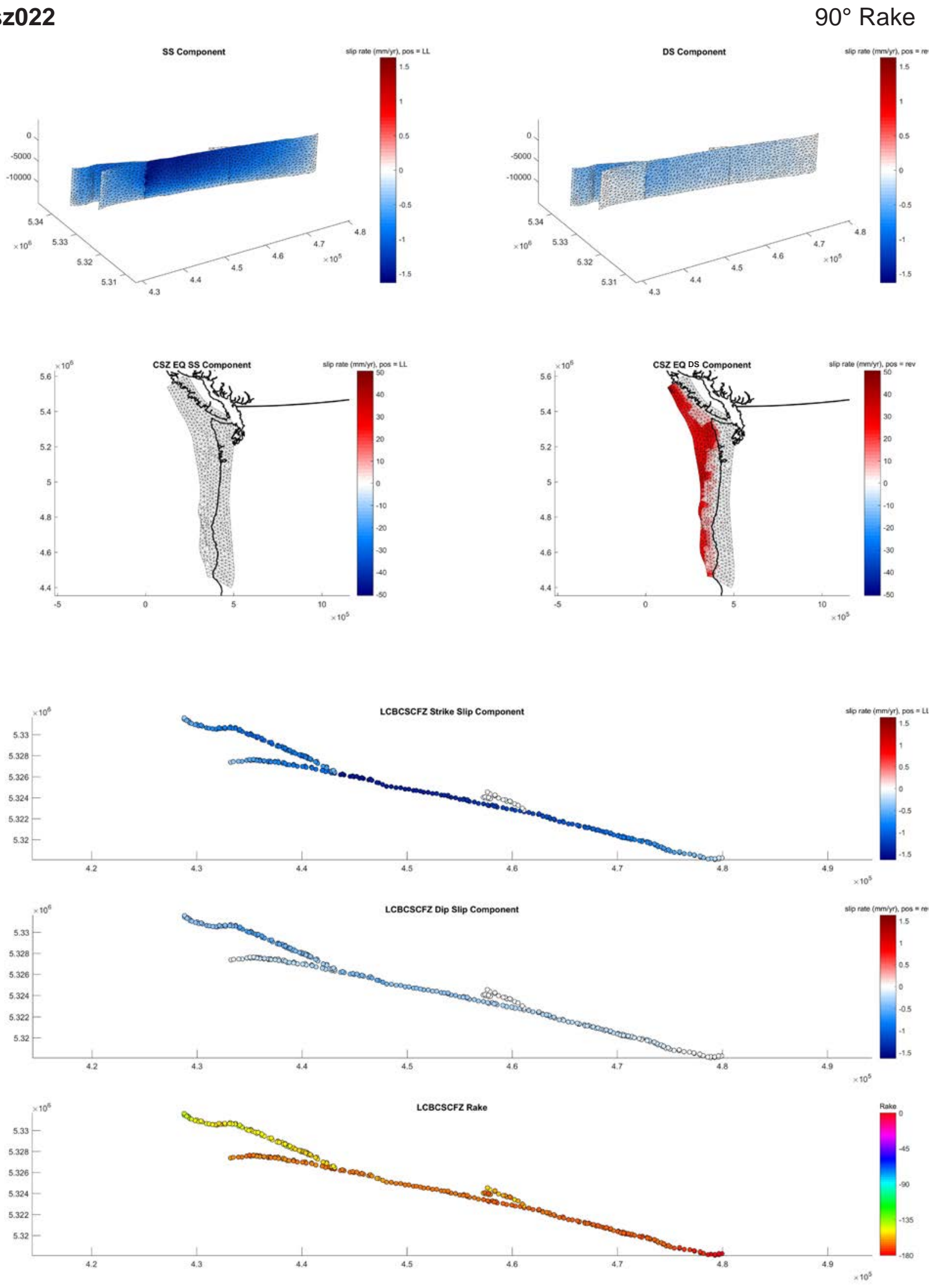

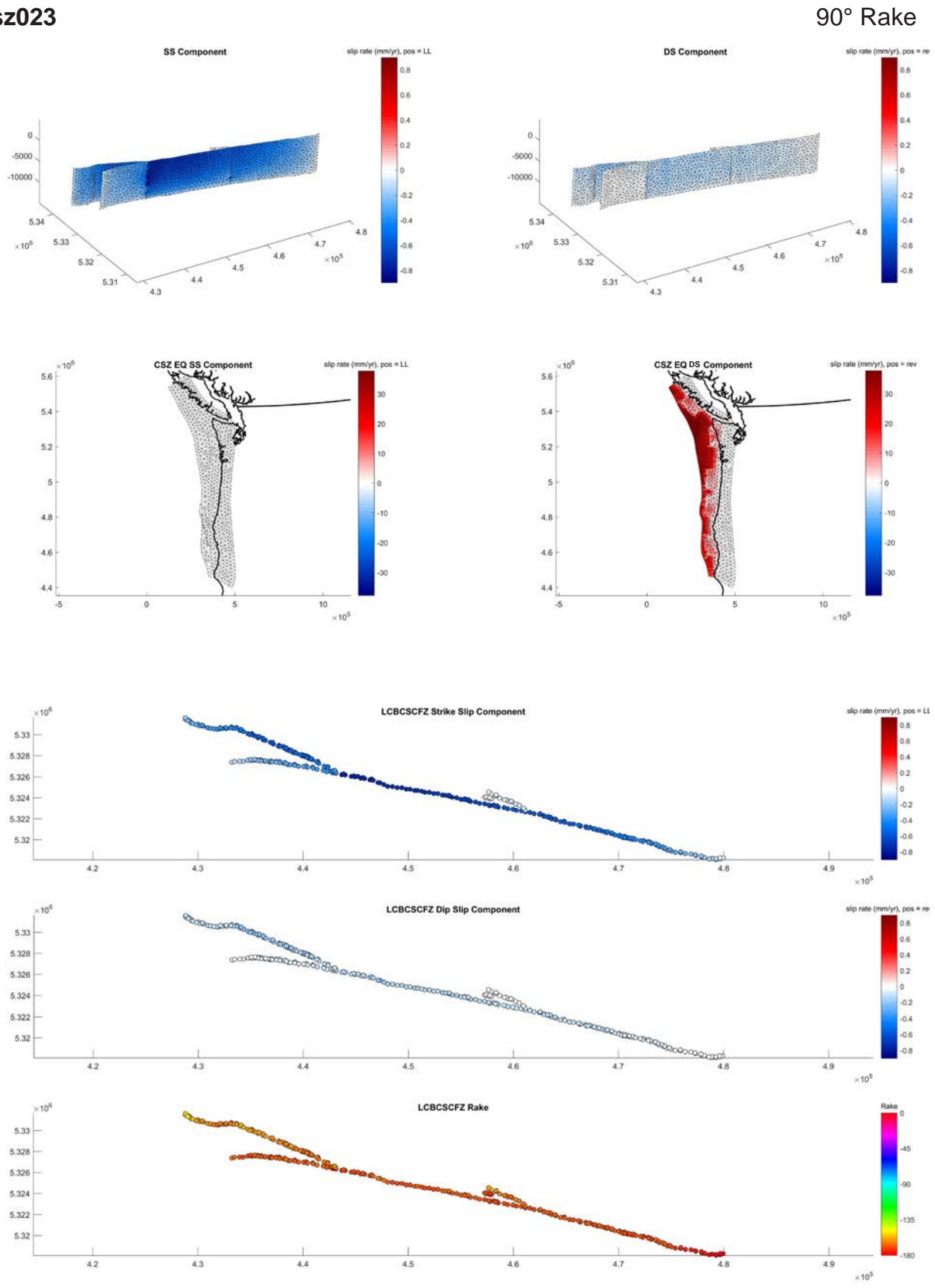

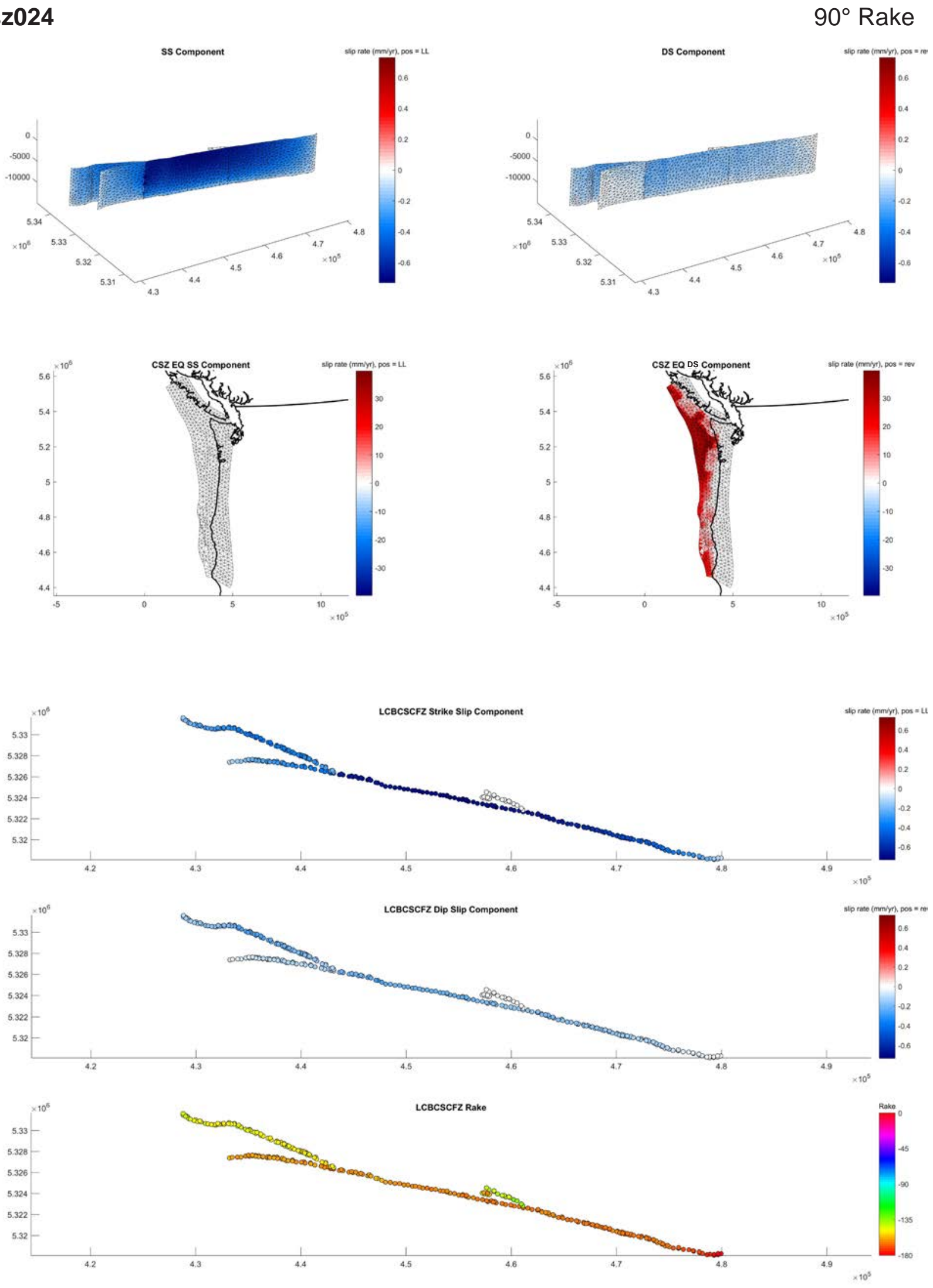

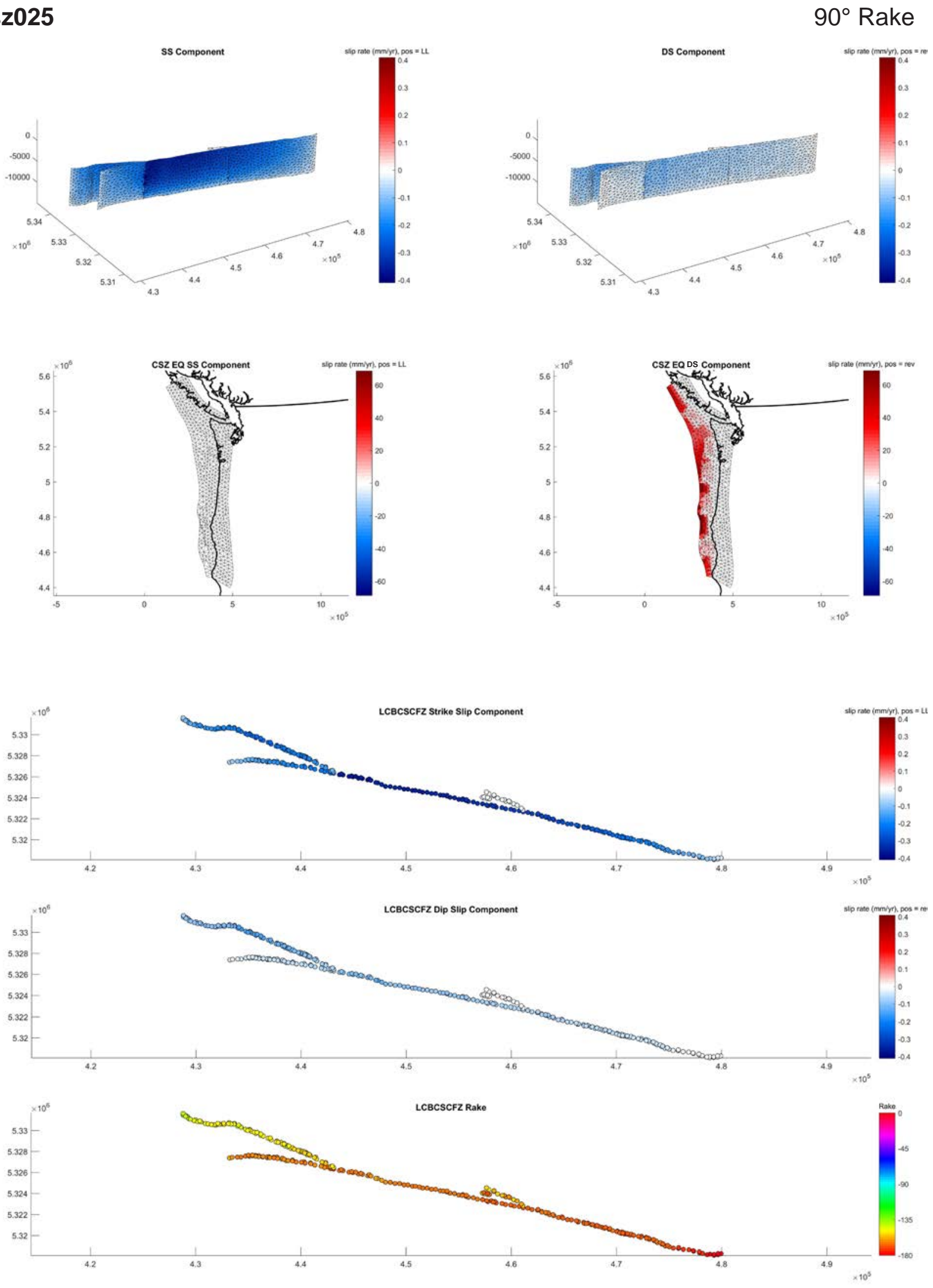

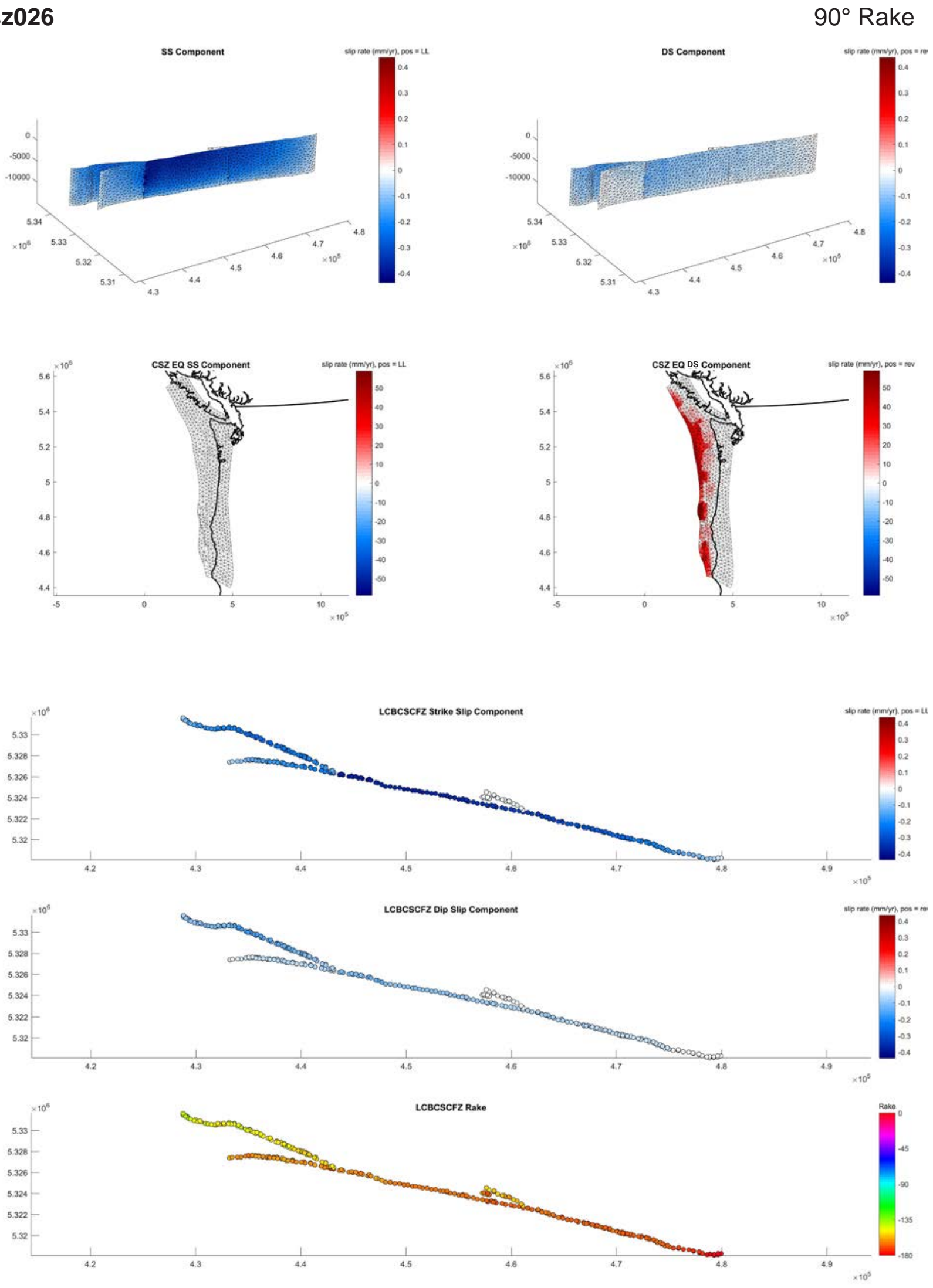

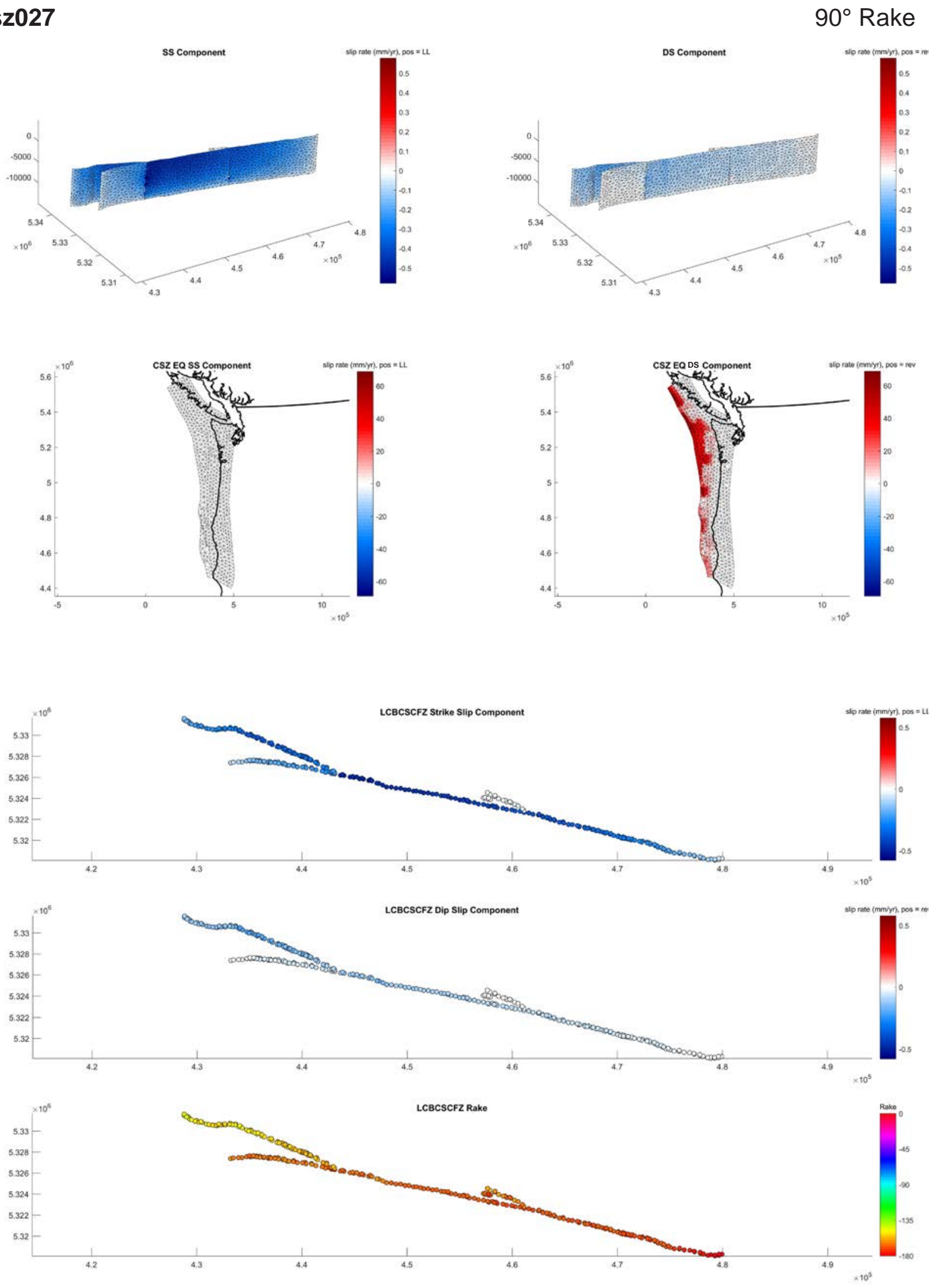

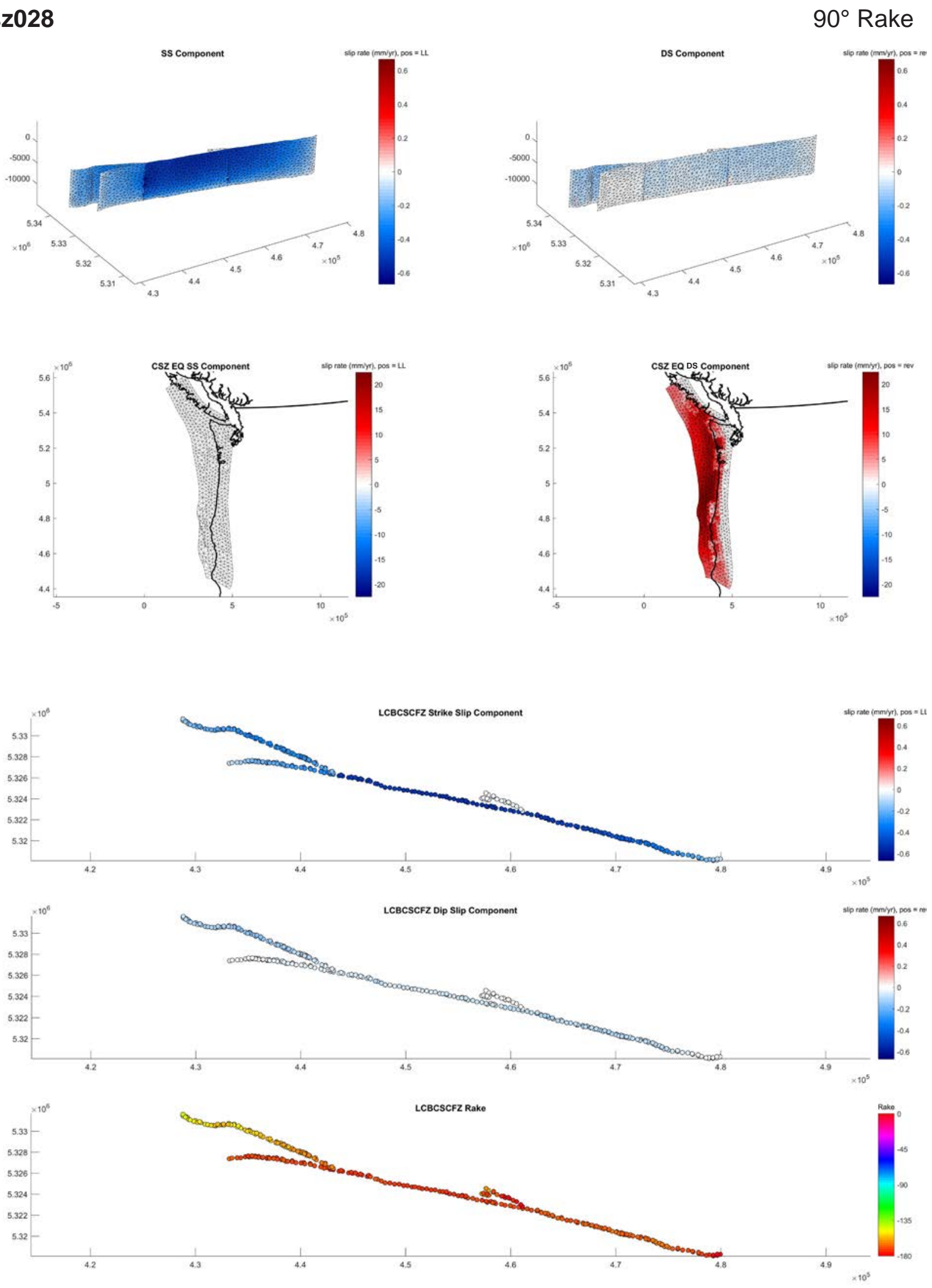

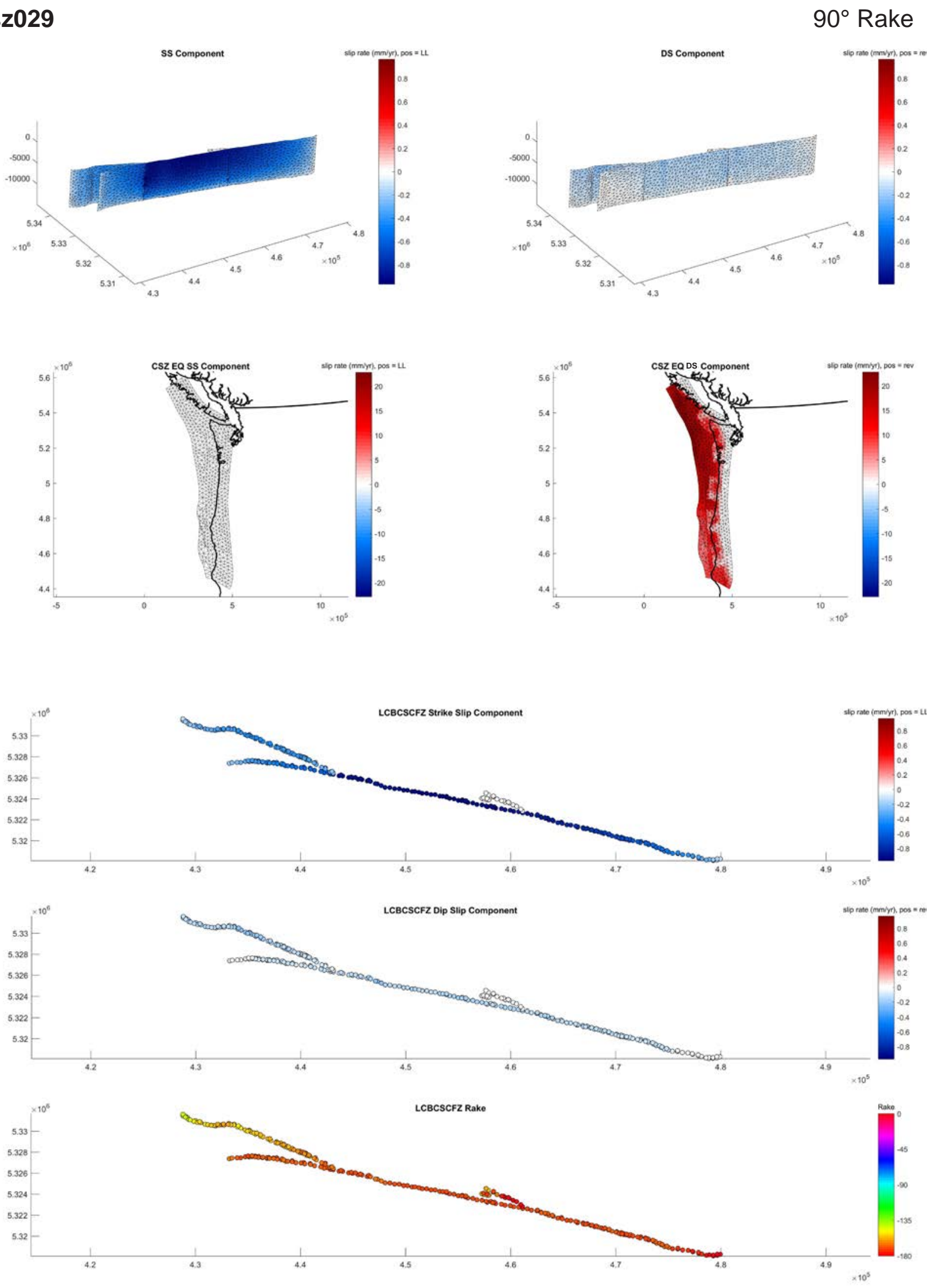

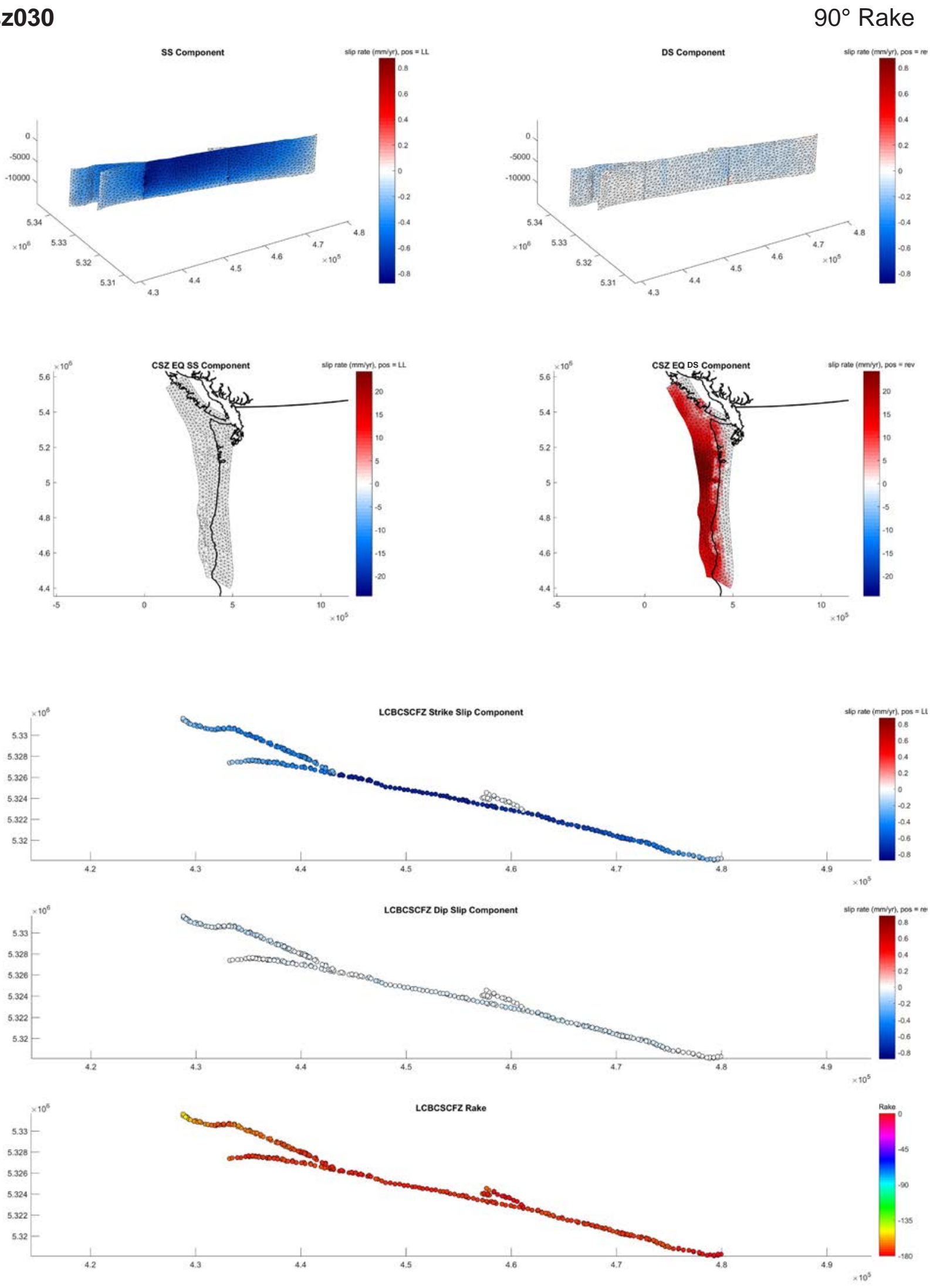
csz031
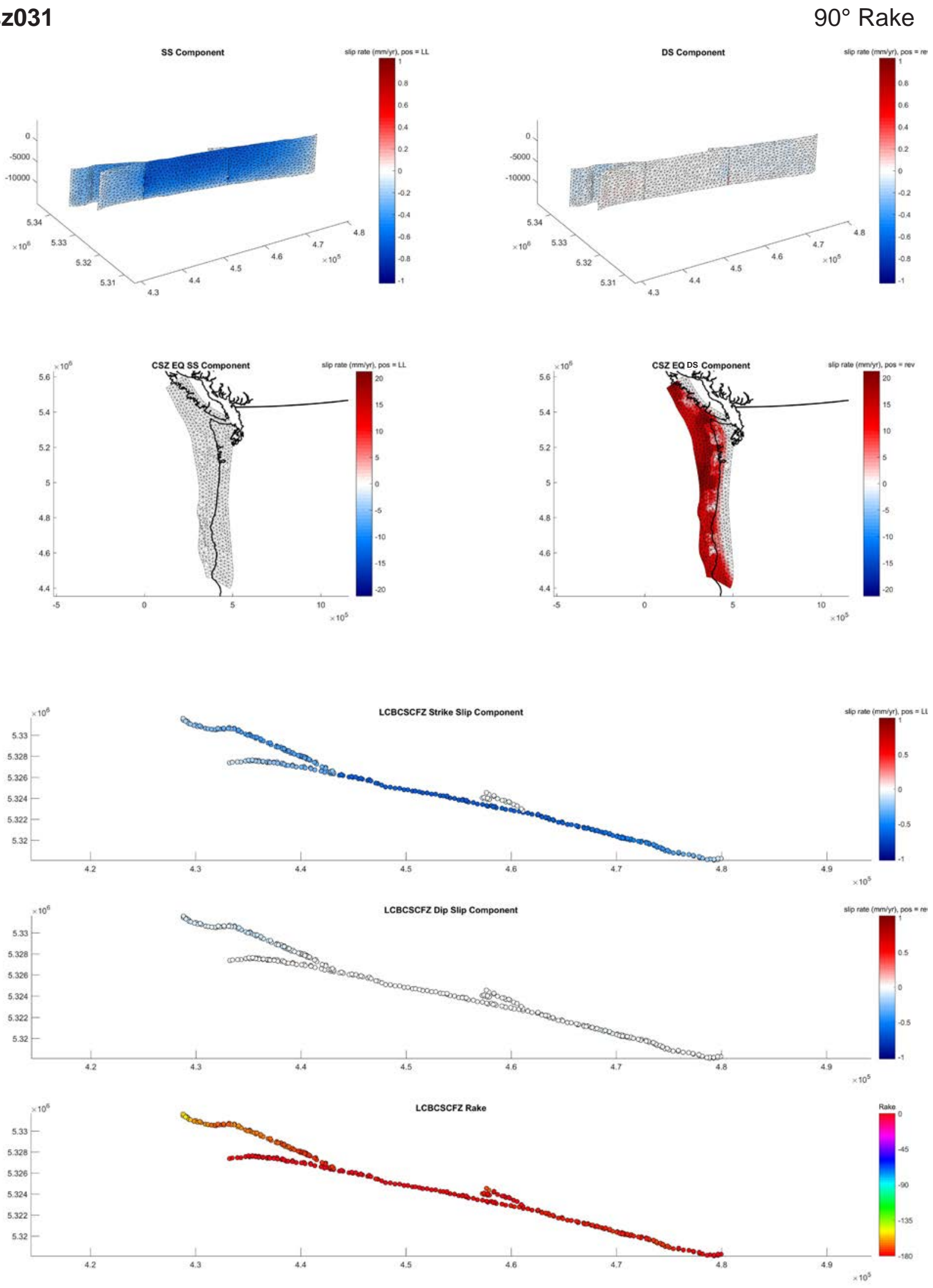

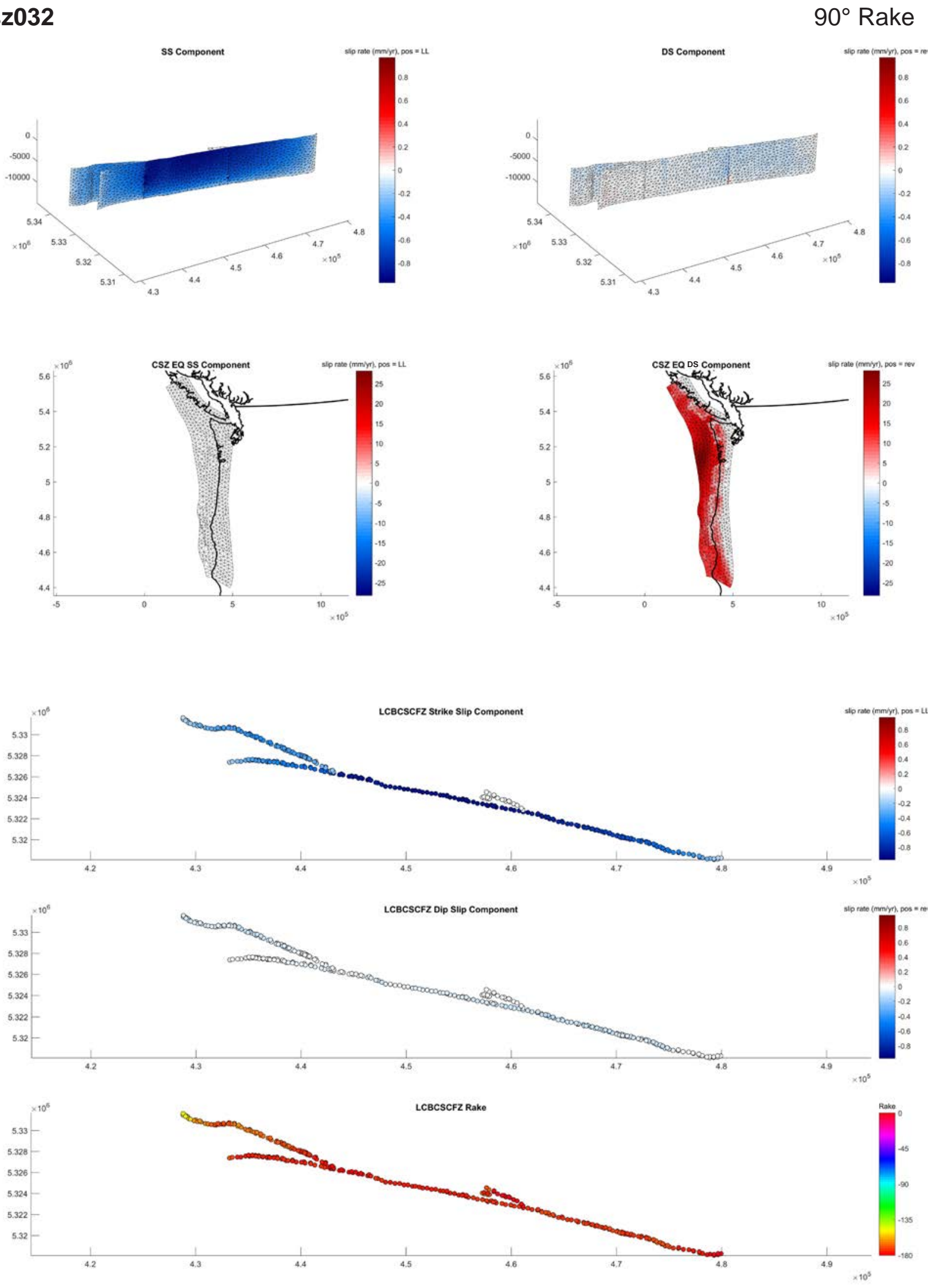

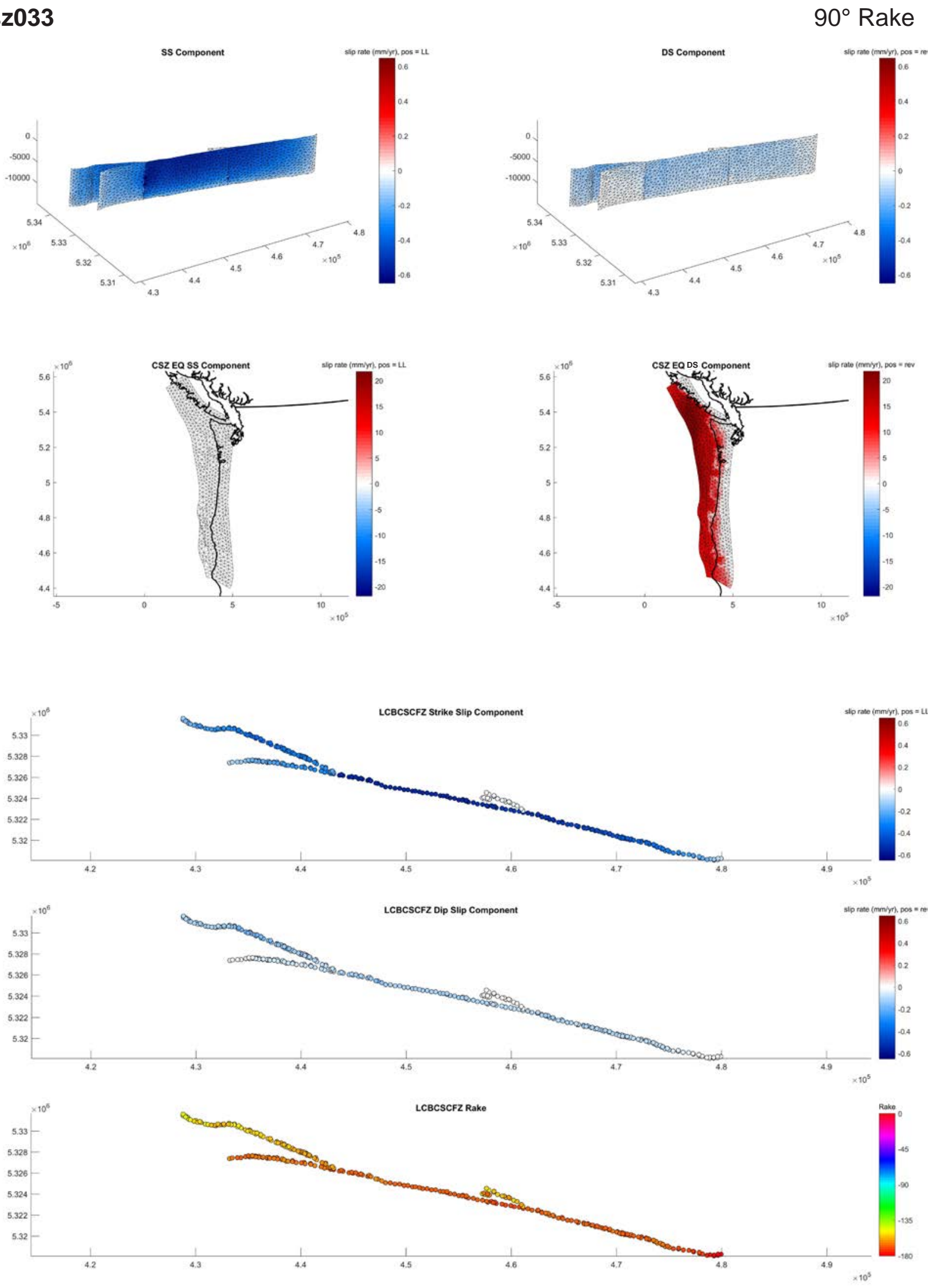

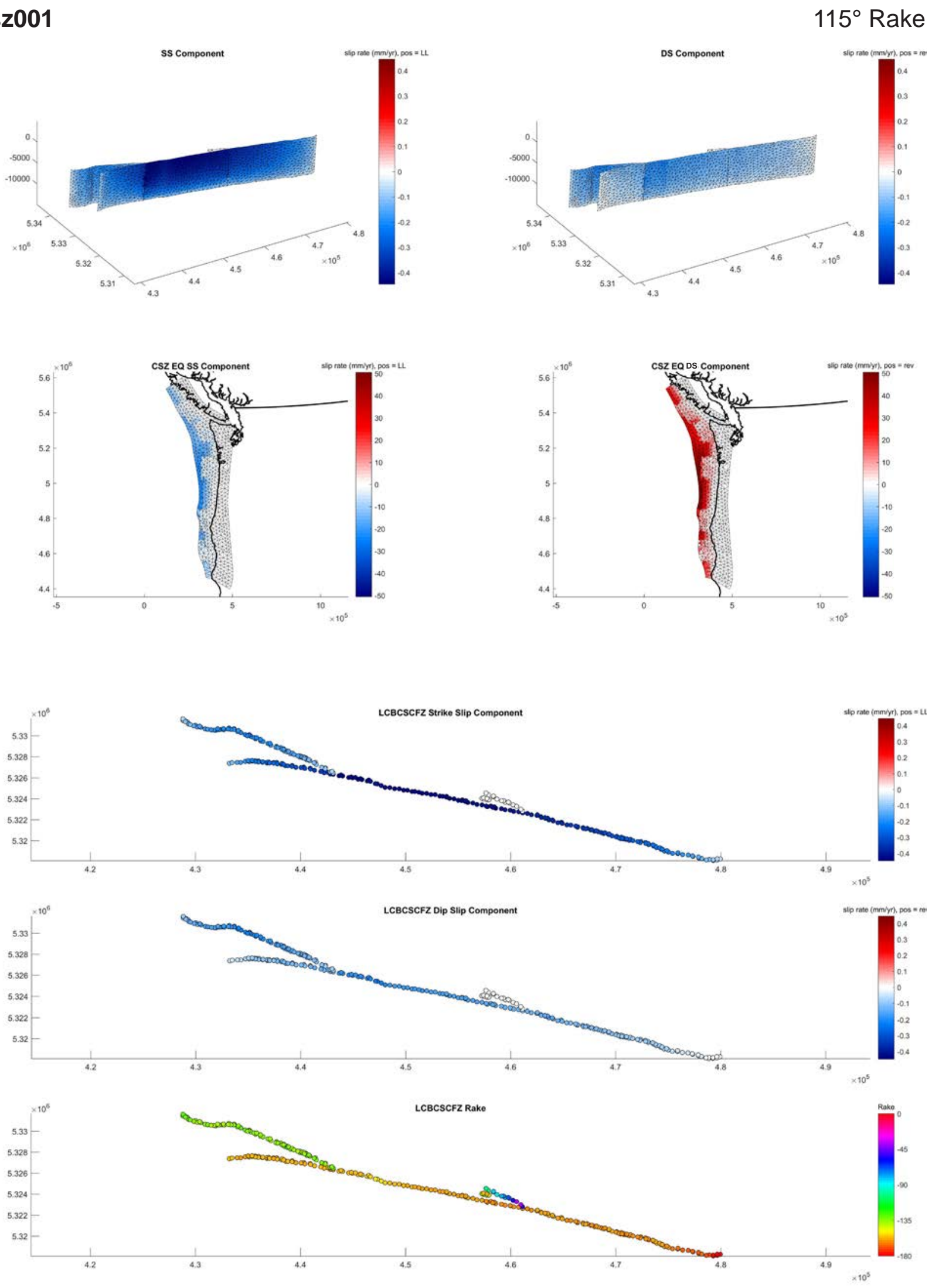

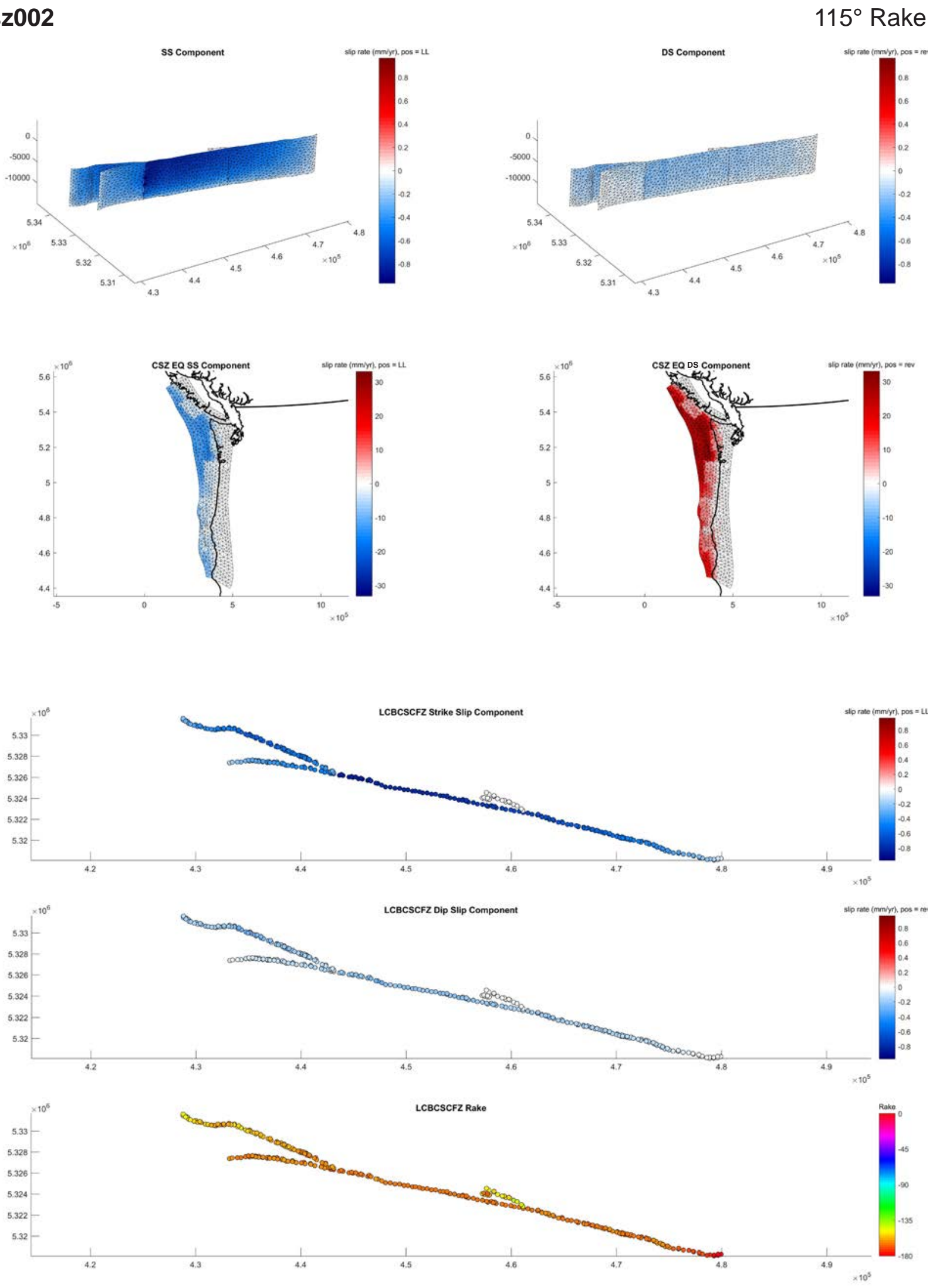

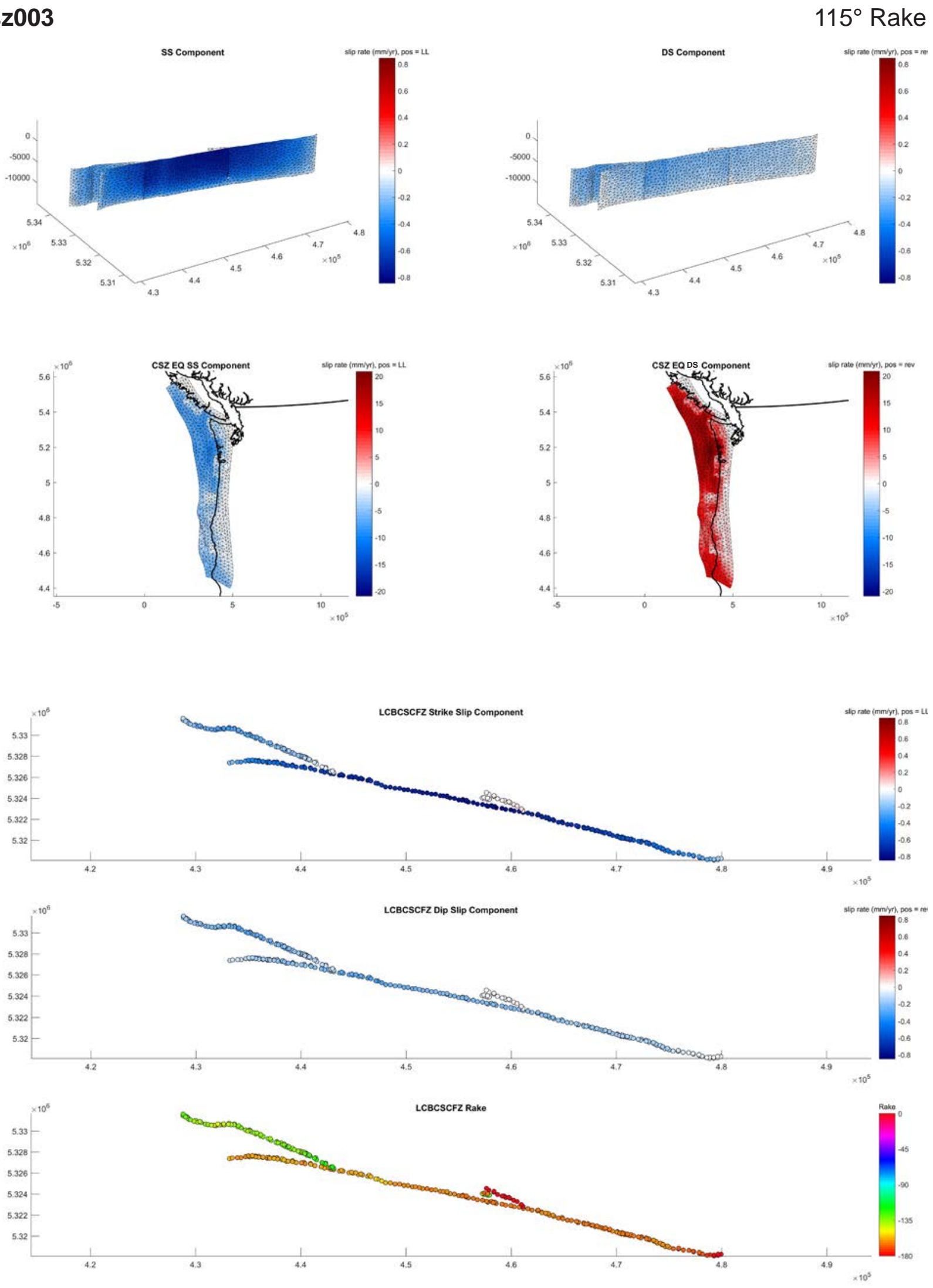

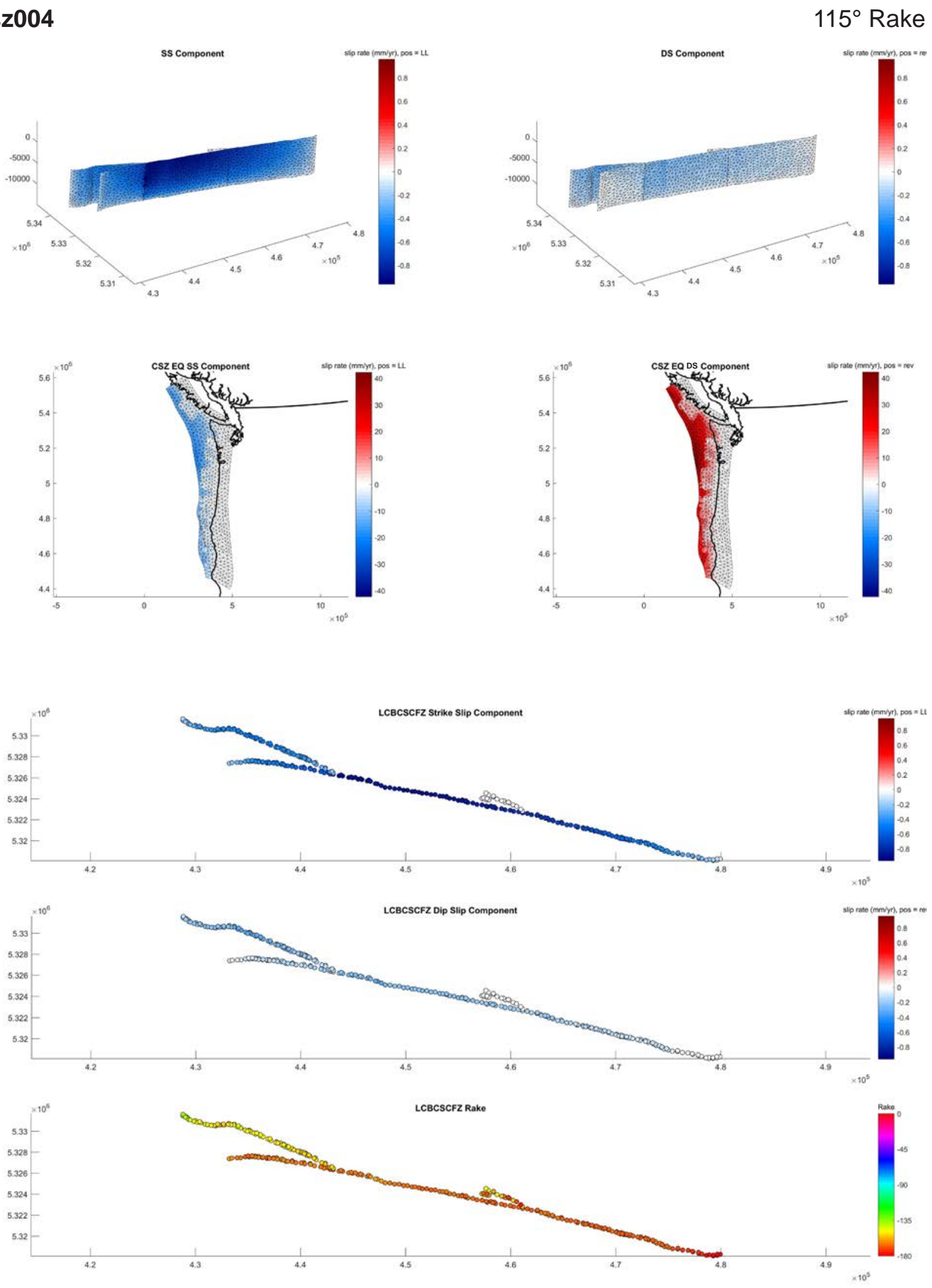

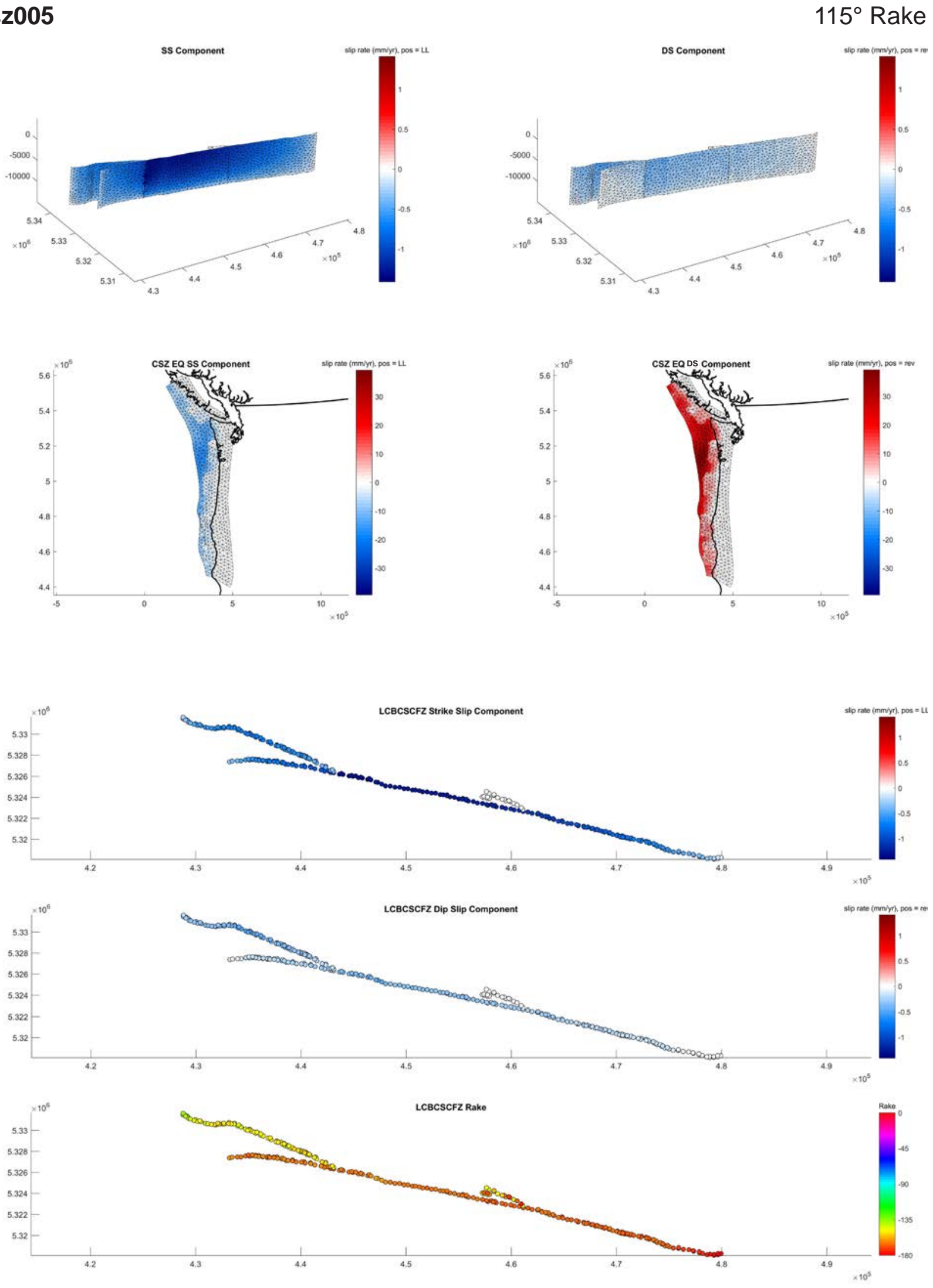

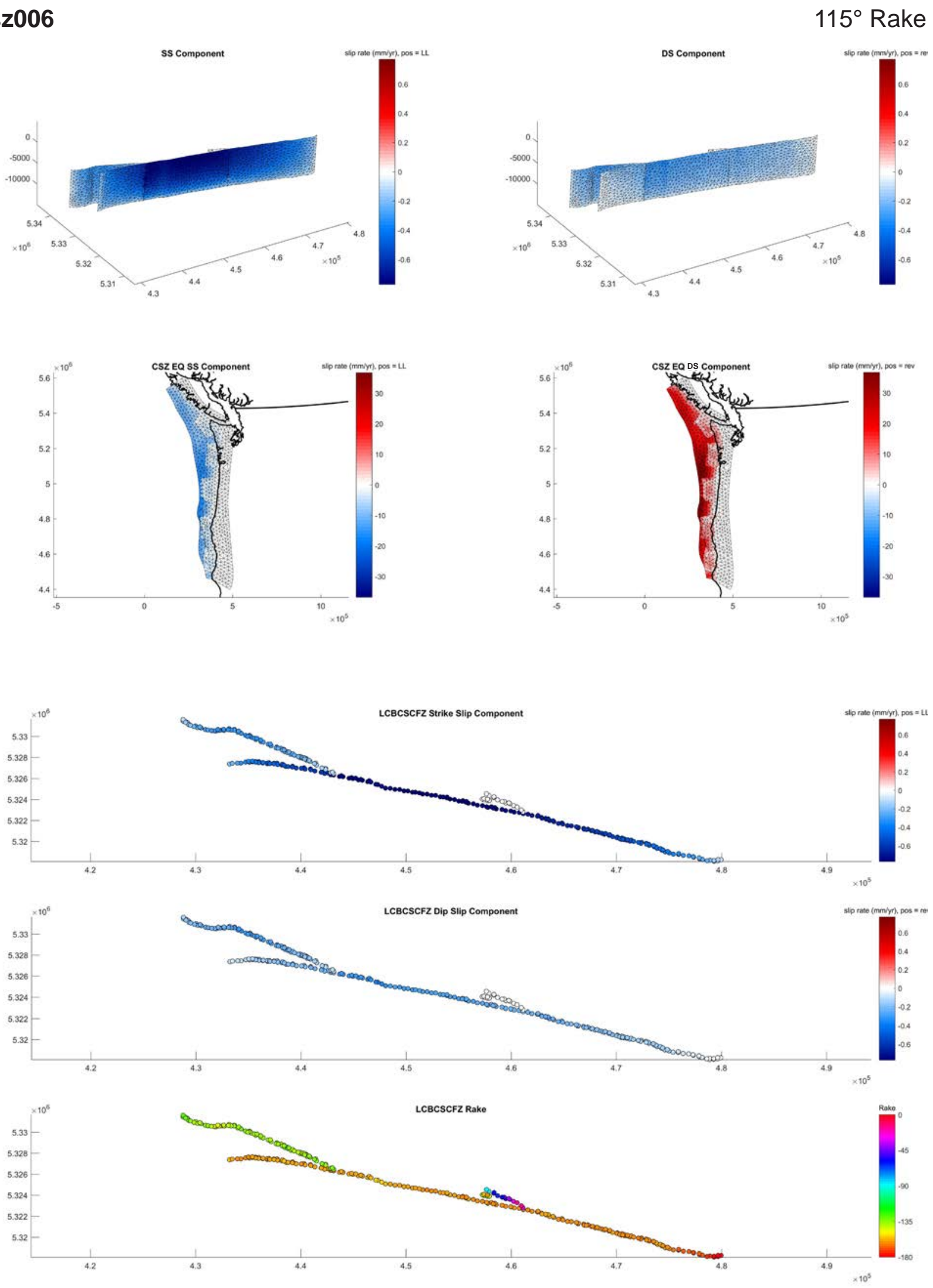

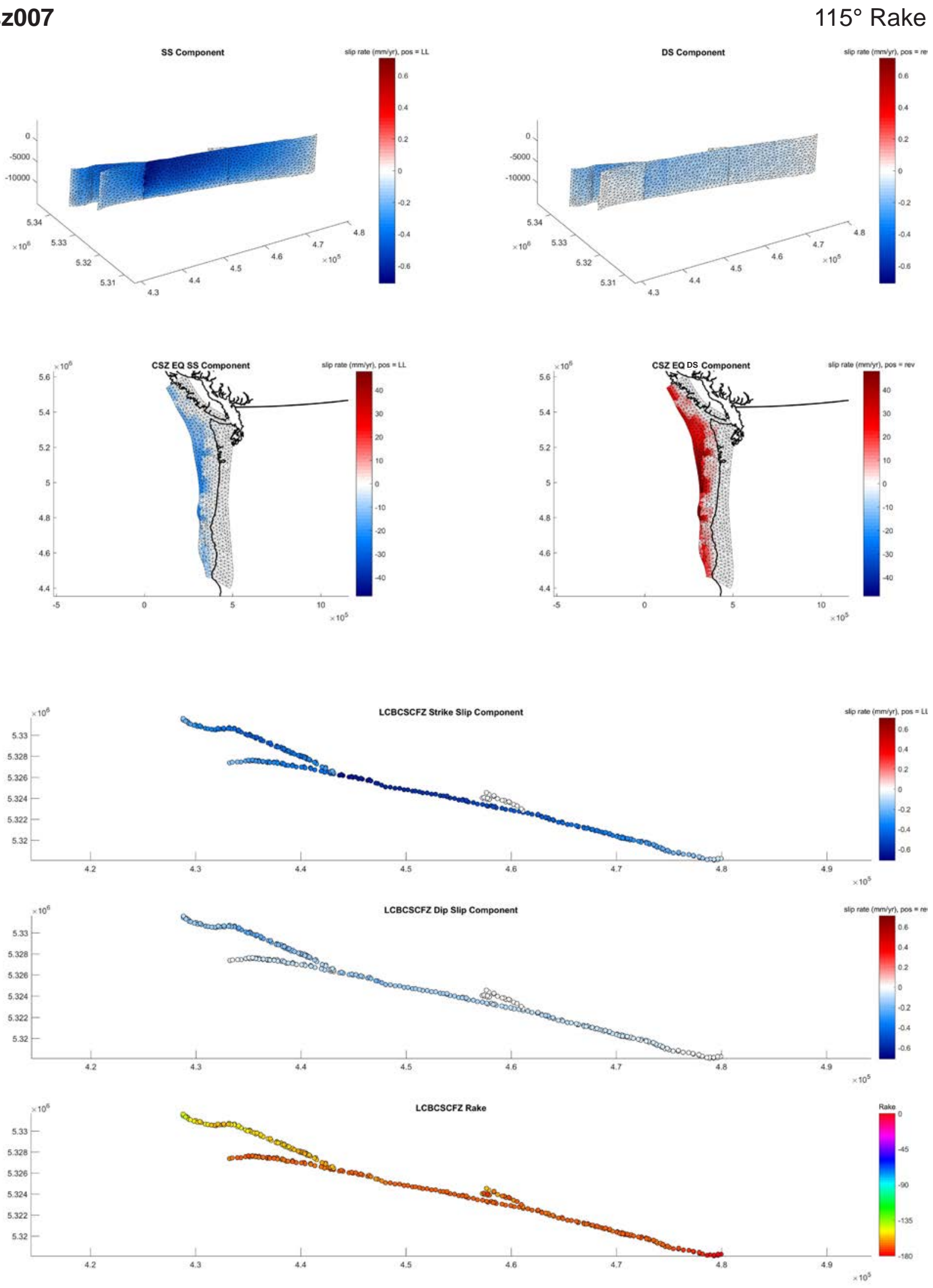

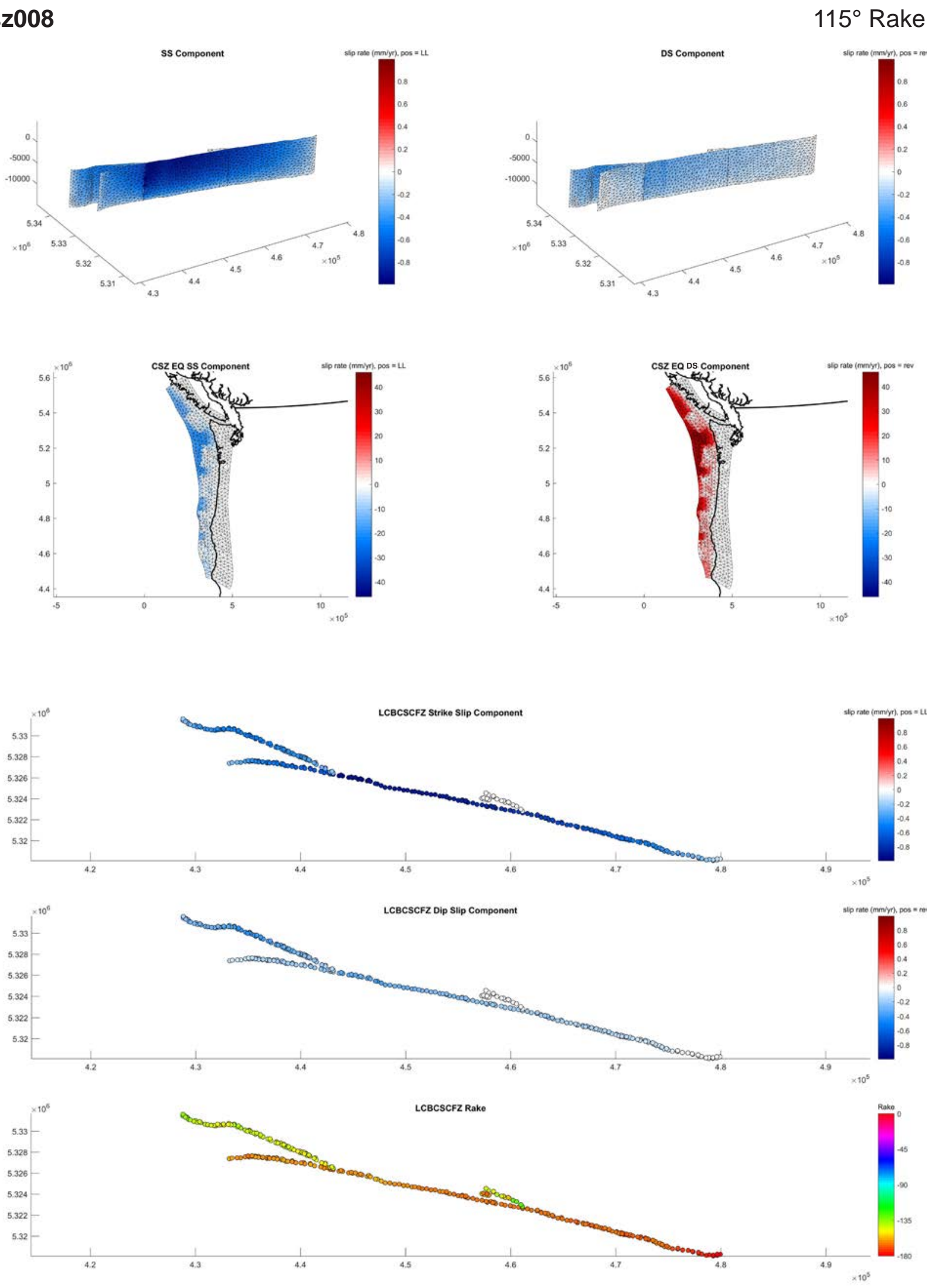

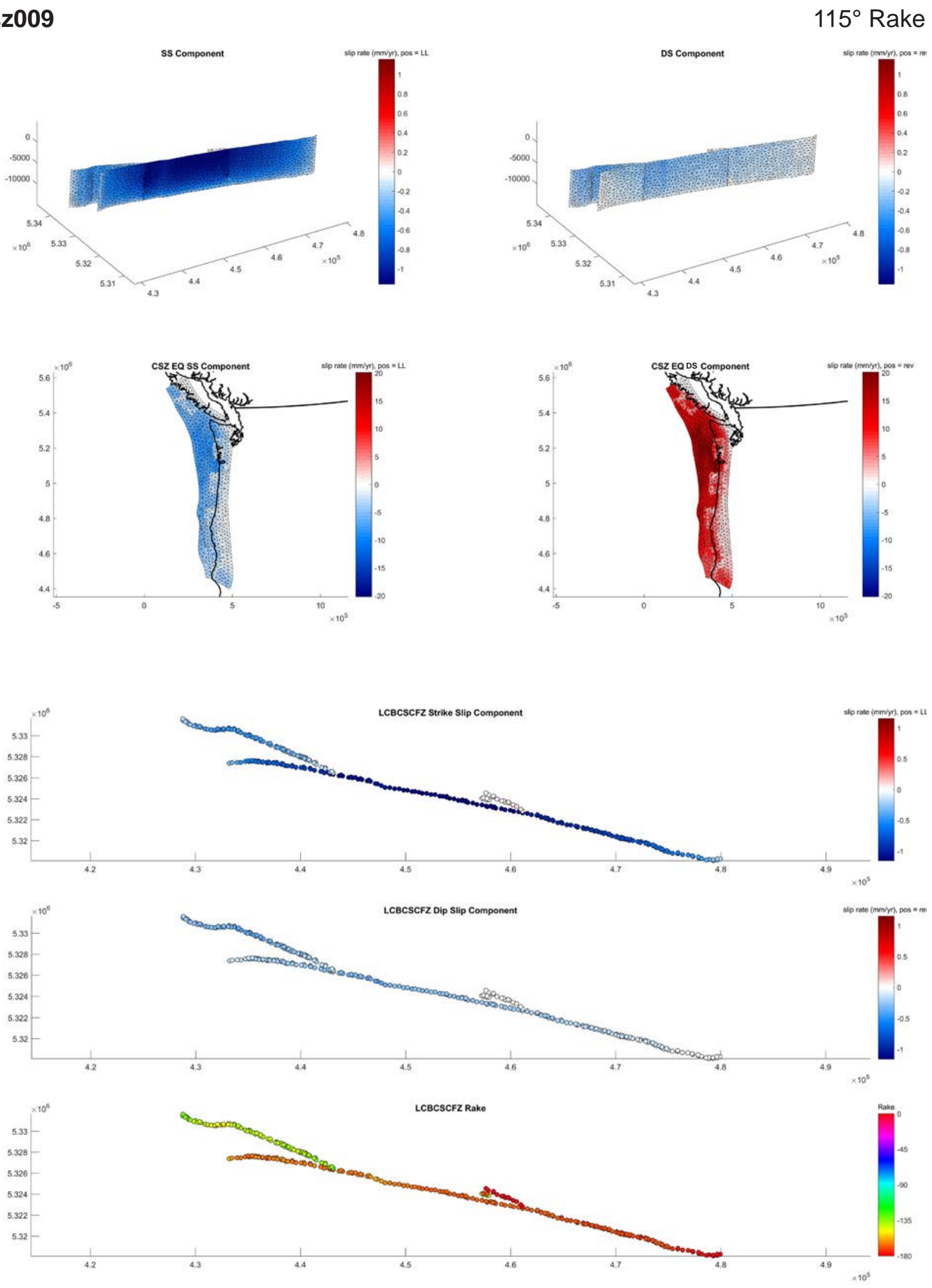

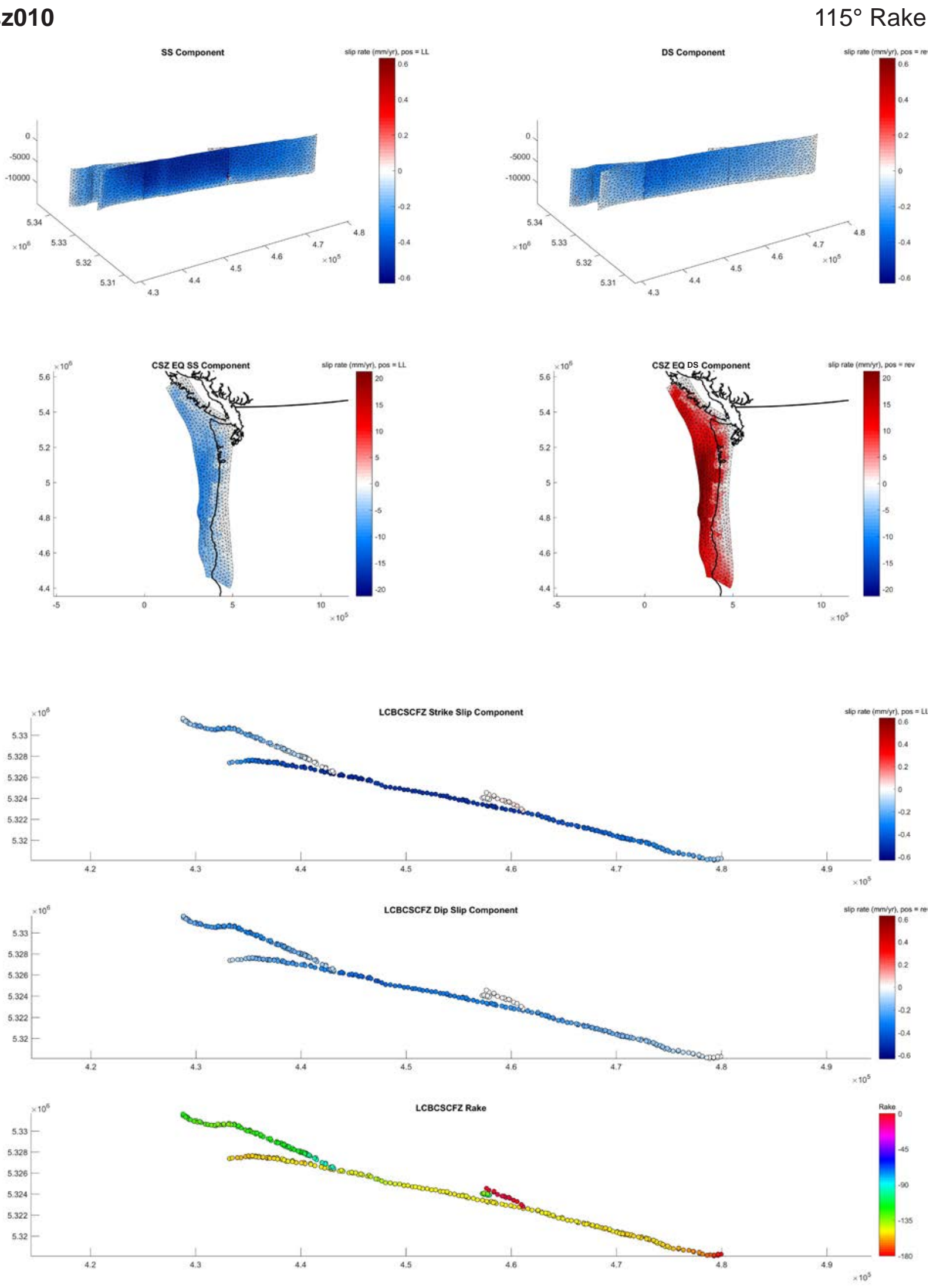

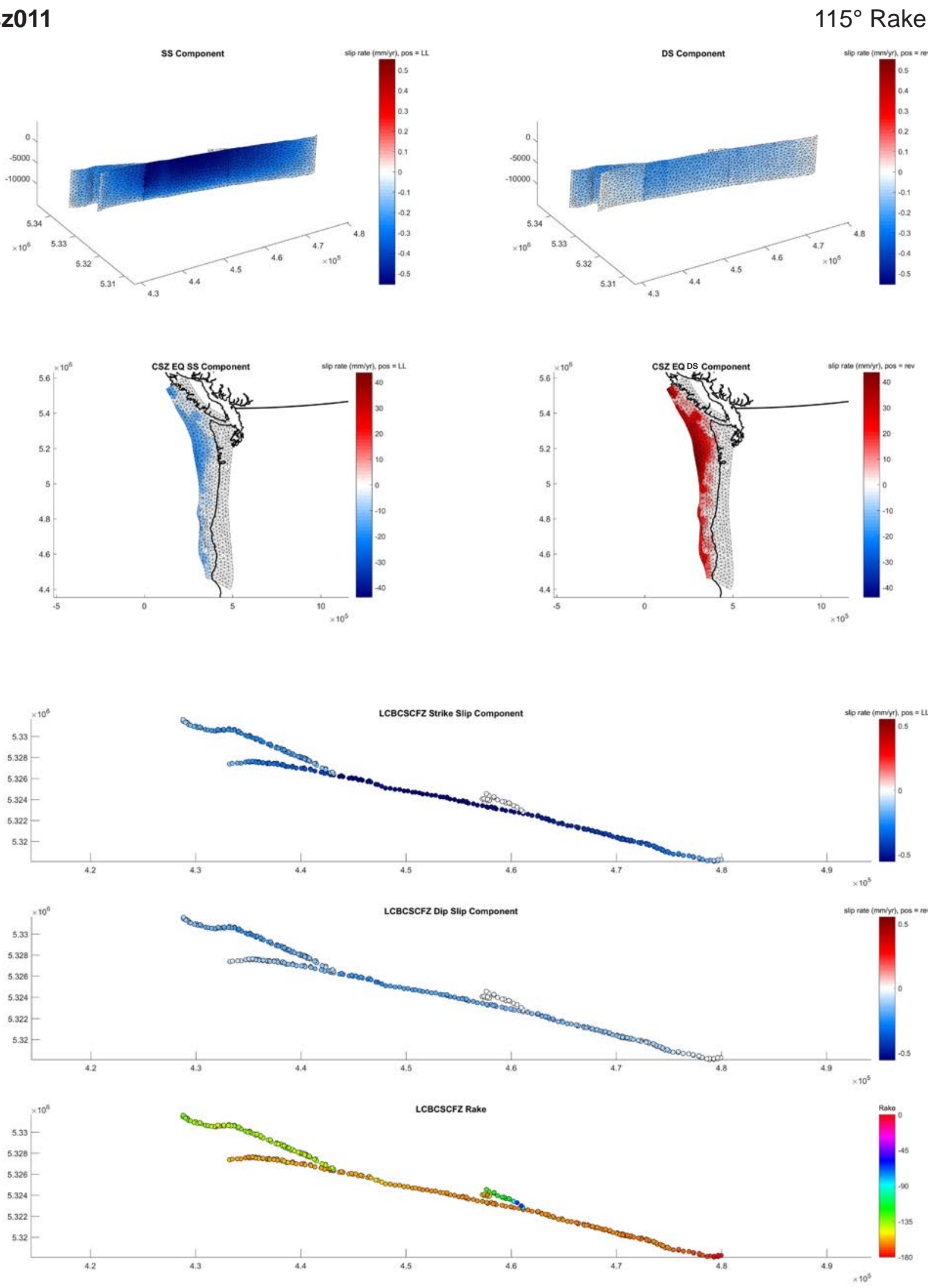

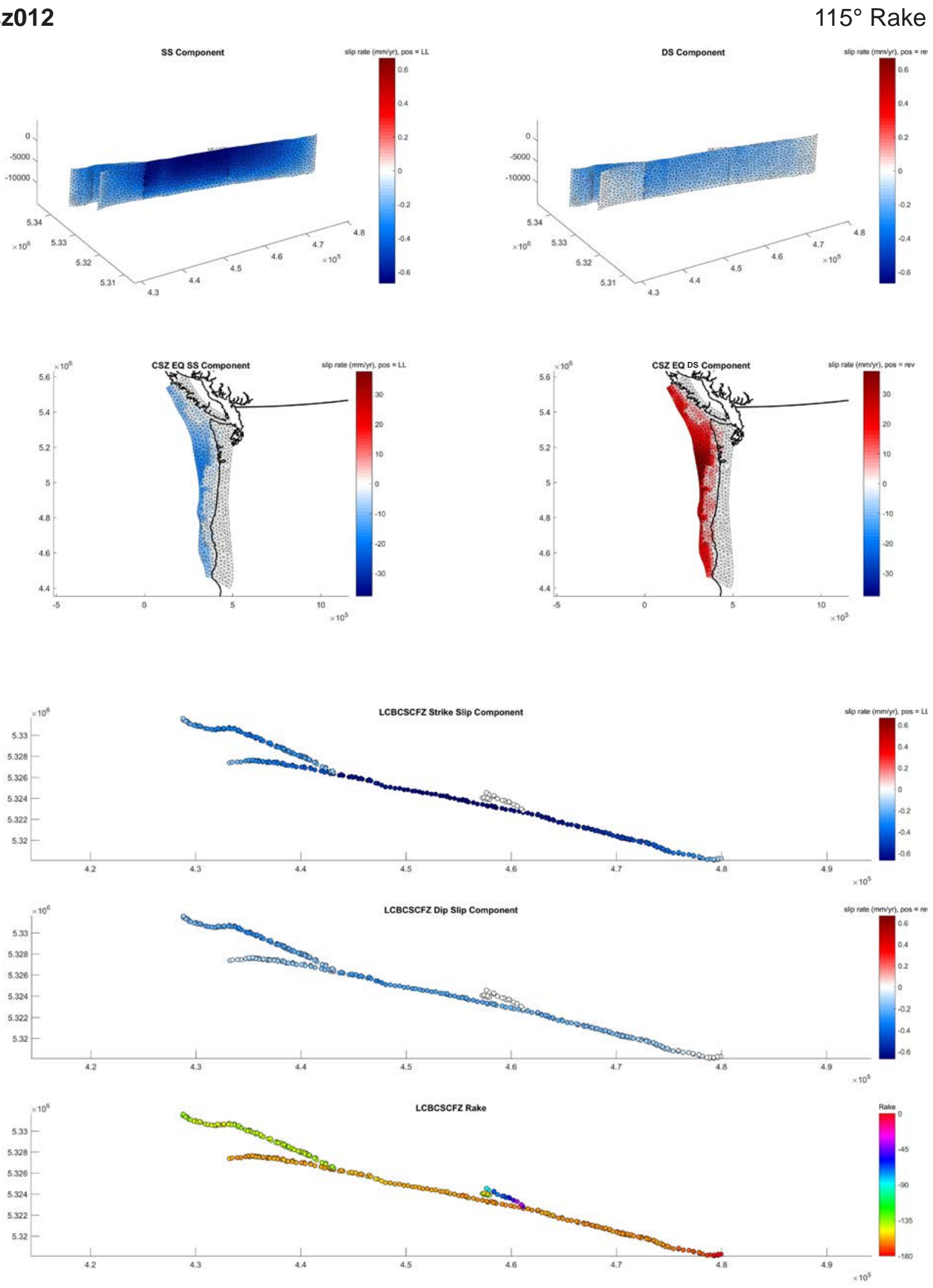

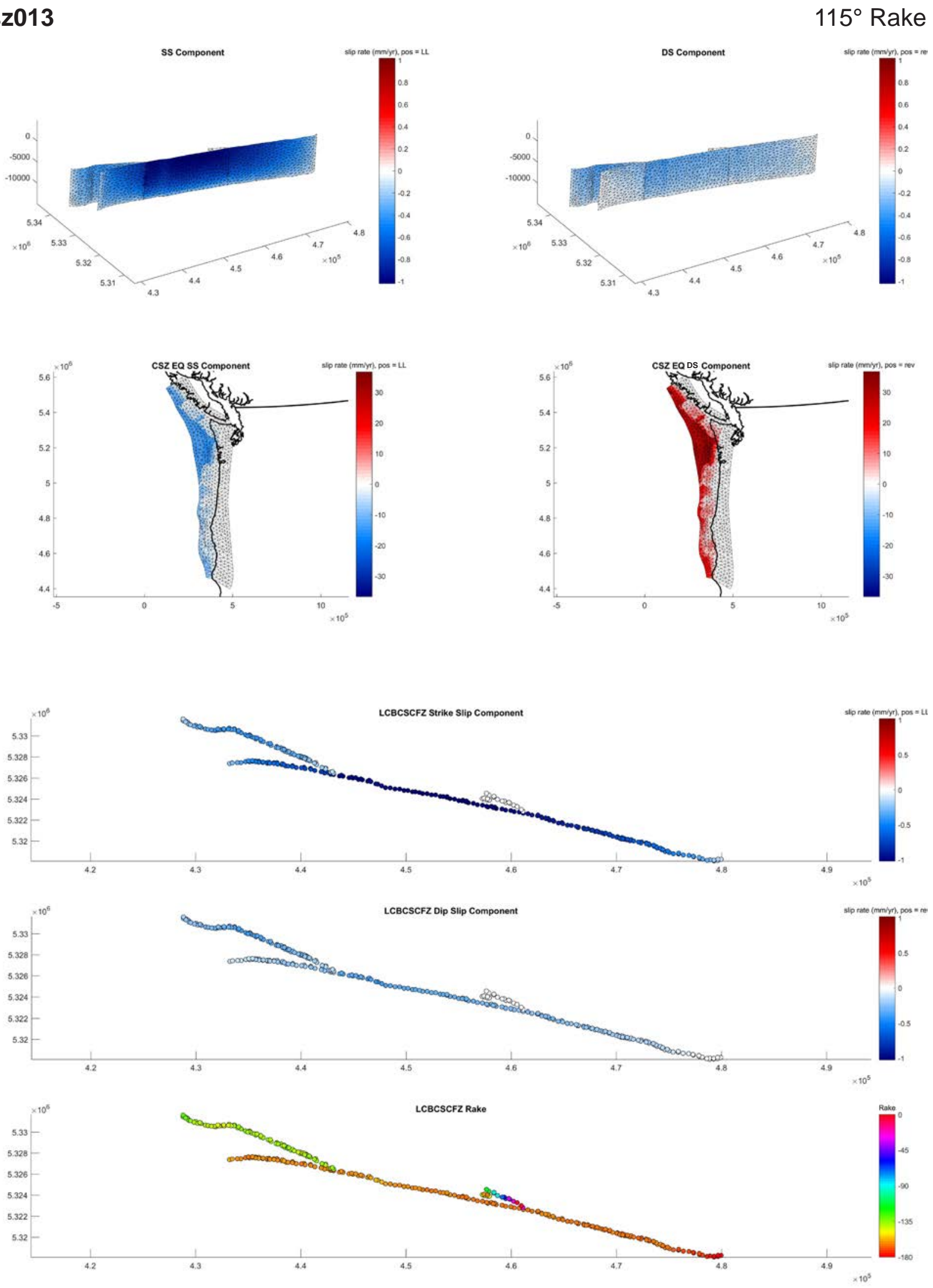

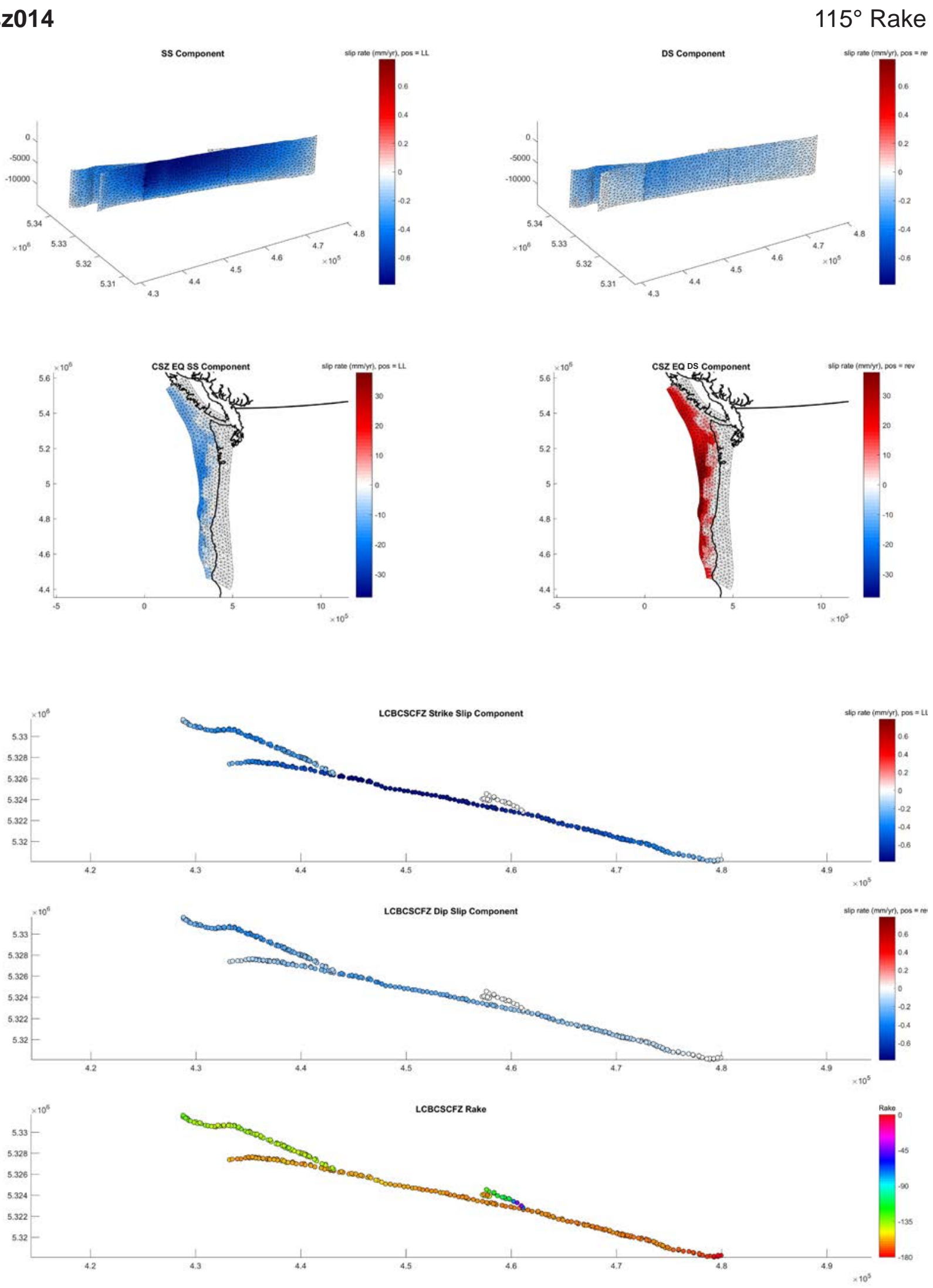

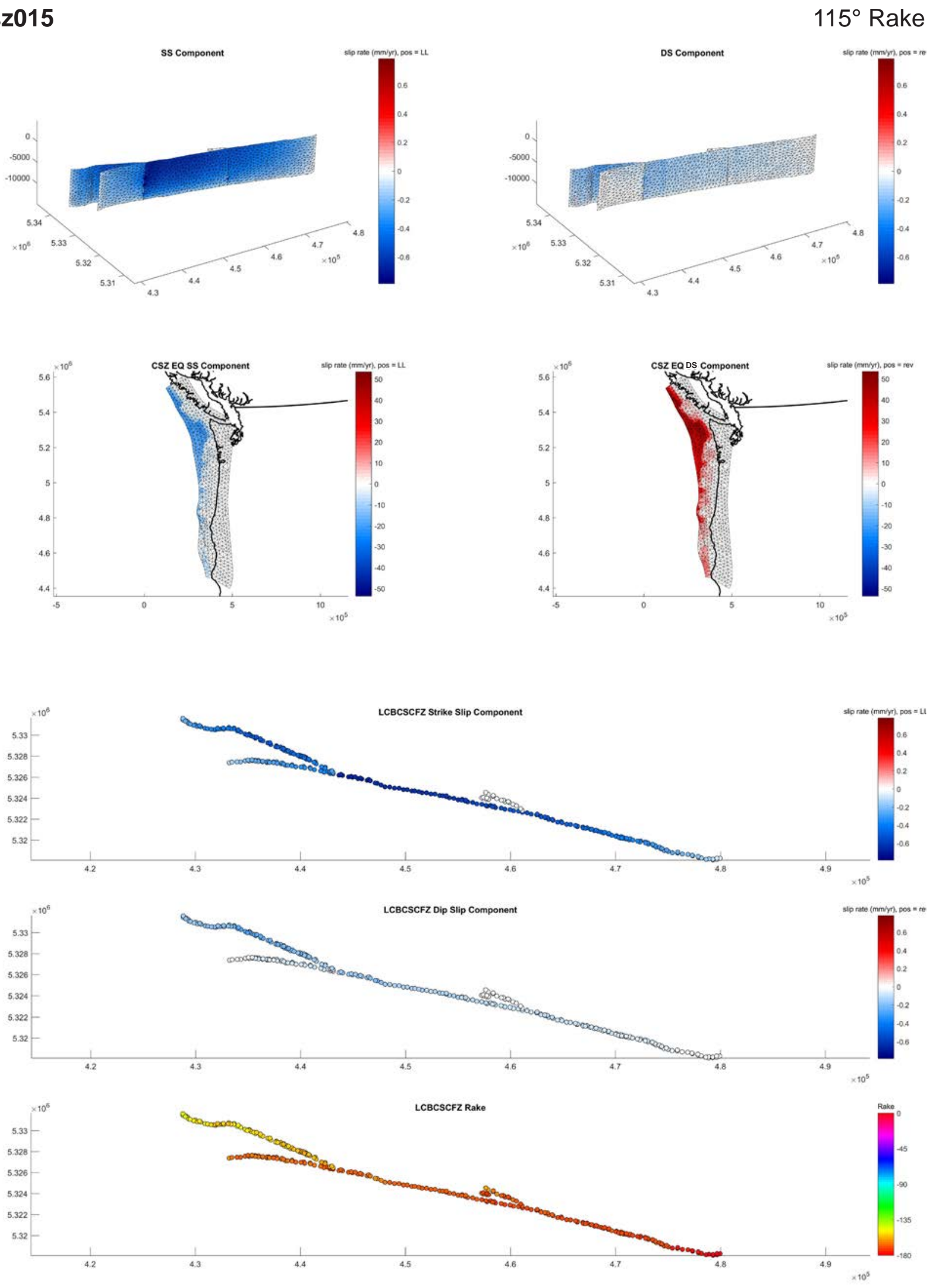

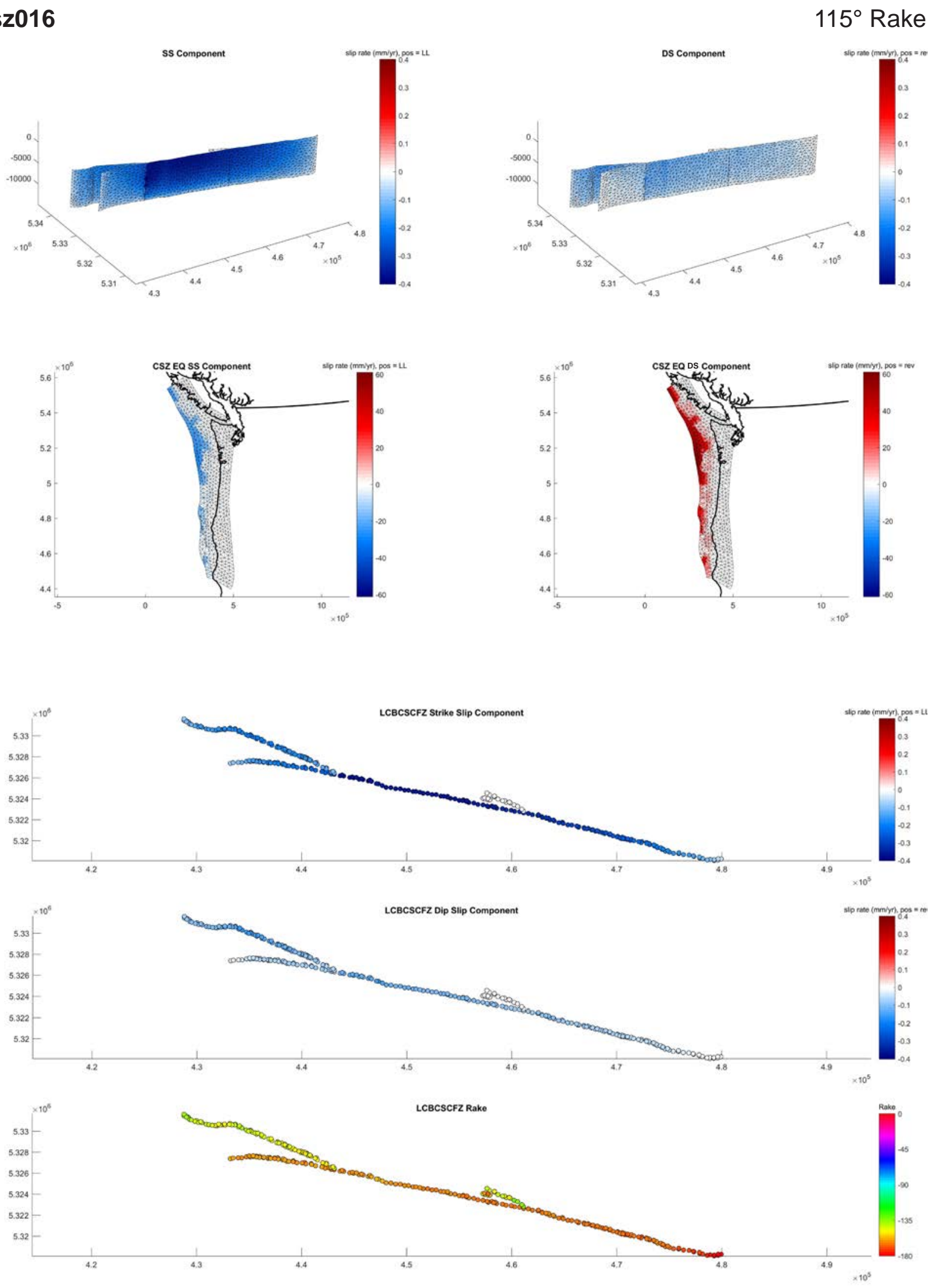

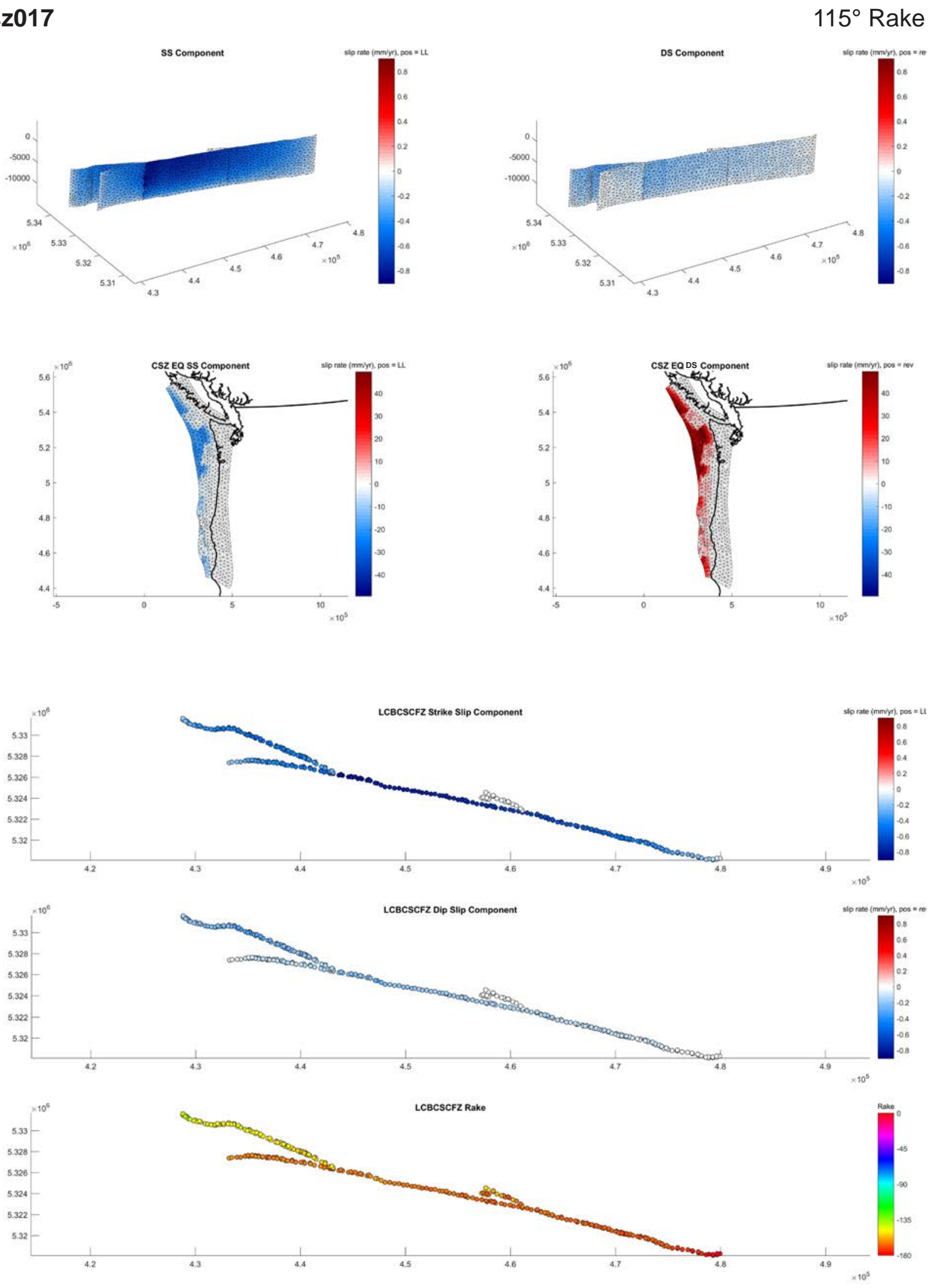

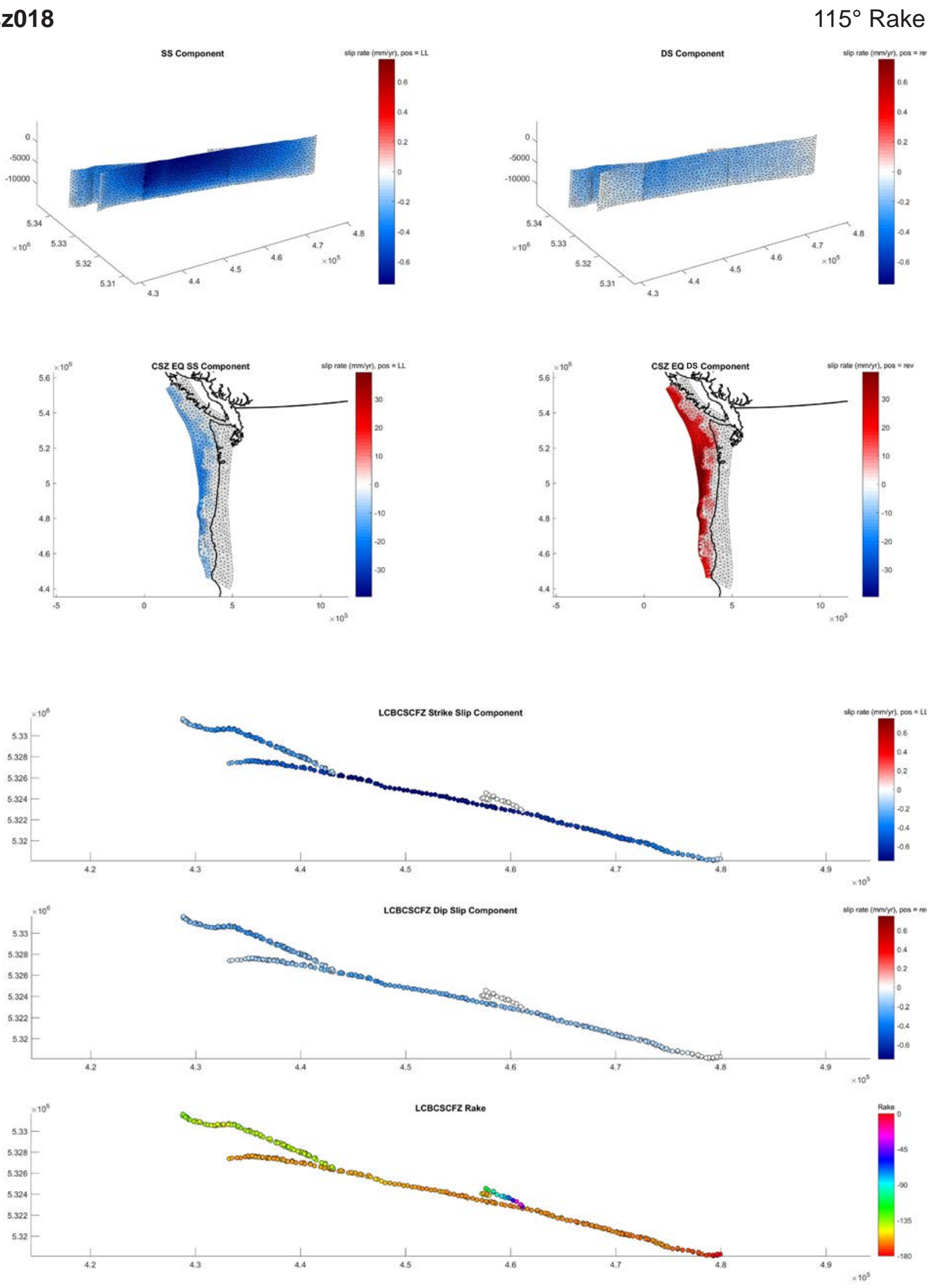

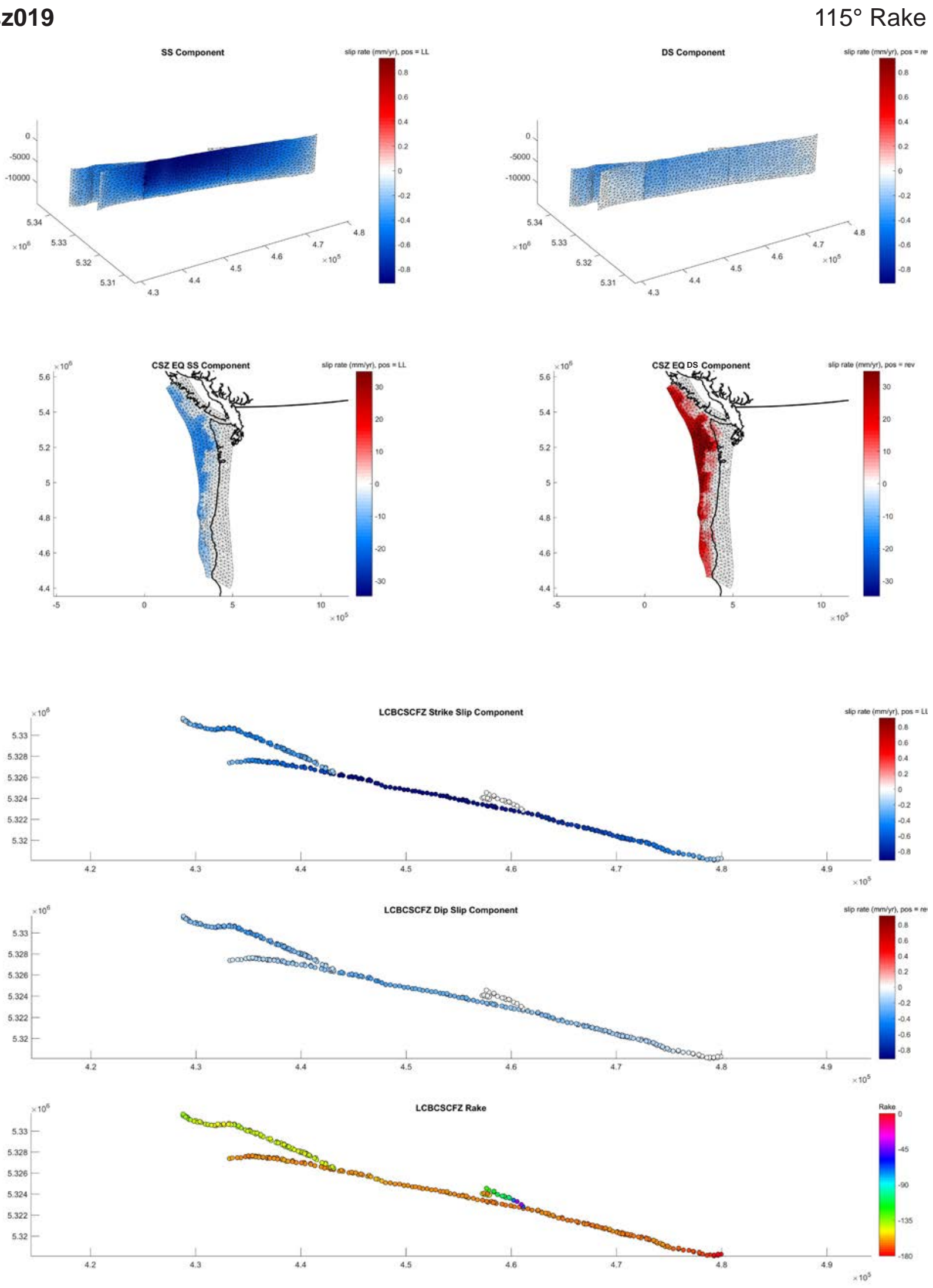

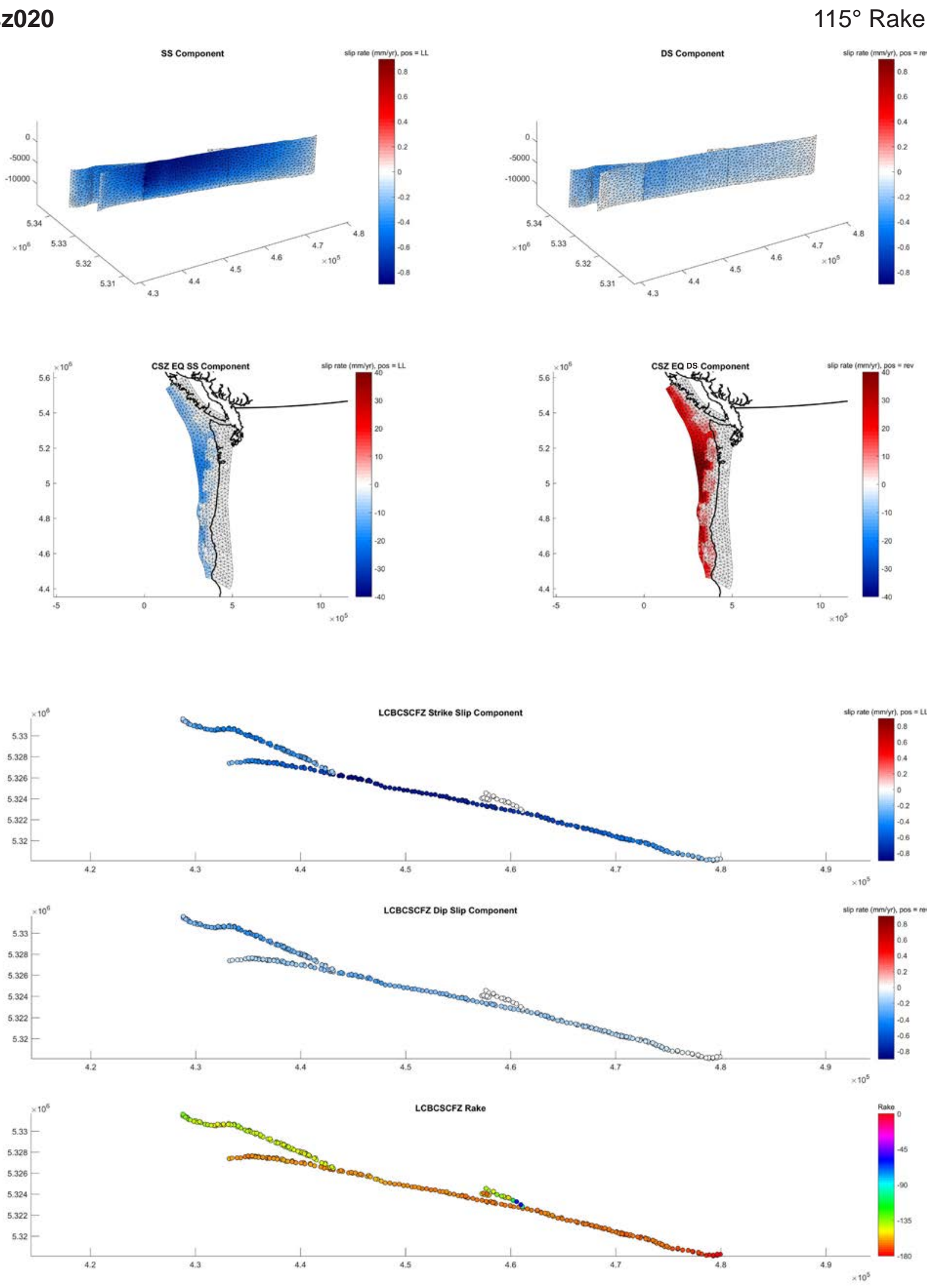

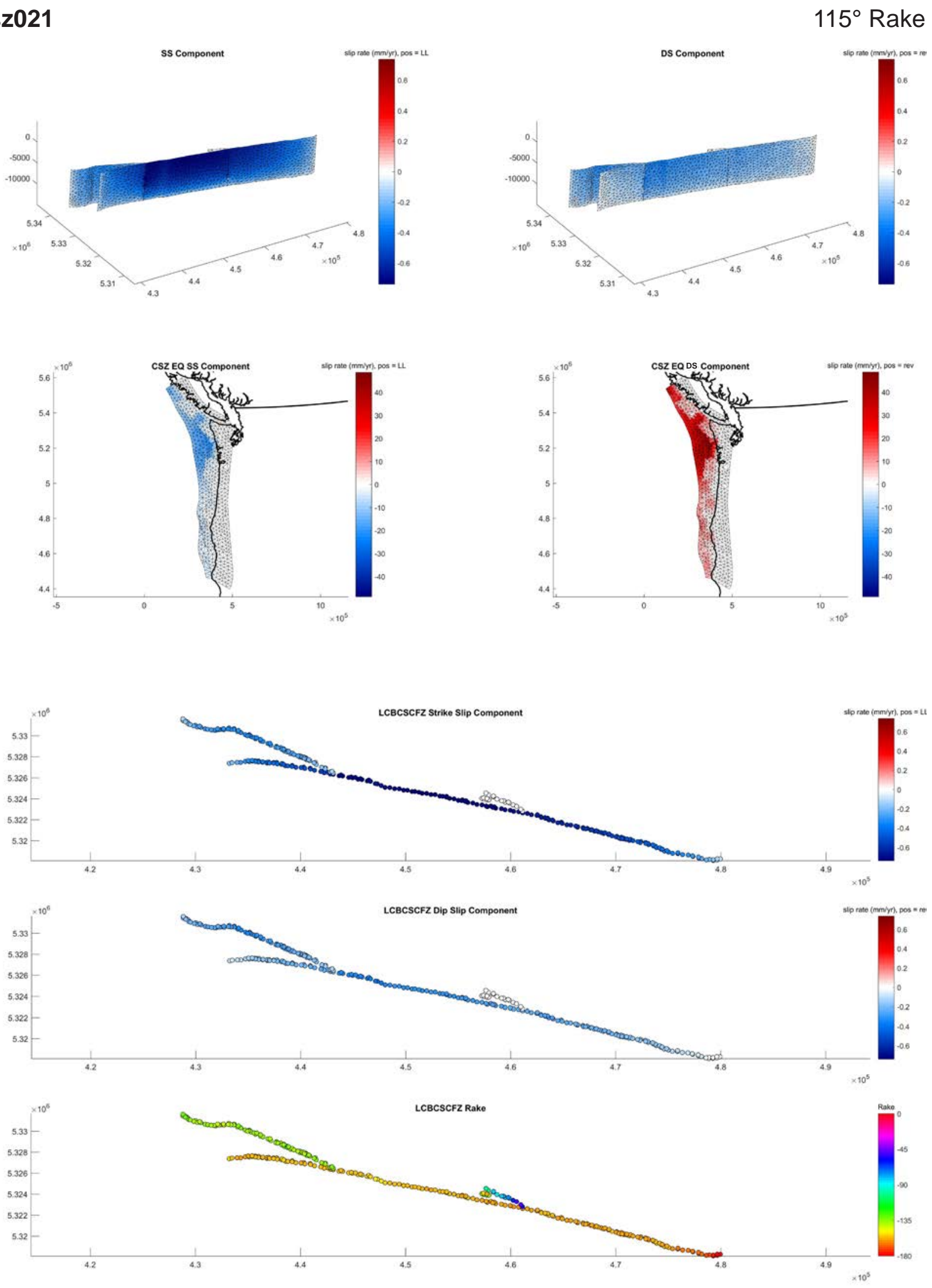

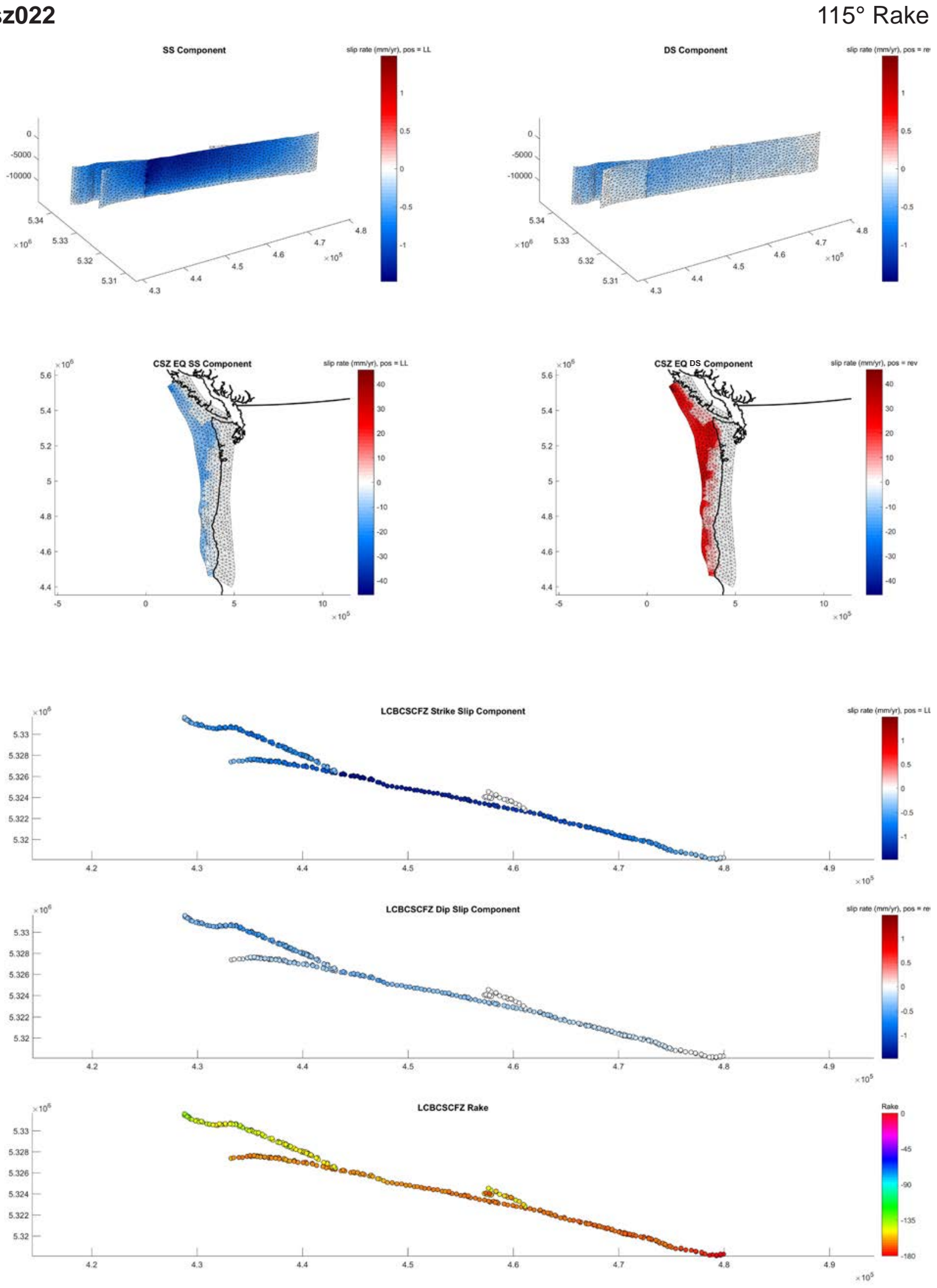

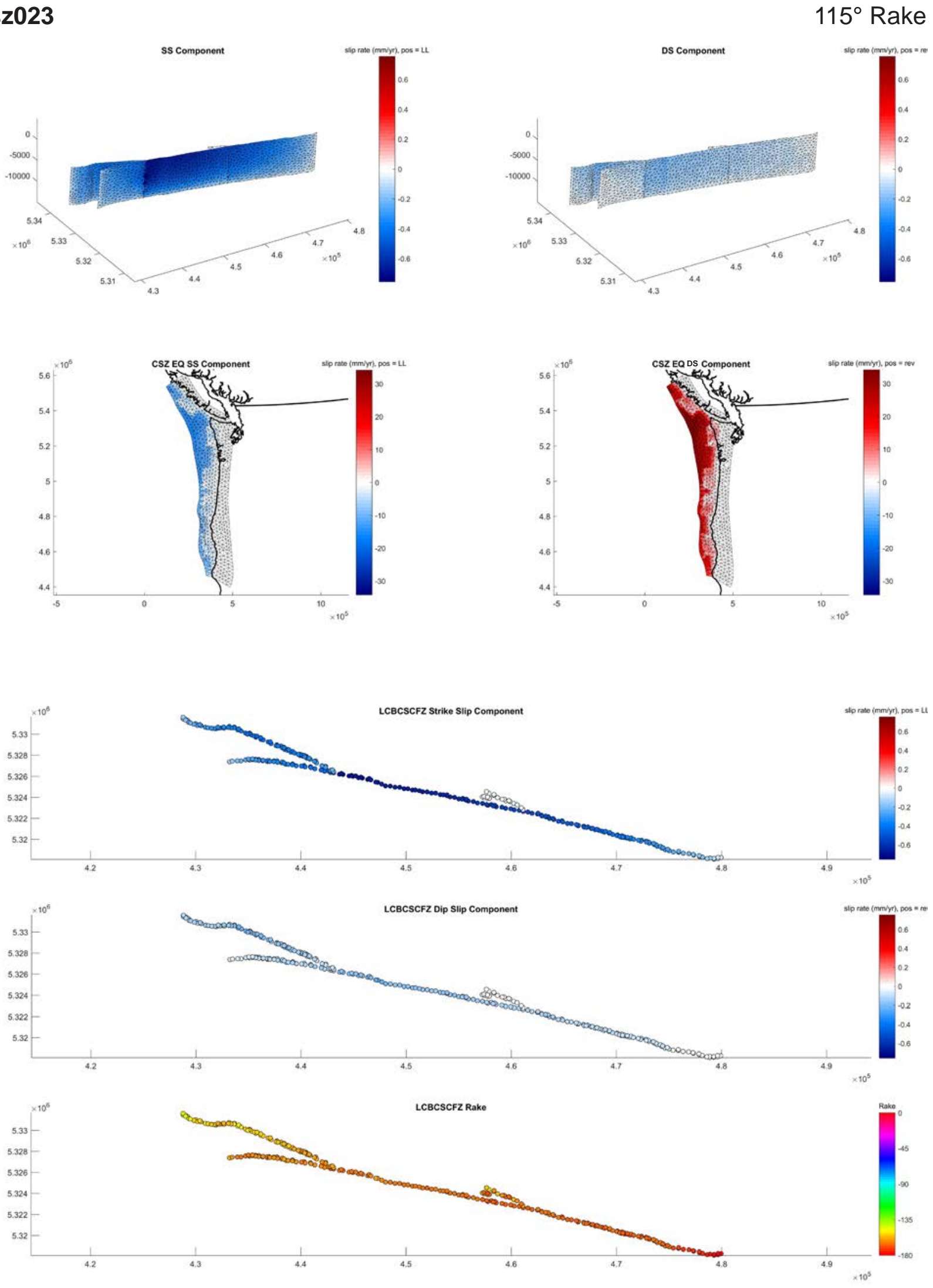

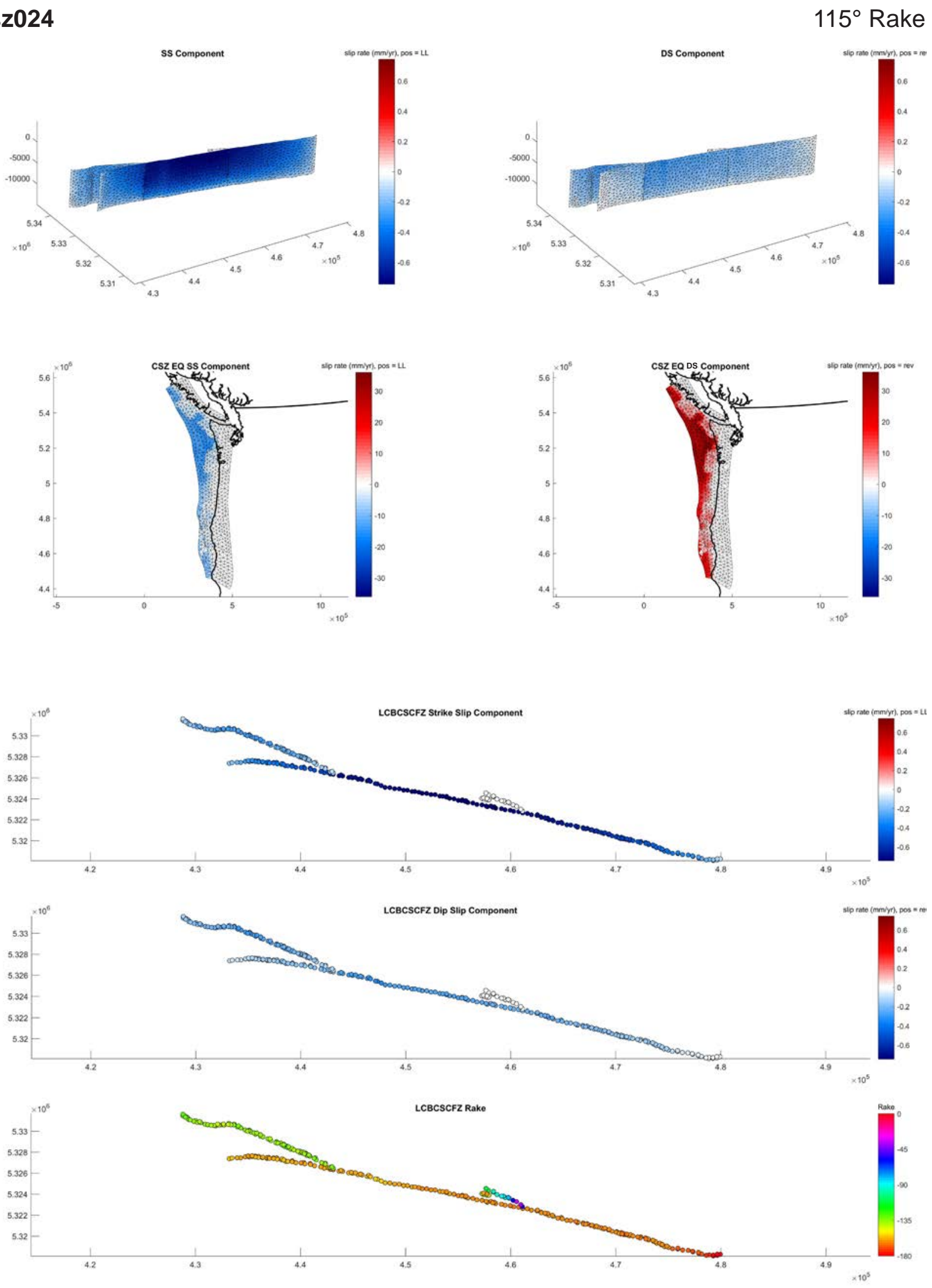

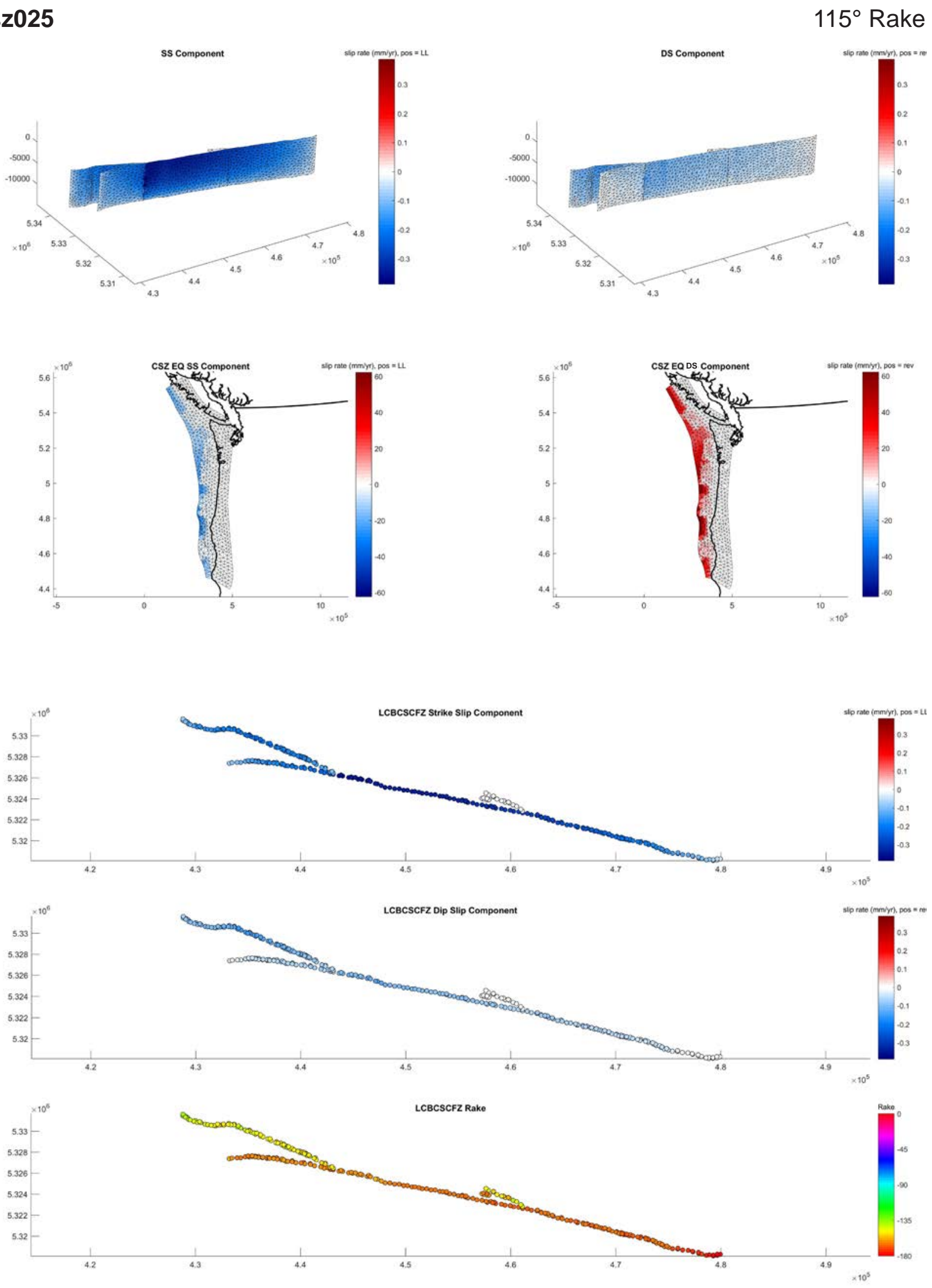

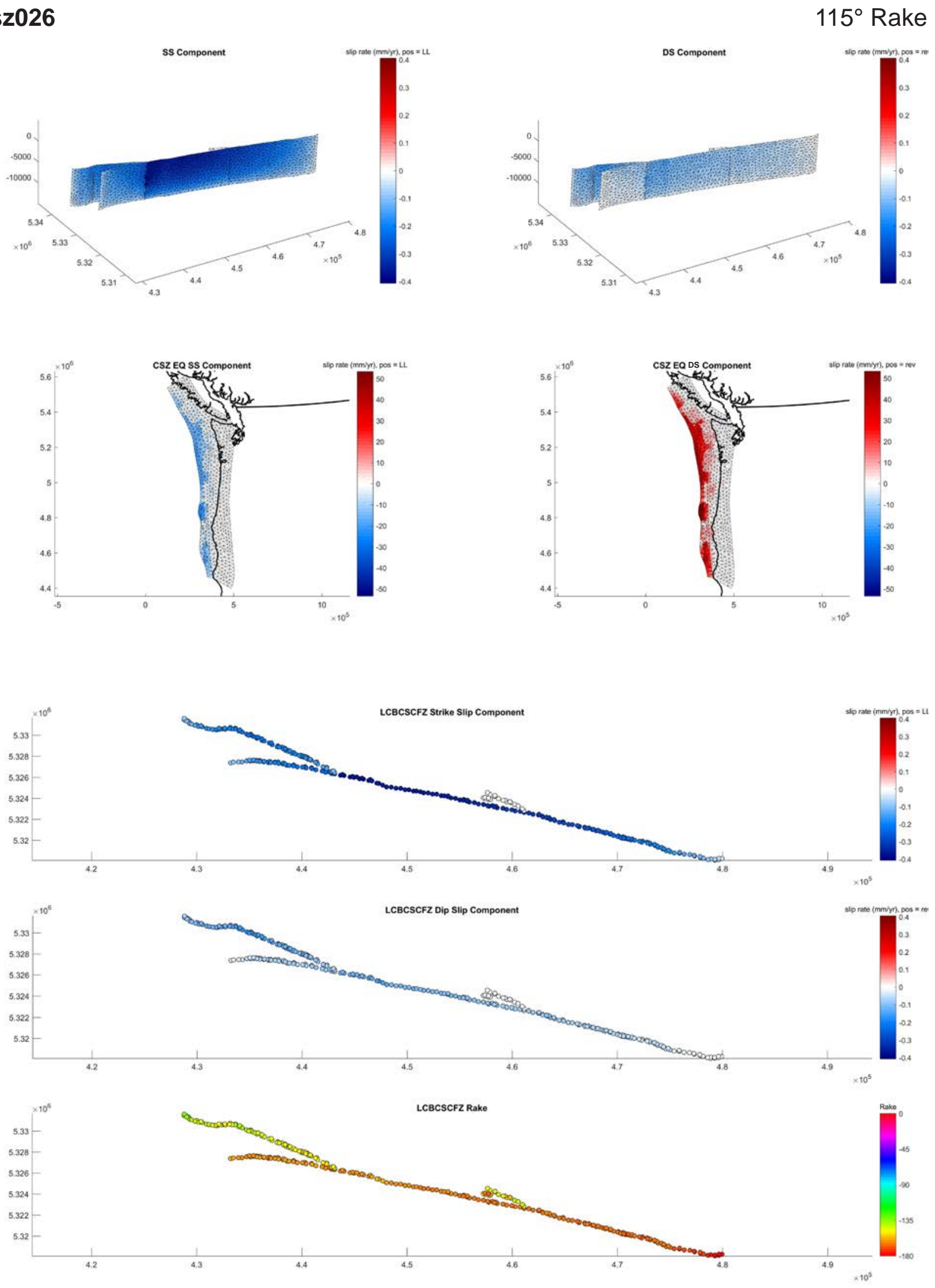

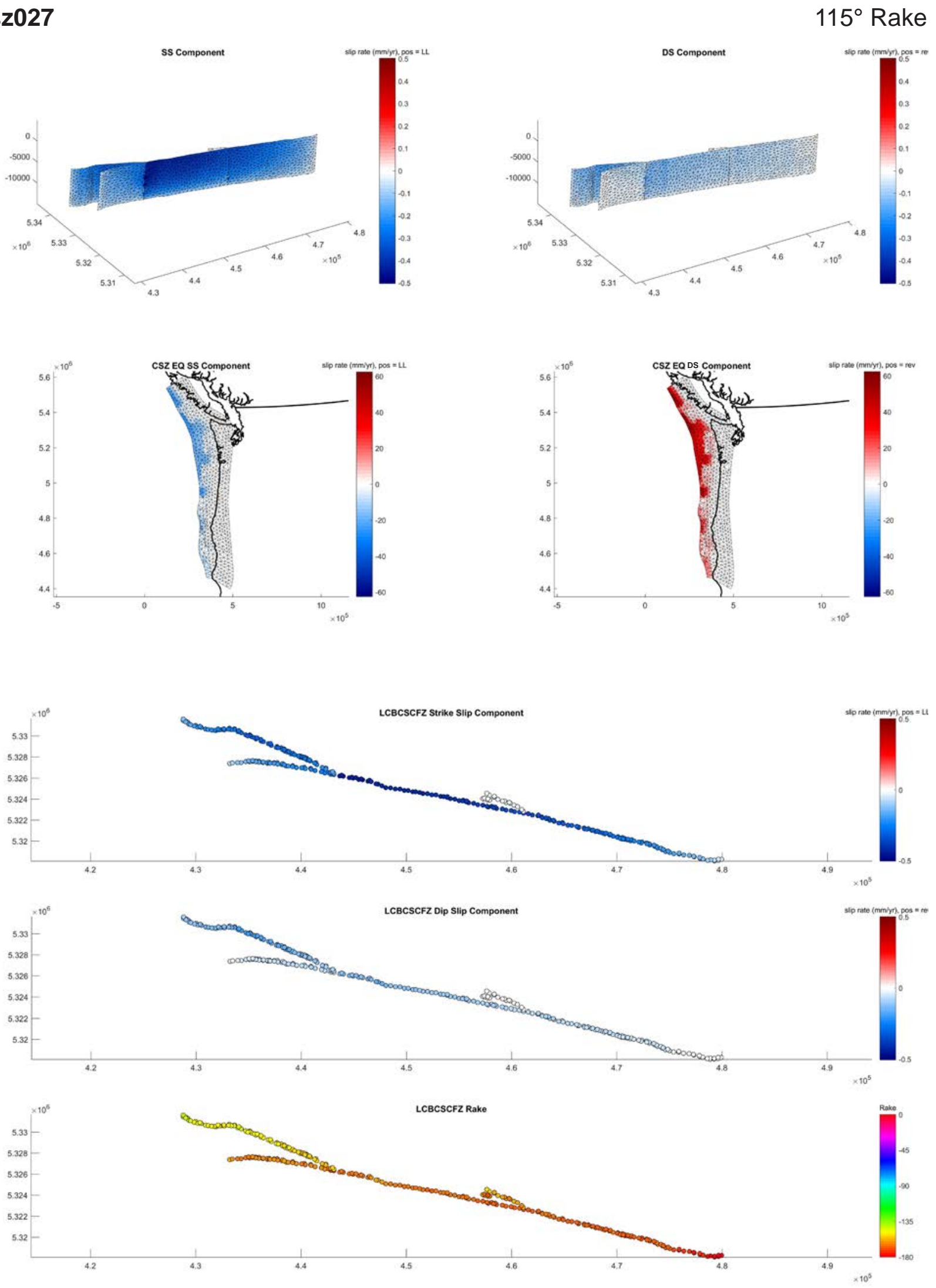

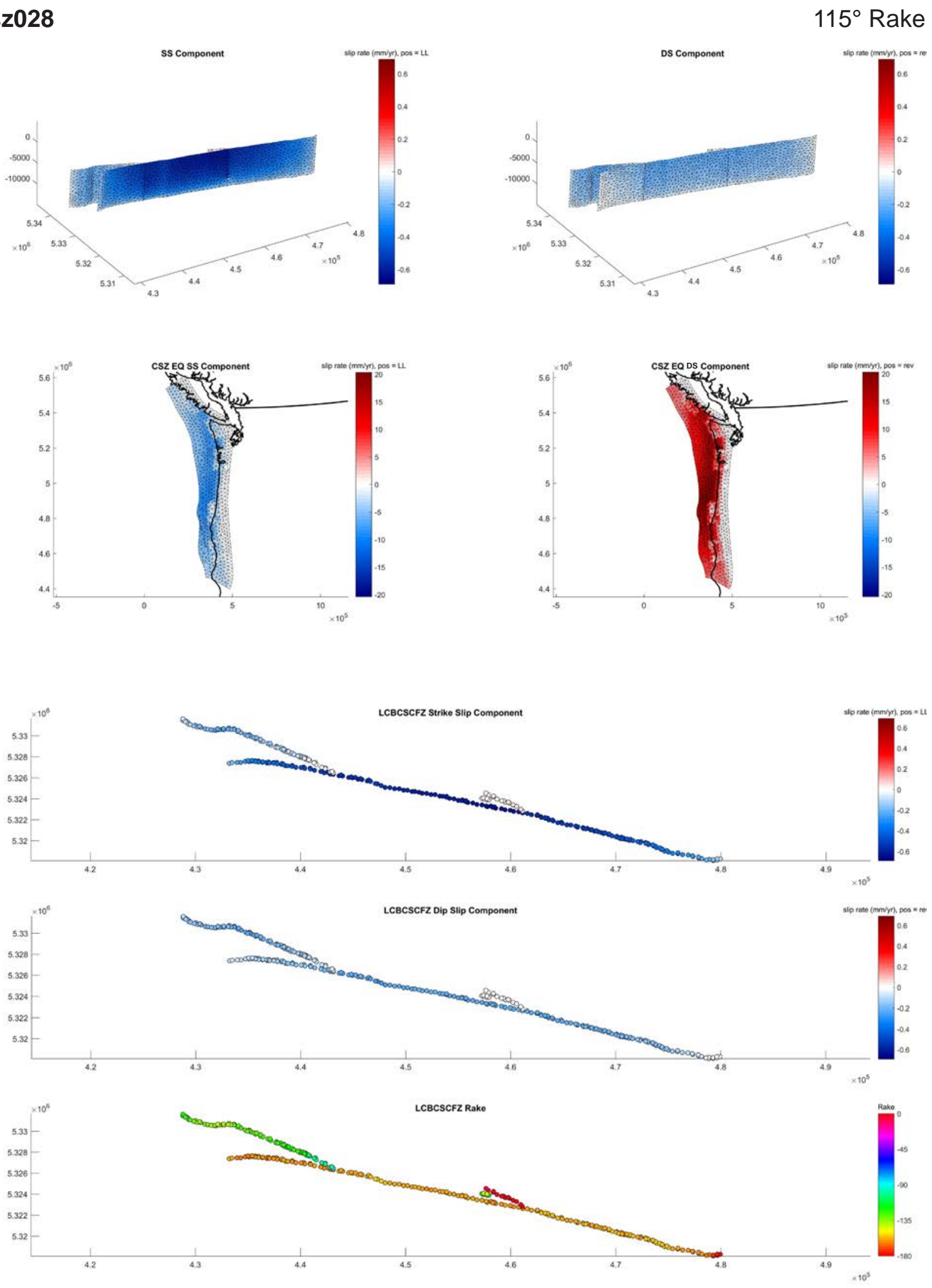

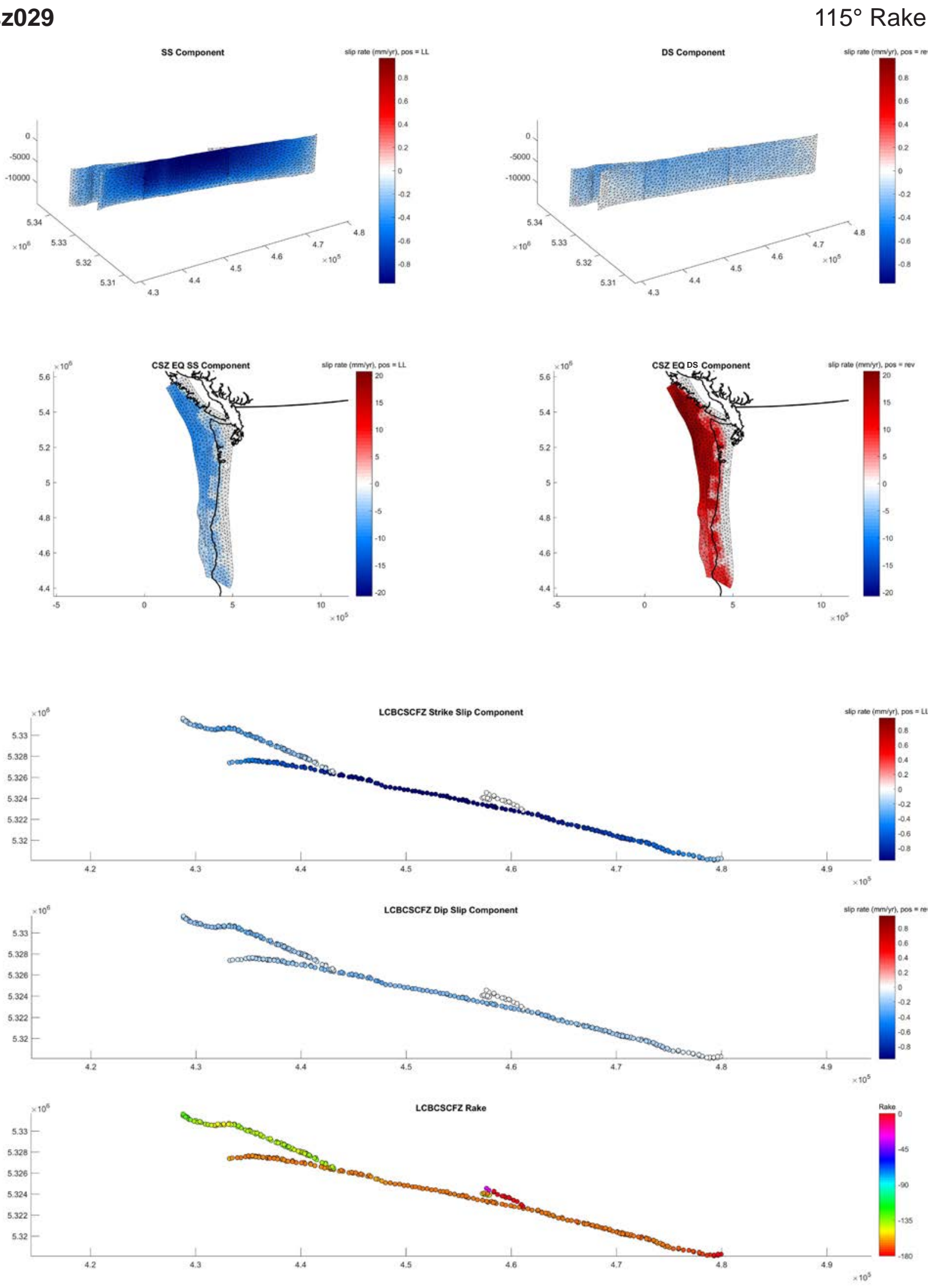

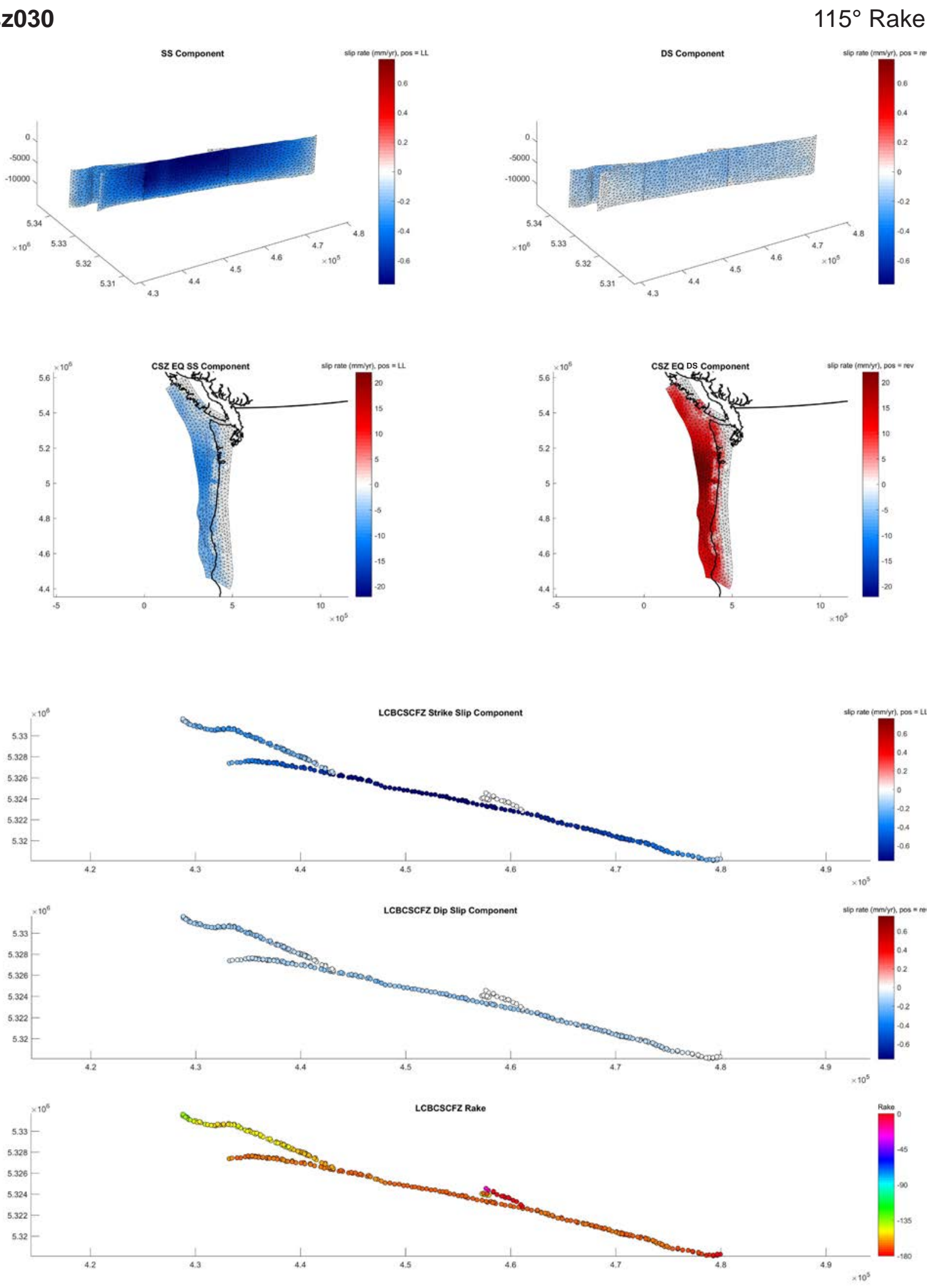

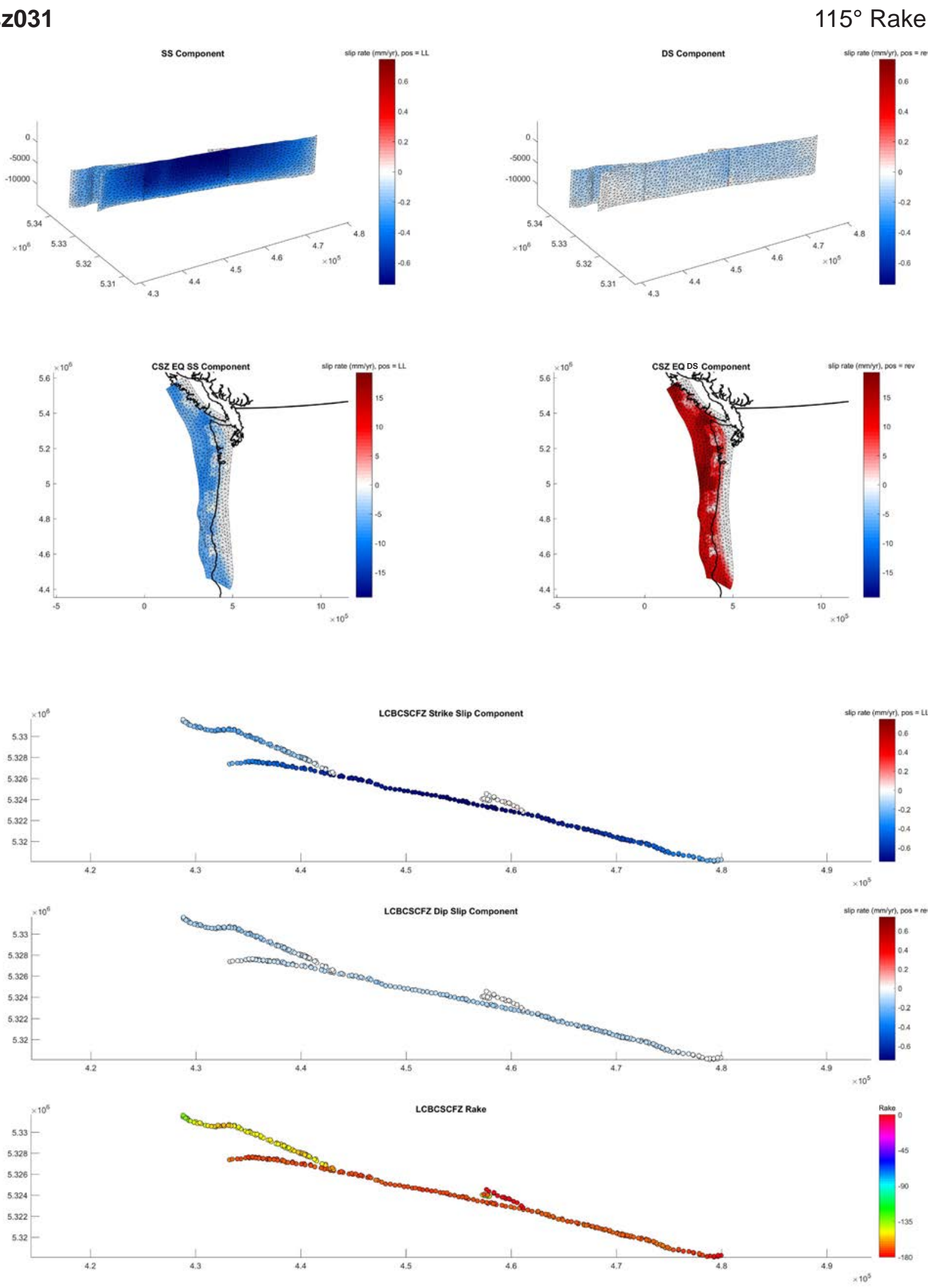

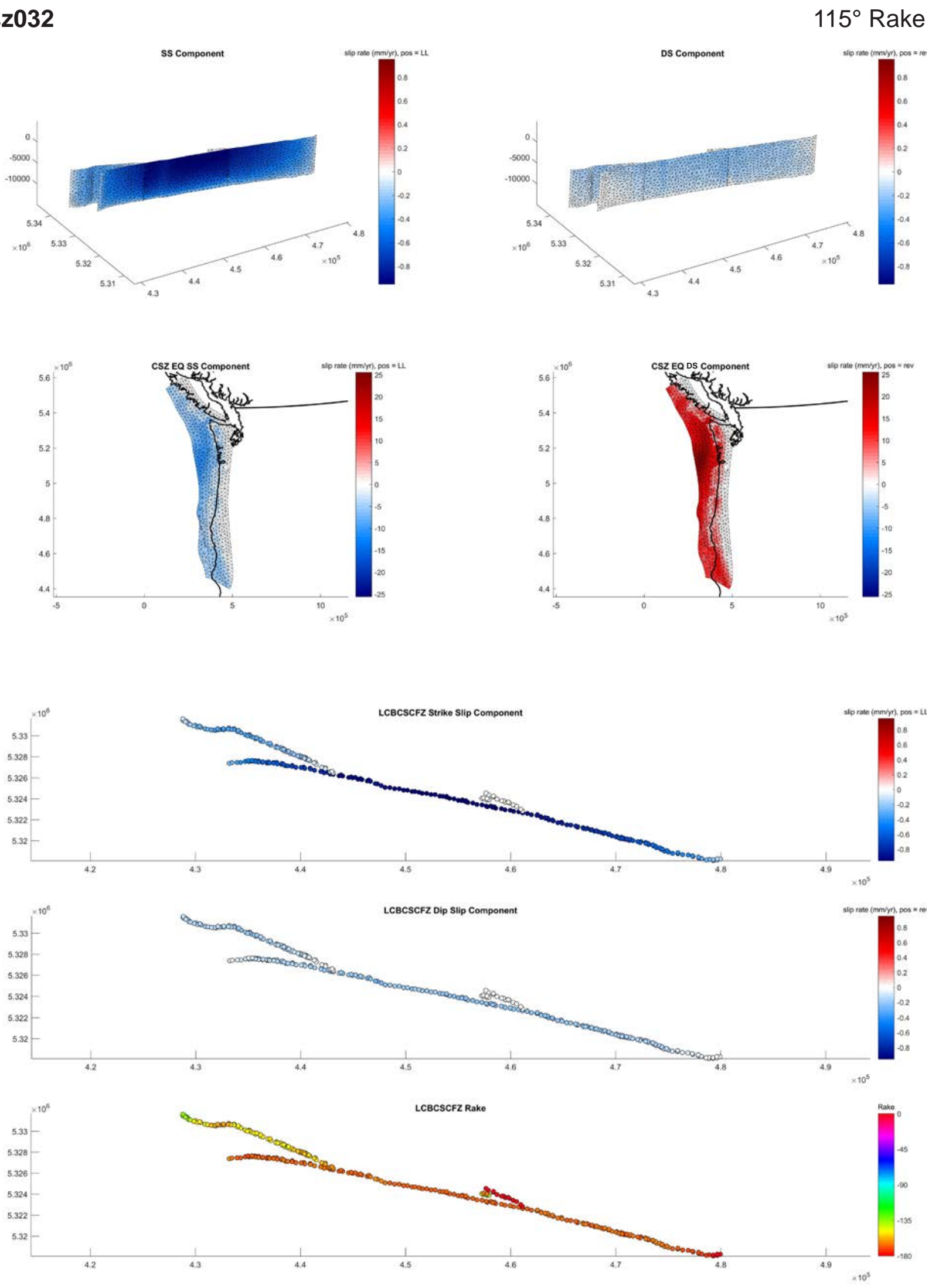

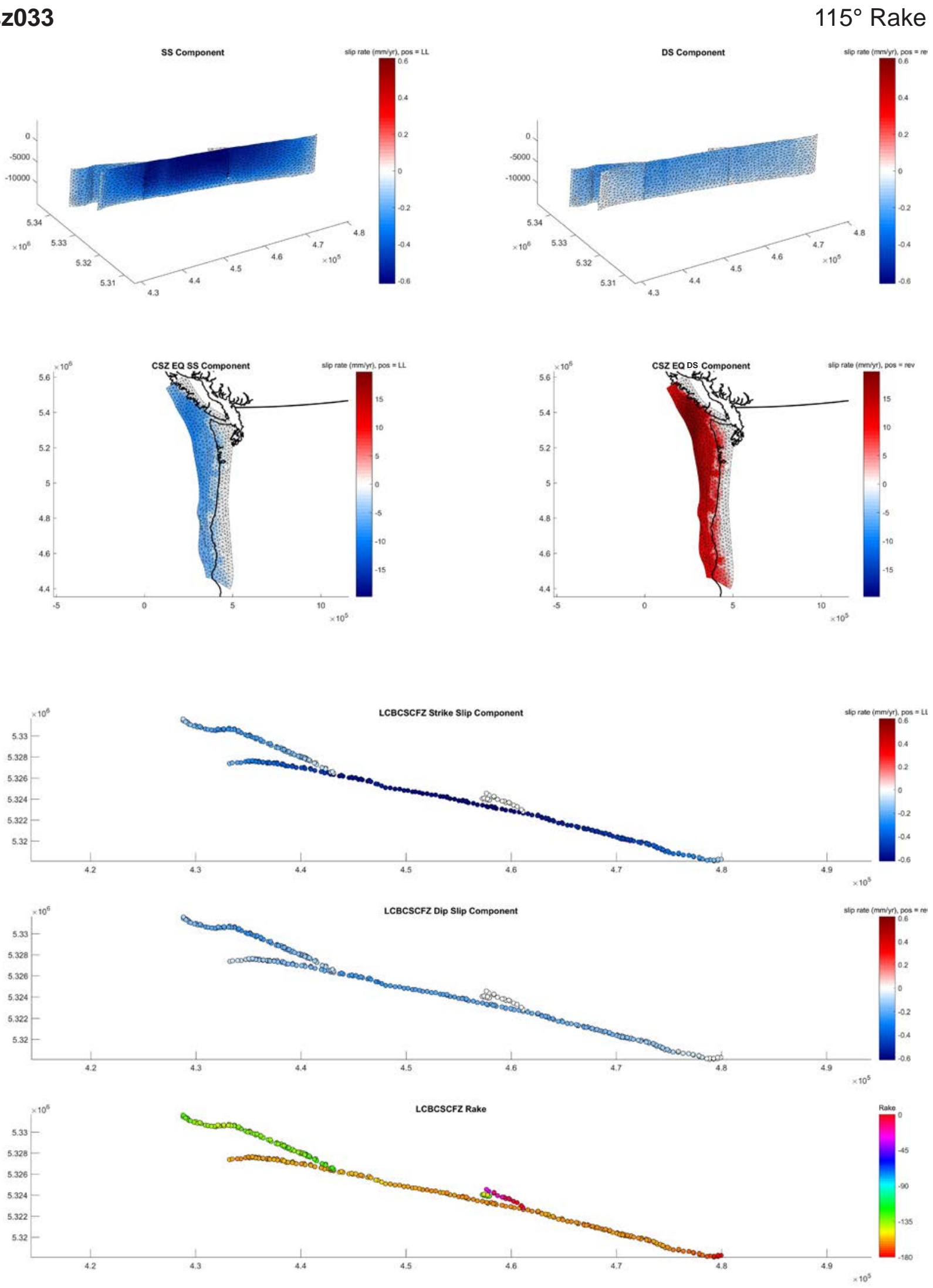
TABLE TS1. RESULTS OF SCARP PROFILING ON THE SADIE CREEK FAULT

\begin{tabular}{|c|c|c|c|c|c|c|c|c|c|c|c|c|}
\hline \multirow[b]{2}{*}{ Name } & \multirow[b]{2}{*}{ Distance* $^{*}$} & \multicolumn{4}{|c|}{ Vertical Separation (m) } & \multicolumn{4}{|c|}{ Dip-Slip Displacement (m) } & \multirow{2}{*}{ Quality $^{\dagger}$} & \multirow{2}{*}{$\begin{array}{c}\text { Relative } \\
\text { Age }^{\S}\end{array}$} & \multirow{2}{*}{$\begin{array}{c}\text { Lateral } \\
\text { Slip } \\
\text { Site }^{\#}\end{array}$} \\
\hline & & Mean & Median & $\begin{array}{l}\text { Upper } \\
\text { Bound }\end{array}$ & $\begin{array}{l}\text { Lower } \\
\text { Bound }\end{array}$ & Mean & Median & $\begin{array}{l}\text { Upper } \\
\text { Bound }\end{array}$ & $\begin{array}{l}\text { Lower } \\
\text { Bound }\end{array}$ & & & \\
\hline SP35 & 102 & 1.03 & 1.03 & 1.26 & 0.79 & 1.07 & 1.07 & 1.34 & 0.82 & 1 & G & - \\
\hline SP34 & 546 & 2.59 & 2.59 & 3.08 & 2.13 & 2.75 & 2.74 & 3.36 & 2.22 & 2 & G & - \\
\hline SP33 & 682 & 3.39 & 3.38 & 3.78 & 3.03 & 3.58 & 3.56 & 4.17 & 3.11 & 2 & G & - \\
\hline SP32 & 933 & 1.80 & 1.80 & 2.06 & 1.56 & 1.88 & 1.87 & 2.21 & 1.60 & 1 & G & - \\
\hline SP31 & 1140 & 5.34 & 5.35 & 6.00 & 4.63 & 5.53 & 5.53 & 6.41 & 4.71 & 2 & $\mathrm{G}$ & - \\
\hline SP30 & 3658 & 5.60 & 5.60 & 6.44 & 4.78 & 6.27 & 6.20 & 7.77 & 5.06 & 2 & $\mathrm{G}$ & - \\
\hline SP29 & 3930 & 3.83 & 3.80 & 4.91 & 2.86 & 4.17 & 4.12 & 5.61 & 2.99 & 2 & G & - \\
\hline SP28 & 4867 & 5.92 & 5.89 & 7.52 & 4.48 & 6.54 & 6.45 & 8.86 & 4.71 & 3 & $\mathrm{G}$ & - \\
\hline SP27 & 5325 & 2.02 & 2.02 & 2.22 & 1.82 & 2.15 & 2.14 & 2.47 & 1.88 & 1 & PG & - \\
\hline SP26 & 5581 & 2.17 & 2.17 & 2.26 & 2.08 & 2.30 & 2.28 & 2.56 & 2.12 & 2 & PG & - \\
\hline GB & 5668 & 2.58 & 2.59 & 2.69 & 2.46 & 2.73 & 2.70 & 3.03 & 2.51 & 1 & PG & - \\
\hline SP25 & 5792 & 2.62 & 2.63 & 2.84 & 2.39 & 2.77 & 2.76 & 3.18 & 2.45 & 2 & PG & - \\
\hline SP24 & 5895 & 1.20 & 1.19 & 1.36 & 1.04 & 1.27 & 1.26 & 1.49 & 1.08 & 1 & $\mathrm{G}$ & - \\
\hline SP23 & 6270 & 0.94 & 0.94 & 1.16 & 0.71 & 0.99 & 0.99 & 1.24 & 0.74 & 2 & PG & - \\
\hline SP22 & 6511 & 2.70 & 2.70 & 2.81 & 2.58 & 2.85 & 2.82 & 3.17 & 2.63 & 2 & PG & - \\
\hline SP21 & 6728 & 3.53 & 3.53 & 3.70 & 3.37 & 3.75 & 3.71 & 4.21 & 3.43 & 1 & PG & - \\
\hline SP20 & 6857 & 3.28 & 3.28 & 3.50 & 3.07 & 3.49 & 3.46 & 3.94 & 3.14 & 2 & PG & - \\
\hline SP19 & 7620 & 1.35 & 1.35 & 1.43 & 1.27 & 1.42 & 1.41 & 1.58 & 1.29 & 1 & PG & - \\
\hline SP18 & 8254 & 7.64 & 7.65 & 10.22 & 5.07 & 7.47 & 7.47 & 10.00 & 4.95 & 4 & $\mathrm{G}$ & $\mathrm{K}$ \\
\hline SP17 & 8337 & 4.68 & 4.68 & 4.87 & 4.48 & 5.25 & 5.16 & 6.18 & 4.60 & 2 & G & $\mathrm{K}$ \\
\hline NOL3C & 8451 & 3.70 & 3.70 & 3.88 & 3.52 & 4.14 & 4.07 & 4.88 & 3.62 & 2 & $\mathrm{G}$ & $\mathrm{J}$ \\
\hline NOL3R & 8472 & 5.05 & 5.04 & 5.31 & 4.80 & 5.76 & 5.65 & 6.96 & 4.94 & 2 & $\mathrm{G}$ & $\mathrm{J}$ \\
\hline SP16 & 9259 & 3.22 & 3.22 & 3.46 & 3.01 & 3.55 & 3.50 & 4.18 & 3.10 & 2 & G & - \\
\hline SP15 & 9369 & 4.43 & 4.44 & 4.84 & 4.02 & 5.04 & 4.96 & 6.14 & 4.22 & 1 & G & I \\
\hline NOL2W & 9381 & 3.05 & 3.04 & 3.77 & 2.40 & 3.39 & 3.35 & 4.51 & 2.53 & 3 & G & I \\
\hline NOL2E & 9435 & 2.17 & 2.17 & 2.68 & 1.70 & 2.40 & 2.37 & 3.12 & 1.80 & 3 & G & I \\
\hline SP14 & 9453 & 4.88 & 4.87 & 5.22 & 4.56 & 5.43 & 5.35 & 6.44 & 4.71 & 1 & G & I \\
\hline SP13 & 9578 & 1.67 & 1.67 & 1.99 & 1.37 & 1.87 & 1.85 & 2.37 & 1.46 & 1 & G & $\mathrm{H}$ \\
\hline NOL1E & 9617 & 2.56 & 2.56 & 2.98 & 2.18 & 2.87 & 2.83 & 3.63 & 2.29 & 2 & $\mathrm{G}$ & $\mathrm{H}$ \\
\hline SP12 & 9664 & 2.52 & 2.53 & 2.93 & 2.11 & 2.81 & 2.78 & 3.49 & 2.24 & 2 & G & $\mathrm{G}, \mathrm{H}$ \\
\hline SP11 & 9795 & 2.57 & 2.56 & 3.06 & 2.13 & 2.83 & 2.80 & 3.58 & 2.24 & 2 & $\mathrm{G}$ & $\mathrm{F}$ \\
\hline NOL11W & 9819 & 3.98 & 3.96 & 4.73 & 3.29 & 4.43 & 4.37 & 5.68 & 3.46 & 3 & G & $\mathrm{F}$ \\
\hline NOL11C & 9840 & 3.18 & 3.19 & 3.37 & 2.98 & 3.55 & 3.49 & 4.17 & 3.08 & 2 & G & $\mathrm{F}$ \\
\hline SP10 & 9854 & 1.26 & 1.25 & 1.80 & 0.76 & 1.43 & 1.40 & 2.15 & 0.83 & 4 & $\mathrm{G}$ & $\mathrm{F}$ \\
\hline NOL11E & 9865 & 1.05 & 1.05 & 1.54 & 0.57 & 1.20 & 1.19 & 1.81 & 0.63 & 3 & G & $\mathrm{F}$ \\
\hline SP09 & 9911 & 0.58 & 0.58 & 0.97 & 0.20 & 0.67 & 0.66 & 1.17 & 0.22 & 3 & G & $\mathrm{F}$ \\
\hline SP08 & 9944 & 4.19 & 4.20 & 4.62 & 3.71 & 4.76 & 4.69 & 5.84 & 3.92 & 2 & G & $\mathrm{F}$ \\
\hline SP36 & 10196 & 4.02 & 4.01 & 4.76 & 3.36 & 4.56 & 4.50 & 5.90 & 3.56 & 1 & G & - \\
\hline SP07 & 10274 & 4.01 & 3.99 & 5.02 & 3.09 & 4.52 & 4.44 & 6.17 & 3.27 & 2 & G & - \\
\hline $\mathrm{BL}$ & 10489 & 5.37 & 5.35 & 6.03 & 4.77 & 5.89 & 5.82 & 7.18 & 4.94 & 1 & G & - \\
\hline SP06 & 12110 & 2.36 & 2.36 & 2.73 & 1.98 & 2.58 & 2.56 & 3.18 & 2.08 & 2 & G & - \\
\hline SP05 & 12489 & 4.09 & 4.10 & 4.90 & 3.26 & 4.75 & 4.68 & 6.35 & 3.52 & 3 & G & $\mathrm{E}$ \\
\hline SP04 & 12567 & 2.32 & 2.32 & 2.75 & 1.90 & 2.64 & 2.60 & 3.39 & 2.03 & 1 & G & E \\
\hline SP03 & 13001 & 2.19 & 2.19 & 2.47 & 1.91 & 2.09 & 2.08 & 2.36 & 1.82 & 1 & G & $\mathrm{B}, \mathrm{C}, \mathrm{D}$ \\
\hline SP02 & 13059 & 4.44 & 4.44 & 4.78 & 4.11 & 4.27 & 4.26 & 4.60 & 3.96 & 3 & G & $\mathrm{B}, \mathrm{C}, \mathrm{D}$ \\
\hline NOL8W & 13064 & 2.32 & 2.32 & 2.58 & 2.06 & 2.24 & 2.23 & 2.48 & 1.99 & 2 & G & $\mathrm{B}, \mathrm{C}, \mathrm{D}$ \\
\hline NOL8E & 13116 & 2.06 & 2.06 & 2.33 & 1.79 & 2.01 & 2.01 & 2.27 & 1.74 & 2 & $\mathrm{G}$ & $\mathrm{B}, \mathrm{C}, \mathrm{D}$ \\
\hline SP01 & 13128 & 2.42 & 2.42 & 2.63 & 2.20 & 2.37 & 2.37 & 2.58 & 2.15 & 1 & $\mathrm{G}$ & $\mathrm{B}, \mathrm{C}, \mathrm{D}$ \\
\hline
\end{tabular}


*Measured in meters from West to East, beginning at the SCF fault trace terminus with the West Twin River.

$\uparrow$ Quality ranking based on quality of the lidar data and confidence that the offset surfaces/deposits on either side of fault scarp are coincident; $1=$ high quality, $4=$ low quality. $\S$ Relative age based on mapping done in this study. $\mathrm{G}=$ Glacial; $\mathrm{PG}=$ Post glacial.

\# Letters indicate the names of proximal offset channels. Measurements with this designation were used to calculate strike-slip to dip-slip ratio, rake, and total slip. 
TABLE TS2. RESULTS OF SCARP PROFILING ON THE LAKE CREEK BOUNDARY CREEK FAULT

\begin{tabular}{|c|c|c|c|c|c|c|c|c|c|c|c|c|}
\hline \multirow{2}{*}{ Name* } & \multirow{2}{*}{ Distance $^{* *}$} & \multicolumn{4}{|c|}{ Vertical Separation (m) } & \multicolumn{4}{|c|}{ Dip-Slip Displacement (m) } & \multirow{2}{*}{ Quality $^{\dagger}$} & \multirow{2}{*}{$\underset{\text { Age }^{\S}}{\text { Relative }}$} & \multirow{2}{*}{$\begin{array}{c}\text { Lateral } \\
\text { Slip } \\
\text { Site }^{\#}\end{array}$} \\
\hline & & Mean & Median & $\begin{array}{l}\text { Upper } \\
\text { Bound }\end{array}$ & $\begin{array}{l}\text { Lower } \\
\text { Bound }\end{array}$ & Mean & Median & $\begin{array}{l}\text { Upper } \\
\text { Bound }\end{array}$ & $\begin{array}{l}\text { Lower } \\
\text { Bound }\end{array}$ & & & \\
\hline tp2 & 33566 & 1.46 & 1.74 & 1.20 & 1.46 & 1.52 & 1.52 & 1.86 & 1.23 & 2 & G & - \\
\hline tp3 & 35036 & 2.95 & 3.47 & 2.34 & 2.96 & 3.12 & 3.12 & 3.82 & 2.42 & 2 & G & OL07 \\
\hline tp4 & 36264 & 1.47 & 1.75 & 1.21 & 1.47 & 1.53 & 1.52 & 1.85 & 1.24 & 3 & $\mathrm{G}$ & $\begin{array}{l}\text { OL04, } \\
\text { OL05, } \\
\text { OL06 }\end{array}$ \\
\hline tp5 & 36377 & 2.43 & 3.31 & 1.55 & 2.43 & 2.54 & 2.54 & 3.49 & 1.61 & 2 & G & $\begin{array}{l}\text { OL04, } \\
\text { OL05, } \\
\text { OL07 }\end{array}$ \\
\hline tp6 & 37254 & 1.95 & 2.91 & 0.99 & 1.94 & 1.97 & 1.97 & 2.95 & 1.00 & 2 & G & - \\
\hline tp7 & 39767 & 2.34 & 2.94 & 1.73 & 2.34 & 2.62 & 2.60 & 3.48 & 1.87 & 2 & $\mathrm{G}$ & - \\
\hline tp8 & 40099 & 2.23 & 2.79 & 1.66 & 2.23 & 2.39 & 2.38 & 3.06 & 1.75 & 2 & $\mathrm{G}$ & - \\
\hline tp9 & 40975 & 2.69 & 3.28 & 2.15 & 2.69 & 2.94 & 2.91 & 3.78 & 2.25 & 2 & G & - \\
\hline tp10 & 42115 & 2.37 & 3.25 & 1.49 & 2.36 & 2.55 & 2.54 & 3.57 & 1.58 & 2 & $\mathrm{G}$ & - \\
\hline $\operatorname{tp} 11$ & 42685 & 2.73 & 3.80 & 1.61 & 2.74 & 3.00 & 2.99 & 4.33 & 1.71 & 3 & G & - \\
\hline tp12 & 43188 & 1.95 & 2.56 & 1.33 & 1.95 & 2.12 & 2.11 & 2.86 & 1.42 & 3 & G & $\begin{array}{c}\text { LCBC- } \\
\text { CD1, } \\
\text { LCBC- } \\
\text { CD2 }\end{array}$ \\
\hline tp13 & 44560 & 1.03 & 1.43 & 0.62 & 1.04 & 1.08 & 1.08 & 1.52 & 0.64 & 2 & $\mathrm{G}$ & - \\
\hline tp14 & 45294 & 1.06 & 1.49 & 0.61 & 1.06 & 1.11 & 1.11 & 1.59 & 0.63 & 2 & G & - \\
\hline tp15 & 46534 & 2.90 & 3.28 & 2.53 & 2.90 & 3.10 & 3.08 & 3.67 & 2.63 & 2 & G & $\mathrm{MC}$ \\
\hline tp16 & 48980 & 4.38 & 4.95 & 3.84 & 4.37 & 4.58 & 4.56 & 5.31 & 3.94 & 4 & G & - \\
\hline tp17 & 49163 & 2.89 & 3.22 & 2.57 & 2.89 & 3.06 & 3.04 & 3.56 & 2.64 & 4 & G & - \\
\hline tp18 & 49525 & 1.09 & 1.93 & 0.25 & 1.09 & 1.15 & 1.15 & 2.06 & 0.26 & 2 & G & - \\
\hline tp19 & 49935 & 2.29 & 2.69 & 1.91 & 2.29 & 2.44 & 2.43 & 2.96 & 1.99 & 2 & G & - \\
\hline tp21 & 50680 & 2.93 & 4.56 & 1.17 & 2.95 & 3.27 & 3.27 & 5.32 & 1.24 & 2 & $\mathrm{G}$ & - \\
\hline $\operatorname{tp} 22$ & 51109 & 0.72 & 1.17 & 0.29 & 0.72 & 0.76 & 0.75 & 1.24 & 0.30 & 2 & G & $\begin{array}{l}\text { OL02, } \\
\text { OL03 }\end{array}$ \\
\hline
\end{tabular}

*Three profiles (tp1, tp20, tp23) originally reported by Nelson et al. (2017), were not able to be confidently measured by this study.

**Measured in meters from West to East, beginning at the SCF terminus with the West Twin River and ending at the LCBCF terminus with Seibert Creek.

$\dagger$ Quality ranking based on quality of the lidar data and confidence that the offset surfaces/deposits on either side of fault scarp are coincident; $1=$ high quality, $4=$ low quality.

$\S$ Relative age based on 1:24,000 surficial geologic mapping (Polenz et al., 2004; Schasse et al., 2004, Schasse and Polenz, 2002). G= Glacial; PG = Post glacial.

\# Indicate the names of proximal dextrally offset features. Measurements with this designation were used to calculate strike-slip to dip-slip ratio, rake, and total slip at. 